\title{
ESTUDO DA RECIDIVA EM PACIENTES COM MÁ-OCLUSÃO DE CLASSE II, TRATADOS PELA TÉCNICA DO ARCO DE CANTO COM EXTRAÇÕES DE PRÉ-MOLARES PERTENCENTES ÀS CATEGORIAS DE CRESCIMENTO DE PETROVIC
}

Alexandre Moro

Tese apresentada à Faculdade de Odontologia de Bauru, da Universidade de São Paulo, como parte dos requisitos para obtenção do título de Doutor em Odontologia, área de Ortodontia.

(Edição Revisada)

Bauru 


\section{ESTUDO DA RECIDIVA EM PACIENTES COM MÁ-OCLUSÃO DE CLASSE II, TRATADOS PELA TÉCNICA DO ARCO DE CANTO COM EXTRAÇÕES DE PRÉ-MOLARES PERTENCENTES ÀS CATEGORIAS DE CRESCIMENTO DE PETROVIC}

Alexandre Moro

Tese apresentada à Faculdade de Odontologia de Bauru, da Universidade de São Paulo, como parte dos requisitos para obtenção do título de Doutor em Odontologia, área de Ortodontia.

Orientador: Prof. Dr. Marcos Roberto de Freitas

(Edição Revisada)

Bauru 
Moro, Alexandre

m828a Estudo da recidiva em pacientes com má-oclusão de Classe II, tratados pela técnica do arco de canto com extrações de pré-molares pertencentes às categorias de crescimento de Petrovic./ Alexandre Moro. -- Bauru, 2001.

$306 p+$ apend.: il.; $30 \mathrm{~cm}$.

Tese. (Doutorado) -- Faculdade de Odontologia de Bauru. USP.

Orientador: Prof. Dr. Marcos Roberto de Freitas.

Autorizo, exclusivamente para fins acadêmicos e científicos, a reprodução total ou parcial desta tese, por processos fotocopiadores e outros meios eletrônicos.

Alexandre Moro

Assinatura: 


\section{ALEXANDRE MORO}

23 de março de1970 Nascimento - Floraí - PR

$1988-1991$

Curso de Graduação em Odontologia - Universidade Federal do Paraná (UFPR)

$1991-1992$

Estágio na Disciplina de Ortodontia Preventiva da UFPR

$1993-1996$

Curso de Pós-Graduação em Odontologia, ao nível de Mestrado - área de concentração: Ortodontia, pela Universidade Metodista de São Paulo

1995

Professor Auxiliar do Departamento de Anatomia da UFPR.

1996

Professor do Curso de Especialização em Ortodontia e Ortopedia Facial da ABO Curitiba - PR

1997

Professor do Curso de Especialização em Ortodontia e Ortopedia Facial da UFPR

$1998-2001$

Curso de Pós-Graduação em Ortodontia, ao nível de Doutorado, pela Faculdade de Odontologia de Bauru Universidade de São Paulo

Associações

Sociedade Paranaense de Ortodontia.

Associação Brasileira de Ortodontia.

Associação Paranaense de Ortopedia Maxilar.

Associação Brasileira de Odontologia - PR. 
Grupo Brasileiro de Professores de Ortodontia e Odontopediatria.

European Orthodontic Society.

World Federation of Orthodontists. 
"A ciência não é a aceitação estática da verdade; ao contrário, é uma permanente busca da verdade".

\section{Karl Popper}


É importante distinguir confusão de complexidade. A complexidade diz algo vital sobre nossas interações com o mundo. A confusão é um sistema de alarme que nos informa que não estamos conseguindo ver a simplicidade básica dentro do complexo, ou que estamos ignorando as ligeiras nuances dentro do simples.

John Briggs; F. David Peat em

A Sabedoria do Caos. 
DEDICO ESTE TRABALHO 
"PAULO FILHO MORO, meu pai,

foi simples e bom, viveu ensinando,

e de sua vida fez a melhor das lições.

Por te incentivar constantemente

a descortinar novos horizontes ........"

Carlos Cesar Moro, 15/04/1996

eu cheguei aqui!

Meu pai, Dr. PAULO FILHO MORO (in memoriam) foi meu melhor professor. Quanto mais o tempo passa, mais enxergo o quanto ele me ensinou.

Espero poder fazer o mesmo, um dia. 
À minha mãe DEOLINDA, exemplo de paciência e amor infinito, e a meus irmãos PAULO, DENISE, CARLOS e FERNANDO, exemplo de união familiar. Essa base permite-me alçar vôos longínquos. 
À minha querida Érica, pelo constante estímulo e paciência nas horas difíceis desta caminhada. Espero poder retribuir todo o amor recebido. 
AGRADECIMENTOS
ESPECIAIS 
Ao Prof. Dr. MARCOS ROBERTO DE

FREITAS, pelo constante apoio e pela confiança em mim depositada durante toda esta jornada. 
Ao Prof. Dr. JOSÉ FERNANDO CASTANHA HENRIQUES, Coordenador do Curso de Doutorado em Ortodontia da FOB USP, por ter-me aberto as portas do Departamento de Ortodontia e pelo incentivo constante, confiança duradoura e estímulo ao crescimento profissional. 
Ao professor LYSLE E. JOHNSTON Jr., Chefe do Departamento de Ortodontia e Odontopediatria da Universidade de Michigan em Ann Arbor, USA, pela valiosa orientação na utilização da sua análise de sobreposição cefalométrica e também nos testes estatísticos. 
Aos Professores Doutores ARNALDO PINZAN, DÉCIO RODRIGUES MARTINS, GUILHERME DOS REIS PEREIRA JANSON, RENATO RODRIGUES DE ALMEIDA, pelos conhecimentos e experiências transmitidos. 
Ao Prof. Dr. EROS PETRELLI. O seu amor e luta pela especialidade, dão-me força para prosseguir adiante. A sua amizade e confiança muito me honram. 
À Profa. Dra. DAYSE URIAS, amiga, que, além de ter-me despertado para o estudo científico da Ortodontia, permitiu o meu desenvolvimento profissional no Curso de Especialização da ABO - Curitiba. 
Ao Prof. Dr. JOÃO MARIA BAPTISTA, grande amigo e professor. Que o seu espírito científico continue a estimularme. 
AGRADECIMENTOS 


\section{AGRADECIMENTOS}

Ao Professor Doutor Aymar Pavarini, diretor da FOB-USP.

Ao Professor Doutor Luiz Fernando Pegoraro, Presidente da Comissão de Pós-Graduação da FOB-USP.

Ao meu amigo Evandro Toigo, pela confecção do programa Análise de PETROVIC/LAVERGNE 1.0, que foi utilizado neste trabalho.

À minha amiga Lucia H. S. Cevidanes, Professora da UMESP e doutoranda em Biologia Oral pelo Centro de Pesquisa Dentária da Universidade da Carolina do Norte, em Chapel Hill, pelas sugestões sobre o capítulo de discussão.

Ao amigo Julio Vargas, por ter emprestado sua "planilha" para o cálculo dos erros casuais e sistemáticos.

Aos meus colegas do Curso de Doutorado Acácio Fuziy, Liliana A. M. Brangelli, Maria Helena Vasconcelos, Marcio Rodrigues de Almeida, e Ricardo Takahashi, pelos momentos convividos durante esta caminhada.

Aos colegas do Doutorado "antigo", Eduardo Dainesi, Ênio Mazziero, Jorge Toruño, Júlio Gurgel, Marcia Kawauchi, e Pedro Gondin, pelas experiências transmitidas. 
Aos colegas do Mestrado "velho" Ana Carla, Ana Cláudia, Daniela Garib, Danilo Siqueira, Fausto Bramante, Karina Cruz, Karyna Valle, Paulo Carvalho, Renata Almeida, e Roberto Bombonatti, pela convivência agradável e amizade demonstrada.

Aos colegas do Mestrado "novo" Adriana, Celia, Cláudia, Daniele, Denise, Fábio, Fabrício, Fernanda, José Eduardo, José Norberto, Karina, Maria Fernanda, Rejane, e Sandra, pelo convívio e amizade.

Aos funcionários da Disciplina de Ortodontia Daniel F. R. Selmo ("Bonné"), Luiz Sérgio Vieira ("Panda - CBJ"), Maria J. S. Formenti ("Tia Maria"), Teresa Cristina A. C. Ducatti, e Vera L. R. Purgato, pela amizade e colaboração recebida durante o Curso.

Aos funcionários da Pós-Graduação, Ana Maria M. Bocchio, Giane T. Quintela, Heloísa F. Silva e Neide E. Russo, pela colaboração necessária ao desenvolvimento do Curso.

Aos funcionários da biblioteca Ademir, Cesar, Cybelle, Jane, José Roberto, Maria Helena, Mônica, Rita, Valéria, e Vera Boccato, pela atenção e eficiência com que sempre me atenderam.

Aos funcionários da Associação de Pós-Graduandos (APG) Salvador Félix ("Presidente"), Marcos ("Sebastião") e Joice, pela atenção e eficiência com que sempre me atenderam. 
Ao Sr. Carlos H. Domenech, pelo trabalho estatístico realizado.

A todos os professores Doutores da FOB-USP, que contribuíram para a minha formação profissional.

Aos professores da Disciplina de Anatomia Odontológica II, da UFPR, Armin Weber e Ricardo Moresca, por permitirem meu afastamento para a realização do Doutorado.

Aos professores da Disciplina de Ortodontia Preventiva da UFPR, Ademir Brunetto, Gerson I. Köhler, e Marco Antônio L. Feres, pelo incentivo durante esta jornada.

Aos professores do Curso de Especialização em Ortodontia da ABO-Curitiba, Fábio S. Telles e Gilce C. A. Costa, pelo incentivo durante esta jornada.

Ao professor Doutor Camillo Ferronato, ex- professor do Departamento de Lingüística (Letras Clássicas e Vernáculas) da UFPR, professor da UTP, pela revisão do texto.

À Fundação de Amparo à Pesquisa do Estado de São Paulo (FAPESP), pela concessão de bolsa de estudo para a realização deste projeto.

Enfim, a todos que, direta ou indiretamente, contribuíram para a realização deste trabalho. 
SUMÁRIO 


\section{SUMÁRIO}

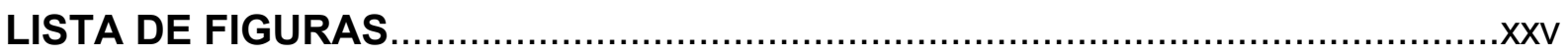

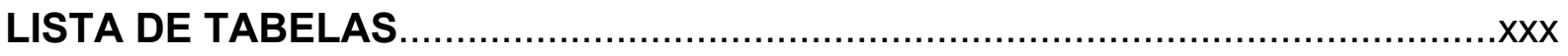

RESUMO

1 INTRODUÇÃO

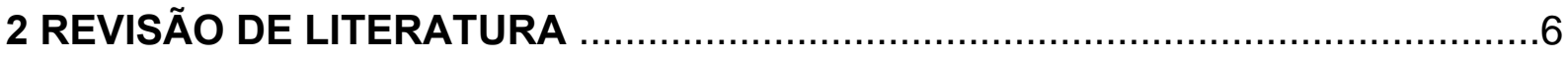

2.1 A MÁ-OCLUSÃO DE CLASSE II...............................................................

2.2 AS ROTAÇÕES DE CRESCIMENTO DA MANDÍBULA E AS SUAS

RELAÇÕES COM A PREVISÃO DO CRESCIMENTO FACIAL.........................12

2.3 TRABALHOS REALIZADOS COM A ANÁLISE DE PETROVIC/ LAVERGNE.....20

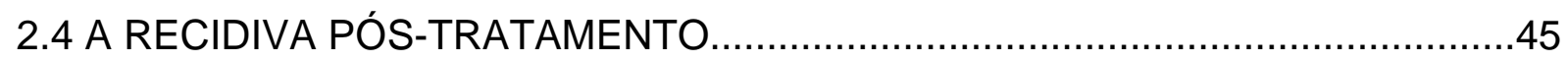

2.4.1 Índices utilizados para a avaliação da recidiva...............................................45

2.4.2 O desenvolvimento da oclusão e sua relação com a irregularidade dentária....48

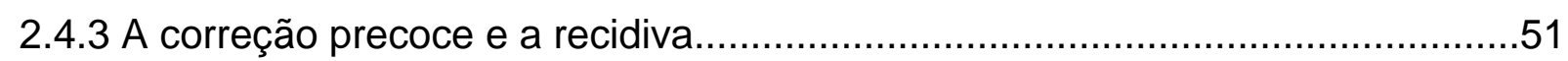

2.4.4 A relação entre a forma da arcada inferior e a recidiva..................................53

2.4.5 A relação entre a recidiva dos trespasses horizontal e vertical e o

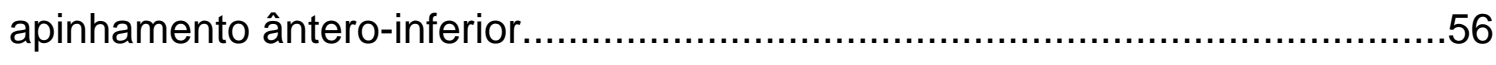

2.4.6 A recidiva nos casos com extrações de pré-molares........................................58

2.4.7 A posição cefalométrica dos incisivos e a estabilidade do tratamento..............68

2.4.8 O papel dos terceiros molares na recidiva...................................................

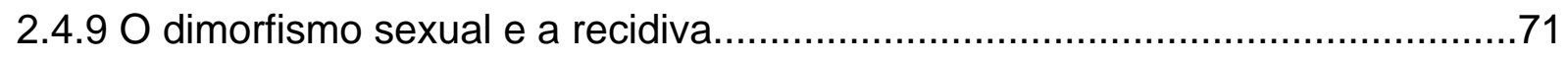


2.4.10 A relação da morfologia e do crescimento craniofacial com a

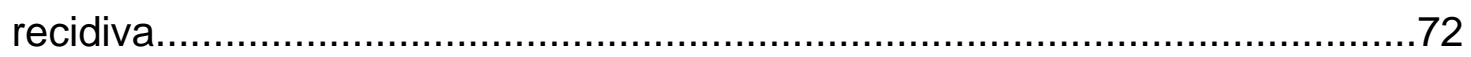

2.4.11 Alterações longitudinais no perfil tegumentar facial....................................89

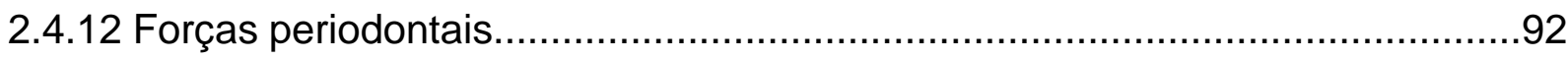

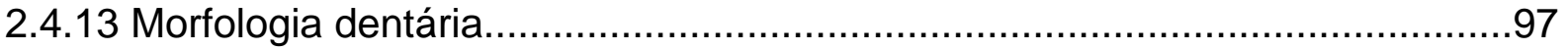

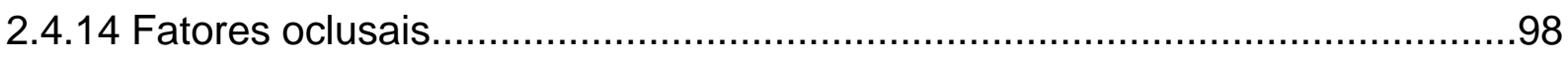

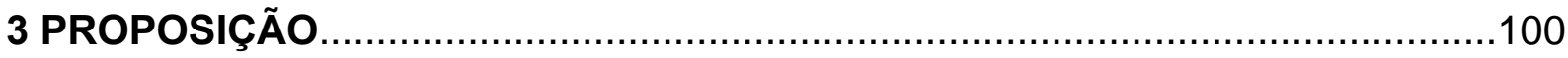

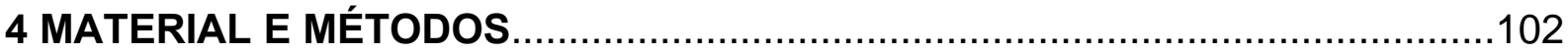

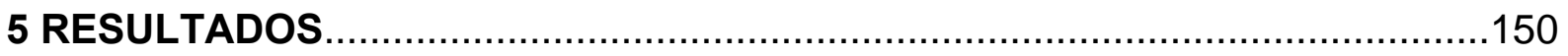

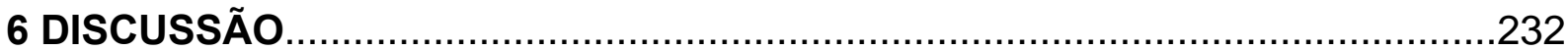

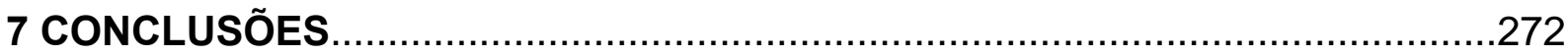

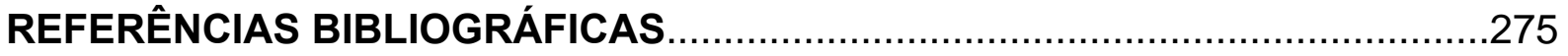

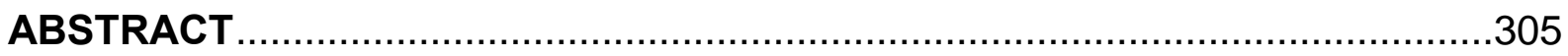

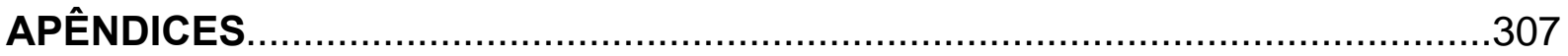




\section{LISTA DE FIGURAS}

FIGURA 2.1 - $\quad$ As seis categorias de crescimento mandibular e as distâncias Co-Pog correspondentes, segundo PETROVIC ${ }^{137} \quad 28$

FIGURA 2.2 - $\quad$ Arborização em três níveis ${ }^{99} \quad 29$

FIGURA 2.3- $\quad$ Fluxograma para a identificação dos grupos rotacionais $\quad 37$

FIGURA 2.4 - $\quad$ Objetivos terapêuticos segundo LAVERGNE ${ }^{92} 39$

FIGURA 4.1 - Variáveis avaliadas na análise de modelo 110

FIGURA 4.2 - $\quad$ Índice de irregularidade de Little 110

FIGURA 4.3 - Sobreposição mandibular $\quad 113$

FIGURA 4.4 - Sobreposição na base do crânio $\quad$ S 115

FIGURA 4.5 - $\quad$ Sobreposição regional maxilar 117

FIGURA 4.6 - Sobreposição regional mandibular $\quad 118$

FIGURA 4.7 - $\quad$ Correção molar total 119

FIGURA 4.8 - Correção incisal total $\quad 120$

FIGURA 4.9 - Diagrama de JOHNSTON JÚNIOR $\quad$ D0,82 (“Pitchfork Analysis”) 121

FIGURA 4.10 - O padrão de crescimento translatório 123

FIGURA 4.11 - Desenho anatômico, e pontos cefalométricos 126

FIGURA 4.12 - $\quad$ Linhas e planos cefalométricos 128

FIGURA 4.13 - Avaliação da posição e do comprimento da maxila 129

FIGURA 4.14 - $\quad$ Avaliação da posição e do comprimento da mandíbula 131

FIGURA 4.15 - Avaliação da relações intermaxilares 132 
FIGURA 4.16 - $\quad$ Avaliação das relações verticais

FIGURA 4.17 - $\quad$ Avaliação das relações dentárias

FIGURA 4.18 - $\quad$ Avaliação do perfil tegumentar

FIGURA 4.19 - Traçado Cefalométrico de PETROVIC/LAVERGNE

FIGURA 4.20 - Estimativa da Unidade de Crescimento Esperado (EGU)

FIGURA 5.1 - Comportamento das categorias ao longo do tempo para a variável comprimento do arco (6-1)

FIGURA 5.2 - Distribuição dos valores individuais do índice de Little por categoria no período inicial

FIGURA 5.3 - Distribuição dos valores individuais do índice de Little por categoria no período final

FIGURA 5.4 - Distribuição dos valores individuais do índice de Little por categoria no período de pós-contenção

FIGURA 5.5 - Gráfico das porcentagens do índice de Little por categoria de crescimento no período de pós-contenção

FIGURA 5.6 - Comportamento dos grupos com diferentes rotações mandibulares ao longo do tempo para a variável trespasse vertical

FIGURA 5.7 - $\quad$ Comportamento dos grupos com diferentes rotações mandibulares ao longo do tempo para a variável curva de Spee

FIGURA 5.8 - $\quad$ Comparação das alterações produzidas na categoria 1177

FIGURA 5.9 - Comparação das alterações produzidas na categoria $2 \quad$ C 177

FIGURA 5.10 - Comparação das alterações produzidas na categoria 3177

FIGURA 5.11 - Comparação das alterações produzidas na categoria $4 \quad 178$

FIGURA 5.12 - Comparação das alterações produzidas na categoria 5178

FIGURA 5.13 - Comparação das alterações produzidas na rotação posterior 179 
FIGURA 5.14 - Comparação das alterações produzidas na rotação anterior 179

FIGURA 5.15 - Comparação das alterações produzidas na rotação neutra 179

FIGURA 5.16 - Traçado composto médio para os pacientes da categoria 1 na fase inicial

FIGURA 5.17 - Traçado composto médio para os pacientes da categoria 1 na fase final

FIGURA 5.18 - Traçado composto médio para os pacientes da categoria 1 na fase de pós-contenção

FIGURA 5.19 - Sobreposição dos traçados compostos médios para os pacientes da categoria 1 nas fases inicial, final e de pós-contenção

FIGURA 5.20 - Traçado composto médio para os pacientes da categoria 2 na fase inicial

FIGURA 5.21 - Traçado composto médio para os pacientes da categoria 2 na fase final

FIGURA 5.22 - Traçado composto médio para os pacientes da categoria 2 na fase de pós-contenção

FIGURA 5.23 - Sobreposição dos traçados compostos médios para os pacientes da categoria 2 nas fases inicial, final e de pós-contenção

FIGURA 5.24 - Traçado composto médio para os pacientes da categoria 3 na fase inicial

FIGURA 5.25 - $\quad$ Traçado composto médio para os pacientes da categoria 3 na fase final

FIGURA 5.26 - $\quad$ Traçado composto médio para os pacientes da categoria 3 na fase de pós-contenção

FIGURA 5.27 - Sobreposição dos traçados compostos médios para os pacientes da categoria 3 nas fases inicial, final e de pós-contenção

FIGURA 5.28 - $\quad$ Traçado composto médio para os pacientes da categoria 4 
FIGURA 5.29 - $\quad$ Traçado composto médio para os pacientes da categoria 4 na fase final 206

FIGURA 5.30 - $\quad$ Traçado composto médio para os pacientes da categoria 4 na fase de pós-contenção

FIGURA 5. 31 - Sobreposição dos traçados compostos médios para os pacientes da categoria 4 nas fases inicial, final e de pós-contenção

FIGURA 5.32 - $\quad$ Traçado composto médio para os pacientes da categoria 5 na fase inicial

FIGURA 5.33 - $\quad$ Traçado composto médio para os pacientes da categoria 5 na fase final

FIGURA 5.34 - $\quad$ Traçado composto médio para os pacientes da categoria 5 na fase de pós-contenção

FIGURA 5.35 - Sobreposição dos traçados compostos médios para os pacientes da categoria 5 nas fases inicial, final e de pós-contenção

FIGURA 5.36 - $\quad$ Traçado composto médio para os pacientes com rotação anterior da mandíbula na fase inicial

FIGURA 5.37 - $\quad$ Traçado composto médio para os pacientes com rotação anterior da mandíbula na fase final

FIGURA 5.38 - $\quad$ Traçado composto médio para os pacientes com rotação anterior da mandíbula na fase de pós-contenção

FIGURA 5.39 - Sobreposição dos traçados compostos médios para os pacientes com rotação anterior nas fases inicial, final e de pós-contenção

FIGURA 5.40 - $\quad$ Traçado composto médio para os pacientes com rotação neutra da mandíbula na fase inicial

FIGURA 5.41 - $\quad$ Traçado composto médio para os pacientes com rotação neutra da mandíbula na fase final

FIGURA 5.42 - $\quad$ Traçado composto médio para os pacientes com rotação 
FIGURA 5.43 - Sobreposição dos traçados compostos médios para os pacientes com rotação neutra nas fases inicial, final e de pós-contenção

FIGURA 5.44 - $\quad$ Traçado composto médio para os pacientes com rotação posterior da mandíbula na fase inicial

FIGURA 5.45 - $\quad$ Traçado composto médio para os pacientes com rotação posterior da mandíbula na fase final

FIGURA 5.46 - $\quad$ Traçado composto médio para os pacientes com rotação posterior da mandíbula na fase de pós-contenção

FIGURA 5.47 - Sobreposição dos traçados compostos médios para os pacientes com rotação posterior nas fases inicial, final e de pós-contenção

FIGURA 5.48 - Coeficientes de correlação da Tabela 5.53 


\section{LISTA DE TABELAS}

TABELA 2.1 - Intensidade de crescimento (EGU): anos de crescimento padronizados, segundo JOHNSTON JÚNIOR ${ }^{83}$

TABELA 2.2 - Efetividade clínica dos aparelhos ortopédicos, funcionais e ortodônticos relacionados aos grupos de rotação de crescimento facial

TABELA 4.1 - Distribuição dos pacientes por extração de pré-molares inferiores e categoria de crescimento

103

TABELA 4.2 - Distribuição dos pacientes por extração de pré-molares inferiores e grupo de rotação mandibular

TABELA 4.3 - Distribuição dos pacientes por extração de pré-molares inferiores e dimensão vertical (mordida)

TABELA 4.3 - Distribuição dos pacientes por sexo e categoria de crescimento, e médias de idade por categoria para cada momento

TABELA 4.4 - $\quad$ Distribuição dos pacientes por sexo e rotação mandibular, e médias de idade por rotação para cada momento

TABELA 4.5 - Distribuição dos pacientes por sexo e dimensão vertical, e médias de idade por dimensão para cada momento

TABELA 4.6 - Desvios padrão do erro (DPe) e resultados do teste "t" para as diferenças entre as médias da primeira $e$ da segunda medições para as variáveis da análise de modelos

TABELA 4.7 - Desvios padrão do erro (DPe) e resultados do teste "t" para as diferenças entre as médias da primeira $e$ da segunda medições para as variáveis da análise de JOHNSTON JÚNIOR

TABELA 4.8 - Desvios padrão do erro (DPe) e resultados do teste "t" para as diferenças entre as médias da primeira $e$ da segunda medições para as variáveis da análise cefalométrica convencional

TABELA 5.1 - Médias e desvios padrão para as variáveis da análise de modelos nas fases inicial, final e de pós-contenção 
TABELA 5.2 - Médias e desvios padrão para as variáveis da análise de modelos por categoria de crescimento e momento

TABELA 5.3 - $\quad$ Alterações do tratamento $(F-I)$, pós-tratamento $(P C-F)$ e totais (PC - I) para as variáveis da análise de modelos nas diferentes categorias de crescimento

TABELA 5.4 - $\quad$ Testes de hipóteses para avaliar as variáveis da análise de modelos nas fases inicial, final e de pós-contenção por categoria de crescimento

TABELA 5.5 - Níveis descritivos para a variável trespasse vertical após a comparação entre as categorias de crescimento

TABELA 5.6 - Distribuição dos pacientes por categoria de crescimento no período de pós-contenção, segundo valor para o índice de Little menor ou maior que $3,5 \mathrm{~mm}$

TABELA 5.7 - Médias e desvios padrão para as variáveis da análise de modelos por rotação mandibular e momento

TABELA 5.8 - $\quad$ Alterações do tratamento $(F-I)$, pós-tratamento (PC - F) e totais (PC - I), para as variáveis da análise de modelos nos diferentes grupos de rotações mandibulares

TABELA 5.9 - Testes de hipóteses para avaliar as variáveis da análise de modelos nas fases inicial, final e de pós-contenção por grupo de rotação mandibular

TABELA 5.10 - Médias e desvios padrão para as variáveis da análise de modelos por tipos de mordida $(\mathrm{OB}=$ aberta; $\mathrm{DB}=$ profunda; $\mathrm{N}=$ normal) e momento

TABELA 5.11 - Testes de hipóteses para avaliar as variáveis da análise de modelos nas fases inicial, final e de pós-contenção por tipo de mordida

TABELA 5.12 - Correlação entre as diferenças do índice de Little (IL póscontenção - IL final) e as diferenças das distâncias intercaninos (3-3 Final - 3-3 Inicial) e entre pré-molares (5-5 Final - 5-5 Inicial)

TABELA 5.13 - Médias e desvios padrão para as variáveis da análise de JOHNSTON JÚNIOR avaliadas entre as fases inicial $X$ final, 
TABELA 5.14 - Testes de hipóteses para avaliar as diferenças das variáveis da análise de JOHNSTON JÚNIOR entre as fases inicial $X$ final, por categoria

TABELA 5.15 - Médias e desvios padrão para as variáveis da análise de JOHNSTON JÚNIOR avaliadas entre as fases inicial $\mathrm{X}$ final, por grupo de rotação mandibular

TABELA 5.16 - Testes de hipóteses para avaliar as diferenças das variáveis da análise de JOHNSTON JÚNIOR entre as fases inicial $X$ final, por rotação

TABELA 5.17 - Médias e desvios padrão para as variáveis da análise de JOHNSTON JÚNIOR avaliadas entre as fases final $X$ pós-contenção, por categoria de crescimento

TABELA 5.18 - Testes de hipóteses para avaliar as diferenças das variáveis da análise de JOHNSTON JÚNIOR entre as fases final $X$ pós-contenção, por categoria

TABELA 5.19 - Médias e desvios padrão para as variáveis da análise de JOHNSTON JÚNIOR avaliadas entre as fases final $X$ póscontenção, por tipos de rotação mandibular

TABELA 5.20 - Testes de hipóteses para avaliar as diferenças das variáveis da análise de JOHNSTON JÚNIOR entre as fases final $X$ pós-contenção, por tipos de rotação mandibular

TABELA 5.21 - Médias e desvios padrão das variáveis da análise de JOHNSTON JÚNIOR avaliadas entre as fases inicial X póscontenção, por categoria de crescimento

TABELA 5.22 - Testes de hipóteses para avaliar as diferenças das variáveis da análise de JOHNSTON JÚNIOR entre as fases inicial $X$ pós-contenção, por categoria de crescimento

TABELA 5.23 - Médias e desvios padrão para as variáveis da análise de JOHNSTON JÚNIOR avaliadas entre as fases inicial $X$ póscontenção, por grupo de rotação mandibular

TABELA 5.24 - Testes de hipóteses para avaliar as diferenças das variáveis da análise de JOHNSTON JÚNIOR entre as fases inicial X 
TABELA 5.25 - Médias e desvios padrão das variáveis rotações maxilar e mandibular para os momentos inicial $X$ final $\mathrm{e}$ final $\mathrm{X}$ póscontenção em função do tipo de mordida (aberta = OB; profunda $=\mathrm{DB} ;$ normal $=\mathrm{N}$ )

TABELA 5.26 - Testes de hipóteses para as variáveis rotações maxilar e mandibular para os momentos inicial $X$ final e final $X$ póscontenção em função do tipo de mordida (aberta $=\mathrm{OB}$; profunda $=\mathrm{DB} ;$ normal $=\mathrm{N}$ )

TABELA 5.27 - Coeficientes de correlação $(r)$ e níveis descritivos $(p)$ para a relação entre 0 crescimento e as alterações dentárias e rotacionais acontecidas durante o tratamento (inicial $\mathrm{X}$ final) para toda a amostra

TABELA 5.28 - Coeficientes de correlação $(r)$ e níveis descritivos $(p)$ para a relação entre o crescimento e as alterações dentárias e rotacionais acontecidas durante o tratamento (inicial $X$ final) para os pacientes do grupo $A$

TABELA 5.29 - Coeficientes de correlação ( $r$ ) e níveis descritivos (p) para a relação entre o crescimento e as alterações dentárias e rotacionais acontecidas durante o tratamento (inicial $\mathrm{X}$ final) para os pacientes do grupo $P$

TABELA 5.30 - Coeficientes de correlação $(r)$ e níveis descritivos $(p)$ para a relação entre $o$ crescimento e as alterações dentárias e rotacionais acontecidas durante o tratamento (inicial $\mathrm{X}$ final) para os pacientes do grupo $R$

TABELA 5.31 - Coeficientes de correlação $(r)$ e níveis descritivos $(p)$ para a relação entre $o$ crescimento e as alterações dentárias e rotacionais acontecidas após o tratamento (final $X$ póscontenção) para toda amostra

TABELA 5.32 - $\quad$ Coeficientes de correlação $(r)$ e níveis descritivos $(p)$ para a relação entre o crescimento e as alterações dentárias e rotacionais acontecidas após o tratamento (final $X$ póscontenção) para os pacientes do grupo A

TABELA 5.33 - Coeficientes de correlação ( $r$ ) e níveis descritivos $(p)$ para a relação entre o crescimento e as alterações dentárias e 
rotacionais acontecidas após o tratamento (final $X$ póscontenção) para os pacientes do grupo $\mathrm{P}$

TABELA 5.34 - Coeficientes de correlação ( $r$ ) e níveis descritivos (p) para a relação entre 0 crescimento e as alterações dentárias e rotacionais acontecidas após o tratamento (final X póscontenção) para os pacientes do grupo $R$

TABELA 5.35 - Coeficientes de correlação ( $r$ ) e níveis descritivos (p) para a relação entre as alterações pós-tratamento do índice de Little e as rotações maxilar e mandibular, e o trespasse vertical (PC - final)

TABELA 5.36 - Coeficientes de correlação $(r)$ e níveis descritivos $(p)$ para a relação entre as alterações pós-tratamento do trespasse vertical (PC - final) e as rotações maxilar e mandibular (PC $X$ final), bem como entre as rotações

TABELA 5.37 - Médias e desvios padrão das variáveis da análise convencional por categoria de crescimento, nas fases inicial (I), final (F), e de pós-contenção (PC)

TABELA 5.38 - Testes de hipóteses para avaliar as diferenças das variáveis da análise convencional entre as fases inicial, final e de pós-contenção por categoria

TABELA 5.39 - Alterações médias do tratamento (Final - Inicial) para as variáveis da análise convencional por categoria de crescimento

TABELA 5.40 - Testes de hipóteses para avaliar as diferenças médias das variáveis da análise convencional quanto às alterações do tratamento (Final - Inicial) por categoria de crescimento

TABELA 5.41 - Alterações médias pós-tratamento (Pós-contenção X Final) para as variáveis da análise convencional por categoria de crescimento

TABELA 5.42 - Testes de hipóteses para avaliar as diferenças médias das variáveis da análise convencional quanto às alterações póstratamento (pós-contenção - final) por categoria de crescimento

TABELA 5.43 - Alterações médias totais (pós-contenção $X$ inicial) para as 
variáveis da análise convencional por categoria de crescimento

TABELA 5.44 - $\quad$ Testes de hipóteses para avaliar as diferenças médias das variáveis da análise convencional quanto às alterações totais (pós-contenção - inicial) por categoria de crescimento

TABELA 5.45 - Médias e desvios padrão das variáveis da análise convencional, nas fases inicial (I), final $(F)$ e de póscontenção (PC) por rotação mandibular

TABELA 5.46 - Testes de hipóteses para avaliar as diferenças das variáveis da análise convencional entre as fases inicial, final e de pós-contenção por rotação

TABELA 5.47 - Alterações médias do tratamento (final-inicial) para as variáveis da análise convencional por rotação mandibular

TABELA 5.48 - Testes de hipóteses para avaliar as diferenças médias das variáveis da análise convencional quanto às alterações do tratamento (Final - Inicial) por rotação mandibular

TABELA 5.49 - Alterações médias pós-tratamento (pós-contenção $X$ final) para as variáveis da análise convencional por rotação mandibular

TABELA 5.50 - Testes de hipóteses para avaliar as diferenças médias das variáveis da análise convencional quanto às alterações póstratamento (pós-contenção - final) por rotação mandibular

TABELA 5.51 - Alterações médias totais (pós-contenção $X$ inicial) para as variáveis da análise convencional por rotação mandibular

TABELA 5.52 - Testes de hipóteses para avaliar as diferenças médias das variáveis da análise convencional quanto às alterações totais (pós-contenção - inicial) por rotação mandibular

TABELA 5.53 - Coeficientes de correlação linear para a relação entre a alteração do índice Little pós-tratamento (IL PC - IL F) e as alterações pós-tratamento $(\mathrm{PC}-\mathrm{F})$ das variáveis da análise convencional

TABELA 5.54 - Coeficientes de correlação linear para a relação entre a alteração do índice Little pós-tratamento (IL PC - IL F ) e as 
alterações pós-tratamento (PC - F) nos grupos de rotação mandibular das variáveis da análise convencional com correlação significante para toda a amostra 
RESUMO 


\section{RESUMO}

O tratamento ortodôntico possui diversos objetivos, sendo que um dos mais importantes é a estabilidade das correções alcançadas, entretanto, após várias décadas de estudos, ficou evidenciado que a estabilidade do alinhamento dos dentes é altamente variável e amplamente imprevisível. Considerando que é de grande valia para os ortodontistas clínicos a possibilidade de se prever prováveis alterações oclusais no período pós-tratamento, resolvemos investigar a recidiva, motivados pelos aspectos promissores da análise de PETROVIC/LAVERGNE em relação ao seu prognóstico. A amostra utilizada neste estudo consistiu de 100 pacientes leucodermas, com média de idade inicial de 12 anos e 4 meses, de ambos os sexos, com má-oclusão de Classe II, pertencentes às categorias de crescimento de PETROVIC, tratados pela técnica do Arco de Canto Simplificada e aparelho extrabucal com extrações de quatro pré-molares. As telerradiografias laterais e os modelos de estudo das fases inicial, final e de pós-contenção (média de 10 anos) foram avaliados utilizando-se as análises de modelos, a cefalométrica convencional e a de JOHNSTON JÚNIOR, para a comparação da recidiva entre os grupos. Como resultado, foi encontrado que, sob o ponto de vista clínico, os pacientes da categoria 4 apresentaram melhor estabilidade do alinhamento dos incisivos inferiores no período pós-tratamento, tendo um resultado satisfatório em $78,57 \%$ dos casos. 0 crescimento da maxila e da mandíbula não apresentou uma correlação significante com a recidiva do apinhamento dentário ântero-inferior. Os pacientes da categoria 1 
apresentaram menor tendência enquanto, os pacientes da categoria 3 apresentaram maior tendência para o aumento do trespasse vertical após o tratamento ortodôntico. De forma geral, os principais fatores responsáveis pela recidiva das relações molar e incisal foram, respectivamente, as mesializações dos molares e incisivos superiores. E, ao se considerar as alterações totais em todas as categorias estudadas, o crescimento/deslocamento anterior da mandíbula foi o principal responsável pela correção das relações molar e incisal. Os pacientes pertencentes aos grupos com rotação neutra e posterior apresentaram uma rotação mandibular em sentido antihorário (anterior) durante os períodos de tratamento e de pós-tratamento. A rotação mandibular não apresentou uma relação significativa com a recidiva do apinhamento dos incisivos inferiores pós-tratamento. A análise do perfil facial na fase de póscontenção foi mais satisfatória nos pacientes das categorias 1, 2 e 3, enquanto os pacientes das categorias 4 e 5 apresentaram o perfil acentuadamente retruído. 
1 INTRODUÇÃO 


\section{INTRODUÇÃO}

O tratamento ortodôntico possui diversos objetivos, sendo que um dos mais importantes é a estabilidade das correções alcançadas. Já em 1907, $\mathrm{ANGLE}^{5}$ citava que os dentes não permanecem em suas novas posições se o tratamento não estabelecer uma oclusão normal.

Normalmente, os tratamentos ortodônticos são longos e empregam técnicas complexas, conseguindo, muitas vezes, resultados admiráveis; estes, entretanto, podem se perder em graus variados após a remoção dos aparelhos ativos. O tipo típico de recidiva ortodôntica está bem documentado na literatura ${ }^{201}$, e inclui o apinhamento ou espaçamento dos dentes, o retorno de trespasses horizontal e vertical aumentados, e a instabilidade das correções da relação molar de Classe II e de Classe III.

É lamentável, entretanto, que o fracasso no tratamento ortodôntico sempre seja julgado pelos pacientes e ortodontistas como estando associado com a recorrência da irregularidade ântero-inferior ${ }^{32}$.

A etiologia do apinhamento inferior após o tratamento ortodôntico parece ser multifatorial. Alguns fatores dependem de medidas relacionadas ao tratamento ortodôntico ${ }^{212}$, como: falta de uma completa correção da giroversão dos dentes, o que leva a uma quebra dos pontos de contato ${ }^{219}$; aumento da distância intercaninos ${ }^{163,177,194}$; alteração da forma dos $\operatorname{arcos}$ dentários ${ }^{37,40}$; protrusão excessiva dos incisivos ${ }^{1,26,178}$; uma oclusão em desarmonia ${ }^{212}$; habilidade do profissional ${ }^{201}$; falha na remoção das causas da má-oclusão ${ }^{62}$; 
tempo de contenção ${ }^{105,177,201}$. Outros fatores mencionados, entretanto, são dependentes do paciente em si como: a recidiva da correção do trespasse vertical $^{207}$; a irrupção dos terceiros molares ${ }^{158}$; o componente anterior de força da oclusão e o grau de união entre os contatos interdentários ${ }^{64,189,190}$; a continuação do crescimento da maxila e da mandíbula após o término do tratamento ${ }^{54,207}$; a idade e o sexo do paciente ${ }^{166}$; o tamanho e a forma dos dentes ${ }^{69,155}$; a morfologia das bases apicais ${ }^{51,171}$; a rotação de crescimento da mandíbula ${ }^{133,157,201}$; os hábitos bucais ${ }^{164}$; alteração nas atividades de repouso e de função dos músculos faciais e mastigatórios ${ }^{216}$; a diferença no padrão de crescimento entre o esqueleto facial e o tecido tegumentar circundante ${ }^{180}$; o estiramento das fibras colágenas do ligamento periodontal ${ }^{153,154}$; a alteração das propriedades elásticas de todo o tecido gengival ${ }^{152}$. Esses são alguns dos fatores relacionados com a recidiva póstratamento. A maioria deles parece estar relacionada com o crescimento craniofacial, com o desenvolvimento dentário e com a função muscular ${ }^{73,201}$.

Após várias décadas de estudos, ficou evidenciado que a estabilidade do alinhamento dos dentes é altamente variável e amplamente imprevisível. Alguns estudos liderados por LITTLE ${ }^{106,109}$ mostram que um alinhamento dentário inferior satisfatório, 10 anos após a remoção da contenção foi mantido em menos de 30\% dos pacientes, com aproximadamente $20 \%$ dos casos, demonstrando um apinhamento marcante muitos anos após a remoção da contenção. As alterações continuaram durante a segunda década de vida dos pacientes e somente diminuíram após a idade de 30 anos. Entretanto, a raridade com que oclusões ideais são encontradas e a similaridade das alterações no período pós- 
tratamento com aquelas observadas em estudos longitudinais de oclusões normais $^{17,158,182,201}$, como: uma diminuição na largura e no comprimento do arco inferior e um aumento no apinhamento dos incisivos inferiores, sugerem que as alterações pós-tratamento são parte do processo normal de maturação da oclusão, ao invés de resultado da terapia ${ }^{201}$. Muitos autores ${ }^{87,105,132,168,179}$ têm considerado a estabilidade dos incisivos inferiores após o tratamento ortodôntico como um ideal utópico e têm sugerido que a contenção indefinida é a única solução.

Esses dados pessimistas não deveriam gerar uma atitude negativa entre os ortodontistas, mas, sim, estimular maiores esforços no sentido de se tentar conseguir os melhores resultados possíveis para os pacientes ${ }^{219}$, além de uma intensificação na elaboração de estudos que possam detectar e anular as causas das recidivas, conseguindo-se, assim, resultados mais estáveis ${ }^{39,84}$.

LAVERGNE $^{91}$, PETROVIC; STUTZMANN ${ }^{142}$, PETROVIC; STUTZMANN; LAVERGNE $^{147}$, baseados em estudos cefalométricos e biológicos, propuseram uma classificação do crescimento facial com seis categorias de crescimento, a qual fornece grupos homogêneos e estáveis que se desenvolvem semelhantemente e respondem de uma mesma forma a um mesmo tipo de tratamento. Segundo LAVERGNE ${ }^{92}$, os pacientes dos grupos rotacionais R2D e R1N, que possuem uma rotação neutra da mandíbula, apresentam uma maior estabilidade pós-tratamento ortodôntico.

Caso a análise de PETROVIC/LAVERGNE realmente mostre os diferentes níveis de recidiva pós-tratamento, ela pode ser tornar uma ferramenta 
indispensável no arsenal ortodôntico, facilitando não só o diagnóstico e o planejamento do tratamento, mas também a previsão de resposta dos pacientes no período pós-contenção.

Considerando que é de grande valia para os ortodontistas clínicos a possibilidade de se prever prováveis alterações oclusais no período póstratamento, e motivados pelos aspectos promissores da análise de PETROVIC/LAVERGNE, resolvemos investigá-la. Para isso, foram empregados pacientes com má-oclusão de Classe II, pertencentes às categorias de crescimento de PETROVIC, tratados pela técnica do Arco de Canto Simplificada e aparelho extrabucal com extrações de dois pré-molares superiores e dois inferiores. Foram utilizadas as análises de modelos de estudo, a cefalométrica convencional e a de JOHNSTON JÚNIOR para a comparação entre os grupos. 
2 REVISÃO DE
LITERATURA 


\section{REVISÃO DE LITERATURA}

Tendo por objetivo facilitar a leitura e também a compreensão dos assuntos abordados neste trabalho, a revisão de literatura foi dividida em tópicos. Assim, ela permitiu descrever passo a passo cada um dos assuntos, até que se chegasse a estudos que tratam da recidiva pós-tratamento ortodôntico, com os quais os nossos resultados foram comparados. Além disso, os tópicos não tinham a finalidade de esgotar individualmente 0 assunto, mas, sim, de descrever alguns trabalhos relevantes dentro da literatura específica.

\subsection{A MÁ-OCLUSÃO DE CLASSE II}

A classificação das más-oclusões foi realizada por $\mathrm{ANGLE}^{4}$ em 1899; ele definiu a Classe II, Divisão 1, como uma relação mésio-distal deficiente dos arcos dentários, com todos os dentes inferiores ocluindo distalmente em relação à posição normal, produzindo uma desarmonia acentuada na região dos incisivos e nas linhas faciais. $\mathrm{O}$ arco superior deveria apresentar-se atrésico, e os incisivos, superiores protruídos.

Em 1907, ANGLE ${ }^{5}$, simplificou sua definição, relatando estar o arco dentário inferior em relação distal quanto ao superior, apresentando incisivos superiores em protrusão e, pelo menos inicialmente, associados à respiração bucal.

SASSOUNI ${ }^{170}$, em 1970, afirmou haver pelo menos 64 situações diferentes nas más-oclusões de Classe II com mordida profunda e outras 64 com mordida aberta. 
VIGORITO $^{209}$, em 1973, observou que a mandíbula se apresenta retroposicionada ou com tamanho diminuído na má-oclusão de Classe II, Divisão 1 , e que ela geralmente exibe um plano mandibular com valor aumentado.

MOYERS et al. ${ }^{126}$ realizaram, em 1980, um estudo no qual dividiram uma amostra de 697 pacientes com má-oclusão de Classe II em 6 tipos horizontais $(A, B, C, D, E, F)$ e 5 verticais $(1,2,3,4,5)$. Nem todos os tipos verticais apresentam correspondência com cada tipo horizontal; tampouco é necessário um tipo horizontal estar associado com um tipo vertical, mas há um forte relacionamento entre as características horizontais e as verticais, que permite a identificação de 15 subtipos com características distintivas. Segundo os autores ${ }^{126}$, as pessoas dentro desses tipos deveriam parecer semelhantes, crescer semelhantemente, requerer um mesmo tratamento e responder de uma mesma forma a um mesmo tratamento. Para os autores ${ }^{126}$, essa classificação mais precisa da Classe II pode resultar em tratamentos baseados no tipo facial específico ao qual o paciente individualmente pertence. Além disso, é mais fácil fazer modificações individualizadas para as necessidades de um dado paciente dentro de um conhecimento descritivo preciso com respeito à morfologia e crescimento de cada tipo facial, em vez do amplo contexto da Classe II.

SOLOW ${ }^{187}$, em 1980, ao descrever o mecanismo compensatório dentoalveolar, relatou que as más-oclusões que refletem as discrepâncias no relacionamento das bases ósseas não são causadas diretamente pela discrepância no relacionamento dos maxilares. Ao contrário, elas podem ser consideradas como sendo originadas pelo fato de que a discrepância no relacionamento da base óssea não foi compensada devido a um mecanismo compensatório dentoalveolar insuficiente ou inoperante. Segundo o autor ${ }^{187}$, isso 
é de grande importância na interpretação dos numerosos estudos nos quais a morfologia esquelética de indivíduos com más-oclusões de Classe I, II e III é comparada. Tais estudos não chegam a resultados conclusivos porque, em todos os tipos de anomalias oclusais, pode-se ver uma grande variação de relações intermaxilares. As diferenças nas relações interarcos de más-oclusões de Classe I, II e III não são diretamente devidas às diferenças nas morfologias esqueléticas, mas, sim, ao fato de que, no grupo de Classe I, a variação na relação intermaxilar foi compensada pelo mecanismo dentoalveolar, enquanto que nos grupos de Classe II ou III, ela não foi.

Em 1981, McNAMARA JÚNIOR ${ }^{117}$ realizou um estudo em 277 pacientes com má-oclusão de Classe II, a fim de avaliar a presença e a distribuição de quatro componentes horizontais e de um vertical, que seriam responsáveis pelas alterações dentoesqueléticas. O autor ${ }^{117}$ concluiu que a má-oclusão de Classe II não é uma entidade clínica única. Ao contrário, ela pode resultar de numerosas combinações dos componentes. A partir dessa amostra, foram encontradas 77 combinações, ou seja, 77 tipos diferentes de Classes II. Segundo o autor ${ }^{117}$, a escolha do tratamento da Classe II deveria estar baseada no problema individual do paciente e não na preferência do clínico.

Pesquisando sobre o crescimento longitudinal de crianças com máoclusão de Classe II, Divisão 1, sem tratamento, BUSCHANG et al. ${ }^{30}$, em 1988, analisaram telerradiografias de 42 jovens canadenses, acompanhados dos 6 aos 15 anos. Observaram que a taxa de crescimento da mandíbula nessa má-oclusão é menor em comparação com a amostra com oclusão normal $(0,2$ a 0,4 mm/ano menor) em uma fase mais precoce (dos 6 aos 10 anos), nivelando-se posteriormente (dos 10 aos 15 anos). Observaram, ainda, a existência uma 
tendência de crescimento vertical maior nos indivíduos com má-oclusão, embora não estatisticamente significante.

CEVIDANES;VIGORITO ${ }^{33}$, em 1995, fizeram um estudo com uma amostra de 69 pacientes com retroversão facial, os quais apresentavam má-oclusão de Classe II, Divisão 1. A análise das Contrapartes foi utilizada para o estudo das características morfológicas do complexo craniofacial. Entre outros resultados, os autores $^{18}$ encontraram, com o auxílio de uma análise de "clusters", a existência de 15 subgrupos na amostra, utilizando as variáveis das Contrapartes, o que evidenciou a variabilidade do padrão dentoesquelético craniofacial.

No contexto do tratamento da má-oclusão de Classe II, segundo JOHNSTON JÚNIOR ${ }^{83}$, a maioria provavelmente concordaria em que um excesso de crescimento mandibular seria útil, tanto para o paciente quanto para 0 ortodontista. A literatura demonstra uma módica evidência de que isso é precisamente o tipo de padrão que se vê em muitos pacientes com Classe II, independentemente da estratégia de tratamento. Há, entretanto, uma tendência no sentido de se esperar (e talvez para ver) um crescimento favorável apenas nos pacientes tratados com aparelhos funcionais. Como resultado, a terapia de modificação do crescimento pode receber mais crédito que ela merece no mundo das observações clínicas e impressões otimistas, embora não controladas. Neste estudo $^{83}$, o padrão sagital de crescimento e/ou deslocamento maxilomandibular ("alteração da base apical") foi examinado em 120 pacientes com Classe II tratados pela técnica do Arco de Canto. Independentemente do tratamento (com 
ou sem extrações), 9 de cada 10 pacientes mostraram um padrão de alteração,

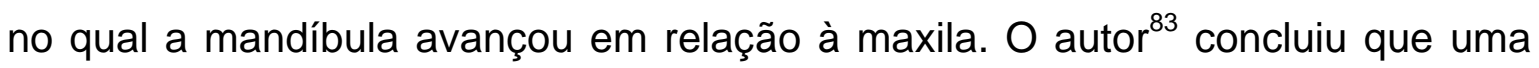
verificação das alternativas de tratamento, especialmente daquelas destinadas a modificar o crescimento, deve seguir esse padrão favorável como uma linha de base a partir da qual os efeitos da modificação do crescimento são julgados. Nesse estudo, o autor ${ }^{83}$ descreveu os valores para a unidade de crescimento esperado (EGU), que são apresentados na TABELA 2.1.

TABELA 2.1 - Intensidade de crescimento (EGU): anos de crescimento padronizados, segundo JOHNSTON JÚNIOR ${ }^{83}$

\section{Intervalo (idade em anos)}

\begin{tabular}{lllllllllllllllll} 
Sexo & $4-5$ & $5-6$ & $6-7$ & $7-8$ & $8-9$ & $9-10$ & $10-11$ & $11-12$ & $12-13$ & $13-14$ & $14-15$ & $15-16$ & $16-17$ & $17-18$ & $18-19$ \\
Homem & 1,28 & 1,23 & 1,18 & 1,14 & 1,08 & 1,01 & 0,9 & 0,83 & 1,08 & 1,4 & 1,68 & 1,48 & 1,09 & 0,69 & 0,29 \\
Mulher & 1,31 & 1,27 & 1,24 & 1,22 & 1,2 & 1,17 & 1,26 & 1,54 & 1,37 & 1,14 & 0,78 & 0,27 & 0 & & & \\
\hline
\end{tabular}

HENRIQUES et al. ${ }^{68}$, em 1998, avaliaram as características dentoesqueléticas da má-oclusão de Classe II, Divisão 1, sem tratamento. Vinte e cinco jovens, com idade inicial de 9 anos e 4 meses e, final, de 12 anos e 8 meses, foram acompanhados por um período de 3 anos e 4 meses. Os autores ${ }^{68}$ verificaram que, em $75 \%$ dos casos, a mandíbula se apresentava retruída, enquanto a maxila variava entre retruída, bem posicionada e protruída. O padrão de crescimento denotou variabilidade, com distribuição uniforme de indivíduos com predominância de crescimento vertical, horizontal e equilíbrio entre os vetores. 
KARLSEN; KROGSTAD ${ }^{86}$, em 1999, realizaram um estudo com dois grupos de meninas, um com relação ântero-posterior normal das bases ósseas, e outro com uma relação distal. As pacientes foram selecionadas aos 6 anos de idade e comparadas longitudinalmente até os 18 anos. Segundo os autores ${ }^{86}$, a relação sagital distal não é uma entidade morfológica causada por alguma aberração específica na base do crânio ou nos maxilares. Ao contrário, é o resultado de uma combinação de desvios predisponentes com graus variados de gravidade. Um corpo mandibular curto e um valor aumentado para o ângulo SN.PM foram as únicas alterações que apresentaram diferença significante entre os grupos. Em todas as jovens investigadas, o prognatismo mandibular aumentou mais que o prognatismo maxilar. O perfil esquelético, portanto, ficou mais próximo do normal (reto) com o crescimento em ambos os grupos, mas menos no grupo com relação distal. Então, as relações sagitais distais nem sempre melhoraram com a idade; ao contrário, elas foram agravadas, quando comparadas ao grupo com relação ântero-posterior normal. O aumento inadequado do comprimento do corpo mandibular, no período de 6 a 12 anos, contribuiu para a piora da relação distal, assim como também contribuiu o crescimento mais vertical que o normal da mandíbula após os 12 anos.

\subsection{AS ROTAÇÕES DE CRESCIMENTO DA MANDÍBULA E AS SUAS RELAÇÕES COM A PREVISÃO DO CRESCIMENTO FACIAL}

BJÖRK ${ }^{22}$, em 1969, demonstrou que, pelo método estrutural, é possível prever, a partir de um único cefalograma, o caminho da rotação de crescimento 
mandibular, quando esta é marcante. Sete sinais estruturais de rotação de crescimento extremo foram considerados em relação à direção do crescimento condilar. Esses sinais são: inclinação da cabeça condilar; curvatura do canal da mandíbula; forma da borda inferior da mandíbula; inclinação da sínfise; ângulo interincisivo; ângulos entre pré-molares e intermolares; e altura da face inferior. A inclinação da borda inferior da mandíbula não foi incluída entre os sinais porque, segundo o autor ${ }^{22}$, ela não ajuda na avaliação.

BJÖRK; SKIELLER ${ }^{23}$, em 1972, realizaram um estudo por meio do método de implantes, onde as alterações do crescimento foram seguidas numa série longitudinal de telerradiografias laterais de 21 pacientes perto da puberdade, por um período de 6 anos. Os autores ${ }^{23}$ observaram que a rotação média da mandíbula, avaliada a partir da linha dos implantes em relação à base do crânio era de - $6^{\circ}$ (sentido anti-horário, anterior), e que a média para a maxila era de $-2,5^{\circ}$. A intensidade do crescimento condilar estava fortemente correlacionada com a rotação da mandíbula, e também significantemente, mas de forma menos acentuada, com a rotação da maxila. A alteração no trespasse vertical foi significantemente correlacionada com a rotação de ambos os maxilares, mais intensamente com a mandíbula. A alteração da inclinação dos incisivos superiores e inferiores em relação à linha Sela-Násio não foi significantemente correlacionada com a rotação da maxila e da mandíbula, nem o foi a alteração do ângulo interincisal. Para os autores ${ }^{23}$, os dentes posteriores essencialmente seguem a rotação dos maxilares. A inclinação dos dentes anteriores, por outro lado, é determinada numa maior extensão, por fatores funcionais, considerando que suas posições na face e em relação uns aos outros tende a persistir, independentemente das rotações dos maxilares. A rotação da face necessita de uma adaptação compensatória dos caminhos de irrupção dos 
dentes. Quando há um desenvolvimento oclusal compensatório completo, os incisivos inferiores mantêm sua inclinação praticamente constante, independentemente da rotação da mandíbula, devido a uma inclinação anterior da base óssea. Os dentes posteriores inferiores também estão envolvidos nesse desenvolvimento oclusal compensatório e também são inclinados para frente. $O$ arco dentário inferior, então, se translada para frente na base óssea, sem sofrer nenhuma alteração apreciável na forma.

SKIELLER; BJÖRK; LINDE-HANSEN ${ }^{186}$ fizeram uma pesquisa em 1984, a qual tinha por objetivo estimar a possibilidade de previsão da direção e da quantidade de rotação da mandíbula com base no critério morfológico observado em uma única telerradiografia tomada na fase pubescente de crescimento. A amostra estudada consistiu de 21 pacientes com padrões de crescimento extremos e com implantes metálicos que foram estudados por seis anos. Durante esse período, a mandíbula sofreu uma rotação anterior (anti-horária) média de $6^{0}$. As quatro variáveis que, em combinação, deram a melhor estimativa do prognóstico $(86 \%)$ da rotação de crescimento mandibular foram a inclinação mandibular, o ângulo intermolares, a forma da borda inferior da mandíbula e a inclinação da sínfise. Segundo os autores ${ }^{186}$, como a análise estatística foi baseada numa amostra de casos extremos, é possível que, em crianças com um padrão de crescimento mais próximo do normal, essas características possam ser menos desenvolvidas.

BAUMRIND; KORN; WEST ${ }^{8}$ realizaram um experimento, em 1984, na tentativa de determinar empiricamente a efetividade de cinco ortodontistas clínicos na diferenciação de pacientes com rotação posterior (horária) e anterior (anti-horária) da mandíbula, com base na informação da telerradiografia inicial, 
realizada antes da correção da má-oclusão de Classe II. Sessenta e quatro pacientes foram divididos em rotação anterior e posterior, com base na magnitude de alteração do plano mandibular de Downs entre as radiografias iniciais e finais. Como resultados, concluíram que: nenhum clínico teve uma avaliação melhor que o acaso; houve uma forte evidência de que os clínicos utilizaram uma série de regras, embora inefetivas, ao fazer as suas previsões; a análise estatística de algumas variáveis cefalométricas também não foi efetiva na previsão. Para os autores ${ }^{8}$, a habilidade dos clínicos em identificar a rotação mandibular é pobre. Portanto, acredita-se que seja improvável que tais previsões desempenhem qualquer papel operacional importante no planejamento do tratamento ortodôntico eficaz no presente estado da arte.

DIBBETS $^{41}$, em 1985, examinou o conceito de rotação intramatriz definido por BJÖRK; SKIELLER ${ }^{25}$ em 1983 e também explorado por LAVERGNE; GASSON $^{93}$. BJÖRK; SKIELLER ${ }^{25}$ afirmaram que essa rotação é uma expressão da remodelação da borda inferior da mandíbula e que a rotação acontecia no corpo da mandíbula. LAVERGNE; GASSON ${ }^{93}$, por outro lado, afirmaram que a rotação afetava o ramo e o ângulo goníaco e, conseqüentemente, o comprimento diagonal condílio-pogônio. Baseado na exploração de dois padrões de crescimento hipoteticamente divergentes, o autor ${ }^{41}$ apresenta uma interpretação alternativa: 1- um crescimento circular com o centro de rotação no mento e nenhum aumento da mandíbula, mas com máxima rotação; 2- uma direção de crescimento linear com o máximo aumento da mandíbula, mas com uma rotação mínima. Na realidade, segundo o autor ${ }^{41}$, a maioria das crianças cairá no meio desses dois padrões extremos. Esse mecanismo para o aumento seletivo da mandíbula em resposta aos incrementos do crescimento condilar pode ser nomeado de rotação contrabalanço. Essa rotação diz respeito ao crescimento 
condilar circular, acompanhado pela remodelação coordenada seletiva, que não contribui para o crescimento da mandíbula.

LEE et al. ${ }^{100}$ fizeram, em 1987, um estudo para determinar a efetividade do método de SKIELLER; BJÖRK; LINDE-HANSEN ${ }^{186}$ de previsão da rotação mandibular. A amostra consistiu de 25 indivíduos (tratados e não tratados ortodonticamente) com implantes metálicos, os quais não apresentavam padrões faciais extremos e eram mais similares aos pacientes que rotineiramente se encontram sob tratamento ortodôntico. A idade inicial dos pacientes era de 8 anos e meio; eles foram estudados por 8 anos. Durante esse período, a mandíbula sofreu uma rotação anterior (anti-horária) média de $-4,9^{\circ}$. Como resultado, foi encontrado que as quatro variáveis do método estudado conseguiram prever apenas $8 \%$ da variância. Os autores ${ }^{100}$ acreditam que a utilização clínica de previsões individualizadas do desenvolvimento craniofacial ainda não é possível.

SOLOW; HOUSTON ${ }^{188}$, em 1988, afirmaram que DIBBETS ${ }^{41}$ introduziu a expressão rotação contrabalanço para descrever o que é essencialmente o mesmo que rotação intramatriz, com a implicação de que as alterações descritas por esse termo representam ajustes da contribuição condilar para o crescimento global em extensão da mandíbula. Esses autores ${ }^{188}$ sugerem as seguintes expressões para descrever as alterações na inclinação das linhas de referência mandibulares: rotação real da mandíbula - rotação do corpo mandibular, representada pelos implantes ou estruturas de referência estáveis em relação à 
base anterior do crânio. Foi denominada de rotação total por BJÖRK; SKIELLER ${ }^{25}$; rotação aparente da mandíbula - alteração angular da linha mandibular em relação à base anterior do crânio. Foi denominada de rotação matriz por BJÖRK; SKIELLER ${ }^{25}$; remodelação angular da borda mandibular alteração angular da linha mandibular quando a mandíbula é registrada em implantes ou estruturas trabeculares estáveis. Foi denominada de rotação intramatriz por BJÖRK; SKIELLER ${ }^{25}$.

DIBBETS $^{42}$, em 1990, quantificou a relação entre a recolocação condilar e o aumento mandibular. Para esse objetivo, a proporção contrabalanço foi definida como a porcentagem de crescimento condilar, detectada pelos implantes, que contribuiu para o aumento da dimensão condílio-pogônio. Essa proporção provou variar amplamente nos 21 casos documentados por BJÖRK; SKIELLER ${ }^{23}$. A conclusão revelou que a rotação contrabalanço, na verdade, deve ser considerada como um mecanismo capaz de neutralizar o crescimento condilar incremental e pode apresentar implicações clínicas.

JOHNSTON JÚNIOR ${ }^{81}$, em 1993, afirmou que a verdadeira previsão de crescimento pode exceder as capacidades da técnica cefalométrica. $O$ autor ${ }^{81}$ questiona por que medidas derivadas a partir de sombras radiográficas deveriam conter, tanto individualmente quanto coletivamente, informações úteis sobre o futuro padrão de crescimento. Além dessa falta de informação, deveria ser somado o erro cefalométrico e a sensibilidade às condições iniciais (um elemento 
básico da teoria do caos). Independentemente da tecnologia, esses fatores limitantes conspirarão para derrotar mesmo a nossa mais imaginativa tentativa de gerar previsões cefalométricas individualizadas e eficientes de crescimento.

Segundo SAMPSON ${ }^{169}$, em 1995, estima-se que ocorra pelo menos o dobro de rotação de crescimento da mandíbula se comparada com a da maxila, o que poderia parcialmente explicar a maior incidência de apinhamento ânteroinferior.

KARLSEN $^{85}$, em 1997, publicou um estudo que tinha por finalidade examinar extensivamente associações entre o crescimento craniofacial vertical e a rotação de crescimento da mandíbula. Para isso, dois grupos de 29 crianças cada, com valores alto e baixo para o ângulo SN.PM, foram estudados longitudinalmente dos 6 aos 15 anos. $O$ aumento na altura facial posterior inferior distinguiu-se por estar consistentemente correlacionado de maneira positiva com a rotação matriz anterior, independentemente do ângulo do plano mandibular e da idade. O mesmo se aplicou para o aumento na altura do ramo. O aumento na altura facial anterior foi, com surpresa, fracamente correlacionado com a rotação mandibular, mas forte e positivamente correlacionado com o aumento no comprimento do corpo. O sobredesenvolvimento da altura facial anterior inferior, nos casos com um ângulo do plano mandibular aumentado, ocorreu porque a inclinação desse plano direcionou o crescimento do corpo mais para baixo que 0 normal, e não porque a mandíbula rotacionou para trás. No presente estudo, os casos com ângulo aumentado apresentaram a rotação total direcionada para frente. Não foi observado nenhum caso com rotação total posterior. Tradicionalmente, acredita-se que os casos com ângulo aumentado apresentem 
rotação posterior. Entretanto, segundo 0 autor ${ }^{85}$, os presentes achados sugerem que o termo "hipo-rotadores anteriores" é mais realista que "rotadores posteriores".

LESLIE et al. ${ }^{103}$ realizaram, em 1998, um estudo a fim de testar o método de previsão da rotação mandibular proposto por SKIELLER; BJÖRK; LINDEHANSEN ${ }^{186}$. A amostra consistiu de 40 indivíduos, não tratados ortodonticamente, sem implantes metálicos. A idade inicial dos pacientes era de 9 anos, tendo eles sido estudados por 6 anos. Durante esse período, a mandíbula sofreu uma rotação anterior (anti-horária) média de $-1,9^{\circ}$. Como resultado, foi encontrado que as quatro variáveis do método estudado conseguiram prever apenas $9 \%$ da variância. Os autores ${ }^{103}$ concluíram que as informações derivadas do traçado cefalométrico inicial, utilizando esse método, não permite previsões clinicamente úteis numa população geral em relação à direção da futura rotação de crescimento da mandíbula.

Em 1998, LUX et $\mathrm{al}^{113}$ publicaram um estudo que tinha por objetivo investigar o emprego da rede neural ("neural network") para agrupar diferentes padrões de crescimento da mandíbula. A amostra empregada consistiu de 43 crianças não tratadas ortodonticamente, que foram analisadas por meio da cefalometria lateral, entre os 7 e 15 anos. A análise do crescimento mandibular por meio da rede neural foi paradigmaticamente apresentada por meio das alterações dos pontos sela, násio e gnátio. Para a descrição das alterações do crescimento, foi empregado o conceito da análise Tensor. Por meio de uma rede neural artificial, chamada de mapas neurais auto-organizados, os dados resultantes do crescimento foram classificados segundo a alteração do tamanho (leve ou grande alteração) e da forma (padrão de crescimento horizontal, vertical 
ou neutro), e as relações dos vários padrões de crescimento foram monitorados. Como resultado da auto-organização, as crianças foram ordenadas topologicamente no mapa resultante, de acordo com suas alterações craniofaciais em forma e tamanho durante o crescimento. Considerando que um novo paciente pode ser alocado no mapa, esse tipo de rede fornece uma estrutura de referência para classificar e analisar casos previamente desconhecidos com respeito a seu padrão de crescimento. Além disso, a posição do paciente no mapa fornece informação se há um padrão de crescimento extremo ou patológico, bem como se um certo padrão de crescimento favorece ou impede o tratamento pretendido.

Segundo BISHARA ${ }^{15}$, em 2000, os ortodontistas clínicos estão interessados em descobrir se o aumento em extensão da mandíbula é traduzido num posicionamento mais para frente do pogônio. Para ele, o posicionamento anterior do mento é mais dependente da rotação/translação da mandíbula para frente que do simples aumento no comprimento mandibular. Isso já foi previamente ilustrado por $\mathrm{BJÖRK}^{22}$, que encontrou que quantidades e direções similares de crescimento nos côndilos podem ser expressas diferentemente no pogônio; tal fato depende do centro de rotação da mandíbula, que pode estar nos côndilos, nos pré-molares ou nos incisivos.

\section{3- TRABALHOS REALIZADOS COM A ANÁLISE DE PETROVIC/LAVERGNE}

Para o desenvolvimento da análise de PETROVIC/LAVERGNE, foram gastos mais de 25 anos de pesquisa ${ }^{136,137}$. Essas pesquisas se desenvolveram inicialmente em duas áreas distintas, sendo uma relacionada com estudos cefalométricos em pacientes com implantes metálicos, e a outra envolvendo 
pesquisas laboratoriais com fragmentos de osso alveolar e osso do ramo mandibular. Essas duas linhas de estudo serão descritas a seguir.

LAVERGNE; GASSON ${ }^{55,56,93}$, ao estudar as rotações mandibular e maxilar e o seu relacionamento com o crescimento facial numa série de pacientes com implantes metálicos, encontraram que, na maioria dos casos, a rotação da mandíbula durante o crescimento parece ser um fenômeno complexo, mostrando variações anuais na direção e na intensidade. A rotação mandibular não é apenas dependente de um mecanismo mandibular isolado, mas também deve ser vista em relação ao crescimento global da face. A rotação é parte de um mecanismo de regulação que tenta harmonizar a taxa de crescimento das diferentes partes componentes da face. Em indivíduos com rotação posterior, todas as partes da mandíbula parecem estar organizadas para atingir um comprimento máximo da mandíbula, o côndilo tem uma direção posterior e o ângulo goníaco apresenta um valor elevado. Por outro lado, nos indivíduos com uma rotação anterior, todas as partes da mandíbula parecem estar adaptadas para um comprimento reduzido, o côndilo tem uma direção vertical e o ângulo goníaco tem um valor reduzido. Com relação à maxila, foi observado que o grau de rotação maxilar mostra variações na direção e na intensidade a cada ano, e que, além disso, é menor, em valor absoluto, que o grau de rotação mandibular. Devido ao fato de a direção das rotações maxilar e mandibular não ser sempre a mesma, parece que a interação entre as rotações maxilar e mandibular desempenha um importante papel na determinação das relações vertical e sagital de ambos os maxilares. Além disso, concluíram que não há ligação entre a variação da rotação maxilar e o crescimento da base do crânio. Uma forte correlação foi encontrada entre a variação do crescimento condilar e a variação da rotação maxilar. 
LAVERGNE; GASSON ${ }^{94}$, em 1977, propuseram duas definições para a rotação mandibular: 1- rotação morfogenética, utilizada para dar informações sobre a alteração na forma da mandíbula; 2- rotação posicional, utilizada para fornecer informações sobre as alterações na posição da mandíbula em relação às estruturas adjacentes. Além disso, foi estabelecida uma relação entre a variação do ângulo goníaco e a variação de ambas as rotações da mandíbula: a morfogenética e a posicional. Segundo os autores ${ }^{94}$, a rotação mandibular anterior parece ser um processo de encurtamento da mandíbula relacionado com alterações específicas no ângulo goníaco e na direção de crescimento condilar, enquanto a rotação posterior parece determinar a máxima extensão da mandíbula, ou seja, ela aumenta o comprimento mandibular.

Para esses autores ${ }^{95}$, a variação da relação sagital intermaxilar e a variação do grau de rotação mandibular são dois fenômenos que mostram um "mecanismo de equilíbrio" quando relacionados com a diferença na quantidade de crescimento da maxila e mandíbula. Essa diferença poderia ser compensada tanto pela rotação mandibular quanto pelas alterações na posição relativa de ambos os maxilares. Além disso, demonstraram ${ }^{96}$ que as más-oclusões sagitais são mais dependentes da forma de utilização do potencial de crescimento que do próprio potencial. As más-oclusões na dimensão vertical parecem estar mais relacionadas com a rotação maxilar. E os presentes achados levam ao conceito de harmonia dos maxilares durante o crescimento. "Deficiências" ou "erros" podem aparecer em dois estágios diferentes, durante o crescimento (ajuste sagital da mandíbula ao complexo maxilar pela rotação, e sincronização das rotações maxilar e mandibular quanto a direção, intensidade e centro), resultando em várias combinações de más-oclusões sagitais e verticais. Essas combinações foram resumidas em um diagrama da morfogênese da face. 
Em 1982, LAVERGNE; GASSON ${ }^{97}$ realizaram um estudo para tentar chegar a uma análise e classificação do padrão de crescimento rotacional sem a utilização de implantes metálicos, utilizando apenas a telerradiografia lateral. A amostra utilizada para o estudo consistiu de 35 pacientes (20 meninos e 15 meninas) com implantes metálicos, que foram radiografados anualmente. Os autores $^{61}$ acharam útil classificar as rotações mandibulares em posterior (rotação, em sentido horário, anual maior que $0^{\circ}$ ), anterior (rotação, em sentido antihorário, anual menor que $-1^{\circ}$ ) e neutra (rotação, em sentido horário, anual entre 0 e $\left.-1^{0}\right)$. Além disso, os resultados dos estudos permitiram o desenvolvimento de um diagrama, que possui a forma de uma arborização em dois níveis e que mostra os padrões de crescimento que já haviam sido descritos ${ }^{96}$. Entretanto, no presente diagrama, o tipo facial é determinado com apenas um cefalograma do paciente, sem a necessidade de implantes. Para se chegar ao tipo facial do paciente, era necessário realizar o traçado cefalométrico de Bergen e utilizar uma tabela de "normas flutuantes" proposta por Hasund. Primeiro, a inclinação mandibular era comparada com seu valor esperado na tabela, levando em conta o ângulo SNB. Segundo, apesar de todas as suas desvantagens, o ângulo ANB foi escolhido para dar uma idéia da diferença no crescimento de ambos os maxilares. E, finalmente, a dimensão vertical seria dada pela inclinação maxilar esperada (E-SN.PP) (obtida na tabela a partir da inclinação mandibular medida SN.PM), menos a medida no paciente (SN.PP).

LAVERGNE ${ }^{91}$, em 1982, propôs uma classificação morfogenética da máoclusão como uma base para a previsão do crescimento e para o planejamento do tratamento. A amostra utilizada no trabalho consistiu de um grupo principal de 216 indivíduos (117 meninos e 99 meninas) selecionados na Universidade de Bergen, e que não foram tratados ortodonticamente. Quatro telerradiografias 
laterais foram tomadas desses pacientes. A primeira, entre 7 anos e 4 meses e 7 anos e 10 meses, e as seguintes foram tomadas com 2 anos de intervalo. $O$ segundo grupo consistiu de dois subgrupos de pacientes tratados. O primeiro, com 12 pacientes pertencentes ao grupo A1DDB e que foram observados entre 11 e 13 anos; eles foram tratados por 8 meses com uma combinação dos aparelhos ativador e extrabucal. O segundo subgrupo possuía 30 pacientes do grupo $\mathrm{P} 1 \mathrm{MOB}$, que foram tratados com uma mentoneira por 18 meses. Nesse trabalho, LAVERGNE ${ }^{91}$ mostrou o desenvolvimento dos diferentes grupos faciais.

LAVERGNE; PETROVIC $^{98}$, em 1983, fizeram um estudo que tinha por objetivo testar o conceito de regularidade global (TODD; MARK ${ }^{202}$ ) do mecanismo biológico que controla o crescimento facial. A amostra utilizada consistiu de 230 pacientes, que foram classificados cefalometricamente pelo método de LAVERGNE; GASSON ${ }^{97}$. Coeficientes de transformação foram calculados para 25 pontos do perfil ósseo a fim de verificar se o desenvolvimento facial era regular ou irregular (com bifurcações ou descontinuidades). Se os valores dos coeficientes de transformação entre telerradiografias sucessivas fossem iguais para todos os pontos de referência, o crescimento facial seria considerado uniforme; se os valores dos coeficientes fossem diferentes, o crescimento facial seria considerado irregular. Como resultado, os autores ${ }^{98}$ encontraram que, quando há uma alteração na relação molar, os coeficientes de transformação vão diferir quanto aos pontos localizados na mandíbula, na maxila e no crânio. Isso indica a existência de descontinuidades durante o crescimento facial pós-natal, que podem ser explicadas utilizando-se a teoria Catástrofe. Essas descontinuidades existem no funcionamento do comparador periférico do Servossistema, o qual controla o crescimento facial. O comparador possui posições de estado estáveis (intercuspidações de Classe I, II, e III), que são 
separadas por estados não estáveis (posições cúspide a cúspide), que são descontinuidades funcionais. O padrão final da relação oclusal emerge como resultado de uma série de bifurcações. Uma Classe I, II ou III pode ter sido iniciada por flutuações casuais, mas, uma vez formado, o padrão oclusal permanece relativamente inalterado porque flutuações de crescimento são compensadas pelos mecanismos regulatórios e por processos locais de otimização. A existência de descontinuidades no comparador periférico implica que o crescimento facial pode ser levado em conta utilizando-se modelos estocásticos ou discretos (modelos nos quais o futuro comportamento do sistema não é totalmente determinado pelos eventos passados ou presentes, e o conhecimento disso torna as várias possibilidades futuras mais ou menos prováveis), em vez de modelos determinísticos ou contínuos (aqueles nos quais toda a informação desejada está disponível durante todo o tempo, e a função de critério pode ser calculada para descobrir o efeito de qualquer tipo de tratamento). Isso aplica-se igualmente em modelos designados para a previsão do crescimento no tratamento ortodôntico.

STUTZMANN; PETROVIC; SHAYE ${ }^{199}$, STUTZMANN; PETROVIC ${ }^{196-198}$, PETROVIC et al. $^{138}$, PETROVIC; STUTZMANN ${ }^{142}$, STUTZMANN ${ }^{195}$ realizaram estudos em pacientes de 10 a 13 anos sobre a velocidade de renovação do osso alveolar humano, a partir de fragmentos ósseos removidos durante extrações de pré-molares. Esses estudos, ao se basearem na taxa de reabsorção (o parâmetro utilizado para medir a intensidade foi a atividade da ß-glucoronidase e da fenilfosfatase ácida) e na formação óssea (a atividade da fosfatase alcalina foi utilizada como um parâmetro da atividade osteoblástica, e a incorporação de ${ }^{45} \mathrm{Ca}$ como um parâmetro para a taxa de mineralização óssea), demonstraram que uma alta velocidade de renovação alveolar está associada com uma rotação de 
crescimento anterior (anti-horária) da mandíbula, e uma baixa velocidade está associada com uma rotação posterior (horária). Isso veio corroborar o conceito de que a velocidade de ossificação subperiostal (o parâmetro utilizado para medir a intensidade foi o índice de divisão celular), estudada a partir de fragmentos ósseos removidos de fraturas no ramo da mandíbula, e a taxa de crescimento da cartilagem condilar estão aumentadas na presença de uma rotação de crescimento anterior da mandíbula. Portanto, conclui-se que a efetividade de um aparelho funcional sobre a cartilagem condilar e a de um aparelho fixo sobre o osso alveolar serão maiores na presença de uma rotação de crescimento anterior da mandíbula. $\mathrm{Na}$ literatura ortodôntica, vários autores ${ }^{71,130,175}$ citam que os aparelhos atuam melhor nos casos de rotação anterior (anti-horária) da mandíbula.

As variações interindividuais detectadas por PETROVIC; STUTZMANN ${ }^{142}$, pela da taxa de crescimento da cartilagem condilar, da velocidade de ossificação subperiostal e da velocidade de renovação do osso alveolar motivaram a categorização das crianças em seis categorias biológicas de crescimento e de capacidade de resposta ao tratamento ${ }^{140}$.

Nas categorias 1,2,3, o crescimento da mandíbula é menor que o da maxila.

Na categoria 4, o crescimento da mandíbula é igual ao da maxila.

Nas categorias 5 e 6, o crescimento da mandíbula é maior que o da maxila.

A resposta ao tratamento aumenta da categoria 1 para a 5 . Pela amostra de PETROVIC; LAVERGNE; STUTZMANN ${ }^{141}$, os pacientes da categoria 6 necessitam de tratamento cirúrgico devido ao alongamento excessivo da mandíbula. 
A etapa seguinte dos estudos consistiu em confrontar as 6 categorias de crescimento com diferentes análises cefalométricas, visando a classificação dos tipos faciais. A categorização que melhor correspondeu foi a proposta por LAVERGNE; GASSON ${ }^{96,97}$, que tinha a forma de uma arborização em dois níveis. De acordo com essa classificação, as categorias de crescimento correspondem a 11 tipos rotacionais.

Os 11 tipos rotacionais foram dispostos, então, numa seqüência de aumento dos valores médios correspondentes ao potencial de crescimento a nível tecidual representado pela velocidade de renovação do osso alveolar e pela velocidade de ossificação subperiostal. Levando-se em conta o valor médio dos parâmetros dessas duas velocidades, esses 11 tipos rotacionais foram classificados dentro das 6 categorias de crescimento ${ }^{142,146}$ (Figura 2.1), como segue:

- a categoria 1 apresenta um tipo rotacional: O P2D;

- a categoria 2 apresenta dois tipos rotacionais: o P1N e o A2D;

- a categoria 3 apresenta um tipo rotacional: o R2D;

- a categoria 4 apresenta um tipo: o R1N;

- a categoria 5 apresenta quatro tipos rotacionais: R3M, A1N, A1D, P1M;

- a categoria 6 apresenta dois tipos rotacionais: A3M e P3M.

Esses conjuntos trinominais tem o seguinte significado:

- a primeira letra significa a rotação de crescimento da mandíbula (inclinação seria mais apropriado, pois está se lidando com uma característica de um indivíduo estimada em um dado momento), que pode ser: $(P)$ posterior, $(R)$ neutra, (A) anterior;

- a segunda significa a diferença no potencial de crescimento entre a mandíbula e a maxila: (1) potencial de crescimento da mandíbula é igual ao da 
maxila, (2) potencial de crescimento da maxila é maior que o da mandíbula, (3) potencial de crescimento da mandíbula é maior que o da maxila;

- a terceira significa a relação sagital intermaxilar: (D) distal, (N) normal, (M) mesial.

A posterior subdivisão dos 11 tipos rotacionais de acordo com a dimensão vertical, ou seja, mordida profunda (DB), aberta (OB) ou normal (N) levou a 33 grupos rotacionais.

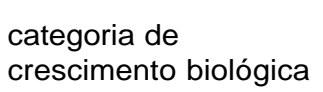

rotação de crescimento da mandíbula

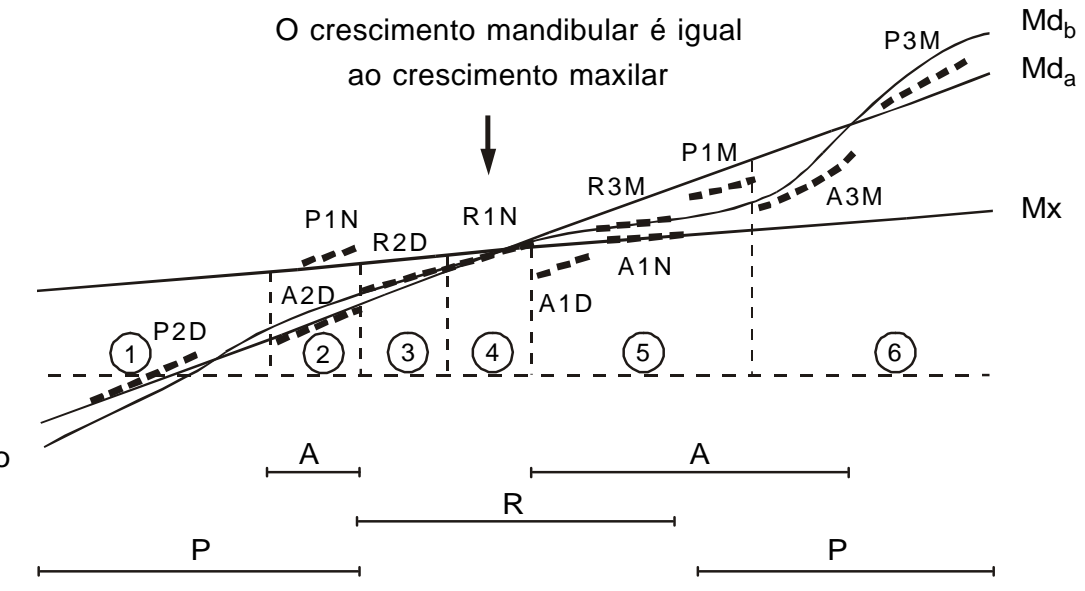

\footnotetext{
Md : mandíbula

Mx : maxila

Md : sem regulação dependente da oclusão

$\mathrm{Md}_{\mathrm{b}}^{\mathrm{a}}$ : com regulação dependente da oclusão

- - distância Co-Pog para cada tipo rotacional

Relação vertical : normal
}

FIGURA 2.1 - As seis categorias de crescimento mandibular e as distâncias CoPog correspondentes, segundo PETROVIC ${ }^{137}$

Em 1985, LAVERGNE; PETROVIC ${ }^{99}$ desenvolveram essa classificação sob a forma de uma arborização em três níveis (Figura 2.2), levando-se em conta o comparador periférico do Servossistema. Nessas condições, distinguem-se 70 situações clínicas. 


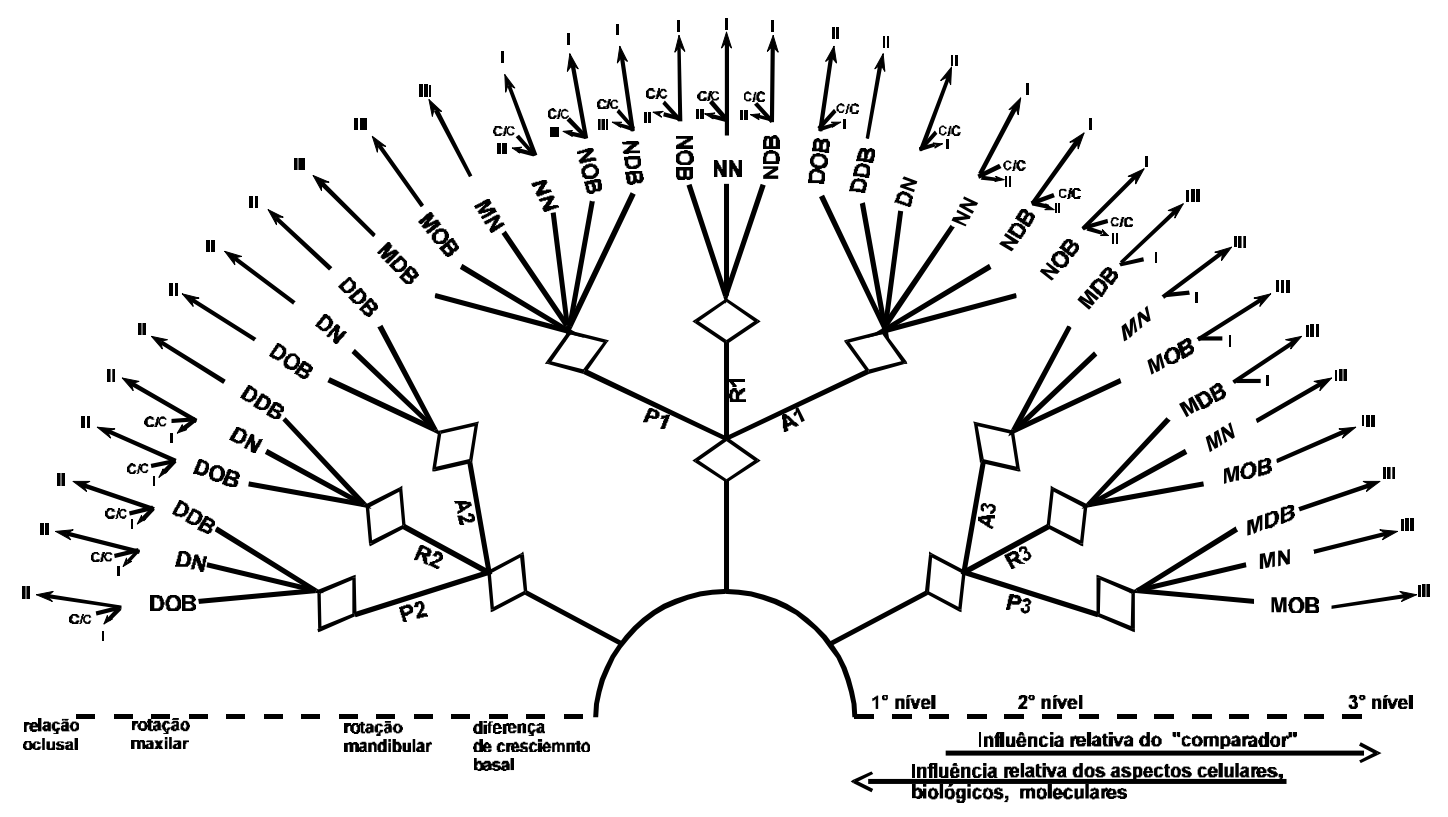

FIGURA 2.2 - Arborização em três níveis ${ }^{99}$. Tipo de rotação mandibular: A, anterior; $R$, neutra; $P$, posterior. Diferença de crescimento basal: 1 , mandíbula = maxila; 2, mandíbula < maxila; 3, mandíbula > maxila. Relação ântero-posterior: $\mathrm{N}$, normal; $\mathrm{D}$, distal; $\mathrm{M}$, mesial. Relação vertical: OB, mordida aberta; $\mathrm{N}$, mordida normal; DB, mordida profunda. I, II, III: relação (estável) dos primeiros molares. $\mathrm{C} / \mathrm{C}$ : relação molar cúspide a cúspide (instável). $\rightarrow$ resultado principal. $\rightarrow$ resultado menos freqüente. -- resultado não alcançado

Biologicamente, os três níveis da arborização têm a seguinte correspondência ${ }^{99,140}$ :

- O primeiro nível está baseado na diferença quantitativa entre o crescimento da maxila e o da mandíbula, originando, assim, os três ramos principais.

- O segundo nível está baseado na variação da direção de crescimento da mandíbula e da maxila, pelas rotações (inclinações) de crescimento. Segundo a direção e a intensidade das rotações, cada um dos três ramos principais se subdivide de modo a dar origem a 11 tipos rotacionais e a 33 grupos rotacionais. Nesse nível, a respiração, fonação e deglutição parecem desempenhar um papel importante nas variações observadas. 
- No terceiro nível da arborização, a relação oclusal atua como o comparador periférico do Servossistema ${ }^{135,147}$,ou seja, o modo como as modalidades de ajuste da oclusão modificam a velocidade e a direção de crescimento do côndilo mandibular. As subdivisões do terceiro nível representam uma piora ou uma tendência de melhora da má-oclusão.

Nesse mesmo trabalho, os autores ${ }^{99}$ apresentaram uma tabela de decisão terapêutica (Tabela 2.2), que foi idealizada levando-se em conta dados relativos a 5.000 pacientes. Esse diagrama está baseado na combinação específica de um aparelho para o paciente, em que a escolha do tratamento está alicerçada muito mais nas características biológicas dos tecidos e no comparador periférico do Servossistema que propriamente no desenho mecânico do aparelho.

Essa categorização fornece uma base para a heterogeneidade biológica do crescimento mandibular ${ }^{139,147,148}$. Além disso, a identificação do tipo rotacional pela análise cefalométrica é, na verdade, uma identificação indireta do potencial de crescimento e da resposta de uma criança que está em crescimento, frente aos aparelhos ortodônticos e ortopédicos. Segundo os autores ${ }^{142}$, a existência de categorias de crescimento é uma situação afortunada, porque ela permite o agrupamento de crianças que são morfologicamente similares, que crescem da mesma forma e que, provavelmente, responderão de forma similar a um dado tipo de tratamento.

LAVERGNE; PETROVIC ${ }^{99}$ observaram que um dado potencial de crescimento pode dar origem a dois ou mais tipos rotacionais. Em outras palavras, um dado padrão morfológico (relação intermaxilar distal, normal, ou 


\section{DECISÃO TERAPÊUTICA EM FUNÇÃO DO GRUPO ROTACIONAL}

\begin{tabular}{|c|c|c|c|c|c|c|}
\hline $\begin{array}{l}\text { CATEGO } \\
\text { RIA }\end{array}$ & $\begin{array}{l}\text { GRUPO } \\
\text { ROTACIO } \\
\text { NAL }\end{array}$ & OCLUSÃO & $\begin{array}{l}\text { COMPARA } \\
\text { DOR }\end{array}$ & EXTRAÇÃO & $\begin{array}{l}\text { SUGESTÃO DE } \\
\text { TRATAMENTO }\end{array}$ & COMENTÁRIOS \\
\hline 1 & P2DOB & 1 & $\mathrm{M}$ & + & & \\
\hline \multirow[t]{2}{*}{1} & P2DN & $\mathrm{c} / \mathrm{c}$ & M & + & 9 & \\
\hline & & II & $\mathrm{M}$ & ++ & 9 & \\
\hline 2 & P1NOB & I & $M$ & & & \\
\hline \multirow[t]{2}{*}{2} & P1NN & $\mathrm{c} / \mathrm{c}$ & M & ++ & 2 & \\
\hline & & III & $\mathrm{M}$ & ++ & 2 & \\
\hline 2 & A2DN & II & I & ++ & 9 & \\
\hline 2 & A2DDB & II & I ou $\mathrm{P}$ & ++ & 9 & \\
\hline 3 & R2DN & 1 & $M$ & & & A relação do $1^{\circ}$ molar \\
\hline \multirow[t]{2}{*}{3} & R2DOB & $\mathrm{c} / \mathrm{c}$ & $M$ & + & $1+9$ & determina a oclusão \\
\hline & & II & $M$ & ++ & 9 & \\
\hline 3 & R2DDB & II & $\mathrm{M}$ & ++ & 9 & \\
\hline 4 & R1NN & I & $M$ & & & \\
\hline 4 & R1NOB & $c / c$ & $M$ & ++ & $1+9$ & \\
\hline 4 & R1NDB & II & $M$ & ++ & $1+9$ & \\
\hline 5 & R3MDB & I & M & & & \\
\hline 5 & R3MN & III & M & & $1+10$ & \\
\hline 5 & $\mathrm{R} 3 \mathrm{MOB}$ & III & $\mathrm{M}$ & & $1+10$ & \\
\hline \multirow{3}{*}{5} & & $\mathrm{I}$ & $\mathrm{I}$ & & & \\
\hline & A1NN & $\mathrm{c} / \mathrm{c}$ & I & & 1 & \\
\hline & & II & $\mathrm{I}$ & + & $5,7,8,(4),(6)$ & \\
\hline \multirow{3}{*}{5} & & I & I ou $P$ & 0 & & \\
\hline & A1NDB & $c / c$ & I ou $\mathrm{P}$ & 0 & $5,7,8,(4),(6)$ & \\
\hline & & $\|$ & I ou $\mathrm{P}$ & 0 & $5,7,8,(4),(6)$ & \\
\hline \multirow{3}{*}{5} & & ॥ & I & + & $5,7,8,(4),(6)$ & \\
\hline & A1DN & $c / c$ & I & + & $5,7,8,(4),(6)$ & \\
\hline & & 1 & $\perp$ & & & \\
\hline 5 & A1DDB & II & I ou $P$ & + & $5,7,8,(4),(6)$ & \\
\hline 5 & P1MOB & III & M & & 2 & grande crescimento \\
\hline 5 & $\mathrm{P} 1 \mathrm{MN}$ & III & $\mathrm{M}$ & & 2 & mandibular \\
\hline 6 & A3MN & I & I & & 10 & cirurgia indicada \\
\hline 6 & A3MDB & III & 1 & & 10 & \\
\hline 6 & P3MN & III & M & & $2+10$ & cirurgia indicada \\
\hline 6 & P3MOB & III & M & & $2+10$ & \\
\hline
\end{tabular}

TABELA 2.2 - Efetividade clínica dos aparelhos ortopédicos, funcionais e ortodônticos relacionados aos grupos de rotação de crescimento facial (Segundo LAVERGNE; PETROVIC ${ }^{99}$ )

COMPARADOR: constituído por (I) incisivos, (P) pré-molares ou (M) molares, $(\bullet)$ I+P+M oclusão completa.

EXTRAÇÃO: (++) inevitável, (+) indicação freqüente, (0) contra-indicada.

APARELHO SUGERIDO: (1) aparelho fixo; (2) mentoneira; (3) hiperpropulsor postural da mandíbula; (4) elástico de Classe II; (5) ativador LSU; (6) tração anterior da mandíbula; (7) Fränkel; (8) Bionator; (9) aparelho extrabucal; (10) tração anterior da maxila.

*1a escolha; (*) opção possível

O tratamento e as extrações são discutidos unicamente em função da correção da anomalia basal. 
mesial) pode ser originado a partir de várias formas. Uma correlação óbvia aparece entre o nível da taxa de renovação alveolar e as 6 categorias. Entretanto, não é óbvio por quê algumas categorias biológicas se dividem em dois ou mesmo mais tipos rotacionais ${ }^{142}$. A existência de situações do tipo bifurcação na relação oclusal durante a irrupção dos dentes, pode ser uma das possíveis explicações.

Nas categorias 1, 2 e 3, o potencial de crescimento a nível tecidual da mandíbula é inferior àquele da maxila (Figura 2.1). Dessa maneira, há uma tendência em direção à má-oclusão de Classe II. Na categoria 4, o crescimento mandibular é equivalente ao maxilar, e há uma tendência à Classe I. Nas categorias 5 e 6 , o potencial de crescimento da mandíbula é maior que o da maxila, e há uma tendência à Classe III.

Ao identificar os grupos rotacionais cefalometricamente, o reconhecimento do fenômeno denominado por "letras" é fácil ${ }^{137,144}$. A dificuldade consiste na verificação do "potencial de crescimento cefalométrico" designado pelos números 2,1 ou 3 , que correspondem respectivamente ao potencial de crescimento mandibular, o qual é inferior, igual ou superior ao potencial de crescimento maxilar. O potencial de crescimento cefalométrico 2 corresponde ao potencial auxológico (de crescimento) 1, 2 ou 3; o potencial de crescimento cefalométrico 1 corresponde ao potencial auxológico 4 ou 5; o potencial de crescimento cefalométrico 3 corresponde ao potencial auxológico 5 ou 6 . Essa correspondência somente é válida, entretanto, quando a categorização cefalométrica é feita antes do início do tratamento, em vista da observação de 
que nenhum aparelho parece poder aumentar o potencial básico de crescimento mandibular, de acordo com pesquisas realizadas a nível tecidual e celular ${ }^{147}$.

LAVERGNE $^{91}$, em 1982, PETROVIC; LAVERGNE; STUTZMANN ${ }^{140}$, em 1986, e LAVERGNE ${ }^{92}$, em 1992, descreveram os diferentes tipos rotacionais. Segundo LAVERGNE ${ }^{91}$, os diferentes grupos não podem ser diferenciados por uma única variável cefalométrica, e sim por diferentes padrões de associação craniofacial. $\mathrm{O}$ autor $^{91}$ também destacou que os grupos com rotação (inclinação) anterior (A) são relativamente mais retrognáticos. Apenas os tipos rotacionais referentes a cada categoria de crescimento utilizada nesse trabalho, serão descritos aqui:

\section{CATEGORIA 1}

P2D - Este tipo rotacional se caracteriza por apresentar um maior crescimento da maxila em relação à mandíbula. Há uma tentativa de regulação do crescimento, que leva a uma rotação posterior da mandíbula, incapaz, contudo, de eliminar a relação sagital distal. Uma contenção com força extrabucal pode ser necessária ${ }^{92}$.

\section{CATEGORIA 2}

P1N - Este tipo rotacional deveria se chamar P2N, pois o potencial de crescimento da mandíbula é menor que o da maxila. Neste tipo rotacional a rotação de crescimento posterior da mandíbula compensa plenamente a relativa 
insuficiência do potencial de crescimento a nível tecidual mandibular. O resultado final tende a ser a correção da relação basal distal por meio do crescimento.

A2D - Para os pacientes desse tipo rotacional, o potencial de crescimento da mandíbula é menor que o da maxila. Como eles são Classe II, o comparador periférico atua inadequadamente (deveria atuar com uma relação de classe I) e leva a um superencurtamento da mandíbula, pela rotação anterior.

\section{CATEGORIA 3}

R2D - Este tipo rotacional é categorizado por um maior crescimento maxilar. Além disso, não há qualquer regulação de crescimento, fato esse que ainda não possui explicação. A rotação mandibular é neutra. Segundo LAVERGNE $^{92}$ esse tipo rotacional responde melhor ao tratamento com as forças extrabucais (a direção da aplicação da força depende da dimensão vertical) e é sobretudo de grande estabilidade após o tratamento.

\section{CATEGORIA 4}

R1N - O potencial de crescimento da maxila é proporcional ao da mandíbula. Não há rotação mandibular. Os pacientes desse tipo rotacional, que apresentam dimensão vertical normal (R1NN), aproximam-se muito das "normas" dadas na maioria das análises cefalométricas ${ }^{91}$.

\section{CATEGORIA 5}

A1N - Nesse tipo rotacional, a rotação anterior da mandíbula compensa plenamente o maior potencial de crescimento a nível tecidual da mandíbula. $O$ resultado é uma relação sagital normal. 
A1D - O potencial de crescimento da mandíbula é maior que o da maxila; mesmo assim, este grupo apresenta uma relação sagital distal devido ao excessivo encurtamento da mandíbula, que é causado pela sua rotação anterior. A excessiva rotação anterior é causada por uma referência inadequada (subótima) no comparador do Servossistema. Segundo LAVERGNE ${ }^{92}$ esse tipo rotacional é indicado para o tratamento com um aparelho funcional seguido do aparelho fixo. A rotação posterior da mandíbula induzida por todos os aparelhos funcionais permite o restabelecimento de uma regulação correta do crescimento mandibular. Para esse grupo, o autor ${ }^{92}$ afirma que a recidiva dentária não deve ser temida, e pelo contrário, pode-se assistir a uma reprise da evolução do tipo primitivo se o paciente possuir ainda um potencial de crescimento no final do tratamento. E, é por isso que uma contenção com o ativador seja preferível.

Há três maneiras ${ }^{97}$ para que, por meio da cefalometria, se possa chegar indiretamente à categoria de crescimento do paciente e ao seu tipo rotacional. A primeira forma seria através das rotações posicionais da maxila e da mandíbula, onde as medidas cefalométricas (SNA, SNB, ANB, SN.PM, SN.PP) do paciente são comparadas a um conjunto de valores correspondentes, presumidamente normais. A partir dessa comparação, são encontrados dois ângulos esperados (E-SN.PM, E-SN.PP). A normalidade aqui não é definida em relação a normas fixas mas sim em relação a uma combinação de "normas flutuantes" de Hasund. De posse desses sete ângulos, parte-se para um fluxograma onde então se encontra o grupo rotacional do paciente. A segunda forma está baseada nas rotações morfogenéticas de crescimento da mandíbula, e se utiliza de quatro parâmetros: 1- forma do côndilo (distância entre o centro do côndilo e o eixo condilar); 2- ângulo goníaco (ArTGoMe); 3- taxa mandibular (extensão máxima do corpo / extensão máxima do ramo); 4- SNPog - SNB. A terceira consiste na estimativa cefalométrica do potencial de crescimento mandibular, que está 
baseada em três parâmetros: 1- taxa condilar (largura mínima do colo condilar / largura mínima do ramo); 2- taxa do ramo (extensão máxima do ramo / largura mínima do ramo); 3- taxa do corpo (distância entre S e N / extensão máxima do corpo).

PETROVIC; STUTZMANN; LAVERGNE ${ }^{147}$ afirmaram, em 1990, que o conceito biológico que se utiliza a respeito do potencial de crescimento mandibular a nível tecidual e de resposta aos aparelhos funcionais e ortodônticos, baseado nas investigações dos tecidos mandibulares humanos, é uma tentativa de levar em conta as diferenças interindividuais que o clínico enfrenta diariamente no consultório. E numa criança, a variabilidade interindividual com relação ao potencial de crescimento e de resposta ao tratamento é muito maior na mandíbula que na maxila. Considerando que o ângulo ANB está ligado matematicamente à inclinação do plano mandibular pela medida SN.PM e ao ângulo $S_{N A}{ }^{77}$, o que estava então permitindo erros na determinação do tipo rotacional de pacientes com adenóide, os autores ${ }^{147}$ resolveram alterar o fluxograma que havia sido publicado em 1986. Portanto, nesse trabalho ${ }^{147}$, um novo fluxograma foi introduzido (Figura 2.3), visando englobar os pacientes ortodônticos com e sem problemas adenoidais. 


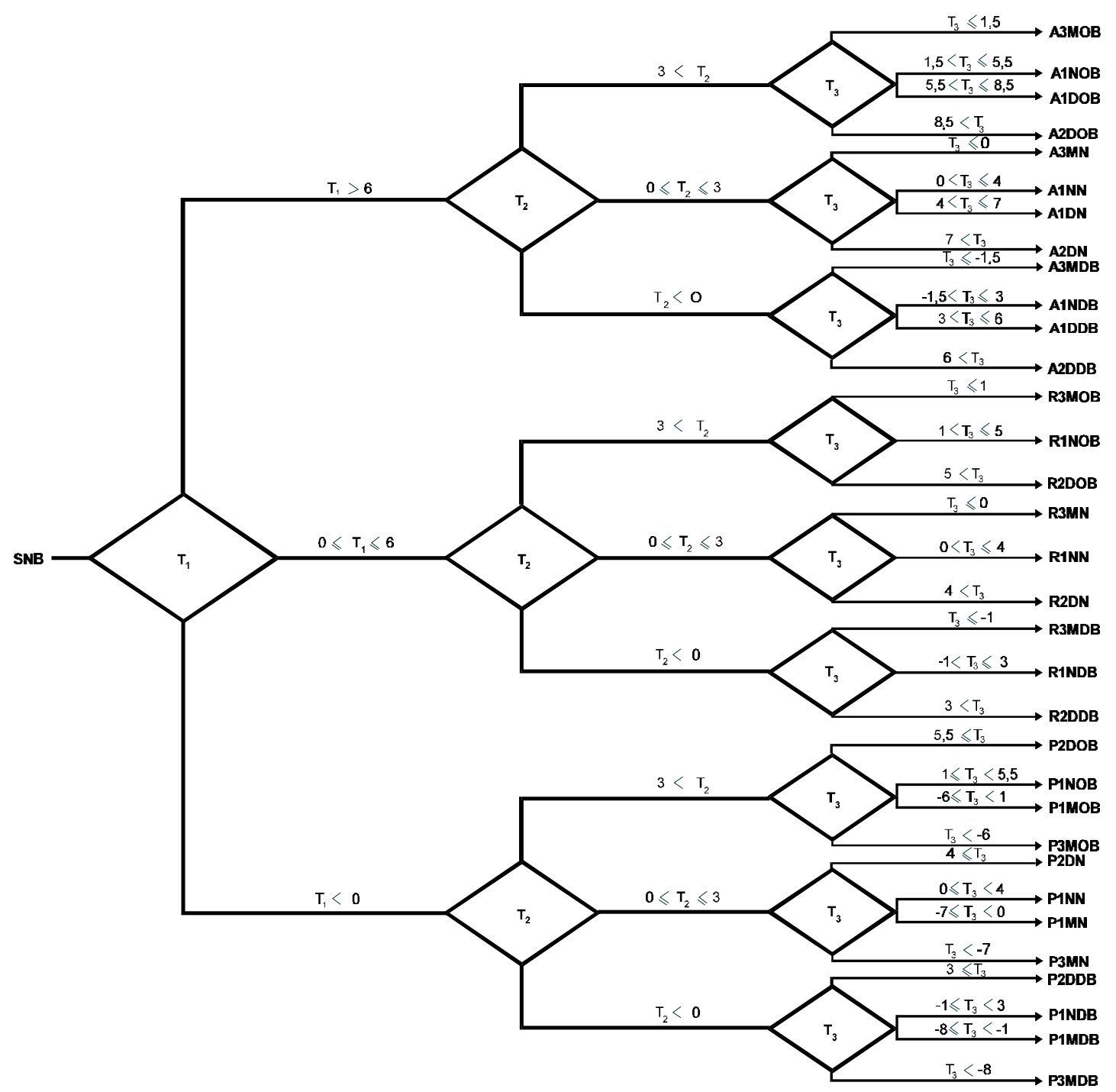

FIGURA 2.3- Fluxograma ${ }^{147}$ para a identificação dos grupos rotacionais

LAVERGNE $^{92}$, num artigo publicado em 1992, preconiza a troca do diagnóstico morfológico, que descreve os sintomas, pelo diagnóstico morfogenético, que tenta explicar o mecanismo de gênese e de evolução da máoclusão e que permite simultaneamente o exame dos meios de ação para contrapor-se a essa evolução e à previsão da evolução após o tratamento. Segundo o autor ${ }^{92}$, os grupos rotacionais são definidos por sua morfologia, sua morfogênese, suas características biológicas, e por sua evolução própria sem 
tratamento, com tratamento, e pós-tratamento. Além disso, o conhecimento da evolução do caso permite decidir o momento de intervenção e as modalidades de contenção. Neste trabalho, LAVERGNE $^{92}$ apresenta um esquema de ação dos objetivos terapêuticos sobre o tipo facial (Figura 2.4). A estratégia do tratamento é de tentar deslocar o paciente para o grupo "normal" mais próximo ao seu por ação das rotações de crescimento. Existem três grupos que apresentam as relações intermaxilares sagitais e verticais normais: A1NN; P1NN; e R1NN. No grupo A1NN, o potencial de crescimento mandibular é superior ao da maxila, mas a diferença é absorvida por uma rotação mandibular anterior. No grupo P1NN, o potencial de crescimento mandibular é inferior ao potencial de crescimento maxilar, mas a diferença é compensada por uma rotação posterior da mandíbula. No grupo R1NN, os dois potenciais de crescimento são aproximadamente iguais, não sendo necessária uma regulação no crescimento; portanto, a rotação mandibular é neutra. Dentro desses três grupos, a harmonização das rotações maxilar e mandibular em direção e em intensidade permite a obtenção de uma dimensão vertical normal. Mas, para certos pacientes que apresentam máoclusão muito severa, é impossível obter-se um resultado ótimo (o deslocamento para um grupo normal). Para esses casos, as terapêuticas paliativas, como as extrações, visam o restabelecimento das relações dentárias corretas.

O que acontece quando, durante o tratamento, o grupo rotacional muda cefalometricamente para outro grupo? Uma possibilidade é de que, mesmo com nenhuma alteração no potencial de crescimento fisiológico básico, a denominação cefalométrica do grupo rotacional, após o tratamento, simplesmente pode refletir a nova relação anatômica induzida pelo aparelho, entre a maxila e a mandíbula ${ }^{144}$. 


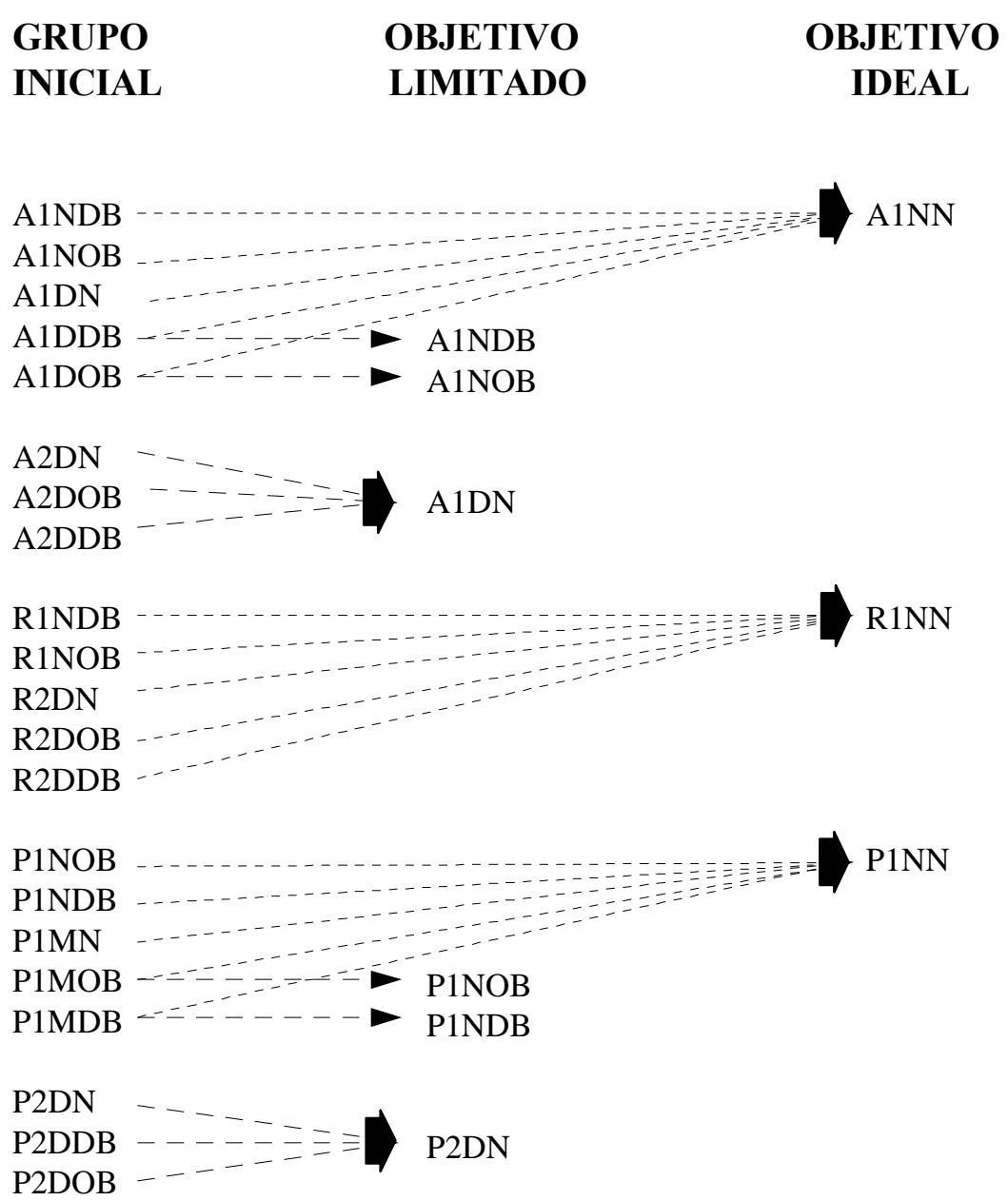

Figura 2.4 - Objetivos terapêuticos segundo LAVERGNE ${ }^{92}$

PETROVIC; STUTZMANN ${ }^{143}$ publicaram, em 1993, um estudo onde abordaram aspectos referentes ao melhor momento para 0 tratamento ortodôntico. Nesse trabalho, a estatura dos pacientes foi medida de três em três meses, dos 7 aos 16 anos, com o objetivo de construir uma curva individual de crescimento. A amostra foi dividida em dois grupos de meninos com másoclusões de Classe II, que foram tratados pela técnica do Arco de Canto e 
usaram elásticos de Classe II. O primeiro grupo consistia de 150 pacientes que foram tratados durante a fase ascendente da curva de crescimento pubescente, e de 152 controles. O segundo grupo consistia de 138 pacientes, que foram tratados durante a fase descendente da curva de crescimento, e de 138 controles. Os autores ${ }^{143}$ observaram, durante seis meses do uso de elásticos de Classe II, os seguintes resultados para o alongamento da distância condíliopogônio:

- grupo 1:

- o grupo P2D (categoria 1) teve um aumento de 1,19 mm; o grupo P2D controle, $0,87 \mathrm{~mm}$;

- o grupo A2D (categoria 2) teve um aumento de 2,46 mm; o grupo A2D controle, $1,33 \mathrm{~mm}$;

- o grupo R2D (categoria 3) teve um aumento de 1,89 mm; o grupo R2D controle, $1,28 \mathrm{~mm}$;

- o grupo R1N (categoria 4) teve um aumento de 2,26 mm; o grupo R1N controle, $1,38 \mathrm{~mm}$;

- o grupo A1D (categoria 5) teve um aumento de 5,35 mm; o grupo A1D controle, $2,08 \mathrm{~mm}$;

- o grupo A1N (categoria) teve um aumento de 5,33 mm; o grupo A1N controle, 2,12 mm;

- grupo 2:

- o grupo P2D teve um aumento de 0,49 mm; o grupo P2D controle, 0,31 mm;

- o grupo A2D teve um aumento de 0,85 mm; o grupo A2D controle, 0,45 mm;

- o grupo R2D teve um aumento de 0,70 mm; o grupo R2D controle, 0,46 mm;

- o grupo R1N teve um aumento de 0,82 mm; o grupo R1N controle, 0,51 mm;

- o grupo A1D teve um aumento de 1,24 mm; o grupo A1D controle, 0,57 mm;

- o grupo $\mathrm{A} 1 \mathrm{~N}$ teve um aumento de 1,20 mm; o grupo $\mathrm{A} 1 \mathrm{~N}$ controle, 0,63 mm. 
Baseados nesses resultados, os autores ${ }^{143}$ concluíram que é possível estimular o crescimento da mandíbula com aparelhos da técnica do Arco de Canto, utilizando-se elásticos de Classe II, quando colocados no momento adequado, ou seja, durante a fase ascendente da aceleração de crescimento pubescente. Além disso, quanto maior a categoria auxológica, isto é, crescimento biológico, mais efetivo será, a nível tecidual, o tratamento funcional.

MORO; URIAS ${ }^{123}$ publicaram, em 1994, um estudo que, por meio de uma revisão da literatura, se preocupou em discutir as alterações de crescimento do côndilo mandibular decorrentes do uso de aparelhos de ortopedia funcional dos maxilares. Observaram, entre outros aspectos, que o crescimento da mandíbula pode ser estimulado clinicamente, porém, não em todos os pacientes com Classe II. Somente os pacientes da categoria 5 (tipos rotacionais A1D e A1N) de PETROVIC têm um grande aumento no comprimento mandibular.

LASCALA; CAMAROTE; FALTIN JÚNIOR ${ }^{90}$ realizaram, em 1994, um levantamento clínico de 70 casos tratados, a fim de verificar uma possível correlação da terapêutica executada nesses casos, com a sugestão de terapia proposta por LAVERGNE; PETROVIC ${ }^{99}$ em sua tabela de decisão terapêutica. O resultado final reforçou a condição proposta pelos autores ${ }^{99}$ de que existe uma variação interindividual no mecanismo de resposta de crescimento a nível tecidual. O sexo, a idade, a raça e, eventualmente, as condições do periodonto podem influir na velocidade e quantidade de crescimento. A terapêutica 
disponível, ainda que seja a mais conveniente para os diversos casos, não provoca a mesma resposta em indivíduos diferentes. Portanto, segundo LASCALA; CAMAROTE; FALTIN JÚNIOR ${ }^{90}$, o uso da classificação das rotações não é uma receita magistral para a indicação terapêutica. Entretanto, é um instrumento conceitual clínico importante.

NOACHTAR et al. ${ }^{128}$ publicaram, em 1999, um estudo em 34 pacientes, que tinha por objetivo avaliar as alterações morfogenéticas durante o tratamento ortodôntico. Para isso, foram realizados traçados cefalométricos com a análise morfogenética, no início (T1), após o tratamento com o Bionator (T2), após o tratamento com o aparelho fixo (T3) e 20 anos após o tratamento (T4). A classificação dos pacientes foi baseada na rotação de crescimento (posterior, neutra e anterior), na relação sagital (mesial, neutra e distal) e na relação vertical (mordida aberta, normal ou profunda). Como resultado, os autores ${ }^{128}$ encontraram $^{2}$ que $21 \%$ dos pacientes demonstraram um rotação posterior da mandíbula durante o tratamento com o Bionator. Nenhuma alteração na rotação de crescimento foi observada em $71 \%$ dos indivíduos a partir de T1 até T4. A relação sagital tornou-se mais mesial a partir de $\mathrm{T} 1$ até $\mathrm{T} 4$, em $47 \%$ dos pacientes. Os autores ${ }^{128}$ concluíram que esse estudo indica que o tratamento com o Bionator resulta numa rotação posterior da mandíbula e numa diminuição da relação sagital distal. Os efeitos sobre a dimensão vertical continuam após o término do tratamento em direção a um aprofundamento da mordida. 
PETROVIC; STUTZMANN ${ }^{145}$, em 1999, relataram que o crescimento facial não é um sistema caótico de baixa dimensão, ou seja, que ele não pode ser caracterizado por um modelo que utiliza um pequeno número de equações matemáticas de acordo com as relações descobertas entre os determinantes fisiológicos predominantes. Para os autores ${ }^{145}$, o número total de equações correspondentes aos fatores fisiológicos conhecidos provavelmente se aproxima de 100 (cerca de 25 determinantes principais e, pelo menos, 60 determinantes secundários), tornando uma previsão clínica hic et nunc além das fronteiras da razão. Ortodontistas experientes, podem hoje identificar peculiaridades do crescimento facial numa criança melhor que qualquer modelo de computação existente. Mas, conceitos como o da teoria do Caos, Redes Neurais, a própria categorização de crescimento dos autores ${ }^{145}$, e variações dependentes da idade observadas numa criança individualmente podem ser úteis na prática clínica. No futuro, a lógica Fuzzy oferecerá uma abordagem inovadora para o crescimento facial e para os problemas ortodônticos, especialmente aqueles que dizem respeito às fronteiras mal definidas entre as categorias de crescimento, assim como para os grupos e tipos rotacionais.

Considerando que um dos fatores mais importantes para o tratamento da má-oclusão de Classe II é o crescimento mandibular, torna-se fundamental, para o ortodontista clínico, que ele saiba se o seu paciente terá ou não um bom crescimento da mandíbula durante o tratamento. Dentro desse contexto, MORO; SCANAVINI; VIGORITO ${ }^{124}$, em 2000, realizaram uma avaliação da correção das 
más-oclusões de Classe II em pacientes das categorias de crescimento 3 e 5 de PETROVIC. A amostra utilizada consistiu de 50 pacientes (25 pertencentes à categoria 3, e 25 pertencentes à categoria 5) de ambos os sexos, com idade inicial entre 10 e 15 anos, que foram tratados pela técnica do Arco de Canto com extrações de quatro primeiros pré-molares e com aparelho extrabucal. Para a comparação do tratamento nos dois grupos, foi utilizada a análise de JOHNSTON JÚNIOR. Como resultado, foi encontrado que não houve diferença estatisticamente significante entre a correção molar nas duas categorias, sendo que o crescimento diferencial dos maxilares (ABA) contribuiu com $75 \%$ da correção molar na categoria 3 , e com $107,5 \%$ na categoria 5 . Com relação à perda de ancoragem superior e inferior, não houve diferença estatisticamente significante entre as categorias 3 e 5 . O crescimento mandibular foi o fator mais importante para a correção das relações molar e incisal, sendo que, na categoria 5, houve 1,9 $\mathrm{mm}$ a mais de avanço mandibular em relação à base do crânio que na categoria 3. Não houve diferença estatisticamente significante para a correção incisal em ambas as categorias, assim como também não houve para as retrações dos incisivos superior e inferior. Os grupos rotacionais, tanto na categoria 3 como na 5, sofreram alterações após o tratamento. Baseando-se nos resultados obtidos em relação aos objetivos terapêuticos propostos por LAVERGNE $^{92}$, este trabalho nos demonstrou que a técnica do Arco de Canto com o aparelho extrabucal está mais indicada para os pacientes da categoria 3 de PETROVIC que para os pacientes da categoria 5. 


\subsection{A RECIDIVA PÓS-TRATAMENTO}

\subsection{1 Índices utilizados para a avaliação da recidiva}

Para LITTLE $^{104}$, a evidência da progressiva instabilidade do tratamento ortodôntico é sempre primeiro notada pelo apinhamento progressivo dos incisivos inferiores após a remoção das contenções. Qualquer que seja a multiplicidade de causas para a recidiva, a irregularidade dos incisivos inferiores é sempre a precursora do apinhamento superior, do aprofundamento da mordida e da deterioração generalizada do caso tratado. E desde que a situação dos seis dentes ântero-inferiores parece ser um fator limitante no tratamento e na estabilidade, seria lógico desenvolver um índice de diagnóstico que refletisse precisamente a condição ântero-inferior. Sendo assim, em 1975, LITTLE $^{104}$ apresentou um método quantitativo a fim de verificar a irregularidade dos dentes ântero-inferiores. A técnica envolve a medição direta a partir do modelo da arcada inferior com um paquímetro (calibrado até pelo menos em décimos de milímetro e possuindo pontas finas) mantido paralelamente ao plano oclusal. É determinado o deslocamento linear dos pontos de contato anatômicos adjacentes dos incisivos inferiores, e a soma das cinco medições representa o valor do índice de irregularidade do caso. Essa medida representa a distância para a qual os pontos de contato devem ser movidos para ganhar o alinhamento anterior. Segundo o autor ${ }^{104}$, embora os pontos de contato possam variar no sentido vertical, a correção das discrepâncias verticais não afetará significativamente o 
comprimento anterior do arco, e pode ser desconsiderada. O autor ${ }^{104}$ também $^{2}$ recomenda que espaços mésio-distais sejam desconsiderados desde que os dentes em questão estejam alinhados apropriadamente. A confiabilidade e a validade do método foi testada, apresentando resultados favoráveis. Essa técnica pode ser utilizada como um dos vários métodos para a verificação da situação da má-oclusão, antes do início do tratamento, e da alteração após o tratamento.

Em 1992, foi introduzido, por RICHMOND et al. ${ }^{159}$, o índice PAR ("Peer Assessment Rating"), que tem sido considerado confiável e válido. Esse índice é utilizado como uma avaliação para o grau de melhora do tratamento, por meio da verificação da diferença entre os valores dados aos modelos pré-tratamento e pós-tratamento. Ele avalia o alinhamento anterior superior, a oclusão dos segmentos posteriores, os trespasses vertical e horizontal e as discrepâncias das linhas médias. Os componentes individuas são ponderados e somados. A recidiva pode ser avaliada ao se comparar os valores obtidos pelos modelos finais e de pós-contenção.

JOHAL; BATTAGEL ${ }^{79}$, em 1997, realizaram um estudo que tinha por finalidade explorar um novo método de verificação do apinhamento dentário a partir de modelos de estudo. Esse método foi testado em relação a duas estratégias previamente relatadas. Para a realização do trabalho, um único examinador comparou os seguintes métodos: exame visual, fio de latão/paquímetro e um microscópio reflexo com um programa computadorizado 
próprio. Sessenta modelos de estudo (30 superiores e 30 inferiores) foram medidos utilizando cada técnica em duas ocasiões separadas. Os resultados mostraram que o método do microscópio reflexo é o mais reprodutível, seguido pelos métodos de exame visual e do fio de latão. Esses dois métodos mostraram uma tendência positiva em direção à sobreestima (fio de latão) e à subestima (exame visual) no grau de apinhamento.

BeGOLE; SADOWSKY ${ }^{11}$ realizaram, em 1999, uma revisão da literatura sobre as metodologias para se estudar a estabilidade oclusal a longo prazo. Os autores concentraram-se sobre a avaliação realizada a respeito dos modelos de estudo, pois as alterações oclusais são mais bem refletidas em modelos longitudinais. De particular interesse é a verificação do apinhamento na dentição e os vários procedimentos físicos e matemáticos utilizados para avaliar a

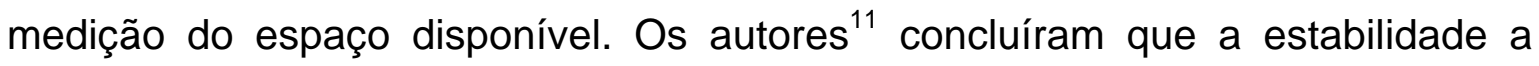
longo prazo continuará a ser uma preocupação dos pacientes e dos ortodontistas. Os achados das pesquisas tendem a ser desapontadores, particularmente com respeito à irregularidade dos incisivos inferiores. Entretanto, relatos anedóticos por parte dos clínicos são sempre mais otimistas. Eles representam o sucesso com aderência a um rigoroso protocolo de contenção e ao uso de estratégias para aumentar a estabilidade, incluindo atenção a detalhes na finalização, fibrotomia supracristal, desgaste interproximal do esmalte e contenção fixa a longo prazo. É insensato esperar um resultado perfeitamente 
estável por toda a vida, dada a maturação da face e da dentição que está se processando.

\subsubsection{O desenvolvimento da oclusão e sua relação com a irregularidade dentária}

As alterações fisiológicas da dentição, a partir da infância até a adolescência, e da fase adulta jovem até a idade adulta, constituem num processo gradual $^{201}$. O estabelecimento da relação entre arcos dentários permanentes é, de forma alguma, o estágio final no desenvolvimento da oclusão. Incrementos significantes da altura dentoalveolar já foram constatados, indicando um movimento eruptivo dos dentes e um desenvolvimento vertical dos tecidos vizinhos $^{50}$

Fica evidente, a partir de estudos longitudinais em indivíduos não tratados, que as dimensões dos arcos se alteram com o passar dos anos.

A distância intercaninos em amostras não tratadas já foi estudada por BARROW; WHITE ${ }^{7}$, MOORREES; CHADHA ${ }^{122}$, SILLMAN ${ }^{181}$, BISHARA et al. ${ }^{19}$. Todos observaram que há um rápido aumento nessa distância dos 6 aos 9 anos, devido à irrupção dos incisivos e caninos. Dos 10 aos 12 anos ela diminui, e a diminuição permanece estável segundo MOORREES;CHADHA ${ }^{122}$ e SILLMAN $^{181}$, mas continua a diminuir segundo os outros autores ${ }^{7,19}$.

SINCLAIR; LITTLE ${ }^{182}$, ao examinarem 65 pacientes com oclusão normal, observaram uma ligeira diminuição na distância intercaninos, especialmente nas 
mulheres a partir dos 13 até os 20 anos $(0,73 \mathrm{~mm})$. CARTER; McNAMARA JÚNIOR ${ }^{32}$, em 1998, examinaram as alterações nos arcos dentários que ocorreram em pessoas não tratadas entre o final da adolescência e a quinta ou sexta década de vida, encontrando uma diminuição da distância intercaninos de 0,6 $\mathrm{mm}$ para as mulheres e de $0,9 \mathrm{~mm}$ para os homens.

A distância intercaninos apresenta maior diminuição que a distância intermolares; esta, segundo SINCLAIR; IITTLE $^{182}$, geralmente permanece a mesma.

Vários estudos mostram o aumento da irregularidade dos incisivos inferiores em indivíduos não tratados ortodonticamente. No estudo de SINCLAIR; LITTLE $^{182}$, a irregularidade dos incisivos aumentou nas mulheres dos 13 aos 20 anos $(0,85 \mathrm{~mm})$, sendo que elas exibiram uma maior irregularidade que os homens em todos os estágios. Para CARTER; McNAMARA JÚNIOR ${ }^{32}$, em 1998, o aumento na irregularidade incisal inferior que ocorreu nos homens e nas mulheres foi o mesmo. Entretanto, a irregularidade não aumentou em todos os indivíduos; ela diminuiu em 3\% dos homens e em 7\% das mulheres.

RICHARDSON ${ }^{158}$, em 1999, fez uma revisão das alterações no alinhamento do arco inferior de indivíduos não tratados ortodonticamente, em vários estágios de desenvolvimento: 7 a 10 anos, 10 a 12 anos, 12 a 15 anos, 13 a 18 anos, 18 a 21 anos, 21 a 28 anos, e 18 a 50 anos. Em média, o apinhamento diminuiu entre 7 e 12 anos e aumentou após essa idade. O maior aumento ocorreu na adolescência entre 13 e 18 anos (média de 2,3 mm), pouco ou 
nenhuma alteração ocorreu na terceira década, e pequenos aumentos ocorreram mais tarde, na vida. Segundo a autora ${ }^{158}$, isso sugere que as causas do apinhamento tardio podem variar em diferentes estágios do desenvolvimento.

BISHARA et al. ${ }^{17}$, em 1989, avaliaram as alterações nos incisivos entre os 13 e os 26 anos de idade em pacientes com oclusão normal, e reavaliaram os mesmos indivíduos aos 45 anos de idade ${ }^{18}$. Seus achados indicaram que houve um aumento da discrepância entre o tamanho dentário e o comprimento do arco. As alterações médias foram de 2,7 $\mathrm{mm}$ nos homens e de $3,5 \mathrm{~mm}$ nas mulheres. Essas alterações no alinhamento dos dentes consistem primariamente no resultado de uma diminuição no comprimento disponível do arco. Essas alterações não foram significantemente relacionadas a qualquer variável dentária ou facial, ou seja, a causa é multifatorial e está associada com alterações na altura facial, trespasse vertical, inclinação incisal, dimensões do arco e diâmetro mésio-distal de vários dentes ${ }^{17}$.

Para THILANDER ${ }^{201}$, a falta de estabilidade nos arcos dentários da maioria das oclusões normais, a partir da adolescência até a idade adulta, aumenta o questionamento sobre a possibilidade de se conseguir estabilidade nos resultados após o tratamento ortodôntico. E, considerando que o desenvolvimento dentário continua numa taxa lenta persistente a partir da adolescência, não há um método definitivo para se distinguir entre os eventos normais relacionados com a idade e a recidiva após o tratamento ortodôntico. 


\subsubsection{A correção precoce e a recidiva}

As correções ortodônticas realizadas durante os períodos de crescimento e de irrupção dos dentes são consideradas como menos susceptíveis à recidiva para alguns autores. De acordo com REITAN ${ }^{154}$, haverá pouca ou nenhuma recidiva após a movimentação ortodôntica de um dente em irrupção, devido ao fato de os tecidos de suporte estarem em um estágio de proliferação, como resultado do processo eruptivo. Novas fibras serão formadas à medida que a raiz se desenvolve, e essas novas fibras auxiliarão na manutenção da nova posição dentária. PETROVIC; STUTZMANN ${ }^{144}$ corroboram essa afirmação.

LITTLE; RIEDEL; STEIN ${ }^{108}$, em 1990, após avaliarem longitudinalmente (6 anos após a contenção) uma amostra, cujo tratamento envolveu o aumento do arco durante a dentição mista por meio de aparelhos fixos da técnica do Arco de Canto, arcos linguais ativos, placas lábio-ativas ou aparelhos removíveis, observaram que $89 \%$ dos exames pós-contenção demonstraram, clinicamente, um alinhamento insatisfatório. A média no período pós-contenção para o índice de Little foi de 6,06 $\mathrm{mm}$.

DUGONI et al. ${ }^{44}$ realizaram, em 1995 , um estudo sobre o tratamento na dentição mista, com um arco lingual removível passivo, bandas nos primeiros molares superiores e inferiores, bem como bráquetes nos incisivos superiores e inferiores. Dezenove dos 25 casos (76\%) demonstraram clinicamente um 
alinhamento inferior satisfatório no período pós-contenção. A média do índice de Little na fase pós-contenção foi de 2,65 mm.

HARUKI; LITTLE ${ }^{67}$, em 1998, avaliaram as diferenças da estabilidade longitudinal das alterações induzidas ortodonticamente na forma de arco entre pacientes que receberam tratamento ortodôntico precoce (dentadura mista) e pacientes que foram tratados mais tarde (dentadura permanente) pela técnica do Arco de Canto, que incluiu a extração dos primeiros pré-molares superiores e inferiores. No estágio pós-contenção, o grupo com tratamento tardio apresentou maior irregularidade ântero-inferior: 3,09 mm, para o grupo precoce, e 4,15 mm para o grupo tardio. Os casos do presente estudo mostraram mais sucesso que os casos de extração sucessiva seguidos apenas pela migração fisiológica dos dentes, como está relatado em outro trabalho ${ }^{107}$. Para LITTLE $^{105}$, o alinhamento precoce na dentição mista é preferível à migração fisiológica sem o alinhamento dos dentes anteriores

WOODSIDE et al. $^{217}$, em 1999, realizaram um estudo que tinha por finalidade avaliar o alinhamento dos incisivos inferiores nos casos de extração seriada. Os indivíduos não tratados e os tratados apenas com extrações sucessivas mostraram resultados longitudinais similares. Entretanto, o grupo com extração que também recebeu tratamento ortodôntico pareceu mostrar mais apinhamento incisal inferior a longo prazo. Segundo os autores ${ }^{217}$, é possível que a mecanoterapia ortodôntica utilizada e o resultante aumento na distância 
intercaninos deixem os dentes em uma posição inerentemente instável com respeito à neuromusculatura circundante, levando à recidiva pós-contenção. Tal apinhamento pós-contenção pode ser um tanto angustiante para o paciente mal informado. Como alternativa para a recidiva, uma contenção por toda a vida ou um segundo tratamento ortodôntico numa época posterior em sua vida pode ser necessário.

CETLIN; SPENA; VANARSDALL JÚNIOR ${ }^{34}$, em 2000, descreveram que o tratamento na dentição mista com a placa lábio-ativa, em conjunto com a placa de Cetlin e o aparelho de ancoragem extrabucal, resulta no nivelamento espontâneo da curva de Spee, crescimento mandibular favorável e irrupção precoce dos dentes. Esse tratamento influencia o desenvolvimento das bases apicais nos três planos do espaço, pelos músculos, irrupção e crescimento, levando a um alargamento dentoalveolar, que fornece uma forma ampla do arco em todos os casos, independentemente do tipo facial. Os autores ${ }^{34}$ citam um estudo utilizando essa técnica, no qual o índice de Little 14 anos pós-tratamento foi de 0,36 mm.

\subsubsection{A relação entre a forma da arcada inferior e a recidiva}

Está bem estabelecido na literatura que aumentar a largura e o comprimento do arco dentário, durante o tratamento, leva a uma tendência de retorno às dimensões iniciais, no período pós-contenção. Os dentes e as 
estruturas de suporte apresentam uma tendência natural de se moverem na direção da má-oclusão inicial ${ }^{37,53,109,163,177,178,194,203,211}$.

A tendência dos dentes e estruturas de suporte de sofrerem alterações dimensionais durante o tratamento pode acarretar mudanças nas formas dos arcos dentários. Vários autores ${ }^{40,163,194}$ acreditam que 0 estabelecimento adequado da forma e da dimensão do arco dentário inferior é um fator de estabilidade dos resultados terapêuticos, e que a elaboração imprópria dos arcos pode contribuir com muitos efeitos indesejáveis, durante e após o tratamento.

BeGOLE; FOX; SADOWSKY ${ }^{10}$, em 1998, realizaram um estudo sobre as formas dos arcos. Os achados sugerem que a estabilidade pode não estar relacionada com a quantidade de alteração produzida durante o tratamento. Significante expansão pode ser conseguida nas regiões dos pré-molares, podendo-se esperar a sua estabilidade. O maior ganho na largura do arco foi para os segundos pré-molares; em seguida veio o dos primeiros pré-molares, molares e, então, o dos caninos. As distâncias intercaninos para ambos os arcos diminuíram em relação aos valores pré-tratamento. Essa estabilidade na região de pré-molares já havia sido evidenciada por GARDENER; CHACONAS ${ }^{53}$.

BURKE et al. $^{31}$, em 1998, pelo processo da metanálise de 26 artigos publicados e de algumas dissertações de Mestrado (não publicadas), avaliaram as alterações na largura intercaninos inferior após o período de contenção. A amostra combinada compreendeu 1.233 indivíduos que foram divididos em 
subgrupos baseados na classificação da má-oclusão inicial e no tipo de tratamento em relação às extrações. Como conclusões, observaram que: 1) a largura intercaninos tende a expandir-se, durante o tratamento, entre 0,8 e 2,0 mm, independentemente da classificação da má-oclusão e de o tratamento ter sido realizado com ou sem extrações; 2) a largura intercaninos tende a diminuir, após o período de contenção, entre 1,2 e 1,9 mm, independentemente da classificação da má-oclusão e de o tratamento ter sido realizado com ou sem extrações; 3) a largura intercaninos tende a mostrar uma alteração "líquida" no período pós-contenção na ordem de $0,5 \mathrm{~mm}$ de expansão a 0,6 $\mathrm{mm}$ de constrição, independentemente da classificação da má-oclusão e de o tratamento ter sido realizado com ou sem extrações; 4) desde que a alteração "líquida" na largura intercaninos foi achada como sendo de aproximadamente zero, esse estudo claramente participa do conceito da manutenção da largura intercaninos original no tratamento ortodôntico.

Para TOIGO; MANDETTA ${ }^{203}$, em 2000, as maiores alterações na forma do arco no período pós-contenção ocorreram quando houve grandes alterações com o tratamento. Segundo os autores ${ }^{203}$, a manutenção da distância intercaninos durante o tratamento ortodôntico não tem influência no apinhamento dos incisivos inferiores, pois seus casos foram tratados sem expansão, e mesmo assim, apresentaram estreitamento e apinhamento no período pós-contenção. 0 conceito de STRANG ${ }^{194}$ e SHAPIRO ${ }^{177}$ de que a distância intercaninos deveria permanecer inalterada para alcançar-se estabilidade não foi confirmada. Também 
não foi corroborada a idéia de $\operatorname{STRANG}^{177}$ de que a extração de pré-molares permite o movimento distal dos caninos para uma área de maior distância óssea e, dessa forma, proporciona uma estabilidade da expansão.

\subsubsection{A relação entre a recidiva dos trespasses horizontal e vertical e o apinhamento ântero-inferior}

Muitos estudos têm sido realizados sobre a recidiva do trespasse vertical. Dentre os fatores dentários estudados, destaca-se a preocupação em intruir os incisivos durante a correção, pois esse movimento poderia sofrer uma recidiva pós-tratamento ${ }^{35,173}$. Por outro lado, alguns pesquisadores acreditam que a extrusão dos molares seria mais preocupante que a intrusão dos incisivos, pois a invasão do espaço funcional livre não seria tolerada pela musculatura ${ }^{61},{ }^{218}$. Outros fatores, como o ângulo interincisivos muito aberto, levariam a uma maior recidiva $^{48}$. Fatores esqueléticos, como as alturas faciais anterior e posterior, a rotação mandibular e o padrão de crescimento facial também foram estudados $^{22,58,59}$. Pesquisas sobre a recidiva do apinhamento ântero-inferior tentaram correlacionar com a recidiva do trespasse vertical, sem apresentarem dados concretos ${ }^{6,47,214}$.

Em 1999, KIM; LITTLE $^{89}$ publicaram um estudo que tinha por finalidade avaliar a estabilidade a longo prazo da correção da mordida profunda na máoclusão de Classe II, Divisão 2. Os resultados mostraram que os pacientes com 
incisivos superiores e inferiores muito verticalizados antes do tratamento tenderam a ter um trespasse vertical mais profundo inicialmente e uma tendência a retornar a sua relação original no período de pós-contenção. Pela análise de regressão múltipla escalonada, o trespasse vertical inicial foi selecionado como o fator mais importante a fim de prever trespasse vertical pós-contenção. Também foi observado que a extração de dentes não pareceu causar um aumento no trespasse vertical.

KAWAUCHI et al. ${ }^{88}$, em 1999, realizaram uma avaliação cefalométrica e um estudo em modelos de estudo da recidiva da mordida profunda. A amostra utilizada consistiu de 48 jovens, leucodermas, de ambos os sexos, que apresentavam, inicialmente, Classe I e Classe II, Divisão 1, com mordida profunda de no mínimo 3,5 mm, tratados com extrações dos quatro primeiros prémolares. As tomadas radiográficas e os modelos de estudo foram obtidos em 3 fases: ao início, ao final e 5 anos após o tratamento ortodôntico. Os resultados permitiram concluir que os fatores dentários tiveram uma contribuição maior na recidiva, principalmente, o aumento do trespasse horizontal, a intrusão dos incisivos, a falta de desenvolvimento dentoalveolar dos molares e o aumento do ângulo interincisivos. Para os fatores esqueléticos, somente apresentou correlação estatisticamente significante a variável N-Me (altura facial anterior total). A rotação mandibular não se correlacionou significativamente com a recidiva. Verificou-se, também, uma forte correlação da quantidade de correção com a quantidade de recidiva. 
SIQUEIRA et al. ${ }^{183}$, em 1999, realizaram um estudo cefalométrico longitudinal, propondo verificar a influência do crescimento craniofacial sobre a recidiva da sobressaliência. Utilizaram telerradiografias tomadas em norma lateral, ao início, final e 5 anos após o término do tratamento ortodôntico, de 48 jovens leucodermas de ambos os sexos, que apresentavam, inicialmente, máoclusão de Classe II, Divisão 1, e que se submeteram às extrações dos quatro primeiros pré-molares. Verificou-se significância estatística apenas para as alterações observadas nos valores de Co-A; SN.PP e PP.GoGn e a recidiva da sobressaliência, indicando que essas grandezas seriam fatores de risco para a recidiva, mas a análise de regressão não confirmou essa observação. Segundo os autores ${ }^{184}$, as jovens do sexo feminino possuem probabilidade quatro vezes e meia maior de apresentar recidiva da sobressaliência.

\subsubsection{A recidiva nos casos com extrações de pré-molares}

LITTLE; WALLEN; RIEDEL ${ }^{109}$, em 1981, descreveram que o sucesso em se manter um alinhamento ântero-inferior satisfatório 10 anos após o tratamento foi inferior a 30\% numa amostra de 65 pacientes tratados com extrações de quatro primeiros pré-molares. O valor pós-contenção médio para o índice de Little foi de $4,63 \mathrm{~mm}$.

OLIVEIRA JÚNIOR et al. ${ }^{129}$ publicaram um estudo em 1991, com a finalidade de avaliar a associação entre a idade no início de tratamento, o 
dimorfismo sexual, as características da má-oclusão inicial, o grau de apinhamento inicial, a posição final dos incisivos inferiores, o padrão de crescimento e o envolvimento hereditário com a recidiva do apinhamento dos incisivos inferiores. Os resultados das avaliações de 60 pacientes tratados pela mecânica do Arco de Canto com extrações dos quatro primeiros pré-molares revelaram que nenhuma das variáveis estudadas demonstrou confiabilidade na previsão da recidiva da correção do apinhamento ântero-inferior; revelaram também que os jovens com padrão de crescimento vertical e os que possuíam envolvimento hereditário, no apinhamento da região ântero-inferior, demonstraram maior associação com a recidiva pós-contenção.

PAQUETTE; BEATTIE; JOHNSTON JÚNIOR ${ }^{131}$ publicaram um trabalho em 1992, onde fizeram um estudo comparativo de longa duração do tratamento com a técnica do Arco de Canto com e sem extrações, em pacientes em situação limítrofe ("borderline"). O objetivo era comparar a estabilidade pós-tratamento e o impacto estético das duas modalidades de tratamento. A amostra consistiu de 33 casos com extrações e de 30 casos sem extrações. O intervalo pós-tratamento teve, como média, 14 anos e 5 meses. Como resultado, os autores ${ }^{131}$ encontraram que, para o paciente "limítrofe", o tratamento sem extrações produziu uma dentição significantemente mais protruída (cerca de $2 \mathrm{~mm}$ ), tanto ao final do tratamento quanto depois do período pós-tratamento. A maioria dos pacientes em ambos os grupos mostrou menos que $3,5 \mathrm{~mm}$ de apinhamento inferior pós-contenção. A recidiva pareceu constituir uma compensação 
dentoalveolar produzida pelo crescimento diferencial dos maxilares após o tratamento. Considerando que no final, os vários movimentos dentários tenderam a cancelar um ao outro, tanto a correção longitudinal do trespasse horizontal quanto a correção molar foram derivadas quase que exclusivamente do crescimento diferencial dos maxilares, sendo que o crescimento mandibular foi o mais importante contribuinte. Embora a alteração da base apical (ABA) tenha apresentado coeficientes de correlação significantes com quase todas as alterações dentárias pós-tratamento nos grupos avaliados, ela não se relacionou com o retorno da irregularidade dos incisivos inferiores. Essa falta de correlação, segundo os autores ${ }^{131}$, talvez possa constituir um subproduto de variação estranha na duração e tipo de contenção ou na cooperação do paciente; isso também pode implicar que os fatores que causam a irregularidade incisal inferior talvez não possam ser inferidos a partir dos modelos de estudo e dos traçados cefalométricos. Os autores ${ }^{131}$ também ressaltam que, apesar de o presente trabalho e de outros não terem conseguido detectar uma relação entre a expansão da distância intercaninos e a irregularidade incisal, esses resultados não deveriam ser utilizados para justificar o retorno da expansão como uma resposta genérica para o apinhamento.

LUPPANAPORNLARP; JOHNSTON JÚNIOR ${ }^{112}$ publicaram um trabalho em 1993, que tinha por objetivo fazer uma comparação dos efeitos de longa duração do tratamento da Classe II com e sem extrações em pacientes distintos, ou seja, não "limítrofes". A amostra contou com 62 pacientes (33 tratados com 
extrações e 29 sem extrações), que foram tratados com a técnica do Arco de Canto, e que foram examinados no final do tratamento e após uma média de 15 anos depois do término do tratamento. Entre outros achados, os autores ${ }^{112}$ observaram que muitos dos componentes dentários da correção da relação molar e do trespasse horizontal e também das alterações pós-tratamento tiveram uma correlação significante com o crescimento ântero-posterior e/ou deslocamento da mandíbula. A avaliação dos casos tratados com extrações mostrou, ao final do tratamento, que houve um deslocamento anterior de $1,1 \mathrm{~mm}$ da maxila, um deslocamento anterior da mandíbula de 3,8 $\mathrm{mm}$, uma alteração na base apical de 2,7 mm, uma mesialização do molar superior de 2,1 $\mathrm{mm}$, uma perda de ancoragem do molar inferior de 2,7 mm, uma retração incisal superior de 3,6 mm, e uma retração incisal inferior de $2 \mathrm{~mm}$. No período pós-tratamento esses casos apresentaram um deslocamento anterior da maxila de $1,9 \mathrm{~mm}$, um deslocamento anterior da mandíbula de 3,2 mm, uma alteração na base apical de 1,3 mm, uma mesialização do molares superior de $2,5 \mathrm{~mm}$ e inferior de $0,8 \mathrm{~mm}$, uma retração dos incisivos superior de $1,4 \mathrm{~mm}$ e inferior de $1,6 \mathrm{~mm}$, e uma recidiva de $-0,5 \mathrm{~mm}$ para a relação molar e de $-1,7 \mathrm{~mm}$ para a relação incisal. Para os autores ${ }^{112}$, não foi surpresa o fato de que todos os pacientes tiveram o mesmo tipo de alteração, durante os períodos avaliados, pois, se a alteração futura fosse uma simples função da forma facial individual, a previsão cefalométrica ter-se-ia rendido há muito tempo para as várias técnicas estatísticas quer simples, quer multivariadas. O resultado ortodôntico final pode ser visto como uma compensação 
dentoalveolar para o padrão de crescimento e/ou deslocamento mandibular póstratamento combinado com o impacto do tratamento escolhido pelo clínico.

FIDLER et al. $^{49}$ realizaram, em 1995, um estudo longitudinal sobre a estabilidade da má-oclusão de Classe II, Divisão 1 tratada com resultados oclusais bem-sucedidos ao final do tratamento ativo. O objetivo era encontrar fatores que pudessem prever a recidiva como também características associadas ao sucesso do tratamento. Foram avaliados exames realizados antes e após o tratamento, com uma média de 14 anos após a remoção da contenção em pacientes adolescentes tratados com e sem extrações de pré-molares. A amostra incluiu 78 pacientes com média de idade inicial de 11, 2 anos e de pós-contenção com 31,1 anos. A correção da Classe II foi atingida principalmente pela utilização do aparelho de ancoragem extrabucal cervical. Não houve alterações no período pós-contenção nas relações de molar, de pré-molar e de canino, tendo ocorrido 0,5 mm de alteração nos trepasses horizontal e vertical. A recidiva máxima foi de 3,5 $\mathrm{mm}$ nas relações de molar, de pré-molar e de canino, e de $3 \mathrm{~mm}$ no trepasse horizontal e 4,5 mm no vertical. A análise de regressão múltipla não revelou qualquer associação tanto entre as características pré-tratamento, quanto entre as alterações esqueléticas e dentárias do tratamento com a recidiva do trespasse horizontal. Entretanto, a recidiva do trespasse horizontal estava associada à recidiva das relações de molar, de pré-molar e de canino, ao aumento póstratamento do trespasse vertical, vestibuloversão pós-tratamento dos incisivos superiores, e linguoversão dos incisivos inferiores. As alterações do tratamento 
ativo incluíram redirecionamento ou inibição do crescimento maxilar e retração dos incisivos superiores. Também foi observada a diminuição dos ângulos do plano mandibular e oclusal, e um aumento da altura facial posterior. Poucos pacientes com padrão facial hiperdivergente (vertical) foram incluídos na amostra, e, na maioria dos pacientes, o crescimento mandibular foi favorável tanto durante quanto após o tratamento. Essas observações podem levar à especulação de que pacientes em crescimento com relações verticais normais apresentarão bons resultados no tratamento e estabilidade a longo prazo. $\mathrm{Na}$ opinião dos autores ${ }^{49}$, os fatores mais importantes para a estabilidade a longo prazo são as relações oclusais pós-tratamento e a função. Foi concluído que o tratamento bem-sucedido da má-oclusão de Classe II por meio do crescimento diferencial adaptativo e do movimento dentário parece ser estável.

FREITAS; HENRIQUES; PINZAN ${ }^{52}$, em 1996, realizaram um estudo em modelos, objetivando avaliar se há uma correlação da recidiva do apinhamento ântero-inferior com as distâncias intercaninos, intermolares e comprimento do arco. A amostra consistiu dos modelos inferiores de 33 pacientes, com másoclusões de Classe I e Classe II, tratados ortodonticamente pela técnica do Arco de Canto Simplificada, com extrações dos primeiros pré-molares superiores e inferiores. Os modelos foram realizados no início, final, 5 e 10 anos póscontenção. A amostra foi dividida em 2 grupos: o grupo I, formado por 21 pacientes com uma recidiva mínima do apinhamento inferior, e o grupo II, formado por 12 pacientes que apresentavam uma recidiva severa, de acordo com 
o índice de Little. Na análise comparativa dos modelos para ambos os grupos, os resultados evidenciaram que a diminuição das distâncias intercaninos, intermolares e o do comprimento do arco, não foram os fatores responsáveis pela maior recidiva observada no grupo II, pois os resultados apresentaram-se estatisticamente não significantes.

Em 1996, ARTUN; GAROL; LITTLE ${ }^{6}$ publicaram um estudo que tinha por finalidade avaliar a estabilidade, a longo prazo, do alinhamento ântero-inferior num grande grupo de pacientes que apresentavam má-oclusão de Classe II, Divisão 1, e que demonstraram bons resultados oclusais no final do tratamento ativo. A amostra foi composta por 78 adolescentes, sendo que 37 foram tratados com extrações dos quatro primeiros pré-molares e 41 foram tratados sem extrações. Avaliações cefalométricas e dos modelos de estudo dos pacientes foram realizadas em três fases: pré-tratamento, final do tratamento e póscontenção (média de 14 anos). Os resultados mostraram um aumento da irregularidade dos incisivos e uma redução da largura intercaninos e do comprimento do arco na fase de pós-contenção. Além disso, na fase póscontenção, 9\% dos pacientes apresentaram um valor para o índice de irregularidade de $6,5 \mathrm{~mm}$ ou mais, e $47,4 \%$ tiveram valor de $3,5 \mathrm{~mm}$ ou menos. $\mathrm{A}$ análise de regressão múltipla revelou que a largura intercaninos estreita e um índice de irregularidade alto antes do início do tratamento foram fatores significantes para prever a recidiva. Segundo os autores ${ }^{6}$, as alterações póscontenção dos comprimentos da face média e da mandíbula foram positivamente 
ou negativamente associadas, respectivamente, à recidiva, o que pode ser interpretado como uma indicação de que as alterações do crescimento, que tendem a causar um retorno a um relativo retrognatismo mandibular, aumentam a tendência para a irregularidade dos incisivos. Entretanto, nenhuma associação foi encontrada entre as alterações da relação esquelética ântero-posterior e a irregularidade dos incisivos, o que, de certa forma minimiza a significância desses achados. Os autores ${ }^{6}$ também ressaltaram que o aumento da largura intercaninos durante o tratamento e a sua diminuição pós-contenção estavam associados à recidiva, o que, em associação com a alta tendência para a recidiva, pode ser interpretado como embasamento para o raciocínio de se utilizar uma contenção "semi permanente" para o segmento ântero-inferior.

VADEN; HARRIS; GARDNER ${ }^{207}$, em 1997, ao estudar as alterações dentárias 6 e 15 anos após o tratamento, ressaltaram que as pessoas que apresentam uma mandíbula que cresce mais para a frente que a maxila tendem a mostrar um maior aumento na irregularidade dos incisivos inferiores e também um aumento do ângulo interincisivo. Segundo os autores ${ }^{207}$, uma possível explicação para a recidiva da irregularidade dentária, seria o "princípio do arco contido", segundo o qual, a medida que o trespasse vertical aumenta, a força lingual imposta sobre os incisivos inferiores, a partir dos incisivos superiores, tende a comprimir e a apinhar o arco inferior que está contido. 
MIYAZAKI et al. $^{121}$ realizaram, em 1997, um estudo para comparar a estabilidade, no período pós-tratamento (média de 4 anos), da oclusão em adultos e adolescentes tratados com extrações dos quatro primeiros pré-molares devido ao apinhamento ou à protrusão maxilar. O tratamento empregou a técnica do Arco de Canto. A média de idade no início do tratamento ficou entre 11,8 e 19,8 anos nos grupos adolescente e adulto, respectivamente. A amostra adolescente (com 2,3 mm) mostrou, no período pós-tratamento, um aumento significantemente maior no apinhamento ântero-inferior que a amostra adulta (1,2 $\mathrm{mm}$ ). Um apinhamento incisal inicial severo não tornou o paciente mais susceptível a apresentar uma maior recidiva pós-tratamento. A mandíbula do grupo adolescente cresceu para frente e para baixo no período pós-tratamento, enquanto o grupo adulto não mostrou alteração esquelética. Os trespasses horizontal e vertical pós-tratamento permaneceram mais estáveis nos adolescentes. Foi notada uma correlação entre a expansão durante o tratamento e a diminuição pós-tratamento da distância intercaninos nos adultos. Com base nos achados, os autores ${ }^{121}$ consideram melhor para o paciente adolescente usar a contenção pelo menos até o final do crescimento a fim de prevenir o aumento do apinhamento.

KASHNER $^{87}$ realizou, em 1999, um estudo que tinha por finalidade avaliar a qualidade longitudinal de casos que possuíam um excelente alinhamento (índice de Little menor que $1,0 \mathrm{~mm}$ ) no final do tratamento. Para representar esse grupo "mais bem tratado", 27 casos com extrações dos primeiros pré-molares 
inferiores foram obtidos do "Board" de Ortodontia Americano (índice de Little médio de 0,49 mm). Vinte e sete pacientes, correspondentes ao grupo experimental no início do tratamento, que possuiam um alinhamento final de tratamento aceitável (irregularidade de 1,0 a $3,5 \mathrm{~mm}$, com média de 2,02 mm), foram escolhidos como grupo controle. Ambos os índices PAR, o britânico e o americano, foram utilizados na avaliação dos casos. Não havia uma diferença significante no índice de irregularidade de Little ou nos índices PAR dos dois grupos na fase inicial. Na fase pós-contenção, não houve diferenças significantes para o índice de Little entre os grupos experimental e controle. Ambos os grupos exibiram um alinhamento mandibular aceitável após o período de contenção (experimental: 2,02 $\mathrm{mm}$; controle: 2,89 mm). Depois de avaliar individualmente a variabilidade do grupo experimental, o autor ${ }^{87}$ afirma que a revelação das inconsistências e dos resultados imprevisíveis deveria fazer parte da discussão do consentimento informado do paciente. Além disso, sem um protocolo de contenção continuada, resultados a longo prazo não podem ser garantidos.

Em 1999, LITTLE ${ }^{105}$ relatou que, por mais de 40 anos, o Departamento de Ortodontia da Universidade de Washington, em Seattle, se concentrou na coleta de mais de 800 conjuntos de exames de pacientes para verificar a estabilidade e a recidiva no tratamento ortodôntico. Todos os pacientes completaram o tratamento há uma década ou mais antes do último conjunto de dados. Segundo o autor ${ }^{105}$, as extrações de pré-molares, a fim de permitir o alinhamento dos dentes apinhados, têm sido um procedimento aceito por décadas e continua 
sendo o tratamento mais comum utilizado para pacientes com arcos desalinhados. Apesar de se alcançar normas cefalométricas sugeridas e aceitas, e apesar de se aderir aos padrões clínicos usuais de forma do arco, trespasse vertical, etc., a manutenção, a longo prazo, de resultados aceitáveis é desapontadora, com apenas $30 \%$ dos pacientes mostrando resultados aceitáveis a longo prazo. O uso indefinido de contenções fixas ou removíveis, talvez para a vida toda, pareça ser o único recurso lógico. Infelizmente, as seqüelas indesejáveis de tal programa de contenção não são conhecidas.

\subsubsection{A posição cefalométrica dos incisivos e a estabilidade do tratamento}

SHIELDS; LITTLE; CHAPKO ${ }^{178}$ realizaram, em 1985, uma verificação, pelo menos 10 anos após o tratamento ortodôntico de 54 casos previamente tratados com extrações dos quatro primeiros pré-molares pela técnica do Arco de Canto. Segundo os autores ${ }^{178}$, a resposta longitudinal do alinhamento ânteroinferior foi imprevisível. Nenhum parâmetro cefalométrico, como inclinação dos incisivos superior e inferior, quantidade de crescimento horizontal e vertical, ângulo do plano mandibular, etc. foi útil no estabelecimento de um prognóstico. Poucas associações com valor foram encontradas entre os parâmetros cefalométricos e as medições dos modelos de estudo, como trespasses horizontal e vertical, comprimento do arco e distância intercaninos. Houve uma ligeira tendência para os incisivos retornarem a suas inclinações originais; entretanto, a falta de previsibilidade da quantidade de recidiva reduz a 
significância clínica desse achado. A variação tipificou a amostra, provavelmente refletindo a capacidade individual da dentição e dos tecidos bucais circundantes de se adaptarem às alterações criadas pela mecanoterapia ortodôntica. Também é concebível que exista um "envelope" no qual o movimento dentário possa ser realizado sem recidiva significante da inclinação e que alterações extremas violando esses limites estejam mais associadas com a recidiva a longo prazo. Os indivíduos que tendiam a apresentar valores baixos para os ângulos dos planos oclusal e mandibular, bem como ângulos SNA e SNB mais altos, foram mais propensos a apresentar um aprofundamento da mordida.

ACKERMAN; PROFFIT ${ }^{1}$, em 1997, afirmaram que, apesar de repetidos esforços para se descrever regras para as posições ideais para o incisivo, baseadas em relações esqueléticas cefalométricas, está claro agora que diferenças raciais, étnicas e individuais tornam isso quase impossível. Baseados na literatura sobre o desenvolvimento do arco dentário, as forças dos tecidos moles e a estabilidade do tratamento, os autores ${ }^{1}$ propõem um diagrama com os limites de estabilidade para a expansão do arco inferior. A estabilidade está amplamente em risco com a expansão ântero-posterior dos incisivos inferiores além de $2 \mathrm{~mm}$ ou com uma expansão transversal do arco inferior além de 4 a 5 mm. Segundo os autores ${ }^{1}$, a estabilidade após o tratamento ortodôntico é determinada pela habilidade dos tecidos moles em se adaptar às alterações na morfologia do tecido duro. 
Cefalogramas laterais e modelos de estudo de 55 pacientes foram avaliados por LENS; WOODS ${ }^{102}$, em 1999, a fim de determinar se existia alguma relação entre as posições e as angulações incisais, como também entre as suas alterações e a estabilidade oclusal a longo prazo. Nenhuma relação significante pôde ser encontrada entre as alterações a longo prazo que ocorrem num número de medidas incisais comumente utilizadas e as posições incisais ao final do tratamento, alterações nas posições incisais durante o tratamento, ou alterações a longo prazo no ângulo do eixo facial, ângulo ANB, ou o índice PAR. As alterações incisais que ocorreram a longo prazo nos pacientes individuais não estavam necessariamente associadas com alterações oclusais negativas. Considerando que as posições incisais sempre alteram a longo prazo, é sugerido que a utilização de normas publicadas ou objetivos absolutos recomendados para as posições incisais ao final tratamento sejam utilizados mais como um guia clínico funcional geral e estético, ao invés de serem utilizadas como fator de previsão da estabilidade.

\subsubsection{O papel dos terceiros molares na recidiva}

Segundo a Associação Americana de Ortodontia ${ }^{3}$, a teoria de que os terceiros molares, quando em irrupção, empurram o arco mandibular, forçando os dentes posteriores para frente e apinhando os incisivos, constitui-se na explicação mais proclamada pelos clínicos gerais e pelos próprios pacientes para a recidiva pós-tratamento. Esse conceito é atraente, visto que ele implica que os 
dentistas podem prevenir 0 apinhamento simplesmente pela extração dos terceiros molares, antes que o apinhamento se desenvolva.

HARRADINE; PEARSON; TOTH ${ }^{63}$, em 1998, num teste clínico aleatório ("randomized"), mostraram que não há uma redução clinicamente significante na incidência do apinhamento incisal após a extração dos terceiros molares.

Outro aspecto importante é que pacientes com ausência congênita ${ }^{2}$ dos terceiros molares também são afetados pelo apinhamento tardio. Embora haja razões válidas para a extração dos terceiros molares, prevenir o apinhamento dos incisivos inferiores não parece ser uma delas ${ }^{3}$.

\subsubsection{O dimorfismo sexual e a recidiva}

ROSSOUW; PRESTON; LOMBARD ${ }^{166}$ realizaram, em 1999, um estudo que tinha por finalidade verificar as diferenças longitudinais entre os homens e as mulheres durante e após o tratamento ortodôntico ativo, como também determinar se existe uma relação entre o dimorfismo sexual e o apinhamento incisal inferior pós-tratamento. A amostra avaliada consistiu de 33 homens e 55 mulheres tratados pela técnica do Arco de Canto, acompanhados durante um período de cerca de 7 anos após o término do tratamento. Após a avaliação dos modelos de estudo e das telerradiografias laterais, os autores concluíram que: os homens cresceram mais, por mais tempo, e se tornaram maiores que as mulheres; a rotação mandibular anterior foi mais óbvia nos homens; o grupo masculino, que foi tratado com menos extrações, desenvolveu lábios mais retruídos com a idade, 
em comparação com o grupo feminino, que teve mais extrações realizadas durante o seu tratamento; o crescimento (pós-tratamento), sobre o qual o ortodontista não possui nenhum controle, pareceu influenciar a irregularidade dos incisivos inferiores no período pós-tratamento. Uma pergunta pode ser feita: os ortodontistas terminam o tratamento muito cedo, ou, vice-versa, eles iniciam o tratamento muito cedo nas más-oclusões convencionais? A contenção, embora igualmente importante para ambos os sexos, deveria ser mais rigidamente prescrita e utilizada nos homens.

\subsubsection{A relação da morfologia e do crescimento craniofacial com a recidiva}

HERZBERG $^{70}$, em 1973, examinou, no final do tratamento e dois anos após o tratamento, 48 casos de Classe II, Divisão 1, tratados na sua maioria com extrações de quatro pré-molares pela técnica do Arco de Canto. Nesse trabalho, o autor $^{70}$ observou que um bom crescimento da mandíbula (medido a partir do SNB) para frente e para baixo era o fator isolado mais importante para a correção das más-oclusões de Classe II e também para a manutenção da correção, podendo até mesmo compensar efeitos desfavoráveis do tratamento, como a inclinação do plano oclusal.

VAN DER LINDEN²08, em 1974, descreveu a expressão "apinhamento terciário", que se refere ao apinhamento que ocorre durante o período da adolescência e do da pós-adolescência. Os incisivos inferiores e, em menor 
extensão, os superiores se verticalizam, enquanto o crescimento da maxila e particularmente o da mandíbula continuam. Arcos dentários idealmente alinhados podem começar a mostrar uma sobreposição dos dentes anteriores, um fenômeno que é observado mais em homens que em mulheres. Isso está relacionado às diferenças entre os dois sexos no crescimento facial tardio. A presença dos terceiros molares parece ter pouco efeito nesse tipo de apinhamento, já que ele também acontece quando não há terceiros molares. Para o autor $^{208}$, a continuação do crescimento mandibular, numa época em que não há mais ou há pouco crescimento no resto do complexo craniofacial, parece ser o fator contribuinte mais importante para a ocorrência desse apinhamento.

SCHUDY ${ }^{174}$, em 1974, ao estudar cefalometricamente 64 pacientes tratados ortodonticamente, a fim de analisar os efeitos do crescimento terminal pós-tratamento, encontrou que: o crescimento terminal é caracterizado por uma diminuição nos ângulos SN.PM, SN.Ocl e ANB; a mandíbula move-se mais para frente que a maxila durante esse período; o incisivo superior normalmente inclina-se para frente; o perfil facial torna-se progressivamente menos convexo, devido ao crescimento do nariz e ao movimento anterior do mento; a rotação mandibular (diminuição no ângulo SN.PM) e o movimento lingual dos incisivos inferiores são fatores críticos na etiologia da sobremordida e da redução do comprimento do arco. 
SAKUDA et al. ${ }^{171}$, em 1976, realizaram um estudo cefalométrico e de modelos em 18 pacientes do sexo masculino e em 12 do feminino não tratados ortodonticamente, que foram avaliados nas idades de 12,14 e 17 anos. $O$ objetivo era investigar as alterações no apinhamento dos arcos superior e inferior durante a adolescência e sua relação com o crescimento facial. Os autores ${ }^{171}$ concluíram que, de acordo com a análise de regressão múltipla, o apinhamento no arco inferior parece estar amplamente relacionado a algumas alterações cefalométricas ocorridas com o crescimento (menor protrusão dos incisivos superiores, pouco crescimento da maxila, grande crescimento vertical no segmento posterior superior, diminuição do ângulo intermolares), bem como a algumas características cefalométricas presentes aos 12 anos (alto valor para o ângulo do plano mandibular, grande comprimento efetivo da mandíbula, pequeno comprimento do corpo mandibular, primeiros molares inferiores inclinados mesialmente, pequena dimensão vertical no segmento superior posterior, grande altura facial superior). Portanto, o apinhamento secundário parece ser causado não apenas pelo padrão específico de crescimento, mas também pelo tipo de esqueleto susceptível ao apinhamento no começo da adolescência.

EL-MANGOURY ${ }^{47}$ publicou, em 1979, um estudo que tinha por finalidade investigar a recidiva ortodôntica em indivíduos com graus variados de displasia ântero-posterior e/ou vertical. A amostra consistiu de 50 casos bem tratados, que foram divididos em dois grupos, estável e com recidiva, baseado nas alterações pós-tratamento dos trespasses horizontal e vertical, e nas relações dos caninos e 
molares. Como resultados, encontrou: o ângulo PP.GoGn e a largura intercaninos foram as duas variáveis mais importantes associadas com a recidiva; a alteração do ângulo PP.GoGn, tanto pelo tratamento quanto pelo crescimento, foi associada com a recidiva; a diminuição da distância intercaninos foi maior no grupo com recidiva e tendeu a voltar para o seu valor original; considerando que não houve interação entre a recidiva (ou estabilidade) e a inclusão ou não de extrações, a autora $^{47}$ concluiu que o trespasse vertical aumentado não é uma contra-indicação para o tratamento com extrações.

LEIGHTON; HUNTER ${ }^{101}$ estudaram, em 1982, as características esqueléticas faciais associadas com o espaçamento ou apinhamento da dentição inferior nas dentaduras mista e permanente de uma amostra longitudinal de 80 indivíduos agrupados da seguinte forma: a) 34 pacientes com espaços na dentição inferior; b) 30 pacientes com dentições inferiores moderadamente apinhadas; e c) 24 pacientes com dentições inferiores severamente apinhadas. Esse estudo revelou que os indivíduos com apinhamentos severos possuíam uma inclinação maior dos planos mandibular e oclusal em relação à linha SN que os outros indivíduos. Esse grupo também apresentava uma altura facial posterior diminuída, um menor valor para o comprimento do corpo mandibular, tendo a sínfise e as dentições posicionadas mais para trás que os indivíduos dos outros dois grupos. Os indivíduos com espaçamento apresentaram um maior crescimento mandibular anterior e uma maior rotação anterior da mandíbula. Os autores $^{101}$ concluíram que as dentições inferiores apinhadas existem numa 
estrutura de suporte morfologicamente distinta, que possui uma direção de crescimento inferior e uma relativa deficiência na quantidade de crescimento.

LUNDSTRÖM; McWILLIAM $^{111}$ realizaram, em 1984, um estudo com dois grupos, compostos de 68 adultos e 42 pares de adultos gêmeos, com respeito às variações ântero-posteriores na relação das bases apicais e sua associação com o trepasse horizontal, bem como à inclinação dos incisivos superiores e inferiores. Uma fraca correlação com o trespasse horizontal foi estabelecida enquanto fortes associações foram encontradas com a inclinação dos incisivos, especialmente considerando os incisivos inferiores. Uma grande relação basal apical positiva então parece ser primariamente compensada pela vestibuloversão dos incisivos inferiores, enquanto valores negativos causaram uma correspondente linguoversão. Quando coeficientes de correlação associados foram comparados com valores previamente publicados, associações um tanto mais fortes foram encontradas. Além disso, quando as compensações incisais médias para variações na relação da base apical foram comparadas com o modelo de Steiner, elas mostraram ser ligeiramente maiores que aquelas recomendadas por ele. Para os autores ${ }^{111}$, a adaptação das inclinações dos incisivos em relação às bases apicais está também associada com as influências dos tecidos moles. O desvio devido a fatores genéticos é maior para relação basal apical que para o trespasse horizontal, enquanto a influência não genética é a mesma para ambas as variáveis. 
PERERA $^{133}$, em 1987, estudou o crescimento rotacional da mandíbula em relação ao apinhamento dos incisivos em 29 indivíduos não tratados ortodonticamente, com as idades variando de 11 a 19 anos. Ele encontrou uma média de $4,09^{\circ}$ para a rotação mandibular anterior, que estava significantemente correlacionada com o aumento do apinhamento dos incisivos inferiores $(r=0,51$, $\mathrm{p}<0,01)$.

Segundo um estudo conduzido por BEHRENTS ${ }^{12}$, em 1985, as alterações dentofaciais podem ocorrer por toda a vida (dos 17 aos 80 anos), assim como a irrupção dentária e a verticalização dos incisivos. Além de demonstrar pequenas, mas importantes alterações dentofaciais em 141 indivíduos (113 não tratados e 28 tratados ortodonticamente) pertencentes ao estudo de crescimento Bolton, ele relatou que os homens tinham uma rotação de crescimento da mandíbula para cima (anti-horária) e para frente, enquanto as mulheres apresentaram uma rotação para baixo (horária) e para trás. O efeito sobre os incisivos inferiores foi de verticalização nos homens e de vestibularização nas mulheres, sendo que o apinhamento continuou a aumentar e o os molares inferiores a mesializarem nas mulheres. As alterações tegumentares foram dramáticas e de maior magnitude que as alterações esqueléticas, envolvendo principalmente o alongamento do nariz, a retrusão dos lábios, e o aumento do mento.

BEHRENTS et al. ${ }^{13}$ relataram, em 1989 que fatores associados à previsão das alterações no apinhamento estão mais relacionados a 
características anatômicas que a características dentoalveolares. Quanto maior o aumento do comprimento maxilar (Sela-A), menor o valor do índice de irregularidade (menor o apinhamento ântero-inferior), o que sugere que a recidiva pode ocorrer como resultado do movimento dentário em equilíbrio com o crescimento. Portanto, ao invés de relacioná-lo com o crescimento mandibular, o apinhamento dos dentes anteriores inferiores seria uma resposta às alterações dentárias e esqueléticas da maxila. Segundo os autores ${ }^{13}$, a contenção deveria ser continuada, dependendo da quantidade de crescimento que está acontecendo. Sendo assim, a contenção deveria ser continuada até a segunda e a terceira década de vida, se possível. O crescimento é importante durante o tratamento e deve também ser planejado, utilizado e respeitado após o tratamento.

NANDA; $\operatorname{NANDA}^{127}$, em 1992, afirmaram que, apesar de as manifestações clínicas das relações esqueléticas receberem considerável importância antes do início e durante o tratamento ortodôntico, pouca ou nenhuma consideração é dada às alterações esqueléticas pós-tratamento devido ao crescimento e ao seu efeito no resultado final. Os pacientes com a síndrome da face curta deveriam utilizar uma placa com batente anterior até o término do crescimento. Falha no reconhecimento do padrão de crescimento morfogenético horizontal dominante pode resultar num perfil "afundado", após o tratamento com ou sem extrações de dentes. O crescimento do nariz no paciente com mordida profunda e altura facial vertical diminuída pode acentuar o padrão facial côncavo. 
Os pacientes com a síndrome da face longa podem necessitar de um aparelho extrabucal de tração alta, a fim de manter a posição dos molares e evitar o crescimento dentoalveolar para baixo e para trás. Para esses autores ${ }^{127}$, é extremamente importante prestar atenção ao padrão de crescimento da pessoa e realizar uma distinção na seleção dos aparelhos de contenção, tendo por base a natureza e a extensão da displasia dentofacial. A natureza e a duração da contenção deveriam depender do estado de maturação do paciente e do crescimento futuro antecipado. Guiar a fase de contenção é necessário para o ajuste da dentição às alterações devido ao crescimento tardio e à maturação do equilíbrio neuromuscular. A resposta para a estabilidade a longo prazo é uma contenção a longo prazo: dinâmica, não estática.

FREITAS ${ }^{51}$, em 1993, realizou um estudo em modelos, objetivando avaliar se há uma correlação da recidiva do apinhamento ântero-inferior com as distâncias intercaninos, intermolares, com o comprimento do arco e os valores cefalométricos referentes às bases ósseas (NAP, WITS, SNA, SNB, ANB e SND), com o padrão do esqueleto cefálico (ÂBS, ÂBI, FMA, SN.Oclusal, SN.GoGn e SN.Gn) e com o posicionamento dos incisivos inferiores (1.NB, 1-NB, Linha I e IMPA). A amostra consistiu dos modelos inferiores e de telerradiografias em norma lateral de 33 pacientes, sendo 24 do sexo feminino e 9 do masculino, com más-oclusões de Classe I (14 casos) e Classe II, Divisão 1 (19 casos), tratados ortodonticamente pela técnica do Arco de Canto Simplificada, com extrações dos primeiros pré-molares superiores e inferiores. Os modelos foram realizados nos 
períodos inicial, final, 5 anos e 10 anos após a contenção. A amostra foi dividida em 2 grupos distintos, a partir da análise do grau de apinhamento apresentado no controle 10 anos após a contenção: o grupo I, formado por 21 pacientes, com uma recidiva mínima do apinhamento ântero-inferior, de acordo com o índice de Little, abaixo de $3,9 \mathrm{~mm}$; e o grupo II, formado por 12 pacientes, que apresentavam uma recidiva severa, de acordo com o índice de Little, acima de 4,0 mm. Na análise comparativa dos modelos entre ambos os grupos, os resultados evidenciaram que a diminuição das distâncias intercaninos, intermolares e do comprimento do arco, não foram os fatores responsáveis pela maior recidiva observada no grupo II, pois os resultados apresentaram-se estatisticamente não significantes. Com referência ao estudo cefalométrico utilizado, depreende-se que as medidas utilizadas para as bases ósseas apresentaram alterações semelhantes em ambos os grupos, com os resultados estatisticamente não significantes. Com referência ao padrão do esqueleto cefálico, as medidas SN.GoGn e SN.Gn demonstraram que, no grupo II, o crescimento predominante vertical colaborou com a recidiva acentuada do apinhamento ântero-inferior, pois os resultados apresentaram-se estatisticamente significantes. A posição dos incisivos inferiores no início do tratamento apresentou correlação com a quantidade de recidiva do apinhamento do arco inferior. O grupo II apresentou uma protrusão maior dos incisivos inferiores que o grupo I no início do tratamento. 
RICHARDSON ${ }^{156}$, em 1994, estudou o papel do crescimento horizontal diferencial no apinhamento tardio do arco dentário inferior. Oitenta e cinco indivíduos, possuindo, alguns, oclusões normais, outros, próximas do normal, outros, ainda, várias más-oclusões, avaliados logo após a irrupção dos segundos molares permanentes, foram acompanhados longitudinalmente por 3 ou 4 anos. Como resultados, a autora ${ }^{156}$ não encontrou qualquer diferença significante na quantidade ou direção de deslocamento entre os dentes superiores e inferiores ou entre a maxila e a mandíbula. O pogônio alterou-se mais no sentido horizontal que o ponto B. O aumento no apinhamento dentário inferior foi fracamente associado ao crescimento horizontal diferencial dos maxilares e dos dentes. $O$ crescimento horizontal reduzido e o maior crescimento vertical da maxila, o deslocamento anterior dos incisivos superiores e inferiores, e o aumento do crescimento da base mandibular foram até certo ponto relacionados ao aumento no apinhamento incisal.

O tratamento ortodôntico no adolescente confia muito no crescimento, enquanto, no paciente adulto, o clínico deve reposicionar os dentes dentro de arcos que não crescem. Segundo HARRIS et al. ${ }^{65}$ (1994), essa diferença pode criar um potencial para uma maior recidiva pós-contenção no adulto; por outro lado, o contínuo crescimento no subadulto pode diminuir a estabilidade do caso. Sendo assim, duas amostras de casos com má-oclusão de Classe II, Divisão 1, todos tratados por um único especialista, foram examinados dentro de uma média de 5 anos após o tratamento. Um grupo tinha sido tratado durante a adolescência 
(aproximadamente 12 anos de idade), o outro, na idade adulta (aproximadamente 28 anos). Observou-se que dois tipos de alterações ocorreram na mesma extensão em ambos os grupos e pareceram ser previsíveis independentemente da idade: a) o primeiro molar superior se "assenta" após o tratamento ativo, tanto por inclinação anterior da coroa quanto por movimento mesial de corpo; b) a correção molar total voltou ligeiramente para a relação de Classe II por volta de $1 \mathrm{~mm}$. Essa alteração foi estatisticamente equivalente nos dois grupos. O primeiro molar superior migrou mesialmente bem mais $(2,7 \mathrm{~mm})$ nas pacientes adolescentes que nas adultas $(1 \mathrm{~mm})$. Isso não afetou a correção molar total porque o molar inferior foi para frente pelo crescimento diferencial mandibular, que foi muito maior nas pacientes adolescentes que nas adultas $(2,0$ versus 0 $\mathrm{mm})$. Houve um crescimento apreciável para frente tanto da maxila $(-1,62 \mathrm{~mm})$ quanto da mandíbula $(3,66 \mathrm{~mm})$ nas adolescentes, mas não nas adultas $(0,04$ e 0,12 mm, respectivamente). Nestas, a maior alteração ficou por conta do movimento desfavorável, tanto de corpo como de inclinação mesial $(-1,05 \mathrm{~mm})$ do molar superior, que, mesmo assim, ficou mais estável que nas adolescentes. Portanto, as correções ortodônticas foram estáveis em ambos os grupos, mas por motivos diferentes.

ZAHER, BISHARA e JAKOBSEN ${ }^{220}$, em 1994, realizaram um estudo que tinha por finalidade descrever e comparar as alterações que ocorrem durante e após o tratamento ortodôntico em três tipos faciais: face curta, face média e face longa. Foram avaliados 66 indivíduos com má-oclusão de Classe II, Divisão 1. 
Todos os casos foram tratados sem extrações, utilizando a técnica do Arco de Canto e o aparelho de ancoragem extrabucal. O cefalograma lateral e os modelos de estudo foram medidos em três diferentes estágios: antes do tratamento, imediatamente após a remoção do aparelho e pelo menos dois anos após o tratamento. Houve uma grande gama de variação individual na alteração póstratamento para os vários parâmetros esqueléticos e dentários medidos. Com poucas exceções, os três tipos faciais não mostraram diferenças significantes na alteração pós-tratamento. Entretanto, uma tendência maior de recidiva do trespasse vertical e de diminuição da distância intercaninos foi observada nos pacientes com tipo facial curto. A protrusão relativa do incisivo central superior tendeu a aumentar após o tratamento, no tipo de face longa, e diminuir, no tipo de face curta. As mulheres com face longa, quando comparadas com os outros grupos, mostraram maior aumento incremental pós-tratamento, na altura facial anterior, e também maior diminuição pós-tratamento, no comprimento do arco superior. Os homens manifestaram maiores aumentos incrementais póstratamento que as mulheres em várias medidas lineares da altura facial. Segundo os autores ${ }^{220}$, as diferenças nas alterações pós-tratamento para os diferentes tipos faciais não requerem considerações especiais para a contenção.

RICHARDSON ${ }^{157}$, em 1994, após uma revisão da literatura, relatou que não há evidência suficiente para apoiar uma ligação causativa direta entre o apinhamento incisal tardio e um padrão facial específico, mas os padrões de rotação mandibular foram suspeitos de contribuir com esse apinhamento. 
Em 1995, WILLIAMS; ANDERSEN ${ }^{214}$ publicaram uma pesquisa a fim de avaliar se a vestibularização dos incisivos inferiores seria estável quando realizada em pacientes que estavam em crescimento, nos quais a mandíbula apresentasse um padrão de rotação anterior segundo o método de previsão de BJÖRK $^{22}$, de 1969. A amostra consistiu de 42 crianças, com más-oclusões de Classe I e Classe II, nas quais os incisivos inferiores foram vestibularizados durante o tratamento ortodôntico pela técnica do Arco de Canto. Apenas 2 pacientes foram tratados sem extrações no arco inferior. Todos os pacientes foram selecionados com base na previsão de possuírem um padrão rotacional de crescimento anterior da mandíbula. Para a avaliação, foram utilizados os modelos de estudo e as telerradiografias realizadas antes do tratamento, após o término e após o período de contenção (média de 7 anos e 4 meses). Os resultados demonstraram a aceitação clínica do princípio do tratamento empregado no qual a maioria das alterações do tratamento foram mantidas satisfatoriamente após a suspensão da contenção. Nenhuma correlação foi encontrada entre o índice de irregularidade e as seguintes variáveis: o comprimento do arco, a inclinação incisal, a alteração no prognatismo mandibular, a relação intermaxilar (ANB) e a rotação mandibular. A recidiva da irregularidade dos incisivos inferiores se relacionou levemente $(r=0,39 ; p<0,05)$ com o aumento do trespasse vertical e com a diminuição da distância intercaninos. Segundo os autores ${ }^{214}$, a previsão de um padrão de crescimento anterior utilizando apenas o método de determinação morfológica é difícil quando se trata de formas suaves de rotação. 
Segundo MELROSE ${ }^{119}$, em 1998, a curto prazo, as forças gengivais e periodontais são propensas a manifestar maior significância na recidiva, mas, a longo prazo, o impacto do contínuo crescimento durante a fase adulta é provavelmente fundamental. Para o autor ${ }^{119}$, estamos numa fase em que a qualidade e a efetividade de muitos procedimentos clínicos são questionadas e orientações para a prática clínica estão sendo buscadas para auxiliar na tomada de decisão a cerca dos cuidados apropriados para condições específicas. Sendo assim, a pergunta a ser feita é: estamos praticando uma Ortodontia baseada em evidências, com relação à contenção? Para ele ${ }^{119}$, a resposta no presente é não.

HARRIS, GARDNER; VADEN ${ }^{66}$, num estudo cefalométrico realizado em 1999, avaliaram 36 pacientes, em média, 5,5 anos após o tratamento e novamente após uma média de 14,4 anos a contar do término deste. A maioria das dimensões lineares aumentou significantemente a partir do final do tratamento até a primeira avaliação (variação da idade de 16 a 21 anos), presumidamente como resultado do contínuo crescimento na adolescência; entretanto, poucas alterações foram significantes posteriormente (variação da idade de 21 a 30 anos). As relações dos arcos (ANB, NAP, AOBO, Eixo Y) continuaram a melhorar após o tratamento, provavelmente como resultado do crescimento tardio da mandíbula produzindo um perfil mais ortognático. Houve pouca alteração entre a primeira e a segunda avaliações para todas as variáveis. Os resultados sugeriram que, se a recidiva ocorrer, é provável que fique evidente logo após o tratamento e diminua após, e que o crescimento craniofacial contínuo 
geralmente aumenta a correção ortodôntica. Além disso, observaram também que uma rotação para cima e para frente da mandíbula e do plano oclusal ocorreu entre a idade de 16 a 21 anos. Essa rotação foi concomitante com o aumento na razão entre as alturas faciais posterior e anterior.

ROSSOUW ${ }^{165}$, em 1999, ao avaliar a expressão RETOMADA DO CRESCIMENTO, afirma que as alterações esqueléticas ou a metamorfose ortopédica podem ser induzidas como parte da primeira fase ou tratamento precoce no paciente jovem, quando os processos de crescimento ainda estão ativos. Fatores, como as características genéticas, as forças da gravidade e o padrão esquelético tornam-se reoperativos e expressam-se de novo. Subseqüentemente, padrões de crescimento vão "retomar" o desenvolvimento anterior a partir das alterações de tratamento, e uma segunda metamorfose de volta ao padrão genético determinado originalmente será vista ocorrendo, especialmente na mandíbula. Esse tipo de alteração não caracteriza recidiva; compreende, sim, alterações impróprias do crescimento.

WEST; McNAMARA JÚNIOR ${ }^{213}$ realizaram, em 1999, um estudo que tinha por objetivo avaliar cefalometricamente as alterações e os ajustes do crescimento craniofacial que ocorrem a partir da adolescência até a idade adulta média em pessoas que não se submeteram previamente a tratamento ortodôntico. Foram estudados cefalogramas laterais seriados de 58 indivíduos, que foram reavaliados no final da quarta década de vida. Quinze desses 
pacientes também possuíam cefalogramas realizados por volta dos 30 anos. Alterações estatisticamente significantes ocorreram devido ao crescimento. $O$ comprimento da mandíbula e da face média, assim como, as alturas faciais posterior e anterior inferior aumentaram significantemente nos homens e nas mulheres ao longo de ambos os intervalos. O padrão de expressão dessas alterações foi diferente nos dois gêneros: os homens mostraram uma rotação anterior da mandíbula, enquanto as mulheres demonstraram uma rotação posterior. As alterações do tecido mole também foram diferentes. Nos homens, o nariz e o mento cresceram para baixo e para frente, com os lábios geralmente se movendo diretamente para baixo. Em contraste, as mulheres apresentaram um crescimento nasal para baixo e para frente, bem como uma leve retrusão dos lábios com o decorrer do tempo. Uma continuação da irrupção dentária também foi observada em ambos os sexos. Nos homens, observou-se que os dentes inferiores estavam irrompendo e se movendo para trás (distal), enquanto que, nas mulheres, os dentes irromperam e se moveram para frente (mesial). Segundo os autores ${ }^{213}$, esses movimentos podem ser compensatórios para o tipo de crescimento mandibular diferencial que ocorreu previamente, o que pode ser 0 resultado combinado da irrupção real dos dentes e do aumento da altura alveolar.

PINTO; WOODS; CRAWFORD ${ }^{149}$, em 2000, surpreenderam-se por não encontrarem diferenças significativas nas alterações do valor do índice PAR no período pós-tratamento para subgrupos verticais diferentes. Isso, segundo os autores $^{149}$, considerando-se tudo que foi escrito previamente a respeito da 
provável influência dos tipos faciais verticais no planejamento e no tratamento. Como o grupo braquifacial habitualmente apresenta uma musculatura mais potente, talvez ele pudesse tolerar melhor a expansão no arco dentário e também apresentar uma recidiva maior da sobremordida. A amostra de 65 pacientes foi dividida pelo quociente de altura facial de Jarabak ${ }^{185}$ em hipodivergente, neutra, e hiperdivergente. Foi concluído nesse estudo ${ }^{149}$ que o padrão facial vertical prétratamento, por si próprio, não é um fator de previsão da quantidade de alteração oclusal pós-tratamento.

BEATRICE; WOODS ${ }^{9}$, em 2000, utilizaram uma amostra de 65 pacientes, que foi dividida pelo quociente de altura facial de Jarabak ${ }^{185}$ em hipodivergente, neutra e hiperdivergente. A finalidade do estudo era determinar se existia alguma relação entre as alterações do Eixo Facial durante e após o tratamento (6,5 anos após a contenção) com os tipos faciais citados, bem como com a quantidade de alteração oclusal pós-tratamento avaliada pelo índice PAR. Nenhuma relação significante foi encontrada. As alterações do Eixo Facial foram pequenas, durante e após o tratamento, e não pareceram estar diretamente relacionadas com o tipo facial vertical.

Jovens com má-oclusão de Classe II, Divisão 1, e com oclusão normal que formaram uma amostra de 44 jovens do sexo masculino entre as idades de 12 anos e 10 meses e 18 anos e 10 meses, foram avaliados por GURGEL; ALMEIDA; PINZAN ${ }^{60}$, em 2001, a fim de determinar os efeitos da correção 
ortodôntica ao final do tratamento e três anos após o término. Os resultados demonstraram que as alterações encontradas ao final do tratamento reforçam a premissa de que o tratamento ortodôntico corretivo da Classe II surte um discreto efeito esquelético, preferentemente na maxila. No período pós-tratamento observou-se também a ocorrência de incrementos maxilares e mandibulares, menores, entretanto, que os encontrados no período anterior. Estes últimos, embora reduzidos, exibiram-se de modo mais marcante no sentido vertical e com predominante ocorrência no grupo controle.

\subsubsection{Alterações longitudinais no perfil tegumentar facial}

Segundo SIATKOWSKI ${ }^{180}$ (1974), uma possível explicação para a verticalização dos incisivos no final da adolescência seria a diferença no padrão de crescimento entre o esqueleto facial e o tecido tegumentar circundante, o qual sofre uma desaceleração mais rápida no seu crescimento que o tecido ósseo, resultando numa força com direção lingual sobre os incisivos. Outra possibilidade seria um aumento da dureza, com o passar da idade, no tecido tegumentar bucal durante o crescimento tardio.

BISHARA; HESSION; PETERSON ${ }^{20}$ realizaram, em 1985, um estudo longitudinal sobre as alterações do perfil tegumentar. A amostra utilizada consistiu de 20 homens e 15 mulheres, leucodermas, com oclusões aceitáveis, que foram estudados dos 5 aos 25 anos. Para a medida ângulo Z, os autores ${ }^{20}$ 
encontraram uma média, aos 13 anos, em torno de $67^{\circ}$ e, aos 15 anos de $69^{\circ}$, tanto para os homens, quanto para as mulheres. Na idade adulta, a média do ângulo $Z$ foi de $75^{\circ}$ para os homens e de $71^{0}$ para as mulheres. Para a posição do lábio superior em relação à linha $E$ encontraram: a média aos 13 anos, foi de $-1,2$ $\mathrm{mm}$ para os homens e $-2,5 \mathrm{~mm}$ para as mulheres; aos 15 anos, foi de $-1,9 \mathrm{~mm}$ para os homens e de $-4,1 \mathrm{~mm}$ para as mulheres; na idade adulta, foi de $-5,1 \mathrm{~mm}$ para os homens e de $-4,8 \mathrm{~mm}$ para as mulheres. Para a posição do lábio inferior em relação à linha $\mathrm{E}$ encontraram: a média aos 13 anos, foi de $-0,6 \mathrm{~mm}$, tanto para os homens, quanto para as mulheres; aos 15 anos, foi em torno de -1,6 mm, tanto para os homens, quanto para as mulheres; na idade adulta, foi de $-3,9 \mathrm{~mm}$ para os homens e de $-2 \mathrm{~mm}$ para as mulheres.

SCAVONE JÚNIOR; FREITAS; HENRIQUES ${ }^{172}$, em 1993, avaliaram, em intervalos médios de um a cinco anos após o tratamento, uma amostra de 12 jovens leucodermas do sexo masculino, que apresentavam má-oclusão de Classe I, tratados com extrações dos quatro primeiros pré-molares superiores e inferiores. Os resultados evidenciaram que os pacientes apresentaram um considerável crescimento facial, mesmo após os 15 anos de idade, propiciando modificações no perfil facial tegumentar, destacando-se uma tendência para a progressiva retrusão da região subnasal e dos lábios, notadamente do superior, em relação aos demais componentes faciais. Esse processo conduziu a uma redução gradativa na convexidade do perfil quando avaliado pelos ângulos H.NB e Gl' Sn.P'. 
DAINES ${ }^{36}$, em 1988, realizou um estudo cefalométrico sobre a influência dos padrões extremos de crescimento da face sobre o perfil tegumentar, em 38 jovens leucodermas brasileiros, com oclusão satisfatória, sem tratamento ortodôntico prévio. De acordo com a proporção entre a altura facial ântero-inferior (AFAl) e a altura facial anterior total (AFAT), dividiu-se a amostra em dois grupos, um com 19 jovens apresentando um padrão de crescimento facial horizontal, e um outro grupo também com 19 jovens, apresentando um padrão vertical. Esses jovens foram radiografados nas faixas etárias de 6, 9, 12, 15 e 18 anos. Como resultado o autor ${ }^{36}$ encontrou que, o maior aumento do nariz, tanto em espessura quanto em altura, apresentou-se como característica do padrão horizontal, enquanto que, o maior aumento em altura do mento tegumentar apresentou-se como característica do padrão vertical. Em relação à convexidade facial, ambos os padrões apresentaram uma diminuição da mesma. Porém, incluindo-se o nariz, essa convexidade aumentou no padrão horizontal. Segundo o autor ${ }^{36}$, os planejamentos ortodônticos com extrações dentárias em ambos os arcos devem ser realizados com parcimônia em jovens braquifaciais, durante o crescimento, pois pode-se prejudicar o perfil.

ZIERHUT et al. ${ }^{221}$, em 2000, realizaram um estudo a fim de comparar os perfis após o tratamento e após o período pós-contenção de casos com másoclusões de Classe II, Divisão 1, tratados, tanto com extrações de 4 primeiros pré-molares quanto, sem extrações, que tiveram sucesso e que apresentavam estabilidade. A amostra consistiu de 63 adolescentes (23 com extrações e 40 
sem). Foram avaliadas as telerradiografias laterais inicial, pós-tratamento e póscontenção (média de 14 anos). O perfil tegumentar das amostras com e sem extrações foram iguais após o tratamento e após o período pós-contenção. 0 progressivo achatamento do perfil facial foi observado em ambos os grupos. Esse achatamento foi atribuído às alterações de maturação associadas com o contínuo crescimento mandibular e com o desenvolvimento nasal, não tendo sido influenciado pela remoção ou não dos dentes. A posição longitudinal dos lábios se mostrou mais retrusiva que os ideais sugeridos por Ricketts e Steiner, mas próxima dos valores relatados para adultos normais, não tratados, com idades similares. A posição pré-tratamento e a espessura do lábio inferior, assim como a relação maxilomandibular esquelética inicial podem prenunciar a posição póstratamento ou a longo prazo do lábio inferior.

\subsubsection{Forças periodontais}

Há quase 60 anos, WALDRON ${ }^{210}$ citou que a função do sistema de fibras transeptais consiste em estabilizar os dentes contra as forças que tendem a separá-los. Se tal estabilização é realizada pela manutenção dos contatos vizinhos num estado de ligeira compressão, então o efeito a longo prazo dessa compressão poderia ser um deslize dos contatos dentários e o colapso do arco. A remoção dos pontos de contato permite a contração das fibras transeptais e a aproximação dos dentes adjacentes $^{125}$. Essa força interproximal ${ }^{191}$ é aumentada após a carga oclusal e pode auxiliar a explicar a migração fisiológica e o 
apinhamento incisal a longo prazo. Portanto, parece que o próprio periodonto pode estar ligado à recidiva pós-tratamento ${ }^{191,201}$.

PROFFIT $^{151}$, em 1978, afirmou que dois fatores principais estão envolvidos no equilíbrio que determina a posição final dos dentes: a) as pressões da posição de repouso do lábio, da bochecha e da língua; b) as forças produzidas pela atividade metabólica dentro da membrana periodontal, análoga às forças da irrupção dentária.

Segundo BEERTSEN ${ }^{14}$ (1979), aceita-se que a posição estável dos dentes após o movimento dentário ortodôntico pode ser estabelecida apenas quando os tecidos conjuntivos do ligamento periodontal se tenham adaptado à nova posição criada. Se a adaptação não ocorrer, os dentes podem mostrar uma tendência a voltar a suas posições originais após a remoção dos aparelhos ortodônticos.

$\mathrm{BOESE}^{27,28}$, em 1980, publicou um estudo, que tinha por objetivo avaliar os resultados clínicos a longo prazo da fibrotomia supracristal e o desgaste interproximal em arcos inferiores apinhados, que foram tratados ortodonticamente com extrações de pré-molares e nunca receberam contenção. A amostra consistiu de 40 pacientes que foram acompanhados durante um período de 4 a 9 anos. Esse pacientes apresentaram, no início do tratamento, um índice de Little de $9,18 \mathrm{~mm}$ e, no final do período de observação, 0,62 mm. Também não 
apresentaram um aumento significante da distância intercaninos durante o tratamento.

EDWARDS $^{46}$ (1988) conduziu, durante um período de aproximadamente 15 anos, um estudo prospectivo que envolveu 320 casos selecionados consecutivamente, a fim de avaliar estatisticamente a eficácia da fibrotomia circunferencial supracristal na diminuição da recidiva dentária após o tratamento ortodôntico. O procedimento cirúrgico da fibrotomia foi realizado na época da remoção do aparelho e seguido imediatamente pela colocação das contenções. O índice de Little foi utilizado para registrar quantitativamente a recidiva dos casos controle e dos casos com fibrotomia aproximadamente de 4 a 6 anos após o tratamento ativo e, novamente, após 12 a 14 anos depois do término do tratamento. As diferenças entre as médias de recidivas do grupo controle e do grupo com fibrotomia foram altamente significantes em ambos os intervalos. $O$ procedimento cirúrgico pareceu ser um tanto mais efetivo em aliviar a recidiva rotacional pura que a recidiva vestíbulo-lingual. Em termos longitudinais, a fibrotomia mostrou ser mais efetiva na redução da recidiva do segmento ânterosuperior que no segmento ântero-inferior.

Num estudo mais recente, REDLICH et al. ${ }^{152}$ (1996) questionava sobre a metodologia utilizada em trabalhos mais antigos, os quais relatavam que a explicação para a recidiva da rotação ortodôntica tinha sido baseada em estudos com microscopia óptica; estes mostravam que fibras gengivais supra-alveolares 
estiradas puxariam de volta o dente, o que levaria a um relaxamento das fibras. A recidiva rotacional poderia ser prevenida realizando-se a fibrotomia gengival supra-alveolar em volta do dente. Para testar essas hipóteses, foram realizadas análises na gengiva utilizando a microscopia eletrônica de varredura e de transmissão. Os resultados desse estudo sugerem que a recidiva pode não ser devido ao estiramento das fibras colágenas, e sim pode ser originada na alteração das propriedades elásticas de todo o tecido gengival.

TANER et al. ${ }^{200}$ conduziram, em 2000 , um estudo para avaliar os efeitos da fibrotomia sobre a recidiva dos incisivos após o tratamento. A amostra consistiu de 23 pacientes com incisivos superiores e inferiores apinhados antes do tratamento ortodôntico. A fibrotomia foi realizada em 11 pacientes uma semana após a remoção do aparelho. Os outros 12 pacientes serviram como grupo controle. Um aumento significante no índice de Little foi observado no grupo controle em ambos os segmentos anteriores, o superior e o inferior. 0 grupo com fibrotomia não apresentou qualquer aumento significante no índice de Little.

BOESE $^{29}$, em 2000, relata que os clínicos experientes consideram que o objetivo de melhorar a estabilidade pós-tratamento ortodôntico se tornou o "filho adotivo" da Ortodontia. A discussão sobre as várias estratégias para promover a estabilidade tem pouco impacto sobre a nossa era presente, na qual tudo funciona (desde que utilizemos contenção permanente) e nada importa. Essa 
filosofia de "tudo vai" desconta o fato de que objetivos definitivos para melhorar a estabilidade pós-tratamento têm sido consistentemente relatados na literatura. Para o autor ${ }^{29}$, causa desapontamento o fato de que apenas $20 \%$ dos ortodontistas americanos utilizem a fibrotomia como uma estratégia para melhorar a estabilidade pós-tratamento. Mas ele $^{29}$ acha que, numa era em que tudo funciona e nada importa, isso não é surpreendente.

Segundo THILANDER ${ }^{201}$ (2000), a recidiva rápida que ocorre durante o período de remodelação das estruturas periodontais não deve ser confundida com as alterações tardias lentas que ocorrem durante o período pós-contenção. Geralmente, essas alterações contínuas não podem ser distinguidas dos processos normais de envelhecimento que ocorrem independentemente do fato de a pessoa ter sido tratada ortodonticamente ou não. Os pacientes devem estar cientes de que a contenção é destinada a manter a oclusão durante a remodelação dos tecidos periodontais, bem como, durante o envelhecimento da oclusão, isto é, durante as alterações transicionais no crescimento, desenvolvimento dentoalveolar e adaptação muscular. A contenção é uma continuação do tratamento ortodôntico. Antes do início do tratamento, o paciente deve estar bem informado e motivado para cooperar durante esse estágio póstratamento a fim de evitar possível recidiva. Segundo a autora ${ }^{201}$, acredita-se que o apinhamento incisal inferior está relacionado com a rotação anterior (para cima) da mandíbula. 


\subsubsection{Morfologia dentária}

HENRIQUES; MARTINS ${ }^{69}$, em 1983, com o objetivo de estabelecer um índice morfológico das coroas dos incisivos inferiores em oclusão normal, para posterior aplicação em jovens leucodermas brasileiros a serem tratados ortodonticamente, realizaram um estudo com duas amostras. Cada amostra constou de 40 pares de modelos, sendo uma com indivíduos com oclusão normal, e outra com indivíduos apresentando más-oclusões de Classe I e Classe II, Divisão 1. Como conclusões, encontraram que: a) o índice morfológico estabelecido era de 89,4 para o incisivo central, e de 91,4 para o lateral; b) quando os valores coronários dos incisivos inferiores se apresentam iguais ao índice estabelecido, tem-se uma estabilidade pós-contenção; c) quando esses valores se exibem maiores do que o índice estabelecido, certamente ocorre uma recidiva pós-contenção, mínima ou moderada.

Em 1984, GILMORE; LITTLE ${ }^{57}$, após avaliarem as dimensões dos incisivos inferiores e a sua relação com o apinhamento, concluíram que, para se prever a estabilidade pós-contenção, nenhuma correlação clinicamente útil foi encontrada entre o índice de Peck e Peck e outras variáveis dos modelos de estudo e cefalométricas. Larguras mésio-distais menores para os incisivos inferiores não garantiram uma melhora na estabilidade a longo prazo. 
RHEE; NAHM ${ }^{155}$ realizaram, em 2000, um estudo que tinha por objetivo estabelecer se há correlação entre a forma da face vestibular das coroas dos incisivos e o apinhamento. Após avaliar modelos de estudo de 69 indivíduos (30 homens e 39 mulheres), divididos em dois grupos, encontraram que o valor médio mésio-distal para o grupo apinhado era significantemente maior na área incisal, e menor na área cervical; portanto, a prevalência de apinhamento é maior em indivíduos com incisivos com forma triangular. A razão da largura (cervical X incisal) da face vestibular dos incisivos está correlacionada com o índice de Little.

\subsection{Fatores oclusais}

SOUTHARD; BEHRENTS; TOLLEY ${ }^{189}$, em 1989, determinaram a distribuição e a disseminação da força promovida pelo componente anterior de força. Quando uma carga foi colocada nos dentes posteriores, esse componente da força oclusal progrediu anteriormente pelos contatos interproximais. Após avaliarem 15 indivíduos, os autores ${ }^{190}$ concluíram que o mau alinhamento dos dentes anteriores inferiores estava relacionado à magnitude do componente anterior e à firmeza dos contatos interproximais nos segmentos posteriores inferiores.

WEILAND ${ }^{212}$, em 1994, realizou um estudo que tinha por finalidade verificar a influência das discrepâncias oclusais na estabilidade a longo prazo do tratamento ortodôntico. Os modelos de estudo (montados num articulador semi- 
ajustável em relação cêntrica) e os registros cefalométricos de 40 pacientes foram avaliados antes do início do tratamento, ao final e pelo menos 9 anos após a remoção da contenção. Como resultado, encontrou que a largura e o comprimento do arco diminuíram significantemente após a contenção. A posição dos incisivos inferiores permaneceu relativamente estável, enquanto os molares inferiores se moveram substancialmente para frente. A irregularidade anterior inferior aumentou após o tratamento, e 60\% dos casos apresentaram um alinhamento ântero-inferior insatisfatório. A quantidade de deslize mandibular diminuiu com o tempo e teve uma influência estatisticamente significante, embora clinicamente apenas moderada, no aumento da irregularidade ântero-inferior, ou seja, contribuiu com apenas $15 \%$ da variação na irregularidade.

WOODS; LEE; CRAWFORD ${ }^{215}$ analisaram, em 2000, por meio do índice PAR, a oclusão de 65 pacientes, nas fases início do tratamento, final e em média 10 anos após a contenção. Os valores médios desse índice nas fases inicial, final e de pós-contenção foram, respectivamente, de $25,5,3,0$ e 7,0 . Houve uma diminuição de $85,6 \%$ com o tratamento, e um aumento de 15,2\% após a contenção. Os autores ${ }^{215}$ concluíram que nem todas as alterações oclusais são negativas e, em alguns casos, é mesmo possível que ocorra uma considerável melhora oclusal durante o período pós-tratamento. Nesse estudo ${ }^{215}$, nem o padrão de oclusão final nem a quantidade de alterações oclusais que ocorreram durante ou após o tratamento podem ser utilizadas para a previsão dos resultados oclusais a longo prazo. 
3 PROPOSIÇÃO 


\section{PROPOSIÇÃO}

Após a revisão da literatura ortodôntica, propusemo-nos a estudar a recidiva do tratamento ortodôntico em pacientes com má-oclusão de Classe II, tratados com extrações de pré-molares pertencentes às categorias de crescimento de PETROVIC, objetivando elucidar as seguintes questões:

3.1 Há diferença na quantidade de apinhamento dentário ântero-inferior pós-contenção entre os pacientes das diferentes categorias de crescimento de PETROVIC?

3.2 Há uma correlação entre o crescimento da maxila e da mandíbula com a recidiva do apinhamento dentário ântero-inferior?

3.3 Há diferença na quantidade de recidiva do trespasse vertical entre os pacientes das diferentes categorias de crescimento de PETROVIC?

3.4 Os fatores esqueléticos e dentários contribuem para a recidiva da máoclusão de Classe II? Há diferença para esses fatores entre os pacientes das diferentes categorias de crescimento?

3.5 A rotação da mandíbula dos pacientes que possuem a denominação de rotação neutra e posterior se comporta conforme essa classificação? Há uma relação entre a recidiva do apinhamento dos incisivos inferiores pós-tratamento com a rotação mandibular?

3.6 Há diferenças nas alterações do perfil tegumentar na fase póstratamento nas diferentes categorias de crescimento? 
4 MATERIAL E MÉTODOS 


\section{MATERIAL E MÉTODOS}

\subsection{MATERIAL}

A amostra utilizada neste estudo consistiu de 100 pacientes tratados no Curso de Pós-graduação em Ortodontia da Universidade de São Paulo Faculdade de Odontologia de Bauru, que apresentavam inicialmente má-oclusão de Classe II. A idade inicial variou de 9 a 16 anos, com média de 12 anos e 4 meses. Os pacientes eram leucodermas de ambos os sexos. Esses pacientes foram tratados ortodonticamente pela técnica do Arco de Canto Simplificada, com extrações de quatro pré-molares, sendo dois superiores (os primeiros) e dois inferiores. Quantos às extrações dos inferiores, houve uma variação. Em 82 pacientes, foram extraídos os primeiros pré-molares, e nos outros 18 pacientes, foram extraídos os segundos pré-molares. Nas Tabelas 4.1 a 4.3 encontra-se a distribuição dos pacientes por extração de pré-molares inferiores e a categoria de crescimento, a rotação mandibular, e o tipo de mordida (dimensão vertical), respectivamente.

TABELA 4.1 - Distribuição dos pacientes por extração de pré-molares inferiores e categoria de crescimento

\begin{tabular}{cccc} 
Categorias & \multicolumn{2}{c}{ Pré-molares extraídos } & Total \\
\cline { 2 - 3 } & $\mathbf{4}$ & $\mathbf{5}$ & \\
\hline $\mathbf{1}$ & 11 & 4 & 15 \\
$\mathbf{2}$ & 15 & 6 & 21 \\
$\mathbf{3}$ & 26 & 1 & 27 \\
$\mathbf{4}$ & 11 & 3 & 14 \\
$\mathbf{5}$ & 19 & 4 & 23 \\
Total & 82 & 18 & 100 \\
\hline
\end{tabular}


TABELA 4.2 - Distribuição dos pacientes por extração de pré-molares inferiores e rotação mandibular

\begin{tabular}{cccc} 
Rotacões mandibulares & Pré-molares extraídos & Total \\
\cline { 2 - 3 } & $\mathbf{4}$ & $\mathbf{5}$ & \\
\hline Posterior & 22 & 7 & 29 \\
Neutra & 37 & 4 & 41 \\
Anterior & 23 & 7 & 30 \\
Total & 82 & 18 & 100 \\
\hline
\end{tabular}

TABELA 4.3 - Distribuição dos pacientes por extração de pré-molares inferiores e dimensão vertical (mordida)

\begin{tabular}{cccc} 
Dimensões verticais & \multicolumn{2}{c}{ Pré-molares extraídos } & Total \\
\cline { 2 - 3 } (Mordidas) & $\mathbf{4}$ & $\mathbf{5}$ & \\
\hline Aberta (OB) & 39 & 8 & 47 \\
Normal (N) & 26 & 3 & 29 \\
Profunda (DB) & 17 & 7 & 24 \\
Total & 82 & 18 & 100 \\
\hline
\end{tabular}

Foram utilizadas telerradiografias laterais e modelos de estudo efetuados no início do tratamento, ao final e pelo menos 4 anos após o término do tratamento ortodôntico (período pós-contenção). O tempo médio de tratamento foi de 30 meses. Todos os pacientes utilizaram, como contenção após o tratamento, uma placa de Hawley modificada superior e uma barra lingual colada de canino a canino no arco inferior, por um período médio de 22 meses. O período médio de avaliação após o término do tratamento foi de 126 meses.

A amostra foi dividida de acordo com a análise de PETROVIC/LAVERGNE em 5 categorias de crescimento (categoria 1 à categoria 5), em 3 grupos de rotação (inclinação) mandibular (anterior, neutra e posterior) e em 3 tipos de mordida (aberta, normal e profunda).

Nas Tabelas 4.4 a 4.6 está descrita a distribuição dos pacientes por categoria de crescimento, a rotação mandibular, o tipo de mordida (dimensão vertical), a idade e o sexo. 
TABELA 4.4 - Distribuição dos pacientes por sexo e categoria de crescimento, e médias de idade por categoria para cada momento

\begin{tabular}{|c|c|c|c|c|c|c|}
\hline \multirow[b]{2}{*}{ Categorias } & \multirow[b]{2}{*}{$\boldsymbol{n}$} & \multirow[b]{2}{*}{ Homens } & \multirow[b]{2}{*}{ Mulheres } & \multicolumn{3}{|c|}{ Média de idade (anos) } \\
\hline & & & & Início & Final & Pós-contenção \\
\hline 1 & 15 & 3 & 12 & $\begin{array}{l}12 \text { anos } \\
7 \text { meses }\end{array}$ & $\begin{array}{l}15 \text { anos } \\
2 \text { meses }\end{array}$ & $\begin{array}{l}24 \text { anos } \\
2 \text { meses }\end{array}$ \\
\hline 2 & 21 & 8 & 13 & $\begin{array}{l}13 \text { anos } \\
7 \text { meses }\end{array}$ & $\begin{array}{c}15 \text { anos } \\
11 \text { meses }\end{array}$ & $\begin{array}{l}27 \text { anos } \\
4 \text { meses }\end{array}$ \\
\hline 3 & 27 & 11 & 16 & $\begin{array}{l}12 \text { anos } \\
9 \text { meses }\end{array}$ & $\begin{array}{l}15 \text { anos } \\
1 \text { meses }\end{array}$ & $\begin{array}{l}25 \text { anos } \\
2 \text { meses }\end{array}$ \\
\hline 4 & 14 & 4 & 10 & $\begin{array}{l}12 \text { anos } \\
9 \text { meses }\end{array}$ & $\begin{array}{l}15 \text { anos } \\
3 \text { meses }\end{array}$ & 25 anos \\
\hline 5 & 23 & 7 & 16 & $\begin{array}{l}13 \text { anos } \\
2 \text { meses }\end{array}$ & $\begin{array}{c}15 \text { anos } \\
11 \text { meses }\end{array}$ & $\begin{array}{l}26 \text { anos } \\
3 \text { meses }\end{array}$ \\
\hline
\end{tabular}

TABELA 4.5 - Distribuição dos pacientes por sexo e rotação mandibular, e médias de idade por rotação para cada momento

\begin{tabular}{|c|c|c|c|c|c|c|}
\hline \multirow[b]{2}{*}{$\begin{array}{c}\text { Rotações } \\
\text { mandibulares }\end{array}$} & \multirow[b]{2}{*}{$n$} & \multirow{2}{*}{ Homens } & \multirow{2}{*}{ Mulheres } & \multicolumn{3}{|c|}{ Média de idade (anos) } \\
\hline & & & & Início & Final & Pós-contenção \\
\hline Posterior & 29 & 8 & 21 & $\begin{array}{c}12 \text { anos } \\
10 \text { meses }\end{array}$ & $\begin{array}{l}15 \text { anos } \\
4 \text { meses }\end{array}$ & $\begin{array}{l}25 \text { anos } \\
4 \text { meses }\end{array}$ \\
\hline Neutra & 41 & 15 & 26 & $\begin{array}{l}12 \text { anos } \\
9 \text { meses }\end{array}$ & $\begin{array}{l}15 \text { anos } \\
2 \text { meses }\end{array}$ & $\begin{array}{c}25 \text { anos } \\
1 \text { mês }\end{array}$ \\
\hline Anterior & 30 & 10 & 20 & $\begin{array}{l}13 \text { anos } \\
5 \text { meses }\end{array}$ & $\begin{array}{l}16 \text { anos } \\
2 \text { meses }\end{array}$ & $\begin{array}{c}26 \text { anos } \\
10 \text { meses }\end{array}$ \\
\hline
\end{tabular}

TABELA 4.6 - Distribuição dos pacientes por sexo e dimensão vertical, e médias de idade por dimensão para cada momento

\begin{tabular}{|c|c|c|c|c|c|c|}
\hline \multirow{2}{*}{$\begin{array}{c}\text { Dimensões } \\
\text { Verticais } \\
\text { (Mordidas) }\end{array}$} & \multirow[b]{2}{*}{$n$} & \multirow[b]{2}{*}{ Homens } & \multirow[b]{2}{*}{ Mulheres } & \multicolumn{3}{|c|}{ Média de idade (anos) } \\
\hline & & & & Início & Final & Pós-contenção \\
\hline Aberta (OB) & 47 & 18 & 29 & $\begin{array}{l}12 \text { anos } \\
9 \text { meses }\end{array}$ & $\begin{array}{l}15 \text { anos } \\
3 \text { meses }\end{array}$ & $\begin{array}{l}24 \text { anos } \\
9 \text { meses }\end{array}$ \\
\hline Normal (N) & 29 & 8 & 21 & 13 anos & $\begin{array}{l}15 \text { anos } \\
7 \text { meses }\end{array}$ & $\begin{array}{l}26 \text { anos } \\
6 \text { meses }\end{array}$ \\
\hline $\begin{array}{l}\text { Profunda } \\
\text { (DB) }\end{array}$ & 24 & 7 & 17 & $\begin{array}{l}13 \text { anos } \\
6 \text { meses }\end{array}$ & $\begin{array}{c}15 \text { anos } \\
11 \text { meses }\end{array}$ & $\begin{array}{l}26 \text { anos } \\
6 \text { meses }\end{array}$ \\
\hline
\end{tabular}

Para a realização da análise de PETROVIC/LAVERGNE foi empregado um programa desenvolvido por TOIGO; MORO; VIGORITO ${ }^{204}$, utilizado em um computador Pentium MMX $233 \mathrm{MHZ}$. 
As medições da análise de modelos e da análise de JOHNSTON JÚNIOR foram realizadas com um paquímetro digital (Mitutoyo, Japão) com precisão de até $0,01 \mathrm{~mm}$ e com um esquadro de acrílico.

Para a realização da análise cefalométrica convencional, foi empregado o programa Dentofacial Planner 7.2 (Toronto, Ontário, Canadá), em conjunto com uma mesa digitalizadora (Houston Instrument DT-11) e um computador Pentium $586 \mathrm{MHZ}$. Esse programa também foi utilizado para produzir os traçados "compostos médios" dos pacientes pertencentes a cada uma das 5 categorias de crescimento de PETROVIC e a cada um dos grupos de rotação mandibular.

\subsection{MÉTODOS}

\subsubsection{TELERRADIOGRAFIAS}

De cada paciente obtiveram-se três telerradiografias em norma lateral, uma ao início, outra ao término do tratamento, e outra, em média, 126 meses após o término do tratamento.

Essas telerradiografias foram obtidas em máxima intercuspidação habitual.

No que se refere à técnica e ao processamento, as telerradiografias em norma lateral foram obtidas seguindo os princípios recomendados pela Disciplina de Radiologia da Faculdade de Odontologia de Bauru, da Universidade de São Paulo. Essas radiografias possuíam um fator de magnificação da imagem radiográfica em torno de $6 \%$, que foi corrigido pelo programa Dentofacial Planner.

Foram utilizados, para o traçado cefalométrico, folha de papel acetato (ultraphan), negatoscópio, lapiseira Pentel com grafite HB 0,3 mm, e régua . 


\subsubsection{SELEÇÃO DA AMOSTRA}

Os pacientes foram selecionados a partir de uma amostra total de 1200 pacientes que foram tratados pelos alunos do Curso de Pós-graduação em Ortodontia da Universidade de São Paulo - Faculdade de Odontologia de Bauru. A seleção foi feita de forma consecutiva, ou seja, foram selecionados os primeiros 100 pacientes a serem encontrados, que já possuíssem uma documentação ortodôntica realizada há pelo menos 4 anos após o término do tratamento, ou, então, que se dispusessem a voltar à faculdade para realizar novos exames.

A seleção não levou em conta se a Classe II era Divisão 1 ou 2, pois esse fato não teria importância para a classificação realizada pela análise de PETROVIC/LAVERGNE. Dentro dos pacientes selecionados, apenas 1 apresentava Classe II, Divisão 2, e os restantes eram Classe II, Divisão 1.

Para evitar a introdução de tendências ou vícios na medição ("bias"), as avaliações, tanto das telerradiografias quanto dos modelos de estudo, foram realizadas sem que se soubesse a qual categoria de crescimento o paciente pertencia, ou seja, as avaliações foram realizadas em "estado cego" ("blinding") ${ }^{150}$. Para se conseguir isso, iniciou-se com a análise dos modelos de estudo, seguida pela análise de JOHNSTON JÚNIOR, depois pela análise cefalométrica convencional e, por último, foi realizada a análise de PETROVIC/LAVERGNE, onde, então, os pacientes tiveram as suas categorias de crescimento, seus grupos de rotação mandibular, bem como seus tipos de mordida determinados. 


\subsubsection{ANÁLISE DOS MODELOS}

Os modelos de estudo referentes às fases inicial e final e pós-contenção de cada paciente foram avaliados. Esses modelos foram recortados e polidos de acordo com o método de INTERLANDI; VIGORITO ${ }^{74}$.

\subsubsection{Variáveis estudadas}

Com o uso de um paquímetro digital e de um esquadro, foram estudadas as seguintes variáveis (Figuras 4.1 e 4.2 ):

Trespasse horizontal (TH): distância em milímetros, no sentido horizontal e paralelamente ao plano oclusal, da porção vestibular da margem incisal do incisivo inferior mais vestibularizado até a porção lingual da margem incisal do incisivo superior mais vestibularizado, estando os modelos em oclusão.

Trespasse vertical (TV): distância medida em milímetros, no sentido vertical, da margem incisal do incisivo central inferior mais extruído até o nível demarcado na face vestibular desse dente, com o auxílio de um esquadro, da margem incisal do incisivo central superior mais extruído, estando os modelos em oclusão.

Curva de Spee (CS): distância medida em milímetros, no sentido vertical, a partir de uma reta (representada pelo esquadro que passava pela face oclusal do 
primeiro ou segundo molar inferior até o ápice do canino) até o ápice cuspídeo vestibular mais baixo em relação ao plano oclusal. Foram realizadas medições para o lado direito e esquerdo, que, uma vez somadas, representaram o valor para o modelo.

Comprimento do arco inferior (CA): corresponde ao somatório das distâncias medidas entre o ponto de contato dos incisivos centrais inferiores e a face mesial dos primeiros molares nos lados direito e esquerdo.

Distância intercaninos (3-3): distância medida em milímetros, de ápice a ápice, das cúspides dos caninos inferiores direito e esquerdo. Nos casos com facetas de desgaste nos caninos, o ápice da cúspide era estimado.

Distância entre pré-molares (4-4 e 5-5): distância medida em milímetros, de ápice a ápice, das cúspides vestibulares dos primeiros e segundos pré-molares inferiores direitos e esquerdos. Nos casos com facetas de desgaste, o ápice da cúspide era estimado.

Distância intermolares (6-6): distância medida em milímetros, de ápice a ápice, das cúspides mésio-vestibulares dos primeiros molares inferiores direito e esquerdo. Nos casos com facetas de desgaste, o ápice da cúspide era estimado. 


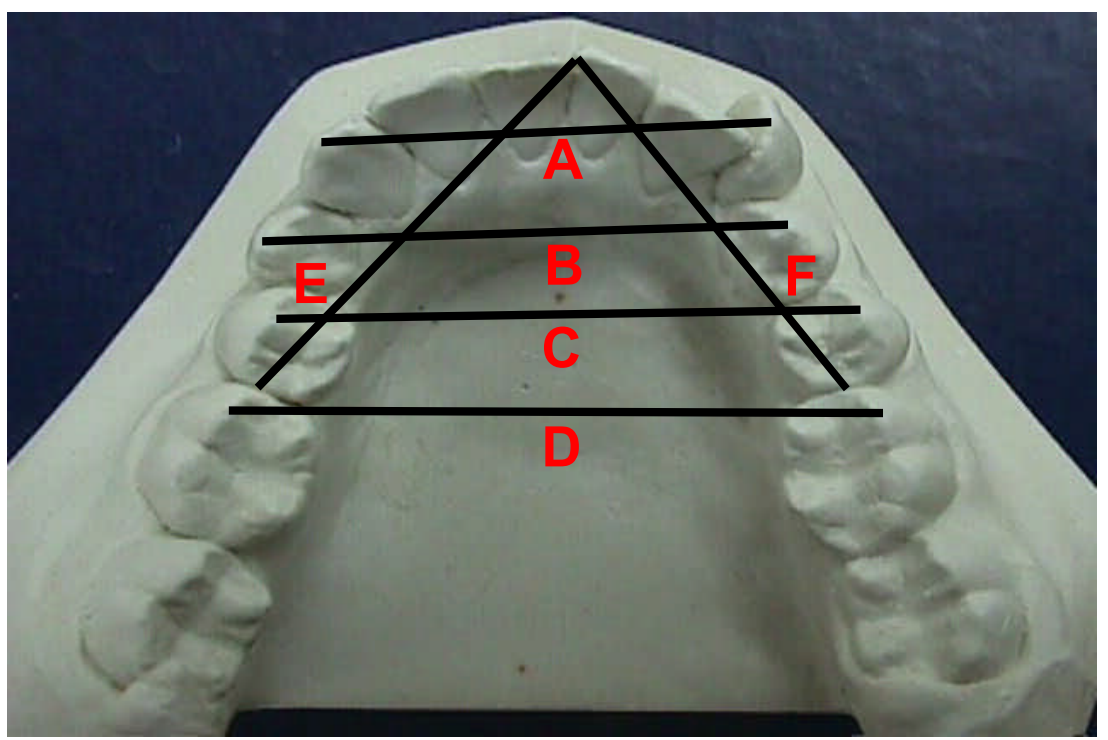

FIGURA 4.1 - Variáveis avaliadas na análise de modelos. A: distância intercaninos (3-3); B: distância entre primeiros pré-molares (4-4); C: distância entre segundos pré-molares (5-5); $D$ : distância intermolares (6-6); $E+F$ : comprimento do arco inferior (CA)

Índice de irregularidade de LITTLE $^{104}$ (IL): somatório das distâncias lineares entre os pontos de contato anatômicos dos dentes anteriores (caninos e incisivos) inferiores. A medição foi realizada por meio de um paquímetro

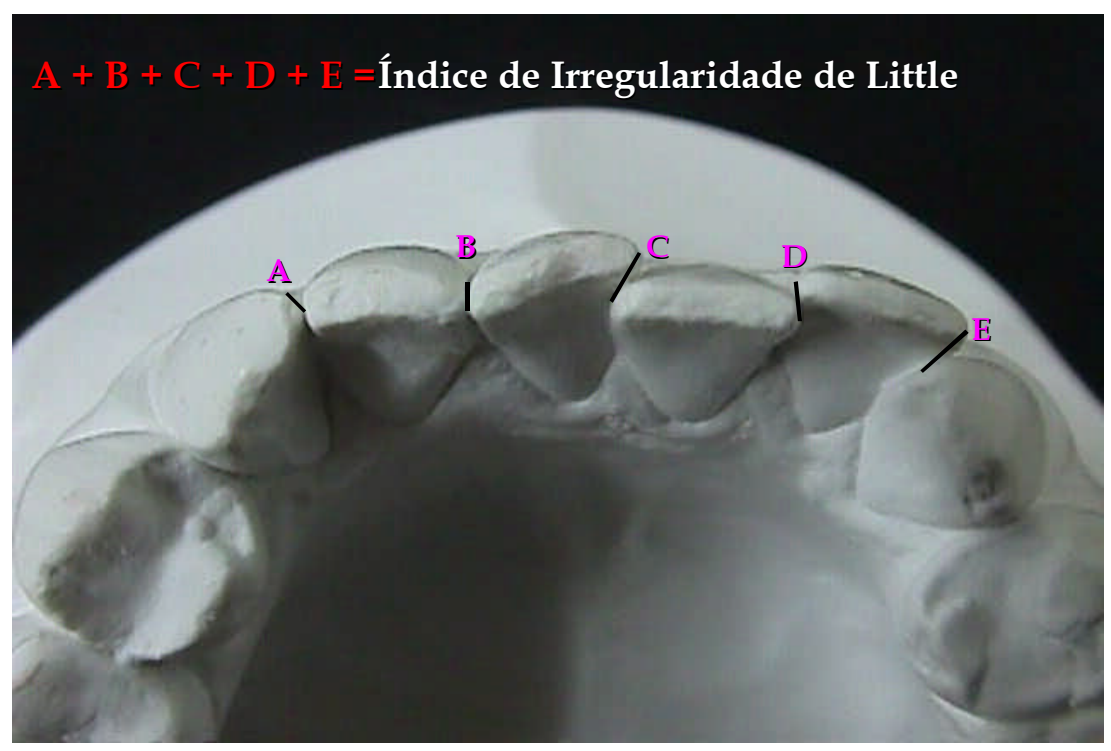

FIGURA 4.2 - Índice de irregularidade de Little, definido como o somatório dos deslocamentos dos pontos de contato anatômicos dos dentes ântero-inferiores 
posicionado paralelamente ao plano oclusal.

\subsubsection{ANÁLISE DE JOHNSTON JÚNIOR}

A análise de JOHNSTON JÚNIOR ${ }^{80,82}$ foi realizada a fim de comparar os resultados do tratamento e das alterações pós-tratamento nas diferentes categorias de crescimento.

Essa análise leva em consideração os vários fatores individuais que contribuem para as correções da relação molar e do trespasse horizontal, e para as suas recidivas após o tratamento. Para atingir esse objetivo, ela se utiliza dos métodos de BJÖRK ${ }^{22}$ e de BJÖRK; SKIELLER ${ }^{23-25}$ de sobreposição na base do crânio, na maxila e na mandíbula, para medir o movimento dos segmentos posteriores em relação ao osso basal e o deslocamento (devido ao crescimento ou às alterações ortopédicas) dos maxilares em relação à base do crânio. Além disso, utiliza-se também do método de $\mathrm{JENKINS}^{78}$ de projeção sobre o plano oclusal, pois os componentes da correção molar são medidos paralelamente a esse plano.

\subsubsection{Desenho anatômico}

As telerradiografias inicial, final e de pós-contenção de cada paciente foram colocadas lado a lado em um negatoscópio, e as estruturas anatômicas foram traçadas da mesma forma e ao mesmo tempo para os três traçados, de acordo com a descrição de JOHNSTON JÚNIOR ${ }^{82}$. 


\section{Base do crânio:}

- sela túrcica;

- asas maiores do esfenóide;

- lâmina crivosa do etmóide;

- teto da órbita;

- superfície interna e externa do osso frontal

- ponto SE: intersecção entre a média das asas maiores com o plano do esfenóide (jugo esfenoidal);

- uma linha fiduciária é traçada (arbitrariamente) acima das lâminas orbitais de um traçado (por conveniência, o traçado da fase final de tratamento), e, então, a sobreposição na base do crânio é utilizada para passar essa linha e o ponto SE para os outros traçados da série (Figura 4.4).

\section{Maxila:}

- contorno (lados direito e esquerdo) do processo zigomático da maxila (crista chave);

- fissura pterigomaxilar (PTM);

- arquitetura trabecular do palato;

- uma linha fiduciária é traçada arbitrariamente.

\section{Mandíbula:}

- arquitetura da sínfise mandibular comum a ambas as telerradiografias; 
- ponto D, marcado no centro da sínfise por inspeção. Esse ponto foi transferido de um traçado (final de tratamento) para os outros da série pela sobreposição na arquitetura cortical vestibular da sínfise (Figura 4.3);

- uma linha fiduciária é traçada arbitrariamente. Essa linha também é transferida de um traçado (final de tratamento) para os outros da série pela sobreposição na arquitetura cortical vestibular da sínfise (Figura 4.3).

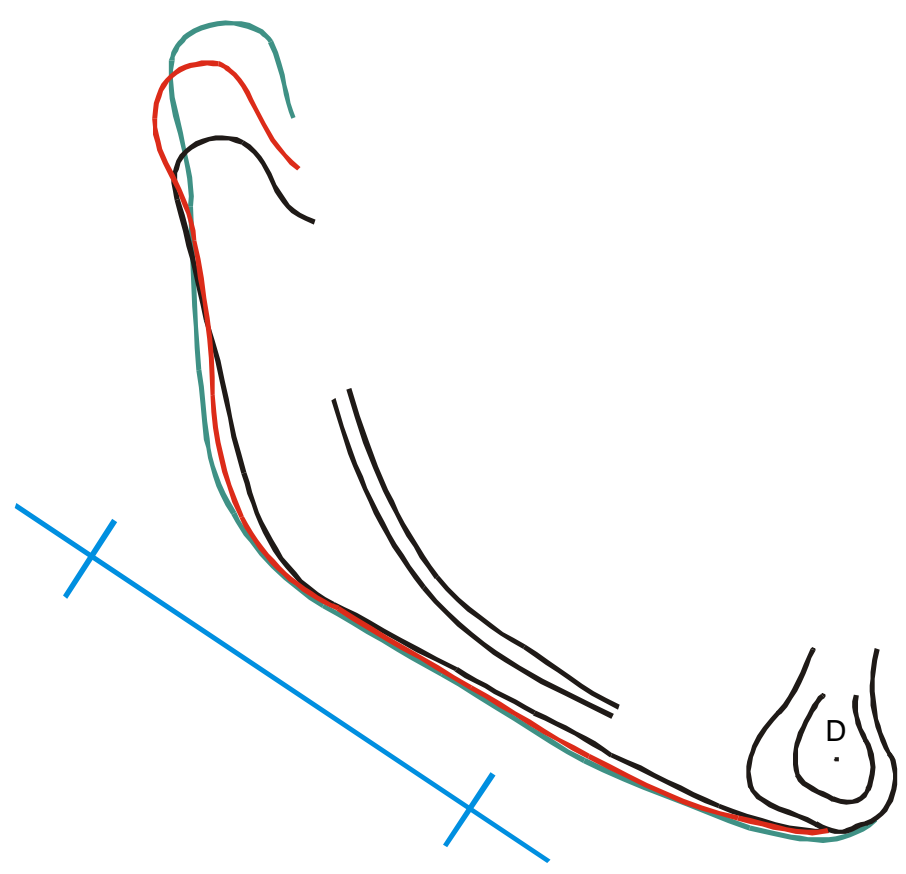

FIGURA 4.3 - Sobreposição mandibular: o registro é alcançado pelo alinhamento da arquitetura óssea da metade vestibular da sínfise. Essa sobreposição é utilizada para passar tanto a linha fiduciária como o ponto $D$ de um traçado para outro

\section{Dentes:}

- foram traçados, com o auxílio na visualização dos modelos dos pacientes, os molares superiores e inferiores e os incisivos superiores e inferiores mais protruídos. Realizou-se para os molares e para os incisivos de cada paciente, um 
"template", com papel ultraphan, da melhor radiografia, sendo que, para os molares, foi adicionado o ponto de contato. Com a técnica de sobreposição de melhor encaixe ("best fit") na radiografia, transferiu-se o contorno do dente do "template" para a outra radiografia.

- foi traçado, para cada radiografia, o plano oclusal funcional, que é definido pelos pré-molares e primeiros molares permanentes. A linha é traçada por inspeção respeitando as radiolucências espalhadas entre as cúspides ao longo da linha de oclusão. Por meio da sobreposição maxilar dos traçados inicial e de pós-contenção, os dois planos oclusais funcionais são subdivididos por inspeção para que seja traçado o plano oclusal funcional médio (POFM), que será passado para todos os traçados da série.

\subsubsection{Sobreposições para as avaliações}

\section{Sobreposição na base do crânio}

A sobreposição realizada sobre a base do crânio (Figura 4.4) teve como finalidade passar o ponto SE do traçado final para o traçado inicial e o de póscontenção. Essa sobreposição foi realizada sobre a parede anterior da sela túrcica (e seu ponto de intersecção com os contornos inferiores dos processos clinóides anteriores), as asas maiores do esfenóide, a lâmina crivosa do etmóide, o teto da órbita e a superfície interna do osso frontal. 


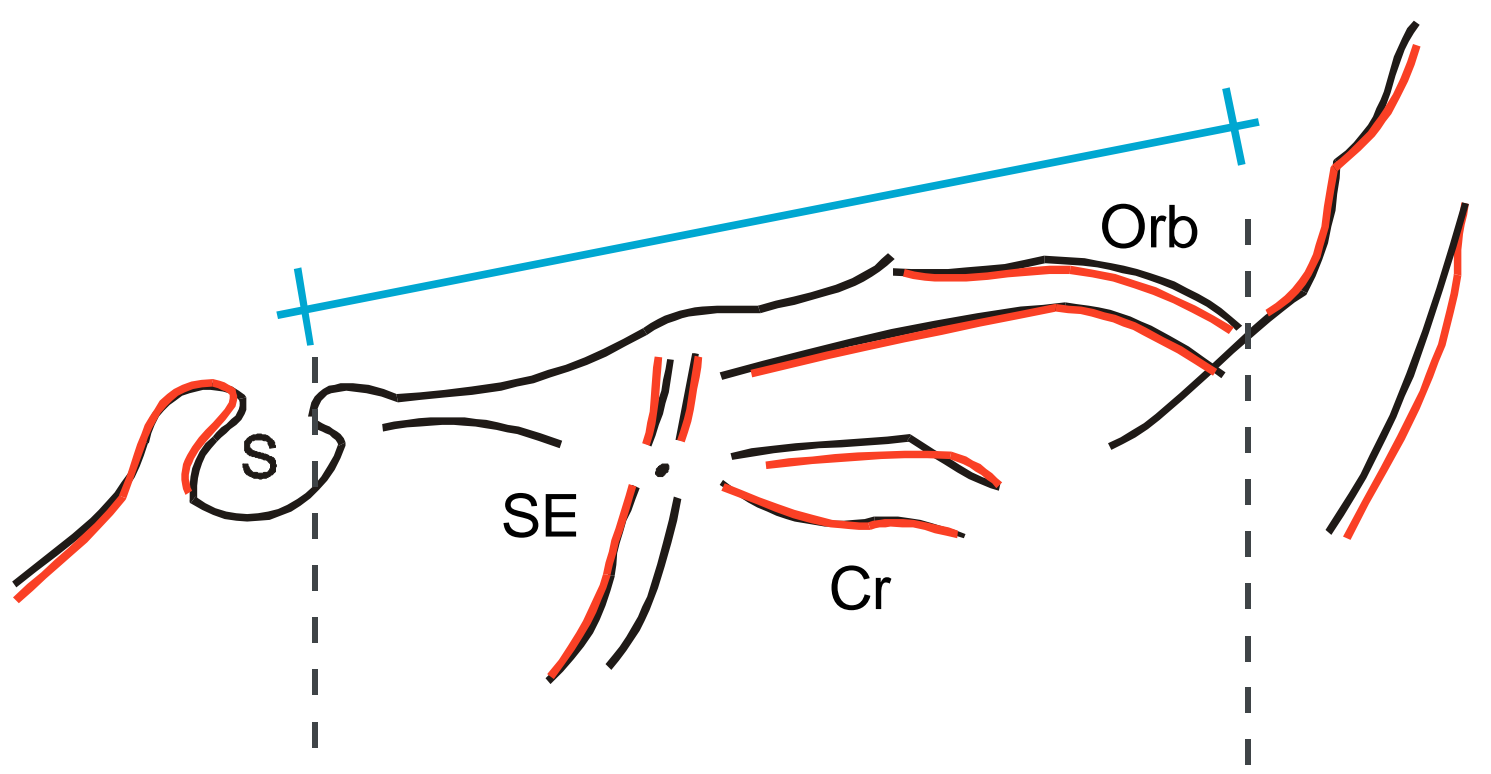

FIGURA 4.4 - Sobreposição na base do crânio: apenas as estruturas entre as linhas pontilhadas verticais são empregadas na sobreposição. Ênfase é dada aos elementos da "linha basal" de DE COSTER ${ }^{38}$; a metade posterior da sela túrcica e as estruturas na região do ponto Násio não são utilizadas. Uma longa linha arbitrária, com cruzes em cada extremidade (linha fiduciária) é traçada acima das lâminas orbitais no traçado da fase final de tratamento. A sobreposição na base do crânio então é utilizada para passar essa linha para o traçado inicial e o de pós-contenção

\section{Sobreposição regional maxilar}

A sobreposição maxilar (Figura 4.5) teve registro no processo zigomático da maxila (média dos lados direito e esquerdo) e nos detalhes anatômicos ósseos acima dos incisivos superiores (DOPPEL et al. ${ }^{43}$ ). As superfícies superior e inferior da parte posterior do palato auxiliaram na orientação. Cuidado foi tomado para se assegurar que a fissura PTM do traçado final estivesse junto ou posterior à fissura do traçado inicial. A linha de referência maxilar foi então passada de um traçado para o outro. 
Após a sobreposição das linhas fiduciárias maxilares, as seguintes medidas foram executadas paralelamente ao POFM:

a - Movimento da coroa do primeiro molar superior (6s) - a alteração na posição dos pontos de contato mesiais médios dos primeiros molares superiores; b - Alteração da Base Apical (ABA) - a alteração ântero-posterior na posição da mandíbula (ponto $\mathrm{D})$ em relação à maxila;

C - Crescimento translatório maxilar em relação à base do crânio (Max.-BC) a distância entre a posição inicial e final de SE;

O avanço mandibular translatório em relação à base do crânio (Mand) foi então calculado somando-se o deslocamento maxilar relativo à base do crânio e o deslocamento mandibular relativo à maxila (algebricamente, Mand $=\mathbf{A B A}$ Max.). Segundo LIVIERATOS; JOHNSTON JÚNIOR ${ }^{110}$, deveria ser utilizada a palavra avanço (deslocamento anterior) ao invés de crescimento, pois o presente método de sobreposição não é capaz de fazer a distinção entre crescimento mandibular e movimentos funcionais de corpo da mandíbula.

O movimento do incisivo superior também é medido nessa sobreposição, paralelamente ao POFM.

d - Movimento da coroa do incisivo superior (1s) - alteração na posição da margem incisal do incisivo superior mais protruído. 


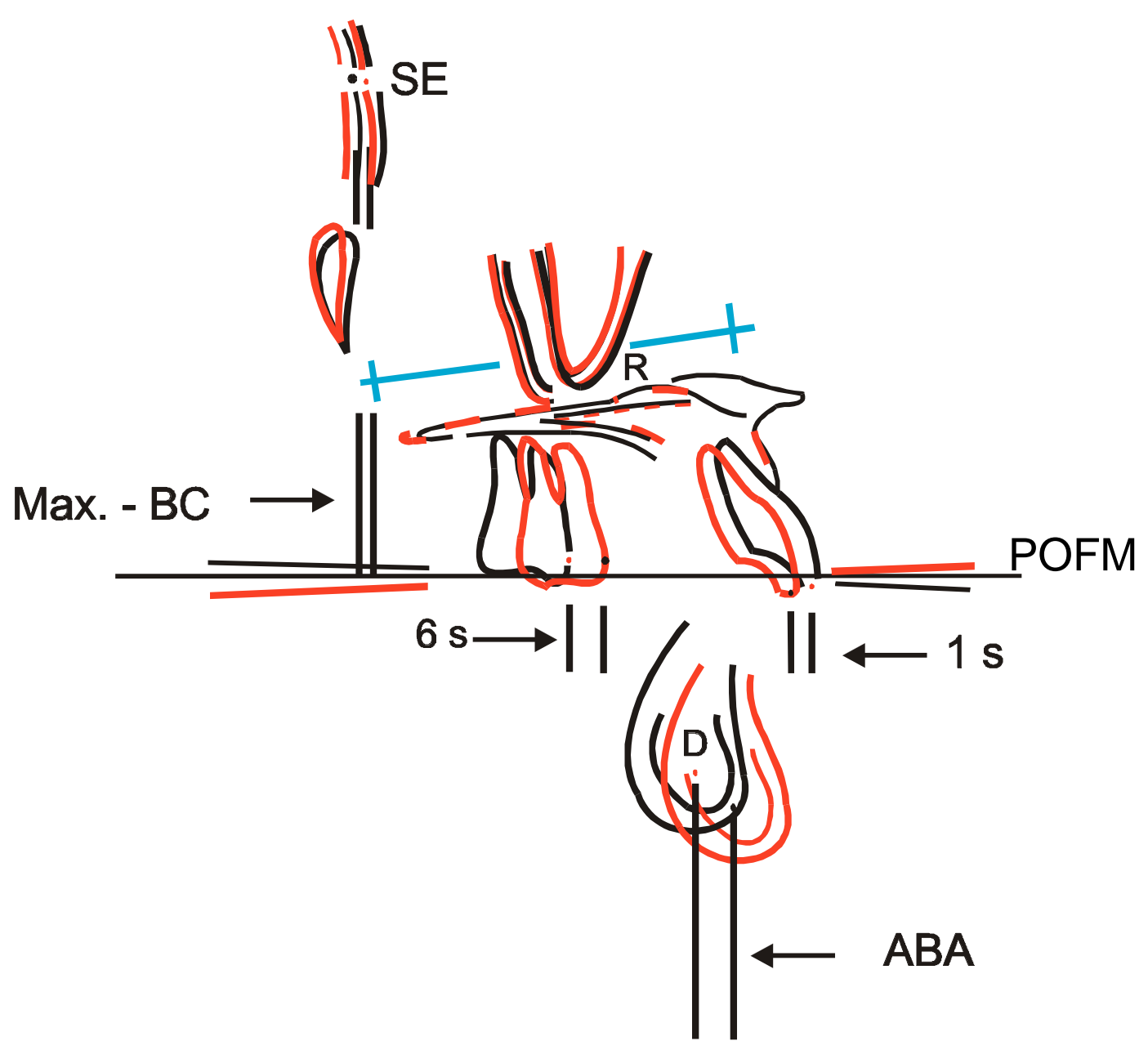

FIGURA 4.5 - Sobreposição regional maxilar: o registro é realizado no processo zigomático da maxila ("crista chave") e na curvatura do palato (estruturas na região de $\mathrm{R}$ ); orientação, nas estruturas horizontais do palato duro. Cuidado foi tomado para que a fissura pterigomaxilar do traçado final (em vermelho) estivesse junto ou atrás da fissura do traçado inicial (em preto). Uma vez mais, a sobreposição é preservada por uma linha fiduciária (em azul). O avanço maxilar em relação à base do crânio (Max.-BC) é medido em SE; o deslocamento mandibular em relação à maxila $(A B A)$ é medido em $D$

\section{Sobreposição regional mandibular}

A sobreposição regional mandibular (Figura 4.6) foi realizada sobre os planos oclusais funcionais médios (POFM), e os traçados mandibulares foram registrados sobre linhas perpendiculares ao POFM, passando pelo ponto D. Efetuou-se as seguintes medidas paralelamente ao POFM: 
e - Movimento da coroa do primeiro molar inferior (6i) - a distância entre os pontos de contato mesiais médios dos primeiros molares inferiores.

f - Movimento da coroa do incisivo inferior (1i) - alteração na posição da margem incisal do incisivo inferior mais protruído.
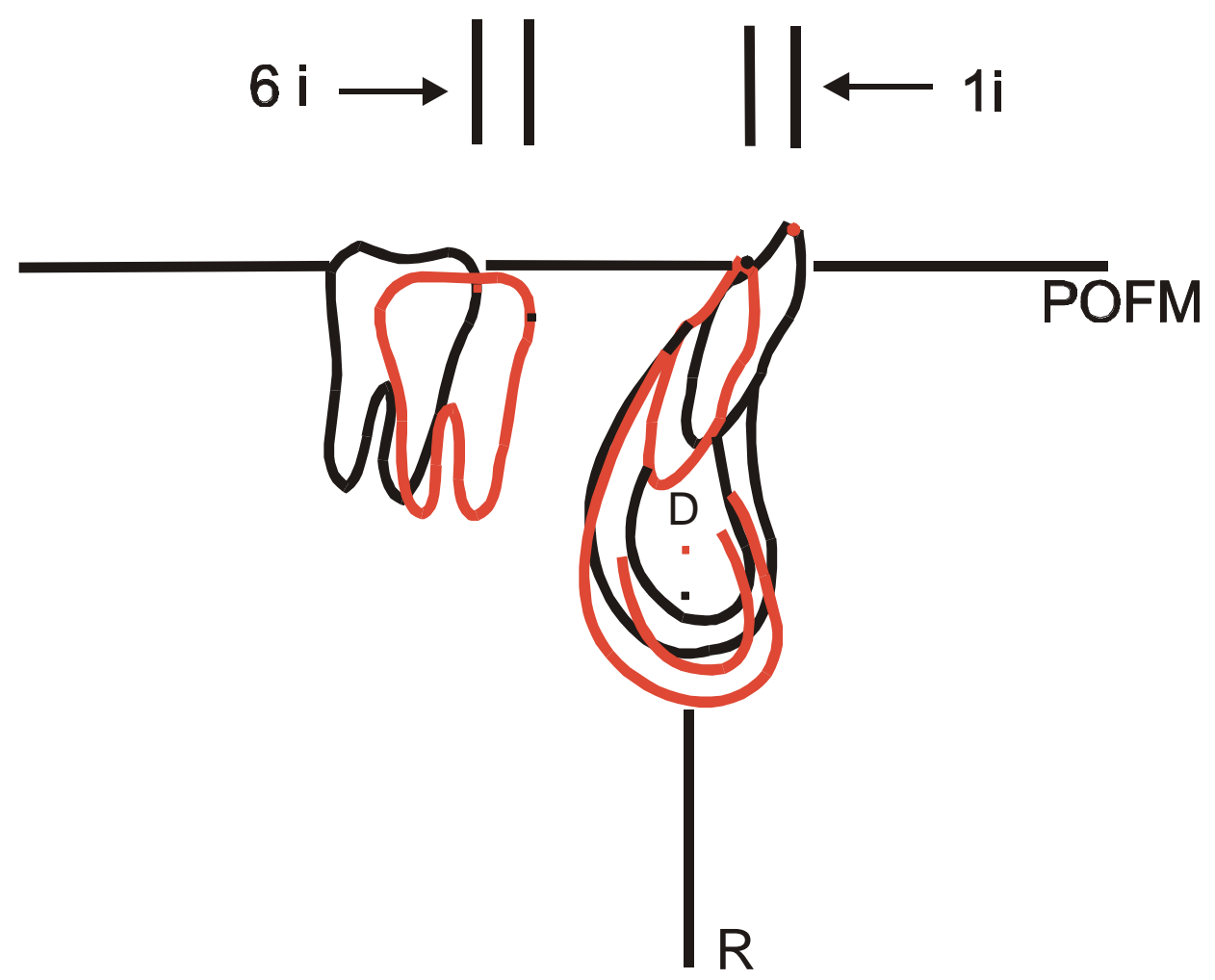

FIGURA 4.6 - Sobreposição regional mandibular: a orientação é realizada sobre os planos oclusais funcionais médios, tendo, como registro, perpendiculares a partir do ponto $\mathrm{D}$, permitindo, então, a medição do movimento dos dentes inferiores. Não há o emprego da linha de referência nessa sobreposição

\section{Sobreposições dentárias}

$\mathrm{Na}$ quinta sobreposição (Figura 4.7), o registro foi realizado sobre os pontos de contato mesiais dos primeiros molares superiores, e os POFM foram colocados paralelamente, onde se verificou:

g - Correção molar total (6/6) - distância entre os pontos de contato mesiais dos primeiros molares inferiores medida paralelamente ao POFM. 


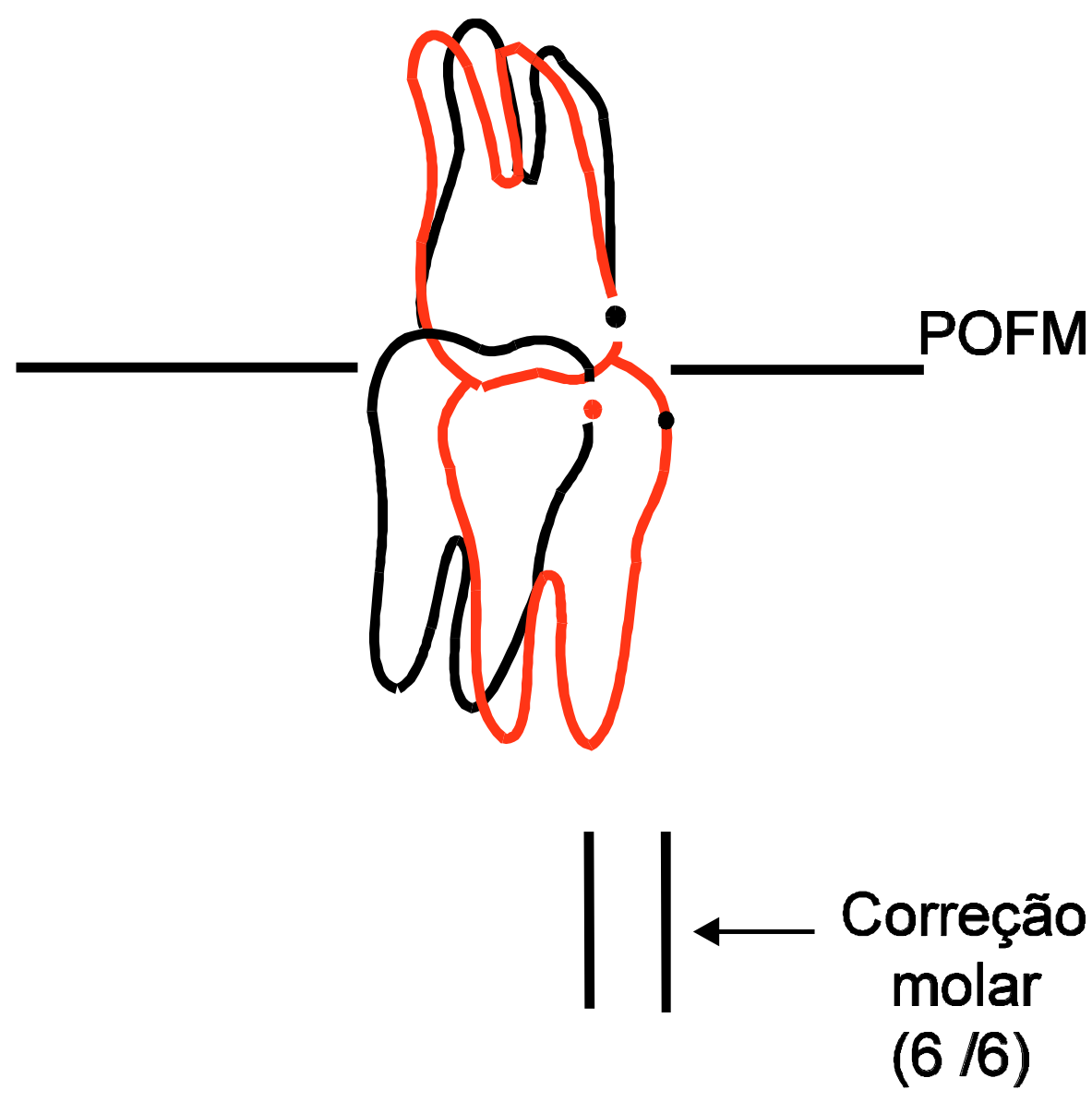

FIGURA 4.7 - Correção molar total: os traçados são registrados nos pontos de contato mesiais dos primeiros molares superiores, e os planos oclusais funcionais médios são colocados paralelamente

Na sexta sobreposição (Figura 4.8), o registro foi realizado sobre os incisivos superiores, estando os POFM paralelos, onde se verificou:

h - Correção incisal total (trespasse horizontal - 1/1) - distância entre as margens incisais dos incisivos inferiores medida paralelamente ao POFM. 


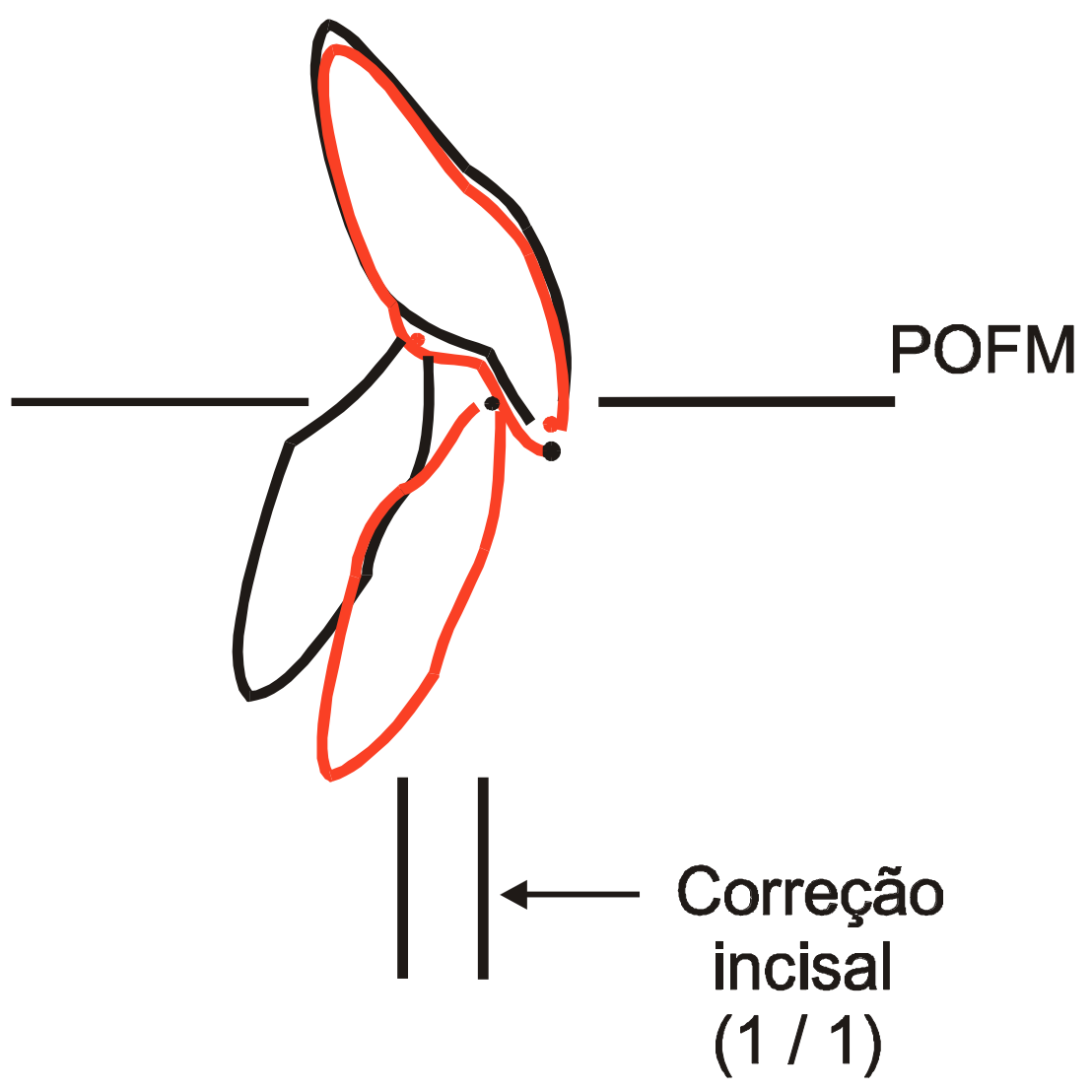

FIGURA 4.8 - Correção incisal total: os traçados são registrados nas bordas incisais dos incisivos superiores, e a orientação é feita ao longo do POFM. A alteração do trespasse horizontal é medida paralelamente ao POFM, como a separação das margens incisais dos dentes nas arcadas opostas

As várias alterações dentárias e esqueléticas foram registradas no diagrama de JOHNSTON JÚNIOR ${ }^{80,82}$ ("Pitchfork Analysis") (Figura 4.9) com sinais que refletem sua significância para a correção da relação molar (estabelecimento de uma Classe I) e para a redução do trespasse horizontal ou, então, para a suas recidivas. Aquelas alterações que ajudariam no estabelecimento de uma relação de Classe I e na correção do trespasse horizontal receberam sinal positivo (+); aquelas que prejudicariam receberam sinal negativo (-). Por exemplo, o movimento distal da maxila ou dos molares 


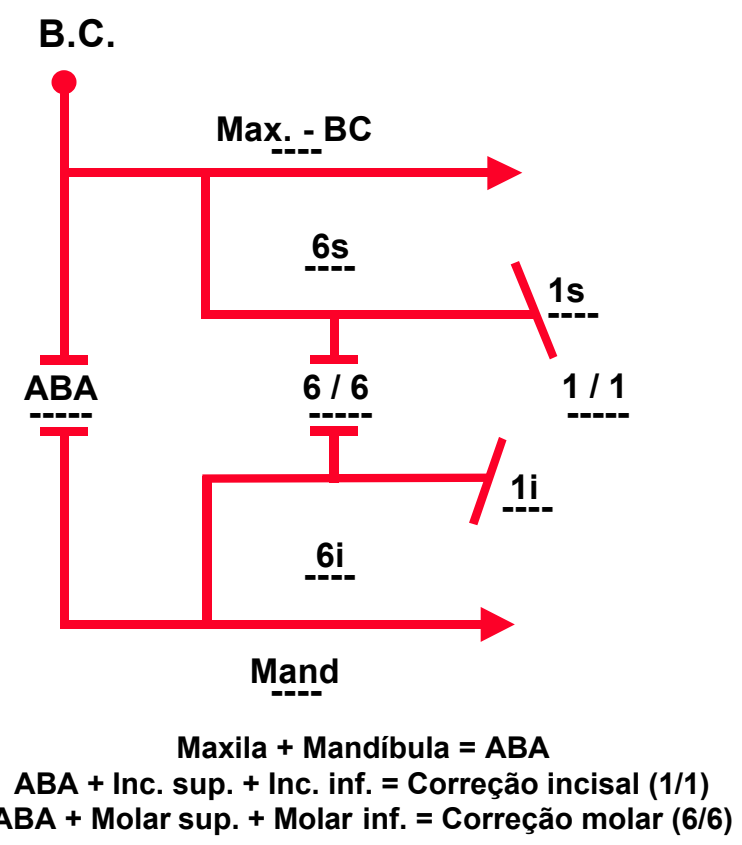

FIGURA 4.9 - Diagrama de JOHNSTON JÚNIOR ${ }^{80,82}$ (“Pitchfork Analysis"): as várias alterações esqueléticas e dentárias se somam para produzir as alterações nas relações molar (6/6) e incisal (1/1)

superiores e o deslocamento anterior da mandíbula ou dos molares inferiores receberam sinal positivo. Dada a presente convenção de sinal e esquema da análise, a medida independente da correção molar total (6/6) tinha que ser igual à soma algébrica de $A B A+6 s+6 i$, assim como a correção incisal total (1/1) deveria ser igual à soma de $\mathbf{A B A}+1 \mathrm{~s}+1 \mathbf{i}$, ambas permitindo um erro dentro de 0,2 a $0,3 \mathrm{~mm}^{82}$; caso contrário, as medidas eram refeitas.

Cabe ressaltar que foram realizadas duas medições com a análise de JOHNSTON JÚNIOR, uma na sobreposição entre os traçados inicial e final, e outra para a sobreposição dos traçados final e de pós-contenção. 


\section{Padrão de crescimento translatório}

Considerando que as linhas fiduciárias são invioláveis, ou seja, nunca devem ser alteradas durante os procedimentos de sobreposição, após terem sido transferidas através da série radiográfica, elas servem também para fornecer um quadro bastante simplificado das alterações observadas a partir do ponto de vista de qualquer uma das três áreas faciais ${ }^{82}$.

Na sétima sobreposição (Figura 4.10), quando as linhas de referência da base do crânio são sobrepostas, a separação das linhas de referência da mandíbula e da maxila representa o crescimento translatório - tanto em quantidade, quanto em angulação - da maxila e da mandíbula em relação à base do crânio.

Essa sobreposição foi empregada para avaliar as rotações maxilares e mandibulares, representadas pelas alterações das respectivas linhas fiduciárias, após o tratamento e após o período de pós-contenção.

Com a sobreposição dos traçados inicial e final foram avaliadas:

i - a rotação da maxila em relação à base do crânio;

j - a rotação da mandíbula em relação à base do crânio.

Com a sobreposição dos traçados final e de pós-contenção foram avaliadas:

I - a rotação da maxila em relação à base do crânio;

m - a rotação da mandíbula em relação à base do crânio. 


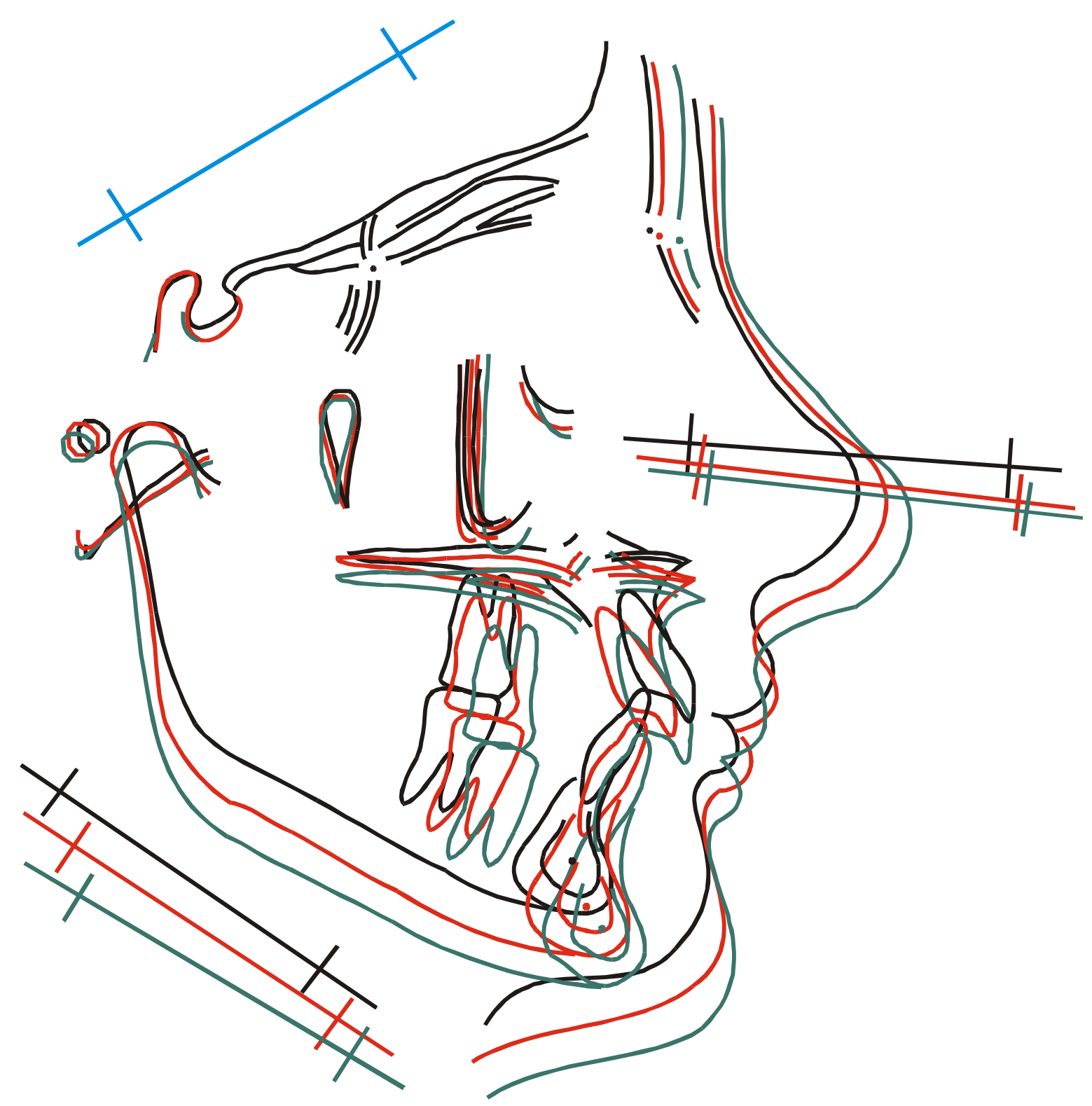

FIGURA 4.10 - O padrão de crescimento translatório de uma paciente, pertencente à categoria 3 de crescimento, aos 11 anos (preto), 14 anos (vermelho) e 33 anos (verde). A sobreposição na base do crânio ilustra um padrão mais ou menos típico de crescimento translatório maxilar e mandibular. As linhas de referência fornecem um quadro bastante simplificado do deslocamento e da rotação

Essas rotações receberam sinais de acordo com o seu sentido: a rotação com sentido posterior (horário) recebeu sinal positivo, e a rotação anterior (antihorário) recebeu sinal negativo. 


\subsubsection{ANÁLISE CEFALOMÉTRICA CONVENCIONAL}

Com o intuito de caracterizar as alterações esqueléticas, dentárias e do perfil tegumentar, que ocorreram tanto durante como após o tratamento ortodôntico, foram selecionadas algumas variáveis de diversas análises cefalométricas, como as de TWEED ${ }^{205,206}$, RIEDEL ${ }^{162}$, STEINER ${ }^{192,193}$, RICKETTS ${ }^{160,161}$, e McNAMARA JÚNIOR ${ }^{118}$.

\subsubsection{Desenho anatômico}

Ele constituiu-se dos detalhes que permitem o traçado dos pontos e linhas cefalométricos e fornecem uma visualização clara dos padrões cefalométricos a serem estudados.

O traçado do desenho anatômico, bem como a definição dos pontos, linhas, planos (Figuras 4.11 e 4.12) foram realizados de acordo com a descrição de MARTINS et al. ${ }^{115}$ e PETRELLI; BAPTISTA ${ }^{134}$.

\subsubsection{Pontos, linhas e planos cefalométricos}

\section{Pontos cefalométricos (Figura 4.11):}

S - (Sela): ponto localizado no centro da sela túrcica, por inspeção;

$\mathbf{N}$ - (Násio): ponto localizado na parte mais anterior da sutura fronto-nasal;

Ar - (Articular): interseção da face inferior da base craniana com o contorno posterior do processo condilar da mandíbula;

Ba - (Básio): ponto mais póstero-inferior da porção anterior do forame magno;

Po - (Pório): ponto mais superior do contorno do meato acústico externo; 
Or - (Orbitário): ponto mais inferior do contorno da órbita;

Pt - (Pterigóideo): ponto mais súpero-posterior do contorno da fissura pterigomaxilar;

Co - (Condílio): ponto mais póstero-superior no contorno da cabeça da mandíbula;

ENA - (Espinha Nasal Anterior): ponto localizado na extremidade anterior e superior da maxila;

ENP - (Espinha Nasal Posterior): ponto localizado na extremidade posterior do palato duro;

A - ponto mais profundo da concavidade anterior da maxila;

B - ponto mais profundo da concavidade anterior da sínfise da mandíbula;

AO - projeção perpendicular do ponto A sobre o plano oclusal funcional;

BO - projeção perpendicular do ponto B sobre o plano oclusal funcional;

Pog - (Pogônio): ponto mais anterior do mento;

Gn - (Gnátio): ponto mais ântero-inferior do contorno do mento;

Me - (Mentoniano): ponto mais inferior do contorno da sínfise da mandíbula;

Go - (Gônio): ponto mais póstero-inferior do contorno do ângulo goníaco, onde toca o plano mandibular (Me-Go), realizado de acordo com a descrição de PETROVIC; LAVERGNE; STUTZMANN ${ }^{140}$;

P.I. - (Pontos Incisais): referem-se às margens incisais dos incisivos;

P.A. - (Pontos Apicais): referem-se aos ápices dos incisivos;

Pn - ( ponta do nariz ): ponto mais anterior do nariz;

Ls - (lábio superior): ponto mais anterior do lábio superior.

Li - (lábio inferior): ponto mais anterior do lábio inferior.

Pog'- (Pogônio tegumentar): ponto mais anterior no contorno do mento tegumentar. 
Linhas e Planos Cefalométricos (Figura 4.12):

Linha Sela - Násio (S-N): do ponto S ao N;

Linha Sela - Gônio (S-Go): do ponto S ao Go;

Linha Sela - Gnátio (S-Gn): do ponto $S$ ao Gn;
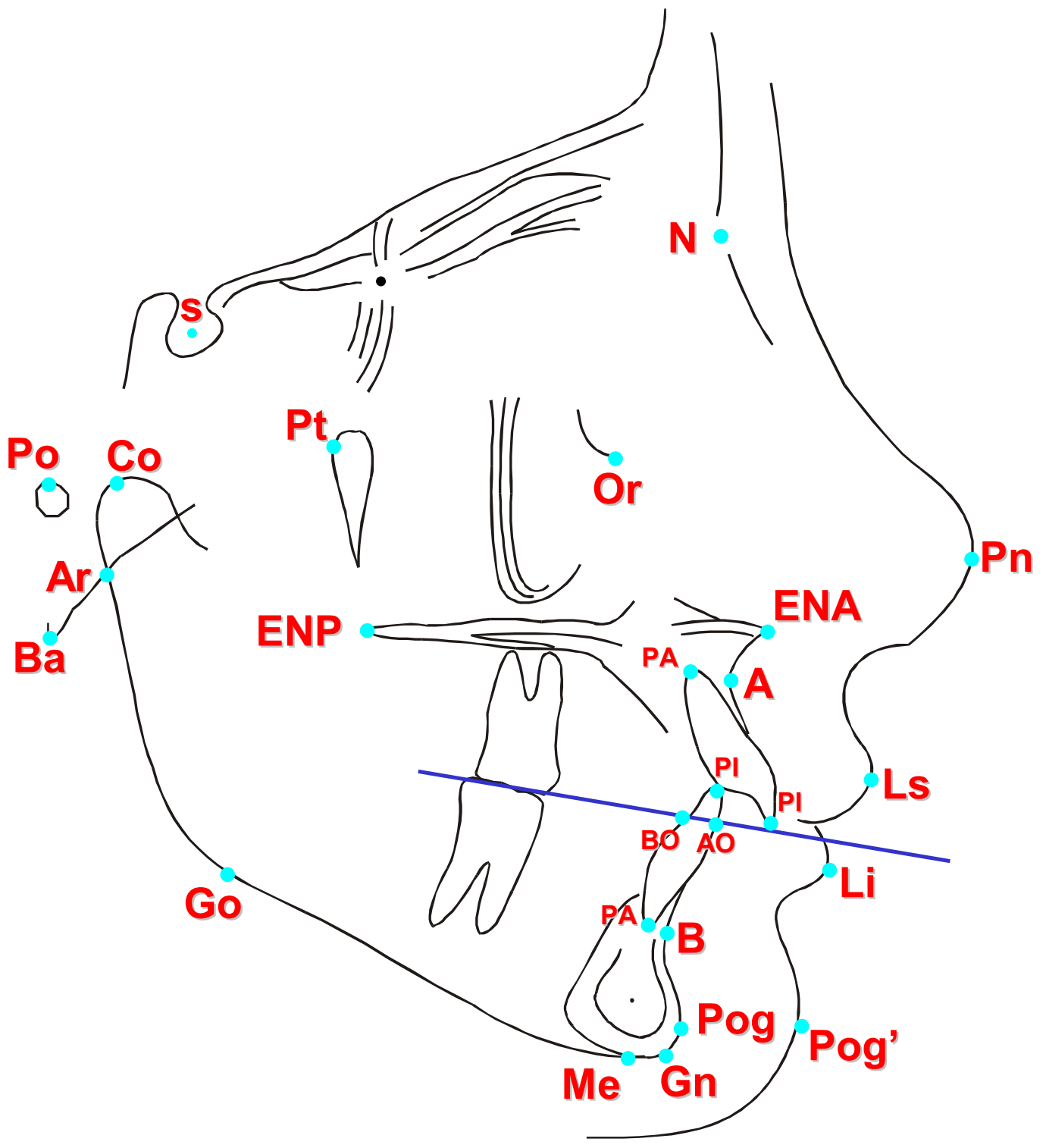

FIGURA 4.11 - Desenho anatômico, e pontos cefalométricos

Linha Básio - Násio (Ba-N): do ponto Ba ao N;

Linha Pterigóideo - Gnátio (Pt-Gn): do ponto Pt ao Gn; 
Linha Násio - Mentoniano (N-Me): do ponto N ao Me;

Linha Násio - A (N-A): do ponto $N$ ao $A$;

Linha Násio - B (N-B): do ponto N ao B;

Linha Násio perpendicular a Francfort (N-Perp): traçada a partir do ponto $\mathrm{N}$ perpendicular a Francfort;

Linha Condílio - A (Co-A): do ponto Co ao A;

Linha Condílio - Gnátio (Co-Gn): do ponto Co ao Gn;

Linha Articular - A (Ar-A): do ponto Ar ao A;

Linha Articular - Gnátio (Ar-Gn): do ponto Ar ao Gn;

Linha Espinha Nasal Anterior - Mentoniano (ENA-Me): do ponto ENA ao Me;

Linha A - Pogônio (A-Pog): do ponto A ao Pog;

Plano palatino (PP): do ponto ENA ao ENP;

Longo eixo do incisivo superior: linha passando pela margem incisal e pelo ápice desse dente;

Longo eixo do incisivo inferior: linha passando pela margem incisal e pelo ápice desse dente;

Plano oclusal funcional (POF): é definido pelos pré-molares e primeiros molares permanentes. A linha é traçada por inspeção respeitando as radiolucências espalhadas entre as cúspides ao longo da linha de oclusão;

Plano de Francfort: do ponto Po ao Or;

Plano Mandibular (PM): do ponto Go ao Me. Quando na presença de dupla imagem, foi traçada a média dos pontos superior e inferior;

Linha "E" ou Plano Estético de Ricketts: linha que une os pontos Pog' e Pn;

Linha do Perfil de Merrifield: linha que une os pontos Pog' e o lábio mais proeminente, estendendo-se superiormente até o plano de Francfort;

Linha H de Holdaway: linha que une o ponto Pog' até o ponto Ls. 


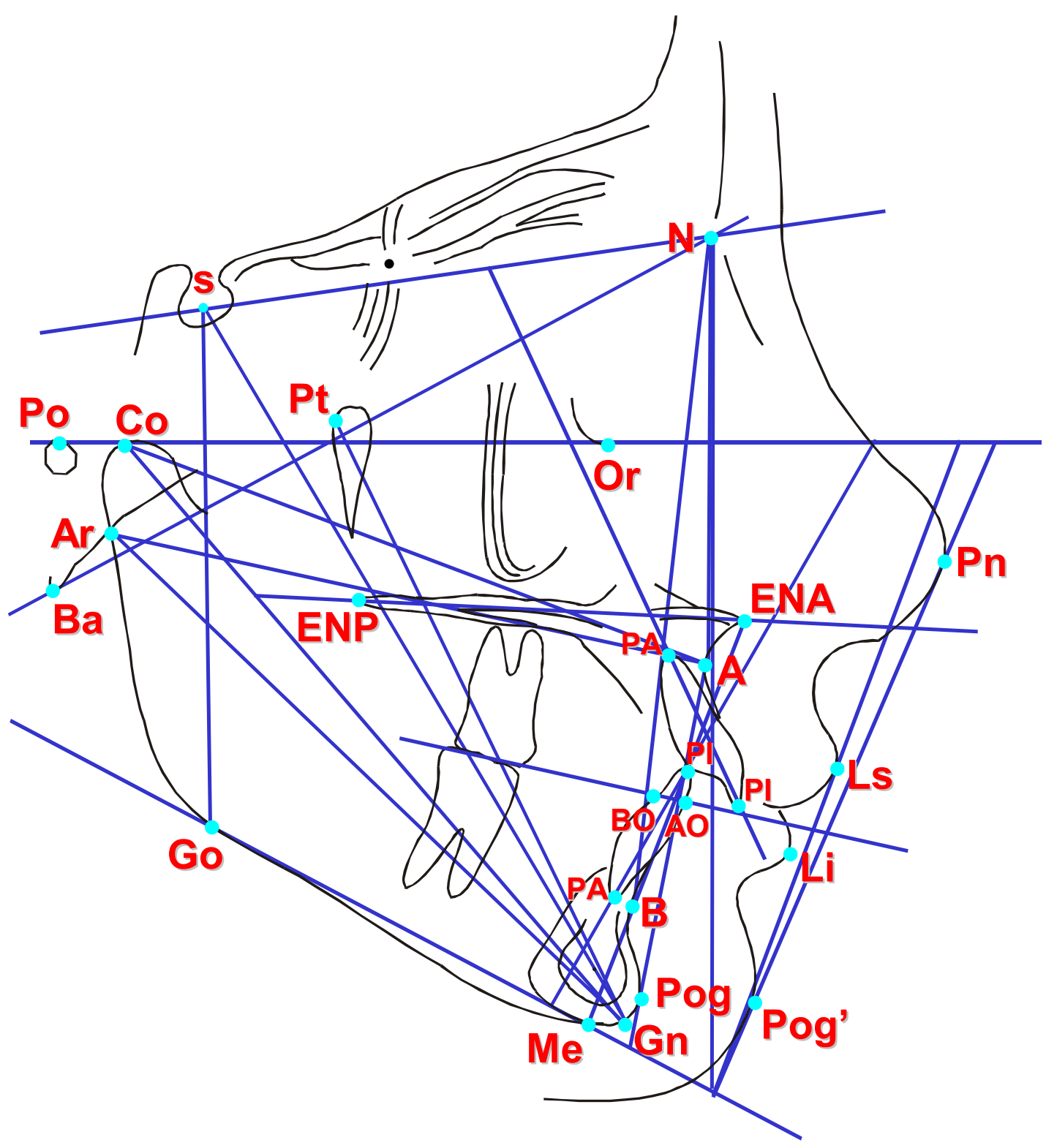

FIGURA 4.12 - Linhas e planos cefalométricos

\subsubsection{Grandezas cefalométricas}

\section{Posição maxilar (Figura 4.13)}

1- SNA: ângulo formado entre a linha SN e a linha NA. A norma cefalométrica ${ }^{162}$ é de $82^{0}$. 
2- A-Nperp: distância linear do ponto $A$ até a linha Násio perpendicular a Francfort. A norma cefalométrica ${ }^{118}$ é de $1 \mathrm{~mm}$.

\section{Comprimento maxilar (da face média) (Figura 4.13)}

3- Co-A: distância linear do ponto Co ao ponto A. A norma cefalométrica ${ }^{115}$ é de $88,9 \mathrm{~mm}$ para as meninas e de $90,9 \mathrm{~mm}$ para os meninos aos 13 anos.

4- Ar-A: distância linear do ponto Ar ao ponto A.

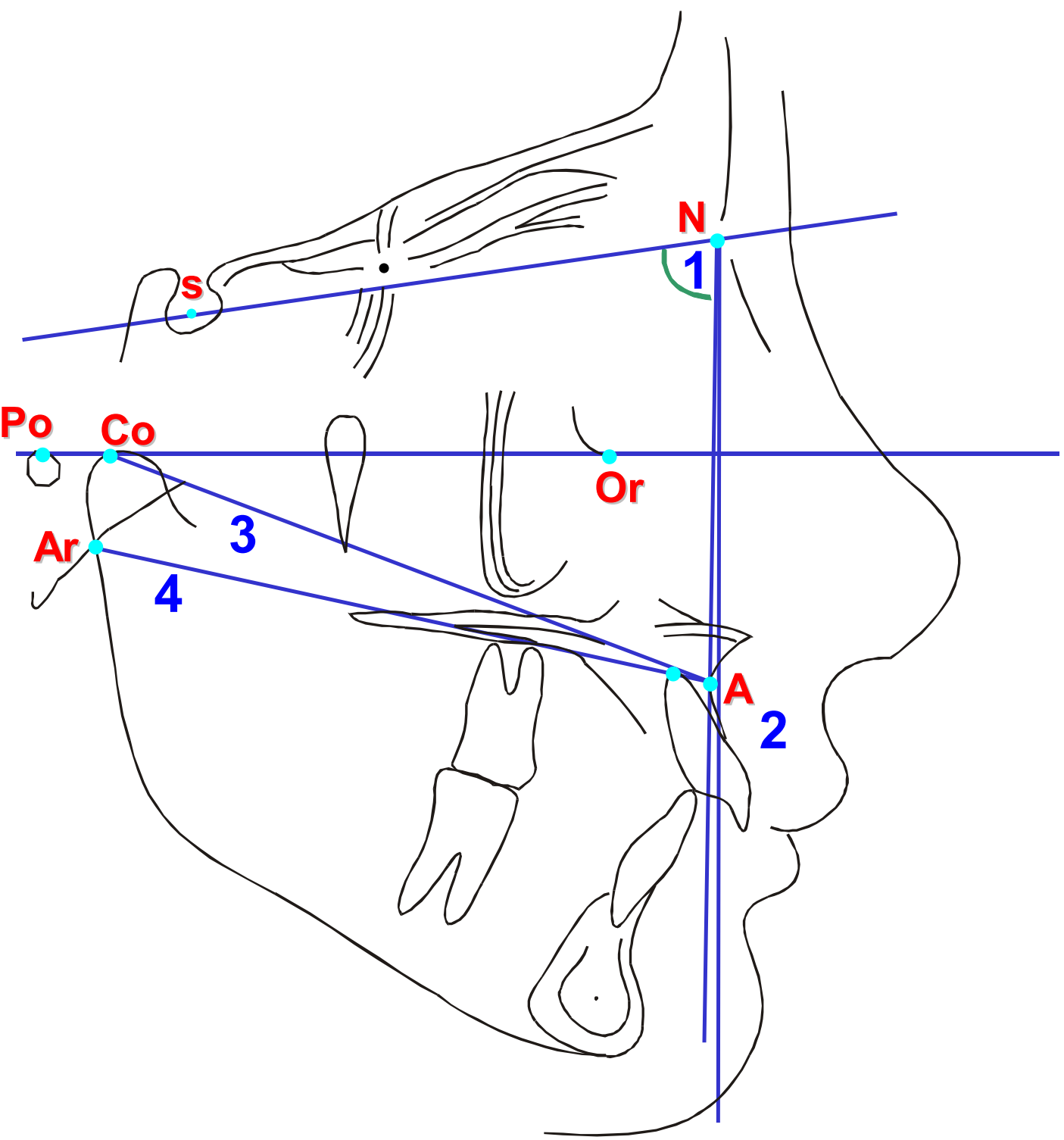

FIGURA 4.13 - Avaliação da posição e do comprimento da maxila 


\section{Posição mandibular (Figura 4.14)}

5- SNB: ângulo formado entre a linha SN e a linha NB. A norma cefalométrica ${ }^{162}$ é de $80^{\circ}$.

6- Pog-Nperp: distância linear do ponto Pog até a linha Násio perpendicular a Francfort. A norma cefalométrica ${ }^{118}$ é de $-2 \mathrm{a}+4 \mathrm{~mm}$.

\section{Comprimento mandibular (Figura 4.14)}

7- Co-Gn: distância linear do ponto Co ao ponto Gn. A norma cefalométrica ${ }^{115}$ é de $116 \mathrm{~mm}$ para as meninas e de $115,8 \mathrm{~mm}$ para os meninos aos 13 anos.

8- Ar-Gn: distância linear do ponto Ar ao ponto Gn. A norma cefalométrica ${ }^{115}$ é de $109,7 \mathrm{~mm}$ para as meninas e de 108,8 mm para os meninos aos 13 anos. 


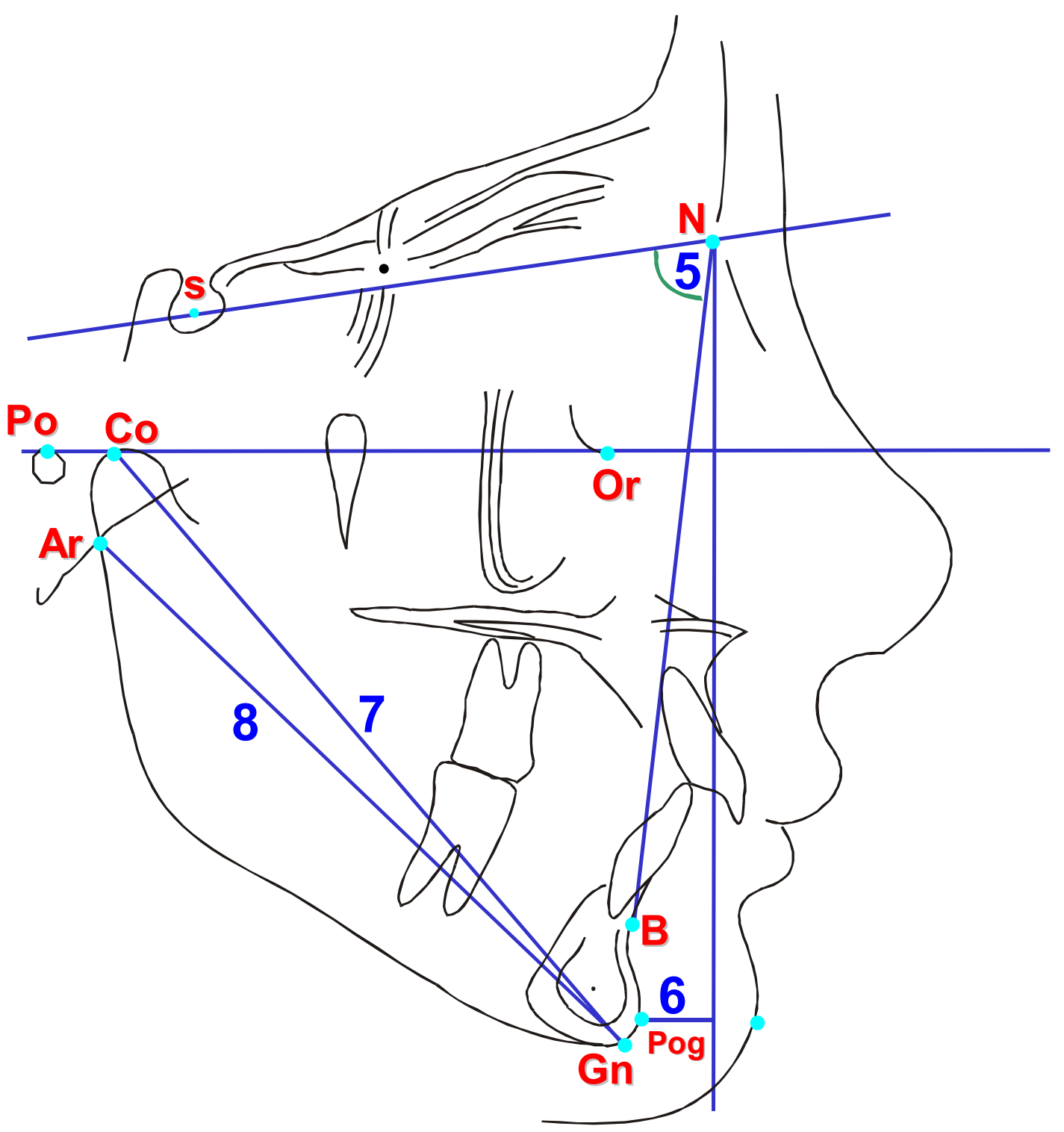

FIGURA 4.14 - Avaliação da posição e do comprimento da mandíbula

\section{Relações intermaxilares (Figura 4.15)}

9- ANB: ângulo formado entre a linha NA e a linha NB. A norma cefalométrica ${ }^{162}$ é de $2^{0}$.

10-WITS: distância linear entre os pontos $A O$ e BO, medida ao longo do plano oclusal funcional. Quando o ponto AO se encontra na frente do BO, o valor da 
medida é positivo. A norma cefalométrica ${ }^{76}$ é 0 no sexo feminino e $-1 \mathrm{~mm}$ no masculino.

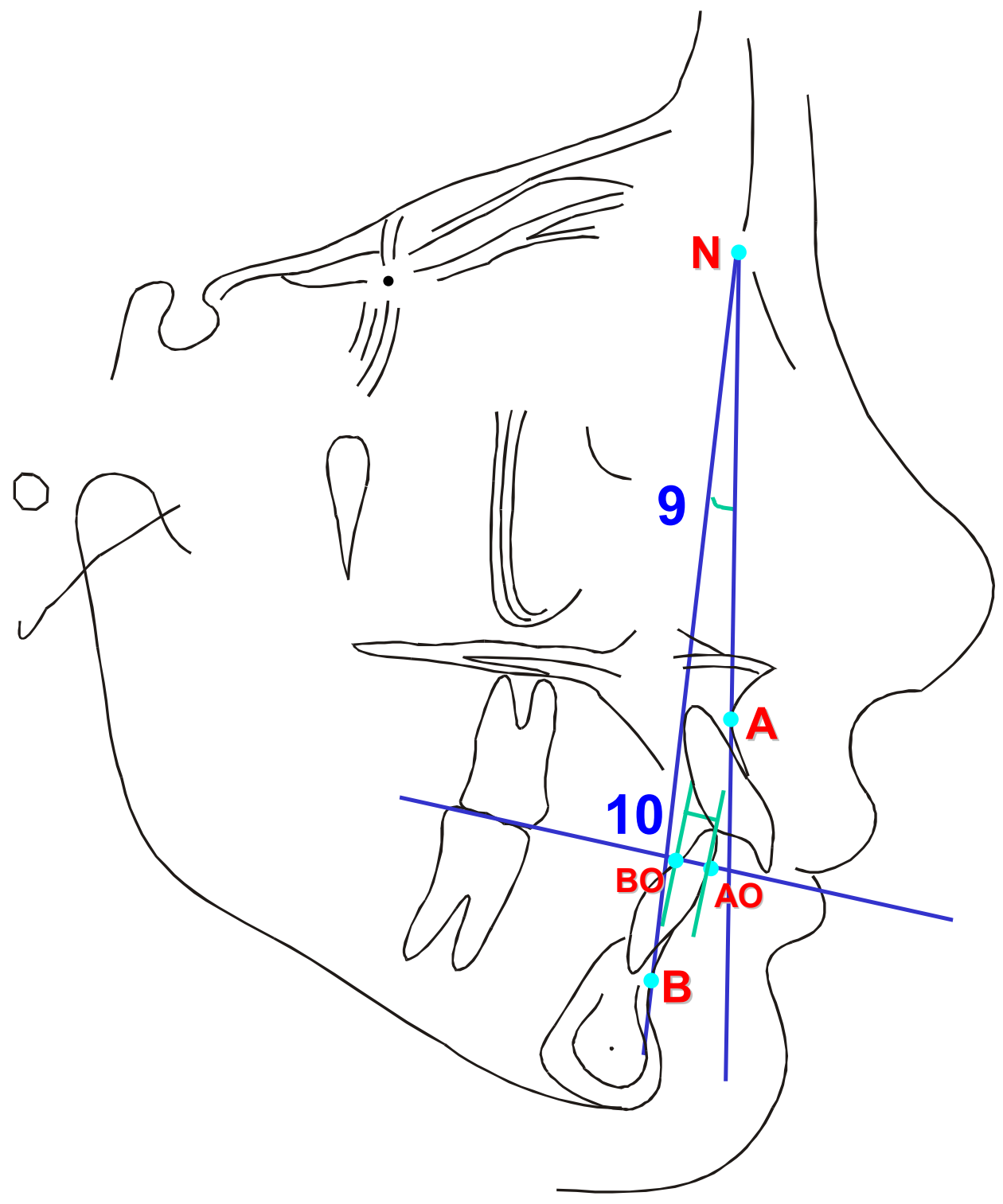

FIGURA 4.15 - Avaliação da relações intermaxilares

Relações verticais (Figura 4.16)

11- SN.PP: ângulo formado entre a linha $\mathrm{SN}$ e o plano palatino. A norma 
cefalométrica $^{97}$ é de $8,5^{0}$.

12- SN.Ocl: ângulo formado entre a linha $\mathrm{SN}$ e o plano oclusal funcional. A norma cefalométrica ${ }^{192}$ é de $14^{0}$.

13- SN.PM: ângulo formado entre a linha SN e o plano mandibular. A norma cefalométrica $^{162}$ é de $32^{0}$.

14- FMA: ângulo formado entre o plano mandibular e o plano de Francfort. A norma cefalométrica ${ }^{206}$ é de $25^{0}$.

15- Eixo Y: ângulo formado entre a linha S-Gn e a linha S-N. A norma cefalométrica $^{134}$ é de $67^{0}$.

16- Eixo facial: ângulo formado entre a linha Ba-N e a linha Pt-Gn. A norma cefalométrica $^{161}$ é de $90^{\circ}$.

17- Altura facial anterior (N-Me): distância linear do ponto Násio ao ponto Me. A norma cefalométrica ${ }^{185}$ aos 10 anos é de $111,7 \mathrm{~mm}$.

18- Altura facial posterior (S-Go): distância linear do ponto $S$ ao ponto Go. A norma cefalométrica ${ }^{184}$ aos 10 anos é de $71,6 \mathrm{~mm}$.

19- Altura facial ântero-inferior (AFAl): distância linear do ponto ENA ao ponto Me. A norma cefalométrica ${ }^{115}$ é de $66,4 \mathrm{~mm}$ para as meninas e de $68 \mathrm{~mm}$ para os meninos aos 13 anos.

20- Proporção entre as alturas faciais anterior e posterior (S-Go:N-Me): divisão da altura facial posterior pela anterior. A norma cefalométrica ${ }^{185}$ aos 10 anos é de $64,1 \%$. 


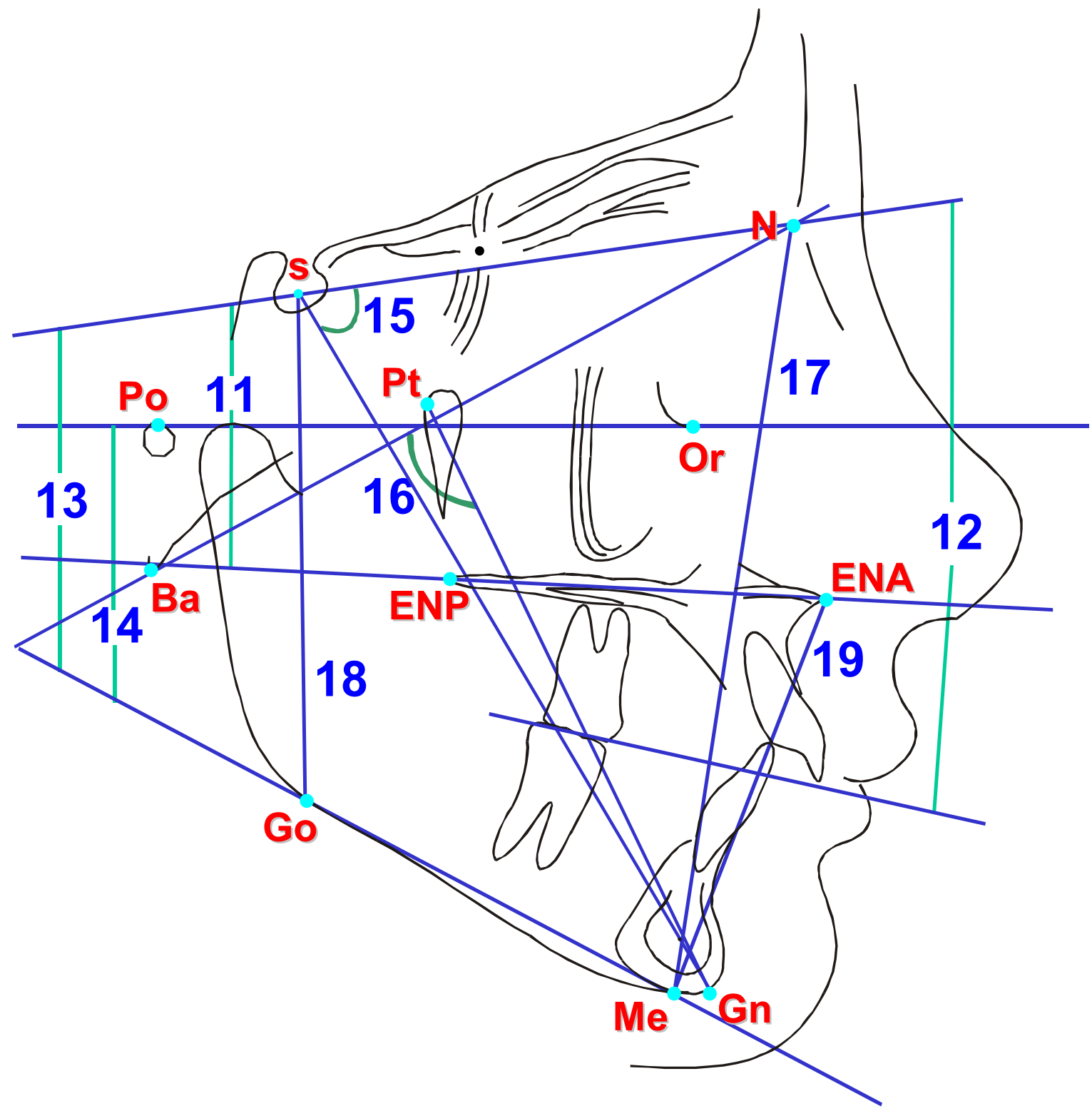

FIGURA 4.16 - Avaliação das relações verticais 


\section{Relações Dentárias (Figura 4.17)}

21- 1s.SN: ângulo formado entre o longo eixo do incisivo superior e a linha SN. A norma cefalométrica ${ }^{162}$ é de $103^{0}$.

22- 1s-NA: distância linear do ponto incisal do incisivo superior mais vestibularizado até a linha NA. A norma cefalométrica ${ }^{192}$ é de $4 \mathrm{~mm}$.

23- 1s.NA: ângulo formado entre o longo eixo do incisivo superior e a linha NA. A norma cefalométrica ${ }^{192}$ é de $22^{0}$.

24- 1i-NB: distância linear do ponto incisal do incisivo inferior mais vestibularizado até a linha NB. A norma cefalométrica ${ }^{192}$ é de $4 \mathrm{~mm}$.

25- 1i.NB: ângulo formado entre o longo eixo do incisivo inferior e a linha NB. A norma cefalométrica ${ }^{192}$ é de $25^{0}$.

26- FMIA: ângulo formado entre o longo eixo do incisivo inferior e o plano de Francfort. A norma cefalométrica ${ }^{206}$ é de $68^{0}$.

27- IMPA: ângulo formado entre o longo eixo do incisivo inferior e plano mandibular. A norma cefalométrica ${ }^{205}$ é de $87^{\circ}$

28- 1i-APog: distância linear do ponto incisal do incisivo inferior mais vestibularizado até a linha A-Pog. A norma cefalométrica ${ }^{161}$ é de $1 \mathrm{~mm}$.

29- 1/1: ângulo entre o longo eixo dos incisivos superior e inferior. A norma cefalométrica ${ }^{162}$ é de $131^{0}$. 


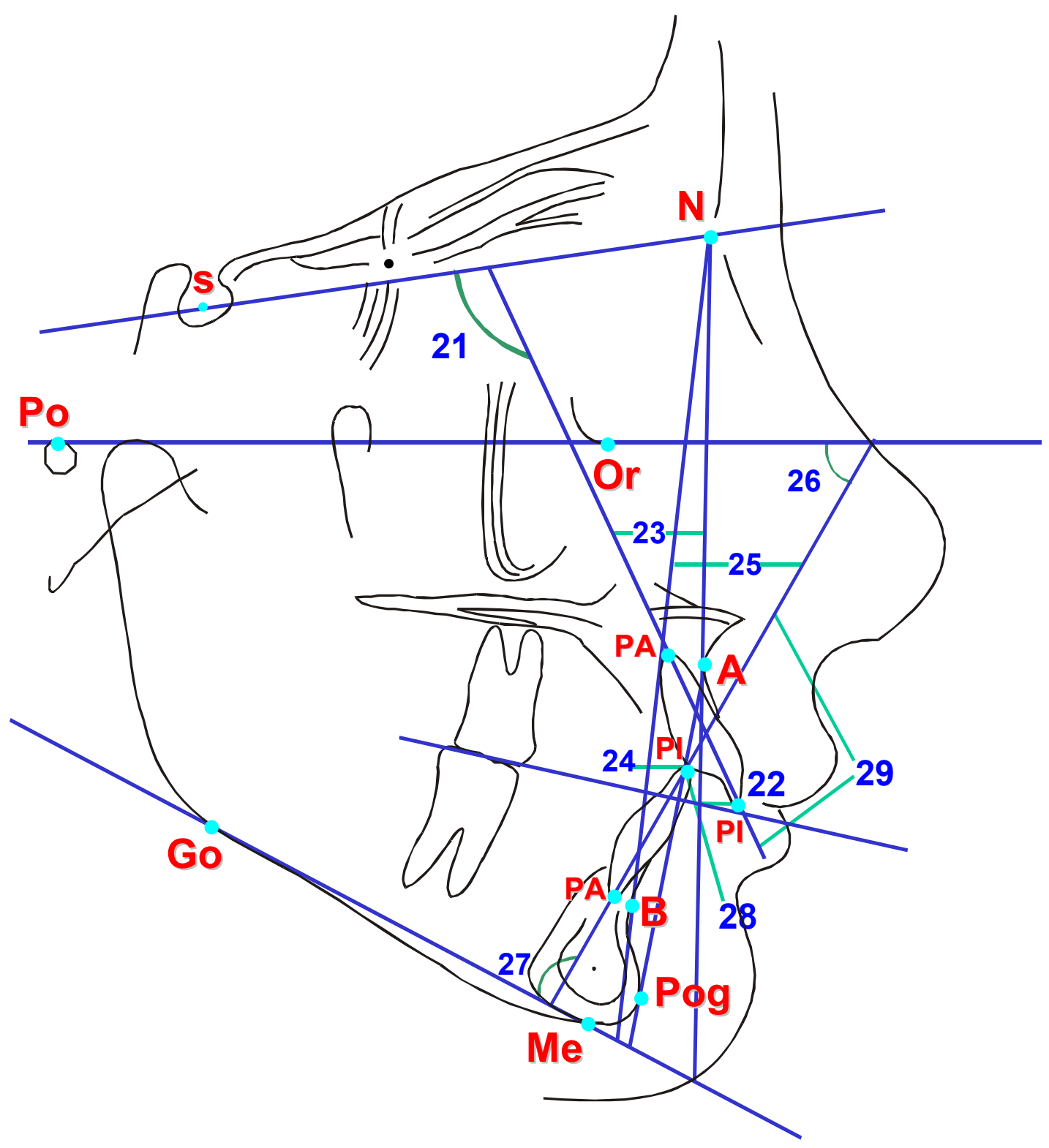

FIGURA 4.17 - Avaliação das relações dentárias

\section{Relações do perfil tegumentar (Figura 4.18)}

30- Ls-E: distância linear do lábio superior à Linha E. A norma cefalométrica é de $-4 \mathrm{~mm}^{160}$.

31- Li-E: distância linear do lábio inferior à Linha E. A norma cefalométrica é de $2 \mathrm{~mm}^{160}$. 
32- Ângulo Z: ângulo formado pela intersecção da linha do perfil de Merrifield ${ }^{120}$ com o plano de Francfort. A norma cefalométrica é de $78^{\circ}$ para adolescentes e de $80^{\circ}$ para adultos.

33- H-Nariz: distância linear da linha $\mathrm{H}$ até o ponto Pn. A norma cefalométrica ${ }^{134}$ é de 9 a $11 \mathrm{~mm}$.

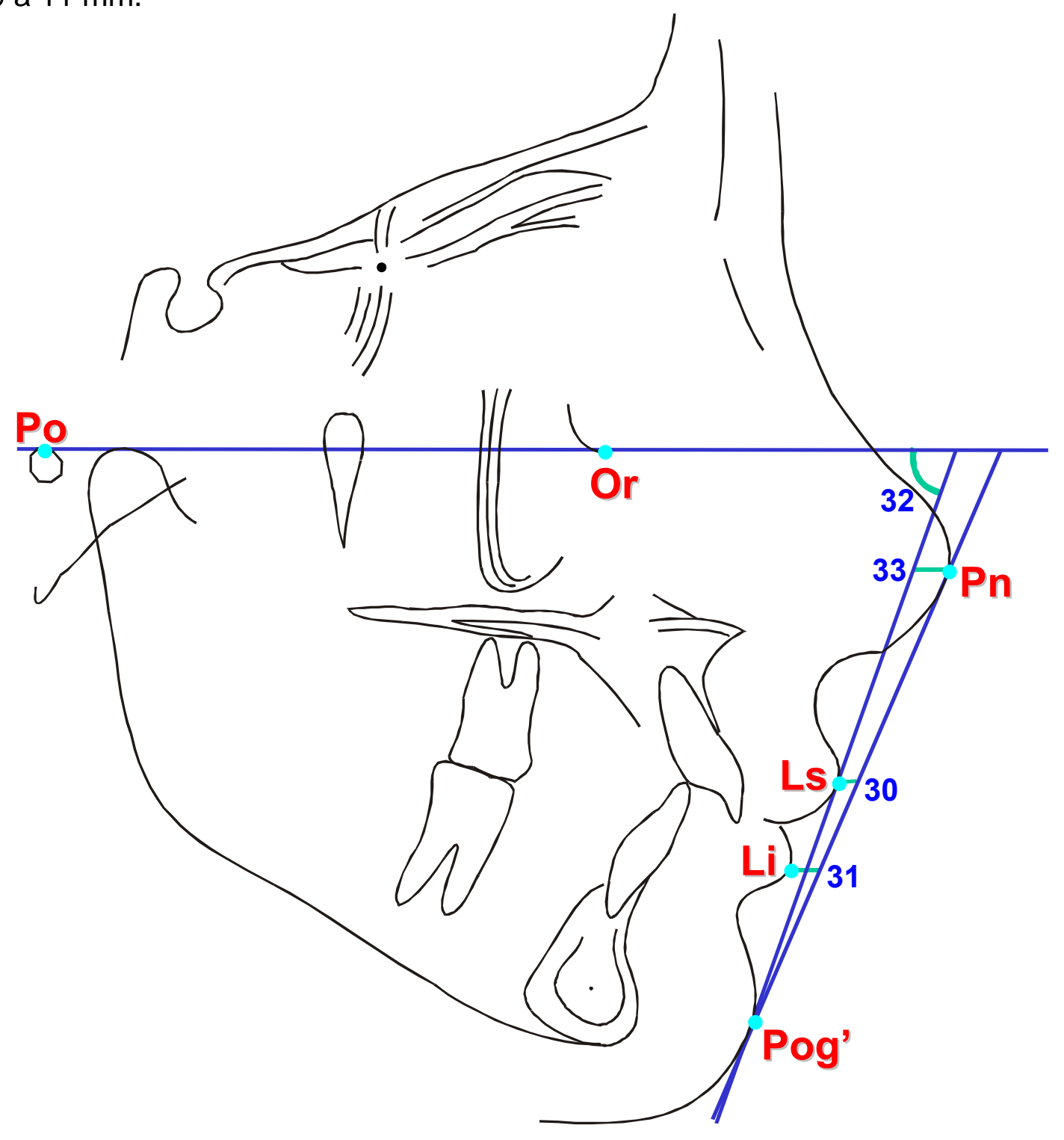

FIGURA 4.18 - Avaliação do perfil tegumentar 


\subsubsection{TRAÇADO CEFALOMÉTRICO DE PETROVIC/LAVERGNE}

O traçado do desenho anatômico, bem como a definição dos pontos, linhas e planos já foram descritos anteriormente.

Para a realização da análise de PETROVIC/LAVERGNE necessita-se da medição de cinco ângulos cefalométricos, SNA, SNB, ANB, SN.PP, SN.PM (Figura 4.19), e da obtenção de dois ângulos esperados, que são obtidos com as seguintes fórmulas:

\section{Ângulo esperado SN.PP}

E. SN.PP $=\frac{\text { SN.PM }}{2}-7$

\section{Ângulo esperado SN.PM \\ E. SN.PM $=192-2$. (SNB)}

\subsubsection{Determinação da categoria de crescimento}

Para se determinar a qual categoria de crescimento o paciente pertence,

é necessário, inicialmente, determinar o grupo rotacional no fluxograma ${ }^{147}$ (Figura 2.3, pg. 37) e, para isso, é preciso achar T1, T2, e T3:

T1 = E. SN.PM- SN.PM

T2 = E. SN.PP - SN.PP

$\mathrm{T} 3=\mathrm{ANB}$

Uma vez encontrado o grupo rotacional, parte-se então para a tabela de decisão terapêutica $^{99}$ (Tabela 2.2, pg. 31), onde se encontra a categoria de crescimento do paciente. Cada grupo rotacional possui no seu nome como primeira letra $\circ \mathrm{A}, \circ \mathrm{R}$ ou $\circ \mathrm{P}$, as quais indicam a rotação (inclinação) da 
mandíbula do paciente ao início do tratamento. Além disso, cada grupo rotacional possui a terminação OB (aberta), DB (profunda) e $\mathrm{N}$ (normal), que permitiu a divisão da amostra de acordo com a dimensão vertical (mordida). Essa classificação da dimensão vertical é apenas esquelética e não dentária, ou seja, ela diz respeito à inclinação da mandíbula em relação à maxila.

Para facilitar essa fase da determinação da categoria de crescimento do paciente, foi utilizado um programa de computador (Análise de PETROVIC/LAVERGNE 1.0$)^{204}$.

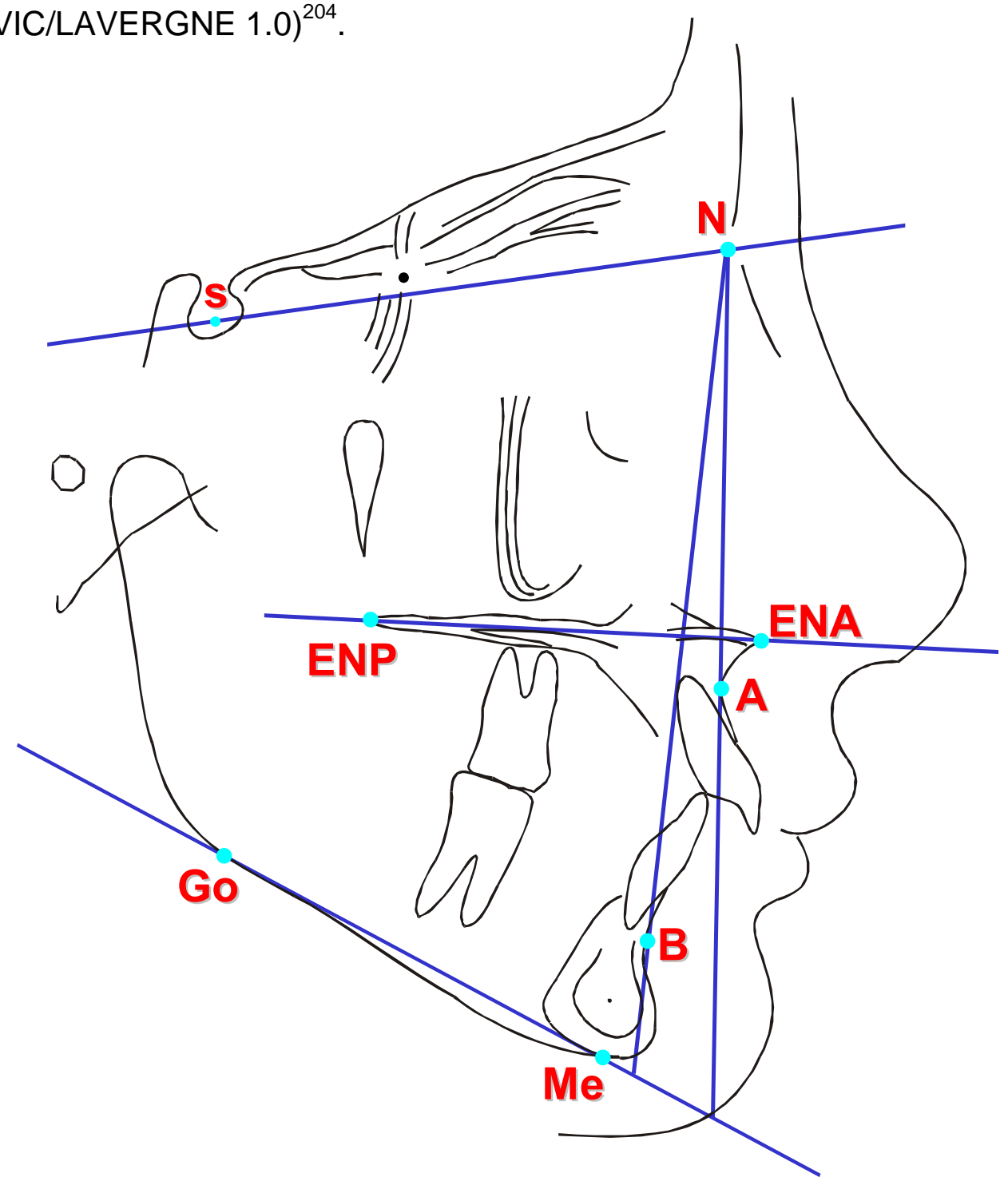

FIGURA 4.19 - Traçado Cefalométrico de PETROVIC/LAVERGNE 


\subsubsection{MÉTODO ESTATÍSTICO}

Inicialmente, foi realizada a distribuição dos pacientes para os grupos constituídos pelos níveis das variáveis: categoria de crescimento, rotação mandibular e dimensão vertical (tipo de mordida). Foram, então, calculadas as médias de idade nas fases estudadas (inicial, final e de pós-contenção).

Para cada um dos tipos de análise (modelos, JOHNSTON JÚNIOR e cefalométrica convencional) foram realizadas análises de valores extremos por meio da distância de Mahalanobis. As análises foram feitas no software JMP v3.2.2 da empresa SAS.

Para todas as variáveis consideradas, foram calculadas as medidas descritivas: tamanho de amostra, média e desvio padrão.

\subsubsection{Análise de modelos}

Para a análise de modelos foram testadas as seguintes hipóteses nulas: H01: Média geral dos grupos são iguais (fazendo-se a média de todos os momentos);

H02: Média geral dos momentos são iguais (fazendo-se a média para todos os grupos);

H03: Os perfis médios dos grupos são paralelos (ao longo de todos os momentos).

Após rejeitar as hipóteses $\mathrm{H} 01$ e H02, foram feitos contrastes entre grupos (ou entre momentos) para avaliar quais eram as médias diferentes. 
Como os pacientes foram avaliados em mais do que uma oportunidade, foram realizados testes para medidas repetidas. Para isso, foi utilizado o procedimento Mixed do "software" SAS.

Para avaliar a recidiva, também foram realizadas correlações entre as diferenças do índice de Little (IL pós-contenção - IL final) e as diferenças das distâncias intercaninos (3-3 final - 3-3 inicial) e entre os segundos pré-molares (5-5 final - 5-5 inicial).

\subsubsection{Análise de JOHNSTON JÚNIOR}

Para a análise de JOHNSTON JÚNIOR, as análises estatísticas foram feitas para as medidas referentes às seguintes fases: de tratamento (inicial $X$ final), de pós-tratamento (final X pós-contenção) e avaliação total (pós-contenção $\mathrm{X}$ inicial). Utilizando essas medidas, foram realizados testes para avaliar as seguintes hipóteses nulas:

H01: as diferenças médias são iguais a zero (para todos os grupos conjuntamente);

H02: as diferenças médias são iguais para todos os níveis das variáveis de grupo;

H03: não há relação entre as diferenças e EGU (Unidade de Crescimento Esperado).

Quando a hipótese H02 foi rejeitada (as diferenças médias são diferentes entre os grupos), foram feitos testes de Tukey para avaliar entre quais grupos existiam diferenças significativas. Também nesse caso, foram realizados 
contrastes para avaliar quais eram os grupos para os quais se rejeitava a hipótese H01, ou seja, quais eram os grupos que não apresentavam diferenças entre os momentos.

Empregando-se algumas das variáveis desta análise, foram estimados coeficientes de correlação de Pearson para avaliar a significância e a magnitude da associação entre elas. Essas correlações foram feitas com os dados de todos os pacientes juntos e dentro de cada grupo de rotação mandibular.

\subsubsection{Análise cefalométrica convencional}

Para a análise cefalométrica convencional, foram realizados dois tipos de análise:

a) As mesmas análises realizadas no caso da análise de JOHNSTON JÚNIOR.

As análises foram feitas com as diferenças entre as fases inicial $\mathrm{X}$ final (alterações do tratamento), final X pós-contenção (alterações pós-tratamento) e pós-contenção $X$ inicial (alterações totais). Utilizando-se essas diferenças foram feitos testes para avaliar as seguintes hipóteses nulas:

H01: as diferenças médias são iguais a zero (para todos os grupos conjuntamente);

H02: as diferenças médias são iguais para todos os níveis das variáveis de grupo;

H03: não há relação entre as diferenças e EGU. 
Quando a hipótese H02 foi rejeitada (as diferenças médias são diferentes entre os grupos), foram feitos testes de Tukey para avaliar entre quais grupos existiam diferenças significativas. Também nesse caso, foram realizados contrastes para avaliar quais eram os grupos para os quais se rejeitava a hipótese H01, ou seja, quais eram os grupos que não apresentavam diferenças entre os momentos.

b) As mesmas análises realizadas na análise de modelos.

Foram testadas as seguintes hipóteses nulas:

H01: Média geral dos grupos são iguais (fazendo-se a média para todos os momentos);

H02: Média geral dos momentos são iguais (fazendo-se a média para todos os grupos);

H03: Os perfis médios dos grupos são paralelos (ao longo de todos os momentos).

Após rejeitar as hipóteses $\mathrm{H} 01$ e $\mathrm{H} 02$ foram realizados contrastes entre grupos (ou entre momentos) para avaliar quais eram as médias diferentes.

Também, quando houve interação grupo $X$ momento, foram feitos contrastes entre grupos dentro de cada momento.

Foram calculados coeficientes de correlação entre as diferenças (índice de Little pós-contenção - índice de Little final) e as diferenças (pós-contenção final) para as variáveis da análise convencional para toda a amostra $(n=100)$. 


\subsubsection{A unidade de crescimento esperado}

Para as variáveis da análise de JOHNSTON JÚNIOR e da análise cefalométrica convencional, foram realizadas análises de covariância para determinar se existiam diferenças entre as categorias de crescimento, e entre os grupos de rotação mandibular, utilizando-se a variável EGU ${ }^{80,83}$ (unidade de crescimento esperado) como covariada. Considerando-se que o presente trabalho empregou pacientes dos sexos masculino e feminino que apresentavam uma grande variação de idade ao início do tratamento, e cujos tratamentos apresentaram diferenças na duração e no acompanhamento pós-tratamento, tornou-se necessário ajustar a amostra utilizando-se a EGU.

A EGU consiste numa área (Figura 4.20) correspondente ao período de tratamento situada em curvas de crescimento específicas para cada sexo da Rocky Mountain Data Systems (RMDS), que é dividida pela área de mínimo crescimento pré-puberal (9 a 10 anos, nas meninas, e 11 a 12, nos meninos). Ela constitui uma estimativa individualizada da intensidade relativa de crescimento e a alteração correspondente na forma - que se esperaria que tivesse um indivíduo que não foi tratado ortodonticamente da mesma idade e sexo durante um intervalo específico.

Neste trabalho foi utilizada a EGU unissex, que nada mais é do que a divisão da área do período de observação (na curva masculina ou feminina) pela média das áreas masculina e feminina de mínimo crescimento pré-puberal. Segundo JOHNSTON JÚNIOR* (1995), é melhor a utilização da EGU unissex,

\footnotetext{
* Comunicação pessoal
} 
porque, neste caso, necessita-se de coeficientes que tratem da intensidade relativa de crescimento, ao invés da quantidade real. Na sua forma unissex, a EGU está correlacionada com o período de crescimento, ou seja, com sua intensidade relativa, mas não com a quantidade real, que é muito maior nos meninos.

Os valores da EGU foram desenvolvidos por JOHNSTON JÚNIOR ${ }^{80,83}$ a partir de curvas de crescimento facial feitas por SCHULHOF; BAGHA ${ }^{176}$, estando descritos na Tabela 2.1 (pg. 11).

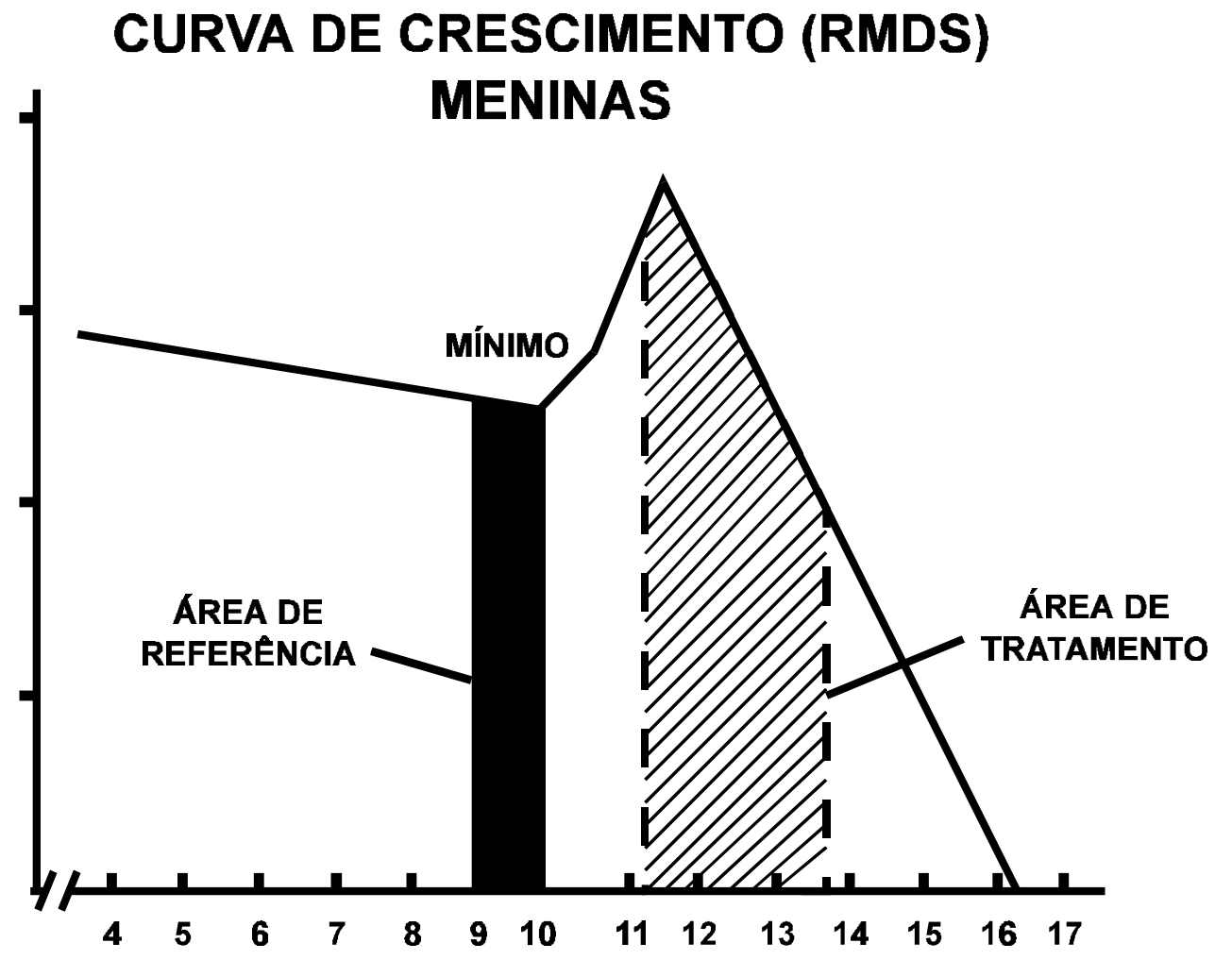

FIGURA 4.20 - Estimativa da Unidade de Crescimento Esperado (EGU) individual. Curvas de crescimento da Rocky Mountain Data Systems (RMDS) específicas para cada sexo foram integradas com relação ao tempo de tratamento e expressas como um múltiplo da área da idade pré-puberal mínima (médias masculina e feminina). Dessa forma, EGU = área de tratamento / área de referência. As curvas foram modificadas por JOHNSTON JÚNIOR ${ }^{80,83}$ a partir da Figura 11 de SCHULHOF; BAGHA ${ }^{176}$ 


\subsubsection{ANÁLISE DE ERROS}

Com o auxílio de uma tabela de números tomados ao acaso, 15 séries de 3 telerradiografias e de 3 pares de modelos de estudo (inicial, final e póscontenção) foram selecionadas e reanalisadas para se estudar os erros casuais e os sistemáticos.

Para o cálculo dos desvios padrão do erro (erro casual), foi utilizada a fórmula de DAHLBERG (HOUSTON $\left.{ }^{72}, 1983\right), D_{E}=\left(\sum D^{2} / 2 N\right)^{1 / 2}$, onde $\sum D^{2}$ corresponde ao somatório dos quadrados das diferenças entre a primeira e a segunda medição, e $\mathrm{N}$ significa o número total de casos utilizados na avaliação. Para a análise convencional, foram obtidas 45 determinações duplas (15 séries $X$ 3 telerradiografias), da mesma forma que foram obtidas para a análise de modelos (15 séries X 3 pares de modelos). Para a análise de JOHNSTON JÚNIOR, foram obtidas 30 determinações duplas ( 15 séries $X 2$ sobreposições).

Para avaliação do erro sistemático, foi empregado o mesmo número de determinações duplas, onde se aplicou o teste "t" de Student para amostras dependentes, ao nível de significância de 5 \%.

Os valores referentes aos casuais e sistemáticos encontram-se nas Tabelas 4.7 a 4.9 . 
TABELA 4.7 - Desvios padrão do erro (DPe) e resultados do teste "t" para as diferenças entre as médias da primeira e da segunda medições para as variáveis da análise de modelos

\begin{tabular}{lcccc} 
Variáveis & DPe & $\begin{array}{c}\text { média 1 } \\
\text { medição }\end{array}$ & $\begin{array}{c}\text { média 2 } \\
\text { medição }\end{array}$ & $\boldsymbol{p}$ \\
\hline IL & 0,5 & 4,37 & 4,41 & 0,6708 \\
$\mathbf{6 - 6}$ & 0,2 & 41,49 & 41,26 & $\mathbf{0 , 0 0 0 9}$ \\
$\mathbf{3 - 3}$ & 0,2 & 25,85 & 25,73 & $\mathbf{0 , 0 4 3 0}$ \\
$\mathbf{5 - 5}$ & 0,3 & 36,10 & 35,91 & $\mathbf{0 , 0 4 3 1}$ \\
$\mathbf{6 - 1}$ & 0,5 & 54,27 & 54,81 & $\mathbf{0 , 0 0 0 1}$ \\
$\mathbf{T H}$ & 0,3 & 4,22 & 4,04 & 0,0539 \\
$\mathbf{T V}$ & 0,3 & 3,86 & 3,78 & 0,4054 \\
CS & 0,3 & 2,91 & 2,56 & $\mathbf{0 , 0 0 0 1}$ \\
\hline
\end{tabular}

TABELA 4.8 - Desvios padrão do erro (DPe) e resultados do teste "t" para as diferenças entre as médias da primeira e da segunda medição para as variáveis da análise de JOHNSTON JÚNIOR

\begin{tabular}{|c|c|c|c|c|}
\hline Variáveis & $\mathrm{DPe}$ & média $1^{\circ}$ traçado & média $2^{\circ}$ traçado & $p$ \\
\hline \multicolumn{5}{|c|}{ Esqueléticas } \\
\hline Max.-BC & 0,5 & $-1,26$ & $-1,22$ & 0,8187 \\
\hline Mand & 1,0 & 3,59 & 3,54 & 0,8579 \\
\hline$A B A$ & 1,1 & 2,32 & 2,28 & 0,8763 \\
\hline \multicolumn{5}{|l|}{ Dentárias } \\
\hline $6 s$ & 1,1 & $-1,27$ & $-1,29$ & 0,9495 \\
\hline $6 i$ & 0,8 & 1,01 & 1,06 & 0,7955 \\
\hline $1 \mathrm{~s}$ & 0,7 & 1,18 & 1,22 & 0,8309 \\
\hline $1 i$ & 0,5 & $-2,15$ & $-2,10$ & 0,7041 \\
\hline \multicolumn{5}{|c|}{ Correções } \\
\hline incisal & 0,4 & $\begin{array}{l}2,00 \\
1,35\end{array}$ & $\begin{array}{l}2,03 \\
1,52\end{array}$ & 0,1512 \\
\hline $\begin{array}{l}\text { Rotações } \\
\text { Maxilar }\end{array}$ & 1,3 & 0,75 & 0,41 & 0,3619 \\
\hline Mandibular & 0,9 & $-1,53$ & $-2,23$ & 0,0073 \\
\hline
\end{tabular}


TABELA 4.9 - Desvios padrão do erro (DPe) e resultados do teste "t" para as diferenças entre as médias da primeira e da segunda medição para as variáveis da análise cefalométrica convencional

\begin{tabular}{|c|c|c|c|c|}
\hline Variáveis & $\mathrm{DPe}$ & média $1^{\circ}$ traçado & média $2^{\circ}$ traçado & p \\
\hline \multicolumn{5}{|l|}{ Maxilares } \\
\hline SNA & 0,3 & 81,19 & 81,27 & 0,2769 \\
\hline A-Nperp & 0,7 & $-0,2$ & $-0,65$ & 0,0268 \\
\hline Co-A & 0,8 & 85,72 & 85,52 & 0,4434 \\
\hline Ar-A & 0,4 & 83,81 & 83,86 & 0,3612 \\
\hline \multicolumn{5}{|c|}{ Mandibulares } \\
\hline SNB & 0,2 & 77,15 & 77,2 & 0,2550 \\
\hline Pg-Nperp & 1,4 & $-6,3$ & $-7,2$ & 0,0191 \\
\hline Co-Gn & 1,0 & 109,53 & 109,26 & 0,3360 \\
\hline Ar-Gn & 0,3 & 102,7 & 102,7 & 0,9233 \\
\hline \multicolumn{5}{|c|}{ Intermaxilares } \\
\hline$A N B$ & 0,3 & 4,0 & 4,0 & 0,8212 \\
\hline WITS & 0,9 & 0,46 & 0,63 & 0,1836 \\
\hline \multicolumn{5}{|l|}{ Verticais } \\
\hline SN.PP & 0,4 & 8,7 & 8,7 & 0,6870 \\
\hline SN.Ocl & 1,5 & 17,9 & 17,8 & 0,5076 \\
\hline SN.PM & 0,2 & 34,12 & 34,12 & 0,4453 \\
\hline SN.Gn & 0,4 & 68,77 & 68,66 & 0,2857 \\
\hline Ba.N.Gn & 0,7 & 88,62 & 88,93 & 0,1828 \\
\hline$F M A$ & 0,7 & 25,5 & 26,0 & 0,0129 \\
\hline $\mathrm{N}-\mathrm{Me}$ & 0,2 & 112,3 & 112,3 & 0,4497 \\
\hline S-Go & 0,4 & 76,51 & 76,46 & 0,9482 \\
\hline$A F P: A F A$ & 0,4 & 68,18 & 68,16 & 0,8325 \\
\hline AFAI & 0,3 & 64,6 & 64,5 & 0,9169 \\
\hline \multicolumn{5}{|l|}{ Dentárias } \\
\hline 1s.SN & 0,6 & 104,2 & 104,4 & 0,6388 \\
\hline 1.NA & 0,5 & 23,08 & 23,13 & 0,9047 \\
\hline $1-N A$ & 0,4 & 3,8 & 3,8 & 0,6418 \\
\hline 1.NB & 0,6 & 26,29 & 26,35 & 0,7278 \\
\hline $1-N B$ & 0,2 & 5,08 & 5,03 & 0,3227 \\
\hline FMIA & 0,9 & 59,49 & 58,95 & 0,0325 \\
\hline IMPA & 0,6 & 95 & 95,02 & 0,7680 \\
\hline $1 i-A P g$ & 0,2 & 2,05 & 1,92 & 0,0227 \\
\hline 1.1 & 0,9 & 126,5 & 126,4 & 0,7986 \\
\hline \multicolumn{5}{|c|}{ Tegumentares } \\
\hline$L s-E$ & 0,2 & $-2,61$ & $-2,62$ & 0,9629 \\
\hline$L i-E$ & 0,2 & $-1,20$ & $-1,13$ & 0,1207 \\
\hline $\mathbf{Z}$ & 1,1 & 71,17 & 70,79 & 0,0942 \\
\hline H-Pn & 0,3 & 4,58 & 4,62 & 0,7095 \\
\hline
\end{tabular}

Os resultados da análise de erros demonstraram que, em relação aos erros casuais, as medidas lineares apresentaram quase sempre um desvio padrão do erro menor que $1 \mathrm{~mm}$, sendo que a variável Pog-Nperp apresentou o maior valor: 1,4 $\mathrm{mm}$. Já as variáveis angulares apresentaram sempre um valor 
que não ultrapassou $1,5^{\circ}$. Quanto aos erros sistemáticos, observou-se que, para algumas variáveis, houve uma diferença significante entre o primeiro e o segundo traçado: entretanto, apesar de estatisticamente significantes, esses erros foram, de forma geral, pequenos.

Os resultados aqui apresentados comparam-se favoravelmente a outras estimativas de erros técnicos ${ }^{49,89,116,131}$, e indicam que as análises utilizadas são suficientemente confiáveis para permitir a avaliação de diferenças entre os grupos de categorias de crescimento, que poderiam ser de significância para o ortodontista. 
5 RESULTADOS 


\section{RESULTADOS}

\subsection{TESTES DE HIPÓTESES PARA A ANÁLISE DE MODELOS}

Após a medição dos modelos de estudo referentes às fases inicial (I), final (F) e de pós-contenção (PC) dos 100 pacientes, foram determinadas as médias e os desvios padrão para as variáveis índice de Little (IL), distâncias intermolares (6-6), intercaninos (3-3), entre os primeiros pré-molares (4-4), entre os segundos pré-molares (5-5), comprimento do arco (6-1), trespasse horizontal (TH), trespasse vertical (TV), e curva de Spee (CS), cujos resultados se encontram nas Tabelas 5.1 a 5.4 .

Antes de realizar os testes de hipóteses, foi feita uma análise de valores extremos pelo critério multivariado de Mahalanobis. Para realizar essa análise, não foram incluídos os dados da distância entre os primeiros pré-molares (4-4) nos momentos final e de pós-contenção devido ao reduzido número de observações, pois apenas 18 pacientes foram tratados com extrações dos segundos pré-molares inferiores. 
TABELA 5.1 - Médias e desvios padrão para as variáveis da análise de modelos nas fases inicial (I), final (F) e de pós-contenção (PC)

\begin{tabular}{lcccccc} 
Variáveis & \multicolumn{2}{c}{ Início } & \multicolumn{2}{c}{ Fim } & \multicolumn{2}{c}{ Pós-contenção } \\
\hline IL $(n=100)$ & Média & DP & Média & DP & Média & DP \\
$6-6(n=99)$ & 6,56 & 3,85 & 1,45 & 0,77 & 3,38 & 1,84 \\
$3-3(n=100)$ & 43,41 & 2,52 & 40,36 & 2,27 & 40,59 & 2,45 \\
$4-4^{*}$ & 25,98 & 2,25 & 26,72 & 1,44 & 25,55 & 1,71 \\
$5-5^{*}$ & 33,12 & 2,69 & 34,36 & 1,74 & 33,25 & 1,65 \\
$6-1(n=100)$ & 38,5 & 3,21 & 35,66 & 1,96 & 34,87 & 2,13 \\
$T H(n=100)$ & 60,51 & 3,52 & 51,8 & 2,46 & 50,08 & 2,64 \\
$T V(n=100)$ & 7,18 & 3,21 & 2,98 & 0,75 & 3,55 & 1,51 \\
CS $(n=100)$ & 3,88 & 2,15 & 3,03 & 0,75 & 3,61 & 1,34 \\
\hline
\end{tabular}

*Devido ao número variado de pacientes nas fases avaliadas, não foi colocado o valor de $\mathrm{n}$ para essas duas variáveis.

$\mathrm{Na}$ Tabela 5.2, encontram-se as médias das variáveis da análise de modelos separadas de acordo com as categorias de crescimento de PETROVIC, e também segundo o momento estudado, ou seja, início, fim, e pós-contenção.

TABELA 5.2 - Médias e desvios padrão para as variáveis da análise de modelos por categoria de crescimento e momento

\begin{tabular}{|c|c|c|c|c|c|c|c|c|c|c|}
\hline Variáveis & \multicolumn{10}{|c|}{$\begin{array}{c}\text { Categorias de crescimento } \\
\text { Início }\end{array}$} \\
\hline & \multicolumn{2}{|c|}{$1(n=15)$} & \multicolumn{2}{|c|}{$2(n=23)$} & \multicolumn{2}{|c|}{$3(n=27)$} & \multicolumn{2}{|c|}{$4(n=27)$} & \multicolumn{2}{|c|}{$5(n=23)$} \\
\hline & Média & DP & Média & DP & Média & DP & Média & DP & Média & DP \\
\hline IL & 7,82 & 2,61 & 5,77 & 3,84 & 7,05 & 4,68 & 5,8 & 3,41 & 6,34 & 3,7 \\
\hline $6-6$ & 42,37 & 3,46 & 43,81 & 2,32 & 43,07 & 2,34 & 44,45 & 1,72 & 43,5 & 2,46 \\
\hline $3-3$ & 26,17 & 1,7 & 25,73 & 2,51 & 26,06 & 2,08 & 25,82 & 1,67 & 26,08 & 2,88 \\
\hline 4-4 & 32,37 & 3,33 & 33,99 & 2,43 & 33,16 & 2,74 & 32,88 & 2,79 & 32,98 & 2,02 \\
\hline $5-5$ & 37,95 & 3,98 & 39,1 & 4,05 & 38,44 & 2,43 & 38,13 & 3,19 & 38,86 & 2,03 \\
\hline $6-1$ & 58,31 & 3,56 & 61,29 & 3,89 & 61,4 & 3,54 & 60,32 & 3,0 & 60,59 & 3,13 \\
\hline$T H$ & 8,34 & 3,14 & $7,33)$ & 3,47 & 13 & 3,54 & 7,84 & 2,68 & 6,04 & 2,87 \\
\hline$T V$ & 2,95 & 3,82 & 4,65 & 1,66 & 3,48 & 1,83 & 3,96 & 1,78 & 4,09 & 0,95 \\
\hline \multirow[t]{2}{*}{$C S$} & 4,89 & 2,25 & 6,03 & 1,85 & 4,78 & 2,13 & 5,18 & 2,12 & 4,24 & 1,74 \\
\hline & \multicolumn{10}{|c|}{ Fim } \\
\hline IL & 1,77 & 0,59 & 1,32 & 0,86 & 1,46 & 0,83 & 1,26 & 0,5 & 1,45 & 0,85 \\
\hline $6-6$ & 40,31 & 2,82 & 40,44 & 2,27 & 40,33 & 2,02 & 40,24 & 1,96 & 40,45 & 2,52 \\
\hline $3-3$ & 26,96 & 1,82 & 26,56 & 1,2 & 26,92 & 1,67 & 26,31 & 1,08 & 26,75 & 1,34 \\
\hline $4-4$ & 34,1 & 1,61 & 34,82 & 2,16 & 34,54 & 1,87 & 31,68 & 0 & 34,64 & 1,34 \\
\hline $5-5$ & 36,1 & 2,59 & 36,06 & 2,4 & 35,4 & 1,39 & 35,52 & 1,85 & 35,24 & 1,37 \\
\hline $6-1$ & 51,47 & 3,23 & 52,08 & 2,51 & 51,55 & 2,11 & 52,19 & 2,13 & 51,29 & 2,71 \\
\hline$T H$ & 2,93 & 0,69 & 2,71 & 0,5 & 2,96 & 0,83 & 3,31 & 0,78 & 2,87 & 0,81 \\
\hline$T V$ & 2,91 & 0,49 & 3,25 & 0,65 & 2,76 & 0,9 & 3,16 & 0,67 & 2,92 & 0,93 \\
\hline CS & 1,96 & 1,04 & 2,34 & 1,12 & 2,16 & 1,0 & 2,19 & 1,04 & 2,4 & 0,98 \\
\hline
\end{tabular}


continuação da TABELA 5.2

\section{Variáveis}

\section{Categorias de crescimento}

\begin{tabular}{|c|c|c|c|c|c|c|c|c|c|c|}
\hline & \multicolumn{10}{|c|}{ Pós-contenção } \\
\hline & \multicolumn{2}{|c|}{$1(n=15)$} & \multicolumn{2}{|c|}{$2(n=23)$} & \multicolumn{2}{|c|}{$3(n=27)$} & \multicolumn{2}{|c|}{$4(n=27)$} & \multicolumn{2}{|c|}{$5(n=23)$} \\
\hline & Média & DP & Média & DP & Média & DP & Média & DP & Média & DP \\
\hline IL & 3,83 & 2,06 & 3,35 & 1,61 & 3,35 & 1,85 & 2,39 & 1,44 & 3,77 & 2,02 \\
\hline $6-6$ & 39,97 & 3,04 & 40,68 & 2,8 & 40,4 & 2,01 & 41,46 & 2,21 & 40,61 & 2,4 \\
\hline $3-3$ & 25,58 & 2,05 & 25,41 & 1,72 & 25,72 & 1,8 & 25,77 & 1,44 & 25,32 & 1,63 \\
\hline $4-4$ & 32,62 & 1,05 & 33,57 & 1,42 & 33,08 & 2,41 & 33,37 & 0 & 33,99 & 1,39 \\
\hline $5-5$ & 35,11 & 2,97 & 35,44 & 2,33 & 34,71 & 1,8 & 34,35 & 2,0 & 35,12 & 1,48 \\
\hline $6-1$ & 49,56 & 3,45 & 50,37 & 2,32 & 49,85 & 2,55 & 50,26 & 2,56 & 50,12 & 2,69 \\
\hline$T H$ & 3,71 & 2,04 & 3,49 & 1,0 & 3,63 & 1,44 & 3,66 & 1,67 & 3,14 & 1,5 \\
\hline$T V$ & 2,8 & 1,9 & 4,02 & 1,08 & 3,61 & 1,42 & 3,78 & 1,12 & 3,45 & 1,07 \\
\hline CS & 2,48 & 0,99 & 3,17 & 1,04 & 2,97 & 1,22 & 2,39 & 0,94 & 2,96 & 0,71 \\
\hline
\end{tabular}

Na Tabela 5.3, encontram-se as médias das alterações do tratamento (F I), pós-tratamento $(P C-F)$ e totais $(P C-I)$ para as variáveis da análise de modelos nas diferentes categorias de crescimento.

TABELA 5.3 - Alterações do tratamento ( $F$ - I), pós-tratamento (PC - F) e totais (PC - I) para as variáveis da análise de modelos nas diferentes categorias de crescimento

\begin{tabular}{|c|c|c|c|c|c|}
\hline \multirow[t]{3}{*}{ Variáveis } & \multicolumn{5}{|c|}{ categorias de crescimento } \\
\hline & \multicolumn{5}{|c|}{ Alterações do tratamento } \\
\hline & $1(n=15)$ & $2(n=23)$ & $3(n=27)$ & $4(n=27)$ & $5(n=23)$ \\
\hline & Média & Média & Média & Média & Média \\
\hline IL & $-6,05$ & $-4,45$ & $-5,59$ & $-4,54$ & $-4,89$ \\
\hline 6-6 & $-2,06$ & $-3,37$ & $-2,74$ & $-4,21$ & $-3,05$ \\
\hline 3-3 & 0,79 & 0,83 & 0,86 & 0,49 & 0,67 \\
\hline 4-4 & 1,73 & 0,83 & 1,38 & $-1,2$ & 1,66 \\
\hline $5-5$ & $-1,85$ & $-3,04$ & $-3,04$ & $-2,61$ & $-3,62$ \\
\hline 6-1 & $-6,84$ & $-9,21$ & $-9,85$ & $-8,13$ & $-9,3$ \\
\hline$T H$ & $-5,41$ & $-4,62$ & $-10,04$ & $-4,53$ & $-3,17$ \\
\hline$T V$ & $-0,04$ & $-1,4$ & $-0,72$ & $-0,8$ & $-1,17$ \\
\hline \multirow[t]{2}{*}{ CS } & $-2,93$ & $-3,69$ & $-2,62$ & $-2,99$ & $-1,84$ \\
\hline & \multicolumn{5}{|c|}{ Alterações pós-tratamento } \\
\hline IL & 2,06 & 2,03 & 1,89 & 1,13 & 2,32 \\
\hline 6-6 & $-0,34$ & 0,24 & 0,07 & 1,22 & 0,16 \\
\hline 3-3 & $-1,38$ & $-1,15$ & $-1,2$ & $-0,54$ & $-1,43$ \\
\hline 4-4 & $-1,48$ & $-1,25$ & $-1,46$ & 1,69 & $-0,65$ \\
\hline $5-5$ & $-0,99$ & $-0,62$ & $-0,69$ & $-1,17$ & $-0,12$ \\
\hline 6-1 & $-1,91$ & $-1,71$ & $-1,7$ & $-1,93$ & $-1,17$ \\
\hline$T H$ & 0,78 & 0,78 & 0,67 & 0,35 & 0,27 \\
\hline$T V$ & $-0,11$ & 0,77 & 0,85 & 0,62 & 0,53 \\
\hline$c S$ & 0,52 & 0,83 & 0,81 & 0,2 & 0,56 \\
\hline
\end{tabular}


continuação da TABELA 5.3

\begin{tabular}{lccccc} 
Variáveis & \multicolumn{5}{c}{ categorias de crescimento } \\
\hline & $\mathbf{5}(\mathrm{n}=15)$ & $\mathbf{2}(\mathrm{n}=23)$ & $\mathbf{3}(\mathrm{n}=27)$ & $\mathbf{4}(\mathrm{n}=\mathbf{2 7})$ & $\mathbf{5 ( n = 2 3 )}$ \\
& Média & Média & Média & Média & Média \\
$\mathbf{I L}$ & $-3,99$ & $-2,42$ & $-3,7$ & $-3,41$ & $-2,57$ \\
$\mathbf{6 - 6}$ & $-2,4$ & $-3,13$ & $-2,67$ & $-2,99$ & $-2,89$ \\
$\mathbf{3 - 3}$ & $-0,59$ & $-0,32$ & $-0,34$ & $-0,05$ & $-0,76$ \\
$\mathbf{4 - 4}$ & 0,25 & $-0,42$ & $-0,08$ & 0,49 & 1,01 \\
$\mathbf{5 - 5}$ & $-2,84$ & $-3,66$ & $-3,73$ & $-3,78$ & $-3,74$ \\
$\mathbf{6 - 1}$ & $-8,75$ & $-10,92$ & $-11,55$ & $-10,06$ & $-10,47$ \\
$\mathbf{T H}$ & $-4,63$ & $-3,84$ & $-9,37$ & $-4,18$ & $-2,9$ \\
$\mathbf{T V}$ & $-0,15$ & $-0,63$ & 0,13 & $-0,18$ & $-0,64$ \\
$\mathbf{C S}$ & $-2,41$ & $-2,86$ & $-1,81$ & $-2,79$ & $-1,28$ \\
\hline
\end{tabular}

Na Tabela 5.4 encontram-se os resultados dos testes de hipóteses para as comparações entre as categorias, juntamente com o nível de significância.

TABELA 5.4 - Testes de hipóteses para avaliar as variáveis da análise de modelos nas fases inicial, final e de pós-contenção por categoria de crescimento

\begin{tabular}{|c|c|c|c|c|c|c|}
\hline Variáveis & categorias & Momentos & categorias $\mathrm{x}$ Momentos & $I X F$ & $I \times P C$ & $F \times P C$ \\
\hline IL & 0,1253 & 0,0001 & 0,8036 & 0,0001 & 0,0001 & 0,0001 \\
\hline $6-6$ & 0,6756 & 0,0001 & 0,1509 & 0,0001 & 0,0001 & 0,1483 \\
\hline 3-3 & 0,9462 & 0,0001 & 0,8998 & 0,0001 & 0,0187 & 0,0001 \\
\hline 4-4 & 0,4392 & 0,0452 & 0,5346 & 0,0137 & 0,2272 & 0,1896 \\
\hline $5-5$ & 0,7943 & 0,0001 & 0,8506 & 0,0001 & 0,0001 & 0,0126 \\
\hline 6-1 & 0,5077 & 0,0001 & 0,0113 & 0,0001 & 0,0001 & 0,0001 \\
\hline$T H$ & 0,1710 & 0,0001 & 0,1390 & 0,0001 & 0,0001 & 0,0378 \\
\hline$T V$ & 0,0416 & 0,0001 & 0,4673 & 0,0001 & 0,1151 & 0,0045 \\
\hline CS & 0,0642 & 0,0001 & 0,1523 & 0,0001 & 0,0001 & 0,0050 \\
\hline
\end{tabular}

Os resultados apresentados nas Tabelas 5.2, 5.3 e 5.4 demonstram que, em geral, para todas as variáveis, o comportamento dos grupos foi parecido ao longo do tempo: não houve diferenças significativas entre as categorias (exceção da variável trespasse vertical, $p<0,05)$, nem houve interação categoria $X$ momento (exceção da variável 6-1, p < 0,05, Figura 5.1). 


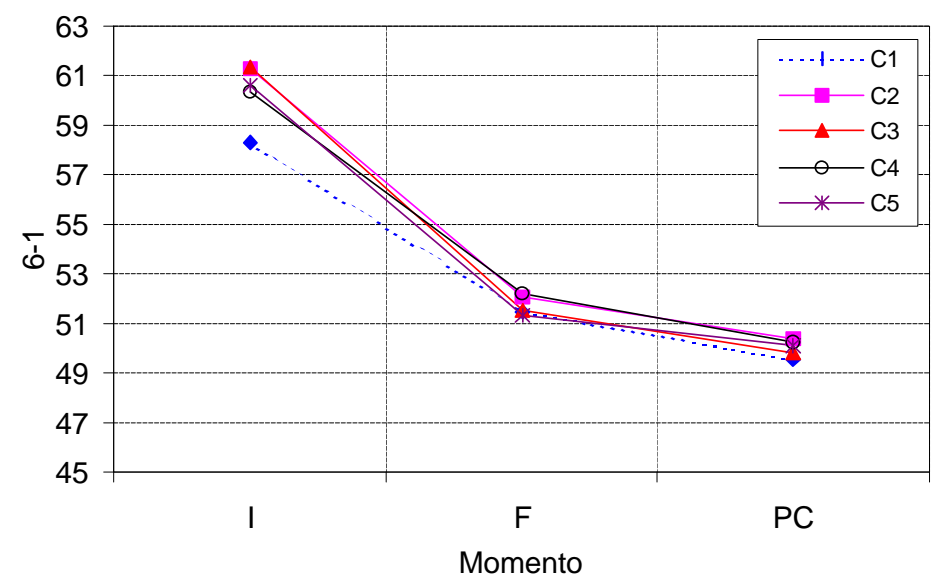

FIGURA 5.1 - Comportamento das categorias ao longo do tempo para a variável comprimento do arco (6-1)

Para a variável TV, como não houve interação categoria X momento (ou seja, as categorias apresentaram perfis médios paralelos ao longo do tempo), foram feitos contrastes entre as categorias utilizando-se as médias para todos os momentos. Os níveis descritivos estão na Tabela 5.5, onde se observa que houve diferenças significativas entre a categoria 1 e as categorias $2(p<0.05)$ e $3(p<$ $0.01)$, e entre as categorias 3 e 4 ( $p<0.05)$, ou seja, a categoria 1 recidivou menos que a 2 e a 3 , e a categoria 3 recidivou mais que a 4 .

TABELA 5.5 - Níveis descritivos para a variável trespasse vertical após a comparação entre as categorias de crescimento

\begin{tabular}{c|cccc} 
Categorias & $\mathbf{2}$ & $\mathbf{3}$ & $\mathbf{4}$ & $\mathbf{5}$ \\
\hline $\mathbf{1}$ & $\mathbf{0 , 0 3 8 3}$ & $\mathbf{0 , 0 0 3 3}$ & 0,2699 & 0,1865 \\
$\mathbf{2}$ & & 0,2827 & 0,2752 & 0,5968 \\
$\mathbf{3}$ & & & $\mathbf{0 , 0 3 6 1}$ & 0,1433 \\
$\mathbf{4}$ & & & & 0,6802 \\
\hline
\end{tabular}

A comparação entre momentos nas Tabelas 5.2, 5.3 e 5.4 apresentou resultados significativos para todas as variáveis. Os resultados da variável 4-4 devem ser considerados exploratórios, já que o número de observações nos momentos final e de pós-contenção foi baixo. Como em geral não houve 
interação categoria $\mathrm{X}$ momento, o comportamento das variáveis pode ser avaliado fazendo-se a média de todas as categorias em conjunto (Tabela 5.4). As variáveis IL, 3-3, 5-5, 6-1, TH e CS apresentaram diferenças significativas entre os momentos I x F, I x PC e F x PC. A variável 6-6 apresentou diferenças significativas entre o início e os momentos final e de pós-contenção, mas não entre os momentos final e de pós-contenção. A variável TV apresentou diferenças significativas entre os momentos I x F e F x PC, mas não entre os momentos I x PC. Os resultados da variável 4-4 devem ser considerados exploratórios.

Apesar de não ter havido diferenças significantes entre as 5 categorias de crescimento para os valores do índice de Little, cuja distribuição pode ser observada nas Figuras de 5.2 a 5.4, a Tabela 5.3 demonstra que os pacientes da categoria 4 apresentaram apenas $1,13 \mathrm{~mm}$ de recidiva na irregularidade dos incisivos inferiores, e as outras categorias não apresentaram alterações superiores a $2 \mathrm{~mm}$. A Figura 5.5 e a Tabela 5.6 demonstram que a grande maioria $(78,57 \%)$ dos pacientes da categoria 4 apresentaram um valor para o IL menor que 3,5 mm, o que é considerado por LITTLE ${ }^{44,109}$ um resultado satisfatório no período pós-tratamento. Entretanto, ao se avaliar a amostra total, observa-se que $41 \%$ dos pacientes apresentaram um valor insatisfatório para o IL 10 anos após tratamento. Os pacientes da categoria 4 também apresentaram a menor expansão da distância intercaninos durante o tratamento $(0,49 \mathrm{~mm})$ e a menor recidiva pós-tratamento $(-0,54)$, que, entretanto, não foram estatisticamente significantes. 


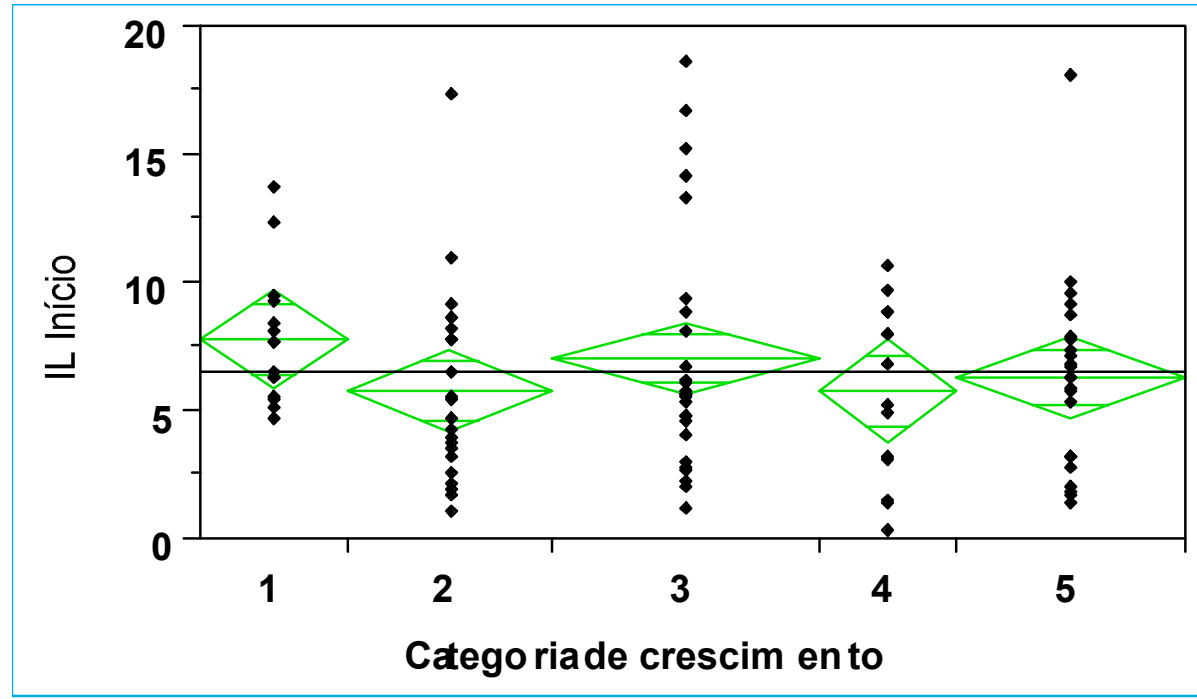

FIGURA 5.2 - Distribuição dos valores individuais do índice de Little por categoria no período inicial

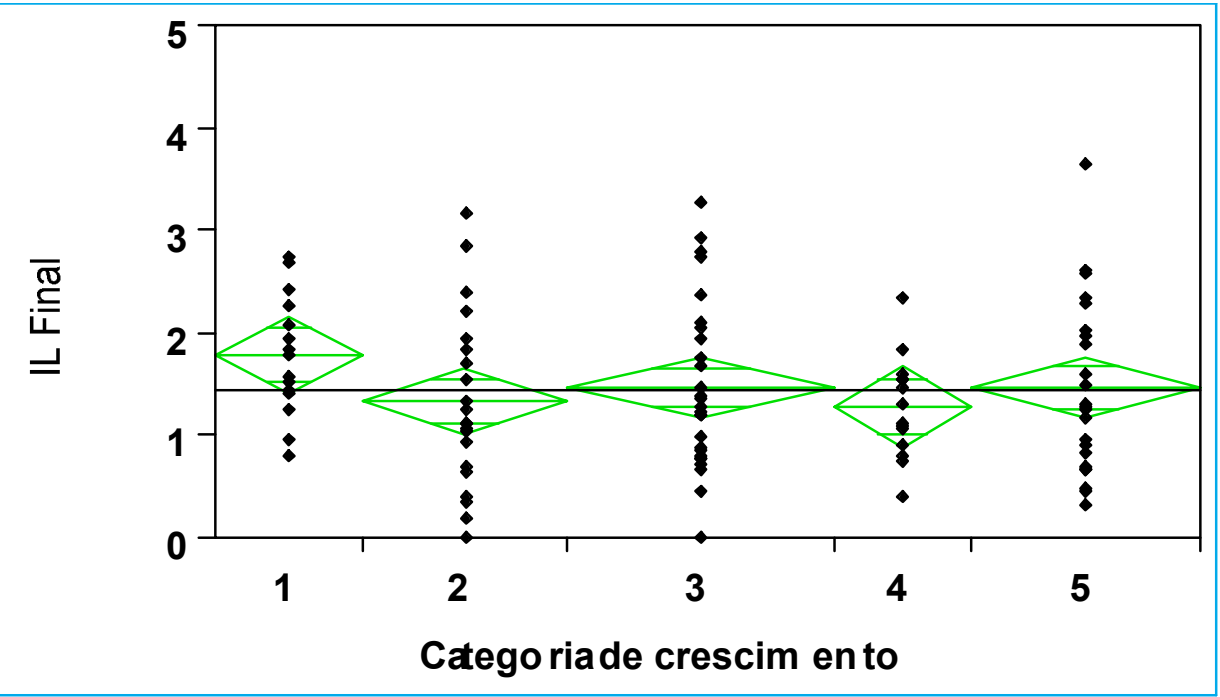

FIGURA 5.3 - Distribuição dos valores individuais do índice de Little por categoria no período final 


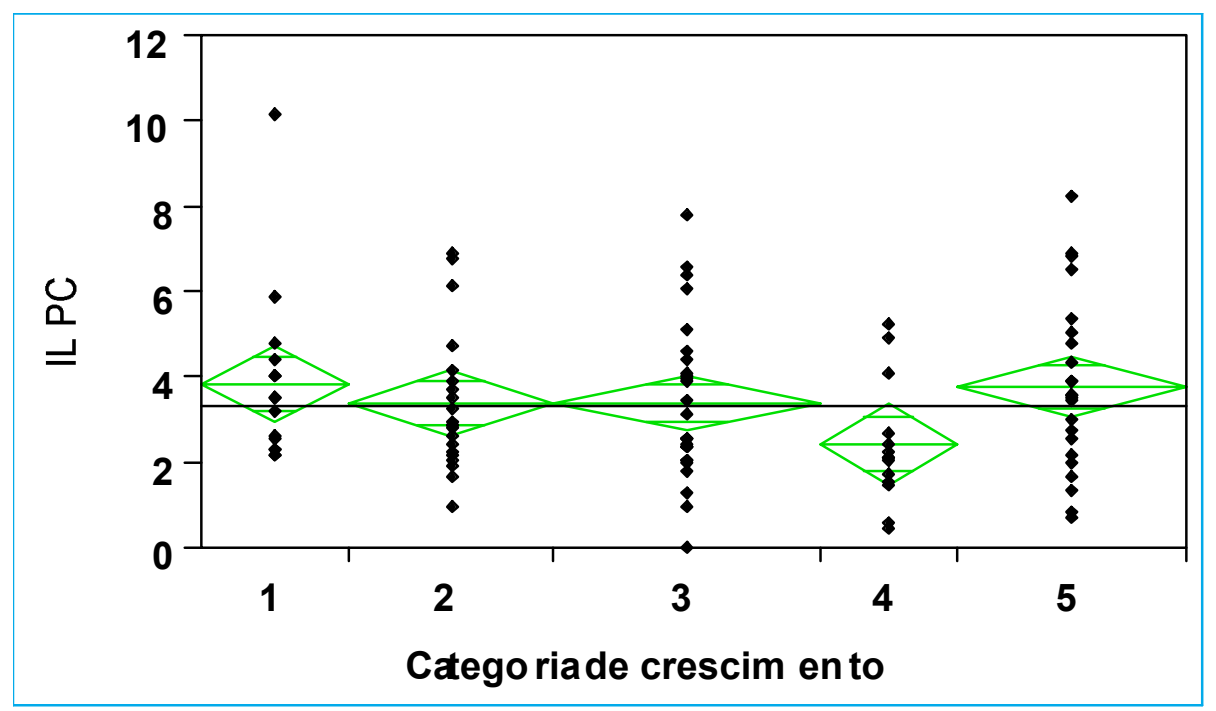

FIGURA 5.4 - Distribuição dos valores individuais do índice de Little por categoria no período de pós-contenção

TABELA 5.6 - Distribuição dos pacientes por categoria de crescimento no período de pós-contenção, segundo valor para o índice de Little menor ou maior que 3,5 $\mathrm{mm}$

\begin{tabular}{cccccc} 
& \multicolumn{3}{c}{$<3,5 \mathbf{~ m m}$} & $>3,5$ & $\mathbf{m m}$ \\
\hline Categorias & $\%$ & $\mathbf{n}$ & $\%$ & $\mathbf{n}$ & Total \\
$\mathbf{1}$ & 53,33 & 8 & 46,67 & 7 & 15 \\
$\mathbf{2}$ & 61,9 & 13 & 38,1 & 8 & 21 \\
$\mathbf{3}$ & 59,26 & 16 & 40,74 & 11 & 27 \\
$\mathbf{4}$ & 78,57 & 11 & 21,43 & 3 & 14 \\
$\mathbf{5}$ & 47,83 & 11 & 52,17 & 12 & 23 \\
Total & & 59 & & 41 & 100 \\
\hline
\end{tabular}




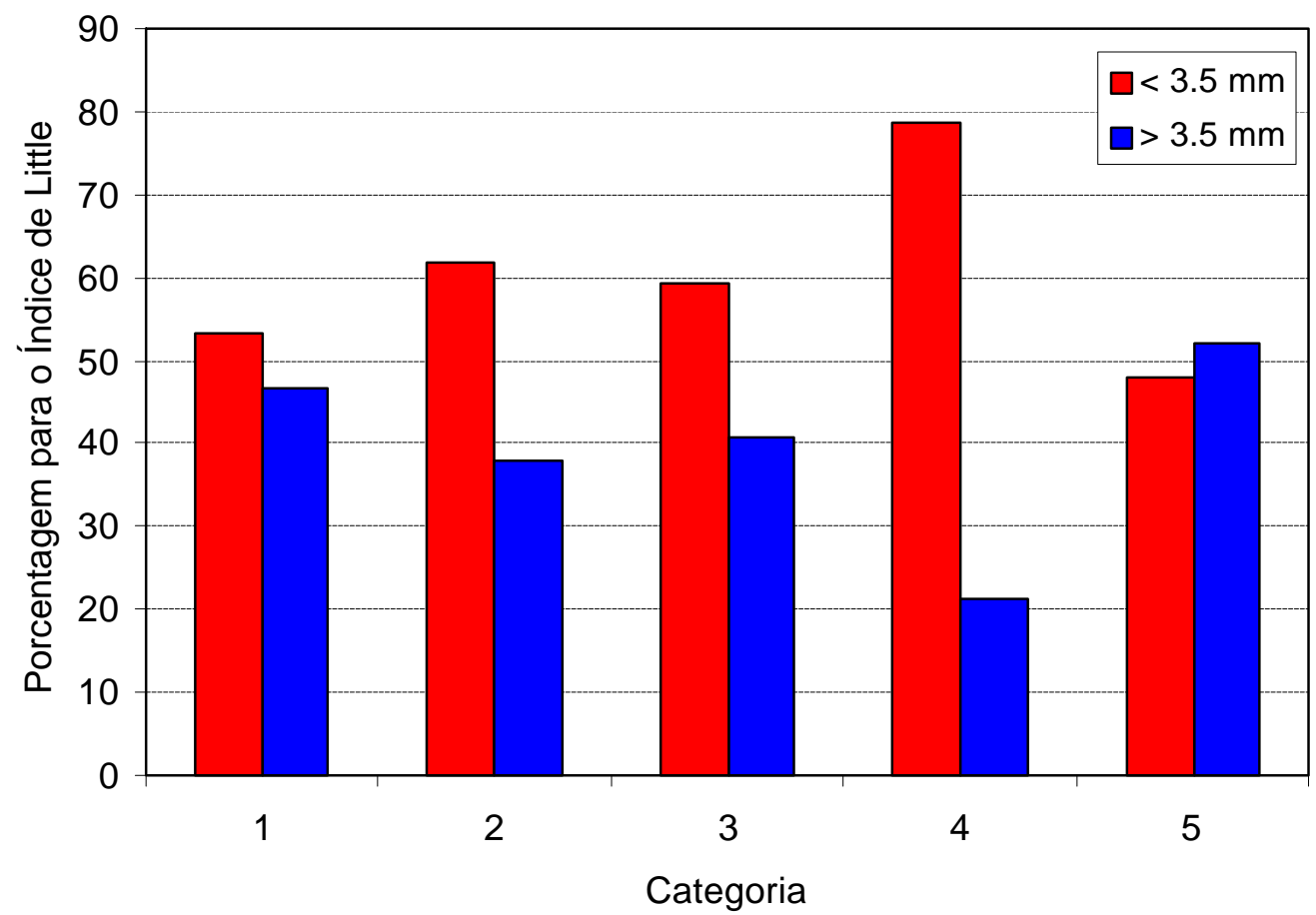

FIGURA 5.5 - Gráfico das porcentagens do índice de Little (maior ou menor que $3,5 \mathrm{~mm}$ ) por categoria de crescimento no período de pós-contenção

Além da classificação em categorias de crescimento, os 100 pacientes foram divididos em três grupos de acordo com o tipo de rotação (inclinação) mandibular, ou seja, posterior $(P)$, neutra $(N)$ e anterior $(A)$. Nas Tabelas 5.7, 5.8 e 5.9 são apresentados os resultados para as comparações entre os tipos de rotação mandibular e as varáveis da análise de modelos. 
Tabela 5.7 - Médias e desvios padrão para as variáveis da análise de modelos por rotação mandibular e momento

\begin{tabular}{|c|c|c|c|c|c|c|}
\hline \multirow[t]{3}{*}{ Variáveis } & \multicolumn{6}{|c|}{ Rotações Mandibulares } \\
\hline & \multicolumn{6}{|c|}{ Início } \\
\hline & \multicolumn{2}{|c|}{ Posterior $(n=29)$} & \multicolumn{2}{|c|}{ Anterior $(n=30)$} & \multicolumn{2}{|c|}{ Neutra $(n=41)$} \\
\hline & Média & DP & Média & DP & Média & DP \\
\hline IL & 7,05 & 3,64 & 5,99 & 3,44 & 6,62 & 4,29 \\
\hline $6-6$ & 42,92 & 3,06 & 43,72 & 2,31 & 43,54 & 2,22 \\
\hline $3-3$ & 25,93 & 2,24 & 26,03 & 2,7 & 25,98 & 1,93 \\
\hline 4-4 & 32,42 & 3,06 & 34,12 & 2,31 & 32,92 & 2,53 \\
\hline $5-5$ & 38,08 & 3,23 & 39,04 & 3,69 & 38,39 & 2,83 \\
\hline $6-1$ & 59,29 & 3,61 & 61,81 & 3,73 & 60,41 & 3,01 \\
\hline$T H$ & 6,44 & 3,4 & 7,85 & 3,45 & 7,22 & 2,84 \\
\hline$T V$ & 2,85 & 2,94 & 4,72 & 1,55 & 4,0 & 1,53 \\
\hline \multirow[t]{2}{*}{ CS } & 4,71 & 2,17 & 5,86 & 1,9 & 4,86 & 2,03 \\
\hline & \multicolumn{6}{|c|}{ Fim } \\
\hline IL & 1,54 & 0,78 & 1,43 & 0,83 & 1,39 & 0,73 \\
\hline $6-6$ & 40,13 & 2,59 & 40,69 & 2,35 & 40,30 & 1,98 \\
\hline $3-3$ & 26,66 & 1,54 & 26,80 & 1,3 & 26,71 & 1,51 \\
\hline $4-4$ & 34,13 & 1,85 & 34,86 & 1,73 & 33,90 & 1,84 \\
\hline $5-5$ & 35,59 & 2,0 & 36,10 & 2,29 & 35,44 & 1,71 \\
\hline $6-1$ & 51,36 & 2,84 & 52,10 & 2,23 & 51,88 & 2,35 \\
\hline$T H$ & 2,87 & 0,71 & 2,84 & 0,65 & 3,16 & 0,81 \\
\hline$T V$ & 2,73 & 0,76 & 3,24 & 0,64 & 3,08 & 0,77 \\
\hline \multirow[t]{2}{*}{ CS } & 2,13 & 1,04 & 2,23 & 1,08 & 2,26 & 1,01 \\
\hline & \multicolumn{6}{|c|}{ Pós-Contenção } \\
\hline IL & 3,59 & 1,86 & 3,68 & 1,92 & 3,02 & 1,76 \\
\hline $6-6$ & 40,18 & 3,08 & 40,77 & 2,22 & 40,76 & 2,11 \\
\hline $3-3$ & 25,50 & 1,95 & 25,34 & 1,56 & 25,74 & 1,66 \\
\hline 4-4 & 32,32 & 1,94 & 33,86 & 1,24 & 33,83 & 1,18 \\
\hline $5-5$ & 34,77 & 2,38 & 35,45 & 2,25 & 34,57 & 1,87 \\
\hline $6-1$ & 49,39 & 3,02 & 50,55 & 2,25 & 50,21 & 2,57 \\
\hline$T H$ & 3,38 & 1,65 & 3,80 & 1,23 & 3,48 & 1,61 \\
\hline$T V$ & 2,93 & 1,56 & 4,18 & 1,14 & 3,67 & 1,1 \\
\hline CS & 2,64 & 1,02 & 3,20 & 1,14 & 2,58 & 0,9 \\
\hline
\end{tabular}


TABELA 5.8 - Alterações do tratamento $(F-I)$, pós-tratamento $(P C-F)$ e totais $(P C-I)$, para as variáveis da análise de modelos nos diferentes grupos de rotações mandibulares

Variáveis Rotações Mandibulares

\begin{tabular}{|c|c|c|}
\hline \multicolumn{3}{|c|}{ Alterações do tratamento } \\
\hline $\begin{array}{c}\text { Posterior } \\
(n=29)\end{array}$ & $\begin{array}{c}\text { Anterior } \\
(n=30)\end{array}$ & $\begin{array}{l}\text { Neutra } \\
(n=41)\end{array}$ \\
\hline Média & Média & Média \\
\hline$-5,51$ & $-4,56$ & $-5,23$ \\
\hline$-2,79$ & $-3,03$ & $-3,24$ \\
\hline 0,73 & 0,77 & 0,73 \\
\hline 1,71 & 0,74 & 0,98 \\
\hline$-2,49$ & $-2,94$ & $-2,95$ \\
\hline$-7,93$ & $-9,71$ & $-8,53$ \\
\hline$-3,57$ & $-5,01$ & $-4,06$ \\
\hline$-0,12$ & $-1,48$ & $-0,92$ \\
\hline$-2,58$ & $-3,63$ & $-2,6$ \\
\hline
\end{tabular}

CS

Alterações pós-tratamento

\begin{tabular}{lccc} 
IL & 2,05 & 2,25 & 1,63 \\
$\mathbf{6 - 6}$ & 0,05 & 0,08 & 0,46 \\
$\mathbf{3 - 3}$ & $-1,16$ & $-1,46$ & $-0,97$ \\
$\mathbf{4 - 4}$ & $-1,81$ & -1 & $-0,07$ \\
$\mathbf{5 - 5}$ & $-0,82$ & $-0,65$ & $-0,87$ \\
$\mathbf{6 - 1}$ & $-1,97$ & $-1,55$ & $-1,67$ \\
$\mathbf{T H}$ & 0,51 & 0,96 & 0,32 \\
TV & 0,2 & 0,94 & 0,59 \\
$\mathbf{C S}$ & 0,51 & 0,97 & 0,32 \\
& Alterações totais \\
IL & $-3,46$ & $-2,31$ & $-3,6$ \\
$\mathbf{6 - 6}$ & $-2,74$ & $-2,95$ & $-2,78$ \\
$\mathbf{3 - 3}$ & $-0,43$ & $-0,69$ & $-0,24$ \\
$\mathbf{4 - 4}$ & $-0,1$ & $-0,26$ & 0,91 \\
$\mathbf{5 - 5}$ & $-3,31$ & $-3,59$ & $-3,82$ \\
$\mathbf{6 - 1}$ & $-9,9$ & $-11,26$ & $-10,2$ \\
TH & $-3,06$ & $-4,05$ & $-3,74$ \\
TV & 0,08 & $-0,54$ & $-0,33$ \\
$\mathbf{C S}$ & $-2,07$ & $-2,66$ & $-2,28$ \\
\hline
\end{tabular}


Tabela 5.9 - Testes de hipóteses para avaliar as variáveis da análise de modelos nas fases inicial, final e de pós-contenção por grupo de rotação mandibular

\begin{tabular}{|c|c|c|c|c|c|c|}
\hline Variáveis & Rotações & Momentos & $\begin{array}{l}\text { Rotações X } \\
\text { Momentos }\end{array}$ & $I \times F$ & $I \times P C$ & $F \times P C$ \\
\hline IL & 0,5172 & 0,0001 & 0,5795 & 0,0001 & 0,0001 & 0,0001 \\
\hline $6-6$ & 0,5082 & 0,0001 & 0,9036 & 0,0001 & 0,0001 & 0,2734 \\
\hline 3-3 & 0,9529 & 0,0001 & 0,7653 & 0,0001 & 0,0083 & 0,0001 \\
\hline $4-4$ & 0,1302 & 0,0057 & 0,5499 & 0,0017 & 0,3127 & 0,0273 \\
\hline 5-5 & 0,3994 & 0,0001 & 0,9235 & 0,0001 & 0,0001 & 0,0056 \\
\hline 6-1 & 0,0789 & 0,0001 & 0,0629 & 0,0001 & 0,0001 & 0,0001 \\
\hline$T H$ & 0,2610 & 0,0001 & 0,2694 & 0,0001 & 0,0001 & 0,0274 \\
\hline$T V$ & 0,0001 & 0,0001 & 0,0714 & 0,0001 & 0,1389 & 0,0016 \\
\hline CS & 0,0142 & 0,0001 & 0,2123 & 0,0001 & 0,0001 & 0,0034 \\
\hline
\end{tabular}

Os resultados apresentados nas Tabelas 5.7, 5.8 e 5.9 demonstram que as únicas variáveis que apresentaram diferenças entre os grupos foram o trespasse vertical (TV) $(p<0,01)$ e a curva de Spee (CS) $(p<0,05)$.

Nas Figuras 5.6 e 5.7 encontram-se os gráficos do trespasse vertical (TV) e da curva de Spee (CS) por tipo de rotação mandibular e momento. Note-se que o comportamento dos grupos para a variável TV apresentou certas diferenças ao longo do tempo, mas a interação não chegou a ser significativa $(p>0,05)$. Ao se realizar contrastes entre os grupos para a variável TV, foram encontradas diferenças significativas entre os grupos posterior $X$ anterior $(p=0,0001)$ e posterior $X$ neutra $(p=0,0036)$, mas não entre os grupos anterior $X$ neutra $(0,0623)$. Ao se realizar comparações entre os grupos para a variável CS, foram encontradas diferenças entre os grupos posterior $x$ anterior $(p=0,0087)$, anterior $x$ neutra $(p=0,0128)$, mas não entre os grupos posterior $x$ neutra $(p=0,7162)$.

Os testes entre momentos foram semelhantes aos obtidos na Tabela 5.4, já que estes testes foram realizados com a média entre os grupos. 


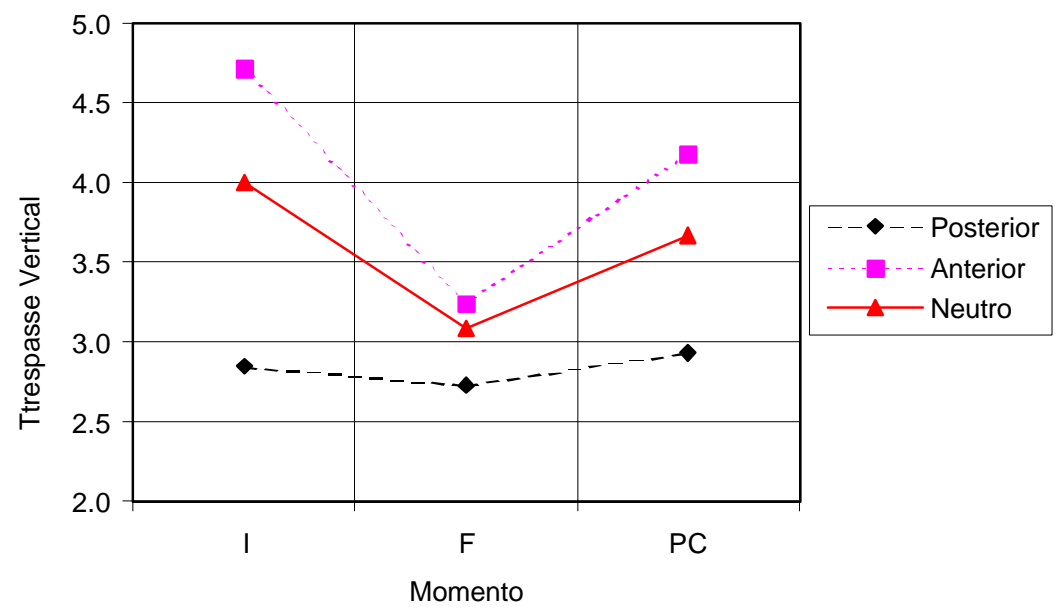

FIGURA 5.6 - Comportamento dos grupos com diferentes rotações mandibulares ao longo do tempo para a variável trespasse vertical

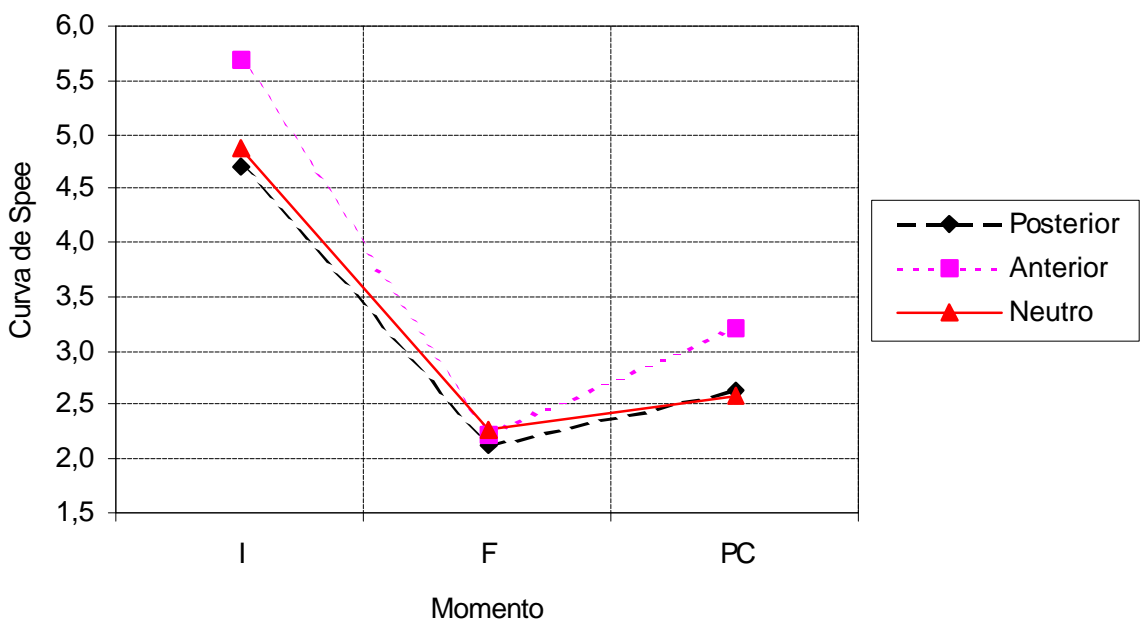

FIGURA 5.7 - Comportamento dos grupos com diferentes rotações mandibulares ao longo do tempo para a variável curva de Spee

Para se estudar a relação da recidiva pós-tratamento ortodôntico com a dimensão vertical do paciente, sem levar em conta a categoria de crescimento, nem a rotação mandibular, os 100 pacientes foram divididos de acordo com a sua mordida em: aberta (OB), profunda (DB) e normal (N). 
Nas Tabelas 5.10 e 5.11 são apresentados os resultados das comparações entre os tipos de mordida e as varáveis índice de Little (IL), distância intercaninos (3-3) e trespasse vertical (TV).

TABELA 5.10 - Médias e desvios padrão para as variáveis da análise de modelos por tipos de mordida ( $\mathrm{OB}=$ aberta; $\mathrm{DB}=$ profunda; $\mathrm{N}=$ normal) e momento

\begin{tabular}{|c|c|c|c|c|c|c|}
\hline \multirow{3}{*}{ Variáveis } & \multicolumn{6}{|c|}{ Mordidas } \\
\hline & \multicolumn{6}{|c|}{ Início } \\
\hline & Média & DP & Média & DP & Média & DP \\
\hline IL & 6,22 & 3,65 & 5,78 & 4,23 & 7,75 & 3,69 \\
\hline $3-3$ & 26,40 & 2,03 & 25,68 & 2,13 & 25,53 & 2,61 \\
\hline \multirow[t]{2}{*}{$T V$} & 3,55 & 2,72 & 4,5 & 1,08 & 3,91 & 1,64 \\
\hline & \multicolumn{6}{|c|}{ Final } \\
\hline IL & 1,42 & 0,79 & 1,50 & 0,77 & 1,44 & 0,77 \\
\hline $3-3$ & 26,89 & 1,51 & 26,42 & 1,07 & 26,70 & 1,61 \\
\hline \multirow[t]{2}{*}{$T V$} & 3,04 & 0,7 & 3,19 & 0,64 & 2,88 & 0,89 \\
\hline & \multicolumn{6}{|c|}{ Pós-contenção } \\
\hline IL & 3,23 & 1,85 & 3,30 & 1,89 & 3,70 & 1,83 \\
\hline $3-3$ & 25,85 & 1,71 & 25,02 & 1,41 & 25,50 & 1,88 \\
\hline$T V$ & 3,24 & 1,33 & 4,40 & 1,0 & 3,54 & 1,36 \\
\hline
\end{tabular}

TABELA 5.11 - Testes de hipóteses para avaliar as variáveis da análise de modelos nas fases inicial, final e de pós-contenção por tipo de mordida

\begin{tabular}{lllcrrr} 
Variáveis & Mordidas & Momentos & Mordidas $\mathbf{x}$ Momentos & I x F & I x PC & F x PC \\
\hline IL & 0,0889 & 0,0001 & 0,2332 & 0,0001 & 0,0001 & 0,0001 \\
3-3 & 0,176 & 0,0001 & 0,3929 & 0,0001 & 0,0168 & 0,0001 \\
TV & 0,0254 & 0,0001 & 0,1956 & 0,0001 & 0,1616 & 0,0002 \\
\hline
\end{tabular}

Os resultados apresentados nas Tabelas 5.10 e 5.11 mostram que somente foram encontradas diferenças entre os grupos de mordida para a variável trespasse vertical $(p<0,05)$. Os contrastes mostraram diferenças entre os grupos $O B \times D B(p=0,0073)$, mas não entre os grupos $O B \times N(p=0,5195)$, nem entre os grupos DB $\times \mathrm{N}(p=0,0557)$. Não foram encontradas interações entre mordida $\mathrm{X}$ momento. As conclusões dos testes entre os momentos foram parecidas com as observadas nas Tabelas 5.4 e 5.9 . 


\subsubsection{Correlações para a análise de modelos}

Para avaliar a recidiva, também foram realizadas correlações entre as diferenças do índice de Little (IL pós-contenção - IL final) e as diferenças das distâncias intercaninos (3-3 final - 3-3 inicial) e entre os segundos pré-molares (5-5 final - 5-5 inicial). Os resultados estão na Tabela 5.12, para todos os pacientes da amostra, e para os grupos de rotações mandibulares anterior (A), posterior $(P)$ e neutra $(R)$.

TABELA 5.12 - Correlação entre as diferenças do índice de Little (IL póscontenção - IL final) e as diferenças das distâncias intercaninos (3-3 Final - 3-3 Inicial) e entre pré-molares (5-5 Final - 5-5 Inicial)

\begin{tabular}{cccc} 
Grupos & Variáveis & $\boldsymbol{r}$ & $\boldsymbol{p}$ \\
\hline amostra total & $\mathbf{3 - 3}$ & 0.0493 & 0.6263 \\
amostra total & $\mathbf{5 - 5}$ & 0.1245 & 0.2808 \\
& & & \\
$\boldsymbol{A}$ & & 0.3704 & 0.0439 \\
$\boldsymbol{P}$ & $\mathbf{3 - 3}$ & -0.2388 & 0.2122 \\
$\boldsymbol{R}$ & & -0.0637 & 0.6924 \\
& & & \\
$\boldsymbol{A}$ & & 0.1900 & 0.3971 \\
$\boldsymbol{P}$ & $\mathbf{5 - 5}$ & 0.4261 & 0.0541 \\
$\boldsymbol{R}$ & & -0.1849 & 0.2951 \\
\hline
\end{tabular}

Em geral, os coeficientes de correlação foram baixos e não significantes. Para os pacientes com rotação anterior, o aumento no índice Little no período pós-tratamento está correlacionado com o aumento da distância 3-3 durante o tratamento. Entretanto, essa correlação explica apenas 14\% da variância do Índice de Little. 


\subsection{TESTES DE HIPÓTESES PARA A ANÁLISE DE JOHNSTON JÚNIOR}

Após a sobreposição e a medição das telerradiografias iniciais, finais e de pós-contenção dos pacientes pertencentes às 5 categorias de crescimento de PETROVIC, foram obtidas as médias e desvios padrão das variáveis da análise de JOHNSTON JÚNIOR: maxila (Max.-BC); mandíbula (Mand); alteração da base apical (ABA); molar superior (6s); molar inferior (6i), correção molar (6-6); correção incisal (1-1); rotações maxilar e mandibular, que estão descritas na Tabela 5.13 e nas Figuras 5.8 a 5.12.

A partir das variáveis acima, foram feitos testes entre as 5 categorias de crescimento e entre os grupos de rotação mandibular: posterior $(P)$, anterior $(A)$ e neutra $(\mathrm{N})$. Em todas as análises a variável EGU (unidade de crescimento esperado) foi utilizada como covariada.

Na Tabela 5.13 encontram-se as médias e os desvios padrão das variáveis acima descritas por categoria, avaliadas no período de tratamento (momento inicial $X$ final), e na Tabela 5.14 encontram-se os testes de hipóteses relacionados com essas variáveis. 
TABELA 5.13 - Médias e desvios padrão para as variáveis da análise de JOHNSTON JÚNIOR avaliadas entre as fases inicial $X$ final, por categoria de crescimento

\begin{tabular}{|c|c|c|c|c|c|c|c|c|c|c|}
\hline \multirow[t]{2}{*}{ Variáveis } & \multicolumn{10}{|c|}{ Categorias } \\
\hline & \multicolumn{2}{|c|}{$1(n=15)$} & \multicolumn{2}{|c|}{$2(n=21)$} & \multicolumn{2}{|c|}{$3(n=27)$} & \multicolumn{2}{|c|}{$4(n=14)$} & \multicolumn{2}{|c|}{$5(n=23)$} \\
\hline Esqueléticas & Média & DP & Média & DP & Média & DP & Média & DP & Média & DP \\
\hline Max.-BC & $-1,78$ & 1,01 & $-1,26$ & 1,11 & $-1,70$ & 1,28 & $-1,37$ & 0,8 & $-1,71$ & 1,27 \\
\hline Mand & 4,91 & 2,68 & 3,46 & 2,85 & 5,56 & 3,28 & 4,70 & 2,27 & 5,37 & 3,57 \\
\hline$A B A$ & 3,13 & 2,49 & 2,20 & 2,32 & 3,82 & 2,53 & 3,33 & 2,13 & 3,66 & 2,64 \\
\hline \multicolumn{11}{|l|}{ Dentárias } \\
\hline $6 s$ & $-2,21$ & 2,06 & $-1,03$ & 1,99 & $-1,92$ & 1,65 & $-1,0$ & 1,89 & $-1,48$ & 2,07 \\
\hline $6 i$ & 2,43 & 2,08 & 2,30 & 2,61 & 1,44 & 1,74 & 1,54 & 2,65 & 1,65 & 2,41 \\
\hline $1 s$ & 4,96 & 2,52 & 3,75 & 3,36 & 4,45 & 2,88 & 3,05 & 3,6 & 4,26 & 3,67 \\
\hline $1 i$ & $-2,91$ & 2,2 & $-3,61$ & 3,3 & $-3,87$ & 2,44 & $-3,10$ & 1,72 & $-3,7$ & 2,06 \\
\hline \multicolumn{11}{|l|}{ Correções } \\
\hline Molar & 3,36 & 1,6 & 3,42 & 1,69 & 3,33 & 1,5 & 3,91 & 1,04 & 3,95 & 1,46 \\
\hline incisal & 5,20 & 2,57 & 2,34 & 2,75 & 4,44 & 2,83 & 3,22 & 2,93 & 4,26 & 3,47 \\
\hline \multicolumn{11}{|l|}{ Rotações } \\
\hline Maxilar & 1,93 & 2,13 & 1,02 & 1,72 & 1,65 & 1,73 & 1,89 & 2,92 & 2,04 & 2,16 \\
\hline Mandibular & $-0,97$ & 3,17 & $-3,21$ & 3,48 & $-3,43$ & 2,35 & $-2,29$ & 3,07 & $-1,33$ & 2,13 \\
\hline
\end{tabular}

TABELA 5.14 - Testes de hipóteses para avaliar as diferenças das variáveis da análise de JOHNSTON JÚNIOR entre as fases inicial $X$ final, por categoria

\begin{tabular}{|c|c|c|c|c|c|c|c|c|c|}
\hline Variáveis & Diferenças & Categorias & & & Categc & & & $E G U$ & Tukey \\
\hline Esqueléticas & & & 1 & 2 & 3 & 4 & 5 & & $(5 \%)$ \\
\hline Max. $-B C$ & 0,0001 & 0,3238 & & & & & & 0.0001 & \\
\hline Mand & 0,0001 & 0,0593 & & & & & & 0.0001 & \\
\hline$A B A$ & 0,0001 & 0,1317 & & & & & & 0.0001 & \\
\hline Dentárias & & & & & & & & & \\
\hline $6 s$ & 0,0001 & 0,2537 & & & & & & 0.4202 & \\
\hline $6 i$ & 0,0001 & 0,5136 & & & & & & 0.0065 & \\
\hline $1 \mathrm{~s}$ & 0,0001 & 0,5388 & & & & & & 0.2754 & \\
\hline $1 i$ & 0,0001 & 0,6851 & & & & & & 0.0006 & \\
\hline Correção Tot & & & & & & & & & \\
\hline Molar & 0,0001 & 0,4874 & & & & & & 0.0640 & \\
\hline $\begin{array}{l}\text { Incisal } \\
\text { Rotações }\end{array}$ & 0,0001 & 0,0377 & 0,0001 & 0,0011 & 0,0001 & 0.0012 & 0.0001 & 0.6147 & $1 \times 2$ \\
\hline Maxilar & 0,0001 & 0,5281 & & & & & & 0.1099 & \\
\hline Mandibular & 0,0001 & 0,0117 & 0,2743 & 0,0001 & 0,0001 & 0.0200 & 0.0073 & 0.0038 & $1 \times 3$ \\
\hline
\end{tabular}

As Tabelas 5.13 e 5.14 demonstram que todas as alterações promovidas pelo tratamento (sobreposição dos traçados inicial $X$ final) foram estatisticamente diferentes de zero $(p<0,01)$. As variáveis correção incisal e rotação mandibular apresentaram diferenças estatisticamente significantes entre as diferenças 
médias das categorias $(p<0,05)$. Pelo teste de Tukey $(5 \%)$ foram encontradas diferenças significantes entre as diferenças médias da categorias 1 (5,2 mm) em relação à categoria $2(2,34 \mathrm{~mm})$ para a correção incisal. Esse teste também mostrou que a rotação mandibular na categoria $3\left(-3,43^{\circ}\right)$ foi significativamente maior que na categoria $1\left(-0,97^{\circ}\right)$. A rotação mandibular apresentou-se como anterior, com sentido anti-horário em todos as categorias.

A variável EGU (que representa a quantidade de crescimento) apresentou relação significativa com as variáveis: Max.-BC, Mand, ABA, 6i, 1i, correção molar e rotação mandibular.

$\mathrm{Na}$ Tabela 5.15 e nas Figuras 5.13 a 5.15 encontram-se as médias e desvios padrão das variáveis da análise de JOHNSTON JÚNIOR, por grupo de rotação mandibular, avaliadas no período de tratamento (momento inicial $\mathrm{X}$ final); na Tabela 5.16 encontram-se os testes de hipóteses relacionados com essas variáveis.

TABELA 5.15 - Médias e desvios padrão para as variáveis da análise de JOHNSTON JÚNIOR avaliadas entre as fases inicial $X$ final, por rotação

\begin{tabular}{|c|c|c|c|c|c|c|}
\hline \multirow{3}{*}{$\begin{array}{l}\text { Variáveis } \\
\text { Esqueléticas }\end{array}$} & \multicolumn{6}{|c|}{ Rotações Mandibulares } \\
\hline & \multicolumn{2}{|c|}{ Posterior $(n=29)$} & \multicolumn{2}{|c|}{ Anterior $(n=30)$} & \multicolumn{2}{|c|}{ Neutra $(n=41)$} \\
\hline & Média & DP & Média & DP & Média & DP \\
\hline Max.-BC & $-1,50$ & 1,09 & $-1,63$ & 1,24 & $-1,58$ & 1,14 \\
\hline Mand & 3,98 & 2,78 & 5,15 & 3,47 & 5,27 & 2,98 \\
\hline$A B A$ & 2,48 & 2,38 & 3,52 & 2,61 & 3,65 & 2,39 \\
\hline \multicolumn{7}{|l|}{ Dentárias } \\
\hline $6 s$ & $-1,91$ & 1,89 & $-1,12$ & 2,16 & $-1,6$ & 1,77 \\
\hline $6 i$ & 2,52 & 2,19 & 1,66 & 2,53 & 1,47 & 2,06 \\
\hline $1 s$ & 3,57 & 2,67 & 4,92 & 3,7 & 3,97 & 3,17 \\
\hline $1 i$ & $-2,85$ & 2,34 & $-4,06$ & 2,69 & $-3,61$ & 2,23 \\
\hline \multicolumn{7}{|l|}{ Correções } \\
\hline Molar & 3,06 & 1,47 & 4,15 & 1,5 & 3,53 & 1,38 \\
\hline incisal & 3,22 & 3,03 & 4,38 & 3,27 & 4,02 & 2,89 \\
\hline \multicolumn{7}{|l|}{ Rotações } \\
\hline Maxilar & 1,41 & 1,96 & 1,88 & 2,1 & 1,73 & 2,17 \\
\hline Mandibular & $-1,78$ & 3,04 & $-2,03$ & 3,11 & $-3,04$ & 2,64 \\
\hline
\end{tabular}


TABELA 5.16 - Testes de hipóteses para avaliar as diferenças das variáveis da análise de JOHNSTON JÚNIOR entre as fases inicial $X$ final, por rotação

\begin{tabular}{|c|c|c|c|c|c|c|c|}
\hline \multirow{2}{*}{$\begin{array}{l}\text { Variáveis } \\
\text { Esqueléticas }\end{array}$} & \multirow[t]{2}{*}{ Diferenças } & \multirow[t]{2}{*}{ Rotações } & \multicolumn{3}{|c|}{ Rotações } & \multirow[t]{2}{*}{ EGU } & \multirow[t]{2}{*}{ TUKEY (5\%) } \\
\hline & & & $\mathbf{P}$ & A & $\mathbf{R}$ & & \\
\hline Max. - BC & 0.0001 & 0.8487 & & & & 0.0001 & \\
\hline Mand & 0.0001 & 0.0900 & & & & 0.0001 & \\
\hline$A B A$ & 0.0001 & 0.0762 & & & & 0.0001 & \\
\hline \multicolumn{8}{|l|}{ Dentárias } \\
\hline $6 s$ & 0.0001 & 0.2839 & & & & 0.2742 & \\
\hline $6 i$ & 0.0001 & 0.1283 & & & & 0.0061 & \\
\hline $1 \mathrm{~s}$ & 0.0001 & 0.2513 & & & & 0.2620 & \\
\hline $1 i$ & 0.0001 & 0.1256 & & & & 0.0010 & \\
\hline \multicolumn{8}{|c|}{ Correção Total } \\
\hline Molar & 0.0001 & 0.0156 & 0.0001 & 0.0001 & 0.0001 & 0.0713 & $A \times P$ \\
\hline Incisal & 0.0001 & 0.3336 & & & & 0.8002 & \\
\hline \multicolumn{8}{|l|}{ Rotações } \\
\hline Maxilar & 0.0001 & 0.6728 & & & & 0.0788 & \\
\hline Mandibular & 0.0001 & 0.1426 & & & & 0.0166 & \\
\hline
\end{tabular}

As Tabelas 5.15 e 5.16 demonstram que todos os resultados foram estatisticamente diferentes de zero $(p<0,01)$. Esses testes são equivalentes aos realizados nas Tabelas 5.13 e 5.14. Somente a variável correção molar apresentou diferenças médias entre os grupos de rotações $(p<0,05)$. Através do teste de comparações múltiplas de Tukey, foram encontradas diferenças entre os grupos anterior $(4,15 \mathrm{~mm})$ e posterior (3,06 mm), ou seja, a correção da Classe II a nível dos molares, durante o tratamento, foi maior para os pacientes com rotação anterior da mandíbula que para os pacientes com rotação posterior.

A variável EGU apresentou relação significativa com as variáveis: Max.BC, Mand, ABA, 6i, 1i e rotação mandibular. Esses resultados são semelhantes aos obtidos na Tabela 5.14.

Na Tabela 5.17 encontram-se as médias e desvios padrão das variáveis da análise de JOHNSTON JÚNIOR, por categoria de crescimento, avaliadas no 
período pós-tratamento (momento final X pós-contenção), e, na Tabela 5.18, encontram-se os testes de hipóteses relacionados com essas variáveis.

TABELA 5.17 - Médias e desvios padrão para as variáveis da análise de JOHNSTON JÚNIOR avaliadas entre as fases final $X$ pós-contenção, por categoria de crescimento

\begin{tabular}{|c|c|c|c|c|c|c|c|c|c|c|}
\hline \multirow[t]{2}{*}{ Variáveis } & \multicolumn{10}{|c|}{ Categorias } \\
\hline & \multicolumn{2}{|c|}{$1(n=15)$} & \multicolumn{2}{|c|}{$2(n=21)$} & \multicolumn{2}{|c|}{$3(n=27)$} & \multicolumn{2}{|c|}{$4(n=14)$} & \multicolumn{2}{|c|}{$5(n=22)$} \\
\hline Esqueléticas & Média & DP & Média & DP & Média & DP & Média & DP & Média & DP \\
\hline Max.-BC & $-0,97$ & 1,53 & $-1,26$ & 1,4 & $-1,13$ & 0,84 & $-1,06$ & 1,06 & $-0,64$ & 0,85 \\
\hline Mand & 0,07 & 3,22 & 2,46 & 4,18 & 1,75 & 3,29 & 2,04 & 2,99 & 0,06 & 4,17 \\
\hline$A B A$ & $-0,9$ & 2,23 & 1,21 & 3,17 & 0,61 & 2,99 & 0,98 & 2,14 & $-0,57$ & 2,78 \\
\hline Dentárias & & & & & & & & & & \\
\hline $6 s$ & $-1,15$ & 1,23 & $-1,88$ & 1,93 & $-1,78$ & 1,69 & $-1,63$ & 1,42 & $-1,21$ & 2,45 \\
\hline $6 i$ & 1,26 & 1,98 & 0,44 & 2,34 & 1,07 & 1,63 & 0,13 & 1,96 & 1,18 & 4,55 \\
\hline $1 \mathrm{~s}$ & $-0,62$ & 1,99 & $-1,93$ & 1,79 & $-1,42$ & 1,98 & $-0,83$ & 1,63 & $-0,52$ & 2,68 \\
\hline $1 i$ & 0,51 & 2,01 & $-0,42$ & 1,91 & 0,05 & 1,8 & $-1,16$ & 2,23 & 0,04 & 3,96 \\
\hline $\begin{array}{l}\text { Correções } \\
\text { Molar }\end{array}$ & $-0,75$ & 1,47 & $-0,24$ & 1,17 & $-0,11$ & 0,58 & $-0,57$ & 1,04 & $-0,58$ & 099 \\
\hline incisal & $-0,95$ & 1,60 & $-0,79$ & 1,04 & $-0,71$ & 1,58 & $-1,11$ & 1,36 & $-0,79$ & 2,69 \\
\hline $\begin{array}{l}\text { Rotações } \\
\text { Maxilar }\end{array}$ & $-1,27$ & 1,91 & $-0,19$ & 1,67 & $-0,2$ & 1,59 & $-0,14$ & 2,13 & $-0,72$ & 2,0 \\
\hline Mandibular & $-1,87$ & 3,2 & $-1,83$ & 3,39 & $-1,91$ & 2,94 & $-2,64$ & 3,43 & $-1,87$ & 2,0 \\
\hline
\end{tabular}

TABELA 5.18 - Testes de hipóteses para avaliar as diferenças das variáveis da análise de JOHNSTON JÚNIOR entre as fases final $X$ pós-contenção, por categoria

\begin{tabular}{|c|c|c|c|c|c|c|c|c|c|}
\hline \multirow{2}{*}{$\begin{array}{l}\text { Variáveis } \\
\text { Esqueléticas }\end{array}$} & \multirow[t]{2}{*}{ Diferenças } & \multirow[t]{2}{*}{ Categorias } & \multicolumn{5}{|c|}{ Categorias } & \multirow[t]{2}{*}{$E G U$} & \multirow{2}{*}{$\begin{array}{l}\text { Tukey } \\
\text { (5\%) }\end{array}$} \\
\hline & & & 1 & 2 & 3 & 4 & 5 & & \\
\hline Max.-BC & 0.0001 & 0.3744 & & & & & & 0.0030 & \\
\hline Mand & 0.0001 & 0.0239 & 0.9347 & 0.0011 & 0.0062 & 0.0189 & 0.8757 & 0.0001 & - \\
\hline$A B A$ & 0.2147 & 0.0212 & 0.1541 & 0.0254 & 0.2590 & 0.0933 & 0.1034 & 0.0001 & - \\
\hline Dentárias & & & & & & & & & \\
\hline $6 s$ & 0.0001 & 0.5114 & & & & & & 0.0019 & \\
\hline $6 i$ & 0.0001 & 0.2895 & & & & & & 0.0685 & \\
\hline $1 \mathrm{~s}$ & 0.0001 & 0.0606 & & & & & & 0.0855 & \\
\hline $1 i$ & 0.3858 & 0.0973 & & & & & & 0.0022 & \\
\hline Correções & & & & & & & & & \\
\hline Molar & 0.0001 & 0.1987 & & & & & & 0.0438 & \\
\hline $\begin{array}{l}\text { Incisal } \\
\text { Rotações }\end{array}$ & 0.0001 & 0.9110 & & & & & & 0.1417 & \\
\hline Maxilar & 0.0101 & 0.2970 & & & & & & 0.7105 & \\
\hline Mandibular & 0.0001 & 0.9235 & & & & & & 0.0003 & \\
\hline
\end{tabular}


Os resultados das Tabelas 5.17 e 5.18 demonstram que foram encontradas diferenças médias estatisticamente diferentes de zero para as variáveis: Max.-BC, Mand, 6s, 6i, 1s, correções molar e incisal, rotações maxilar e mandibular.

Somente foram encontradas diferenças entre as médias das categorias para as variáveis: Mand e ABA $(p<0,05)$. Pelo teste de Tukey $(5 \%)$, não foram encontradas diferenças entre as categorias. Portanto, segundo a análise de JOHNSTON JÚNIOR, concluiu-se que, no período pós-tratamento, os pacientes não apresentaram diferenças significantes nas alterações dentoesqueléticas

A variável EGU apresentou relação significativa com as variáveis: Max.BC, Mand, ABA, 6s, 1i, correção molar e rotação mandibular.

Na Tabela 5.19 encontram-se as médias e desvios padrão das variáveis da análise de JOHNSTON JÚNIOR, por grupo de rotação mandibular, avaliadas no período pós-tratamento (momento final X pós-contenção); na Tabela 5.20 encontram-se os testes de hipóteses relacionados com essas variáveis. 
TABELA 5.19 - Médias e desvios padrão para as variáveis da análise de JOHNSTON JÚNIOR avaliadas entre as fases final X pós-contenção, por tipos de rotação mandibular

\begin{tabular}{|c|c|c|c|c|c|c|}
\hline \multirow[t]{2}{*}{ Variáveis } & \multicolumn{6}{|c|}{ Rotações Mandibulares } \\
\hline & \multicolumn{2}{|c|}{ Posterior $(n=29)$} & \multicolumn{2}{|c|}{ Anterior $(n=30)$} & \multicolumn{2}{|c|}{ Neutra $(n=41)$} \\
\hline Esqueléticas & Média & DP & Média & DP & Média & DP \\
\hline MaX.-BC & $-1,03$ & 1,46 & $-0,86$ & 1,04 & $-1,11$ & 0,91 \\
\hline Mand & 1,19 & 4,0 & 0,66 & 2,75 & 1,85 & 3,16 \\
\hline$A B A$ & 0,16 & 3,06 & $-0,20$ & 2,05 & 0,74 & 2,71 \\
\hline \multicolumn{7}{|l|}{ Dentárias } \\
\hline $6 s$ & $-1,56$ & 1,76 & $-1,31$ & 1,81 & $-1,73$ & 1,59 \\
\hline $6 i$ & 1,0 & 2,27 & 0,87 & 1,6 & 0,75 & 1,78 \\
\hline $1 \mathrm{~s}$ & $-1,24$ & 1,94 & $-0,86$ & 1,7 & $-1,22$ & 1,87 \\
\hline $1 i$ & 0,05 & 2,13 & $-0,05$ & 1,18 & $-0,36$ & 2,02 \\
\hline \multicolumn{7}{|l|}{ Correções } \\
\hline Molar & $-0,38$ & 1,24 & $-0,63$ & 0,99 & $-0,27$ & 0,79 \\
\hline $\begin{array}{l}\text { incisal } \\
\text { Rotações }\end{array}$ & $-0,77$ & 1,31 & $-0,9$ & 1,16 & $-0,84$ & 1,51 \\
\hline Maxilar & $-0,59$ & 2,0 & $-0,75$ & 1,61 & $-0,18$ & 1,77 \\
\hline Mandibular & $-1,64$ & 3,27 & $-2,07$ & 2,52 & $-2,16$ & 3,09 \\
\hline
\end{tabular}

TABELA 5.20 - Testes de hipóteses para avaliar as diferenças das variáveis da análise de JOHNSTON JÚNIOR entre as fases final X pós-contenção, por tipos de rotação mandibular

\begin{tabular}{lccc} 
Variáveis & Diferenças & Rotações & EGU \\
\hline Esqueléticas & & & \\
\hline Max. - BC & 0,0001 & 0,6342 & 0,0034 \\
Mand & 0,0001 & 0,2561 & 0,0001 \\
ABA & 0,2348 & 0,2651 & 0,0001 \\
Dentárias & & & \\
$\mathbf{6 s}$ & 0,0001 & 0,5632 & 0,0025 \\
$\mathbf{6 i}$ & 0,0001 & 0,8525 & 0,0902 \\
$\mathbf{1 s}$ & 0,0001 & 0,6582 & 0,1108 \\
$\mathbf{1 i}$ & 0,4001 & 0,5907 & 0,0049 \\
Correção Total & & & \\
Molar & 0,0001 & 0,3116 & 0,0538 \\
Incisal & 0,0001 & 0,9400 & 0,1401 \\
Rotações & & & \\
Maxilar & 0,0105 & 0,3930 & 0,8050 \\
Mandibular & 0,0001 & 0,7316 & 0,0003 \\
\hline
\end{tabular}

Os resultados das Tabelas 5.19 e 5.20 demonstram que foram encontradas diferenças médias estatisticamente diferentes de zero para as variáveis: Max.-BC, Mand, 6s, 6i, 1s, correções molar e incisiva, rotações maxilar 
e mandibular. Esses testes são equivalentes aos realizados na Tabela 5. 18. Não foram encontradas diferenças estatisticamente significantes entre os grupos de rotação mandibular para nenhuma das variáveis consideradas.

A variável EGU apresentou relação significativa com as variáveis: Max.$B C$, Mand, ABA, 6s, 1i, rotação mandibular. Esses resultados são semelhantes aos obtidos na Tabela 5.18.

Na Tabela 5.21 encontram-se as médias e desvios padrão das variáveis da análise de JOHNSTON JÚNIOR, por categoria de crescimento, avaliadas em relação à alteração total (momento inicial X pós-contenção); na Tabela 5.22 encontram-se os testes de hipóteses relacionados com essas variáveis.

Tabela 5.21 - Médias e desvios padrão das variáveis da análise de JOHNSTON JÚNIOR avaliadas entre as fases inicial $X$ pós-contenção, por categoria de crescimento

\begin{tabular}{|c|c|c|c|c|c|c|c|c|c|c|}
\hline \multirow[t]{2}{*}{ Variáveis } & \multicolumn{10}{|c|}{ Categorias } \\
\hline & \multicolumn{2}{|c|}{$1(n=15)$} & \multicolumn{2}{|c|}{$2(n=21)$} & \multicolumn{2}{|c|}{$3(n=27)$} & \multicolumn{2}{|c|}{$4(n=14)$} & \multicolumn{2}{|c|}{$5(n=22)$} \\
\hline $\begin{array}{l}\text { Esqueléticas } \\
\text { Max.-BC }\end{array}$ & $\begin{array}{l}\text { Média } \\
-2,75\end{array}$ & $\begin{array}{l}\text { DP } \\
1,83\end{array}$ & $\begin{array}{c}\text { Média } \\
-2,52\end{array}$ & $\begin{array}{l}\text { DP } \\
1,99\end{array}$ & $\begin{array}{c}\text { Média } \\
-2,83\end{array}$ & $\begin{array}{l}\text { DP } \\
1,39\end{array}$ & $\begin{array}{c}\text { Média } \\
-2,44\end{array}$ & $\begin{array}{l}\text { DP } \\
1,0\end{array}$ & $\begin{array}{c}\text { Média } \\
-2,34\end{array}$ & $\begin{array}{l}\text { DP } \\
1,31\end{array}$ \\
\hline Mand & 4,98 & 3,86 & 5,92 & 5,62 & 7,31 & 4,59 & 6,74 & 3,75 & 5,44 & 4,0 \\
\hline$A B A$ & 2,23 & 3,29 & 3,41 & 4,27 & 4,43 & 4,03 & 4,31 & 3,42 & 3,1 & 3,14 \\
\hline $\begin{array}{l}\text { Dentárias } \\
\text { 6s }\end{array}$ & $-3,36$ & 2,62 & $-2,9$ & 2,84 & $-3,7$ & 2,16 & $-2,63$ & 2,58 & $-2,54$ & 2,47 \\
\hline $6 i$ & 3,69 & 2,6 & 2,74 & 2,85 & 2,51 & 2,65 & 1,67 & 3,11 & 2,84 & 2,54 \\
\hline $1 \mathrm{~s}$ & 4,33 & 3,06 & 1,82 & 3,46 & 3,04 & 2,23 & 2,22 & 2,91 & 3,73 & 3,83 \\
\hline $1 i$ & $-2,4$ & 2,78 & $-4,03$ & 3,53 & $-3,82$ & 3,15 & $-4,26$ & 2,45 & $-3,66$ & 2,34 \\
\hline $\begin{array}{l}\text { Correções } \\
\text { Molar }\end{array}$ & 2,61 & 1,37 & 3,18 & 1,59 & 3,21 & 1,65 & 3,33 & 1,59 & 3,36 & 1,63 \\
\hline incisal & 4,24 & 2,58 & 1,55 & 2,42 & 3,73 & 2,75 & 2,11 & 2,51 & 3,46 & 3,29 \\
\hline $\begin{array}{l}\text { Rotações } \\
\text { Maxilar }\end{array}$ & 0,67 & 1,68 & 0,83 & 1,68 & 1,44 & 1,86 & 1,75 & 3,03 & 1,33 & 1,84 \\
\hline Mandibular & $-2,83$ & 5,26 & $-5,05$ & 5,58 & $-5,33$ & 4,58 & $-4,93$ & 4,25 & $-3,2$ & 3,26 \\
\hline
\end{tabular}


Tabela 5.22 - Testes de hipóteses para avaliar as diferenças das variáveis da análise de JOHNSTON JÚNIOR entre as fases inicial $X$ pós-contenção, por categoria de crescimento

\begin{tabular}{|c|c|c|c|c|c|c|c|c|c|}
\hline Variáveis & Diferenças & Categorias & & & Categor & & & $E G U$ & Tukey \\
\hline Esqueléticas & & & 1 & 2 & 3 & 4 & 5 & & $(5 \%)$ \\
\hline Max.-BC & 0,0001 & 0,6881 & & & & & & 0,0001 & \\
\hline Mand & 0,0001 & 0,1913 & & & & & & 0,0001 & \\
\hline$A B A$ & 0,0001 & 0,1905 & & & & & & 0,0001 & \\
\hline Dentárias & & & & & & & & & \\
\hline $6 s$ & 0,0001 & 0,4670 & & & & & & 0,0220 & \\
\hline $6 i$ & 0,0001 & 0,3372 & & & & & & 0,0014 & \\
\hline $1 \mathrm{~s}$ & 0,0001 & 0,0986 & & & & & & 0,0500 & \\
\hline $1 i$ & 0,0001 & 0,3578 & & & & & & 0,0001 & \\
\hline $\begin{array}{l}\text { Correções } \\
\text { Molar }\end{array}$ & 0,0001 & 0,6202 & & & & & & 0,0010 & \\
\hline incisal & 0,0001 & 0,0174 & 0,0001 & 0,0075 & 0,0001 & 0,0049 & 0,0001 & 0,5541 & $1 \times 2$ \\
\hline $\begin{array}{l}\text { Rotações } \\
\text { Maxilar }\end{array}$ & 0,0001 & 0,4816 & & & & & & 0,0146 & \\
\hline Mandibular & 0,0001 & 0,2342 & & & & & & 0,0003 & \\
\hline
\end{tabular}

Nas Tabelas 5.21 e 5.22 foram encontradas diferenças médias estatisticamente diferentes de zero para todas as variáveis consideradas. Somente foram encontradas diferenças entre as médias das categorias para a variável correção incisal $(p<0.05)$. Quando foram realizados testes para avaliar diferenças entre categorias, encontraram-se diferenças entre a categoria $1(4,24$ $\mathrm{mm}$ ) e a categoria $2(1,55 \mathrm{~mm})$, ou seja, durante todo o período avaliado, a correção incisal foi significantemente maior na categoria 1 que na 2. Portanto, somando-se o período de tratamento ao período pós-tratamento, as diferentes categorias de crescimento apresentaram praticamente as mesmas alterações dentoesqueléticas.

Na Tabela 5.22 observa-se que a EGU apresentou relação significante com todas as variáveis, sendo exceção a correção incisal. 
$\mathrm{Na}$ Tabela 5.23 encontram-se as médias e os desvios padrão das variáveis da análise de JOHNSTON JÚNIOR, por rotação de crescimento, avaliadas em relação à alteração total (momento inicial $X$ pós-contenção). $\mathrm{Na}$ Tabela 5.24, encontram-se os testes de hipóteses relacionados com essas variáveis.

TABELA 5.23 - Médias e desvios padrão para as variáveis da análise de JOHNSTON JÚNIOR avaliadas entre as fases inicial X pós-contenção, por grupo de rotação mandibular

\begin{tabular}{|c|c|c|c|c|c|c|}
\hline Variáveis & & & tações $n$ & ndibu & & \\
\hline & & & & & I & \\
\hline Esqueléticas & Média & DP & Média & DP & Média & DP \\
\hline Max.-BC & $-2,53$ & 1,91 & $-2,49$ & 1,48 & $-2,69$ & 1,27 \\
\hline Mand & 5,16 & 4,61 & 5,81 & 4,54 & 7,12 & 4,28 \\
\hline$A B A$ & 2,64 & 3,62 & 3,32 & 3,58 & 4,39 & 3,79 \\
\hline $\begin{array}{l}\text { Dentárias } \\
\text { 6s }\end{array}$ & $-3,47$ & 2,81 & $-2,31$ & 2,32 & $-3,33$ & 2,34 \\
\hline $6 i$ & 3,52 & 2,47 & 2,53 & 2,77 & 2,22 & 2,8 \\
\hline $1 \mathrm{~s}$ & 2,33 & 3,53 & 4,06 & 3,55 & 2,76 & 2,48 \\
\hline $1 i$ & $-2,8$ & 2,57 & $-4,12$ & 3,17 & $-3,97$ & 2,9 \\
\hline $\begin{array}{l}\text { Correções } \\
\text { Molar }\end{array}$ & 2,68 & 1,21 & 3,52 & 1,76 & 3,26 & 1,61 \\
\hline incisal & 2,45 & 2,86 & 3,49 & 3,09 & 3,18 & 2,75 \\
\hline $\begin{array}{l}\text { Rotações } \\
\text { Maxilar } \\
\text { Mandibular }\end{array}$ & $\begin{array}{c}0,83 \\
-3,41\end{array}$ & $\begin{array}{l}1,64 \\
4,81\end{array}$ & $\begin{array}{r}1,13 \\
-4,10\end{array}$ & $\begin{array}{l}1,84 \\
4,71\end{array}$ & $\begin{array}{r}1,55 \\
-5,20\end{array}$ & $\begin{array}{l}2,29 \\
4,42\end{array}$ \\
\hline
\end{tabular}


TABELA 5.24 - Testes de hipóteses para avaliar as diferenças das variáveis da análise de JOHNSTON JÚNIOR entre as fases inicial X pós-contenção, por grupo de rotação mandibular

\begin{tabular}{lccc} 
Variáveis & Diferenças & Grupos & EGU \\
\hline Esqueléticas & & & \\
\hline Max.-BC & 0,0001 & 0,7789 & 0,0001 \\
Mand & 0,0001 & 0,0576 & 0,0001 \\
ABA & 0,0001 & 0,0645 & 0,0001 \\
$\begin{array}{l}\text { Dentárias } \\
\text { 6s }\end{array}$ & 0,0001 & 0,1249 & 0,0190 \\
$\mathbf{6 i}$ & 0,0001 & 0,1122 & 0,0018 \\
$\mathbf{1 s}$ & 0,0001 & 0,0856 & 0,1028 \\
$\mathbf{1 i}$ & 0,0001 & 0,1181 & 0,0001 \\
Correções & & & \\
Molar & 0,0001 & 0,0858 & 0,0009 \\
incisal & 0,0001 & 0,3698 & 0,3542 \\
Rotações & & & \\
Maxilar & 0,0001 & 0,3014 & 0,0141 \\
Mandibular & 0,0001 & 0,2318 & 0,0005 \\
\hline
\end{tabular}

Para as comparações entre os grupos de rotação mandibular (Tabelas 5.23 e 5.24), foram encontradas diferenças médias estatisticamente diferentes de zero para todas as variáveis do estudo.

Não foram encontradas diferenças estatisticamente significantes entre os grupos para nenhuma das variáveis consideradas. Portanto, somando-se o período do tratamento ao período pós-tratamento, os diferentes grupos de rotação mandibular apresentaram as mesmas alterações dentoesquléticas.

A variável EGU apresentou relação significante com as variáveis: Max.BC, Mand, ABA, 6s, 6i, 1i, correção molar, rotações maxilar e mandibular. 


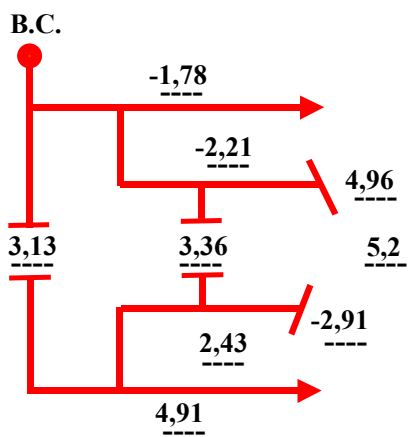

I X F

\section{Categoria 1}

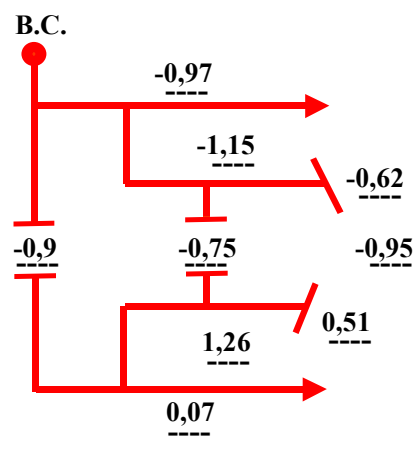

F X PC

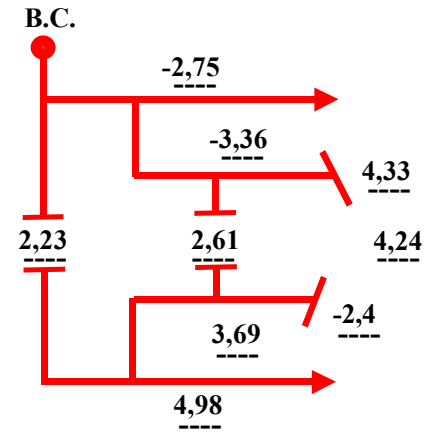

I X PC

FIGURA 5.8 - Comparação das alterações produzidas durante o tratamento (IXF), pós-tratamento (FXPC) e alterações totais (IXPC) na categoria de crescimento 1

B.C.

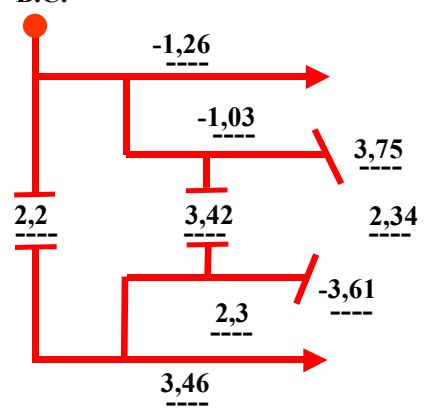

I X F

\section{Categoria 2}

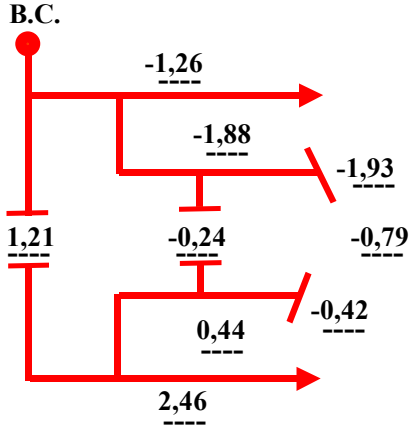

F X PC

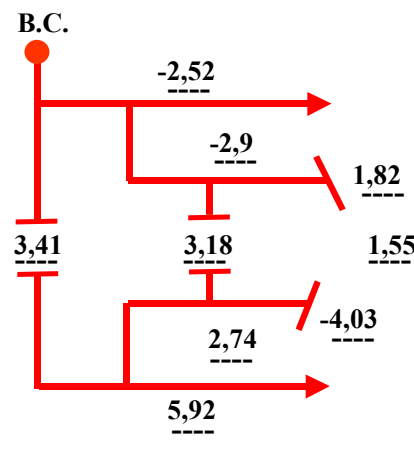

I X PC

FIGURA 5.9 - Comparação das alterações produzidas durante o tratamento (IXF), pós-tratamento (FXPC) e alterações total (IXPC) na categoria de crescimento 2

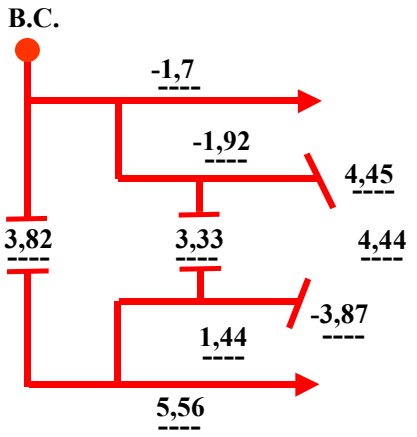

I X F

\section{Categoria 3}

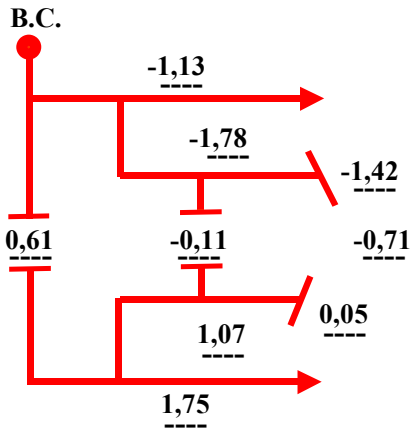

F XPC

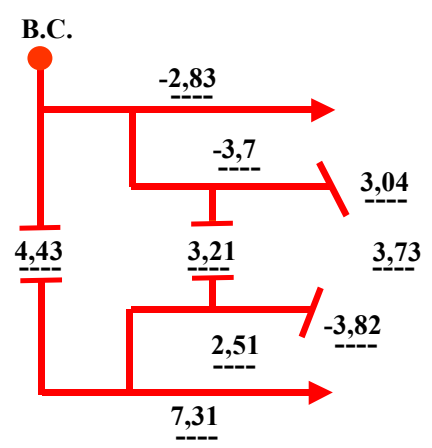

I X PC

FIGURA 5.10 - Comparação das alterações produzidas durante o tratamento (IXF), pós-tratamento (FXPC) e alterações totais (IXPC) na categoria de crescimento 3 


\section{Categoria 4}

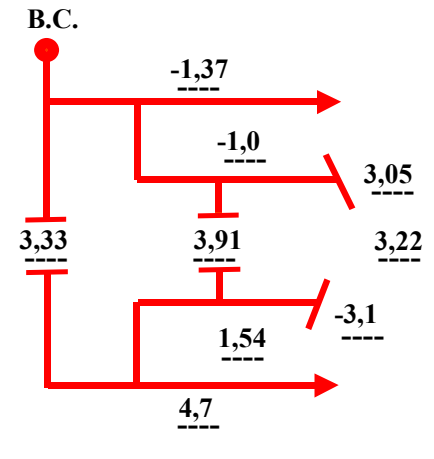

I X F

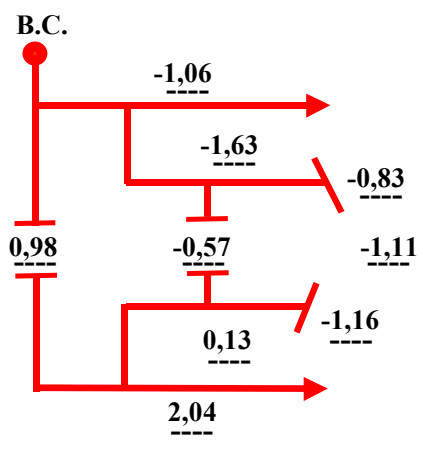

F XPC

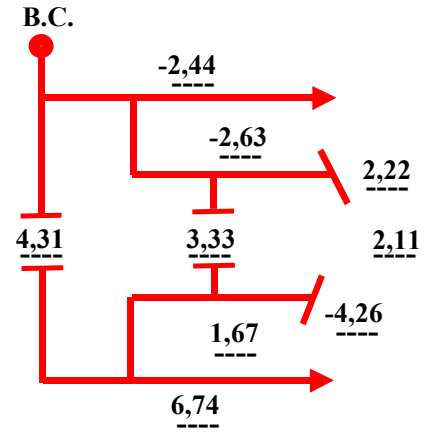

I X PC

FIGURA 5.11 - Comparação das alterações produzidas durante o tratamento (IXF), pós-tratamento (FXPC) e alterações totais (IXPC) na categoria de crescimento 4

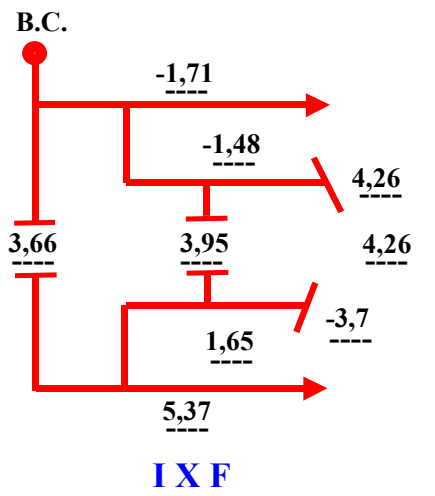

\section{Categoria 5}

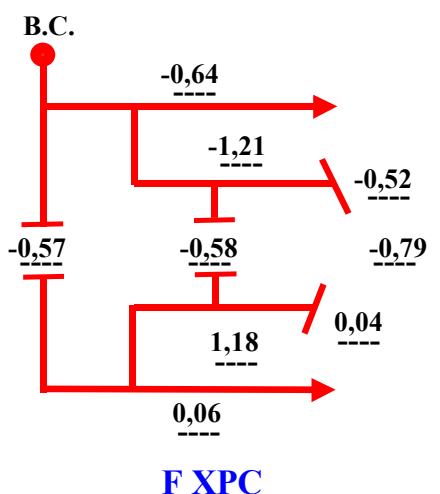

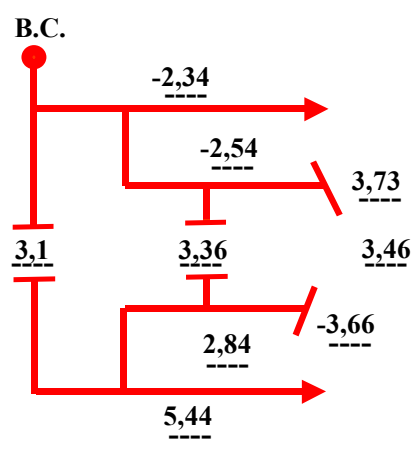

I X PC

FIGURA 5.12 - Comparação das alterações produzidas durante o tratamento (IXF), pós-tratamento (FXPC) e alterações totais (IXPC) na categoria de crescimento 5 

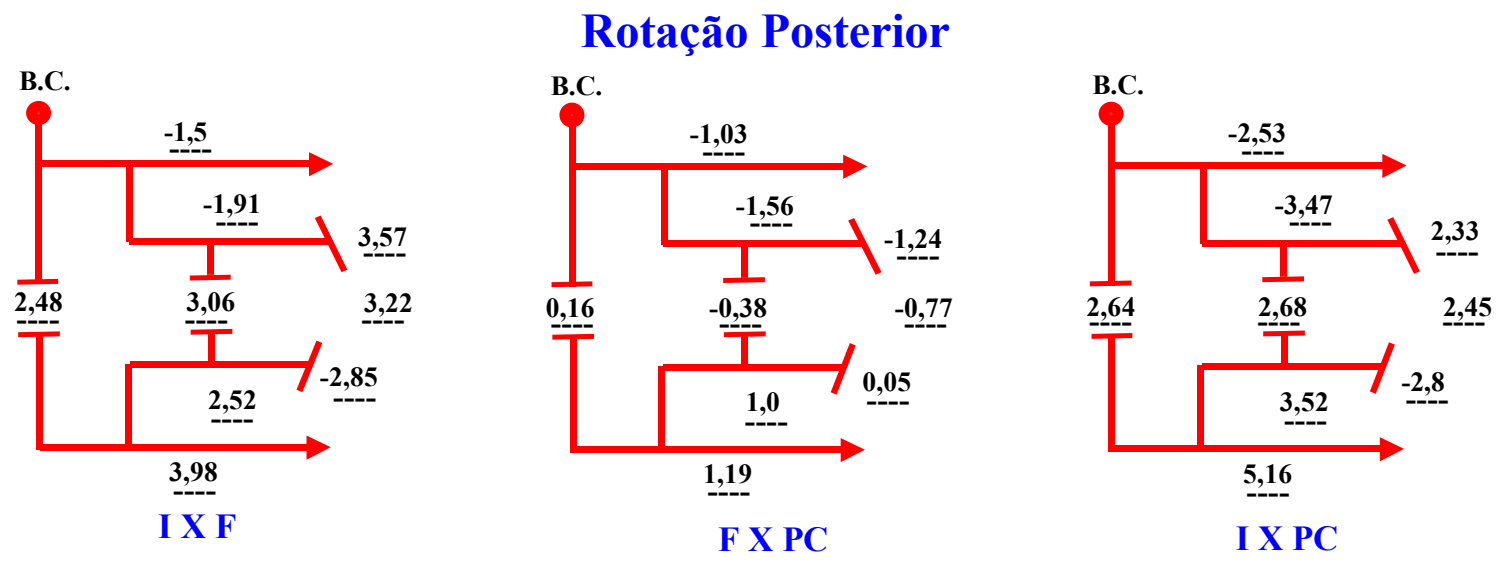

FIGURA 5.13 - Comparação das alterações produzidas durante o tratamento (IXF), pós-tratamento (FXPC) e alterações totais (IXPC) na rotação posterior

\section{Rotação Anterior}

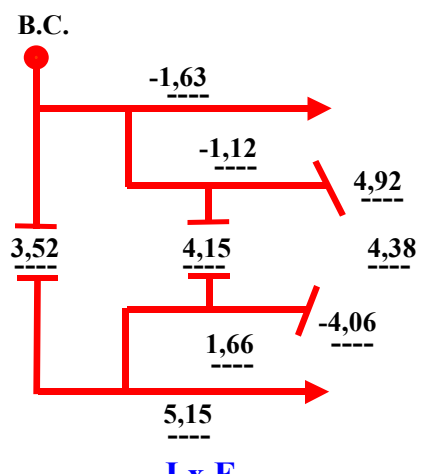

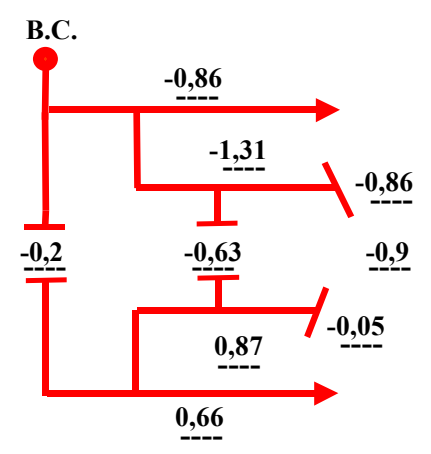

F X PC

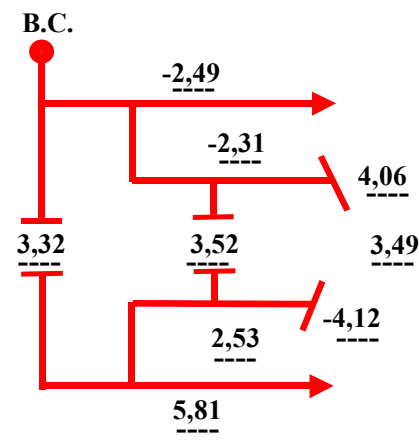

I X PC

FIGURA 5.14 - Comparação das alterações produzidas durante o tratamento (IXF), pós-tratamento (FXPC) e alterações totais (IXPC) na rotação anterior

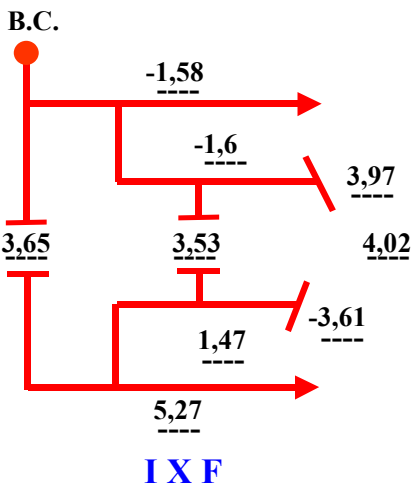

\section{Rotação Neutra}

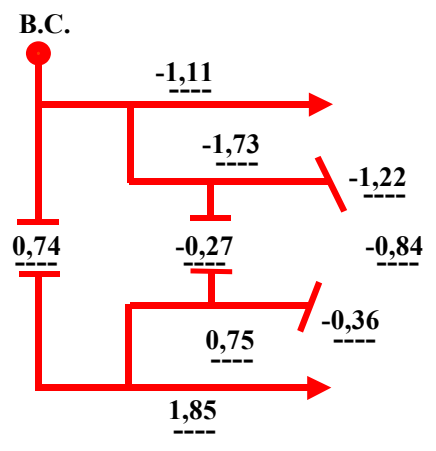

F XPC

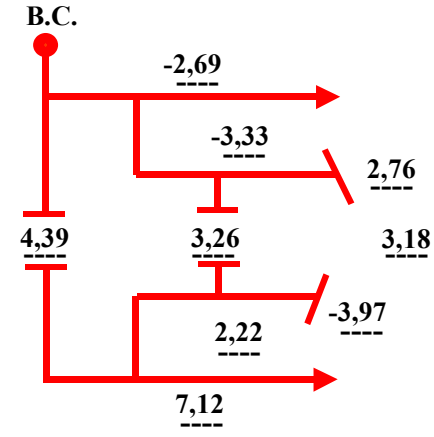

I X PC

FIGURA 5.15 - Comparação das alterações produzidas durante o tratamento (IXF), pós-tratamento (FXPC) e alterações totais (IXPC) na rotação neutra 
As variáveis rotação maxilar e rotação mandibular, da análise de JOHNSTON JÚNIOR, também foram analisadas após a divisão dos pacientes de acordo com dimensão vertical, em mordida: aberta (OB), profunda (DB), e normal $(\mathrm{N})$.

$\mathrm{Na}$ Tabela 5.25 encontram-se as médias e os desvios padrão das variáveis rotação maxilar e rotação mandibular para os momentos início $X$ final e final X pós-contenção em função do tipo de mordida.

$\mathrm{Na}$ Tabela 5.26 encontram-se testes de hipóteses realizados tendo a variável EGU como covariada.

TABELA 5.25 - Médias e desvios padrão das variáveis rotações maxilar e mandibular para os momentos inicial $X$ final e final $X$ pós-contenção em função do tipo de mordida (aberta $=\mathrm{OB}$; profunda $=\mathrm{DB}$; normal $=\mathrm{N}$ )

\begin{tabular}{llcccccc} 
Fases & Variáveis & \multicolumn{2}{c}{$\boldsymbol{O B}(\boldsymbol{n}=\mathbf{4 7})$} & \multicolumn{2}{c}{$\mathbf{D B}(\boldsymbol{n}=\mathbf{2 4})$} & \multicolumn{2}{c}{$\boldsymbol{N}(\boldsymbol{n}=\mathbf{2 9})$} \\
\hline \multirow{3}{*}{ I x F } & Rot. Maxilar & Média & DP & Média & DP & Média & DP \\
& Rot. Mandibular & $-2,85$ & 2,24 & 1,42 & 2,21 & 1,64 & 1,71 \\
\multirow{3}{*}{ x X PC } & Rot. Maxilar & $-0,17$ & 1,33 & $-2,15$ & 2,11 & $-2,72$ & 2,86 \\
& Rot. Mandibular & $-1,9$ & 3,41 & $-2,54$ & 1,63 & $-0,90$ & 1,87 \\
\multirow{3}{*}{ x PC } & Rot. Maxilar & 1,68 & 2,12 & 0,88 & 2,54 & $-1,86$ & 2,58 \\
& Rot. Mandibular & $-4,17$ & 5,48 & $-4,42$ & 3,45 & $-4,59$ & 4,11 \\
\hline
\end{tabular}

TABELA 5.26 - Testes de hipóteses para as variáveis rotações maxilar e mandibular para os momentos inicial $X$ final e final $X$ pós-contenção em função do tipo de mordida $($ aberta $=\mathrm{OB}$; profunda $=\mathrm{DB} ;$ normal $=\mathrm{N}$ )

\begin{tabular}{llrrr} 
Fases & Variáveis & Diferenças & Mordidas & EGU \\
\hline Ix F & Rot. Maxilar & 0,0001 & 0,6984 & 0,0863 \\
& Rot. Mandibular & 0,0001 & 0,7211 & 0,0077 \\
F x PC & Rot. Maxilar & 0,0101 & 0,2286 & 0,8942 \\
& Rot. Mandibular & 0,0001 & 0,8417 & 0,0002 \\
\multirow{3}{*}{ x PC } & Rot. Maxilar & 0,0001 & 0,0762 & 0,0217 \\
& Rot. Mandibular & 0,0001 & 0,9186 & 0,0002 \\
\hline
\end{tabular}

As Tabelas 5.25 e 5.26 demonstram que não foram obtidas diferenças significativas entre as médias dos três grupos em nenhuma das variáveis 
consideradas.

\subsubsection{Correlações entre as variáveis da análise de JOHNSTON JÚNIOR}

Nas Tabelas de 5.27 a 5.34 encontram-se os testes de correlação linear para a relação entre as variáveis que representam o crescimento esquelético (Max.-BC, Mand, e ABA), e as variáveis dentárias (6s, 6i, 1s, 1i, índice de Little, correções molar e incisal) e rotacionais (rotações maxilar e mandibular), referentes às alterações ocorridas durante o tratamento e o período póstratamento. Esses testes foram realizados para todos os indivíduos juntos $(\mathrm{n}=$ $100)$, e para os grupos de rotação mandibular, posterior $(P)$, anterior $(A)$ e neutra (R). O objetivo foi avaliar a influência do crescimento sobre as variáveis dentárias e rotacionais.

Para cada variável, encontrou-se o coeficiente de correlação (r) e o nível descritivo (p) da hipótese de não existência de correlação entre as variáveis correspondentes.

TABELA 5.27 - Coeficientes de correlação ( $r$ ) e níveis descritivos (p) para a relação entre o crescimento e as alterações dentárias e rotacionais acontecidas durante o tratamento (inicial $X$ final) para toda a amostra

\begin{tabular}{lcccccc} 
Variáveis & \multicolumn{2}{c}{ MAX.-BC } & \multicolumn{2}{c}{ MAND } & \multicolumn{2}{c}{ ABA } \\
\hline & $\mathbf{r}$ & $\mathbf{p}$ & $\mathbf{r}$ & $\mathbf{p}$ & $\mathbf{r}$ & $\mathbf{p}$ \\
$\mathbf{6 s}$ & 0,0606 & 0,5491 & $-0,1338$ & 0,1844 & $-0,1405$ & 0,1632 \\
$\mathbf{6 i}$ & 0,2404 & $\mathbf{0 , 0 1 6 0}$ & $-0,6703$ & $\mathbf{0 , 0 0 0 1}$ & $-0,7275$ & $\mathbf{0 , 0 0 0 1}$ \\
$\mathbf{1 S}$ & 0,0096 & 0,9248 & $-0,0293$ & 0,7724 & $-0,0382$ & 0,7061 \\
$\mathbf{1 i}$ & 0,1897 & 0,0587 & $-0,5949$ & $\mathbf{0 , 0 0 0 1}$ & $-0,6518$ & $\mathbf{0 , 0 0 0 1}$ \\
$\mathbf{6 / 6}$ & $-0,2605$ & $\mathbf{0 , 0 0 8 8}$ & 0,3884 & $\mathbf{0 , 0 0 0 1}$ & 0,3683 & $\mathbf{0 , 0 0 0 2}$ \\
$\mathbf{1 / 1}$ & $-0,1592$ & 0,1136 & 0,2634 & $\mathbf{0 , 0 0 8 1}$ & 0,2554 & $\mathbf{0 , 0 1 0 3}$ \\
Rot.MAX & $-0,3482$ & $\mathbf{0 , 0 0 0 4}$ & 0,5604 & $\mathbf{0 , 0 0 0 1}$ & 0,5444 & $\mathbf{0 , 0 0 0 1}$ \\
Rot $\boldsymbol{M A N D}$ & 0,0599 & 0,5539 & $-0,1869$ & 0,0626 & $-0,2048$ & $\mathbf{0 , 0 4 1 0}$ \\
I. LITTLE. & 0,1255 & $\mathbf{0 , 2 1 3 4}$ & $-0,2194$ & $\mathbf{0 , 0 2 8 3}$ & $-0,2186$ & $\mathbf{0 , 0 2 8 9}$ \\
\hline
\end{tabular}


TABELA 5.28 - Coeficientes de correlação ( $r$ ) e níveis descritivos (p) para a relação entre o crescimento e as alterações dentárias e rotacionais acontecidas durante o tratamento (inicial $X$ final) para os pacientes do grupo $A$

\begin{tabular}{lcccccc} 
Variáveis & \multicolumn{2}{c}{ MAX.-BC } & \multicolumn{2}{c}{ MAND } & \multicolumn{2}{c}{ ABA } \\
\hline & $\mathbf{r}$ & $\mathbf{p}$ & $\mathbf{r}$ & $\mathbf{p}$ & $\mathbf{R}$ & $\mathbf{p}$ \\
$\mathbf{6 s}$ & 0,0757 & 0,6909 & $-0,0421$ & 0,8253 & $-0,0200$ & 0,9164 \\
$\mathbf{6 i}$ & 0,4580 & $\mathbf{0 , 0 1 0 9}$ & $-0,7152$ & $\mathbf{0 , 0 0 0 1}$ & $-0,7339$ & $\mathbf{0 , 0 0 0 1}$ \\
$\mathbf{1 S}$ & 0,0764 & 0,6884 & 0,0484 & 0,7993 & 0,1008 & 0,5963 \\
$\mathbf{1 i}$ & 0,4720 & $\mathbf{0 , 0 0 8 5}$ & $-0,6310$ & $\mathbf{0 , 0 0 0 2}$ & $-0,6152$ & $\mathbf{0 , 0 0 0 3}$ \\
$\mathbf{6 / 6}$ & $-0,2796$ & 0,1345 & 0,4512 & $\mathbf{0 , 0 1 2 3}$ & 0,4674 & $\mathbf{0 , 0 0 9 2}$ \\
$\mathbf{1 / 1}$ & 0,0050 & 0,9789 & 0,3062 & 0,0998 & 0,4099 & $\mathbf{0 , 0 2 4 5}$ \\
Rot.MAX & $-0,3510$ & 0,0572 & 0,5537 & $\mathbf{0 , 0 0 1 5}$ & 0,5698 & $\mathbf{0 , 0 0 1 0}$ \\
Rot MAND & 0,1711 & 0,3660 & $-0,0917$ & 0,6297 & $-0,0407$ & 0,8308 \\
I. LITTLE. & $\mathbf{0 , 4 7 4 5}$ & $\mathbf{0 , 0 0 8 1}$ & $-0,6720$ & $\mathbf{0 , 0 0 0 1}$ & $-0,6686$ & $\mathbf{0 , 0 0 0 1}$ \\
\hline
\end{tabular}

TABELA 5.29 - Coeficientes de correlação ( $r$ ) e níveis descritivos ( $p$ ) para a relação entre o crescimento e as alterações dentárias e rotacionais acontecidas durante o tratamento (inicial $\mathrm{X}$ final) para os pacientes do grupo $\mathrm{P}$

\begin{tabular}{lcccccc} 
Variáveis & \multicolumn{2}{c}{ MAX.-BC } & \multicolumn{2}{c}{ MAND } & \multicolumn{2}{c}{ ABA } \\
\hline & $\mathbf{r}$ & $\mathbf{p}$ & $\mathbf{r}$ & $\mathbf{p}$ & $\mathbf{R}$ & $\mathbf{p}$ \\
$\mathbf{6 s}$ & $-0,0595$ & 0,7591 & $-0,3255$ & 0,0849 & $-0,4072$ & $\mathbf{0 , 0 2 8 4}$ \\
$\mathbf{6 i}$ & 0,1056 & 0,5857 & $-0,6648$ & $\mathbf{0 , 0 0 0 1}$ & $-0,7280$ & $\mathbf{0 , 0 0 0 1}$ \\
$\mathbf{1 S}$ & $-0,1190$ & 0,5386 & $-0,0551$ & 0,7766 & $-0,1186$ & 0,5402 \\
$\mathbf{1 i}$ & $-0,0456$ & 0,8144 & $-0,5420$ & 0,0024 & $-0,6536$ & $\mathbf{0 , 0 0 0 1}$ \\
$\mathbf{6 / 6}$ & $-0,1992$ & 0,3001 & 0,1113 & 0,5655 & 0,0391 & 0,8405 \\
$\mathbf{1 / 1}$ & $-0,2663$ & 0,1627 & 0,2652 & 0,1644 & 0,1883 & 0,3281 \\
Rot.MAX & $-0,2034$ & 0,2900 & 0,6198 & $\mathbf{0 , 0 0 0 3}$ & 0,6309 & $\mathbf{0 , 0 0 0 2}$ \\
Rot MAND & 0,0325 & 0,8670 & $-0,1319$ & 0,4951 & $-0,1392$ & 0,4713 \\
I. LITTLE & 0,1485 & 0,4421 & $-0,0591$ & 0,7609 & $-0,0013$ & 0,9948 \\
\hline
\end{tabular}

TABELA 5.30 - Coeficientes de correlação ( $r$ ) e níveis descritivos ( $p$ ) para a relação entre o crescimento e as alterações dentárias e rotacionais acontecidas durante o tratamento (incial $\mathrm{X}$ final) para os pacientes do grupo $\mathrm{R}$

\begin{tabular}{lcccccc} 
Variáveis & \multicolumn{2}{c}{ MAX.-BC } & \multicolumn{2}{c}{ MAND } & \multicolumn{2}{c}{ ABA } \\
\hline & $\mathbf{r}$ & $\mathbf{p}$ & $\mathbf{r}$ & $\mathbf{p}$ & $\mathbf{R}$ & $\mathbf{p}$ \\
$\mathbf{6 s}$ & 0,1539 & 0,3368 & $-0,1636$ & 0,3067 & $-0,1347$ & 0,4010 \\
$\mathbf{6 i}$ & 0,1179 & 0,4627 & $-0,5964$ & $\mathbf{0 , 0 0 0 1}$ & $-0,6922$ & $\mathbf{0 , 0 0 0 1}$ \\
$\mathbf{1 S}$ & 0,0390 & 0,8088 & $-0,1434$ & 0,3712 & $-0,1764$ & 0,2699 \\
$\mathbf{1 i}$ & 0,0723 & 0,6535 & $-0,5681$ & $\mathbf{0 , 0 0 0 1}$ & $-0,6634$ & $\mathbf{0 , 0 0 0 1}$ \\
$\mathbf{6 / 6}$ & $-0,2836$ & 0,0723 & 0,4836 & $\mathbf{0 , 0 0 1 4}$ & 0,4762 & $\mathbf{0 , 0 0 1 6}$ \\
$\mathbf{1 / 1}$ & $-0,2179$ & 0,1711 & 0,1740 & 0,2766 & 0,1129 & 0,4823 \\
Rot.MAX & $-0,4284$ & $\mathbf{0 , 0 0 5 2}$ & 0,5280 & $\mathbf{0 , 0 0 0 4}$ & 0,4661 & 0,0021 \\
Rot MAND & $-0,0274$ & 0,8649 & $-0,2697$ & 0,0882 & $-0,3493$ & $\mathbf{0 , 0 2 5 2}$ \\
I. LITTLE & $-0,0973$ & 0,5452 & $-0,0381$ & 0,8131 & $-0,0997$ & 0,5352 \\
\hline
\end{tabular}


TABELA 5.31 - Coeficientes de correlação ( $r$ ) e níveis descritivos ( $p$ ) para a relação entre o crescimento e as alterações dentárias e rotacionais acontecidas após o tratamento (final X pós-contenção) para toda a amostra

\begin{tabular}{lcccccc} 
Variáveis & \multicolumn{2}{c}{ MAX.-BC } & \multicolumn{2}{c}{ MAND } & \multicolumn{2}{c}{ ABA } \\
\hline & $\mathbf{r}$ & $\mathbf{p}$ & $\mathbf{r}$ & $\mathbf{r}$ & $\mathbf{p}$ & $\mathbf{r}$ \\
$\mathbf{6 s}$ & 0,2295 & $\mathbf{0 , 0 2 1 6}$ & $-0,5469$ & $\mathbf{0 , 0 0 0 1}$ & $-0,5914$ & $\mathbf{0 , 0 0 0 1}$ \\
$\mathbf{6 i}$ & 0,4063 & $\mathbf{0 , 0 0 0 1}$ & $-0,6500$ & $\mathbf{0 , 0 0 0 1}$ & $-0,6427$ & $\mathbf{0 , 0 0 0 1}$ \\
$\mathbf{1 S}$ & 0,3540 & $\mathbf{0 , 0 0 0 3}$ & $-0,5387$ & $\mathbf{0 , 0 0 0 1}$ & $-0,5269$ & $\mathbf{0 , 0 0 0 1}$ \\
$\mathbf{1 i}$ & 0,3729 & $\mathbf{0 , 0 0 0 1}$ & $-0,7179$ & $\mathbf{0 , 0 0 0 1}$ & $-0,7444$ & $\mathbf{0 , 0 0 0 1}$ \\
$\mathbf{6 / 6}$ & $-0,0928$ & 0,3583 & 0,3450 & $\mathbf{0 , 0 0 0 4}$ & 0,3960 & $\mathbf{0 , 0 0 0 1}$ \\
$\mathbf{1 / 1}$ & 0,1038 & 0,3041 & 0,0515 & 0,6110 & 0,1087 & 0,2816 \\
Rot.MAX & $-0,3669$ & $\mathbf{0 , 0 0 0 2}$ & 0,4219 & $\mathbf{0 , 0 0 0 1}$ & 0,3745 & $\mathbf{0 , 0 0 0 1}$ \\
Rot $\boldsymbol{M A N D}$ & 0,1799 & 0,0734 & $-0,4199$ & $\mathbf{0 , 0 0 0 1}$ & $-0,4526$ & $\mathbf{0 , 0 0 0 1}$ \\
I. LITTLE & 0,1582 & $\mathbf{0 , 1 1 5 9}$ & $-0,2440$ & $\mathbf{0 , 0 1 4 4}$ & $-0,2410$ & $\mathbf{0 , 0 1 5 7}$ \\
\hline
\end{tabular}

TABELA 5.32 - Coeficientes de correlação ( $r$ ) e níveis descritivos ( $p$ ) para a relação entre o crescimento e as alterações dentárias e rotacionais acontecidas após o tratamento (final $X$ pós-contenção) para os pacientes do grupo $A$

\begin{tabular}{lcccccc} 
Variáveis & \multicolumn{2}{c}{ MAX.-BC } & \multicolumn{2}{c}{ MAND } & \multicolumn{2}{c}{ ABA } \\
\hline & \multicolumn{2}{c}{$\mathbf{r}$} & $\mathbf{p}$ & $\mathbf{r}$ & $\mathbf{r}$ & $\mathbf{p}$ \\
$\mathbf{6 s}$ & 0,2257 & 0,2304 & $-0,4760$ & $\mathbf{0 , 0 0 7 8}$ & $-0,5340$ & $\mathbf{0 , 0 0 2 4}$ \\
$\mathbf{6 i}$ & 0,3904 & $\mathbf{0 , 0 3 2 9}$ & $-0,4062$ & $\mathbf{0 , 0 2 5 9}$ & $-0,3452$ & $\mathbf{0 , 0 6 1 7}$ \\
$\mathbf{1 S}$ & 0,4419 & $\mathbf{0 , 0 1 4 5}$ & $-0,6521$ & $\mathbf{0 , 0 0 0 1}$ & $-0,6488$ & $\mathbf{0 , 0 0 0 1}$ \\
$\mathbf{1 i}$ & 0,3171 & 0,0878 & $-0,5307$ & $\mathbf{0 , 0 0 2 6}$ & $-0,5608$ & $\mathbf{0 , 0 0 1 3}$ \\
$\mathbf{6} / \mathbf{6}$ & $-0,1282$ & 0,4995 & 0,4211 & $\mathbf{0 , 0 2 0 5}$ & 0,5072 & $\mathbf{0 , 0 0 4 2}$ \\
$\mathbf{1 / 1}$ & $-0,0224$ & 0,9063 & 0,0956 & 0,6151 & 0,1122 & 0,5549 \\
Rot.MAX & $-0,3379$ & 0,0678 & 0,4064 & $\mathbf{0 , 0 2 5 8}$ & 0,3738 & $\mathbf{0 , 0 4 1 9}$ \\
Rot $\boldsymbol{M A N D}$ & 0,1404 & 0,4593 & $-0,3630$ & $\mathbf{0 , 0 4 8 6}$ & $-0,4279$ & $\mathbf{0 , 0 1 8 3}$ \\
I. LITTLE & 0,3376 & 0,0681 & $-0,3365$ & 0,0691 & $-0,2905$ & 0,1193 \\
\hline
\end{tabular}

TABELA 5.33 - Coeficientes de correlação ( $r$ ) e níveis descritivos ( $p$ ) para a relação entre o crescimento e as alterações dentárias e rotacionais acontecidas após o tratamento (final $X$ pós-contenção) para os pacientes do grupo $\mathrm{P}$

\begin{tabular}{lcccccc} 
Variáveis & \multicolumn{2}{c}{ MAX.-BC } & \multicolumn{2}{c}{ MAND } & \multicolumn{2}{c}{ ABA } \\
\hline & $\mathbf{r}$ & $\mathbf{p}$ & $\mathbf{r}$ & $\mathbf{r}$ & $\mathbf{p}$ & $\mathbf{r}$ \\
$\mathbf{6 s}$ & 0,3456 & 0,0663 & $-0,6217$ & $\mathbf{0 , 0 0 0 3}$ & $-0,6462$ & $\mathbf{0 , 0 0 0 2}$ \\
$\mathbf{6 i}$ & 0,3911 & $\mathbf{0 , 0 3 5 9}$ & $-0,6843$ & $\mathbf{0 , 0 0 0 1}$ & $-0,7068$ & $\mathbf{0 , 0 0 0 1}$ \\
$\mathbf{1 S}$ & 0,3692 & $\mathbf{0 , 0 4 8 7}$ & $-0,5687$ & $\mathbf{0 , 0 0 1 3}$ & $-0,5698$ & $\mathbf{0 , 0 0 1 3}$ \\
$\mathbf{1 i}$ & 0,3815 & $\mathbf{0 , 0 4 1 2}$ & $-0,7035$ & $\mathbf{0 , 0 0 0 1}$ & $-0,7383$ & $\mathbf{0 , 0 0 0 1}$ \\
$\mathbf{6 / 6}$ & $-0,0153$ & 0,9371 & 0,1770 & 0,3583 & 0,2249 & 0,2408 \\
$\mathbf{1 / 1}$ & 0,1083 & 0,5759 & $-0,0282$ & 0,8847 & 0,0155 & 0,9362 \\
Rot.MAX & $-0,4250$ & $\mathbf{0 , 0 2 1 6}$ & 0,5753 & $\mathbf{0 , 0 0 1 1}$ & 0,5488 & $\mathbf{0 , 0 0 2 0}$ \\
Rot $\boldsymbol{M A N D}$ & 0,1935 & 0,3144 & $-0,3067$ & 0,1056 & $-0,3079$ & 0,1042 \\
I. LITTLE & 0,0974 & 0,6153 & $-0,1186$ & 0,5402 & $-0,1099$ & 0,5705 \\
\hline
\end{tabular}


TABELA 5.34 - Coeficientes de correlação ( $r$ ) e níveis descritivos (p) para a relação entre o crescimento e as alterações dentárias e rotacionais acontecidas após o tratamento (final $X$ pós-contenção) para os pacientes do grupo $R$

\begin{tabular}{lcccccc} 
Variáveis & \multicolumn{2}{c}{ MAX.-BC } & \multicolumn{2}{c}{ MAND } & \multicolumn{2}{c}{ ABA } \\
\hline & $\mathbf{r}$ & $\mathbf{p}$ & $\mathbf{r}$ & $\mathbf{r}$ & $\mathbf{p}$ & $\mathbf{r}$ \\
$\mathbf{6 s}$ & 0,0770 & 0,6322 & $-0,5256$ & $\mathbf{0 , 0 0 0 4}$ & $-0,5900$ & $\mathbf{0 , 0 0 0 1}$ \\
$\mathbf{6 i}$ & 0,4488 & $\mathbf{0 , 0 0 3 2}$ & $-0,7589$ & $\mathbf{0 , 0 0 0 1}$ & $-0,7357$ & $\mathbf{0 , 0 0 0 1}$ \\
$\mathbf{1 S}$ & 0,2739 & 0,0831 & $-0,4467$ & $\mathbf{0 , 0 0 3 4}$ & $-0,4312$ & $\mathbf{0 , 0 0 4 9}$ \\
$\mathbf{1 i}$ & 0,4151 & $\mathbf{0 , 0 0 7 0}$ & $-0,8163$ & $\mathbf{0 , 0 0 0 1}$ & $-0,8136$ & $\mathbf{0 , 0 0 0 1}$ \\
$\mathbf{6 / 6}$ & $-0,1442$ & 0,3684 & 0,4823 & $\mathbf{0 , 0 0 1 4}$ & 0,5162 & $\mathbf{0 , 0 0 0 6}$ \\
$\mathbf{1 / 1}$ & 0,1957 & 0,2201 & 0,0905 & 0,5738 & 0,1729 & 0,2798 \\
Rot.MAX & $-0,3074$ & 0,0506 & 0,2483 & 0,1175 & 0,1900 & 0,2342 \\
Rot MAND & 0,2018 & 0,2057 & $-0,5651$ & $\mathbf{0 , 0 0 0 1}$ & $-0,5914$ & $\mathbf{0 , 0 0 0 1}$ \\
I. LITTLE & 0,0314 & 0,8457 & $-0,2646$ & 0,0946 & $-0,2963$ & 0,0600 \\
\hline
\end{tabular}

Os coeficientes de correlação apresentados nas Tabelas de 5.27 a 5.34 demonstram que, de forma geral, quanto maior o crescimento da mandíbula em relação à maxila, maior será a probabilidade de os molares e incisivos superiores moverem-se para frente, de os incisivos inferiores inclinarem-se para lingual, e de a ancoragem molar inferior ser preservada.

Além disso, essas tabelas também demonstraram que as rotações da maxila e da mandíbula apresentaram coeficientes de correlação em relação às variáveis do crescimento, os quais foram estatisticamente pequenos e não significantes.

Embora a alteração da base apical (ABA) e o crescimento da mandíbula apresentem coeficientes de correlação significantes com quase todas as alterações molares e incisais nos diferentes grupos avaliados, eles não se relacionaram com o retorno da irregularidade dos incisivos inferiores. 


\subsubsection{Correlações adicionais}

Foram calculados os coeficientes de correlação, para toda a amostra, entre as alterações pós-tratamento do índice de Little (IL PC - IL final) e as alterações pós-tratamento das variáveis rotação da maxila, rotação da mandíbula e trespasse vertical (PC - final).

Os resultados dessas correlações encontram-se na Tabela 5.35, tendo sido considerados estatisticamente pequenos e não significantes. Apenas o aumento do trespasse vertical mostrou uma leve relação com o retorno da irregularidade incisal.

TABELA 5.35 - Coeficientes de correlação ( $r$ ) e níveis descritivos ( $p$ ) para a relação entre as alterações pós-tratamento do índice de Little e as rotações maxilar e mandibular, e o trespasse vertical (PC - final)

\begin{tabular}{lcc} 
Variáveis & $\boldsymbol{r}$ & $\boldsymbol{p}$ \\
\hline Rotação da maxila PC - Final & -0.0594 & 0.5575 \\
Rotação da mandíbula PC - Final & 0.1863 & 0.0635 \\
Trespasse vertical PC - Final & 0.2543 & $\mathbf{0 . 0 1 0 7}$ \\
\hline
\end{tabular}

Também foram calculados os coeficientes de correlação, para toda a amostra, entre as alterações pós-tratamento do trespasse vertical (PC - final) e as rotações maxilar e mandibular ( $\mathrm{PC} X$ final), bem como a relação entre as rotações.

Os resultados dessas correlações encontram-se na Tabela 5.36, tendo sido considerados estatisticamente pequenos e não significantes. Portanto, as rotações da maxila e da mandíbula ocorridas no período pós-tratamento não 
apresentaram relação significante com a recidiva do trespasse vertical. Apenas as rotações da maxila e da mandíbula apresentaram uma leve relação entre si.

TABELA 5.36 - Coeficientes de correlação ( $r$ ) e níveis descritivos (p) para a relação entre as alterações pós-tratamento do trespasse vertical (PC - final) e as rotações maxilar e mandibular (PC X final), bem como entre as rotações

\begin{tabular}{llcc}
\multicolumn{1}{c}{ Variáveis } & \multicolumn{1}{c}{ Variáveis } & $\boldsymbol{r}$ & $\boldsymbol{p}$ \\
\hline Rotação da maxila PC - F & Trespasse vertical PC- F & 0,1093 & 0,2789 \\
Rotação da mandíbula PC - F & Trespasse vertical PC- F & $-0,0606$ & 0,5492 \\
Rotação da mandíbula PC - F & Rotação da maxila PC - F & 0,3680 & $\mathbf{0 , 0 0 0 2}$ \\
\hline
\end{tabular}

\subsection{TESTES DE HIPÓTESES PARA ANÁLISE CONVENCIONAL}

Após a medição das telerradiografias iniciais, finais e de pós-contenção dos pacientes pertencentes às 5 categorias de crescimento de PETROVIC, foram obtidas as médias e desvios padrão das 33 variáveis da análise convencional, utilizadas para se estudar a posição e o comprimento da maxila e da mandíbula, as relações intermaxilares, verticais, dentárias e o perfil tegumentar.

A partir das variáveis acima, foram realizados testes entre as 5 categorias de crescimento e entre os grupos de rotação mandibular: posterior $(P)$, anterior (A) e neutra $(\mathrm{N})$. Em todas as análises, a variável EGU foi utilizada como covariada.

Na Tabela 5.37 encontram-se as médias e os desvios padrão das variáveis da análise convencional para as 5 categorias de crescimento; na Tabela 5.38 encontram-se os testes de hipóteses relacionados com essas 
variáveis, comparando essas categorias nas fases inicial, final e de póscontenção. Isso também pode ser visualizado nas Figuras de 5.16 a 5.35.

TABELA 5.37 - Médias e desvios padrão das variáveis da análise convencional por categoria de crescimento, nas fases inicial $(I)$, final $(F)$, e de pós-contenção $(\mathrm{PC})$

\begin{tabular}{|c|c|c|c|c|c|c|c|c|c|c|}
\hline \multirow[t]{2}{*}{ Variáveis } & \multicolumn{10}{|c|}{ Categorias } \\
\hline & \multicolumn{2}{|c|}{1} & \multicolumn{2}{|c|}{2} & \multicolumn{2}{|c|}{3} & \multicolumn{2}{|c|}{4} & \multicolumn{2}{|c|}{5} \\
\hline & Média & DP & Média & DP & Média & DP & Média & DP & Média & DP \\
\hline Maxilares & & & & & & & & & & \\
\hline SNAI & 84.36 & 1.98 & 82.16 & 2.92 & 82.99 & 1.88 & 79.84 & 3.12 & 78.74 & 3.02 \\
\hline SNA F & 81.97 & 2.44 & 80.80 & 3.08 & 81.12 & 2.18 & 78.22 & 3.06 & 76.64 & 2.89 \\
\hline SNA PC & 81.74 & 2.58 & 80.66 & 2.90 & 81.47 & 2.79 & 78.99 & 3.83 & 77.57 & 2.79 \\
\hline A-Nperp I & 1.27 & 2.97 & 0.24 & 3.10 & 0.91 & 2.48 & 0.11 & 1.95 & -1.77 & 2.45 \\
\hline A-Nperp F & -0.29 & 2.40 & -1.63 & 3.53 & -1.19 & 3.45 & -2.49 & 2.94 & -3.83 & 3.61 \\
\hline A-Nperp PC & -0.03 & 3.22 & -1.10 & 3.10 & -0.29 & 3.05 & -1.41 & 2.82 & -3.36 & 3.22 \\
\hline Co-A I & 82.56 & 4.11 & 82.11 & 4.41 & 83.57 & 4.40 & 80.29 & 3.51 & 83.30 & 4.90 \\
\hline Co-A F & 82.65 & 3.99 & 82.50 & 4.22 & 84.87 & 4.97 & 81.44 & 3.65 & 84.07 & 5.03 \\
\hline Co-A PC & 84.67 & 4.58 & 85.41 & 5.29 & 87.46 & 5.09 & 83.79 & 3.64 & 85.74 & 4.36 \\
\hline Ar-A I & 81.03 & 4.22 & 80.22 & 4.44 & 81.81 & 4.28 & 78.19 & 3.70 & 82.00 & 4.26 \\
\hline$A r-A F$ & 80.87 & 4.28 & 80.46 & 4.05 & 82.81 & 5.21 & 78.77 & 4.13 & 82.01 & 4.71 \\
\hline $\begin{array}{l}\text { Ar-A PC } \\
\text { Mandibulares }\end{array}$ & 82.19 & 4.57 & 82.97 & 5.29 & 85.55 & 5.39 & 81.36 & 4.58 & 83.45 & 4.51 \\
\hline SNB I & 77.23 & 2.35 & 77.39 & 3.63 & 77.04 & 2.23 & 76.73 & 3.42 & 73.98 & 2.23 \\
\hline SNB F & 76.85 & 2.88 & 77.16 & 3.61 & 77.20 & 2.64 & 76.41 & 3.67 & 73.95 & 2.95 \\
\hline SNB PC & 76.63 & 2.65 & 77.27 & 3.64 & 77.56 & 3.72 & 76.92 & 4.95 & 74.47 & 3.22 \\
\hline Pog-Nperp I & -9.81 & 6.42 & -7.16 & 6.56 & -8.07 & 5.27 & -4.26 & 4.23 & -10.22 & 4.15 \\
\hline Pog-Nperp F & -8.95 & 6.02 & -7.77 & 7.03 & -7.57 & 7.61 & -4.91 & 5.51 & -9.46 & 5.06 \\
\hline Pog-Nperp PC & -8.37 & 7.33 & -5.88 & 6.19 & -5.59 & 6.78 & -2.84 & 7.05 & -8.82 & 4.92 \\
\hline Co-Gn I & 104.92 & 5.21 & 105.53 & 4.83 & 105.24 & 5.73 & 105.38 & 4.36 & 104.30 & 6.04 \\
\hline Co-Gn F & 108.73 & 6.59 & 109.04 & 5.04 & 110.75 & 6.44 & 109.84 & 5.15 & 109.43 & 6.51 \\
\hline Co-Gn PC & 112.53 & 6.93 & 113.68 & 5.98 & 115.27 & 7.38 & 112.85 & 6.34 & 111.63 & 6.21 \\
\hline Ar-Gn I & 98.35 & 6.05 & 98.72 & 3.85 & 98.08 & 5.22 & 97.75 & 4.41 & 97.97 & 5.14 \\
\hline Ar-Gn F & 101.87 & 6.95 & 102.06 & 3.99 & 103.47 & 6.59 & 101.77 & 5.55 & 102.24 & 5.82 \\
\hline $\begin{array}{l}\text { Ar-Gn PC } \\
\text { Intermaxilares }\end{array}$ & 104.18 & 7.31 & 105.83 & 4.91 & 107.70 & 7.70 & 104.97 & 7.47 & 104.02 & 5.94 \\
\hline ANB I & 7.13 & 1.53 & 4.77 & 2.37 & 5.94 & 1.58 & 3.11 & 0.90 & 4.76 & 1.99 \\
\hline ANB $F$ & 5.13 & 1.40 & 3.64 & 1.77 & 3.92 & 1.48 & 1.81 & 1.57 & 2.70 & 1.90 \\
\hline ANB PC & 5.11 & 1.97 & 3.39 & 1.99 & 3.91 & 2.25 & 2.07 & 2.25 & 3.10 & 1.89 \\
\hline WITS I & -0.12 & 2.52 & -0.45 & 4.70 & 1.12 & 2.01 & -2.50 & 2.09 & 0.48 & 2.42 \\
\hline WITS F & 1.50 & 2.76 & 0.86 & 3.59 & 1.07 & 2.30 & -1.76 & 1.67 & 0.19 & 2.36 \\
\hline $\begin{array}{l}\text { WITS PC } \\
\text { Verticais }\end{array}$ & 0.61 & 2.36 & 0.57 & 4.07 & 1.06 & 2.31 & -0.91 & 2.52 & 0.77 & 2.29 \\
\hline SN.PP I & 6.67 & 2.94 & 7.90 & 3.07 & 7.79 & 2.32 & 7.61 & 3.90 & 9.13 & 3.26 \\
\hline SN.PP F & 8.03 & 2.80 & 8.61 & 2.90 & 8.89 & 2.92 & 8.16 & 3.68 & 10.61 & 3.01 \\
\hline SN.PP PC & 7.87 & 2.85 & 8.63 & 2.75 & 8.63 & 3.08 & 8.39 & 4.10 & 9.66 & 2.76 \\
\hline SN.Ocl I & 22.31 & 3.64 & 19.72 & 4.52 & 19.47 & 4.65 & 21.51 & 6.36 & 22.30 & 3.86 \\
\hline SN.Ocl F & 18.36 & 3.42 & 16.84 & 4.47 & 17.15 & 4.46 & 18.80 & 6.03 & 20.04 & 5.71 \\
\hline SN.Ocl PC & 19.71 & 5.12 & 16.90 & 4.90 & 16.87 & 5.35 & 17.79 & 7.02 & 19.81 & 6.09 \\
\hline SN.PM I & 40.25 & 4.17 & 35.94 & 5.82 & 34.99 & 5.19 & 35.82 & 6.80 & 34.71 & 4.82 \\
\hline SN.PM F & 40.59 & 4.66 & 36.04 & 6.18 & 34.46 & 5.56 & 35.14 & 7.63 & 34.70 & 5.64 \\
\hline SN.PM PC & 40.11 & 5.55 & 34.65 & 6.85 & 32.59 & 6.83 & 33.03 & 9.16 & 33.14 & 6.47 \\
\hline N.S.Gn I & 70.09 & 3.28 & 69.18 & 3.71 & 69.06 & 3.45 & 69.74 & 4.30 & 70.67 & 2.82 \\
\hline N.S.Gn F & 70.51 & 3.66 & 69.61 & 4.10 & 69.22 & 3.71 & 69.77 & 4.62 & 70.74 & 3.49 \\
\hline N.S.Gn PC & 71.00 & 3.73 & 69.37 & 4.33 & 68.69 & 4.53 & 68.85 & 5.57 & 70.26 & 3.98 \\
\hline Ba.N.Gn I & 85.81 & 3.97 & 87.64 & 3.79 & 87.15 & 4.78 & 86.90 & 4.13 & 88.16 & 2.82 \\
\hline Ba.N.Gn F & 85.37 & 4.07 & 86.82 & 4.03 & 87.41 & 4.52 & 86.83 & 5.03 & 88.00 & 2.92 \\
\hline Ba.N.Gn PC & 85.22 & 4.19 & 87.55 & 4.20 & 88.27 & 5.47 & 88.44 & 5.96 & 88.23 & 3.08 \\
\hline FMA I & 33.25 & 4.58 & 27.88 & 6.69 & 27.02 & 5.11 & 25.61 & 4.89 & 25.34 & 3.85 \\
\hline$F M A F$ & 32.89 & 4.34 & 28.40 & 7.04 & 26.69 & 6.14 & 25.78 & 5.96 & 25.06 & 4.28 \\
\hline FMA PC & 31.80 & 5.86 & 26.32 & 7.19 & 24.29 & 6.14 & 23.39 & 6.93 & 23.91 & 4.56 \\
\hline $\mathrm{N}-\mathrm{Me} I$ & 111.76 & 7.31 & 109.23 & 5.92 & 109.66 & 7.24 & 109.61 & 4.25 & 110.40 & 6.17 \\
\hline $\mathrm{N}-\mathrm{Me} F$ & 116.19 & 8.60 & 113.92 & 7.76 & 115.64 & 7.96 & 114.17 & 4.01 & 115.47 & 7.59 \\
\hline
\end{tabular}


continuação da TABELA 5.37

\begin{tabular}{|c|c|c|c|c|c|c|c|c|c|c|}
\hline \multirow[t]{2}{*}{ Variáveis } & \multicolumn{10}{|c|}{ Categorias } \\
\hline & \multicolumn{2}{|r|}{1} & \multicolumn{2}{|c|}{2} & \multicolumn{2}{|c|}{3} & \multicolumn{2}{|c|}{4} & \multicolumn{2}{|c|}{5} \\
\hline & Média & DP & Média & DP & Média & DP & Média & DP & Média & DP \\
\hline$N-M e P C$ & 118.89 & 8.54 & 117.02 & 8.49 & 118.56 & 6.99 & 115.53 & 4.48 & 116.57 & 6.72 \\
\hline S-Go I & 70.80 & 5.11 & 73.27 & 4.85 & 73.42 & 4.88 & 73.11 & 5.50 & 74.34 & 5.23 \\
\hline S-Go F & 73.89 & 6.51 & 77.04 & 5.77 & 78.98 & 6.45 & 77.45 & 6.53 & 78.44 & 6.46 \\
\hline S-Go $P C$ & 76.77 & 7.33 & 80.68 & 7.36 & 82.69 & 7.06 & 80.29 & 8.83 & 80.63 & 7.56 \\
\hline AFP:AFA I & 63.39 & 3.05 & 67.17 & 4.69 & 67.06 & 4.16 & 66.80 & 5.68 & 67.38 & 3.63 \\
\hline AFP:AFA F & 63.61 & 3.61 & 67.77 & 4.56 & 68.39 & 4.54 & 67.90 & 6.07 & 67.99 & 4.21 \\
\hline AFP:AFA PC & 64.55 & 3.93 & 69.01 & 5.04 & 69.81 & 5.54 & 69.53 & 7.59 & 69.19 & 5.30 \\
\hline AFAII & 67.73 & 6.25 & 63.61 & 5.25 & 63.87 & 6.47 & 62.66 & 4.16 & 63.23 & 5.98 \\
\hline AFAI $F$ & 69.77 & 6.33 & 66.51 & 6.34 & 66.86 & 7.12 & 64.61 & 4.06 & 65.71 & 6.53 \\
\hline AFAI PC & 71.69 & 6.62 & 68.14 & 6.80 & 68.81 & 6.84 & 65.14 & 4.54 & 66.55 & 6.18 \\
\hline \multicolumn{11}{|l|}{ Dentárias } \\
\hline 1s.SN I & 112.38 & 6.65 & 108.30 & 5.71 & 112.61 & 6.51 & 107.84 & 8.85 & 105.37 & 10.67 \\
\hline 1s.SN F & 101.89 & 4.91 & 102.88 & 5.94 & 102.07 & 5.74 & 100.60 & 7.52 & 99.90 & 7.63 \\
\hline 1s.SN PC & 103.01 & 5.94 & 103.03 & 7.38 & 103.56 & 6.37 & 102.16 & 8.92 & 99.67 & 7.76 \\
\hline 1.NAI & 28.01 & 6.47 & 26.15 & 5.87 & 29.62 & 6.17 & 27.99 & 8.11 & 26.62 & 10.70 \\
\hline 1.NAF & 19.89 & 5.18 & 22.06 & 5.05 & 20.95 & 5.97 & 22.39 & 6.44 & 23.24 & 7.13 \\
\hline 1.NAPC & 21.26 & 6.08 & 22.38 & 7.12 & 22.09 & 6.45 & 23.16 & 8.34 & 22.12 & 7.29 \\
\hline 1-NA I & 6.01 & 1.93 & 5.39 & 2.49 & 6.46 & 2.53 & 6.17 & 3.25 & 6.11 & 3.77 \\
\hline 1-NA F & 1.67 & 1.68 & 2.23 & 2.13 & 2.33 & 1.93 & 3.55 & 1.86 & 2.70 & 2.49 \\
\hline 1-NA PC & 2.88 & 2.27 & 3.50 & 2.36 & 3.39 & 1.94 & 3.78 & 2.25 & 3.23 & 2.49 \\
\hline 1.NB I & 30.30 & 6.03 & 28.17 & 6.07 & 28.90 & 4.84 & 24.89 & 3.84 & 26.39 & 5.22 \\
\hline 1.NB F & 26.56 & 6.13 & 23.50 & 6.25 & 24.92 & 7.15 & 24.23 & 6.49 & 23.81 & 4.82 \\
\hline 1.NB PC & 27.83 & 6.73 & 22.77 & 6.17 & 25.77 & 7.44 & 21.54 & 5.48 & 23.32 & 4.20 \\
\hline $1-N B I$ & 7.39 & 2.35 & 6.24 & 2.72 & 6.63 & 2.03 & 4.72 & 1.48 & 5.39 & 1.87 \\
\hline 1-NB F & 5.99 & 1.86 & 4.15 & 2.08 & 4.65 & 2.14 & 3.57 & 1.74 & 3.61 & 1.40 \\
\hline 1-NB PC & 6.43 & 2.21 & 4.35 & 2.41 & 4.99 & 2.45 & 3.19 & 1.75 & 3.67 & 1.40 \\
\hline FMIA I & 53.91 & 7.43 & 57.30 & 8.09 & 56.10 & 5.82 & 62.06 & 3.51 & 56.97 & 5.13 \\
\hline FMIA $F$ & 57.98 & 6.41 & 61.29 & 7.07 & 60.03 & 7.43 & 61.54 & 5.92 & 59.76 & 4.64 \\
\hline FMIA PC & 57.12 & 6.63 & 62.82 & 7.20 & 60.08 & 8.18 & 64.98 & 6.15 & 60.38 & 3.87 \\
\hline IMPA I & 92.82 & 5.35 & 94.83 & 9.91 & 96.87 & 4.77 & 92.34 & 5.76 & 97.70 & 5.00 \\
\hline IMPA F & 89.13 & 6.00 & 90.31 & 9.49 & 93.29 & 7.74 & 92.67 & 8.64 & 95.17 & 5.67 \\
\hline IMPA PC & 91.08 & 6.73 & 90.86 & 8.19 & 95.63 & 7.00 & 91.61 & 7.00 & 95.71 & 4.12 \\
\hline 1-APog I & 2.92 & 2.30 & 2.93 & 2.40 & 2.67 & 2.18 & 2.34 & 1.49 & 1.74 & 2.09 \\
\hline 1-APog $F$ & 2.18 & 2.14 & 1.00 & 1.92 & 1.31 & 2.01 & 1.31 & 1.65 & 0.81 & 1.65 \\
\hline 1-APog PC & 2.54 & 2.57 & 1.10 & 2.38 & 1.53 & 2.39 & 0.55 & 1.52 & 0.43 & 1.75 \\
\hline $1.1 I$ & 114.56 & 8.14 & 120.90 & 11.02 & 115.53 & 7.51 & 123.99 & 8.90 & 122.22 & 12.99 \\
\hline $1.1 \mathrm{~F}$ & 128.42 & 7.34 & 130.79 & 8.84 & 130.21 & 10.07 & 131.59 & 9.76 & 130.24 & 7.85 \\
\hline $1.1 P C$ & 125.79 & 9.44 & 131.47 & 11.40 & 128.21 & 9.92 & 133.21 & 10.63 & 131.47 & 8.45 \\
\hline \multicolumn{11}{|c|}{ Tegumentares } \\
\hline$L s-E I$ & 0.61 & 2.04 & -0.81 & 2.35 & 0.41 & 1.89 & -1.69 & 1.64 & -1.36 & 2.40 \\
\hline$L s-E F$ & -3.48 & 2.60 & -3.80 & 1.82 & -3.22 & 2.22 & -4.95 & 2.09 & -5.33 & 1.88 \\
\hline$L s-E P C$ & -4.22 & 2.22 & -5.08 & 2.03 & -4.49 & 2.11 & -7.17 & 2.62 & -6.20 & 2.08 \\
\hline Li-E I & 2.92 & 3.03 & 0.44 & 2.62 & 0.83 & 2.30 & -0.12 & 2.24 & -0.03 & 1.87 \\
\hline Li-E F & -0.76 & 3.27 & -2.17 & 2.11 & -1.95 & 2.40 & -3.84 & 2.22 & -3.68 & 1.81 \\
\hline Li-E PC & -1.25 & 2.90 & -3.63 & 2.72 & -3.15 & 2.64 & -5.11 & 3.24 & -4.48 & 2.33 \\
\hline ZI & 59.78 & 9.23 & 67.90 & 7.06 & 66.27 & 5.57 & 70.59 & 5.75 & 66.32 & 5.60 \\
\hline$Z F$ & 68.42 & 7.17 & 72.64 & 7.00 & 72.24 & 5.36 & 77.12 & 4.47 & 73.99 & 4.87 \\
\hline$Z P C$ & 69.23 & 8.37 & 76.20 & 6.71 & 75.17 & 6.25 & 80.22 & 9.13 & 75.53 & 4.44 \\
\hline H-Pn I & -0.95 & 3.42 & 1.50 & 3.91 & -0.63 & 3.17 & 2.91 & 2.81 & 2.47 & 4.13 \\
\hline$H-P n F$ & 5.91 & 4.38 & 6.73 & 3.28 & 5.45 & 3.77 & 8.65 & 3.79 & 9.41 & 3.43 \\
\hline H-Pn PC & 7.14 & 3.77 & 8.91 & 3.54 & 7.82 & 3.79 & 12.21 & 4.48 & 10.98 & 3.64 \\
\hline
\end{tabular}


TABELA 5.38 - Testes de hipóteses para avaliar as diferenças das variáveis da análise convencional entre as fases inicial, final e de pós-contenção por categoria

\begin{tabular}{|c|c|c|c|c|c|c|c|}
\hline Variáveis & Categorias & Momentos & $\begin{array}{l}\text { Categorias X } \\
\text { Momentos }\end{array}$ & $I X F$ & $I X P C$ & $F X P C$ & Tukey $\mathbf{5 \%}$ \\
\hline \multicolumn{8}{|l|}{ Maxilares } \\
\hline SNA & 0.0001 & 0.0001 & 0.0562 & 0.0001 & 0.0001 & 0.0422 & $\begin{array}{l}1 \times 2,1 \times 5,2 \times 3,2 \times 4,3 \times 5 \\
4 \times 5\end{array}$ \\
\hline A-Nperp & 0.0018 & 0.0001 & 0.9714 & 0.0001 & 0.0001 & 0.0081 & $1 \times 2,2 \times 3,2 \times 4$ \\
\hline Co-A & 0.1467 & 0.0001 & 0.3381 & 0.0045 & 0.0001 & 0.0001 & \\
\hline$A r-A$ & 0.0806 & 0.0001 & 0.0128 & 0.1589 & 0.0001 & 0.0001 & $\begin{array}{l}\text { Início: } 2 \times 5,4 \times 5 \\
\text { Final: } 2 \times 5,4 \times 5 \\
\text { PC: } 1 \times 4\end{array}$ \\
\hline \multicolumn{8}{|l|}{ Mandibulares } \\
\hline SNB & 0.0031 & 0.3343 & 0.6299 & 0.3535 & 0.5918 & 0.1440 & $1 \times 2,2 \times 3,2 \times 4,2 \times 5$ \\
\hline Pog-Nperp & 0.0500 & 0.0003 & 0.8432 & 0.6898 & 0.0003 & 0.0011 & $1 \times 5,2 \times 5$ \\
\hline Co-Gn & 0.7790 & 0.0001 & 0.1531 & 0.0001 & 0.0001 & 0.0001 & \\
\hline $\begin{array}{l}\text { Ar-Gn } \\
\text { Intermaxilares }\end{array}$ & 0.8043 & 0.0001 & 0.0469 & 0.0001 & 0.0001 & 0.0001 & PC: $2 \times 4$ \\
\hline ANB & 0.0001 & 0.0001 & 0.3780 & 0.0001 & 0.0001 & 0.6415 & $\begin{array}{l}1 \times 2,1 \times 3,1 \times 4,1 \times 5,2 \times 4 \\
2 \times 5,3 \times 5,4 \times 5\end{array}$ \\
\hline WITS & 0.0210 & 0.0019 & 0.0311 & 0.0030 & 0.0015 & 0.8328 & $\begin{array}{l}\text { Início: } 1 \times 5,2 \times 5,3 \times 5,4 \times 5 \\
\text { Final: } 1 \times 5,2 \times 5,3 \times 5,4 \times 5 \\
\text { PC: } 4 \times 5\end{array}$ \\
\hline \multicolumn{8}{|l|}{ Verticais } \\
\hline SN.PP & 0.1597 & 0.0001 & 0.5143 & 0.0001 & 0.0001 & 0.2028 & \\
\hline SN.Ocl & 0.1335 & 0.0001 & 0.7783 & 0.0001 & 0.0001 & 0.9505 & \\
\hline SN.PM & 0.0153 & 0.0001 & 0.2161 & 0.5530 & 0.0001 & 0.0001 & $1 \times 2,1 \times 3,1 \times 4,1 \times 5$ \\
\hline SN.Gn & 0.5608 & 0.1493 & 0.1895 & 0.2092 & 0.5037 & 0.0551 & \\
\hline Ba.N.Gn & 0.3898 & 0.0112 & 0.0793 & 0.2682 & 0.0605 & 0.0031 & \\
\hline$F M A$ & 0.0003 & 0.0001 & 0.6424 & 0.8407 & 0.0001 & 0.0001 & $1 \times 2,1 \times 3,1 \times 4,1 \times 5$ \\
\hline $\mathrm{N}-\mathrm{Me}$ & 0.8349 & 0.0001 & 0.2056 & 0.0001 & 0.0001 & 0.0001 & \\
\hline S-Go & 0.2075 & 0.0001 & 0.1709 & 0.0001 & 0.0001 & 0.0001 & \\
\hline$A F P: A F A$ & 0.0299 & 0.0001 & 0.4964 & 0.0008 & 0.0001 & 0.0001 & $1 \times 2,1 \times 3,1 \times 4,1 \times 5$ \\
\hline $\begin{array}{l}\text { AFAl } \\
\text { Dentárias }\end{array}$ & 0.1137 & 0.0001 & 0.2247 & 0.0001 & 0.0001 & 0.0001 & \\
\hline $1 s . S N$ & 0.0474 & 0.0001 & 0.3404 & 0.0001 & 0.0001 & 0.3400 & $1 \times 2,2 \times 4$ \\
\hline 1.NA & 0.9283 & 0.0001 & 0.4618 & 0.0001 & 0.0001 & 0.5657 & \\
\hline 1-NA & 0.6256 & 0.0001 & 0.6428 & 0.0001 & 0.0001 & 0.0033 & \\
\hline 1.NB & 0.0568 & 0.0001 & 0.4081 & 0.0001 & 0.0001 & 0.5527 & \\
\hline 1-NB & 0.0003 & 0.0001 & 0.6315 & 0.0001 & 0.0001 & 0.4617 & $\begin{array}{l}1 \times 2,1 \times 3,1 \times 4,1 \times 5,2 \times 4 \\
4 \times 5\end{array}$ \\
\hline FMIA & 0.0239 & 0.0001 & 0.3686 & 0.0001 & 0.0001 & 0.1275 & $1 \times 3,1 \times 5,2 \times 5,4 \times 5$ \\
\hline IMPA & 0.0318 & 0.0001 & 0.3106 & 0.0001 & 0.0015 & 0.1496 & $1 \times 2,1 \times 4,2 \times 3$ \\
\hline 1i-APog & 0.1539 & 0.0001 & 0.0780 & 0.0001 & 0.0001 & 0.5775 & \\
\hline $\begin{array}{l}1.1 \\
\text { Tegumentares }\end{array}$ & 0.0807 & 0.0001 & 0.3811 & 0.0001 & 0.0001 & 0.8348 & \\
\hline$L s-E$ & 0.0002 & 0.0001 & 0.3923 & 0.0001 & 0.0001 & 0.0001 & $1 \times 2,1 \times 5,2 \times 4,3 \times 5,4 \times 5$ \\
\hline$L i-E$ & 0.0002 & 0.0001 & 0.6688 & 0.0001 & 0.0001 & 0.0001 & $\begin{array}{l}1 \times 2,1 \times 3,1 \times 4,1 \times 5,2 \times 4 \\
4 \times 5\end{array}$ \\
\hline $\mathbf{Z}$ & 0.0001 & 0.0001 & 0.6401 & 0.0001 & 0.0001 & 0.0001 & $\begin{array}{l}1 \times 2,1 \times 3,1 \times 4,1 \times 5,2 \times 5 \\
4 \times 5\end{array}$ \\
\hline$H-P n$ & 0.0001 & 0.0001 & 0.5213 & 0.0001 & 0.0001 & 0.0001 & $\begin{array}{l}1 \times 2,1 \times 5,2 \times 3,2 \times 4,3 \times 5 \\
4 \times 5\end{array}$ \\
\hline
\end{tabular}


As Tabelas 5.37 e 5.38 e as Figuras de 5.16 a 5.35 demonstram que, de forma geral, as 5 categorias de crescimento possuem uma morfologia dentoesquelética diferente nas diferentes fases analisadas.

Com relação à posição e ao tamanho da maxila, pode ser observado que, na fase inicial, os pacientes da categoria 1 tendem a apresentar uma maxila protruída em comparação aos pacientes da categoria 5, enquanto os pacientes da categoria 4 possuem uma maxila bem posicionada (variável A-Nperp) e com menor comprimento. Em todas as categorias, a posição e o comprimento da maxila são diferentes nas fases inicial, final e de pós-contenção.

Os pacientes da categoria 5 foram os que se apresentaram com a mandíbula mais retruída em relação à base do crânio durante todas as fases analisadas. Entretanto, esses pacientes não apresentaram maior diminuição do comprimento da mandíbula em relação aos pacientes das demais categorias.

A relação intermaxilar avaliada pela variável ANB mostrou que os pacientes da categoria 1 apresentaram diferença maior entre a posição ânteroposterior da maxila e a da mandíbula em todas as fases analisadas. Já a medida WITS mostrou os pacientes da categoria 5 com um valor diferente em relação às demais categorias; entretanto, esses valores giram em torno da normalidade para essa variável, que seria de $0 \mathrm{~mm}$ para as mulheres e de $1 \mathrm{~mm}$ para os homens.

Com relação às variáveis verticais, observou-se que as medidas SN.PP, SN.Ocl, SN.Gn, N-Me, S-Go e AFAI não apresentaram diferenças entre as categorias nas diferentes fases estudadas. Já a inclinação do plano mandibular avaliada pelas medidas SN.PM e FMA foi maior para os pacientes da categoria 1 
em relação às demais categorias. Apesar das alturas faciais anterior (N-Me) e posterior (S-Go) não terem apresentado diferenças entre as categorias, a sua proporção foi menor para a categoria 1 em relação às demais, provavelmente devido ao menor valor da altura facial posterior nos pacientes da categoria 1.

Os incisivos superiores praticamente não mostraram diferença no seu posicionamento entre as diferentes categorias. Já os incisivos inferiores mostraram-se mais protruídos na categoria 1 e mais próximos da normalidade na categoria 4.

Com relação ao perfil tegumentar, observou-se que os pacientes da categoria 1 apresentaram maior protrusão labial no início do tratamento, enquanto os da categoria 4 apresentaram-se com valores levemente protruídos, quase próximos da normalidade. Entretanto, no período pós-contenção, observou-se que os pacientes da categoria 1 estavam com um perfil dentro da normalidade, enquanto os pacientes da categoria 4 estavam com o perfil retruído.

Nas Tabelas de 5.39 a 5.44 encontram-se os valores para as variáveis da análise convencional correspondentes às alterações do tratamento (final - inicial), do período pós-tratamento (pós-contenção - final) e totais (pós-contenção inicial), bem como os testes de hipóteses realizados a fim de avaliar se as diferenças médias foram diferentes nas categorias de crescimento, e se houve diferenças significativas entre os momentos. Foram utilizadas, como covariadas, as variáveis: a EGU referente ao período de tratamento, a EGU referente ao período pós-contenção e a EGU total (EGU tratamento+ EGU pós-contenção). 
TABELA 5.39 - Alterações médias do tratamento (Final - Inicial) para as variáveis da análise convencional por categoria de crescimento

\begin{tabular}{|c|c|c|c|c|c|}
\hline \multirow[t]{2}{*}{ Variáveis } & \multicolumn{5}{|c|}{ Categorias } \\
\hline & 1 & 2 & 3 & 4 & 5 \\
\hline \multicolumn{6}{|l|}{ Maxilares } \\
\hline SNA & $-2,39$ & $-1,36$ & $-1,87$ & $-1,62$ & $-2,1$ \\
\hline A-Nperp & $-1,56$ & $-1,87$ & $-2,1$ & $-2,6$ & $-2,06$ \\
\hline Co-A & 0,09 & 0,39 & 1,3 & 1,15 & 0,77 \\
\hline$A r-A$ & $-0,16$ & 0,24 & 1 & 0,58 & 0,01 \\
\hline \multicolumn{6}{|c|}{ Mandibulares } \\
\hline SNB & $-0,38$ & $-0,23$ & 0,16 & $-0,32$ & $-0,03$ \\
\hline Pog-Nperp & 0,86 & $-0,61$ & 0,5 & $-0,65$ & 0,76 \\
\hline Co-Gn & 3,81 & 3,51 & 5,51 & 4,46 & 5,13 \\
\hline$A r-G n$ & 3,52 & 3,34 & 5,39 & 4,02 & 4,27 \\
\hline \multicolumn{6}{|c|}{ Intermaxilares } \\
\hline ANB & -2 & $-1,13$ & $-2,02$ & $-1,3$ & $-2,06$ \\
\hline WITS & 1,62 & 1,31 & $-0,05$ & 0,74 & $-0,29$ \\
\hline \multicolumn{6}{|l|}{ Verticais } \\
\hline SN.PP & 1,36 & 0,71 & 1,1 & 0,55 & 1,48 \\
\hline SN.Ocl & $-3,95$ & $-2,88$ & $-2,32$ & $-2,71$ & $-2,26$ \\
\hline SN.PM & 0,34 & 0,1 & $-0,53$ & $-0,68$ & $-0,01$ \\
\hline SN.Gn & 0,42 & 0,43 & 0,16 & 0,03 & 0,07 \\
\hline Ba.N.Gn & $-0,44$ & $-0,82$ & 0,26 & $-0,07$ & $-0,16$ \\
\hline$F M A$ & $-0,36$ & 0,52 & $-0,33$ & 0,17 & $-0,28$ \\
\hline $\mathrm{N}-\mathrm{Me}$ & 4,43 & 4,69 & 5,98 & 4,56 & 5,07 \\
\hline S-Go & 3,09 & 3,77 & 5,56 & 4,34 & 4,1 \\
\hline$A F P: A F A$ & 0,22 & 0,6 & 1,33 & 1,1 & 0,61 \\
\hline $\begin{array}{l}\text { AFAI } \\
\text { Dentárias }\end{array}$ & 2,04 & 2,9 & 2,99 & 1,95 & 2,48 \\
\hline $1 \mathrm{s.SN}$ & $-10,49$ & $-5,42$ & $-10,54$ & $-7,24$ & $-5,47$ \\
\hline 1.NA & $-8,12$ & $-4,09$ & $-8,67$ & $-5,6$ & $-3,38$ \\
\hline 1-NA & $-4,34$ & $-3,16$ & $-4,13$ & $-2,62$ & $-3,41$ \\
\hline 1.NB & $-3,74$ & $-4,67$ & $-3,98$ & $-0,66$ & $-2,58$ \\
\hline 1-NB & $-1,4$ & $-2,09$ & $-1,98$ & $-1,15$ & $-1,78$ \\
\hline FMIA & 4,07 & 3,99 & 3,93 & $-0,52$ & 2,79 \\
\hline IMPA & $-3,69$ & $-4,52$ & $-3,58$ & 0,33 & $-2,53$ \\
\hline 1i-APog & $-0,74$ & $-1,93$ & $-1,36$ & $-1,03$ & $-0,93$ \\
\hline 1.1 & 13,86 & 9,89 & 14,68 & 7,6 & 8,02 \\
\hline \multicolumn{6}{|c|}{ Tegumentares } \\
\hline$L s-E$ & $-3,68$ & $-2,61$ & $-2,78$ & $-3,72$ & $-3,65$ \\
\hline$L i-E$ & $-3,68$ & $-2,61$ & $-2,78$ & $-3,72$ & $-3,65$ \\
\hline $\mathbf{Z}$ & 8,64 & 4,74 & 5,97 & 6,53 & 7,67 \\
\hline$H-P n$ & 6,86 & 5,23 & 6,08 & 5,74 & 6,94 \\
\hline
\end{tabular}


TABELA 5.40 - Testes de hipóteses para avaliar as diferenças médias das variáveis da análise convencional quanto às alterações do tratamento (Final Inicial) por categoria de crescimento

\begin{tabular}{|c|c|c|c|c|c|c|c|c|c|}
\hline \multirow{2}{*}{ Variáveis } & \multirow[t]{2}{*}{ Diferenças } & \multirow[t]{2}{*}{ Categorias } & \multicolumn{5}{|c|}{ Categorias } & \multirow[t]{2}{*}{$E G U$} & \multirow{2}{*}{$\begin{array}{c}\text { Tukey } \\
\mathbf{5 \%}\end{array}$} \\
\hline & & & 1 & 2 & 3 & 4 & 5 & & \\
\hline Maxilares & & & & & & & & & \\
\hline SNA & 0,0001 & 0,3253 & & & & & & 0,0068 & \\
\hline A-Nperp & 0,0001 & 0,7961 & & & & & & 0,0001 & \\
\hline Co-A & 0,0004 & 0,3722 & & & & & & 0,0158 & \\
\hline $\begin{array}{l}\text { Ar-A } \\
\text { Mandibulares }\end{array}$ & 0,0375 & 0,2220 & & & & & & 0,0106 & \\
\hline SNB & 0,3957 & 0,7031 & & & & & & 0,2365 & \\
\hline Pog-Nperp & 0,5701 & 0,6108 & & & & & & 0,0585 & \\
\hline Co-Gn & 0,0001 & 0,0287 & 0,0001 & 0,0001 & 0,0001 & 0,0001 & 0,0001 & 0,0001 & $2 \times 3$ \\
\hline $\begin{array}{l}\text { Ar-Gn } \\
\text { Intermaxilares }\end{array}$ & 0,0001 & 0,0065 & 0,0001 & 0,0001 & 0,0001 & 0,0001 & 0,0001 & 0,0001 & $1 \times 3,2 \times 3$ \\
\hline ANB & 0,0001 & 0,0815 & & & & & & 0,0001 & \\
\hline $\begin{array}{l}\text { WITS } \\
\text { Verticais }\end{array}$ & 0,0157 & 0,0255 & 0,0308 & 0,0110 & 0,9132 & 0,1524 & 0,4030 & 0,9753 & - \\
\hline SN.PP & 0,0001 & 0,4629 & & & & & & 0,0181 & \\
\hline SN.Ocl & 0,0001 & 0,6515 & & & & & & 0,0309 & \\
\hline SN.PM & 0,3424 & 0,3990 & & & & & & 0,7039 & \\
\hline SN.Gn & 0,1100 & 0,8299 & & & & & & 0,8092 & \\
\hline Ba.N.Gn & 0,2250 & 0,2970 & & & & & & 0,5808 & \\
\hline FMA & 0,7414 & 0,7030 & & & & & & 0,0383 & \\
\hline $\mathrm{N}-\mathrm{Me}$ & 0,0001 & 0,2685 & & & & & & 0,0001 & \\
\hline S-Go & 0,0001 & 0,0011 & 0,0001 & 0,0001 & 0,0001 & 0,0001 & 0,0001 & 0,0001 & $1 \times 3,2 \times 3$ \\
\hline$A F P: A F A$ & 0,0001 & 0,1357 & & & & & & 0,0660 & \\
\hline AFAI & 0,0001 & 0,4961 & & & & & & 0,0001 & \\
\hline $\begin{array}{l}\text { Dentárias } \\
\text { 1s. SN }\end{array}$ & & & & & & & & & \\
\hline $\begin{array}{l}\text { 1s.SN } \\
1 N A\end{array}$ & 0,0001 & 0,1809 & & & & & & 0,0124 & \\
\hline $\begin{array}{l}1 . N A \\
1-N A\end{array}$ & 0,0001 & 0,2399 & & & & & & 0,0035 & \\
\hline 1-NA & 0,0001 & 0,5349 & & & & & & 0,0685 & \\
\hline 1.NB & 0,0001 & 0,4402 & & & & & & 0,0479 & \\
\hline $1-N B$ & 0,0001 & 0,5068 & & & & & & 0,1450 & \\
\hline FMIA & 0,0001 & 0,2556 & & & & & & 0,1694 & \\
\hline IMPA & 0,0001 & 0,3027 & & & & & & 0,0396 & \\
\hline 1i-APog & 0,0001 & 0,2773 & & & & & & 0,7558 & \\
\hline 1.1 & 0,0001 & 0,1962 & & & & & & 0,4511 & \\
\hline Tegumentares & & & & & & & & & \\
\hline$L s-E$ & 0,0001 & 0,3292 & & & & & & 0,0013 & \\
\hline$L i-E$ & 0,0001 & 0,2503 & & & & & & 0,0110 & \\
\hline $\mathbf{Z}$ & 0,0001 & 0,2503 & & & & & & 0,8010 & \\
\hline$H-P n$ & 0.0001 & 0.4176 & & & & & & 0.0023 & \\
\hline
\end{tabular}


As Tabelas 5.39 e 5.40 mostram que as alterações do tratamento avaliadas pela análise convencional não foram diferentes em relação à posição e ao comprimento da maxila nas diferentes categorias de crescimento.

Para a posição mandibular, não foi observada diferença significante entre as diferentes categorias de crescimento; entretanto, a mandíbula apresentou um maior crescimento na categoria 3 que nas categorias 1 e 2.

As alterações nas relações intermaxilares não mostraram diferenças entre as categorias durante o período de tratamento.

Para as variáveis verticais, apenas a altura facial posterior (S-Go) mostrou diferença significante entre as categorias. Os pacientes da categoria 3 apresentaram um maior crescimento facial posterior que os pacientes das categorias 1 e 2.

As variáveis dentárias e tegumentares também não apresentaram diferenças significantes nas alterações durante o tratamento nas diferentes categorias de crescimento. 
TABELA 5.41 - Alterações médias pós-tratamento (Pós-contenção X Final) para as variáveis da análise convencional por categoria de crescimento

\begin{tabular}{|c|c|c|c|c|c|}
\hline \multirow[t]{2}{*}{ Variáveis } & \multicolumn{5}{|c|}{ Categorias } \\
\hline & 1 & 2 & 3 & 4 & 5 \\
\hline \multicolumn{6}{|l|}{ Maxilares } \\
\hline SNA & $-0,23$ & $-0,14$ & 0,35 & 0,77 & 0,93 \\
\hline A-Nperp & 0,26 & 0,53 & 0,9 & 1,08 & 0,47 \\
\hline Co-A & 2,02 & 2,91 & 2,59 & 2,35 & 1,67 \\
\hline$A r-A$ & 1,32 & 2,51 & 2,74 & 2,59 & 1,44 \\
\hline \multicolumn{6}{|c|}{ Mandibulares } \\
\hline SNB & $-0,22$ & 0,11 & 0,36 & 0,51 & 0,52 \\
\hline Pog-Nperp & 0,58 & 1,89 & 1,98 & 2,07 & 0,64 \\
\hline Co-Gn & 3,8 & 4,64 & 4,52 & 3,01 & 2,2 \\
\hline \multicolumn{6}{|c|}{ Intermaxilares } \\
\hline ANB & $-0,02$ & $-0,25$ & $-0,01$ & 0,26 & 0,4 \\
\hline WITS & $-0,89$ & $-0,29$ & $-0,01$ & 0,85 & 0,58 \\
\hline \multicolumn{6}{|l|}{ Verticais } \\
\hline SN.PP & $-0,16$ & 0,02 & $-0,26$ & 0,23 & $-0,95$ \\
\hline SN.Ocl & 1,35 & 0,06 & $-0,28$ & $-1,01$ & $-0,23$ \\
\hline SN.PM & $-0,48$ & $-1,39$ & $-1,87$ & $-2,11$ & $-1,56$ \\
\hline SN.Gn & 0,49 & $-0,24$ & $-0,53$ & $-0,92$ & $-0,48$ \\
\hline Ba.N.Gn & $-0,15$ & 0,73 & 0,86 & 1,61 & 0,23 \\
\hline FMA & $-1,09$ & $-2,08$ & $-2,4$ & $-2,39$ & $-1,15$ \\
\hline$N-M e$ & 2,7 & 3,1 & 2,92 & 1,36 & 1,1 \\
\hline S-Go & 2,88 & 3,64 & 3,71 & 2,84 & 2,19 \\
\hline$A F P: A F A$ & 0,94 & 1,24 & 1,42 & 1,63 & 1,2 \\
\hline $\begin{array}{l}\text { AFAl } \\
\text { Dentárias }\end{array}$ & 1,92 & 1,63 & 1,95 & 0,53 & 0,84 \\
\hline 1s.SN & 1,12 & 0,15 & 1,49 & 1,56 & $-0,23$ \\
\hline 1.NA & 1,37 & 0,32 & 1,14 & 0,77 & $-1,12$ \\
\hline 1-NA & $-4,34$ & $-3,16$ & $-4,13$ & $-2,62$ & $-3,41$ \\
\hline 1.NB & 1,27 & $-0,73$ & 0,85 & $-2,69$ & $-0,49$ \\
\hline 1-NB & 0,44 & 0,2 & 0,34 & $-0,38$ & 0,06 \\
\hline FMIA & $-0,86$ & 1,53 & 0,05 & 3,44 & 0,62 \\
\hline IMPA & 1,95 & 0,55 & 2,34 & $-1,06$ & 0,54 \\
\hline 1i-APog & 0,36 & 0,1 & 0,22 & $-0,76$ & $-0,38$ \\
\hline 1.1 & $-2,63$ & 0,68 & -2 & 1,62 & 1,23 \\
\hline \multicolumn{6}{|c|}{ Tegumentares } \\
\hline$L s-E$ & $-0,74$ & $-1,28$ & $-1,27$ & $-2,22$ & $-0,87$ \\
\hline$L i-E$ & $-0,49$ & $-1,46$ & $-1,2$ & $-1,27$ & $-0,8$ \\
\hline $\mathbf{Z}$ & 0,81 & 3,56 & 2,93 & 3,1 & 1,54 \\
\hline$H-P n$ & 1,23 & 2,18 & 2,37 & 3,56 & 1,57 \\
\hline
\end{tabular}


TABELA 5.42 - Testes de hipóteses para avaliar as diferenças médias das variáveis da análise convencional quanto às alterações pós-tratamento (póscontenção - final) por categoria de crescimento

\begin{tabular}{|c|c|c|c|c|c|c|c|c|c|}
\hline \multirow{2}{*}{ Variáveis } & \multirow[t]{2}{*}{ Diferenças } & \multirow[t]{2}{*}{ Categorias } & \multicolumn{5}{|c|}{ Categorias } & \multirow[t]{2}{*}{$E G U$} & \multirow{2}{*}{$\begin{array}{c}\text { Tukey } \\
5 \%\end{array}$} \\
\hline & & & 1 & 2 & 3 & 4 & 5 & & \\
\hline \multicolumn{10}{|l|}{ Maxilares } \\
\hline SNA & 0,0032 & 0,0075 & 0,4485 & 0,4756 & 0,1600 & 0,0696 & 0,0008 & 0,0614 & $1 \times 5,2 \times 5$ \\
\hline A-Nperp & 0,0006 & 0,6920 & & & & & & 0,6491 & \\
\hline Co-A & 0,0001 & 0,4589 & & & & & & 0,0067 & \\
\hline $\begin{array}{l}\text { Ar-A } \\
\text { Mandibula }\end{array}$ & 0,0001 & 0,1321 & & & & & & 0,0003 & \\
\hline SNB & 0,0572 & 0,5454 & \multicolumn{7}{|c|}{ Mandibulares } \\
\hline Pog-Nperp & 0,0003 & 0,5890 & & & & & & 0,0131 & \\
\hline Co-Gn & 0,0001 & 0,0690 & & & & & & 0,0001 & \\
\hline$A r-G n$ & 0,0001 & 0,0552 & & & & & & 0,0001 & \\
\hline \multicolumn{10}{|c|}{ Intermaxilares } \\
\hline ANB & 0,5441 & 0,4403 & & & & & & 0,0111 & \\
\hline WITS & 0,7864 & 0,1023 & & & & & & 0,8390 & \\
\hline \multicolumn{10}{|l|}{ Verticais } \\
\hline SN.PP & 0,0559 & 0,1101 & & & & & & 0,1073 & \\
\hline SN.Ocl & 0,8531 & 0,3065 & & & & & & 0,0082 & \\
\hline SN.PM & 0,0001 & 0,2916 & & & & & & 0,0001 & \\
\hline SN.Gn & 0,0212 & 0,1442 & & & & & & 0,0026 & \\
\hline Ba.N.Gn & 0,0022 & 0,1608 & & & & & & 0,0036 & \\
\hline$F M A$ & 0,0001 & 0,3449 & & & & & & 0,0001 & \\
\hline $\mathrm{N}-\mathrm{Me}$ & 0,0001 & 0,1601 & & & & & & 0,0023 & \\
\hline S-Go & 0,0001 & 0,3752 & & & & & & 0,0001 & \\
\hline AFP:AFA & 0,0001 & 0,8876 & & & & & & 0,0001 & \\
\hline AFAI & 0,0001 & 0,2658 & & & & & & 0,0199 & \\
\hline \multicolumn{10}{|l|}{ Dentárias } \\
\hline $1 s . S N$ & 0,1303 & 0,6999 & & & & & & 0,2268 & \\
\hline 1.NA & 0,3826 & 0,4823 & & & & & & 0,4352 & \\
\hline $1-N A$ & 0,0001 & 0,2162 & & & & & & 0,2998 & \\
\hline 1.NB & 0,6350 & 0,1324 & & & & & & 0,5604 & \\
\hline $1-N B$ & 0,2023 & 0,3622 & & & & & & 0,4428 & \\
\hline FMIA & 0,1084 & 0,1866 & & & & & & 0,1953 & \\
\hline IMPA & 0,0290 & 0,1916 & & & & & & 0,3243 & \\
\hline 1i-APog & 0,5936 & 0,0192 & 0,1981 & 0,7044 & 0,2548 & 0,0130 & 0,1380 & 0,8997 & $1 \times 4$ \\
\hline 1.1 & 0,6986 & 0,2590 & & & & & & 0,7775 & \\
\hline \multicolumn{10}{|c|}{ Tegumentares } \\
\hline$L s-E$ & 0,0001 & 0,0855 & & & & & & 0,0001 & \\
\hline$L i-E$ & 0,0001 & 0,5084 & & & & & & 0,0001 & \\
\hline $\mathbf{Z}$ & 0,0001 & 0,4611 & & & & & & 0,0048 & \\
\hline$H-P n$ & 0,0001 & 0,1397 & & & & & & 0,0614 & \\
\hline
\end{tabular}

As Tabelas 5.41 e 5.42 mostram que as alterações pós-tratamento avaliadas pela análise convencional foram diferentes em relação à posição da maxila, sendo que os pacientes da categoria 5 apresentaram um maior deslocamento anterior da maxila que os pacientes das categorias 1 e 2 . 
Quanto às alterações dentárias incisais, apenas a variável 1i-Pog apresentou uma maior lingualização dos incisivos inferiores na categoria 4 em relação à categoria 1 .

As variáveis mandibulares, intermaxilares, verticais e tegumentares não mostraram diferenças significantes para as alterações pós-tratamento nas diferentes categorias de crescimento.

TABELA 5.43 - Alterações médias totais (pós-contenção $X$ inicial) para as variáveis da análise convencional por categoria de crescimento

\begin{tabular}{|c|c|c|c|c|c|}
\hline \multirow[t]{2}{*}{ Variáveis } & \multicolumn{5}{|c|}{ Categorias } \\
\hline & 1 & 2 & 3 & 4 & 5 \\
\hline \multicolumn{6}{|l|}{ Maxilares } \\
\hline SNA & $-2,62$ & $-1,5$ & $-1,52$ & $-0,85$ & $-1,17$ \\
\hline A-Nperp & $-1,3$ & $-1,34$ & $-1,2$ & $-1,52$ & $-1,59$ \\
\hline Co-A & 2,11 & 3,3 & 3,89 & 3,5 & 2,44 \\
\hline$A r-A$ & 1,16 & 2,75 & 3,74 & 3,17 & 1,45 \\
\hline \multicolumn{6}{|c|}{ Mandibulares } \\
\hline SNB & $-0,6$ & $-0,12$ & 0,52 & 0,19 & 0,49 \\
\hline Pog-Nperp & 1,44 & 1,28 & 2,48 & 1,42 & 1,4 \\
\hline Co-Gn & 7,61 & 8,15 & 10,03 & 7,47 & 7,33 \\
\hline $\begin{array}{l}\text { Ar-Gn } \\
\text { Intermaxila }\end{array}$ & 5,83 & 7,11 & 9,62 & 7,22 & 6,05 \\
\hline ANB & $-2,02$ & $-1,38$ & $-2,03$ & $-1,04$ & $-1,66$ \\
\hline $\begin{array}{l}\text { WITS } \\
\text { Verticais }\end{array}$ & 0,73 & 1,02 & $-0,06$ & 1,59 & 0,29 \\
\hline SN.PP & 1,2 & 0,73 & 0,84 & 0,78 & 0,53 \\
\hline SN.Ocl & $-2,6$ & $-2,82$ & $-2,6$ & $-3,72$ & $-2,49$ \\
\hline SN.PM & $-0,14$ & $-1,29$ & $-2,4$ & $-2,79$ & $-1,57$ \\
\hline SN.Gn & 0,91 & 0,19 & $-0,37$ & $-0,89$ & $-0,41$ \\
\hline Ba.N.Gn & $-0,59$ & $-0,09$ & 1,12 & 1,54 & 0,07 \\
\hline$F M A$ & $-1,45$ & $-1,56$ & $-2,73$ & $-2,22$ & $-1,43$ \\
\hline$N-M e$ & 7,13 & 7,79 & 8,9 & 5,92 & 6,17 \\
\hline S-Go & 5,97 & 7,41 & 9,27 & 7,18 & 6,29 \\
\hline$A F P: A F A$ & 1,16 & 1,84 & 2,75 & 2,73 & 1,81 \\
\hline $\begin{array}{l}\text { AFAl } \\
\text { Dentárias }\end{array}$ & 3,96 & 4,53 & 4,94 & 2,48 & 3,32 \\
\hline $1 s . S N$ & $-9,37$ & $-5,27$ & $-9,05$ & $-5,68$ & $-5,7$ \\
\hline 1.NA & $-6,75$ & $-3,77$ & $-7,53$ & $-4,83$ & $-4,5$ \\
\hline 1-NA & $-3,13$ & $-1,89$ & $-3,07$ & $-2,39$ & $-2,88$ \\
\hline 1.NB & $-2,47$ & $-5,4$ & $-3,13$ & $-3,35$ & $-3,07$ \\
\hline $1-N B$ & $-0,96$ & $-1,89$ & $-1,64$ & $-1,53$ & $-1,72$ \\
\hline$F M I A$ & 3,21 & 5,52 & 3,98 & 2,92 & 3,41 \\
\hline IMPA & $-1,74$ & $-3,97$ & $-1,24$ & $-0,73$ & $-1,99$ \\
\hline 1i-APog & $-0,38$ & $-1,83$ & $-1,14$ & $-1,79$ & $-1,31$ \\
\hline 1.1 & 11,23 & 10,57 & 12,68 & 9,22 & 9,25 \\
\hline
\end{tabular}


continuação da TABELA 5.43

\begin{tabular}{lccccc} 
Variáveis & \multicolumn{5}{c}{ Categorias } \\
\cline { 2 - 6 } Tegumentares & $\mathbf{1}$ & $\mathbf{2}$ & $\mathbf{3}$ & $\mathbf{4}$ & $\mathbf{5}$ \\
Ls-E & & & & & \\
Li-E & $-4,83$ & $-4,27$ & $-4,9$ & $-5,48$ & $-4,84$ \\
$\mathbf{Z}$ & $-4,17$ & $-4,07$ & $-3,98$ & $-4,99$ & $-4,45$ \\
$\boldsymbol{H}-\boldsymbol{P n}$ & 9,45 & 8,3 & 8,9 & 9,63 & 9,21 \\
\hline
\end{tabular}

TABELA 5.44 - Testes de hipóteses para avaliar as diferenças médias das variáveis da análise convencional quanto às alterações totais (pós-contenção inicial) por categoria de crescimento

\begin{tabular}{|c|c|c|c|c|c|c|c|c|c|}
\hline Variáveis & Diferenças & Categorias & & & Pategoria & & & $E G U$ & Tukey \\
\hline & & & 1 & 2 & 3 & 4 & 5 & & $5 \%$ \\
\hline Maxilares & & & & & & & & & \\
\hline SNA & 0,0001 & 0,1068 & & & & & & 0,0725 & \\
\hline A-Nperp & 0,0001 & 0,9838 & & & & & & 0,0014 & \\
\hline Co-A & 0,0001 & 0,1528 & & & & & & 0,0001 & \\
\hline $\begin{array}{l}\text { Ar-A } \\
\text { Mandibulares }\end{array}$ & 0,0001 & 0,0012 & 0,0486 & 0,0001 & 0,0001 & 0,0008 & 0,0006 & 0,0001 & $1 \times 3,3 \times 5$ \\
\hline SNB & 0,4237 & 0,4167 & & & & & & 0,0034 & \\
\hline Pog-Nperp & 0,0004 & 0,8790 & & & & & & 0,1454 & \\
\hline Co-Gn & 0,0001 & 0,0953 & & & & & & 0,0001 & \\
\hline $\begin{array}{l}\text { Ar-Gn } \\
\text { Intermaxilares }\end{array}$ & 0,0001 & 0,0048 & 0,0003 & 0,0001 & 0,0001 & 0,0001 & 0,0001 & 0,0001 & $1 \times 3,3 \times 5$ \\
\hline ANB & 0,0001 & 0,4254 & & & & & & 0,0001 & \\
\hline $\begin{array}{l}\text { WITS } \\
\text { Verticais }\end{array}$ & 0,0097 & 0,1892 & & & & & & 0,4363 & \\
\hline SN.PP & 0,0001 & 0,8696 & & & & & & 0,2418 & \\
\hline SN.Ocl & 0,0001 & 0,8728 & & & & & & 0,0001 & \\
\hline SN.PM & 0,0001 & 0,0873 & & & & & & 0,0001 & \\
\hline SN.Gn & 0,4680 & 0,1249 & & & & & & 0,0089 & \\
\hline Ba.N.Gn & 0,0693 & 0,0496 & 0,2737 & 0,8522 & 0,0274 & 0,0743 & 0,8754 & 0,0018 & - \\
\hline FMA & 0,0001 & 0,5502 & & & & & & 0,0033 & \\
\hline $\mathrm{N}-\mathrm{Me}$ & 0,0001 & 0,0377 & 0,0001 & 0,0001 & 0,0001 & 0,0001 & 0,0001 & 0,0001 & \\
\hline S-Go & 0,0001 & 0,0162 & 0,0001 & 0,0001 & 0,0001 & 0,0001 & 0,0001 & 0,0001 & $1 \times 3,3 \times 5$ \\
\hline$A F P: A F A$ & 0,0001 & 0,1966 & & & & & & 0,0001 & \\
\hline AFAl & 0,0001 & 0,1005 & & & & & & 0,0007 & \\
\hline Dentárias & & & & & & & & & \\
\hline 1s.SN & 0,0001 & 0,4283 & & & & & & 0,0112 & \\
\hline 1.NA & 0,0001 & 0,5972 & & & & & & 0,0036 & \\
\hline 1-NA & 0,0001 & 0,6692 & & & & & & 0,0166 & \\
\hline 1.NB & 0,0001 & 0,5790 & & & & & & 0,1288 & \\
\hline $1-N B$ & 0,0001 & 0,6699 & & & & & & 0,1123 & \\
\hline FMIA & 0,0001 & 0,7202 & & & & & & 0,0778 & \\
\hline IMPA & 0,0008 & 0,4541 & & & & & & 0,7792 & \\
\hline 1i-APog & 0,0001 & 0,1314 & & & & & & 0,6497 & \\
\hline 1.1 & 0,0001 & 0,8137 & & & & & & 0,4395 & \\
\hline Tegumentares & & & & & & & & & \\
\hline$L s-E$ & 0,0001 & 0,4913 & & & & & & 0,0001 & \\
\hline$L i-E$ & 0,0001 & 0,7031 & & & & & & 0,0001 & \\
\hline $\mathbf{Z}$ & 0,0001 & 0,9636 & & & & & & 0,0369 & \\
\hline$H-P n$ & 0,0001 & 0,5988 & & & & & & 0.0001 & \\
\hline
\end{tabular}


As Tabelas 5.43 e 5.44 mostram que as alterações totais, ou seja, aquelas que compreenderam todo o período de estudo (de tratamento e de póstratamento), avaliadas pela análise convencional, foram diferentes para apenas três variáveis.

Durante esse período, a maxila cresceu mais na categoria $3(\operatorname{Ar}-\mathrm{A}=3,74$ $\mathrm{mm})$ que nas categorias $1(\operatorname{Ar}-\mathrm{A}=1,16 \mathrm{~mm})$ e $5(\operatorname{Ar}-\mathrm{A}=1,45 \mathrm{~mm})$.

A mandíbula apresentou um aumento maior em seu comprimento na categoria $3(\mathrm{Ar}-\mathrm{Gn}=9,62 \mathrm{~mm})$ que nas categorias $1(\mathrm{Ar}-\mathrm{Gn}=5,83 \mathrm{~mm})$ e $5(\mathrm{Ar}-$ $\mathrm{Gn}=6,05 \mathrm{~mm})$.

A altura facial posterior (S-Go) aumentou mais nos pacientes da categoria $3(9,27 \mathrm{~mm})$ que nos pacientes das categorias $1(5,97 \mathrm{~mm})$ e $5(6,29$ $\mathrm{mm})$.

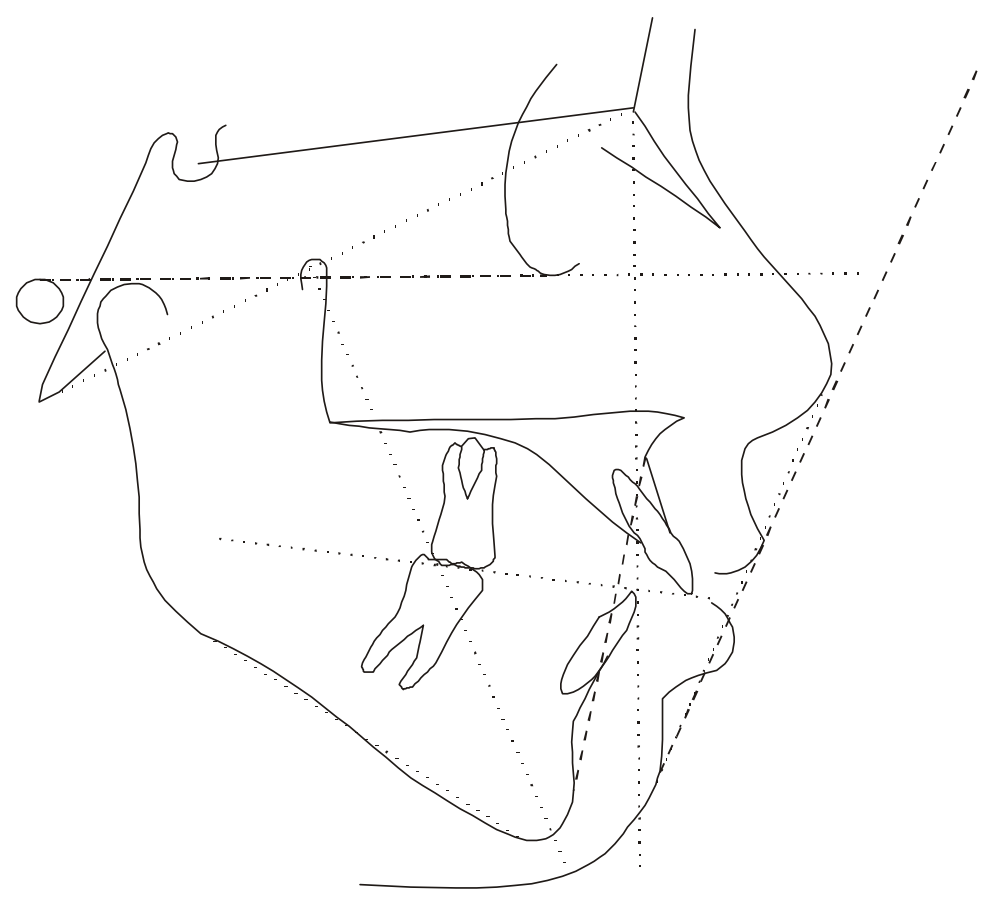

FIGURA 5.16 - Traçado composto médio para os pacientes da categoria 1 na fase inicial 


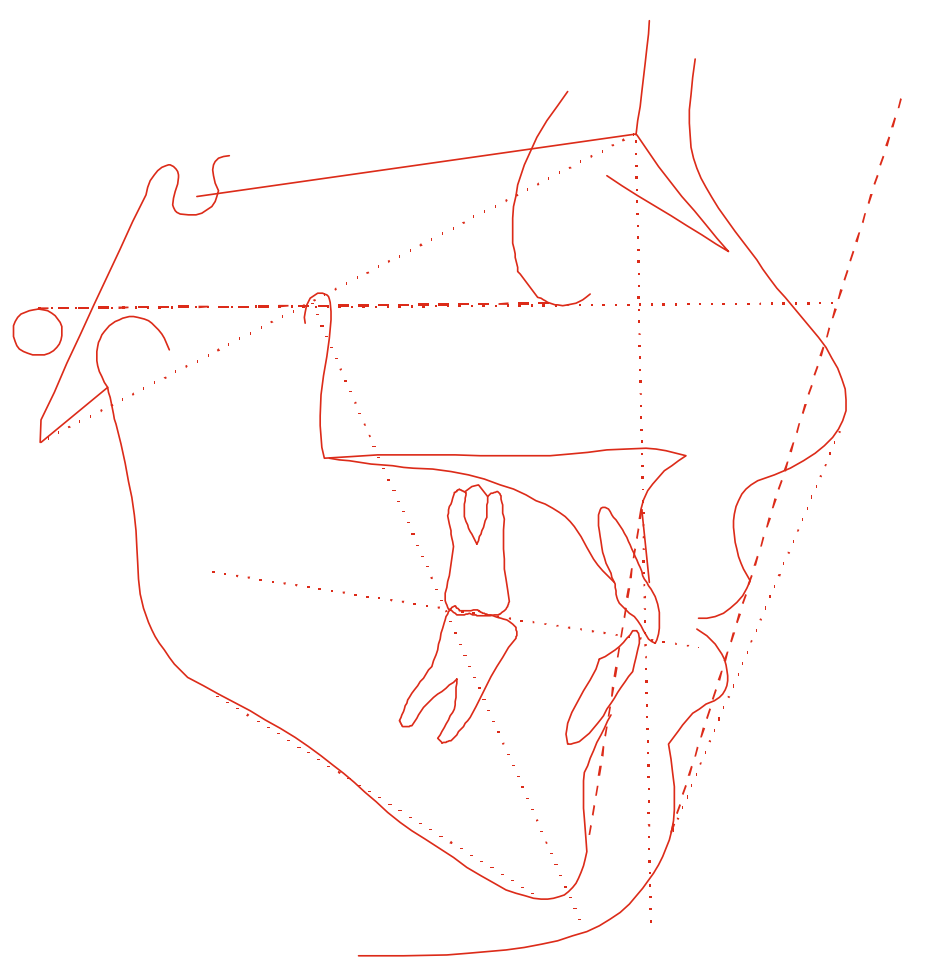

FIGURA 5.17 - Traçado composto médio para os pacientes da categoria 1 na fase final

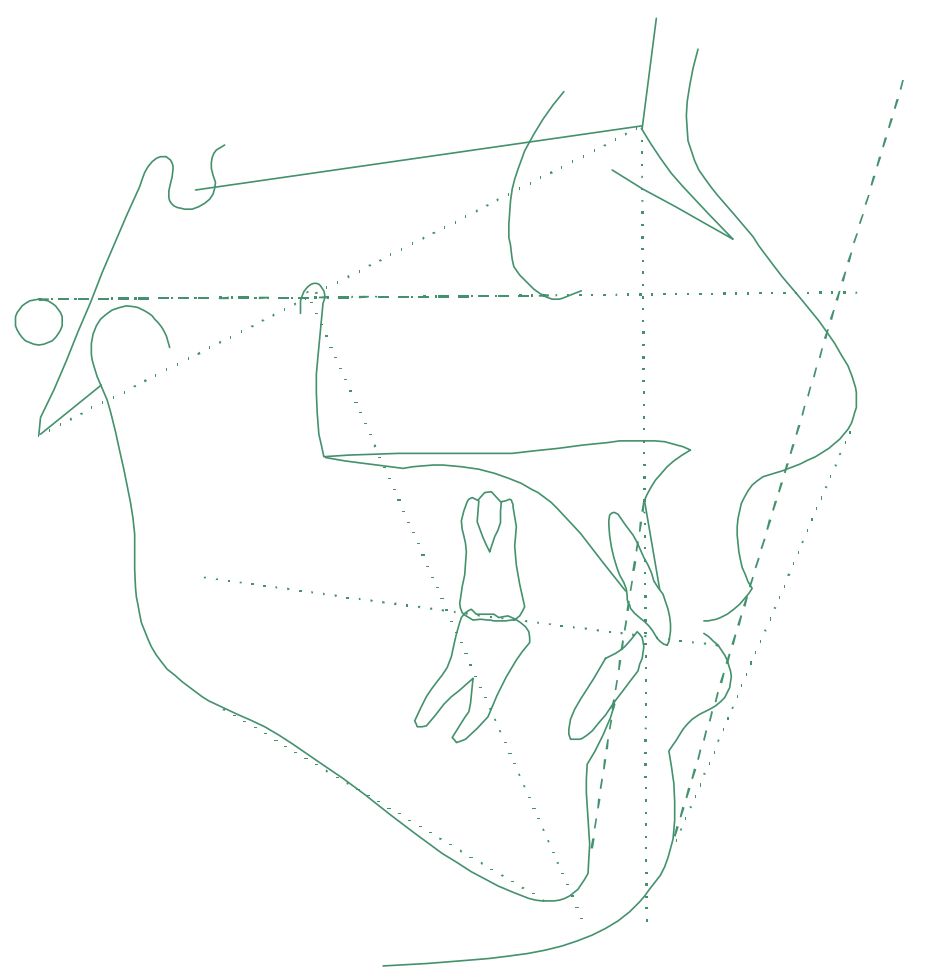

FIGURA 5.18 - Traçado composto médio para os pacientes da categoria 1 na fase de pós-contenção 


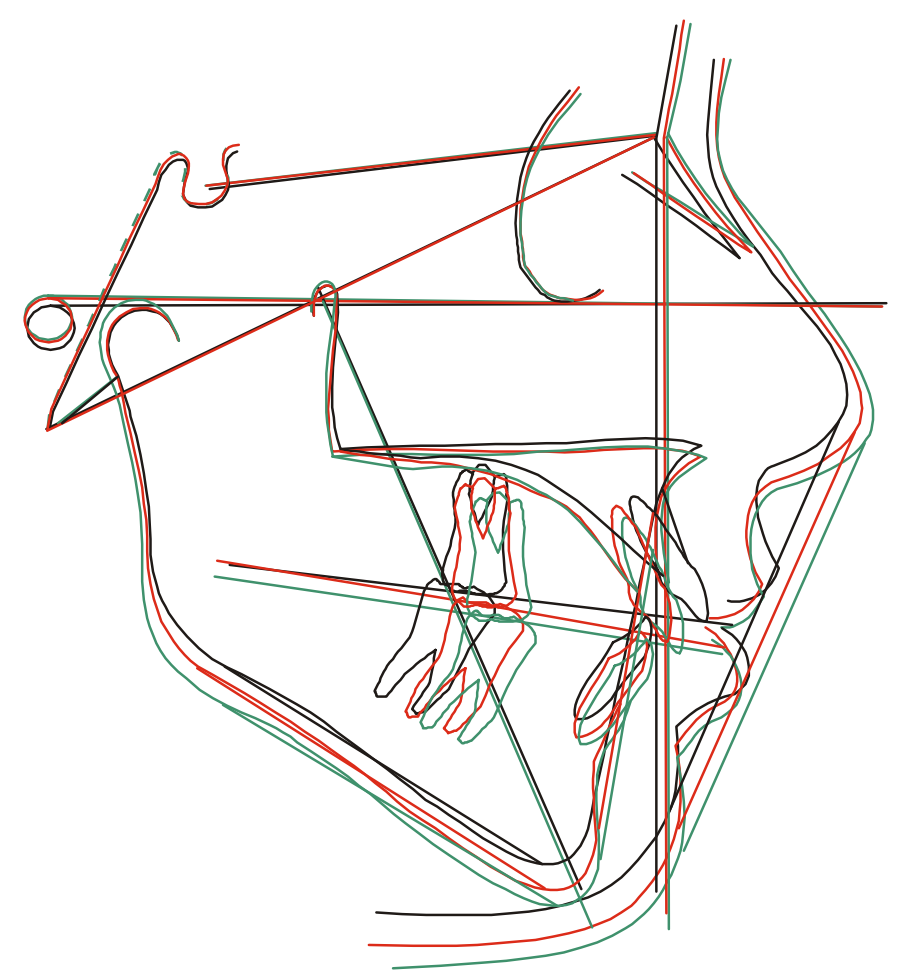

FIGURA 5.19 - Sobreposição dos traçados compostos médios para os pacientes da categoria 1 nas fases inicial, final e de pós-contenção

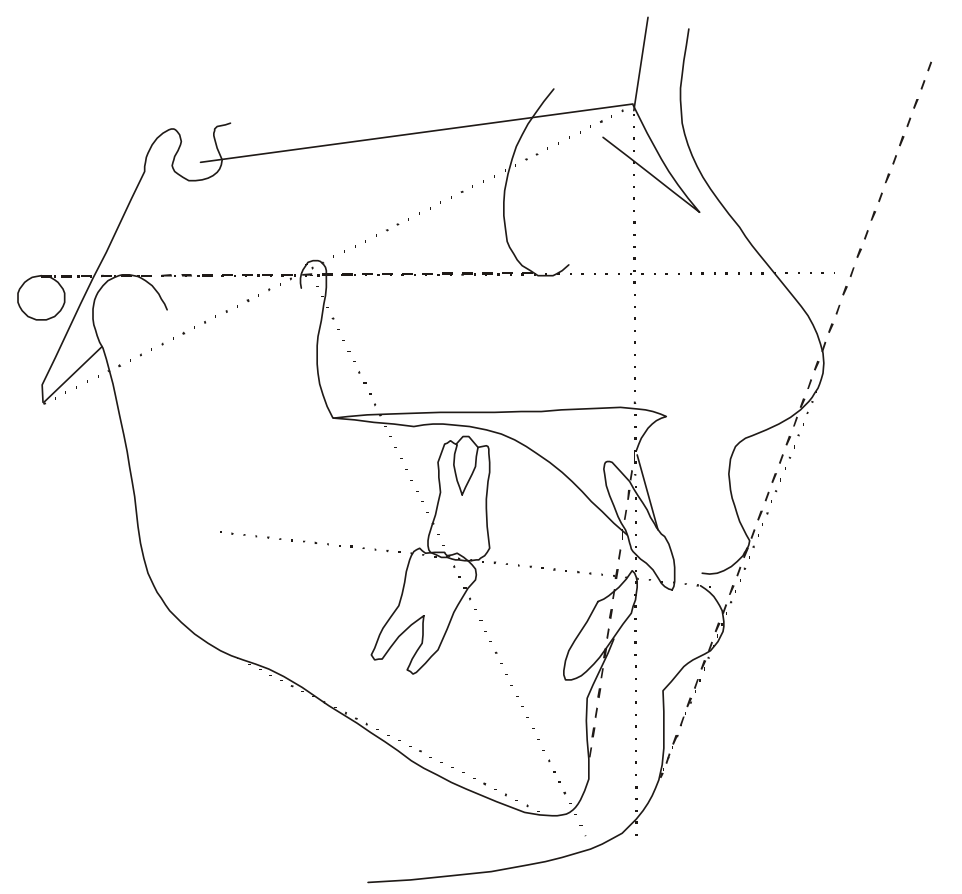

FIGURA 5.20 - Traçado composto médio para os pacientes da categoria 2 na fase inicial 


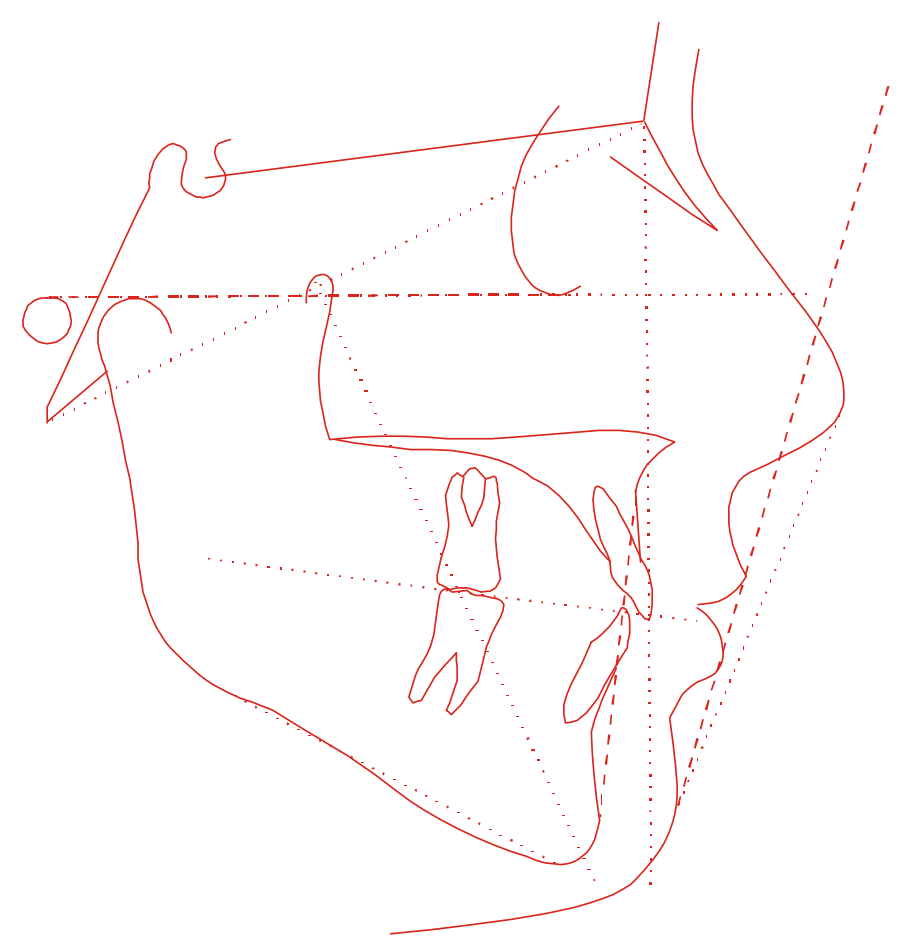

FIGURA 5.21 - Traçado composto médio para os pacientes da categoria 2 na fase final

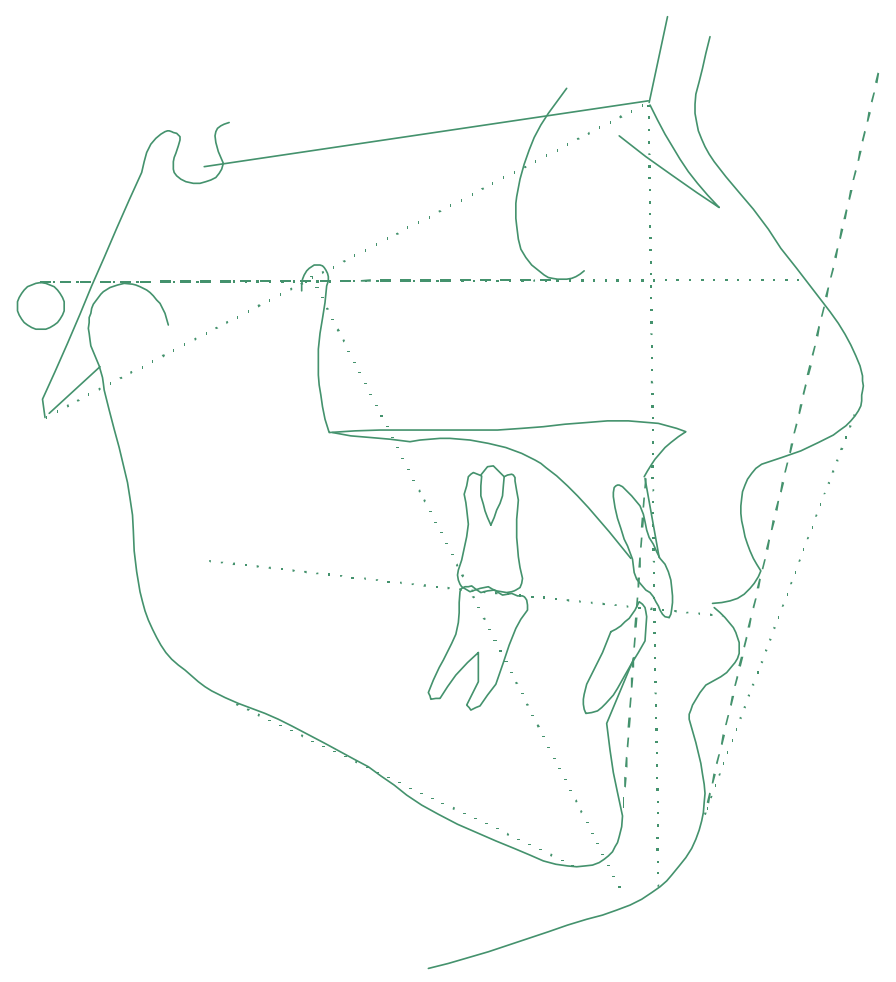

FIGURA 5.22 - Traçado composto médio para os pacientes da categoria 2 na fase de pós-contenção 


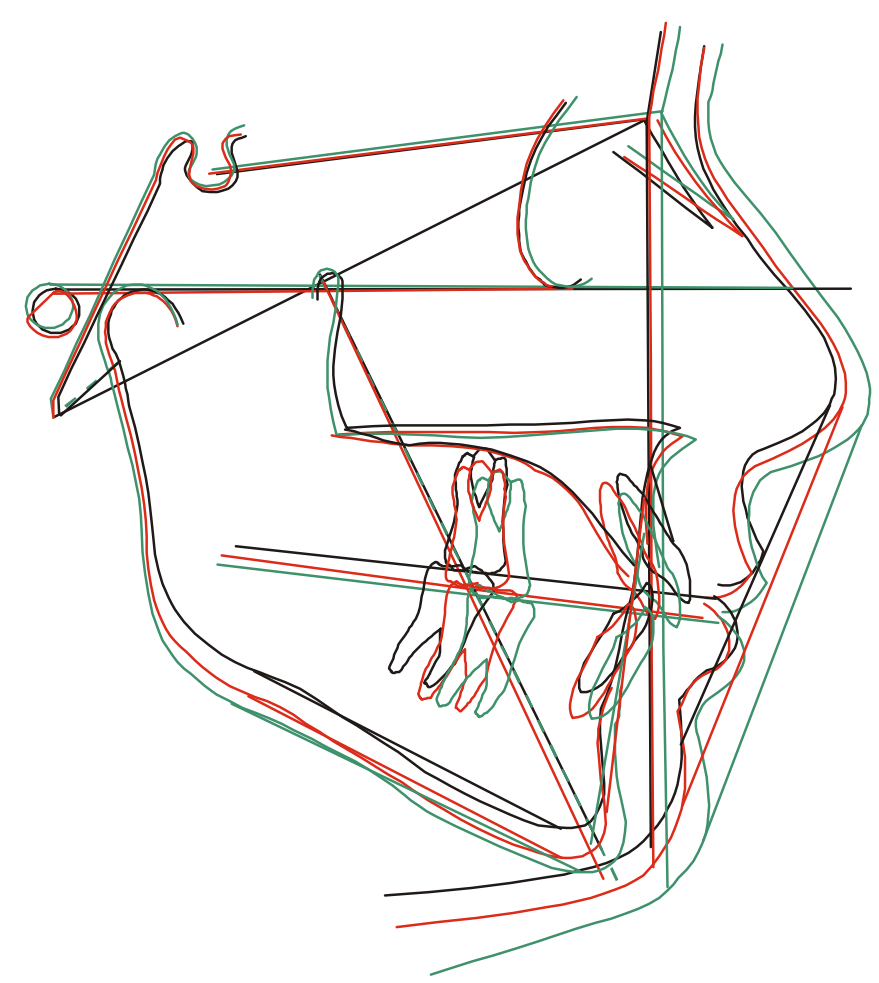

FIGURA 5.23 - Sobreposição dos traçados compostos médios para os pacientes da categoria 2 nas fases inicial, final e de pós-contenção

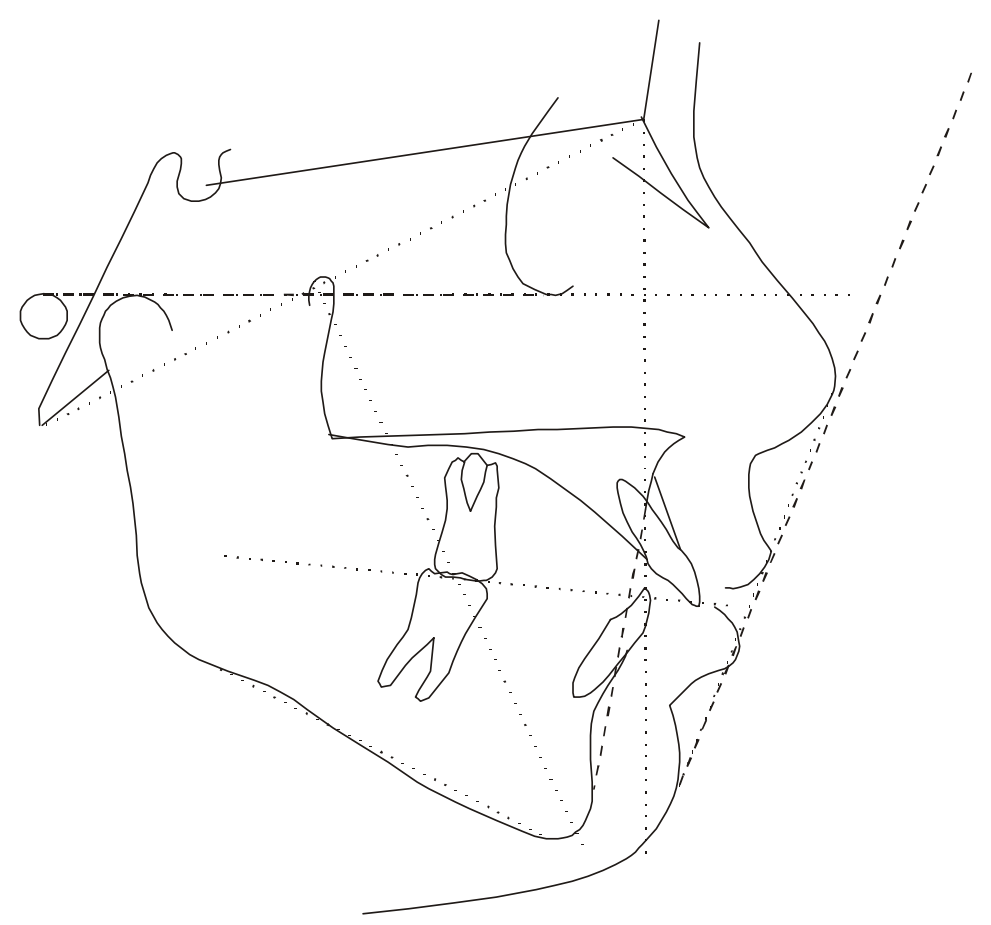

FIGURA 5.24 - Traçado composto médio para os pacientes da categoria 3 na fase inicial 


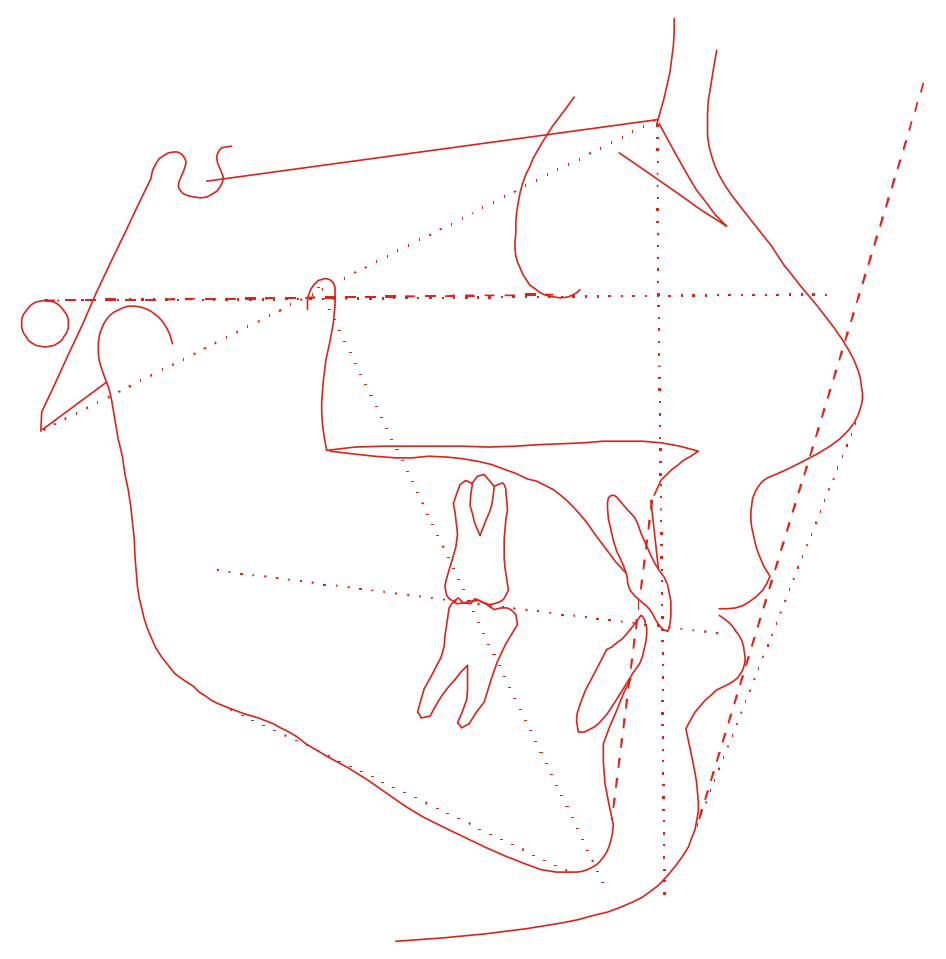

FIGURA 5.25 - Traçado composto médio para os pacientes da categoria 3 na fase final

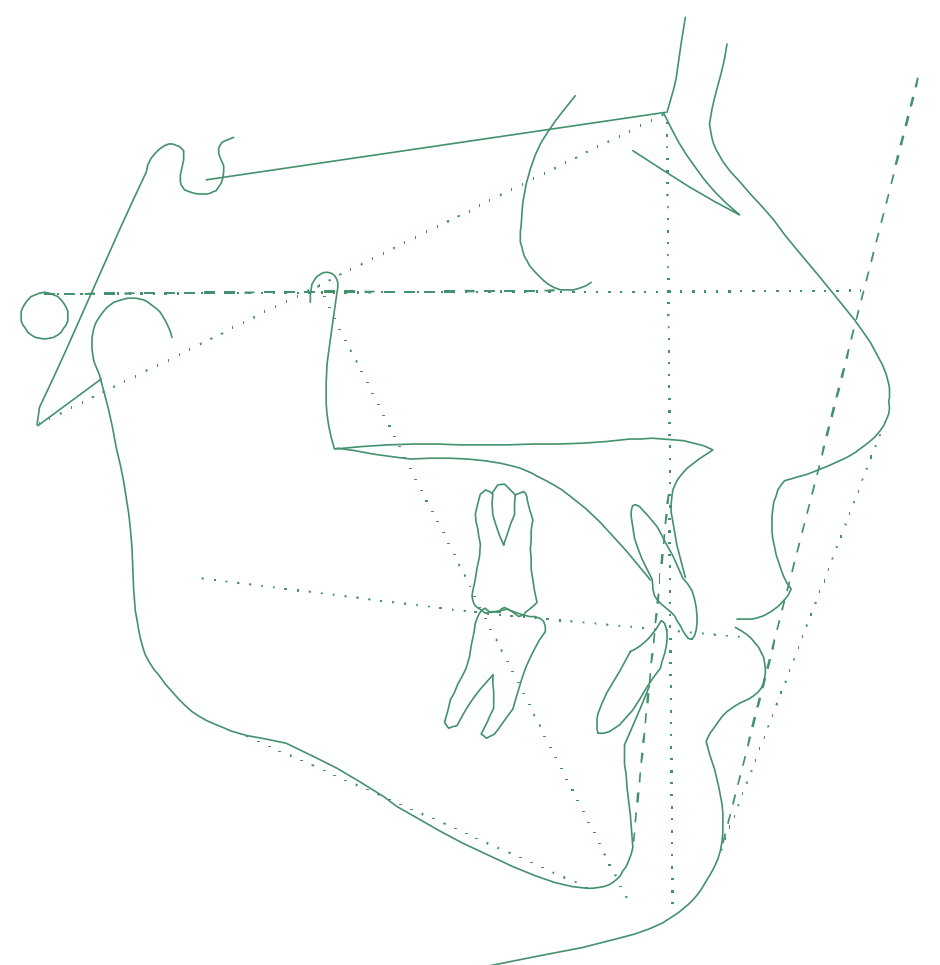

FIGURA 5.26 - Traçado composto médio para os pacientes da categoria 3 na fase de pós-contenção 


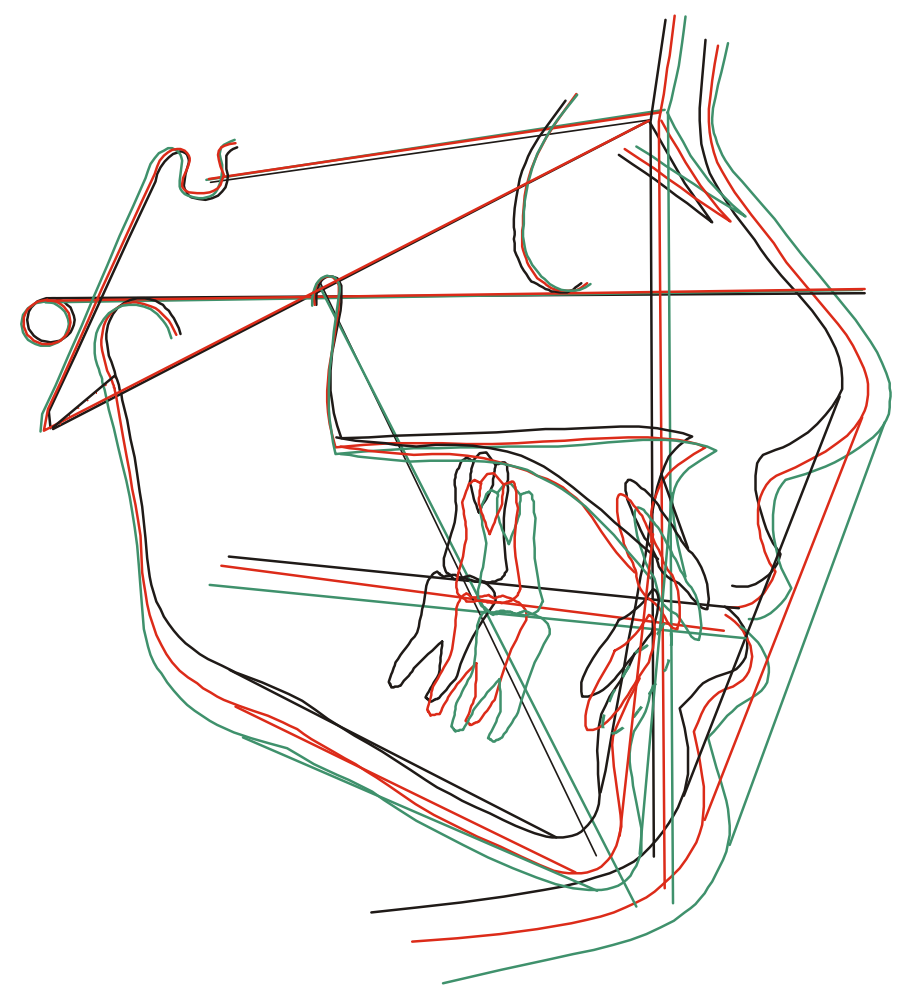

FIGURA 5.27 - Sobreposição dos traçados compostos médios para os pacientes da categoria 3 nas fases inicial, final e de pós-contenção

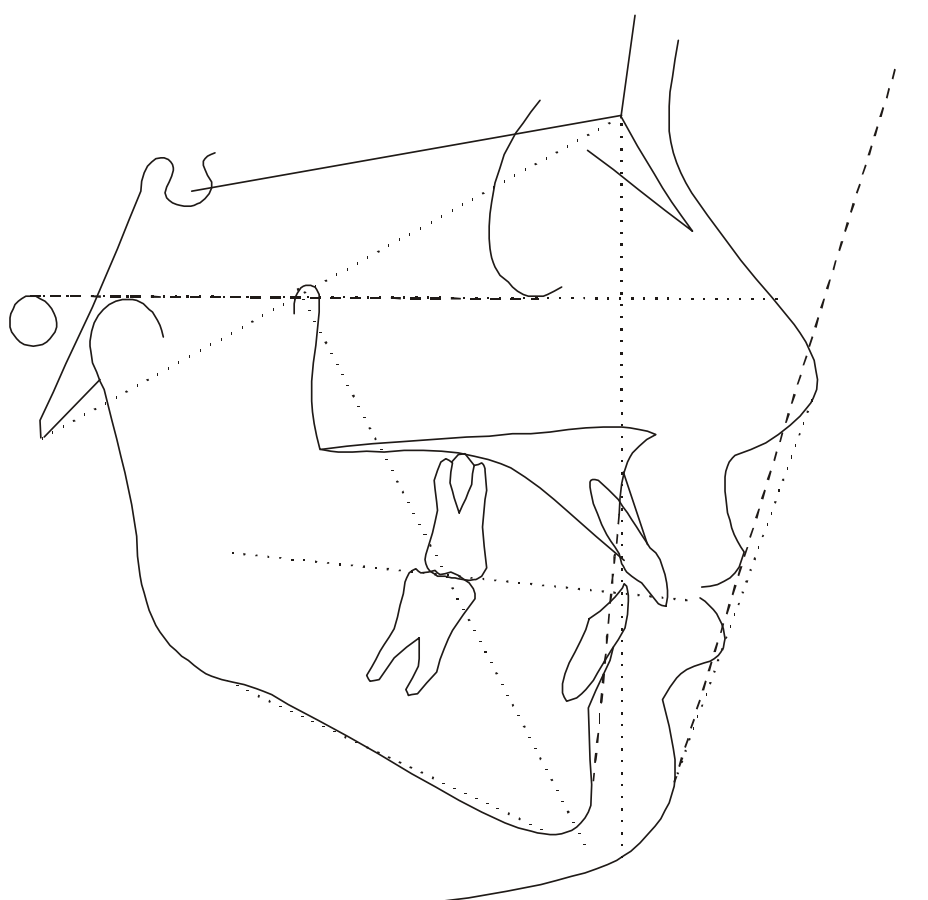

FIGURA 5.28 - Traçado composto médio para os pacientes da categoria 4 na fase inicial 


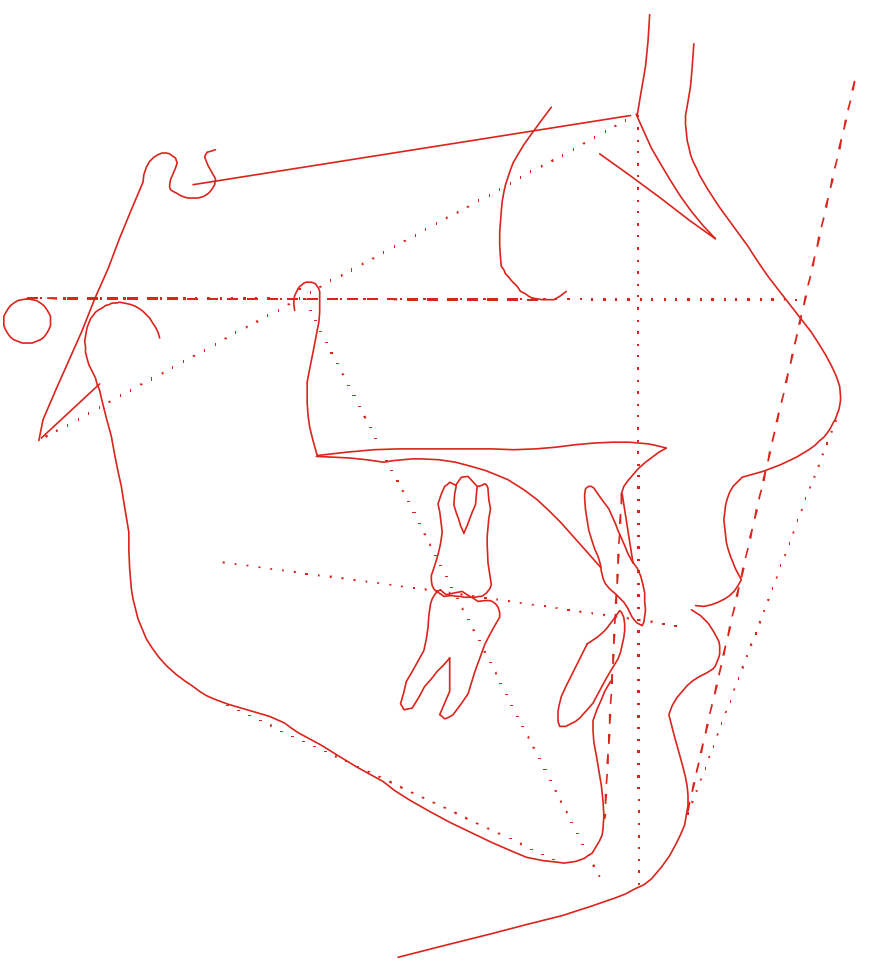

FIGURA 5.29 - Traçado composto médio para os pacientes da categoria 4 na fase final

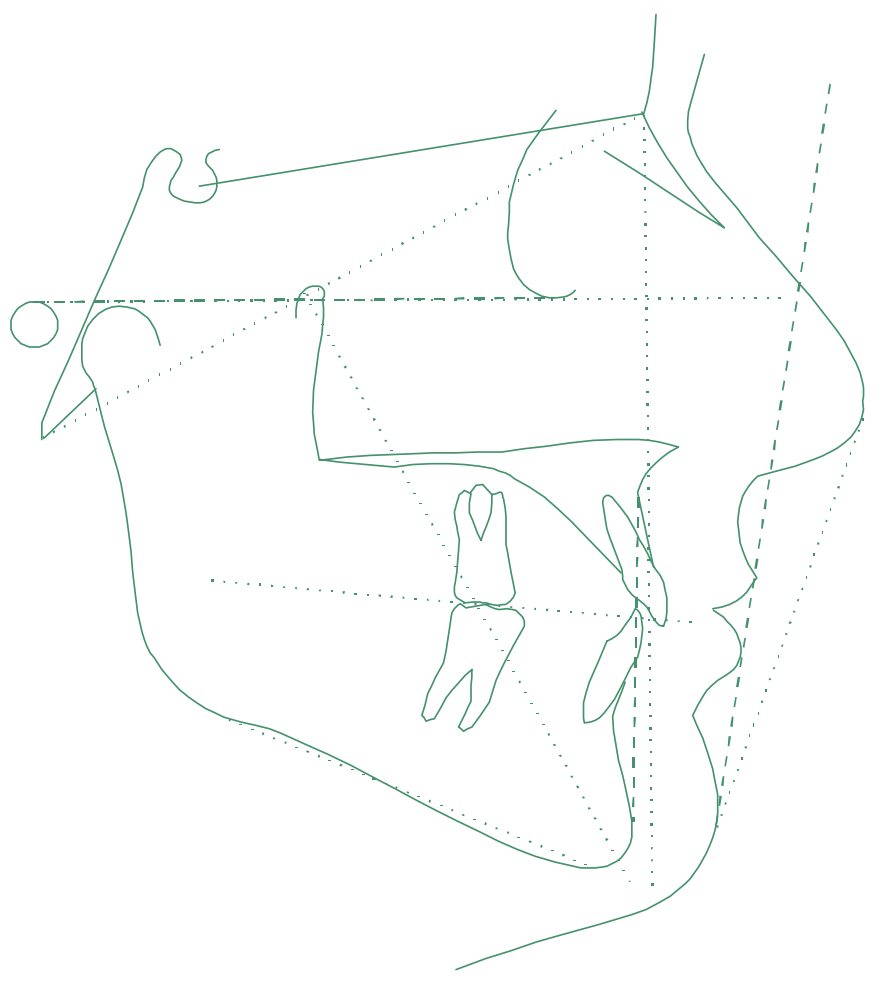

FIGURA 5.30 - Traçado composto médio para os pacientes da categoria 4 na fase de pós-contenção 


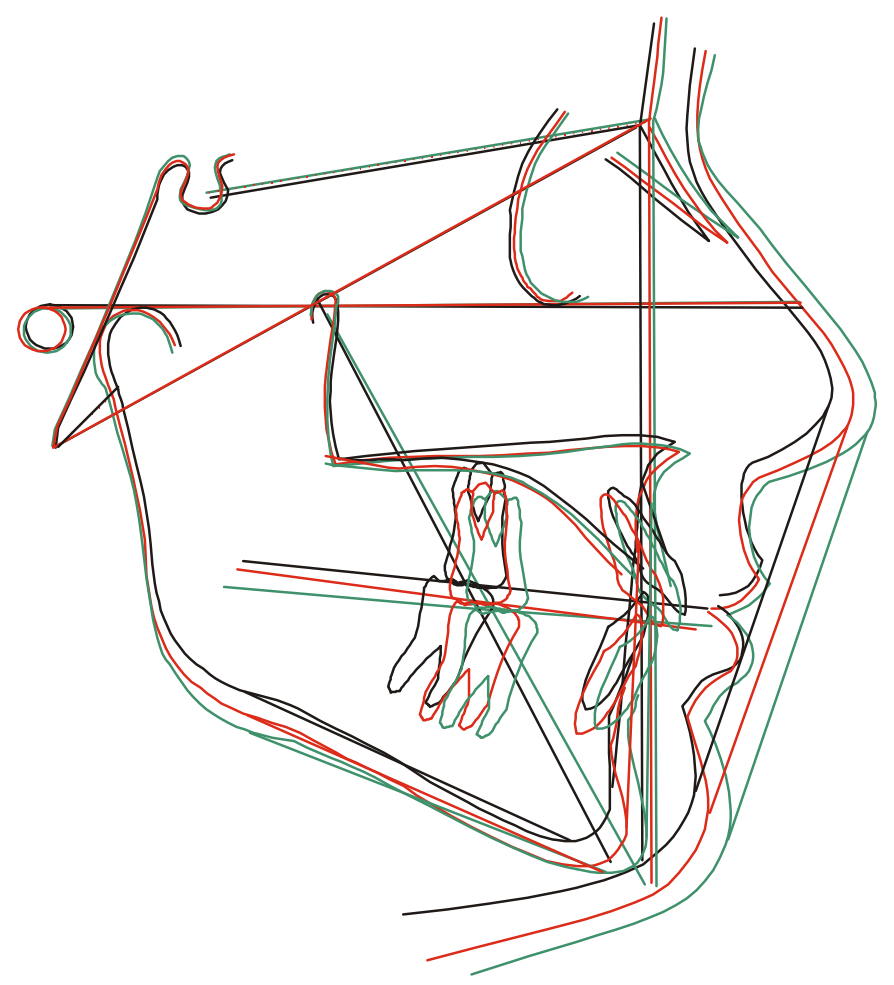

FIGURA 5.31 - Sobreposição dos traçados compostos médios para os pacientes da categoria 4 nas fases inicial, final e de pós-contenção

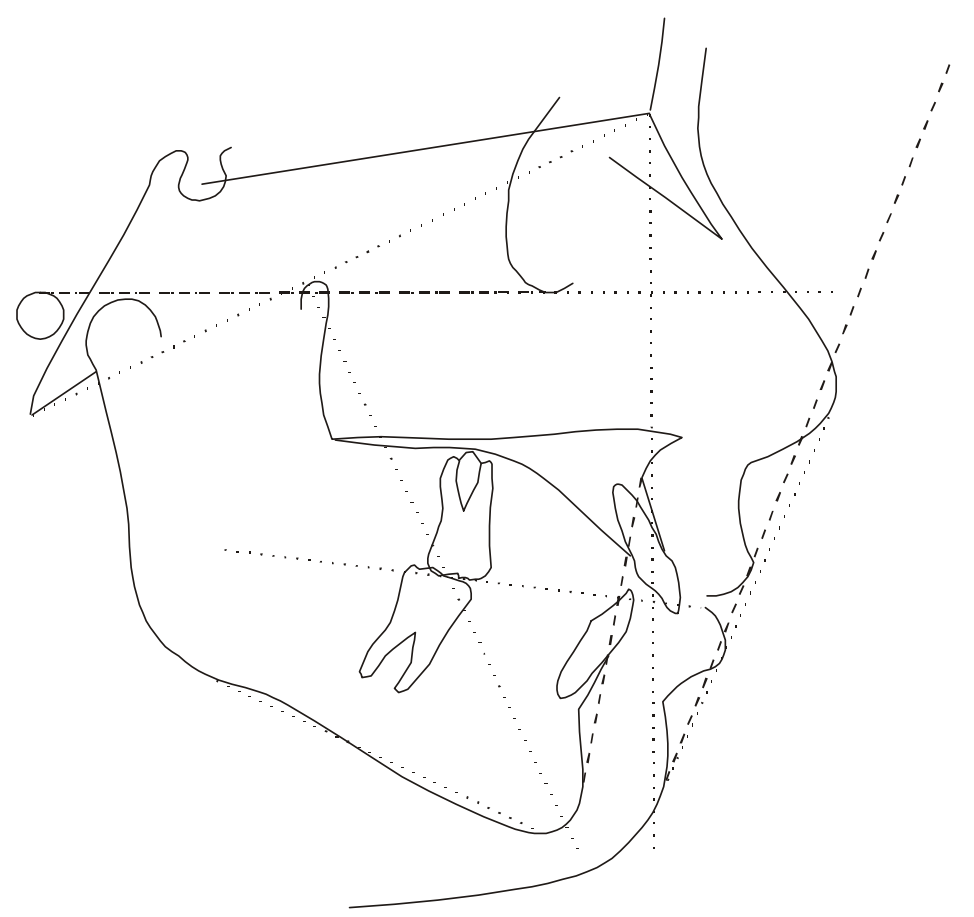

FIGURA 5.32 - Traçado composto médio para os pacientes da categoria 5 na fase inicial 


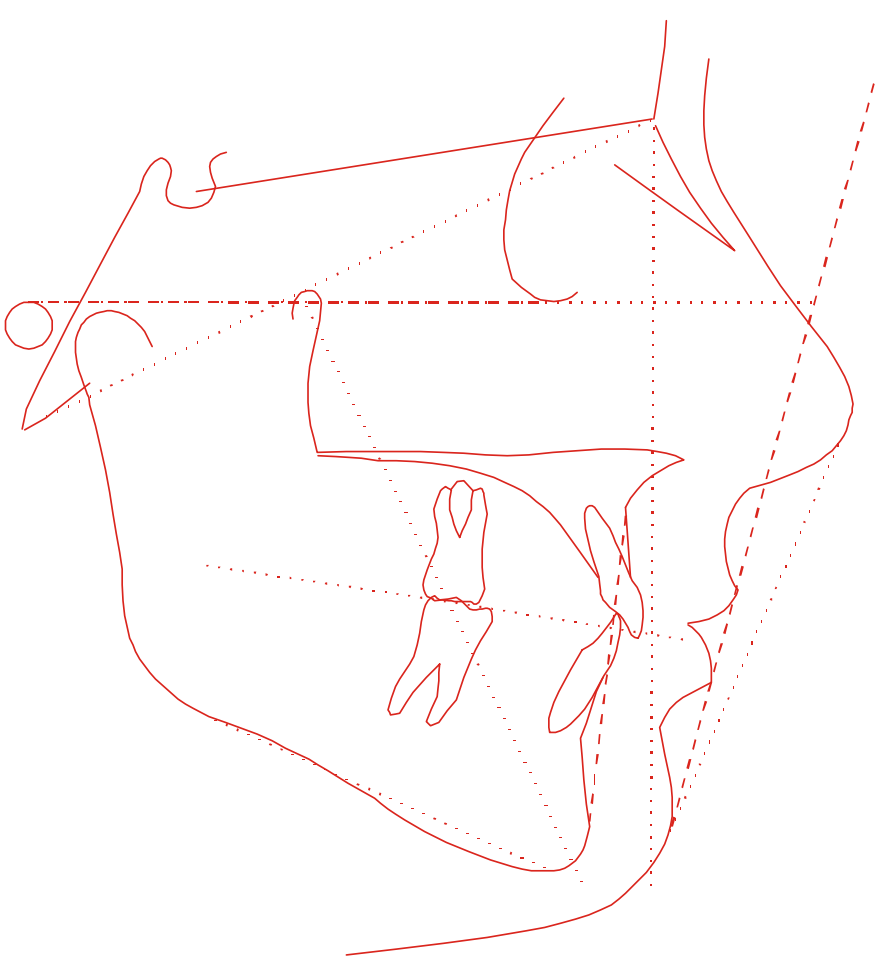

FIGURA 5.33 - Traçado composto médio para os pacientes da categoria 5 na fase final

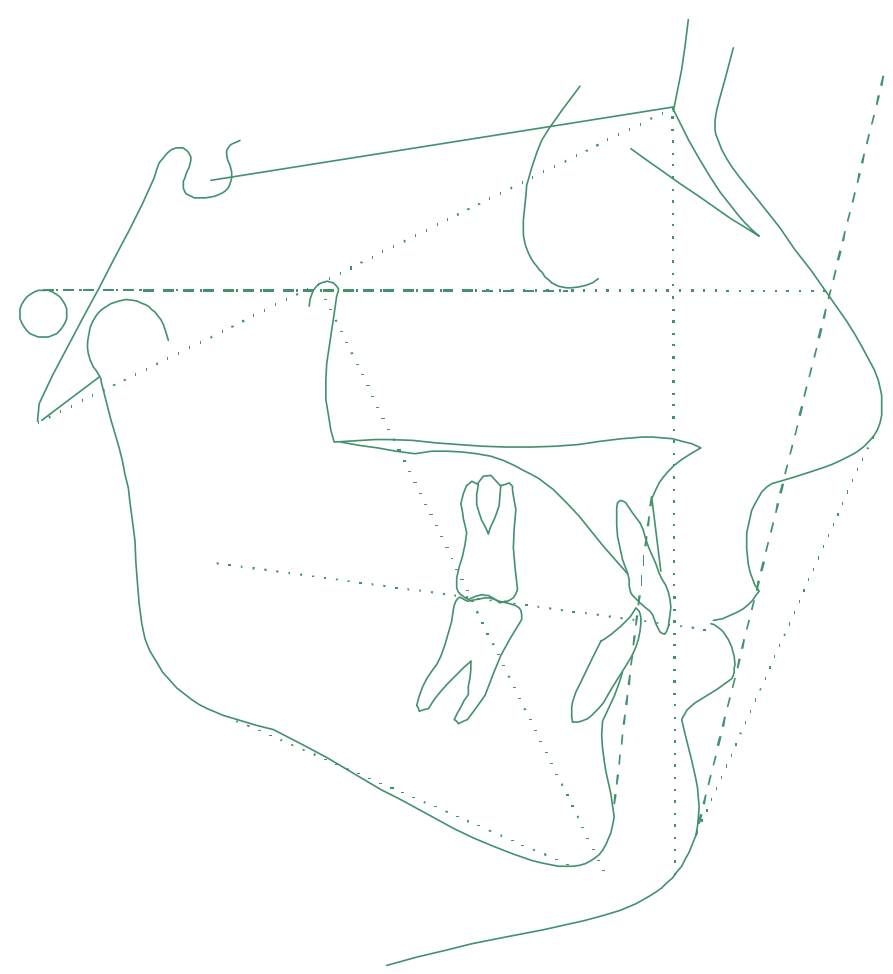

FIGURA 5.34 - Traçado composto médio para os pacientes da categoria 5 na fase de pós-contenção 


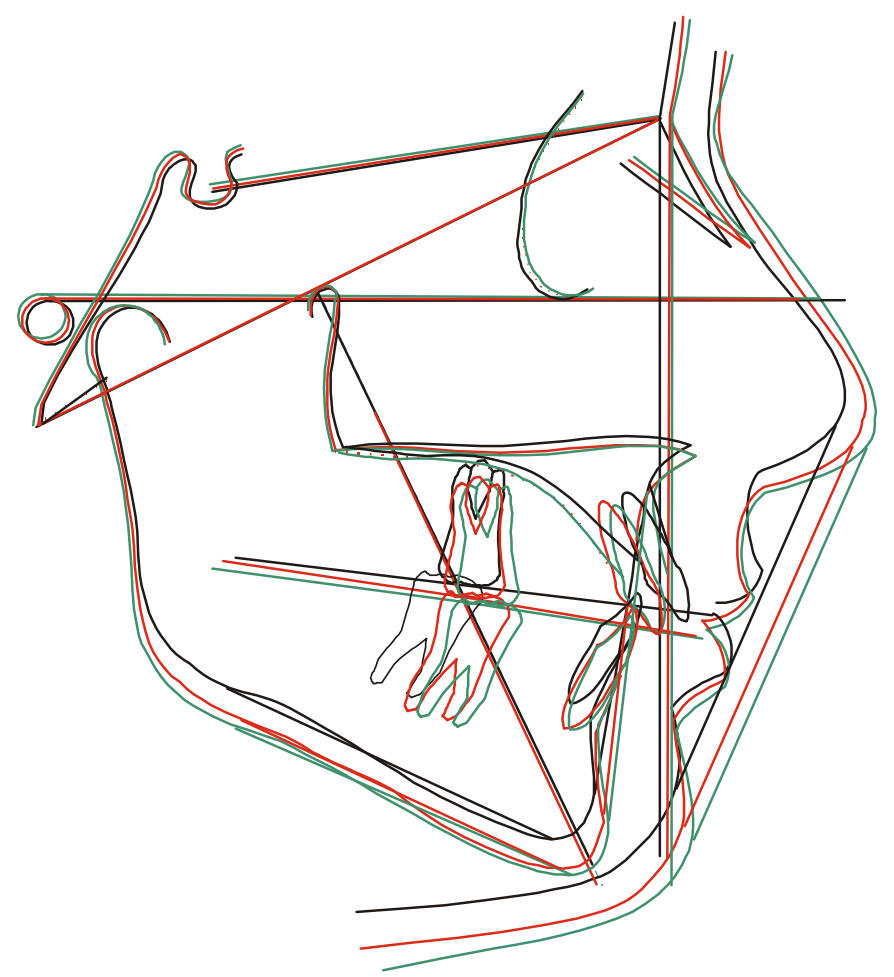

FIGURA 5.35 - Sobreposição dos traçados compostos médios para os pacientes da categoria 5 nas fases inicial, final e de pós-contenção

$\mathrm{Na}$ Tabela 5.45 encontram-se as médias e os desvios padrão das variáveis da análise convencional para os grupos de rotação mandibular; na Tabela 5.46 encontram-se os testes de hipóteses relacionados com essas variáveis, comparando esses grupos nas fases inicial, final e de pós-contenção. Isso também pode ser visualizado nas Figuras de 5.36 a 5.47. 
TABELA 5.45 - Médias e desvios padrão das variáveis da análise convencional, nas fases inicial (I), final (F) e de pós-contenção (PC) por rotação mandibular

\begin{tabular}{|c|c|c|c|c|c|c|}
\hline \multirow[t]{2}{*}{ Variáveis } & \multicolumn{6}{|c|}{ Rotações mandibulares } \\
\hline & \multicolumn{2}{|c|}{ A } & \multicolumn{2}{|c|}{$\mathbf{P}$} & \multicolumn{2}{|c|}{$\mathbf{R}$} \\
\hline & Média & DP & Média & DP & Média & DP \\
\hline \multicolumn{7}{|l|}{ Maxilares } \\
\hline SNA I & 79.44 & 3.25 & 83.40 & 2.63 & 81.91 & 2.78 \\
\hline SNAF & 77.33 & 3.16 & 81.70 & 2.69 & 80.13 & 2.84 \\
\hline SNA PC & 78.02 & 2.88 & 81.50 & 2.66 & 80.63 & 3.35 \\
\hline A-Nperp I & -1.09 & 2.94 & 0.55 & 2.99 & 0.63 & 2.32 \\
\hline A-Nperp F & -3.30 & 3.84 & -0.95 & 2.86 & -1.63 & 3.31 \\
\hline A-Nperp PC & -2.79 & 3.53 & -0.58 & 2.96 & -0.67 & 2.99 \\
\hline Co-A I & 83.83 & 4.70 & 81.51 & 4.00 & 82.45 & 4.37 \\
\hline Co-A F & 84.31 & 4.59 & 81.95 & 4.11 & 83.70 & 4.81 \\
\hline Co-A PC & 86.57 & 4.28 & 84.09 & 4.86 & 86.20 & 4.92 \\
\hline Ar-AI & 82.53 & 4.11 & 79.67 & 4.09 & 80.58 & 4.40 \\
\hline$A r-A F$ & 82.37 & 4.29 & 79.92 & 4.13 & 81.43 & 5.19 \\
\hline $\begin{array}{l}\text { Ar-A PC } \\
\text { Mandibulares }\end{array}$ & \multicolumn{5}{|c|}{ Mandibulares } & 5.45 \\
\hline SNB I & 74.02 & 2.33 & 78.09 & 2.71 & 76.94 & 2.66 \\
\hline SNB F & 74.00 & 2.97 & 77.72 & 2.95 & 76.93 & 3.01 \\
\hline SNB PC & 74.46 & 3.20 & 77.62 & 2.94 & 77.34 & 4.13 \\
\hline Pog-Nperp I & -10.17 & 4.72 & -7.85 & 6.57 & -6.77 & 5.21 \\
\hline Pog-Nperp F & -9.67 & 5.59 & -7.75 & 6.35 & -6.66 & 7.01 \\
\hline Pog-Nperp PC & -8.64 & 5.06 & -6.64 & 6.96 & -4.65 & 6.91 \\
\hline Co-Gn I & 104.16 & 5.68 & 105.66 & 4.99 & 105.29 & 5.25 \\
\hline Co-Gn F & 109.01 & 6.04 & 109.23 & 5.96 & 110.44 & 5.98 \\
\hline Co-Gn PC & 112.03 & 6.04 & 113.16 & 6.56 & 114.44 & 7.06 \\
\hline Ar-Gn I & 97.82 & 4.73 & 98.87 & 5.11 & 97.97 & 4.90 \\
\hline$A r-G n F$ & 101.98 & 5.27 & 102.19 & 5.78 & 102.89 & 6.23 \\
\hline$A r-G n P C$ & 104.49 & 5.74 & 104.93 & 6.24 & 106.77 & 7.64 \\
\hline \multicolumn{7}{|l|}{ Intermaxilares } \\
\hline ANB I & 5.42 & 2.15 & 5.31 & 2.40 & 4.98 & 1.93 \\
\hline ANB $F$ & 3.33 & 2.12 & 3.98 & 1.75 & 3.20 & 1.80 \\
\hline ANB PC & 3.56 & 2.06 & 3.88 & 2.13 & 3.29 & 2.39 \\
\hline WITS I & 1.58 & 3.10 & -1.64 & 2.92 & -0.11 & 2.66 \\
\hline WITS F & 1.24 & 2.97 & 0.26 & 2.88 & 0.10 & 2.49 \\
\hline WITS PC & 1.78 & 3.00 & -0.50 & 2.59 & 0.38 & 2.54 \\
\hline Verticais & & & & & & \\
\hline SN.PP I & 9.20 & 3.34 & 6.90 & 2.66 & 7.73 & 2.91 \\
\hline SN.PP F & 10.64 & 2.87 & 7.79 & 2.62 & 8.64 & 3.17 \\
\hline SN.PP PC & 9.92 & 2.69 & 7.71 & 2.55 & 8.55 & 3.41 \\
\hline SN.Ocl I & 21.37 & 4.27 & 21.40 & 4.16 & 20.16 & 5.31 \\
\hline SN.Ocl F & 19.37 & 5.47 & 17.55 & 4.14 & 17.71 & 5.04 \\
\hline SN.Ocl PC & 18.85 & 6.04 & 18.64 & 5.06 & 17.18 & 5.90 \\
\hline SN.PM I & 34.30 & 4.85 & 38.89 & 5.11 & 35.28 & 5.72 \\
\hline SN.PM F & 34.29 & 5.57 & 39.13 & 5.51 & 34.69 & 6.25 \\
\hline SN.PM PC & 32.69 & 6.36 & 38.30 & 6.31 & 32.74 & 7.59 \\
\hline N.S.Gn I & 70.70 & 3.01 & 69.26 & 3.44 & 69.30 & 3.72 \\
\hline N.S.Gn F & 70.84 & 3.65 & 69.70 & 3.79 & 69.41 & 4.00 \\
\hline N.S.Gn PC & 70.37 & 4.06 & 69.89 & 4.05 & 68.74 & 4.84 \\
\hline Ba.N.Gn I & 88.18 & 3.06 & 86.55 & 3.89 & 87.06 & 4.52 \\
\hline Ba.N.Gn F & 87.85 & 3.36 & 85.95 & 3.91 & 87.21 & 4.64 \\
\hline Ba.N.Gn PC & 88.22 & 3.18 & 86.20 & 4.39 & 88.33 & 5.57 \\
\hline FMA I & 24.89 & 4.33 & 31.74 & 5.53 & 26.54 & 5.02 \\
\hline
\end{tabular}


continuação da TABELA 5.45

\begin{tabular}{|c|c|c|c|c|c|c|}
\hline \multirow[t]{2}{*}{ Variáveis } & \multicolumn{6}{|c|}{ Rotações mandibulares } \\
\hline & \multicolumn{2}{|c|}{ A } & \multicolumn{2}{|c|}{$P$} & \multicolumn{2}{|c|}{$\mathbf{R}$} \\
\hline & Média & DP & Média & DP & Média & DP \\
\hline$F M A F$ & 24.79 & 4.77 & 31.80 & 5.44 & 26.38 & 6.02 \\
\hline$F M A P C$ & 23.32 & 4.94 & 30.35 & 6.29 & 23.98 & 6.34 \\
\hline $\mathrm{N}-\mathrm{Mel}$ & 110.05 & 6.07 & 110.62 & 6.73 & 109.64 & 6.32 \\
\hline$N-M e F$ & 115.18 & 7.72 & 115.03 & 8.08 & 115.14 & 6.85 \\
\hline$N-M e P C$ & 116.88 & 7.54 & 117.78 & 8.12 & 117.52 & 6.36 \\
\hline S-Gol & 74.47 & 4.96 & 71.60 & 5.07 & 73.31 & 5.03 \\
\hline S-Go F & 78.63 & 6.31 & 74.88 & 5.99 & 78.46 & 6.44 \\
\hline S-Go PC & 81.39 & 7.88 & 77.88 & 6.76 & 81.87 & 7.69 \\
\hline AFP:AFA I & 67.73 & 3.76 & 64.81 & 4.20 & 66.97 & 4.66 \\
\hline AFP:AFA F & 68.35 & 4.24 & 65.19 & 4.34 & 68.22 & 5.04 \\
\hline$A F P: A F A P C$ & 69.65 & 5.28 & 66.19 & 4.59 & 69.72 & 6.22 \\
\hline AFAII & 63.00 & 5.79 & 66.07 & 5.93 & 63.46 & 5.76 \\
\hline$A F A I F$ & 65.53 & 6.41 & 68.57 & 6.36 & 66.09 & 6.28 \\
\hline$A F A I P C$ & 66.63 & 6.27 & 70.28 & 6.77 & 67.56 & 6.34 \\
\hline \multicolumn{7}{|l|}{ Dentárias } \\
\hline 1s.SN I & 106.09 & 9.64 & 110.38 & 6.70 & 110.98 & 7.63 \\
\hline 1s.SN F & 100.10 & 7.28 & 102.89 & 5.26 & 101.57 & 6.35 \\
\hline 1s.SN PC & 99.98 & 7.96 & 103.52 & 6.11 & 103.08 & 7.25 \\
\hline 1.NAI & 26.65 & 9.57 & 26.97 & 6.46 & 29.07 & 6.83 \\
\hline 1.NA F & 22.74 & 6.65 & 21.17 & 5.31 & 21.44 & 6.09 \\
\hline 1.NA PC & 21.97 & 7.23 & 22.02 & 6.53 & 22.46 & 7.07 \\
\hline 1-NA I & 6.14 & 3.56 & 5.50 & 2.08 & 6.36 & 2.76 \\
\hline 1-NA F & 2.24 & 2.38 & 2.31 & 1.99 & 2.75 & 1.97 \\
\hline 1-NA PC & 3.04 & 2.36 & 3.44 & 2.38 & 3.52 & 2.03 \\
\hline 1.NB I & 27.81 & 5.85 & 28.23 & 5.95 & 27.53 & 4.87 \\
\hline 1.NB F & 24.21 & 5.30 & 24.60 & 6.26 & 24.69 & 6.86 \\
\hline 1.NB PC & 23.24 & 4.24 & 25.34 & 7.21 & 24.33 & 7.06 \\
\hline 1-NB I & 6.02 & 2.35 & 6.38 & 2.51 & 5.98 & 2.05 \\
\hline $1-N B F$ & 3.88 & 1.45 & 4.96 & 2.35 & 4.28 & 2.05 \\
\hline 1-NB PC & 3.93 & 1.45 & 5.31 & 2.74 & 4.37 & 2.38 \\
\hline FMIA I & 55.63 & 6.29 & 57.01 & 7.57 & 58.14 & 5.85 \\
\hline FMIA F & 59.29 & 5.19 & 60.43 & 6.93 & 60.54 & 6.91 \\
\hline$F M I A P C$ & 60.59 & 4.18 & 60.24 & 7.93 & 61.75 & 7.83 \\
\hline IMPA I & 99.48 & 6.40 & 91.25 & 5.85 & 95.32 & 5.50 \\
\hline IMPA F & 95.91 & 6.73 & 87.76 & 6.36 & 93.08 & 7.95 \\
\hline IMPA PC & 96.09 & 4.76 & 89.41 & 6.94 & 94.26 & 7.18 \\
\hline 1i-APog I & 1.98 & 2.27 & 2.96 & 2.24 & 2.56 & 1.96 \\
\hline 1i-APog F & 0.67 & 1.50 & 1.80 & 2.18 & 1.31 & 1.88 \\
\hline 1i-APog $P C$ & 0.35 & 1.60 & 2.09 & 2.64 & 1.20 & 2.17 \\
\hline $1.1 I$ & 120.12 & 12.40 & 119.48 & 10.65 & 118.42 & 8.88 \\
\hline $1.1 \mathrm{~F}$ & 129.71 & 7.83 & 130.24 & 8.33 & 130.68 & 9.87 \\
\hline $1.1 P C$ & 131.24 & 8.57 & 128.76 & 11.27 & 129.91 & 10.32 \\
\hline \multicolumn{7}{|l|}{ Tegumentares } \\
\hline$L s-E I$ & -0.91 & 2.44 & -0.41 & 2.34 & -0.30 & 2.05 \\
\hline$L s-E F$ & -5.10 & 1.84 & -3.51 & 2.26 & -3.81 & 2.30 \\
\hline Ls-E PC & -6.02 & 2.21 & -4.55 & 1.99 & -5.40 & 2.60 \\
\hline$L i-E I$ & 0.29 & 2.20 & 1.50 & 3.09 & 0.50 & 2.30 \\
\hline$L i-E F$ & -3.41 & 1.82 & -1.35 & 2.88 & -2.59 & 2.48 \\
\hline Li-E PC & -4.39 & 2.44 & -2.30 & 2.96 & -3.82 & 2.97 \\
\hline ZI & 65.46 & 5.82 & 64.98 & 9.48 & 67.75 & 5.93 \\
\hline$Z F$ & 73.08 & 5.38 & 71.07 & 7.59 & 73.91 & 5.54 \\
\hline$Z P C$ & 74.93 & 4.34 & 73.38 & 8.92 & 76.90 & 7.64 \\
\hline H-Pn I & 1.73 & 4.18 & 0.77 & 3.94 & 0.58 & 3.46 \\
\hline$H-P n F$ & 9.07 & 3.34 & 6.01 & 3.86 & 6.54 & 4.03 \\
\hline H-Pn PC & 10.68 & 3.76 & 7.81 & 3.52 & 9.32 & 4.51 \\
\hline
\end{tabular}


TABELA 5.46 - Testes de hipóteses para avaliar as diferenças das variáveis da análise convencional entre as fases inicial, final e de pós-contenção por rotação

\begin{tabular}{|c|c|c|c|c|c|c|c|}
\hline Variáveis & Rotações & Momentos & $\begin{array}{l}\text { Rotações X } \\
\text { Momentos }\end{array}$ & $I X F$ & $I X P C$ & $F X P C$ & Tukey $5 \%$ \\
\hline \multicolumn{8}{|l|}{ Maxilares } \\
\hline SNA & 0.0001 & 0.0001 & 0.2249 & 0.0001 & 0.0001 & 0.0458 & $P \times A, R \times A$ \\
\hline A-Nperp & 0.0078 & 0.0001 & 0.5703 & 0.0001 & 0.0001 & 0.0098 & $P \times A, R \times A$ \\
\hline Co-A & 0.1011 & 0.0001 & 0.2856 & 0.0046 & 0.0001 & 0.0001 & \\
\hline$A r-A$ & 0.0640 & 0.0001 & 0.0086 & 0.1715 & 0.0001 & 0.0001 & $\begin{array}{l}\text { Início: PxA } \\
\text { Final: PxA } \\
\text { PC: PxA, PxR }\end{array}$ \\
\hline \multicolumn{8}{|c|}{ Mandibulares } \\
\hline SNB & 0.0001 & 0.3187 & 0.2187 & 0.4354 & 0.4633 & 0.1310 & $P \times A, R \times A$ \\
\hline Pog-Nperp & 0.0422 & 0.0003 & 0.8219 & 0.5814 & 0.0002 & 0.0012 & $\mathrm{RxA}$ \\
\hline Co-Gn & 0.4653 & 0.0001 & 0.2864 & 0.0001 & 0.0001 & 0.0001 & \\
\hline $\begin{array}{l}\text { Ar-Gn } \\
\text { Intermaxila }\end{array}$ & 0.6928 & 0.0001 & 0.0447 & 0.0001 & 0.0001 & 0.0001 & \\
\hline ANB & 0.4562 & 0.0001 & 0.5165 & 0.0001 & 0.0001 & 0.6734 & \\
\hline WITS & 0.0043 & 0.0057 & 0.0014 & 0.0060 & 0.0047 & 0.9370 & $\begin{array}{l}\text { Início: PxA, PxR, AxR } \\
\text { PC: PxA, RxA }\end{array}$ \\
\hline \multicolumn{8}{|l|}{ Verticais } \\
\hline SN.PP & 0.0036 & 0.0001 & 0.5088 & 0.0001 & 0.0001 & 0.0867 & $P \times A, R \times A$ \\
\hline SN.OcI & 0.4063 & 0.0001 & 0.2058 & 0.0001 & 0.0001 & 0.9676 & \\
\hline SN.PM & 0.0017 & 0.0001 & 0.0412 & 0.6538 & 0.0001 & 0.0001 & $\begin{array}{l}\text { Início: PxA, PxR } \\
\text { Final: PxA, PxR } \\
\text { PC: PxA, PxR }\end{array}$ \\
\hline SN.Gn & 0.2628 & 0.1598 & 0.0559 & 0.1785 & 0.6092 & 0.0641 & \\
\hline Ba.N.Gn & 0.1997 & 0.0271 & 0.0242 & 0.2261 & 0.1371 & 0.0074 & PC: PxR \\
\hline$F M A$ & 0.0001 & 0.0001 & 0.3994 & 0.8203 & 0.0001 & 0.0001 & PxA, PxR \\
\hline $\mathrm{N}-\mathrm{Me}$ & 0.9633 & 0.0001 & 0.6213 & 0.0001 & 0.0001 & 0.0001 & \\
\hline S-Go & 0.0529 & 0.0001 & 0.1209 & 0.0001 & 0.0001 & 0.0001 & \\
\hline$A F P: A F A$ & 0.0155 & 0.0001 & 0.1244 & 0.0008 & 0.0001 & 0.0001 & PxA, PxR \\
\hline AFAI & 0.0899 & 0.0001 & 0.9037 & 0.0001 & 0.0001 & 0.0001 & \\
\hline \multicolumn{8}{|l|}{ Dentárias } \\
\hline $1 s . S N$ & 0.0211 & 0.0001 & 0.5608 & 0.0001 & 0.0001 & 0.4244 & $P \times A, R \times A$ \\
\hline 1.NA & 0.7356 & 0.0001 & 0.4546 & 0.0001 & 0.0001 & 0.6676 & \\
\hline 1-NA & 0.5034 & 0.0001 & 0.6763 & 0.0001 & 0.0001 & 0.0017 & \\
\hline 1.NB & 0.7600 & 0.0001 & 0.7190 & 0.0001 & 0.0001 & 0.7434 & \\
\hline $1-N B$ & 0.1706 & 0.0001 & 0.1968 & 0.0001 & 0.0001 & 0.3222 & \\
\hline FMIA & 0.4764 & 0.0001 & 0.6915 & 0.0001 & 0.0001 & 0.2114 & \\
\hline IMPA & 0.0001 & 0.0001 & 0.5119 & 0.0001 & 0.0005 & 0.0905 & $P x A, P x R, R \times A$ \\
\hline 1i-APog & 0.0311 & 0.0001 & 0.4217 & 0.0001 & 0.0001 & 0.7725 & PxA \\
\hline 1.1 & 0.9033 & 0.0001 & 0.6819 & 0.0001 & 0.0001 & 0.8204 & \\
\hline \multicolumn{8}{|c|}{ Tegumentares } \\
\hline$L s-E$ & 0.0561 & 0.0001 & 0.0939 & 0.0001 & 0.0001 & 0.0001 & \\
\hline$L i-E$ & 0.0086 & 0.0001 & 0.5304 & 0.0001 & 0.0001 & 0.0001 & PxA, PxR \\
\hline $\mathbf{Z}$ & 0.1148 & 0.0001 & 0.7681 & 0.0001 & 0.0001 & 0.0001 & \\
\hline H-Pn & 0.0269 & 0.0001 & 0.0503 & 0.0001 & 0.0001 & 0.0001 & $\begin{array}{l}\text { Final: PxA, RxA } \\
\text { PC: PxA }\end{array}$ \\
\hline
\end{tabular}


As Tabelas 5.45 e 5.46 demonstram que, de forma geral, os pacientes pertencentes aos 3 grupos de rotações mandibulares possuem uma morfologia dentoesquelética diferente, nas diferentes fases analisadas.

Com relação à posição e ao tamanho da maxila, pode ser observado que, na fase inicial, os pacientes com rotação posterior tendem a apresentar uma maxila protruída em comparação com os pacientes com rotação anterior, que possuem uma maxila retruída. Os pacientes com rotação neutra possuem uma maxila bem posicionada em relação à base do crânio. Os pacientes com rotação posterior apresentam o menor comprimento da maxila nas fases inicial, final e de pós-contenção.

Os pacientes com rotação anterior foram os que se apresentaram com a mandíbula mais retruída em relação à base do crânio durante todas as fases analisadas.

Para a medida WITS, os pacientes com rotação posterior tenderam a apresentar a mandíbula levemente à frente da maxila em relação aos demais grupos de rotações; entretanto, esses valores giram em torno da normalidade para essa variável.

Com relação às variáveis verticais, observou-se que o plano palatino (SN.PP) se apresentou com maior inclinação nos pacientes com rotação anterior. O ângulo do eixo facial (Ba.N.Gn) apresentou um valor diminuído na fase póscontenção para os pacientes com rotação posterior em relação aos pacientes com rotação neutra. Já a inclinação do plano mandibular avaliada pelas medidas SN.PM e FMA foi maior para os pacientes com rotação posterior em relação aos 
pacientes com rotação neutra e anterior, em todas as fases analisadas. Apesar de a altura facial anterior (N-Me) e a posterior (S-Go) não terem apresentado diferenças entre os diferentes grupos de rotações, a sua proporção foi menor para os pacientes com rotação posterior em relação aos demais, provavelmente devido ao menor valor da altura facial posterior nos pacientes com rotação posterior.

Os incisivos superiores praticamente não mostraram diferença no seu posicionamento entre os diferentes grupos de rotação mandibular. Já os incisivos inferiores mostraram-se, segundo as variáveis IMPA e 1i-APog, mais protruídos e menos inclinados sobre o plano mandibular nos pacientes com rotação posterior, e menos protruídos e mais inclinados nos pacientes com rotação anterior.

Com relação ao perfil tegumentar, observou-se que os pacientes com rotação posterior apresentaram maior protrusão labial em todas as fases analisadas.

Nas Tabelas de 5.47 a 5.52 encontram-se os valores das variáveis da análise convencional correspondentes às alterações do tratamento (final - inicial), do período pós-tratamento (pós-contenção - final) e totais (pós-contenção inicial), como também os testes de hipóteses realizados a fim de avaliar se as diferenças médias foram diferentes para as categorias de crescimento, e se houve diferenças significativas entre os momentos. Foram utilizadas, como covariadas, as variáveis: a EGU referente ao período de tratamento, a EGU 
referente ao período pós-contenção e a EGU total (EGU tratamento+ EGU póscontenção).

Tabela 5.47 - Alterações médias do tratamento (final - inicial) para as variáveis da análise convencional por rotação mandibular

\begin{tabular}{|c|c|c|c|}
\hline \multirow[t]{2}{*}{ Variáveis } & \multicolumn{3}{|c|}{ Rotações mandibulares } \\
\hline & A & $\mathbf{P}$ & $\mathbf{R}$ \\
\hline \multicolumn{4}{|l|}{ Maxilares } \\
\hline SNA & $-2,11$ & $-1,7$ & $-1,78$ \\
\hline A-Nperp & $-2,21$ & $-1,5$ & $-2,26$ \\
\hline Co-A & 0,48 & 0,44 & 1,25 \\
\hline$A r-A$ & 1,98 & 1,6 & 2,69 \\
\hline \multicolumn{4}{|c|}{ Mandibulares } \\
\hline SNB & $-0,02$ & $-0,37$ & $-0,01$ \\
\hline Pog-Nperp & 0,5 & 0,1 & 0,11 \\
\hline Co-Gn & 4,85 & 3,57 & 5,15 \\
\hline Ar-Gn & 4,16 & 3,32 & 4,92 \\
\hline \multicolumn{4}{|c|}{ Intermaxilares } \\
\hline ANB & $-2,09$ & $-1,33$ & $-1,78$ \\
\hline WITS & $-0,34$ & 1,9 & 0,21 \\
\hline \multicolumn{4}{|l|}{ Verticais } \\
\hline SN.PP & 1,44 & 0,89 & 0,91 \\
\hline SN.Ocl & -2 & $-3,85$ & $-2,45$ \\
\hline SN.PM & $-0,01$ & 0,24 & $-0,59$ \\
\hline SN.Gn & 0,14 & 0,44 & 0,11 \\
\hline Ba.N.Gn & $-0,33$ & $-0,6$ & 0,15 \\
\hline FMA & $-0,1$ & 0,06 & $-0,16$ \\
\hline N-Me & 5,13 & 4,41 & 5,5 \\
\hline S-Go & 4,16 & 3,28 & 5,15 \\
\hline$A F P: A F A$ & 0,62 & 0,38 & 1,25 \\
\hline AFAI & 2,53 & 2,5 & 2,63 \\
\hline \multicolumn{4}{|l|}{ Dentárias } \\
\hline 1s.SN & $-5,99$ & $-7,49$ & $-9,41$ \\
\hline 1.NA & $-3,91$ & $-5,8$ & $-7,63$ \\
\hline 1-NA & $-3,9$ & $-3,19$ & $-3,61$ \\
\hline 1.NB & $-3,6$ & $-3,63$ & $-2,84$ \\
\hline $1-N B$ & $-2,14$ & $-1,42$ & $-1,7$ \\
\hline FMIA & 3,66 & 3,42 & 2,4 \\
\hline IMPA & $-3,57$ & $-3,49$ & $-2,24$ \\
\hline 1i-APog & $-1,31$ & $-1,16$ & $-1,25$ \\
\hline 1.1 & 9,59 & 10,76 & 12,26 \\
\hline \multicolumn{4}{|c|}{ Tegumentares } \\
\hline$L s-E$ & $-4,19$ & $-3,1$ & $-3,51$ \\
\hline$L i-E$ & $-3,7$ & $-2,85$ & $-3,09$ \\
\hline $\mathbf{Z}$ & 7,62 & 6,09 & 6,16 \\
\hline$H-P n$ & 7,34 & 5,24 & 5,96 \\
\hline
\end{tabular}


Tabela 5.48 - Testes de hipóteses para avaliar as diferenças médias das variáveis da análise convencional quanto às alterações do tratamento (Final - Inicial) por rotação mandibular

\begin{tabular}{|c|c|c|c|c|c|c|c|}
\hline \multirow[t]{2}{*}{ Variáveis } & \multirow[t]{2}{*}{ Diferenças } & \multirow[t]{2}{*}{ Rotações } & \multicolumn{3}{|c|}{ Rotações mandibulares } & \multirow[t]{2}{*}{ EGU } & \multirow{2}{*}{$\begin{array}{c}\text { Tukey } \\
5 \%\end{array}$} \\
\hline & & & A & $P$ & $\mathbf{R}$ & & \\
\hline Maxilares & & & & & & & \\
\hline SNA & 0,0001 & 0,5769 & & & & 0,0045 & \\
\hline A-Nperp & 0,0001 & 0,3293 & & & & 0,0001 & \\
\hline Co-A & 0,0004 & 0,1889 & & & & 0,0134 & \\
\hline $\begin{array}{l}\text { Ar-A } \\
\text { Mandibular }\end{array}$ & 0,0357 & 0,0599 & & & & 0,0101 & \\
\hline SNB & 0,3927 & 0,4810 & & & & 0,2458 & \\
\hline Pog-Nperp & 0,5723 & 0,9008 & & & & 0,0866 & \\
\hline Co-Gn & 0,0001 & 0,0217 & 0,0001 & 0,0001 & 0,0001 & 0,0001 & $P \times R$ \\
\hline $\begin{array}{l}\text { Ar-Gn } \\
\text { Intermaxila }\end{array}$ & 0,0001 & 0,0065 & 0,0001 & 0,0001 & 0,0001 & 0,0001 & PxR \\
\hline ANB & 0,0001 & 0,1086 & & & & 0,0001 & \\
\hline $\begin{array}{l}\text { WITS } \\
\text { Verticais }\end{array}$ & 0,0121 & 0,0002 & 0,2458 & 0,0001 & 0,5636 & 0,9831 & $P x R, P x A$ \\
\hline SN.PP & 0,0001 & 0,3891 & & & & 0,0132 & \\
\hline SN.Ocl & 0,0001 & 0,1174 & & & & 0,0216 & \\
\hline SN.PM & 0,3377 & 0,1388 & & & & 0,7244 & \\
\hline SN.Gn & 0,1067 & 0,5457 & & & & 0,7755 & \\
\hline Ba.N.Gn & 0,2235 & 0,1849 & & & & 0,4916 & \\
\hline FMA & 0,7423 & 0,9229 & & & & 0,0579 & \\
\hline $\mathrm{N}-\mathrm{Me}$ & 0,0001 & 0,2310 & & & & 0,0001 & \\
\hline S-Go & 0,0001 & 0,0007 & 0,0001 & 0,0001 & 0,0001 & 0,0001 & PxR \\
\hline$A F P: A F A$ & 0,0001 & 0,0401 & 0,0409 & 0,1653 & 0,0001 & 0,0761 & PxR \\
\hline AFAl & 0,0001 & 0,9684 & & & & 0,0001 & \\
\hline $\begin{array}{l}\text { Dentárias } \\
\text { 1s.SN }\end{array}$ & 0.0001 & 0.3191 & & & & 0.0186 & \\
\hline 1.NA & 0,0001 & 0,2671 & & & & 0,0050 & \\
\hline 1-NA & 0,0001 & 0,7090 & & & & 0,0714 & \\
\hline 1.NB & 0,0001 & 0,8500 & & & & 0,0698 & \\
\hline $1-N B$ & 0,0001 & 0,3050 & & & & 0,2193 & \\
\hline FMIA & 0,0001 & 0,6970 & & & & 0,2033 & \\
\hline IMPA & 0,0001 & 0,6561 & & & & 0,0582 & \\
\hline 1i-APog & 0,0001 & 0,9470 & & & & 0,9941 & \\
\hline 1.1 & 0,0001 & 0,6535 & & & & 0,4634 & \\
\hline Tegumenta & & & & & & & \\
\hline$L s-E$ & 0,0001 & 0,0737 & & & & 0,0009 & \\
\hline$L i-E$ & 0,0001 & 0,2692 & & & & 0,0086 & \\
\hline Z & 0,0001 & 0,4894 & & & & 0,9531 & \\
\hline$H-P n$ & 0,0001 & 0,0396 & 0,0001 & 0,0001 & 0,0001 & 0,0016 & PxA \\
\hline
\end{tabular}


As Tabelas 5.47 e 5.48 mostram que as alterações do tratamento avaliadas pela análise convencional não foram diferentes com relação à posição e ao comprimento da maxila nos diferentes grupos de rotação mandibular.

Quanto à posição mandibular, não foi observada diferença significante entre os diferentes grupos de rotações da mandíbula; entretanto, ela apresentou um maior crescimento nos pacientes com rotação neutra que nos pacientes com rotação posterior.

A variável WITS mostrou um maior aumento positivo nos pacientes com rotação posterior em relação aos pacientes com rotação anterior e neutra, durante o período de tratamento.

Quanto às variáveis verticais, a altura facial posterior (S-Go) e a proporção entre as alturas faciais posterior e anterior mostraram um maior aumento nos pacientes com rotação neutra que nos pacientes com rotação posterior.

As variáveis dentárias não apresentaram diferenças significantes com relação às alterações do tratamento nos diferentes grupos de rotações mandibulares.

$\mathrm{Na}$ avaliação das alterações tegumentares, apenas a variável $\mathrm{H}-\mathrm{Pn}$ mostrou diferença entre os pacientes com rotação anterior em relação aos pacientes com rotação posterior, ou seja, houve um maior aumento no valor dessa variável nos pacientes com rotação anterior. 
Tabela 5.49 - Alterações médias pós-tratamento (pós-contenção X final) para as variáveis da análise convencional por rotação mandibular

\begin{tabular}{|c|c|c|c|}
\hline \multirow[t]{2}{*}{ Variáveis } & \multicolumn{3}{|c|}{ Rotações mandibulares } \\
\hline & A & $\mathbf{P}$ & $\mathbf{R}$ \\
\hline \multicolumn{4}{|l|}{ Maxilares } \\
\hline SNA & 0,69 & $-0,2$ & 0,5 \\
\hline A-Nperp & 0,51 & 0,37 & 0,96 \\
\hline Co-A & 2,26 & 2,14 & 2,5 \\
\hline$A r-A$ & 1,98 & 1,6 & 2,69 \\
\hline \multicolumn{4}{|c|}{ Mandibulares } \\
\hline SNB & 0,46 & $-0,1$ & 0,41 \\
\hline Pog-Nperp & 1,03 & 1,11 & 2,01 \\
\hline Co-Gn & 3,02 & 3,93 & 4 \\
\hline$A r-G n$ & 2,51 & 2,74 & 3,88 \\
\hline \multicolumn{4}{|c|}{ Intermaxilares } \\
\hline ANB & 0,23 & $-0,1$ & 0,09 \\
\hline WITS & 0,54 & $-0,76$ & 0,28 \\
\hline \multicolumn{4}{|l|}{ Verticais } \\
\hline SN.PP & $-0,72$ & $-0,08$ & $-0,09$ \\
\hline SN.Ocl & $-0,52$ & 1,09 & $-0,53$ \\
\hline SN.PM & $-1,6$ & $-0,83$ & $-1,95$ \\
\hline SN.Gn & $-0,47$ & 0,19 & $-0,67$ \\
\hline Ba.N.Gn & 0,37 & 0,25 & 1,12 \\
\hline$F M A$ & $-1,47$ & $-1,45$ & $-2,4$ \\
\hline$N-M e$ & 1,7 & 2,75 & 2,38 \\
\hline S-Go & 2,76 & 3 & 3,41 \\
\hline$A F P: A F A$ & 1,3 & 1 & 1,5 \\
\hline AFAI & 1,1 & 1,71 & 1,47 \\
\hline \multicolumn{4}{|l|}{ Dentárias } \\
\hline $1 s . S N$ & $-0,12$ & 0,63 & 1,51 \\
\hline 1.NA & $-0,77$ & 0,85 & 1,02 \\
\hline 1-NA & 0,8 & 1,13 & 0,77 \\
\hline 1.NB & $-0,97$ & 0,74 & $-0,36$ \\
\hline 1-NB & 0,05 & 0,35 & 0,09 \\
\hline FMIA & 1,3 & $-0,19$ & 1,21 \\
\hline IMPA & 0,18 & 1,65 & 1,18 \\
\hline 1i-APog & $-0,32$ & 0,29 & $-0,11$ \\
\hline 1.1 & 1,53 & $-1,48$ & $-0,77$ \\
\hline \multicolumn{4}{|c|}{ Tegumentares } \\
\hline Ls-E & $-0,92$ & $-1,04$ & $-1,59$ \\
\hline$L i-E$ & $-0,98$ & $-0,95$ & $-1,23$ \\
\hline $\mathbf{Z}$ & 1,85 & 2,31 & 2,99 \\
\hline$H-P n$ & 1,61 & 1,8 & 2,78 \\
\hline
\end{tabular}


Tabela 5.50 - Testes de hipóteses para avaliar as diferenças médias das variáveis da análise convencional quanto às alterações pós-tratamento (pós-contenção final) por rotação mandibular

\begin{tabular}{|c|c|c|c|c|c|c|c|}
\hline \multirow[t]{2}{*}{ Variáveis } & \multirow[t]{2}{*}{ Diferença } & \multirow[t]{2}{*}{ Rotação } & \multicolumn{3}{|c|}{ Rotação mandilbular } & \multirow[t]{2}{*}{$E G U$} & \multirow{2}{*}{$\begin{array}{c}\text { Tukey } \\
5 \%\end{array}$} \\
\hline & & & A & $\mathbf{P}$ & $\mathbf{P}$ & & \\
\hline \multicolumn{8}{|l|}{ Maxilares } \\
\hline SNA & 0,0037 & 0,0122 & 0,0041 & 0,2858 & 0,2858 & 0,0553 & $P \times A, P \times R$ \\
\hline A-Nperp & 0,0006 & 0,3612 & & & & 0,6588 & \\
\hline Co-A & 0,0001 & 0,8081 & & & & 0,0066 & \\
\hline \multicolumn{8}{|c|}{ Mandibulares } \\
\hline SNB & 0,0548 & 0,2561 & & & & 0,0003 & \\
\hline Pog-Nperp & 0,0003 & 0,4984 & & & & 0,0143 & \\
\hline Co-Gn & 0,0001 & 0,4297 & & & & 0,0001 & \\
\hline Ar-Gn & 0,0001 & 0,1522 & & & & 0,0001 & \\
\hline \multicolumn{8}{|c|}{ Intermaxilares } \\
\hline ANB & 0,5458 & 0,5743 & & & & 0,0124 & \\
\hline $\begin{array}{l}\text { WITS } \\
\text { Verticais }\end{array}$ & 0,7850 & 0,0294 & 0,1302 & 0,0765 & 0,0765 & 0,8682 & $P \times A$ \\
\hline SN.PP & 0,0574 & 0,1425 & & & & 0,0794 & \\
\hline SN.Ocl & 0,8506 & 0,0521 & & & & 0,0063 & \\
\hline SN.PM & 0,0001 & 0,1103 & & & & 0,0001 & \\
\hline SN.Gn & 0,0210 & 0,0730 & & & & 0,0026 & \\
\hline Ba.N.Gn & 0,0023 & 0,1572 & & & & 0,0051 & \\
\hline FMA & 0,0001 & 0,2409 & & & & 0,0001 & \\
\hline $\mathrm{N}-\mathrm{Me}$ & 0,0001 & 0,4693 & & & & 0,0026 & \\
\hline S-Go & 0,0001 & 0,6398 & & & & 0,0001 & \\
\hline$A F P: A F A$ & 0,0001 & 0,5449 & & & & 0,0001 & \\
\hline AFAI & 0,0001 & 0,6279 & & & & 0,0174 & \\
\hline \multicolumn{8}{|l|}{ Dentárias } \\
\hline 1s.SN & 0,1270 & 0,3921 & & & & 0,2247 & \\
\hline 1.NA & 0,2799 & 0,2731 & & & & 0,4462 & \\
\hline 1-NA & 0,0001 & 0,6115 & & & & 0,2769 & \\
\hline 1.NB & 0,6406 & 0,3737 & & & & 0,6235 & \\
\hline $1-N B$ & 0,2052 & 0,5609 & & & & 0,4856 & \\
\hline FMIA & 0,1136 & 0,4599 & & & & 0,2328 & \\
\hline IMPA & 0,0310 & 0,4618 & & & & 0,2934 & \\
\hline 1i-APog & 0,6037 & 0,1033 & & & & 0,8570 & \\
\hline 1.1 & 0,6995 & 0,2506 & & & & 0,8109 & \\
\hline \multicolumn{8}{|c|}{ Tegumentares } \\
\hline$L s-E$ & 0,0001 & 0,1626 & & & & 0,0001 & \\
\hline$L i-E$ & 0,0001 & 0,7754 & & & & 0,0001 & \\
\hline $\mathbf{Z}$ & 0,0001 & 0,6544 & & & & 0,0067 & \\
\hline$H-P n$ & 0,0001 & 0,1420 & & & & 0,0001 & \\
\hline
\end{tabular}

As Tabelas 5.49 e 5.50 mostram que as alterações pós-tratamento avaliadas pela análise convencional foram diferentes quanto à posição da maxila, sendo que os pacientes com rotação anterior e neutra apresentaram um maior deslocamento anterior da maxila em relação à base do crânio que os pacientes 
com rotação posterior.

Com relação às alterações intermaxilares, a variável WITS apresentou maior diminuição no seu valor nos pacientes com rotação posterior em relação aos pacientes com rotação anterior.

As variáveis mandibulares, verticais, dentárias e tegumentares não mostraram diferenças significantes nos diferentes grupos de rotação mandibular durante o período pós-tratamento.

Tabela 5.51 - Alterações médias totais (pós-contenção X inicial) para as variáveis da análise convencional por rotação mandibular

\begin{tabular}{|c|c|c|c|}
\hline \multirow[t]{2}{*}{ Variáveis } & \multicolumn{3}{|c|}{ Rotações mandibulares } \\
\hline & A & $\mathbf{P}$ & $\mathbf{R}$ \\
\hline \multicolumn{4}{|l|}{ Maxilares } \\
\hline SNA & $-1,42$ & $-1,9$ & $-1,28$ \\
\hline A-Nperp & $-1,7$ & $-1,13$ & $-1,3$ \\
\hline Co-A & 2,74 & 2,58 & 3,75 \\
\hline$A r-A$ & 1,82 & 1,85 & 3,54 \\
\hline \multicolumn{4}{|c|}{ Mandibulares } \\
\hline SNB & 0,44 & $-0,47$ & 0,4 \\
\hline Pog-Nperp & 1,53 & 1,21 & 2,12 \\
\hline Co-Gn & 7,87 & 7,5 & 9,15 \\
\hline$A r-G n$ & 6,67 & 6,06 & 8,8 \\
\hline \multicolumn{4}{|c|}{ Intermaxilares } \\
\hline ANB & $-1,86$ & $-1,43$ & $-1,69$ \\
\hline WITS & 0,2 & 1,14 & 0,49 \\
\hline \multicolumn{4}{|l|}{ Verticais } \\
\hline SN.PP & 0,72 & 0,81 & 0,82 \\
\hline SN.Ocl & $-2,52$ & $-2,76$ & $-2,98$ \\
\hline SN.PM & $-1,61$ & $-0,59$ & $-2,54$ \\
\hline SN.Gn & $-0,33$ & 0,63 & $-0,56$ \\
\hline Ba.N.Gn & 0,04 & $-0,35$ & 1,27 \\
\hline$F M A$ & $-1,57$ & $-1,39$ & $-2,56$ \\
\hline$N-M e$ & 6,83 & 7,16 & 7,88 \\
\hline S-Go & 6,92 & 6,28 & 8,56 \\
\hline$A F P: A F A$ & 1,92 & 1,38 & 2,75 \\
\hline$A F A I$ & 3,63 & 4,21 & 4,1 \\
\hline \multicolumn{4}{|l|}{ Dentárias } \\
\hline 1s.SN & $-6,11$ & $-6,86$ & $-7,9$ \\
\hline 1.NA & $-4,68$ & $-4,95$ & $-6,61$ \\
\hline 1-NA & $-3,1$ & $-2,06$ & $-2,84$ \\
\hline 1.NB & $-4,57$ & $-2,89$ & $-3,2$ \\
\hline 1-NB & $-2,09$ & $-1,07$ & $-1,61$ \\
\hline FMIA & 4,96 & 3,23 & 3,61 \\
\hline IMPA & $-3,39$ & $-1,84$ & $-1,06$ \\
\hline 1i-APog & $-1,63$ & $-0,87$ & $-1,36$ \\
\hline 1.1 & 11,12 & 9,28 & 11,49 \\
\hline
\end{tabular}




\begin{tabular}{lccc}
\multirow{2}{*}{$\begin{array}{l}\text { Continuação da TABELA } \\
\text { Variáveis }\end{array}$} & \multicolumn{3}{c}{ Rotações } \\
\cline { 2 - 4 } & A & P & \\
& & & R \\
Tegumentares & & & \\
Ls-E & $-5,11$ & $-4,14$ & $-5,1$ \\
Li-E & $-4,68$ & $-3,8$ & $-4,32$ \\
Z & 9,47 & 8,4 & 9,15 \\
H-Pn & 8,95 & 7,04 & 8,74 \\
\hline
\end{tabular}

Tabela 5.52 - Testes de hipóteses para avaliar as diferenças médias das variáveis da análise convencional quanto às alterações totais (pós-contenção - inicial) por rotação mandibular

\begin{tabular}{|c|c|c|c|c|c|c|c|}
\hline \multirow[t]{2}{*}{ Variáveis } & \multirow[t]{2}{*}{ Diferenças } & \multirow[t]{2}{*}{ Rotações } & \multicolumn{3}{|c|}{ Rotações mandibulares } & \multirow[t]{2}{*}{$E G U$} & \multirow{2}{*}{$\begin{array}{c}\text { Tukey } \\
5 \%\end{array}$} \\
\hline & & & A & $P$ & $\mathbf{R}$ & & \\
\hline \multicolumn{8}{|l|}{ Maxilares } \\
\hline SNA & 0,0001 & 0,3980 & & & & 0,0626 & \\
\hline A-Nperp & 0,0001 & 0,6396 & & & & 0,0012 & \\
\hline Co-A & 0,0001 & 0,1143 & & & & 0,0001 & \\
\hline Ar-A & 0,0001 & 0,0022 & 0,0001 & 0,0003 & 0,0001 & 0,0001 & $\mathrm{P} \times \mathrm{R}, \mathrm{A} \times \mathrm{P}$ \\
\hline SNB & 0,4181 & 0,1341 & & & & 0,0027 & \\
\hline Pog-Nperp & 0,0003 & 0,6892 & & & & 0,1313 & \\
\hline Co-Gn & 0,0001 & 0,1728 & & & & 0,0001 & \\
\hline$A r-G n$ & 0,0001 & 0,0063 & 0,0001 & 0,0001 & 0,0001 & 0,0001 & $\mathrm{RxA}, \mathrm{RxF}$ \\
\hline \multicolumn{8}{|c|}{ Intermaxilares } \\
\hline$A N B$ & 0,0001 & 0,6523 & & & & 0,0001 & \\
\hline WITS & 0,0101 & 0,2714 & & & & 0,3344 & \\
\hline \multicolumn{8}{|l|}{ Verticais } \\
\hline SN.PP & 0,0001 & 0,9723 & & & & 0,2299 & \\
\hline SN.Ocl & 0,0001 & 0,8634 & & & & 0,0001 & \\
\hline SN.PM & 0,0001 & 0,0236 & 0,0015 & 0,2667 & 0,0001 & 0,0001 & PxR \\
\hline SN.Gn & 0,4663 & 0,0465 & 0,3196 & 0,0610 & 0,1326 & 0,0094 & PxR \\
\hline Ba.N.Gn & 0,0678 & 0,0114 & 0,9122 & 0,3695 & 0,0034 & 0,0020 & $P \times R$ \\
\hline$F M A$ & 0,0001 & 0,2373 & & & & 0,0030 & \\
\hline $\mathrm{N}-\mathrm{Me}$ & 0,0001 & 0,4595 & & & & 0,0001 & \\
\hline S-Go & 0,0001 & 0,0233 & 0,0001 & 0,0001 & 0,0001 & 0,0001 & PxR \\
\hline AFP:AFA & 0,0001 & 0,0507 & & & & 0,0001 & \\
\hline AFAI & 0,0001 & 0,7327 & & & & 0,0010 & \\
\hline \multicolumn{8}{|l|}{ Dentárias } \\
\hline 1s.SN & 0,0001 & 0,7160 & & & & 0,0173 & \\
\hline 1.NA & 0,0001 & 0,6181 & & & & 0,0052 & \\
\hline 1-NA & 0,0001 & 0,4022 & & & & 0,0259 & \\
\hline 1.NB & 0,0001 & 0,4984 & & & & 0,1655 & \\
\hline $1-N B$ & 0,0001 & 0,1093 & & & & 0,1187 & \\
\hline FMIA & 0,0001 & 0,5237 & & & & 0,0900 & \\
\hline IMPA & 0,0007 & 0,2381 & & & & 0,8464 & \\
\hline 1i-APog & 0,0001 & 0,2481 & & & & 0,5164 & \\
\hline 1.1 & 0,0001 & 0,6881 & & & & 0,4682 & \\
\hline \multicolumn{8}{|c|}{ Tegumentares } \\
\hline$L s-E$ & 0,0001 & 0,0772 & & & & 0,0001 & \\
\hline$L i-E$ & 0,0001 & 0,3171 & & & & 0,0001 & \\
\hline $\mathbf{Z}$ & 0,0001 & 0,7666 & & & & 0,0312 & \\
\hline$H-P n$ & 0,0001 & 0,0552 & & & & 0,0001 & \\
\hline
\end{tabular}


As Tabelas 5.51 e 5.52 mostram que as alterações totais, ou seja, aquelas que compreenderam todo o período de estudo (de tratamento e de póstratamento), avaliadas pela análise convencional, foram diferentes nos grupos de rotação mandibular.

Durante esse período, a maxila cresceu mais no grupo com rotação neutra $(A r-A=3,54 \mathrm{~mm})$ que nos grupos com rotação anterior $(A r-A=1,82 \mathrm{~mm})$ e posterior $(\operatorname{Ar}-\mathrm{A}=1,85 \mathrm{~mm})$.

A mandíbula apresentou um aumento maior em seu comprimento no grupo com rotação neutra $(A r-G n=8,8 \mathrm{~mm})$ que nos grupos com rotação anterior $(\operatorname{Ar}-\mathrm{Gn}=6,67 \mathrm{~mm})$ e posterior $(\operatorname{Ar}-\mathrm{Gn}=6,06 \mathrm{~mm})$.

As variáveis SN.Gn e Ba.N.Gn apresentaram diferenças significantes entre os pacientes com rotação posterior em relação aos pacientes com rotação neutra. Esses resultados mostraram uma tendência de crescimento mandibular mais vertical nos pacientes com rotação posterior. Esses pacientes também apresentaram uma diminuição menor do ângulo SN.PM que os pacientes com rotação neutra.

A altura facial posterior (S-Go) apresentou um aumento maior nos pacientes com rotação neutra $(8,56 \mathrm{~mm})$ em relação aos pacientes com rotação posterior $(6,28 \mathrm{~mm})$. 


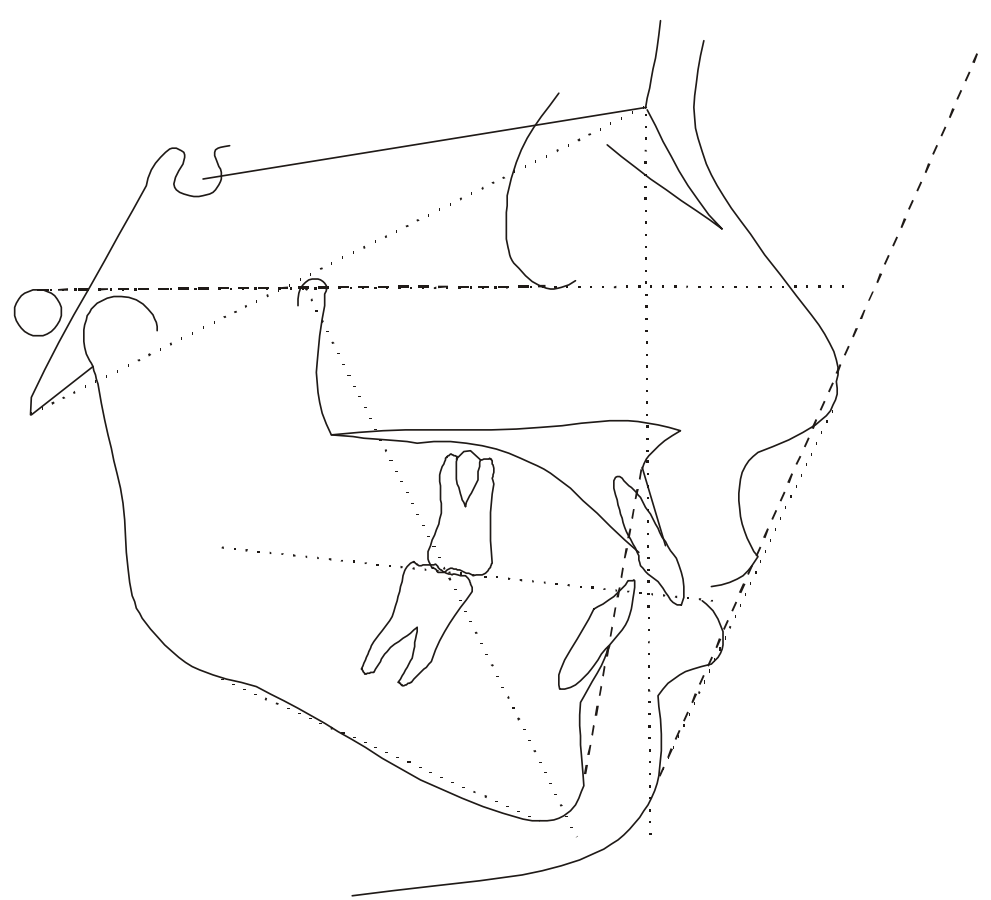

FIGURA 5.36 - Traçado composto médio para os pacientes com rotação anterior da mandíbula na fase inicial

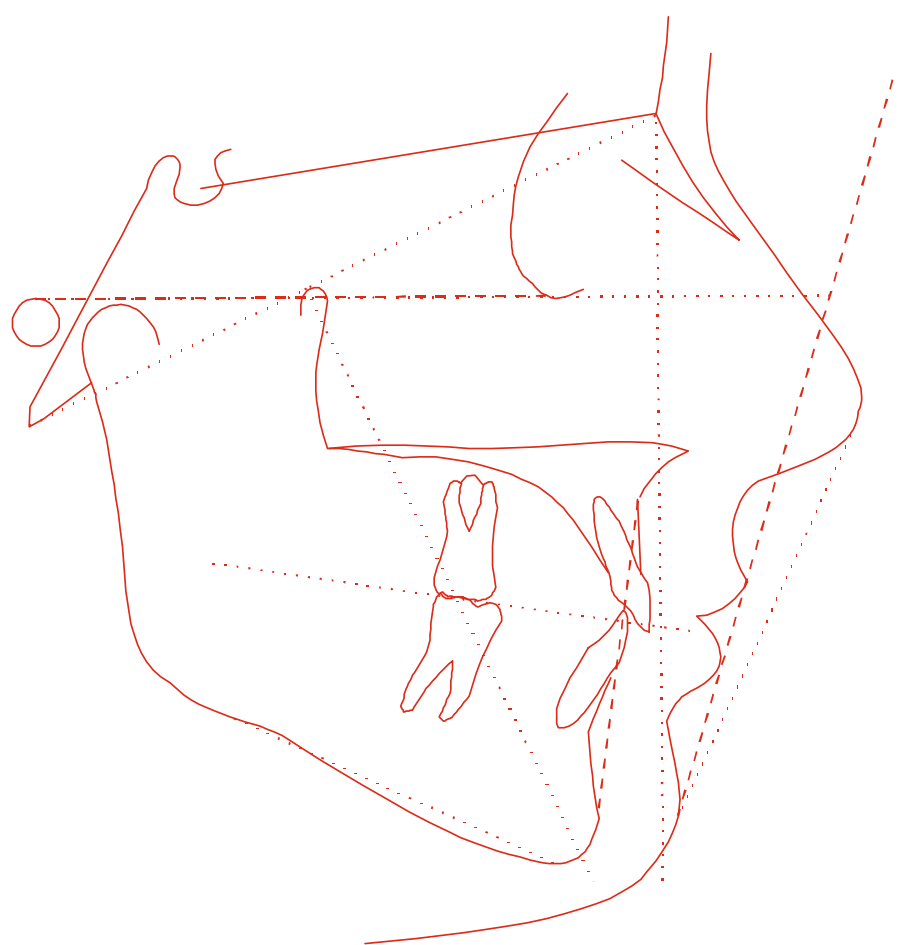

FIGURA 5.37 - Traçado composto médio para os pacientes com rotação anterior da mandíbula na fase final 


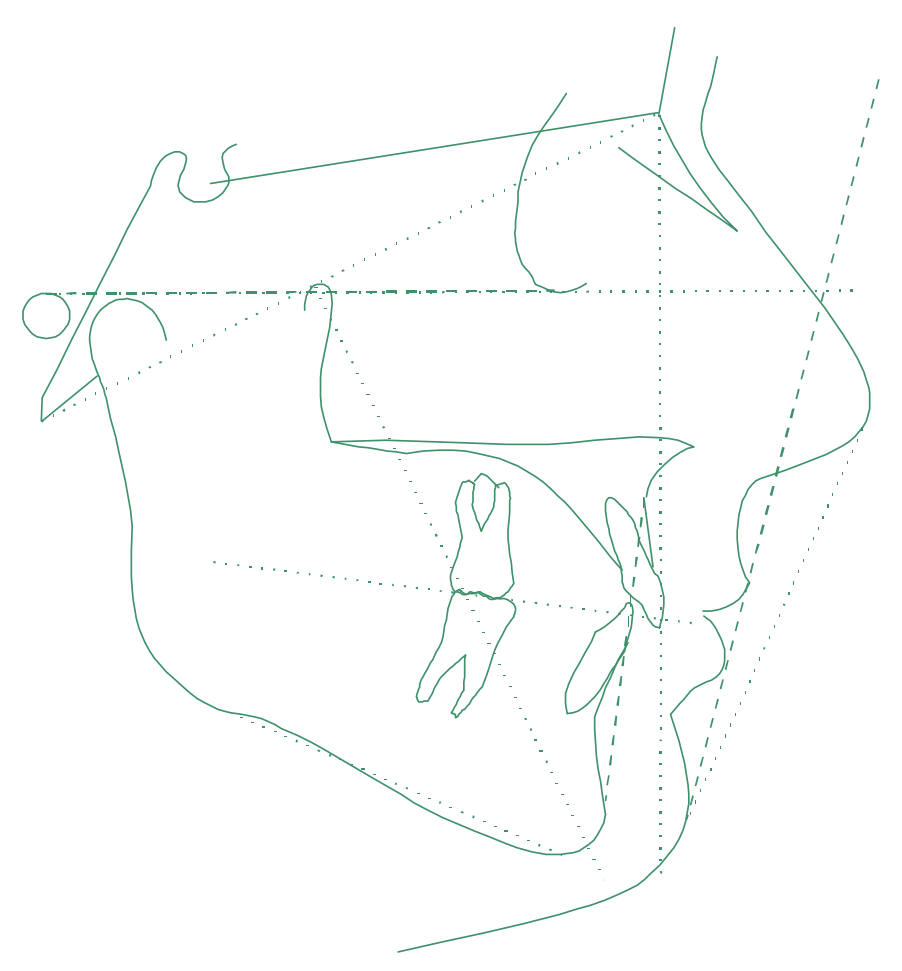

FIGURA 5.38 - Traçado composto médio para os pacientes com rotação anterior da mandíbula na fase de pós-contenção

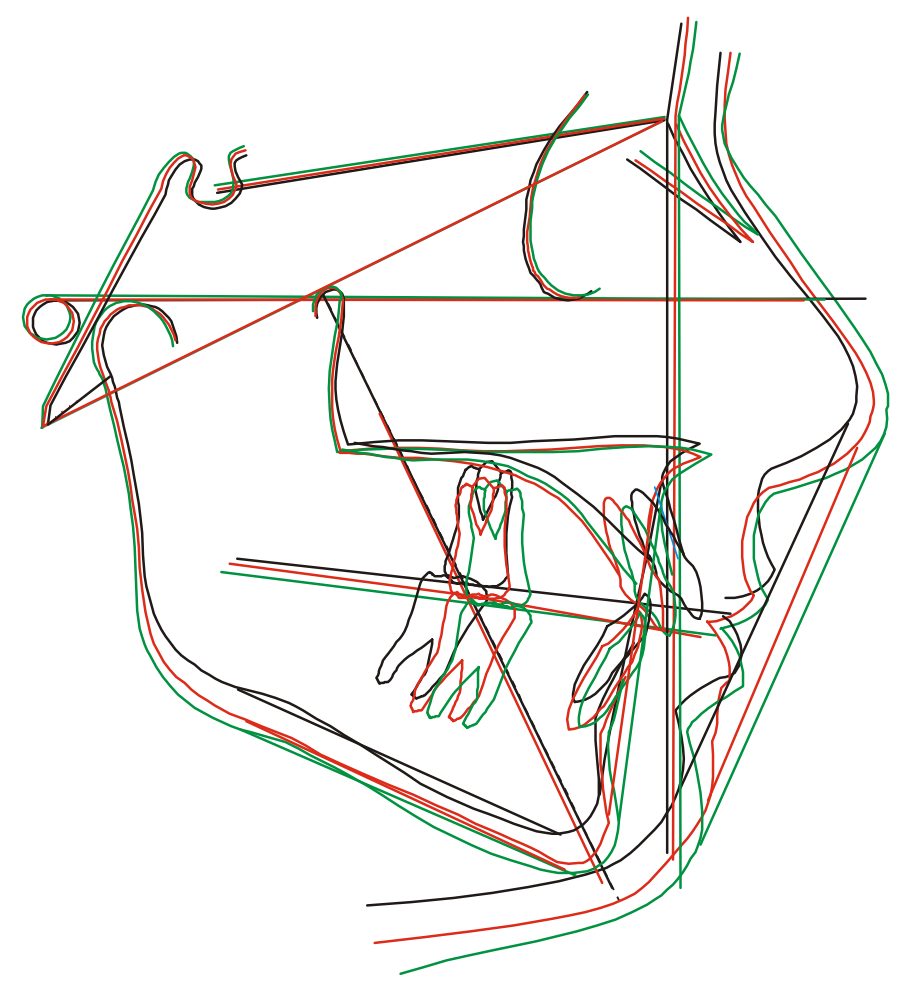

FIGURA 5.39 - Sobreposição dos traçados compostos médios para os pacientes com rotação anterior da mandíbula nas fases inicial, final e de pós-contenção 


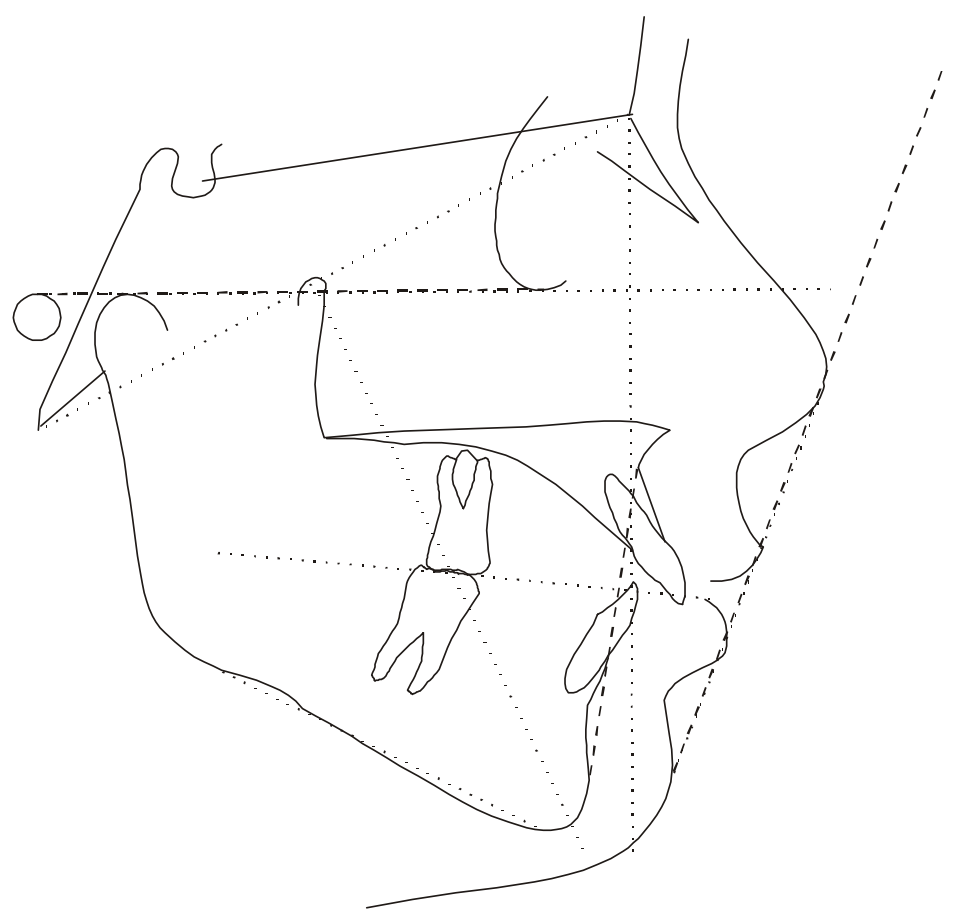

FIGURA 5.40 - Traçado composto médio para os pacientes com rotação neutra da mandíbula na fase inicial

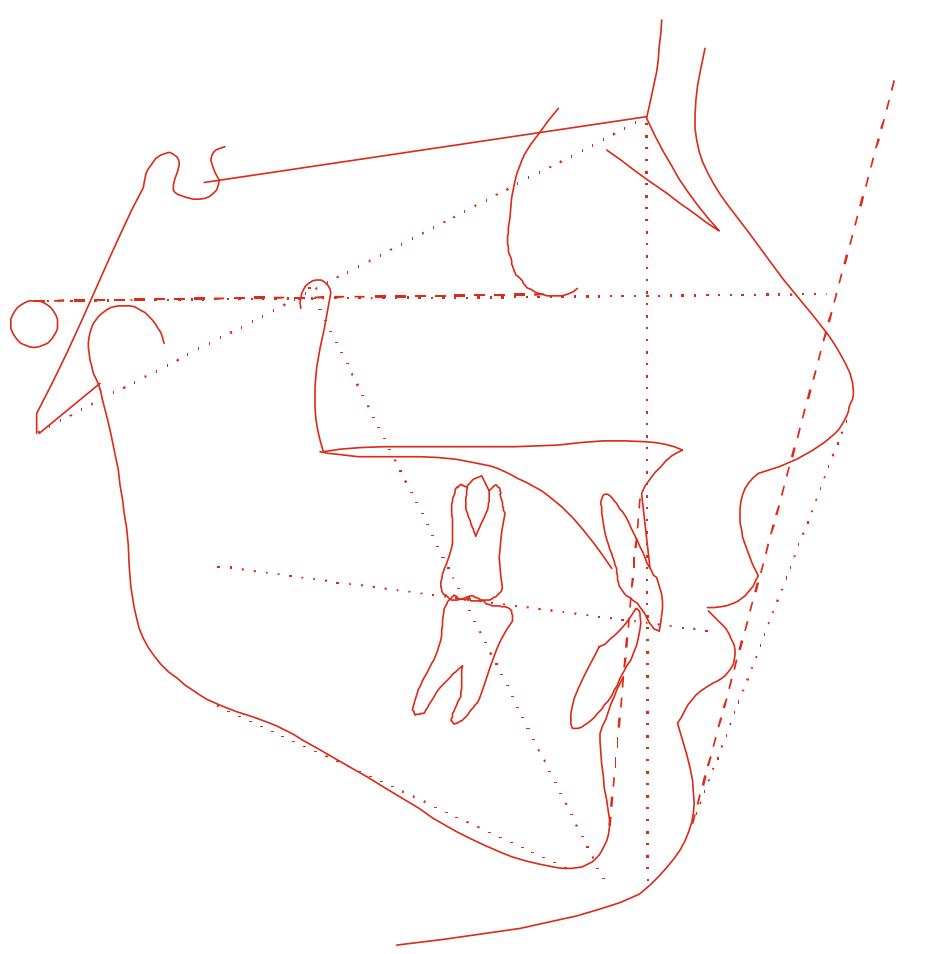

FIGURA 5.41 - Traçado composto médio para os pacientes com rotação neutra da mandíbula na fase final 


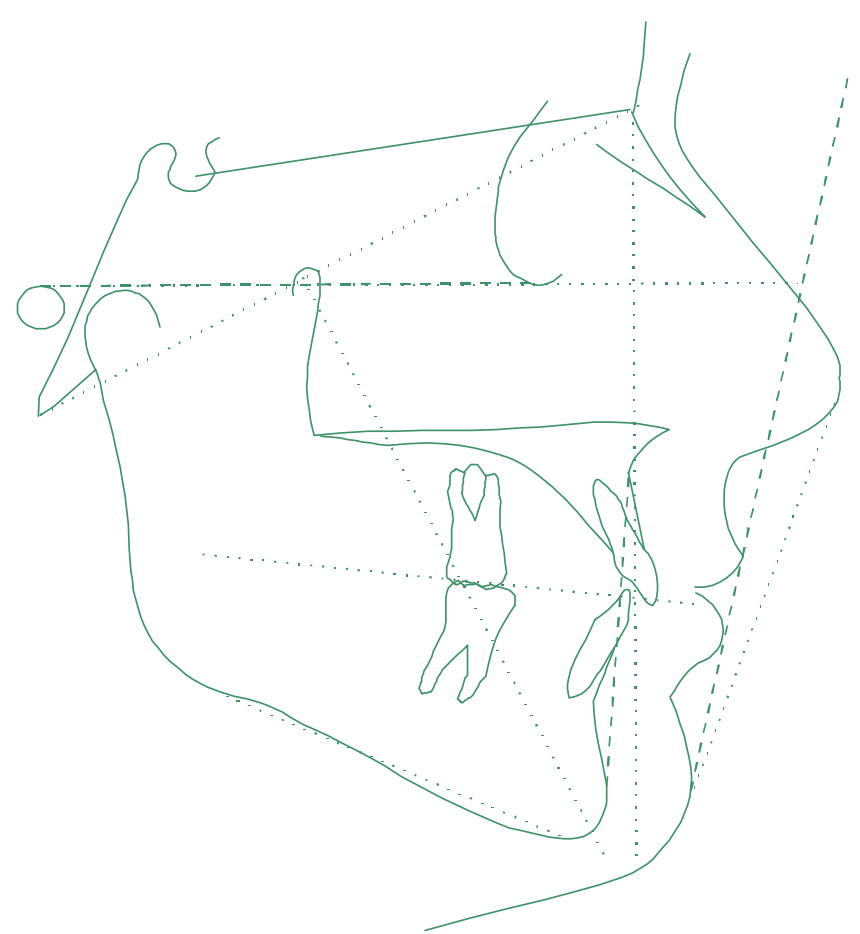

FIGURA 5.42 - Traçado composto médio para os pacientes com rotação neutra da mandíbula na fase de pós-contenção

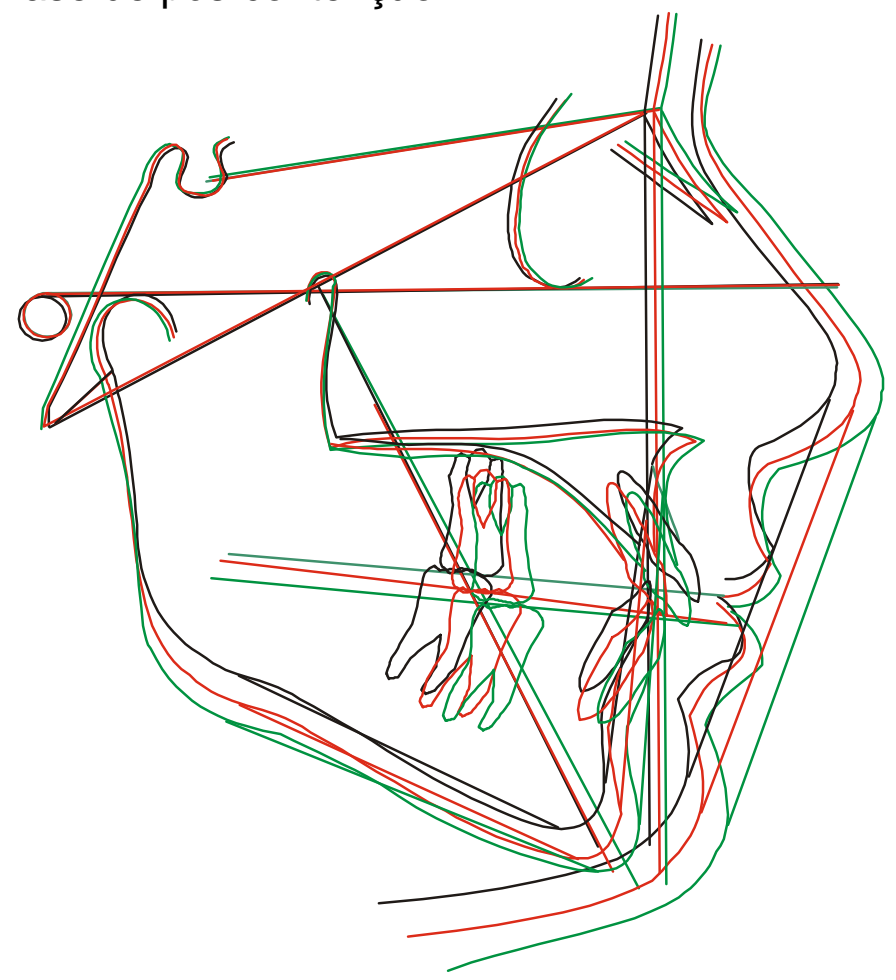

FIGURA 5.43 - Sobreposição dos traçados compostos médios para os pacientes com rotação neutra da mandíbula nas fases inicial, final e de pós-contenção 


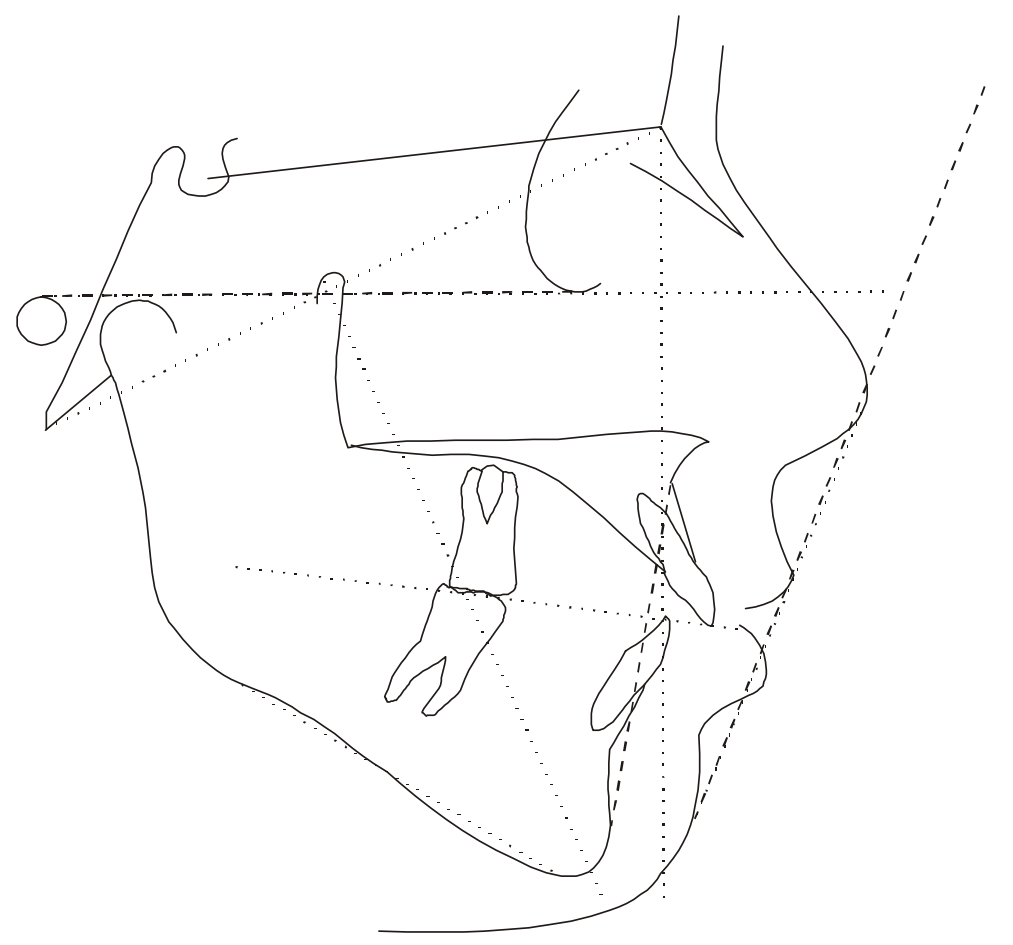

FIGURA 5.44 - Traçado composto médio para os pacientes com rotação posterior da mandíbula na fase inicial

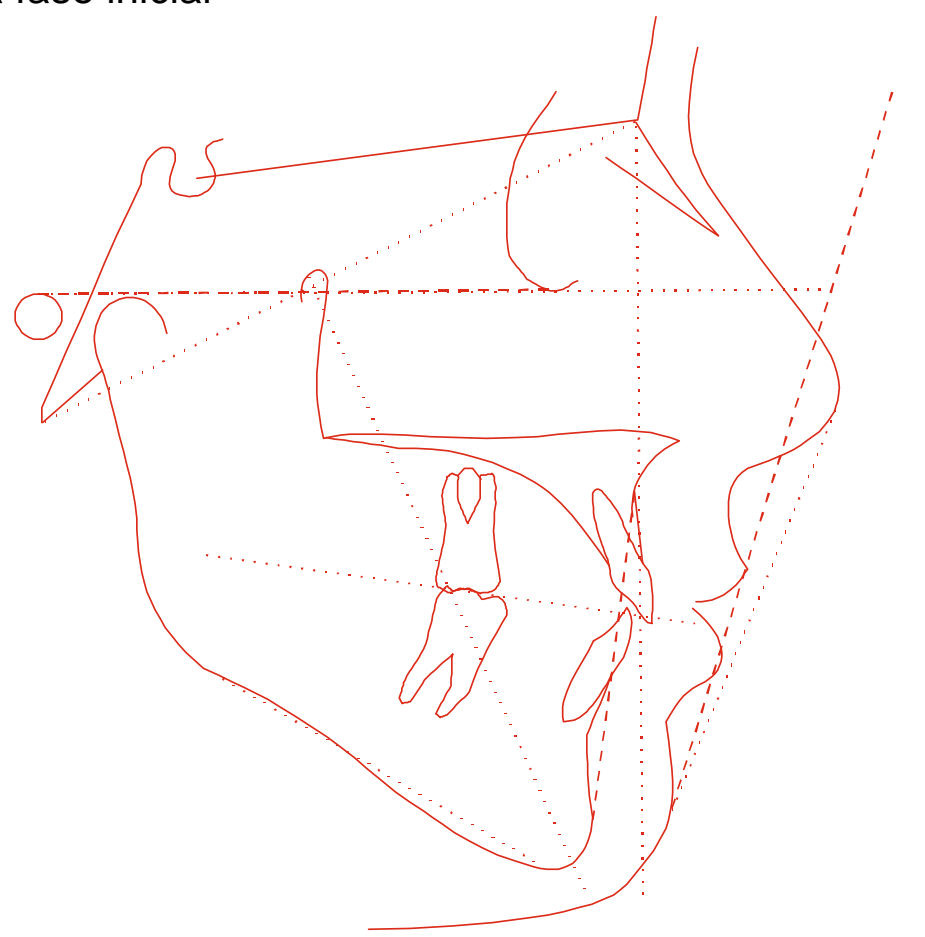

FIGURA 5.45 - Traçado composto médio para os pacientes com rotação posterior da mandíbula na fase final 


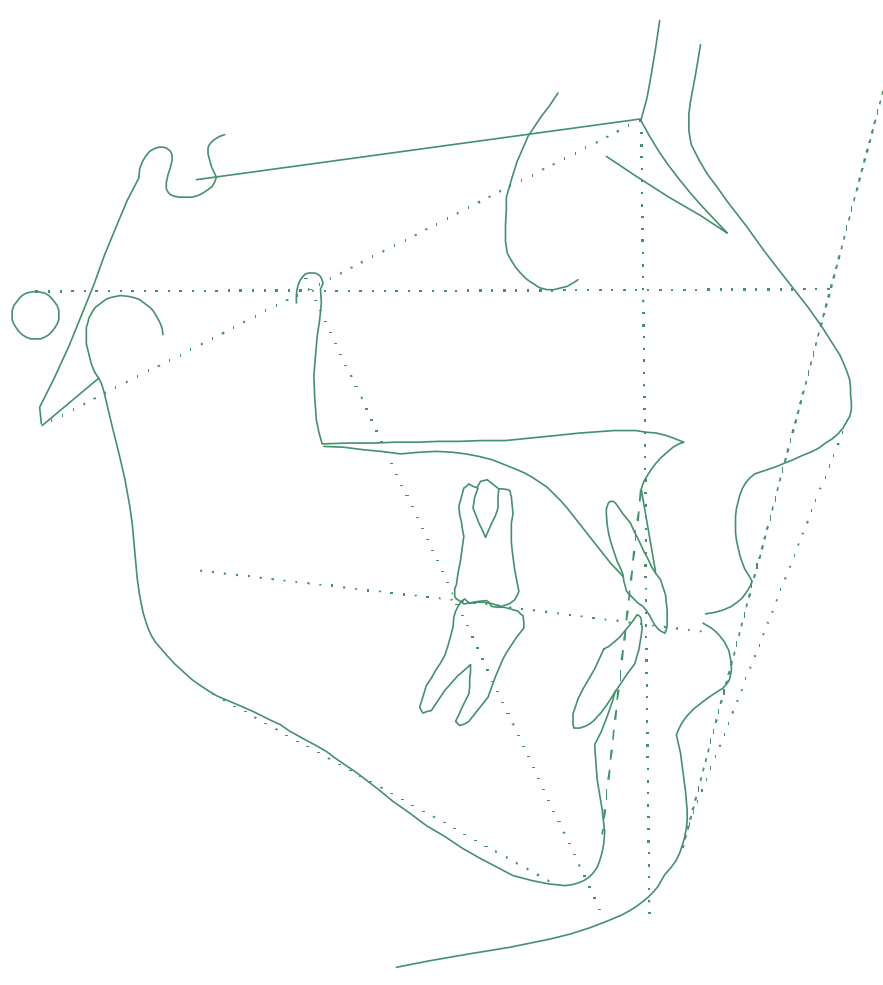

FIGURA 5.46 - Traçado composto médio para os pacientes com rotação posterior da mandíbula na fase de pós-contenção

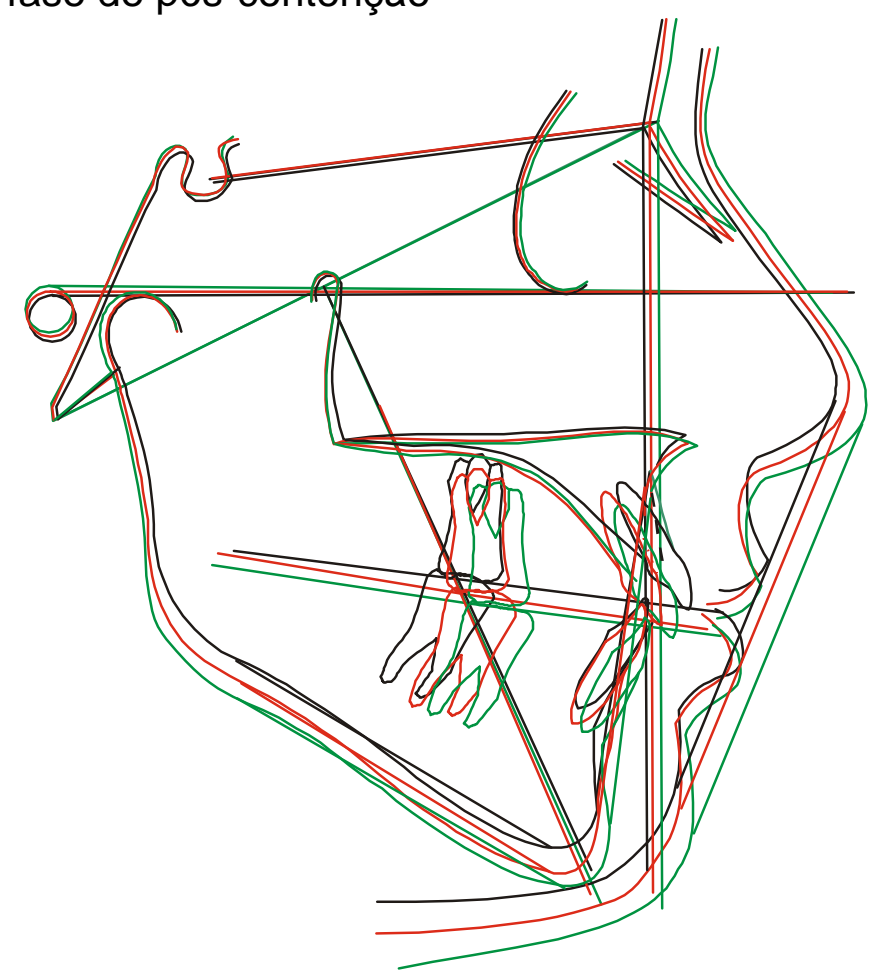

FIGURA 5.47 - Sobreposição dos traçados compostos médios para os pacientes com rotação posterior da mandíbula nas fases inicial, final e de pós-contenção 


\subsubsection{Correlação entre as variáveis da análise convencional}

Foram calculados os coeficientes de correlação entre as diferenças (índice de Little pós-contenção - índice de Little final) e as diferenças (póscontenção - final) para as variáveis da análise convencional, utilizando toda a amostra $(n=100)$. Na Tabela 5.53 encontram-se os coeficientes de correlação e níveis descritivos do teste de hipótese de inexistência de correlação. Os coeficientes foram plotados na Figura $5.48 \mathrm{em}$ ordem crescente para o valor do coeficiente de correlação. Em geral, houve poucos coeficientes de correlação estatisticamente significantes. Nesses casos, o tamanho da correlação foi pequeno.

TABELA 5.53 - Coeficientes de correlação linear para a relação entre a alteração do índice Little pós-tratamento (IL PC - IL F) e as alterações pós-tratamento (PC F) das variáveis da análise convencional

\begin{tabular}{lcc} 
Variáveis & $\boldsymbol{r}$ & $\boldsymbol{p}$ \\
\hline SNA & 0.0242 & 0.8114 \\
ANperp & 0.1332 & 0.1864 \\
CoA & 0.0491 & 0.6278 \\
ArA & -0.0519 & 0.6079 \\
SNB & -0.1840 & 0.0668 \\
PogNperp & -0.0631 & 0.5331 \\
CoGn & -0.0664 & 0.5119 \\
ArGn & -0.1239 & 0.2193 \\
ANB & 0.2531 & $\mathbf{0 . 0 1 1 1}$ \\
WITS & 0.1277 & 0.2056 \\
SN.PP & -0.0757 & 0.4542 \\
SN.Ocl & 0.1216 & 0.2280 \\
SN.PM & 0.2047 & $\mathbf{0 . 0 4 1 0}$ \\
SN.Gn & 0.1933 & 0.0540 \\
Ba.N.Gn & -0.2201 & $\mathbf{0 . 0 2 7 8}$ \\
FMA & 0.1082 & 0.2839 \\
N-Me & 0.0504 & 0.6186 \\
S-Go & -0.1466 & 0.1456 \\
AFP:AFA & -0.2466 & $\mathbf{0 . 0 1 3 4}$ \\
AFAI & 0.1676 & 0.0956 \\
1s-SN & -0.0812 & 0.4220 \\
\hline
\end{tabular}


continuação da TABELA 5.53

\begin{tabular}{lcc} 
Variáveis & $\boldsymbol{r}$ & $\boldsymbol{p}$ \\
\hline 1.NA & -0.0866 & 0.3918 \\
1-NA & 0.0293 & 0.7723 \\
1.NB & 0.1722 & 0.0867 \\
1-NB & 0.1166 & 0.2481 \\
FMIA & -0.1721 & 0.0870 \\
IMPA & 0.1231 & 0.2226 \\
1i-APog & -0.0105 & 0.9178 \\
1.1 & -0.0941 & 0.3518 \\
Ls-E & 0.2619 & $\mathbf{0 . 0 0 8 5}$ \\
Li-E & 0.2098 & $\mathbf{0 . 0 3 6 2}$ \\
Z & -0.0998 & 0.3234 \\
H-Pn & -0.2618 & $\mathbf{0 . 0 0 8 5}$ \\
\hline
\end{tabular}

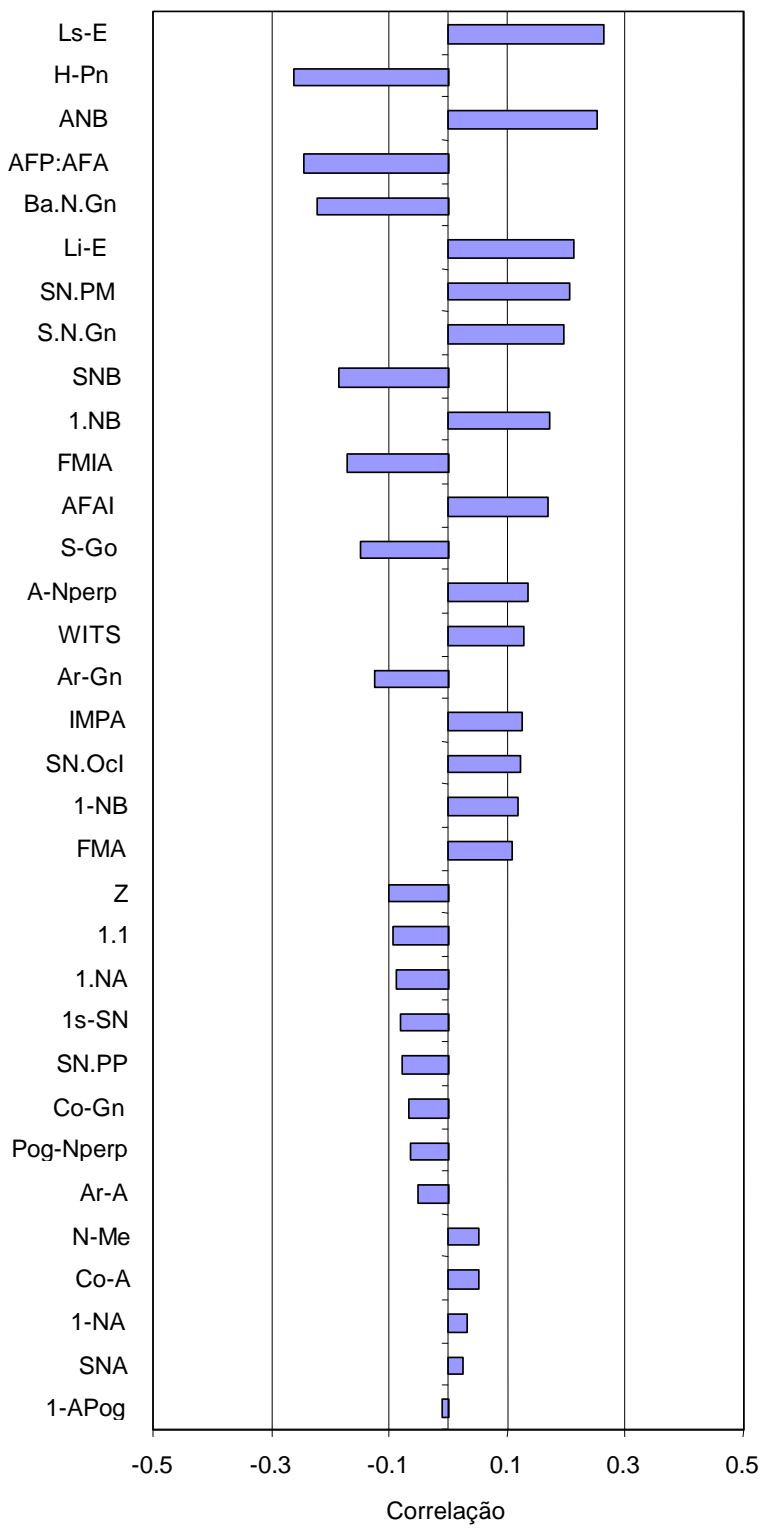

FIGURA 5.48 - Coeficientes de correlação da Tabela 5.53 
Na Tabela 5.54 encontram-se os coeficientes de correlação das variáveis que apresentaram níveis descritivos (valores de p) menores que 0,05 para toda a amostra (Tabela 5.53), os quais foram calculados dentro de cada grupo de rotação mandibular.

TABELA 5.54 - Coeficientes de correlação linear para a relação entre a alteração do índice Little pós-tratamento (IL PC - IL F) e as alterações pós-tratamento (PC F) nos grupos de rotação mandibular das variáveis da análise convencional com correlação significante para toda a amostra

\begin{tabular}{lccccccc} 
Variável & \multicolumn{6}{c}{ Rotações mandibulares } \\
& $\mathbf{A}$ & \multicolumn{4}{c}{$\mathbf{P}$} & $\mathbf{R}$ & $\mathbf{R}$ \\
SN.PM & 0.2908 & 0.1190 & 0.0820 & 0.6724 & 0.2474 & 0.1189 \\
Li-E & 0.3595 & 0.0511 & 0.0108 & 0.9558 & 0.2884 & 0.0674 \\
Ba.N.Gn & -0.2123 & 0.2601 & -0.2114 & 0.2711 & -0.2124 & 0.1825 \\
AFP:AFA & -0.2329 & 0.2155 & -0.1394 & 0.4708 & -0.3416 & $\mathbf{0 . 0 2 8 8}$ \\
ANB & 0.3584 & 0.0518 & 0.2756 & 0.1480 & 0.1732 & 0.2790 \\
H-Pn & -0.3873 & $\mathbf{0 . 0 3 4 5}$ & -0.0226 & 0.9072 & -0.3290 & 0.0357 \\
Ls-E & 0.3960 & $\mathbf{0 . 0 3 0 3}$ & 0.0445 & 0.8186 & 0.3092 & $\mathbf{0 . 0 4 9 2}$ \\
\hline
\end{tabular}

Em geral, houve poucos coeficientes de correlação estatisticamente significantes. Nestes casos, o tamanho da correlação foi pequeno. Isso indica que o reaparecimento da irregularidade dentária após o tratamento ortodôntico não está fortemente relacionado com nenhuma das variáveis da análise convencional. 
6 DISCUSSÃO 


\section{DISCUSSÃO}

"A face ortodôntica estava prevalente em todo lugar e os aparelhos de contenção eram removidos com medo e trepidação" (STRANG $\left.{ }^{194}, 1949\right)$.

A frase acima, apesar de ter sido escrita há mais de 50 anos e de se referir a um período da história da Ortodontia do início do século passado, talvez ainda hoje reflita um pouco do sentimento do ortodontista frente à recidiva póstratamento ortodôntico.

A Ortodontia conquistou muitos avanços científicos e tecnológicos no último século, que acarretaram profundas transformações na forma como ela é executada pelos profissionais e é "entregue" à população. Entretanto, apesar de a estabilidade pós-tratamento ser um dos principais objetivos do tratamento ortodôntico, e de muitos esforços científicos já terem sido despendidos para resolver o problema, a Ortodontia ainda continua sem uma resposta definitiva para ele.

Por que a Ortodontia não consegue resolver esse problema?

Uma provável resposta reside no fato de inúmeros fatores estarem envolvidos nessa questão, tornando-a "caótica", como diria a teoria do caos, ou seja, uma resposta simples, levando em conta apenas um ou dois fatores envolvidos, provavelmente não explicará esse fenômeno.

A fim de posicionar corretamente uma peça nesse quebra-cabeça científico, procurou-se, por meio deste estudo, verificar a relação dos tipos faciais específicos da análise de PETROVIC/LAVERGNE com a recidiva pós-tratamento. 


\subsection{AVALIAÇÃO DOS MODELOS DE ESTUDO}

Segundo LAVERGNE ${ }^{92}$, os pacientes dos grupos rotacionais R2D e R1N devem apresentar uma maior estabilidade pós-tratamento ortodôntico. Entretanto, os resultados mostraram que as diferentes categorias de crescimento praticamente possuem o mesmo padrão de recidiva pós-tratamento ortodôntico, quanto aos modelos de estudo. Somente o trespasse vertical mostrou uma diferença estatisticamente significante entre as categorias. A categoria 1 recidivou menos, o que já seria esperado, considerando-se a morfologia facial mais vertical desses pacientes, e a categoria 3 apresentou a maior recidiva. Entretanto, cabe ressaltar que, para todos os pacientes, o trespasse vertical, 10 anos após o tratamento, apresentou-se estatisticamente igual ao do início do tratamento.

Esses resultados corroboram os dos autores ${ }^{23,59}$ que afirmam que a morfologia facial pode interferir na recidiva do trespasse vertical, e estão contrários aos dos autores ${ }^{88}$ que afirmam que essa recidiva é apenas um fenômeno dentoalveolar.

As variáveis índice de Little, distâncias intercaninos, entre os segundos pré-molares, comprimento do arco, trespasse horizontal e curva de Spee apresentaram uma recidiva que não retornou aos valores iniciais, pois o valor pós-contenção foi diferente do inicial. E a distância entre os segundos prémolares não apresentou a estabilidade relatada na literatura ${ }^{10,53}$. 
Quanto à distância intercaninos, vale ressaltar que, durante o tratamento, houve uma expansão em torno de 0,4 a $0,8 \mathrm{~mm}$. No período pós-contenção, houve uma diminuição entre 0,5 e $1,4 \mathrm{~mm}$. A alteração total foi na ordem de 0 a 0,7 mm de constrição. Esses resultados poderiam suportar o conceito da manutenção da largura intercaninos original no tratamento ortodôntico, pois ela tende a retornar aos valores iniciais, conforme já descrito por STRANG ${ }^{194}$, SHAPIRO ${ }^{177}$, e BURKE et al. $^{31}$. Entretanto, para TOIGO; MANDETTA ${ }^{203}$, a manutenção da distância intercaninos durante o tratamento ortodôntico não tem influência no apinhamento dos incisivos inferiores, pois seus casos foram tratados sem expansão, e, mesmo assim, apresentaram estreitamento e apinhamento no período pós-contenção. Portanto, provavelmente, a chave para a estabilidade não está relacionada com essa distância. Por outro lado, conforme descrito por PAQUETTE; BEATTIE; JOHNSTON JÚNIOR ${ }^{131}$, apesar de o presente trabalho e de outros não terem conseguido detectar uma relação entre a expansão da distância intercaninos e a irregularidade incisal, esses resultados não deveriam ser utilizados para justificar o retorno da expansão como uma resposta genérica para o apinhamento. A diminuição natural da distância intercaninos com o passar dos anos ${ }^{7,19,182}$ também corrobora esse pensamento.

O fato da amostra utilizada conter casos com extrações de primeiros (82 pacientes) e segundos pré-molares (18 pacientes) inferiores, não compromete os resultados, pois: os pacientes com extrações de segundos pré-molares ficaram distribuídos em todas as categorias de crescimento e grupos de rotação mandibular; conforme descrito na literatura ${ }^{203}$, a extração dos primeiros pré- 
molares não faz com que haja um maior aumento da distância intercaninos e nem garante uma maior estabilidade; outras pesquisas ${ }^{2,28,55,177,207}$ também utilizaram casos com extrações de primeiros e segundos pré-molares juntos na sua amostra.

A variável distância intermolares apresentou diferenças significativas entre o início e os momentos final e de pós-contenção, mas não entre os momentos final e de pós-contenção, o que demonstra que essa dimensão apresentou uma boa estabilidade longitudinalmente, como descrito por SINCLAIR; LITTLE $^{182}$.

Apesar de não ter havido diferenças estatisticamente significantes para as alterações no índice de Little entre as diferentes categorias de crescimento, provavelmente devido à grande variabilidade individual, os pacientes da categoria 4 apresentaram o menor valor no período pós-contenção, com 2,39 mm (1,13 mm de recidiva 10 anos após o tratamento), o que seria considerado como uma boa estabilidade (menor que 3,5 mm para o período pós-contenção) por LITTLE $^{44,109}$, e também seria mais estável do que o resultado de muitos trabalhos descritos na literatura ${ }^{105,109,212}$. O mesmo não pode ser dito a respeito dos pacientes das categorias 1 e 5, que apresentaram valores respectivos de 3,83 e 3,77 mm, valores esses que seriam considerados inaceitáveis (maiores que 3,5 $\mathrm{mm}$ para o período pós-contenção). Essas observações corroboram a suposição $^{92}$ de que os pacientes do tipo rotacional R1N (categoria 4) poderiam apresentar uma menor recidiva pós-tratamento, e também corroboram a especulação de FIDLER et al. ${ }^{49}$ de que pacientes em crescimento com relações 
verticais normais apresentarão bons resultados no tratamento e estabilidade a longo prazo, o que é o caso dos pacientes da categoria 4. Pode-se considerar que esses resultados também corroboram os estudos que acreditam na influência do tipo facial sobre a recidiva, como SAKUDA et al. ${ }^{171}$, OLIVEIRA JÚNIOR et al ${ }^{129}$, FREITAS ${ }^{51}$, para os quais, jovens com padrão de crescimento vertical demonstraram uma maior associação com a recidiva pós-contenção. São porém, contrários aos outros ${ }^{149,220}$ que afirmam não haver relação do tipo facial com a recidiva.

Por outro lado, esses $2 \mathrm{~mm}$ de recidiva poderiam ser considerados apenas como a maturação dessas oclusões. Como mostrado por vários autores $^{17,158,182}$ após estudos em pacientes não tratados, o apinhamento incisal inferior aumenta durante a adolescência e o início da idade adulta. Infelizmente, conforme descrito por THILANDER ${ }^{201}$, não há um método definitivo para se distinguir entre os eventos normais relacionados com a idade e a recidiva após o tratamento ortodôntico.

Chama a atenção o fato de que $41 \%$ dos pacientes apresentaram um resultado insatisfatório (índice de Little maior que 3,5 mm) 10 anos após o tratamento, mesmo que esse resultado seja melhor que os $70 \%$ encontrados por LITTLE; WALLEN; RIEDEL ${ }^{109}$ em 1981. Entretanto, se considerarmos que todas as categorias apresentaram, ao final do tratamento, um índice de Little em torno de $1,5 \mathrm{~mm}$ e que a recidiva girou em torno de $2 \mathrm{~mm}$, poderíamos raciocinar que, 
se o índice de Little no final do tratamento tivesse sido 0 , esses $2 \mathrm{~mm}$ de recidiva fariam com que todos os pacientes apresentassem resultados satisfatórios 10 anos após o tratamento. Portanto, além dos objetivos oclusais, funcionais e estéticos do tratamento ortodôntico, o ortodontista deveria buscar zerar o índice de Little no final do tratamento ortodôntico.

A questão do tempo de duração da contenção sobre os incisivos inferiores tem-se mantido como um tema bastante controverso na literatura. Os dados do presente trabalho demonstram que se um paciente que apresenta máoclusão de Classe II quiser que os seus incisivos inferiores permaneçam com o mesmo alinhamento, que eles possuíam na época de conclusão do tratamento, 10 anos após, ele deverá utilizar uma contenção durante todo esse período, a fim de evitar a recidiva. Vários autores ${ }^{87,105,132,168,179}$ têm recomendado o uso contínuo das contenções a fim garantir os resultados do tratamento. Entretanto, não são conhecidas as seqüelas indesejáveis pelo uso prolongado das contenções, principalmente das fixas inferiores ${ }^{105}$.

A divisão das categorias de acordo com a rotação (inclinação) da mandíbula em posterior, anterior e neutra também não mostrou diferenças para a maioria das variáveis. Apenas a curva de Spee e o trespasse vertical apresentaram diferenças significantes. 
A recidiva da correção da curva de Spee foi maior no grupo com rotação anterior em relação aos grupos com rotação posterior e neutra. Entretanto, essa diferença não foi clinicamente significante, ficando em torno de $0,5 \mathrm{~mm}$.

O trespasse vertical apresentou maior recidiva nos pacientes com rotação anterior e neutra que nos pacientes com rotação posterior. Esses resultados não estão de acordo com alguns estudos, os quais afirmam que o tipo facial inicial do paciente não afeta a recidiva do trespasse vertical, como PINTO; WOODS; CRAWFORD $^{149}$, que se surpreenderam por não encontrarem diferenças significativas nas alterações do valor do índice PAR pós-tratamento para subgrupos verticais diferentes. ZAHER; BISHARA; JAKOBSEN ${ }^{220}$ encontraram uma tendência maior de recidiva no trespasse vertical em pacientes com tipo facial curto. Esses autores ${ }^{220}$ também detectaram uma diminuição maior na distância intercaninos nos pacientes com face curta, o que não foi confirmado em nosso estudo. Esses resultados indicam que os pacientes que apresentam uma rotação (inclinação) anterior no início do tratamento deveriam ter o seu trespasse vertical sobrecorrigido durante o tratamento, e/ou, deveriam receber um tipo de contenção que pudesse prevenir essa recidiva, como uma placa com batente anterior, conforme descrito por NANDA; NANDA ${ }^{127}$, em 1992. Entretanto, para ZAHER, BISHARA; JAKOBSEN ${ }^{220}$, os três tipos faciais (mesofacial, braquifacial e dolicofacial) não requerem considerações especiais quanto à contenção.

A divisão dos 100 pacientes de acordo com a dimensão vertical em mordida profunda, mordida aberta e mordida normal representa a relação da 
maxila com a mandíbula, sem levar em conta o fator esquelético, no caso, o potencial de crescimento. Na verdade, tentou-se correlacionar o índice de Little, a distância intercaninos e o trespasse vertical com as diferenças na dimensão vertical. Essa divisão mostrou diferença significante apenas para o trespasse vertical, onde o grupo com mordida profunda mostrou maior recidiva. Esse resultado está de acordo com SHIELDS; LITTLE; CHAPKO ${ }^{178}$, que encontraram pacientes com valores baixos para os ângulos dos planos oclusal e mandibular, sendo mais propensos a apresentar um aprofundamento da mordida.

Por meio do teste de correlação linear entre as alterações no índice de Little e nas demais varáveis dentárias, procurou-se encontrar uma explicação para o reaparecimento da irregularidade dentária 10 anos após o tratamento; em geral, os coeficientes de correlação foram baixos e não significantes (Tabela 5.12). Esses resultados contrariam a afirmação de ARTUN; GAROL; LITTLE ${ }^{6}$ de que o aumento da largura intercaninos durante o tratamento e a sua diminuição pós-contenção estão associados com a recidiva.

Da mesma forma que para WILLIAMS; ANDERSEN ${ }^{214}$, os resultados desse estudo demonstraram que o aumento do trespasse vertical se correlacionou levemente com o aumento do índice de Little pós-tratamento (Tabela 5.35). Entretanto, considerando-se o valor de r, e com base no trabalho de JOHNSTON JÚNIOR ${ }^{81}$, pode-se considerar esse resultado como insignificante.

Essa falta de correlação, segundo PAQUETTE; BEATTIE; JOHNSTON JÚNIOR ${ }^{131}$, talvez possa constituir um subproduto de variação estranha na 
duração e tipo de contenção ou na cooperação do paciente; isso também pode implicar que os fatores que causam a irregularidade incisal inferior talvez não possam ser inferidos a partir dos modelos de estudo. Isso reforça a afirmação de PROFFIT ${ }^{151}$, segundo a qual dois fatores principais estão envolvidos no equilíbrio que determina a posição final dos dentes: as pressões da posição de repouso do lábio, da bochecha e da língua, bem como as forças produzidas pela atividade metabólica dentro da membrana periodontal, análoga às forças da irrupção dentária.

Também foram calculados os coeficientes de correlação, para se estudar a relação das rotações maxilar e mandibular com a recidiva do trespasse vertical Os resultados dessas correlações (Tabela 5.36) evidenciaram que, as rotações da maxila e da mandíbula, ocorridas no período pós-tratamento, não apresentaram relação significante com a recidiva do trespasse vertical. Esses resultados são contrários aos achados de BJÖRK; SKIELLER ${ }^{23}$, e estão de acordo com KAWAUCHI et al. ${ }^{88}$, que também não encontraram uma correlação significante entre a rotação mandibular e a recidiva do trespasse vertical.

\subsection{COMPARAÇÕES NO TRATAMENTO PELA ANÁLISE DE JOHNSTON JÚNIOR}

As alterações dentárias e esqueléticas, que acompanham o tratamento pela técnica do Arco de Canto Simplificada com extrações de quatro pré-molares e a utilização do aparelho de ancoragem extrabucal apresentam poucas 
diferenças quando executadas nas diferentes categorias de crescimento de PETROVIC. Na Tabela 5.13 e 5.14 e nas Figuras de 5.8 a 5.12, pode ser observado que apenas a correção do trespasse horizontal e a rotação mandibular apresentaram diferenças entre as categorias.

Para as outras variáveis não houve nenhuma diferença estatisticamente significante entre as categorias de crescimento, contrariamente ao observado por MORO;SCANAVINI;VIGORITO ${ }^{124}$, de que a alteração da base apical (ABA), como também o avanço mandibular foram maiores para a categoria 5 que para a 3 . Os achados do presente estudo também não corroboram as pesquisas de PETROVIC; STUTZMANN ${ }^{143}$, PETROVIC; STUTZMANN; LAVERGNE $^{147}$, PETROVIC; STUTZMANN; LAVERGNE ${ }^{148}$, que mostraram, em pacientes de grupos de controle, não tratados ortodonticamente, que o alongamento mandibular determinado fisiologicamente aumenta da categoria 1 para a categoria 5. Uma possível explicação encontrar-se-ia no fato segundo o qual esses resultados contraditórios estariam expressando as dificuldades em se classificar, por meio da cefalometria, as diferentes categorias de crescimento, especialmente em pacientes com maior crescimento, ou seja, talvez possa estar havendo uma sobreposição entre os pacientes das categorias 3 e 5 . Segundo PETROVIC; STUTZMANN ${ }^{145}$, talvez, no futuro, a lógica Fuzzy possa esclarecer as fronteiras mal definidas entre as categorias de crescimento.

Com exceção da categoria 2, em todas as outras categorias o movimento dentário teve pouca importância na correção das relações dentárias ânteroposteriores. O crescimento maxilar não contribuiu para a correção molar em 
nenhuma das categorias. Em todas elas, a principal fonte das alterações foi o crescimento diferencial dos maxilares, ou seja, a alteração da base apical (ABA), que significou, na verdade, o quanto a mais a mandíbula avançou anteriormente em relação à maxila. A diferença para essa medida entre as categorias não foi estatisticamente significante após a correção pela EGU (Unidade de Crescimento Esperado).

Anteriormente havia sido relatado ${ }^{124}$ que a perda de ancoragem superior parecia ser um dos maiores problemas durante o tratamento da má-oclusão de Classe II com extrações. Neste estudo, em nenhuma categoria essa variável apresentou um valor superior a 2,2 $\mathrm{mm}$. A perda de ancoragem inferior também apresentou um valor relativamente pequeno. Entretanto, ao se comparar o quanto as movimentações dentária e esquelética contribuíram para a correção molar em cada uma das categorias, nota-se que, na categoria 1, a correção dentária contribuiu com $6,5 \%(2,43 \mathrm{~mm}-2,21 \mathrm{~mm}=0,22 \mathrm{~mm})$ e a esquelética $(A B A=3,13$ $\mathrm{mm}$ ), com $93,5 \%$ da correção molar total, sendo que esses $93,5 \%$ representam, na verdade, o quanto a mandíbula cresceu a mais que a maxila. Na categoria 2, a correção dentária contribuiu com 37,1\% $(2,3 \mathrm{~mm}-1,03 \mathrm{~mm}=1,27 \mathrm{~mm})$ e a esquelética $(A B A=2,2 \mathrm{~mm})$, com $62,9 \%$ da correção molar total. Na categoria 3 , a correção dentária foi de -0,48 mm (1,44 mm - 1,92 mm) e, portanto, prejudicou em (-) $14,4 \%$ a correção molar, que foi corrigida na sua totalidade pela alteração esquelética $(A B A=3,82 \mathrm{~mm}$ ), a qual representou $114,7 \%$ da correção molar. Portanto, na categoria 3, o crescimento mandibular e/ou deslocamento anterior (5,56 mm) foi o responsável pela correção da relação molar. Na categoria 4, a 
correção dentária contribuiu com 13,8\% (1,54 mm - 1,0 mm =0,54 mm) e a esquelética ( $A B A=3,33 \mathrm{~mm}$ ), com $86,2 \%$ da correção molar total. Na categoria 5 , a correção dentária contribuiu com 7,3\% $(1,65 \mathrm{~mm}-1,48 \mathrm{~mm}=0,17 \mathrm{~mm})$ e a esquelética ( $A B A=3,66 \mathrm{~mm})$, com 92,6\% da correção molar total. Esses achados estão de acordo com os resultados de JOHNSTON JÚNIOR ${ }^{80}$, DYER; HARRIS; VADEN $^{45}$, HARRIS et al. ${ }^{65}$, PAQUETTE; BEATTIE; JOHNSTON JÚNIOR ${ }^{131}$, MORO; SCANAVINI; VIGORITO ${ }^{124}$, que também obtiveram, como resultado em seus estudos, que o fator mais importante para a correção molar é o crescimento diferencial dos maxilares. HERZBERG ${ }^{70}$ igualmente ressaltou a importância do crescimento mandibular para a correção da Classe II.

Com relação às alterações incisais, apenas a categoria 1 apresentou maior correção estatisticamente significante que a categoria 2. E, ao se pesquisar quais os componentes que mais contribuíram para a correção incisal, nota-se que, na categoria 1, o movimento dentário contribuiu com 2,05 mm (4,96 mm 2,91 mm), o que corresponde a 39,4\% da correção incisal total. Na categoria 2, o movimento dentário contribuiu com $0,14 \mathrm{~mm}(3,75 \mathrm{~mm}-3,61 \mathrm{~mm})$, o que corresponde a 5,9\% da correção incisal total. Na categoria 3, o movimento dentário contribuiu com $0,58 \mathrm{~mm}(4,45 \mathrm{~mm}-3,87 \mathrm{~mm})$, o que corresponde a 13,06\% dessa correção. Na categoria 4, a movimentação dos incisivos prejudicou a correção com -0,05 mm (3,05 mm - 3,1 mm), o que corresponde a (-) 1,5\% da correção incisal. Portanto, na categoria 4, a ABA foi responsável por 103,4\% $(3,33 \mathrm{~mm})$ da correção incisal, enquanto que, na categoria 5 , o movimento dentário contribuiu com 0,56 mm (4,26 mm - 3,7 mm), o que corresponde a $14 \%$ 
da correção incisal total. Com exceção da categoria 1, todas as outras categorias corroboram os estudos de PAQUETTE; BEATTIE; JOHNSTON JÚNIOR ${ }^{131}$, e de MORO; SCANAVINI; VIGORITO ${ }^{124}$, que já haviam observado que a correção do trespasse horizontal deriva quase que exclusivamente do crescimento diferencial dos maxilares e não da movimentação dos incisivos.

As alterações dentárias e esqueléticas que acompanham o tratamento com a técnica do Arco de Canto não apresentam muitas diferenças quando executadas nos grupos com diferentes rotações (inclinações) da mandíbula. Nas Tabelas 5.15 e 5.16 e nas Figuras de 5.13 a 5.15 , pode ser observado que apenas a correção da relação molar apresentou diferenças entre os grupos posterior e anterior.

Em todos os grupos de rotações, o movimento dentário teve pouca importância na correção das relações dentárias ântero-posteriores. O crescimento maxilar não contribuiu para a correção molar em nenhum dos grupos. A principal fonte das alterações foi a alteração da base apical (ABA). A diferença para essa medida entre as categorias não foi estatisticamente significante após a correção pela EGU.

Da mesma forma que a divisão por categorias, a divisão da amostra por grupos de rotação mandibular mostrou que houve pouca perda de ancoragem superior, não chegando a ser maior que 2,0 mm. A perda de ancoragem inferior também apresentou um valor relativamente pequeno, o que demonstra um bom controle da ancoragem na amostra tratada. 
Entretanto, ao se comparar o quanto as movimentações dentária e esquelética contribuíram para a correção molar em cada um dos grupos de rotação, nota-se que, no grupo com rotação anterior, a correção dentária contribuiu com $15,2 \%$, e a esquelética, com $84,8 \%$ da correção molar total. No grupo com rotação posterior, a correção dentária contribuiu com 19,9\%, e a esquelética, com $80,1 \%$ da correção molar total. No grupo com rotação neutra, a correção dentária foi de $-0,13 \mathrm{~mm}$ e, portanto, prejudicou em (-) 3,6\% a correção molar, que foi corrigida na sua totalidade pela alteração esquelética ( $\mathrm{ABA}=3,65$ mm), a qual representou $103,3 \%$ da correção molar total.

Ao se pesquisar quais os componentes que mais contribuíram para a correção incisal, nota-se que, na rotação anterior, o movimento dentário contribuiu com $19,6 \%$ da correção incisal total. Na posterior, o movimento dentário contribuiu com $22,3 \%$ da correção incisal total. Na neutra, o movimento dentário contribuiu com $8,9 \%$ dessa correção. Portanto, a ABA foi a maior responsável pela correção incisal nas três inclinações da mandíbula.

\subsection{COMPARAÇÕES NO PERÍODO PÓS-TRATAMENTO PELA ANÁLISE DE JOHNSTON JÚNIOR}

As diferentes categorias de crescimento apresentaram alterações semelhantes 10 anos após o tratamento ortodôntico. Não houve diferença estatisticamente significante entre as diferentes categorias de crescimento em 
qualquer das variáveis da análise de JOHNSTON JÚNIOR, conforme apresentado nas Tabelas 5.17 e 5.18 e nas Figuras de 5.8 a 5.12.

Houve uma tendência em todas as categorias para um leve deslocamento anterior da maxila (média de $-1 \mathrm{~mm}$ ), uma pequena alteração da base apical (média de 0,2 mm), uma mesialização dos molares superiores (média de -1,5 $\mathrm{mm}$ ) e inferiores (média de 0,7 $\mathrm{mm}$ ), uma vestibularização dos incisivos superiores (média de $-1,0 \mathrm{~mm}$ ) e uma recidiva das relações molar (média de -0,4 $\mathrm{mm}$ ) e incisal (média de $-0,8 \mathrm{~mm}$ ). Houve certa variação apenas na movimentação dos incisivos inferiores, onde se observou que, nas categorias com maior deslocamento mandibular anterior (categoria 2, com 2,46 mm, e categoria 4, com 2,04 mm), eles posicionaram-se para lingual, sem contudo, serem estas diferenças estatisticamente significantes. Nas outras categorias com pouco avanço mandibular (categoria 1 , com $0,07 \mathrm{~mm}$, e categoria 5 , com 0,06 $\mathrm{mm}$ ), eles sofreram uma vestibularização. Esse dado é corroborado pelo fato de a EGU ter apresentado uma relação significante com o movimento do incisivo inferior (Tabela 5.18) e também pelo fato de essa variável ter-se correlacionado significantemente com o crescimento/deslocamento mandibular (Tabelas de 5.31 a 5.34). Isso está de acordo com estudos ${ }^{112,131}$, que mostram uma relação da alteração da posição dos incisivos inferiores pós-tratamento com o crescimento mandibular.

De forma geral, os principais fatores responsáveis pela recidiva das relações molar e incisal foram, respectivamente, as mesializações dos molares superiores e dos incisivos superiores. Esse padrão de recidiva corrobora HARRIS 
et al. $^{65}$, que encontraram o assentamento (mesialização) do primeiro molar superior, tanto por inclinação anterior de coroa quanto por movimento mesial de corpo, como sendo o principal responsável pela recidiva da relação de Classe II, que foi de aproximadamente $1 \mathrm{~mm}$.

A divisão dos pacientes de acordo com a rotação mandibular não mostrou diferenças significantes entre os grupos no período pós-tratamento, conforme foi apresentado nas Tabelas 5.19 e 5.20 e nas Figuras de 5.13 a 5.15. O padrão de movimentação dentária foi o mesmo que quando da divisão por categorias, sendo, inclusive, possível observar a mesma tendência de movimentação nos incisivos inferiores.

Embora a alteração da base apical (ABA) e o crescimento da mandíbula tenham apresentado coeficientes de correlação linear significantes com quase todas as alterações dentárias nos diferentes grupos avaliados, eles não se relacionaram com o retorno da irregularidade dos incisivos inferiores. Esses resultados corroboram os achados de $\mathrm{RICHARDSON}^{156}$. Isso também pode implicar que os fatores que causam a irregularidade incisal inferior talvez não possam ser inferidos a partir do traçado cefalométrico, conforme descrito por PAQUETTE; BEATTIE; JOHNSTON JÚNIOR ${ }^{131}$.

Os coeficientes de correlação apresentados nas Tabelas de 5.27 a 5.34, demonstram que, de forma geral, quanto maior o crescimento da mandíbula em relação à maxila, maior será a probabilidade de os molares e incisivos superiores 
moverem-se para frente, de os incisivos inferiores inclinarem-se para lingual e de a ancoragem molar inferior ser preservada.

A análise dos coeficientes de correlação nos grupos de rotação mandibular apresentados nas Tabelas de 5.27 a 5.34 também demonstrou essencialmente um padrão de recidiva/assentamento pós-tratamento que estava mais relacionado com o crescimento diferencial dos maxilares que com a posição pós-tratamento e com a orientação da dentição, fatores esses, avaliados pela análise convencional (Tabela 5.53 e 5.54) .

\subsection{COMPARAÇÕES TOTAIS PELA ANÁLISE DE JOHNSTON JÚNIOR}

Ao se avaliar as alterações totais, ou seja, aquelas que ocorreram durante o tratamento ortodôntico somadas àquelas que ocorreram no período pós-contenção, constatou-se que as diferentes categorias de crescimento apresentaram alterações dentoesqueléticas praticamente semelhantes. Com exceção da variável correção incisal, que foi maior na categoria 1 (4,24 mm) que na categoria $2(1,55 \mathrm{~mm})$, para as demais não houve diferenças estatisticamente significantes entre as diferentes categorias de crescimento, conforme apresentado nas Tabelas 5.21 e 5.22 e nas Figuras de 5.8 a 5.12.

Durante cerca de 13 anos de acompanhamento, todas as correções dentárias e esqueléticas mantiveram-se estatisticamente significantes, apesar do contínuo crescimento anterior da maxila, do deslocamento mesial do molar 
superior e do movimento lingual dos incisivos inferiores. Esses fatores, além de representarem a recidiva pós-tratamento ortodôntico, representam também a maturação dentofacial relatada na literatura ${ }^{201}$, que acontece lentamente com o passar dos anos e que é impossível dissociar da recidiva. Contrapondo-se a esses fatores e ajudando a manter as correções alcançadas, observou-se, no período avaliado, uma mesialização do molar inferior, uma retração dos incisivos superiores e um grande crescimento/deslocamento anterior da mandíbula, que, na verdade, foi o principal responsável pelos correções molar e incisal. Para todas as categorias estudadas, o valor total do crescimento mandibular foi maior que as correções molar e incisal totais. HERZBERG ${ }^{70}$ já em 1973, havia afirmado que o bom crescimento da mandíbula para frente e para baixo era o fator isolado mais importante para a correção das más-oclusões de Classe II e também para a manutenção da correção. PAQUETTE; BEATTIE; JOHNSTON JÚNIOR ${ }^{131}$ encontraram, no final de seu estudo, que os vários movimentos dentários tendiam a cancelar um ao outro, e que tanto a correção do trespasse horizontal quanto a da relação molar eram derivadas quase que exclusivamente do crescimento diferencial dos maxilares, sendo que o crescimento mandibular era o mais importante contribuinte. Esses dados também estão de acordo com JOHNSTON JÚNIOR ${ }^{83}$, que encontrou 9 dentre 10 pacientes mostrando um padrão de alteração no qual a mandíbula avançara em relação à maxila.

Esses resultados semelhantes para diferentes categorias confirmaram LUPPANAPORNLARP; JOHNSTON JÚNIOR ${ }^{112}$, que não se surpreenderam com o fato de que pacientes tratados com e sem extrações tivessem apresentado a 
mesma alteração longitudinal, pois, se a alteração futura fosse uma simples função da forma facial individual, a previsão cefalométrica ter-se-ia rendido há muito tempo às várias técnicas estatísticas, quer simples, quer multivariadas.

A divisão dos pacientes de acordo com a rotação mandibular não mostrou diferenças significantes entre os grupos no período pós-tratamento, e o padrão de recidiva e/ou maturação dentofacial foi o mesmo que quando da divisão por categorias.

\subsection{AVALIAÇÃO DAS ROTAÇÕES MAXILAR E MANDIBULAR}

A avaliação das rotações maxilar e mandibular durante o tratamento demonstrou que a rotação mandibular na categoria $3\left(-3,43^{\circ}\right)$ foi significativamente maior que na categoria $1\left(-0,97^{\circ}\right)$. A rotação mandibular apresentou-se como anterior, com sentido anti-horário em todas as categorias. E a rotação maxilar apresentou-se com sentido horário (posterior) em todas as categorias.

É importante ressaltar que a mecânica empregada durante o tratamento pode ter alterado as rotações da maxila e da mandíbula, o que impediria a avaliação das rotações nessa fase, em relação à classificação proposta por LAVERGNE; GASSON ${ }^{97}$. A categoria 1 é composta por pacientes do tipo rotacional P2D, que possuem a denominação de rotação posterior e segundo essa classificação ${ }^{97}$, deveriam apresentar uma rotação mandibular anual maior 
que $0^{\circ}$ em sentido horário. As categorias 3 e 4 são compostas por pacientes com rotação neutra, respectivamente dos tipos rotacionais $R 2 D$ e $R 1 N$, que deveriam, segundo os autores ${ }^{97}$, apresentar uma rotação mandibular anual entre $-1^{\circ}$ e $0^{\circ}$. Já a categoria 5 é composta por pacientes com rotação anterior dos tipos rotacionais A1D e $A 1 N$, que deveriam apresentar rotação mandibular anual menor que $-1^{\circ} \mathrm{em}$ sentido anti-horário.

Esses resultados para a rotação mandibular colocam em dúvida a afirmação de BISHARA ${ }^{15}$, segundo a qual o posicionamento anterior do mento é mais dependente da rotação/translação da mandíbula para frente do que do simples aumento no comprimento mandibular, pois, se assim fosse, os pacientes da categoria 3 também deveriam ter apresentado um maior posicionamento anterior da mandíbula em relação à categoria 1, fato esse que não ocorreu. Além disso, soma-se também o fato de que não houve uma correlação significante entre a rotação mandibular durante o tratamento (Tabelas de 5.27 a 5.30) e o posicionamento anterior da mandíbula.

A avaliação das rotações maxilar e mandibular durante o tratamento demonstrou que elas não apresentaram diferenças significantes entre os diferentes grupos de rotação (inclinação) mandibular (anterior, neutro e posterior). A rotação mandibular apresentou-se como anterior, com sentido antihorário, e a rotação maxilar apresentou-se como posterior, com sentido horário, em todos os grupos de rotação mandibular. Esses resultados não estão de acordo com a classificação proposta por LAVERGNE; GASSON ${ }^{97}$, pois os 
pacientes com rotação posterior, que deveriam apresentar uma rotação mandibular anual maior que $0^{\circ}$, apresentaram $-1,78^{\circ}$. Os pacientes com rotação neutra, que deveriam, segundo os autores ${ }^{97}$, apresentar uma rotação mandibular anual entre $-1^{\circ}$ e $0^{\circ}$, apresentaram $-3,04^{\circ}$. Já os pacientes com rotação anterior, que deveriam apresentar rotação mandibular anual menor que $-1^{\circ}$, apresentaram $-2,03^{\circ}$, corroborando a previsão dos autores ${ }^{97}$, no período de aproximadamente 2 anos de tratamento. Aqui também cabe ressaltar a influência da mecânica empregada sobre as rotações da maxila e da mandíbula, o que impediria a avaliação nessa fase.

Contrariamente ao que seria esperado, as diferentes categorias de crescimento não apresentaram diferenças para as rotações da maxila e da mandíbula no período pós-contenção. Após os cerca de 10 anos (dos 15 aos 25 anos) pós-tratamento, observou-se, para todas as categorias de crescimento, que a maxila teve rotação em torno de $1^{\circ}$ em sentido anti-horário, e que a mandíbula, em torno de $2^{\circ}$, também em sentido anti-horário. O mesmo aconteceu quando os pacientes foram divididos em grupos de rotação mandibular. Considerando que nessa fase nenhuma terapia foi empregada, as rotações anterior, neutra e posterior poderiam ter-se manifestado a fim confirmar a proposição de LAVERGNE;GASSON ${ }^{97}$.

Segundo LAVERGNE;GASSON ${ }^{94}$, a rotação mandibular anterior parece ser um processo de encurtamento da mandíbula relacionado com alterações específicas no ângulo goníaco e na direção de crescimento condilar, e a rotação 
posterior parece determinar a máxima extensão da mandíbula, ou seja, aumenta o comprimento mandibular. O responsável por fazer esse controle do crescimento da mandíbula durante o desenvolvimento facial, de acordo com LAVERGNE; PETROVIC ${ }^{98}$, é o comparador periférico do Servossistema, ou seja, a morfogênese da face é regulada pela relação oclusal de tal forma que vise minimizar o desvio a partir de uma relação oclusal estável, seja ela uma Classe I, II ou III.

Considerando esses aspectos, seria de se esperar que, quanto mais a mandíbula crescesse, maior seria a rotação anterior da mandíbula, a fim de compensar esse crescimento e evitar a alteração da relação molar, principalmente nas categorias com maior potencial de crescimento (4 e 5). Entretanto, os resultados mostraram que durante o período pós-contenção, quando então a mecânica do tratamento não influenciou o crescimento craniofacial, o crescimento mandibular não foi maior em nenhuma das categorias, assim como também não o foi a rotação mandibular anterior. Se por um lado os resultados questionam a previsão da análise em relação à quantidade de crescimento das categorias e a direção de rotação mandibular, por outro, eles não refutam o mecanismo proposto pelos autores ${ }^{94}$ para o funcionamento da rotação mandibular.

Ao se avaliar as rotações maxilar e mandibular durante todo o período de estudo (avaliação total), as diferentes categorias de crescimento não apresentaram diferenças. Todas as categorias apresentaram uma rotação 
positiva (horária) para a maxila, e negativa (anti-horária) para a mandíbula. O mesmo aconteceu quando os pacientes foram divididos em grupos de rotação mandibular. Esses resultados corroboram KARLSEN ${ }^{85}$, que, mesmo nos casos com ângulo do plano mandibular aumentado, encontrou uma rotação anterior da mandíbula e afirmou que o termo "hipo-rotadores anteriores" é mais realista, que "rotadores posteriores".

As variáveis rotação maxilar e rotação mandibular, da análise de JOHNSTON JÚNIOR, também foram analisadas, após a divisão dos pacientes de acordo com a dimensão vertical, em: mordida aberta (OB), mordida profunda (DB) e mordida normal (N). Conforme os resultados apresentados nas Tabelas 5.25 e 5.26, não foram obtidas diferenças significativas entre as médias nos três grupos em nenhuma das variáveis consideradas.

Esses resultados, assim como outros resultados negativos (BAUMRIND; KORN; WEST ${ }^{8}$, LEE et al. ${ }^{100}$, WILLIAMS; ANDERSEN ${ }^{214}$, LESLIE et al. ${ }^{103}$ ) colocam em discussão a possibilidade de se prever, a partir do traçado cefalométrico inicial, a futura rotação que a mandíbula apresentará durante e após o tratamento ortodôntico. Isso ratifica JOHNSTON JÚNIOR ${ }^{81}$, que afirmou que a verdadeira previsão de crescimento pode exceder as capacidades da técnica cefalométrica. Segundo esse autor ${ }^{81}$, por que medidas derivadas a partir de sombras radiográficas deveriam conter, tanto individualmente quanto coletivamente, informações úteis sobre o futuro padrão de crescimento? Além 
dessa falta de informação, deve ser somado o erro cefalométrico e a sensibilidade às condições iniciais (um elemento básico da teoria do caos) ${ }^{81}$.

Os testes de correlação linear demonstraram que o crescimento da maxila e da mandíbula não apresentaram uma relação significante com as rotações maxilar e mandibular nas alterações ocorridas durante o tratamento e o período pós-tratamento, conforme os resultados das Tabelas de 5.27 a 5.34. Os testes de correlação também demonstraram que, contrariamente a alguns autores $^{133,157,201}$, a avaliação da relação entre a rotação da mandíbula e a recidiva do apinhamento incisal pós-tratamento não foi significante (Tabela 5.35), confirmando assim, o estudo de WILLIAMS; ANDERSEN ${ }^{214}$, que, em 1995, também não encontraram uma correlação significante.

\subsection{COMPARAÇÕES NO TRATAMENTO PELA ANÁLISE CONVENCIONAL}

Conforme os resultados apresentados nas Tabelas 5.37 e 5.38 , e nas Figuras de 5.16 a 5.35 , de forma geral, as 5 categorias de crescimento possuem uma morfologia dentoesquelética diferente nas diferentes fases analisadas. Os pacientes das categorias 1 e 5 foram os que apresentaram maiores diferenças em relação aos outros grupos. Esses resultados corroboram LAVERGNE ${ }^{91}$, que afirmou que os diferentes grupos rotacionais e, conseqüentemente, as categorias de crescimento não podem ser diferenciados por uma única variável cefalométrica, mas sim por diferentes padrões de associação craniofacial. 
Os pacientes da categoria 1 se caracterizaram por apresentar uma maxila protruída, uma ampla diferença intermaxilar avaliada pelo ângulo ANB, uma grande inclinação posterior do plano mandibular, a menor proporção entre as alturas faciais e uma protrusão dos incisivos inferiores. Essas características são marcantes para os pacientes com padrão de crescimento vertical, os quais, muitas vezes, possuem um prognóstico desfavorável frente ao tratamento ortodôntico.

Já os pacientes da categoria 5 se caracterizaram por apresentar a maxila e a mandíbula mais retruídas, incisivos inferiores levemente protruídos e a menor inclinação para o plano mandibular. Considerando essas características, provavelmente esses pacientes seriam tratados hoje em dia com algum tipo de aparelho funcional para fazer avançar a mandíbula, e talvez sem extrações, utilizando-se da expansão dos arcos dentários e/ou de desgastes interproximais.

Segundo LAVERGNE ${ }^{91}$, os pacientes da categoria 4, dependendo da dimensão vertical (mordida), muitas vezes se enquadram dentro das normas da maioria das análises cefalométricas. Neste estudo observou-se que eles apresentaram a maxila e a mandíbula bem posicionadas quando avaliadas pelas medidas A-Nperp e Pog-Nperp. O plano mandibular não apresentou uma angulação excessiva, e o incisivo inferior estava bem posicionado a partir da variável 1i-NB.

Ao compararmos o perfil tegumentar dos pacientes das 5 categorias de crescimento, observou-se que os pacientes da categoria 1 apresentaram a maior protrusão labial no início do tratamento. Os pacientes das categorias 2 e 3 
apresentaram uma protrusão intermediária, enquanto os pacientes das categoria 4 e 5 apresentaram-se com valores levemente protruídos em relação à normalidade descrita por RICKETTS ${ }^{160}$ (-4 mm para o lábio superior, e -2 mm para o lábio inferior em relação à linha E). Entretanto, se compararmos esses resultados com valores para pacientes com oclusão normal e com a mesma idade (média, aos 13 anos, de $-2 \mathrm{~mm}$ para o lábio superior e de $-0,6 \mathrm{~mm}$ para o inferior $^{20}$ ), pode-se afirmar que os pacientes das categorias 4 e 5 estariam bem posicionados e os outros estariam protruídos. Na fase final de tratamento, os pacientes das categorias 1, 2 e 3 apresentaram os lábios superior e inferior próximos à normalidade descrita por RICKETTS ${ }^{160}$, e os pacientes das categorias 4 e 5 apresentaram os lábios levemente retruídos. O mesmo pode ser considerado se a comparação for realizada com pacientes com oclusão normal e com a mesma idade (média, aos 15 anos, de -3 mm para o lábio superior e de 1,6 mm para o inferior $\left.{ }^{20}\right)$. No período pós-contenção, observou-se que, em relação ao lábio superior, os pacientes das categorias 1, 2 e 3 estavam praticamente dentro da normalidade, enquanto os pacientes das categorias 4 e 5 estavam bastante retruídos. Em relação ao lábio inferior, observou-se que, para a categoria 1, ele estava bem posicionado, para as categorias 2 e 3 ele estava um pouco retruído, e para as categorias 4 e 5 ele estava muito retruído em relação à normalidade descrita por RICKETTS ${ }^{160}$.

De forma geral, os pacientes começaram e terminaram o período de avaliação diferentes. Entretanto, cabe ressaltar que as alterações ocorridas devido ao tratamento com extrações e ao crescimento facial pós-tratamento 
produziram resultados estéticos satisfatórios para os pacientes da categoria 1, e ruins para os pacientes das categorias 4 e 5 . Esse fato alerta para as implicações do tão proclamado clichê ortodôntico de se "começar o tratamento com o objetivo final na mente", sendo que, na verdade, o que se deveria dizer é "comece com o final do tratamento e o final do crescimento na mente". Pois, para os pacientes das categorias 4 e 5, por exemplo, o ideal seria ter terminado o tratamento com um perfil ligeiramente protruso, permitindo, assim, que o crescimento e/ou a maturação dos tecidos moles o tornasse agradável com o passar do tempo.

A redução gradativa da convexidade do perfil facial após o término do tratamento ortodôntico pode ser atribuída às alterações de maturação associadas com o contínuo crescimento mandibular e com o desenvolvimento nasal, ocorrendo ela independentemente da realização ou não de extrações durante o tratamento $^{112,127,221}$, e tem sido amplamente relatada na literatura ${ }^{12,172}$. Segundo DAINESI $^{36}$, os planejamentos ortodônticos com extrações dentárias em ambos os arcos devem ser realizados com parcimônia em jovens braquifaciais, durante 0 crescimento, pois pode-se prejudicar o perfil. Portanto, cabe ao profissional identificar qual o paciente que tem maior propensão para a ocorrência desse fenômeno.

Após o tratamento pela técnica do Arco de Canto Simplificada com extrações de quatro pré-molares e a utilização do aparelho de ancoragem extrabucal, as Tabelas 5.39 e 5.40 mostram que, da mesma forma que para a análise de JOHNSTON JÚNIOR, as alterações do tratamento avaliadas pela 
análise convencional apresentaram poucas diferenças entre as diferentes categorias de crescimento de PETROVIC.

Para a posição mandibular, não foi observada diferença significante entre as diferentes categorias de crescimento; entretanto, a mandíbula apresentou um maior crescimento na categoria 3 que nas categorias 1 e 2 . Essa alteração foi reforçada pela altura facial posterior (S-Go), variável em que os pacientes da categoria 3 também apresentaram um maior crescimento facial posterior que os pacientes das categorias 1 e 2 .

Conforme já foi descrito anteriormente, esperava-se um maior crescimento mandibular para a categoria 5 que para a 3.

Durante o período de tratamento não houve diferenças significantes entre as categorias de crescimento nas variáveis do perfil.

Conforme os resultados apresentados nas Tabelas 5.45 e 5.46, e nas Figuras de 5.36 a 5.47 , de forma geral, os diferentes grupos de rotação mandibular (anterior, neutro e posterior) possuem uma morfologia dentoesquelética diferente nas diferentes fases analisadas.

Os pacientes com rotação posterior se caracterizaram por apresentar uma maxila protruída, uma ampla diferença intermaxilar avaliada pelo ângulo ANB, uma grande inclinação posterior do plano mandibular, a menor proporção entre as alturas faciais e uma protrusão dos incisivos inferiores. Essas características acarretam um prognóstico desfavorável paro o tratamento desses pacientes. 
Já os pacientes com rotação anterior se caracterizaram por apresentar a maxila e a mandíbula mais retruídas, incisivos inferiores levemente protruídos e menor inclinação para o plano mandibular. LAVERGNE ${ }^{91}$ já havia afirmado que os pacientes com a denominação A são relativamente mais retrognatas. Conforme descrito para os pacientes da categoria 5, provavelmente esses pacientes seriam tratados hoje em dia com algum tipo de aparelho funcional para fazer avançar a mandíbula, e talvez sem extrações, utilizando-se da expansão dos arcos dentários e/ou dos desgastes interproximais.

Os pacientes com rotação neutra se caracterizaram por apresentar uma maxila bem posicionada, uma retrusão mandibular, uma inclinação levemente aumentada para o plano mandibular e os incisivos inferiores levemente protruídos.

Com relação ao perfil tegumentar, observou-se que, para as variáveis labiais, apenas a posição do lábio inferior em relação à linha $E$ apresentou diferença, sendo que os pacientes com rotação posterior apresentaram uma maior protrusão que os pacientes com rotação anterior e neutra em todas as fases analisadas. No início, os três grupos apresentavam protrusão labial. No final, o grupo posterior estava próximo da norma e os grupos anterior e neutro apresentavam-se retruídos. Na fase pós-contenção, os grupos anterior e neutro estavam retruídos, e o posterior próximo à norma.

A maior convexidade do perfil tegumentar para os pacientes do grupo posterior em todas as fases estudadas é confirmada pela variável H-Pn. 
As alterações dentárias e esqueléticas que acompanham o tratamento com a técnica do Arco de Canto apresentam poucas diferenças quando executadas nos grupos com diferentes rotações (inclinações) de crescimento da mandíbula, o que foi observado nas Tabelas 5.47 e 5.48 e nas Figuras de 5.36 a 5.47.

Para a posição mandibular, não foi observada diferença significante entre os diferentes grupos de rotação mandibular; entretanto, a mandíbula apresentou um maior crescimento na rotação neutra que na rotação posterior. Essa alteração foi corroborada pela altura facial posterior (S-Go), onde os pacientes com rotação neutra apresentaram um maior crescimento facial posterior que os pacientes com rotação posterior.

As variáveis dentárias não apresentaram diferenças significantes para as alterações do tratamento nos diferentes grupos de rotações mandibulares.

$\mathrm{Na}$ avaliação das alterações tegumentares, apenas a variável $\mathrm{H}-\mathrm{Pn}$ mostrou diferença entre os pacientes com rotação anterior em relação aos pacientes com rotação posterior, ou seja, houve maior aumento no valor dessa variável para os pacientes com rotação anterior, contribuindo, assim, para a retrusão do perfil desses pacientes.

A comparação dos resultados do tratamento obtidos pela duas análises cefalométricas empregadas neste estudo mostra que a análise de JOHNSTON JÚNIOR evidenciou uma grande alteração esquelética (ABA), o que não ficou claro à primeira vista na análise convencional, principalmente quando se observa 
o ângulo ANB. Entretanto, a avaliação de medidas como Co-Gn e Mand ou então 1-NA e 1s mostra que as duas análises não apresentaram uma diferença muito grande. MÄNNCHEN ${ }^{114}$, após um estudo com metodologia questionável, concluiu que a análise de JOHNSTON JÚNIOR sobrestima as alterações esqueléticas e subestima as alterações dentárias. Entretanto, é importante ressaltar que a análise de JOHNSTON JÚNIOR avalia as alterações ao longo do plano oclusal, onde elas realmente ocorrem. Já a análise convencional, por sua vez, avalia as alterações em relação a outros planos, como por exemplo, o plano de Francfort ou então o plano S-N. Portanto, deve-se ter cuidado com comparações entre as duas análises. E, por isso mesmo, é que o presente trabalho utilizou as duas análises, permitindo assim que elas pudessem se complementar.

\subsection{COMPARAÇÕES NO PERÍODO PÓS-TRATAMENTO PELA ANÁLISE CONVENCIONAL}

As Tabelas 5.41 e 5.42 mostram que as alterações pós-tratamento avaliadas pela análise convencional foram diferentes com relação à posição da maxila, sendo que os pacientes da categoria 5 apresentaram um maior deslocamento anterior da maxila (variável SNA) que os pacientes das categorias 1 e 2. Portanto, houve um maior crescimento maxilar na categoria 5. Esse resultado não foi confirmado pela análise de JOHNSTON JÚNIOR, provavelmente porque, nesta, a avaliação da alteração é feita em relação ao plano oclusal funcional. $O$ maior crescimento da maxila na categoria 5 vai contra 
a proposição de LAVERGNE $^{92}$, segundo a qual, se o paciente ainda possuir um potencial de crescimento no final do tratamento, haveria o retorno do tipo de crescimento inicial. Considerando a sua análise, os pacientes da categoria 1 (tipo rotacional P2D) deveriam ter apresentado um maior crescimento maxilar póstratamento. Portanto, é questionável, a afirmação do autor ${ }^{92}$ de que os pacientes da categoria 2 deveriam receber uma contenção ativa com um extrabucal.

Para as alterações incisais, apenas a variável 1i-Pog apresentou uma maior lingualização dos incisivos inferiores na categoria 4 em relação à categoria 1, fato esse corroborado pela análise de JOHNSTON JÚNIOR, apesar de não ter havido diferença estatística significante entre as categorias.

As variáveis mandibulares, intermaxilares, verticais e tegumentares não mostraram diferenças significantes com relação às alterações pós-tratamento nas diferentes categorias de crescimento.

Durante o período pós-tratamento não houve diferenças significantes entre as categorias de crescimento nas variáveis do perfil.

Esses resultados mais uma vez vêm demonstrar que as alterações relacionadas com a recidiva e/ou a maturação dentofacial pós-tratamento ortodôntico são praticamente idênticas nos pacientes com má-oclusão de Classe II, mesmo que eles apresentem morfologias esqueléticas diferentes no início do tratamento.

Conforme foi demonstrado nas Tabelas 5.49 e 5.50, as alterações póstratamento avaliadas pela análise convencional, após a divisão da amostra em 
grupos de rotação mandibular, apresentaram os pacientes com rotação anterior e neutra com um maior deslocamento anterior da maxila (variável SNA) em relação à base do crânio do que os pacientes com rotação posterior. Para as alterações intermaxilares, a variável WITS apresentou uma diminuição maior no seu valor nos pacientes com rotação posterior em relação aos pacientes com rotação anterior. Isso, provavelmente, devido ao menor crescimento maxilar.

Durante o período pós-tratamento não houve diferenças significantes entre os grupos de rotação mandibular nas variáveis do perfil.

Ao se correlacionar as diferenças no índice de Little (índice de Little póscontenção - índice de Little final) e as diferenças (pós-contenção - final) com relação às variáveis da análise convencional para toda a amostra e para os grupos de rotação mandibular, obteve-se, em geral, coeficientes pequenos e considerados não significantes (Tabela 5.53 e 5.54). Esses resultados corroboram a afirmação de SHIELDS; LITTLE; CHAPKO ${ }^{178}$, de que nenhum parâmetro cefalométrico, como inclinação dos incisivos superior e inferior, quantidade de crescimento horizontal e vertical, ângulo do plano mandibular, etc. é útil no estabelecimento de um prognóstico a respeito da recidiva. Outros autores $^{102}$ também não encontraram relação significante entre as alterações cefalométricas e a recidiva. Para WILLIAMS; ANDERSEN ${ }^{214}$, nenhuma correlação foi encontrada entre o índice de irregularidade e o comprimento do arco, a inclinação incisal, a alteração no prognatismo mandibular e a relação intermaxilar (ANB) ou com a rotação mandibular. Mais uma vez pode ser descrito que os 
fatores que causam a irregularidade incisal inferior talvez não possam ser inferidos a partir do traçado cefalométrico ${ }^{131}$.

\subsection{COMPARAÇÕES TOTAIS PELA ANÁLISE CONVENCIONAL}

Conforme pode ser observado nas Tabelas 5.43 e 5.44 , durante todo 0 período envolvido neste estudo, a maxila cresceu mais na categoria $3(\operatorname{Ar}-\mathrm{A}=$ 3,74 mm) que nas categorias $1(\operatorname{Ar}-A=1,16 \mathrm{~mm})$ e $5(\operatorname{Ar}-A=1,45 \mathrm{~mm})$. A mandíbula apresentou um maior aumento em seu comprimento na categoria 3 $(\operatorname{Ar}-\mathrm{Gn}=9,62 \mathrm{~mm})$ que nas categorias $1(\mathrm{Ar}-\mathrm{Gn}=5,83 \mathrm{~mm})$ e $5(\mathrm{Ar}-\mathrm{Gn}=6,05$ $\mathrm{mm}$ ), resultado esse corroborado pela alteração na altura facial posterior.

Os resultados da análise de JOHNSTON JÚNIOR também mostraram um maior deslocamento anterior da maxila e da mandíbula nos pacientes da categoria 3, embora não estatisticamente significantes.

Esses resultados colocam em dúvida a proposição de que o maior crescimento da mandíbula em relação ao da maxila ${ }^{207,208}$ seja o principal responsável pela recidiva pós-tratamento, pois os pacientes da categoria 3 não apresentaram um aumento maior no índice de Little que os pacientes das categorias 1 e 5.

Esses resultados também colocam em dúvida a proposição da análise de PETROVIC/LAVERGNE de que os pacientes da categoria 5 apresentam um maior crescimento mandibular que os pacientes das demais categorias que possuem má-oclusão de Classe II. 
Durante o período total não houve diferenças significativas entre as categorias de crescimento para as variáveis do perfil.

Um aspecto importante a ser avaliado é o fato de que as alterações no período de tratamento, de pós-tratamento e, conseqüentemente totais, praticamente apresentaram poucas diferenças entre as categorias de crescimento. Isso fez com que elas, que eram diferentes no início, continuassem sendo diferentes no final e no período pós-contenção. Esse fenômeno já havia sido demonstrado por BISHARA; JAKOBSEN ${ }^{21}$, que acompanharam longitudinalmente pacientes com oclusão normal, que foram divididos em três tipos faciais diferentes.

As Tabelas 5.51 e 5.52 mostram que as alterações totais apresentaram algumas diferenças para os grupos de rotação mandibular.

Durante esse período, a maxila e a mandíbula cresceram mais no grupo com rotação neutra que nos grupos com rotação anterior e posterior.

Enquanto os pacientes com rotação anterior e, principalmente, os pacientes com rotação neutra apresentaram uma tendência de diminuição das variáveis verticais, os pacientes com rotação posterior apresentaram uma tendência em manter essas relações. Se, por um lado, esses pacientes não apresentaram uma melhora do padrão vertical, pelo menos eles não pioraram, o que já é um bom resultado em vista da dificuldade de tratamento nesses pacientes, que apresentam um aumento das variáveis verticais. Conforme descrito por MORO;SCANAVINI; VIGORITO ${ }^{124}$, se o profissional não conseguir melhorar o padrão facial do paciente, ele deveria pelo menos tentar não piorá-lo. 
Durante o período total não houve diferenças significantes entre os grupos de rotação mandibular quanto às variáveis do perfil.

\subsection{IMPLICAÇÕES CLÍNICAS}

Algumas orientações clínicas que podem ser sugeridas a partir deste estudo dizem respeito aos tipos faciais mais extremos, como os pacientes da categoria 1 (padrão mais vertical) e os da categoria 5 (padrão mais horizontal). Eles apresentam uma tendência maior de retorno da irregularidade dentária e provavelmente o seu tempo de contenção deveria ser maior; isso em relação aos pacientes da categoria 4 , que têm tendência de maior estabilidade nos incisivos inferiores. E, considerando que muito da recidiva observada tomou a forma de compensações dentoalveolares para o crescimento pós-tratamento, pode-se inferir que a duração mínima para o programa de contenção requerido pelo paciente adolescente seria até o término do crescimento.

Quanto ao trespasse vertical, maior atenção deve ser dada aos pacientes da categoria 3, que apresentaram maior tendência de recidiva. Uma contenção superior com um batente anterior deveria ser utilizada nesses casos. Essa abordagem se enquadra no conceito de contenção ativa descrita por NANDA; NANDA $^{127}$, e LAVERGNE ${ }^{92}$. 
Quanto ao perfil tegumentar, este estudo mostra que, em termos longitudinais, o tratamento da Classe II com quatro extrações pode produzir ótimos resultados estéticos nos pacientes das categorias 1 (principalmente), 2 e 3. Já para os pacientes das categorias 4 e 5, as extrações deveriam ser evitadas devido à conseqüente retrusão dos lábios, pois, com o passar dos anos, esses pacientes tendem a apresentar um "achatamento" do perfil facial. Portanto, o ortodontista não deveria começar o tratamento com o final na mente, mas deveria, sim, pensar em como esse paciente se comportará muitos anos após a remoção do aparelho.

A recidiva não deveria ser uma desculpa para resultados finais pobres no tratamento, ou seja, o ortodontista deveria buscar a excelência por meio da obtenção de um índice de Little igual a zero no final do tratamento, além dos outros objetivos oclusais, estéticos e funcionais do tratamento ortodôntico.

O apinhamento pós-contenção pode ser um tanto angustiante para 0 paciente mal informado; portanto, o paciente deveria ser bem esclarecido quanto ao seu prognóstico pós-tratamento. Caso ele não deseje utilizar contenção por um período prolongado, uma alternativa será um segundo tratamento ortodôntico numa época posterior em sua vida ${ }^{217}$.

Considerando que o crescimento é sempre a fonte longitudinal das correções molar e incisal, a decisão de se extrair apenas os primeiros pré- 
molares superiores, a fim de se deixar os molares em Classe II, seria uma abordagem lógica para o tratamento de pacientes adultos ${ }^{131}$. Da mesma forma, é questionável a extração de pré-molares inferiores em pacientes com Classe II e que não possuam um grande apinhamento dentário, apenas para se posicionar os incisivos inferiores na meta cefalométrica; pois, como já foi descrito anteriormente, a perda de ancoragem superior cancelará a perda inferior, e, caso o paciente não possua um bom crescimento mandibular, a relação molar de Classe II será mantida ${ }^{124,167}$.

O presente trabalho, assim como outros realizados utilizando modelos de estudo e telerradiografias longitudinais, não conseguiu explicar os fatores responsáveis pelo retorno da irregularidade dos incisivos inferiores após a remoção das contenções. Provavelmente, está-se olhando no sentido errado. Cabe ressaltar que um aspecto que não foi estudado neste trabalho e em muitos outros, e que provavelmente poderá esclarecer melhor o fenômeno da recidiva pós-tratamento ortodôntico é o papel da musculatura peribucal. Talvez esse possa ser o caminho, como foi descrito por ROGERS ${ }^{164}$ em 1922, segundo o qual as forças musculares deveriam ser utilizadas para "construir a oclusão, ao invés de destruí-la". Portanto, os limites de adaptação da musculatura peribucal, o tempo necessário para essa adaptação e o papel da mioterapia, em conjunto com o tratamento, são fatores a serem determinados.

Provavelmente, após estudos do efeito da musculatura e pesquisas com um melhor embasamento científico sobre os outros fatores que determinam a 
posição dentária, será possível detectar as ligações entre todos esses fatores e, dessa forma, permitir que o ortodontista consiga resolver o problema da recidiva pós-tratamento. Assim, os ortodontistas não mais removerão os aparelhos de contenção com "medo e trepidação". 
7 CONCLUSÕES 


\section{CONCLUSÕES}

Tendo em vista a metodologia utilizada e os resultados expostos e discutidos, pode-se concluir que:

7.1 Sob o ponto de vista clínico, os pacientes da categoria 4 apresentaram melhor estabilidade do alinhamento dos incisivos inferiores no período pós-tratamento, tendo um resultado satisfatório em $78,57 \%$ dos casos.

7.2 O crescimento da maxila e da mandíbula não apresentou uma correlação significante com a recidiva do apinhamento dentário ântero-inferior.

7.3 Os pacientes da categoria 1 apresentaram menor tendência, enquanto os pacientes da categoria 3 apresentaram maior tendência para 0 aumento do trespasse vertical após o tratamento ortodôntico.

7.4 De forma geral, os principais fatores responsáveis pela recidiva das relações molar e incisal foram, respectivamente, as mesializações dos molares e incisivos superiores. E, ao se considerar as alterações totais, em todas as categorias estudadas o crescimento/deslocamento anterior da mandíbula foi o principal responsável pela correção das relações molar e incisal.

7.5 Os pacientes pertencentes aos grupos com rotação (inclinação) neutra e posterior apresentaram uma rotação mandibular em sentido anti-horário (anterior) durante os períodos de tratamento e de pós-tratamento. A rotação mandibular não apresentou uma relação significativa com a recidiva do apinhamento dos incisivos inferiores pós-tratamento. 
7.6 A análise do perfil facial na fase de pós-contenção foi mais satisfatória nos pacientes das categorias 1,2 e 3, enquanto os pacientes das categorias 4 e 5 apresentaram o perfil acentuadamente retruído. 


\section{REFEREN NCIAS BIBLIOGRÁFICAS}




\section{REFERÊNCIAS BIBLIOGRÁFICAS}

1-ACKERMAN, J.L.; PROFFIT, W.R. Soft tissue limitations in orthodontics: treatment planning guidelines. Angle Orthodont., v. 67, n.5, p.327-36, 1997.

2-ADES, A.G. et al. A long-term study of the relationship of third molars to changes in the mandibular dental arch. Amer. J. Orthodont. Dentofac. Orthop., v.97, n.4, p.323-35, Apr. 1987.

3-AMERICAN ASSOCIATION OF ORTHODONTISTS. Late mandibular incisor crowding. Orthodontic Dialogue, v.11, n.1, Spring, 1999.

4-ANGLE, E.H. Classification of malocclusion. Dent. Cosmos, v.41, n.3, p.24864, Mar. 1899.

5-ANGLE, E.H. Treatment of malocclusion of the teeth. 7 ed. Philadelphia, S. S. White Dental Manufacturing Company, 1907.

6-ARTUN, J.; GAROL, J.D.; LITTLE, R.M. Long-term stability of mandibular incisors following successful treatment of Class II, Division 1, malocclusions. Angle Orthodont. , v.66, n.3, p.229-38, 1996.

7-BARROW, D.B.; WHITE, J.R. Developmental changes of the maxillary and mandibular dental arches. Angle Orthodont., v.22, n.1, p.41-6, Jan. 1952.

8-BAUMRIND, S.; KORN, E.L.; WEST, E.E. Prediction of mandibular rotation: an empirical test of clinician performance. Amer. J. Orthodont., v.86, n.5, p.371-85, Nov. 1984.

\footnotetext{
* Segundo as normas recomendadas para uso no âmbito da Universidade de São Paulo, com base no documento "Referências Bibliográficas: exemplos", emanado do Conselho Supervisor do Sistema Integrado de Bibliotecas da USP, em reunião de 20 de setembro de 1990.
} 
9-BEATRICE, M.; WOODS, M. Vertical facial pattern and orthodontic stability. Part II: facial axis change and stability. Aust. Orthodont. J., v.16, n.3, p.127-32, Nov. 2000.

10-BeGOLE, E.A.; FOX, D.L.; SADOWSKY, C. Analysis of change in arch form with premolar expansion. Amer. J. Orthodont. Dentofac. Orthop., v.113, n.3, p.307-15, Mar. 1998.

11-BeGOLE, E.A.; SADOWSKY, C. Methodologies for evaluating long-term stability of dental relationships after orthodontic treatment. Semin. Orthodont., v.5, n.3, p.142-50, Sept. 1999.

12-BEHRENTS, R.G. Growth in the aging craniofacial skeleton. Ann Arbor, University of Michigan - Center for Human Growth and Development, 1985. 145p. / Craniofacial Growth Series, v.17 /

13-BEHRENTS, R.G. et al. Relapse of orthodontic treatment results: growth as an etiologic factor. J. Charles Tweed Found., v. 17, p.65-80, Apr. 1989.

14-BEERTSEN, W. Remodeling of collagen fibers in the periodontal ligament in the supraalveolar region. Angle Orthodont., v. 49, n.3, p.218-24, July 1979.

15-BISHARA, S.E. Facial and dental changes in adolescents and their clinical implications. Angle Orthodont., v.70, n.6, p.471-83, 2000.

16-BISHARA, S.E.; BAYATI, P.; JAKOBSEN, B.A. Longitudinal comparisons of dental arch changes in normal and untreated Class II, Division 1 subjects and their clinical implications. Amer. J. Orthodont. Dentofac. Orthop., v.110, n.5, 483-9, Nov. 1996. 
17-BISHARA, S.E. et al. Changes in the maxillary and mandibular tooth size-arch length relationship from early adolescence to early adulthood. Amer. J. Orthodont. Dentofac. Orthop., v.95, n.1, 46-59, Jan. 1989.

18-BISHARA, S.E. et al. Changes in the dental arches and dentition between 25 and 45 years of age. Angle Orthodont., v.66, n.6, p.417-22, 1996.

19-BISHARA, S. E. et al. Arch width changes from 6 weeks to 45 years of age. Amer. J. Orthodont. Dentofac. Orthop., v.11, n.4, p.401-9, Apr. 1997.

20-BISHARA, S.E.; HESSION, T.J.; PETERSON, L.C. Longitudinal soft-tissue profile changes: a study of three analysis. Amer. J. Orthodont. Dentofac. Orthop., v.88, n.3, 209-23, Sept. 1985.

21-BISHARA, S.E.; JAKOBSEN, J.R. Longitudinal changes in three normal facial types. Amer. J. Orthodont. Dentofac. Orthop., v.88, n.6, 466-502, Dec. 1985.

22-BJÖRK, A. Prediction of mandibular growth rotation. Amer. J. Orthodont. v.55, n.6, p.585-99, June 1969.

23-BJÖRK, A.; SKIELLER, V. Facial development and tooth eruption. An implant study at the age of puberty. Amer.J.Orthodont. v.62, n.4, p.339-383, Jan. 1972.

24-BJÖRK, A.; SKIELLER, V. Growth of the maxilla in three dimensions as revealed radiographically by the implant method. Brit. J. Orthodont. v.4, n.2, p.53-64, 1977. 
25-BJÖRK, A.; SKIELLER, V. Normal and abnormal growth of the mandible. A synthesis of longitudinal cephalometric implant studies over a period of 25 years. Eur. J. Orthodont., v. 5, p.1-46, 1983.

26-BLAKE M., BIBBY, K. Retention and stability: a review of the literature. Amer. J. Orthodont. Dentofac. Orthop., v 114, n .3, p.299-306 , Sept. 1998.

27-BOESE, L.R. Fiberotomy and reproximation without lower retention 9 years in retrospect: part I. Angle Orthodont., v. 50, n.2, p.88-97, Apr. 1980.

28-BOESE, L.R. Fiberotomy and reproximation without lower retention 9 years in retrospect: part I. Angle Orthodont., v. 50, n.3, p.169-78, July 1980.

29-BOESE, L.R. Commentary. Amer. J. Orthodont. Dentofac. Orthop., v.118, n.6, p.623, Dec. 2000.

30-BUSCHANG, P.H. et al. Mathematical models of longitudinal mandibular growth for children with normal and untreated Class II, division 1 malocclusion. Eur. J. Orthodont., v.10, n.3, p.227-34, Aug. 1988.

31-BURKE, S.P. et al. A meta analysis of mandibular intercanine width in treatment and postretention. Angle Orthodont., v.68, n.1, p.53-60, 1998.

32-CARTER, G.A.; McNAMARA JÚNIOR, J.A. Longitudinal dental arch changes in adults. Amer. J. Orthodont. Dentofac. Orthop., v.114, n.1, p.88-99, July 1998.

33-CEVIDANES, L.H.; VIGORITO, J.W. Estudo das características craniofaciais em pacientes com más-oclusões de Classe II, Divisão 1 e retroversão facial, empregando-se a análise das contrapartes de Enlow. Ortodontia, v.28, n.2, p.24-33, maio/ago. 1995. 
34-CETLIN, N.M.; SPENA R.; VANARSDALL JÚNIOR, R.L. Nonextraction treatment. In: GRABER, T.M.; VANARSDALL JÚNIOR, R.L. Orthodontics: current principles and techniques. 3 ed. Saint Louis, Mosby, 2000. p.74977.

35-DAKE, M.L.; SINCLAIR, P.M. A comparison of the Ricketts and Tweed-type arch levelling techniques. Amer. J. Orthodont. Dentofac. Orthop., v.95, n.1, p.72-8, Jan. 1989.

36-DAINESI, E.A. A influência dos padrões extremos de crescimento da face sobre o perfil tegumentar, analisada cefalometricamente em jovens leucodermas brasileiros. Bauru, 1998. 223p. Tese (Doutorado) Faculdade de Odontologia de Bauru, Universidade de São Paulo.

37-DAVIS, L.M.; BeGOLE, E.A. Evaluation of orthodontic relapse using the cubic spline function. Amer. J. Orthodont. Dentofac. Orthop., v.113, n.3, p.3006, Mar. 1998.

38-DE COSTER, L. Hereditary potentiality versus ambient factors. In: European Orthodontic Society, Report of the Twenty-Fifth Congress, p.227-234. 1951. apud JOHNSTON JÚNIOR, L.E. Balancing the books on orthodontic treatment: An integrated analysis of change. Brit. J. Orthodont. v.23, n.2, p.93-102, May 1996.

39-DE BAETS, J. The role of the upper first molar in lower incisor crowding. J.Clin.Orthodont., v.29,n.3, p.146-57, Mar. 1995 
40-DE LA CRUZ, A. et al. Long-term changes in arch form after orthodontic treatment and retention. Amer. J. Orthodont. Dentofac. Orthop., v.107, n.5, p.518-30, May 1995.

41-DIBBETS, J.M.H. The puzzle of growth rotation. Amer. J. Orthodont., v.87, n.6, p.473-80, June 1985.

42-DIBBETS, J.M.H. Mandibular rotation and enlargment. Amer. J. Orthodont. Dentofac. Orthop., v.98, n.1, p.29-32, July 1990.

43-DOPPEL, D. et al. An investigation of maxillary superimposition techniques using metallic implants. Amer. J. Orthodont. Dentofac. Orthop., v.105, n.2, p.161-8, Feb. 1994.

44-DUGONI, S. A. et. al. Early mixed dentition treatment: postretention evaluation of stability and relapse. Angle Orthod., v.65 , n.5 , p.311-20, 1995.

45-DYER, G.; HARRIS, E.F.; VADEN, J.L. Age effects on orthodontic treatment: adolescents contrasted with adults. Amer. J. Orthodont. Dentofac. Orthop., v.100, n.6, p.523-30, Dec. 1991.

46-EDWARDS, J. G. A long-term prospective evaluation of the circumferential supracrestal fiberotomy in alleviating orthodontic relapse. Amer. J. Orthodont. Dentofac. Orthop., v.93, n.5, p.380-7, May 1988.

47-EL-MANGOURY, N.H. Orthodontic relapse in subjects with varying degrees of anteroposterior and vertical dysplasia. Amer. J. Orthodont., v.75, n.5, p.548-61, May 1979.

48-ENGEL, G. et al. Treatment of deep-bite cases. Amer. J. Orthodont., v.77, n.1, p.1-13, Jan. 1980. 
49-FIDLER, B.C. et al. Long-term stability of Angle Class II, Division 1 malocclusions with successful occlusal results at end of active treatment. Amer. J. Orthodont. Dentofac. Orthop., v.107, n.3, p.276-85, Mar. 1995. 50-FORSBERG, C.M.; ELIASSON, S.; WESTERGREN, H. Face height and tooth eruption in adults. A 20-year follow-up investigation. Eur. J. Orthodont., v.13, p.249-54, 1991.

51-FREITAS, M.R. Recidiva do apinhamento ântero-inferior em pacientes tratados ortodonticamente, com extrações dos primeiros pré-molares, 5 e 10 anos pós-contenção. Estudo cefalométrico e de modelos. Bauru, 1993. 141p. Tese (Livre Docência) - Faculdade de Odontologia de Bauru, Universidade de São Paulo.

52-FREITAS, M.R.; HENRIQUES, J.F.C.; PINZAM, A. Estudo em modelos da recidiva do apinhamento ântero-inferior em pacientes tratados ortodonticamente, com extrações dos primeiros pré-molares, 5 e 10 anos pós-contenção. Ortodontia, v.29, n.1, p.19-30, jan./abr. 1996.

53-GARDNER, S.D.; CHACONAS, S.J. Posttreatment and postretention changes following orthodontic therapy. Angle Orthodont. v.46, n.2, p.151-61, Apr. 1976.

54-GARDNER R.A.; HARRIS, E.F.; VADEN, J.L. Postorthodontic dental changes: A longitudinal study. Amer. J. Orthodont. Dentofac. Orthop., v.114, n.5, p.581-6, Nov. 1998. 
55-GASSON, N.; LAVERGNE, J. Maxillary rotation during human growth: Annual variation and correlations with mandibular rotation. Acta Odont. Scand., v.35, n.1, p.13-21, 1977.

56-GASSON, N.; LAVERGNE, J. The maxillary rotation: Its relation to the cranial base and the mandibular corpus. Acta Odont. Scand., v.35, n.2, p.89-94, 1977.

57-GILMORE, C.A.; LITTLE, R.M. Mandibular incisor dimensions and crowding. Amer. J. Orthodont. Dentofac. Orthop., v .86, n.6, p.493-502, Dec. 1984.

58-GOMEZ-AMEZCUA, E.; MARTINS, D.R. Determinação da correção do trespasse vertical e sua recidiva; sua relação com a movimentação dos incisivos e com a rotação mandibular; e a correlação entre a correção dos trespasses vertical e horizontal e suas recidivas. Ortodontia, v.15, n.3, p.192-208, set./dez. 1982.

59-GONDIM, P.P.C.; FREITAS, M.R.; HENRIQUES, J.F.C. Avaliação cefalométrica da recidiva da sobremordida em pacientes com Classe II, $1^{\mathrm{a}}$ divisão e sua relação com o padrão de crescimento facial. Ortodontia, v.29, n.3, p.32-42, set./dez. 1996.

60-GURGEL, J.A.; ALMEIDA, R.R.; PINZAN, A. Avaliação comparativa das alterações esqueléticas maxilomandibulares entre jovens, do sexo masculino, tratados ortodonticamente da má-oclusão de Classe II, 1a Divisão e com oclusão normal. Rev. Dental Press Ortod. Ortop. Facial, v.6, n.1, p.39-50, jan./fev. 2001. 
61-HAAS, A.J. A biological approach to diagnosis, mechanics and treatment of vertical dysplasia. Angle Orthodont., v.50, n.4, p.279-300, Oct. 1980.

62-HAHN, G.W. Retention: the stepchild of orthodontia. Angle Orthodont., v.14, n.1/2, p.3-12, Jan./Apr. 1944.

63-HARRADINE, N.W.; PEARSON, M.H.; TOTH, B. The effect of extraction of third molars on late lower incisor crowding: a randomized controlled trial. Brit. J. Orthodont., v.25, n.2, p.117-22, May 1998.

64-HARRIS, E.F. A longitudinal study of arch size and form in untreated adults. Amer. J. Orthodont. Dentofac. Orthop. v.111, n.4, p.419-27, Apr. 1997.

65-HARRIS, E.F. et al. Effects of patient age on postorthodontic stability in Class II, Division 1 malocclusions. Amer. J. Orthodont. Dentofac. Orthop., v.105, n.1, p.25-34, Jan. 1994.

66-HARRIS, E.H.; GARDNER, R.Z.; VADEN, J.L. A longitudinal cephalometric study of postorthodontic craniofacial changes. Amer. J. Orthodont. Dentofacial Orthop., v.115, n.1, p.77-82, Jan. 1999.

67-HARUKI, T., LITTLE R.M. Early versus late treatment of crowded first premolar extraction cases: postretention evaluation of stability and relapse. Angle Orthodont., v.68, n.61-7, 1998.

68-HENRIQUES, J.F.C. et al. Estudo longitudinal das características da máoclusão de Classe II, 1a divisão sem tratamento, em jovens brasileiros leucodermas, por um período médio de 3 anos e 4 meses. Rev Dental Press Ortod. Ortop. Facial, v.3, n.3, p.52-66, maio/jun. 1998. 
69-HENRIQUES, J.F.C.; MARTINS, D.R. Determinação de um índice morfológico das coroas dos incisivos inferiores, em adolescentes brasileiros, com oclusão normal para predição da recidiva do apinhamento, pós contenção. Ortodontia, v.16, n.1, p.18-25, jan./abr. 1983.

70-HERZBERG, R.A cephalometric study of Class II relapse. Angle Orthodont., v.43, n.1, p.112-18, Jan. 1973.

71-HORN, J.A. Facial height index. Amer. J. Orthodont. Dentofac. Orthop., v.102, n.2, p.180-6, Aug. 1992.

72-HOUSTON, W.J.B. The analysis of errors in orthodontic measurements. Amer. J. Orthodont., v.83, n.5, p.382-90, May 1983.

73-HOROWITZ, S.L.; HIXON, E.H. Physiologic recovery following orthodontic treatment. Amer. J. Orthodont., v.55, n.1, p.1-4, Jan. 1969.

74-INTERLANDI, S.; VIGORITO, J.W. Uma técnica para o desgaste de modelos de estudo ortodôntico. Ortodontia, v.5, n.2, p.5-10, abr./jun. 1967.

75-ISAACSON, R.J. et al. Effects of rotational jaw growth on the occlusion and profile. Amer. J. Orthodont., v.72, n.3, p.276-86, Sept. 1977.

76-JACOBSON, A. Update on the Wits appraisal. Angle Orthodont., v.58, n.3, p.205-219, July 1988.

77-JARVINEN, S. Floating norms for the ANB angle as guidance for clinical considerations. Amer. J. Orthodont. Dentofac. Orthop., v.90, n.5, p.3837, Nov. 1986. 
78-JENKINS, D.H. Analysis of orthodontic deformity employing lateral cephalostatic radiography. Amer. J. Orthodont., v.41, n.6, p.442-52, June 1955.

79-JOHAL, A.S.; BATTAGEL, J.M. Dental crowding: a comparison of three methods of assessment. Eur. J. Orthodont., v.19, p.543-51, 1997.

80-JOHNSTON JÚNIOR, L.E. A comparative analysis of class II treatments. In: McNAMARA JÚNIOR, J.A.; CARLSON, D.S.; VIG, P.S.; RIBBENS, K.A. Science and clinical judgement in orthodontics. Ann Arbor, University of Michigan - Center for Human Growth and Development, 1986. p.103-48. / Craniofacial Growth Series, v.18 /

81-JOHNSTON JÚNIOR, L.E. Correlation and prediction: interpreting the significance of r. Angle Orthodont., v.63, n.4, p.273-6, 1997.

82-JOHNSTON JÚNIOR, L.E. Balancing the books on orthodontic treatment: An integrated analysis of change. Brit. J. Orthodont., v.23, n.2, p.93-102, May 1996.

83-JOHNSTON JÚNIOR, L.E. Growth and the Class II patient: rendering unto Caesar. Semin. Orthodont., v.4, n.1, p.59-62, Mar. 1998.

84-KAPLAN, H. The logic of modern retention procedures. Amer. J. Orthodont. Dentofac. Orthop., v.93, n.4, p.325-40, Apr. 1988.

85-KARLSEN, A.T. Association between facial height development and mandibular growth rotation in low and high MP-SN angle faces: a longitudinal study. Angle Orthodont., v.67, n.2, p.103-10, 1997. 
86-KARLSEN, A.T.; KROGSTAD, O. Morphology and growth in convex profile facial patterns: a longitudinal study. Angle Orthodont., v.69, n.4, p.334-44, 1999.

87-KASHNER, J.E. Does higher quality of treatment translate into a higher quality long-term result? Seattle, 1999. 42p. Dissertação (Mestrado) University of Washington.

88-KAWAUCHI, M.Y. et al. Avaliação da recidiva da sobremordida profunda: Estudo longitudinal cefalométrico e de modelos. Rev Dental Press Ortod. Ortop. Facial, v.5, n.3, p.14-28, maio/jun. 2000.

89-KIM, T.W.; LITTLE, R.M. Postretention assessment of deep overbite correction in Class II Division 2 malocclusion. Angle Orthodont., v.69, n.2, p.175-86, 1999.

90-LASCALA, C.E.; CAMAROTE, E.A.; FALTIN JÚNIOR, K. Estudo comparativo em humanos avaliando as terapêuticas ortodônticas propostas por LAVERGNE e PETROVIC para cada grupo rotacional com as terapêuticas realizadas em diversas alterações basais. Ortodontia, v.27, n.3, p.78-86, set./dez. 1994.

91-LAVERGNE, J. Morphogenetic classification of malocclusion as a basis for growth prediction and treatment planning. Brit. J. Orthodont. v.9, p.13245, 1982.

92-LAVERGNE, J. Diagnostic orthodontique et informatique. Rev. Orthop. Dento Faciale, v.26, p.295-307, 1992. 
93-LAVERGNE, J.; GASSON, N. A metal implant study of mandibular rotation. Angle Orthodont., v.46, n.2, p.144-50, Apr. 1976.

94-LAVERGNE, J.; GASSON, N. Operational definitions of mandibular morphogenetic and positional rotations. Scand. J. dent. Res., v.85, p.18592, 1977.

95-LAVERGNE, J.; GASSON, N. Direction and intensity of mandibular rotation in the sagittal adjustment during growth of the jaws. Scan. J. dent. Res., v.85, p.193-9, 1977.

96-LAVERGNE, J.; GASSON, N. The influence of jaw rotation on the morphogenesis of malocclusion. Amer. J. Orthodont., v.73, n.6, p.658-66, June 1978.

97-LAVERGNE, J.; GASSON, N. Analysis and classification of the rotational growth pattern without implants. Brit. J. Orthodont., v.9, p.51-6, 1982.

98-LAVERGNE, J.; PETROVIC, A. Discontinuities in occlusal relationship and the regulation of facial growth. A cybernetic view. Eur. J. Orthodont., v.5, p.269-78, 1983.

99-LAVERGNE, J.; PETROVIC, A. Pathogenesis and treatment conceptualization of dentofacial malrelations as related to the pattern of occlusal relationship. In: DIXON, A.D., SARNAT, B.G. Normal and abnormal bone growth: basic and clinical research. New York, Liss, 1985. p.393-402.

100-LEE, R.S. et al. Assessment of a method for prediction of mandibular rotation. Amer. J. Orthodont., v.91, n.5, p.395-402, May 1987. 
101-LEIGHTON, B.C.; HUNTER, W.S. Relationship between lower arch spacing/crowding and facial height and depth. Amer. J. Orthodont., v.82, n.5, p.418-25, Nov. 1982.

102-LENZ, G.J.; WOODS, M.G. Incisal changes and orthodontic stability. Angle Orthodont., 69, n.5, p.424-32, 1999.

103-LESLIE, L.R. et al. Prediction of mandibular growth rotation: assessment of the Skieller, Björk, and Linde-Hansen method. Amer. J. Orthodont. Dentofac. Orthop., v.114, n.6 ,p.659-67, Dec. 1998.

104-LITTLE, R.M. The irregularity index: a quantitative score of mandibular alignment. Amer. J. Orthodont., v.68, n.5, p.554-63, Nov. 1975.

105-LITTLE, R.M. Stability and relapse of mandibular anterior alignment: University of Washington studies. Semin. Orthodont.,v.5, n.3, p.191-204, Sept. 1999.

106-LITTLE, R.M.; RIEDEL, R.A.; ARTUN, J. An evaluation of changes in mandibular anterior alignment from 10 to 20 years postretention. Amer. J. Orthodont. Dentofacial Orthop. v.93, n.5, p.423-8, May 1988.

107-LITTLE, R.M.; RIEDEL, R.A; ENGST, E.D. Serial extraction of first premolars - postretention evaluation of stability and relapse. Angle Orthodont., v.60, p.255-62, 1990.

108-LITTLE, R.M.; RIEDEL, R.A.; STEIN, A. Mandibular arch length increase during the mixed dentition: Postretention evaluation of stability and relapse. Amer. J. Orthodont. Dentofacial Orthop., v.7, n.5, p.393-404, May 1990. 
109-LITTLE, R.M.; WALLEN, T.R.; RIEDEL, R.A. Stability and relapse of mandibular anterior alignment - first premolar extraction cases treated by traditional edgewise orthodontics. Amer. J. Orthodont., v.80, n.4, p.34965, Oct. 1981.

110-LIVIERATOS, F.A.; JOHNSTON JÚNIOR, L.E. A comparison of one-stage and two-stage nonextraction alternatives in matched Class II samples. Amer. J. Orthodont. Dentofac. Orthop., v.108, n.2, p.118-31, Aug. 1995.

111-LUNDSTRÖM, A.; McWILLIAM, J.S. Dento-alveolar compensation for anteroposterior variations between the upper and lower apical bases. Eur. J. Orthodont., v.6, p.116-22, 1984

112-LUPPANAPORNLARP, S.; JOHNSTON JÚNIOR, L.E. The effects of premolar-extraction: a long-term comparison of outcomes in "clear-cut" extraction and nonextraction Class II patients. Angle Orthodont., v.63, n.4, p. 257-72, 1993.

113-LUX, C.J. et al. A neural network approach to the analysis and classification of human craniofacial growth. Growth Dev. Aging., v.62, n.3 p.95-106, 1998.

114-MÄNNCHEN, R. A critical evaluation of the pitchfork analysis. Eur. J. Orthodont., v.23, p.1-14, 2001.

115-MARTINS, D.R. et al. Atlas de crescimento craniofacial. São Paulo: Santos, 1998, 280p. 
116-MARTINS, L.P. et. al. Erro de reprodutibilidade das medidas cefalométricas das análises de Steiner e Ricketts, pelo método convencional e pelo método computadorizado. Ortodontia, v.28, n.1, p.4-17, jan./abr. 1995.

117-McNAMARA JÚNIOR, J.A. Components of Class II malocclusion in children 8-10 years old. Angle Orthodont., v.51, n.3, p.177-202, July 1981.

118-McNAMARA JÚNIOR, J.A. A method of cephalometric evaluation. Amer. J. Orthodont., v.86, n.6, p.449-69, Dec. 1984.

119-MELROSE, C.; MILLETT, D. T. Toward a perspective on orthodontic retention? Amer. J. Orthodont. Dentofac. Orthop., v.113 , n.5 , p.50714, May 1998.

120-MERRIFIELD, L.L. The profile line as an aid in critically evaluating facial esthetics. Amer. J. Orthodont., v.52, n.11, p.804-22, Nov. 1966.

121-MIYAZAKI, H. et al. Occlusal stability after extraction orthodontics therapy in adult and adolescent patients. Amer. J. Orthodont. Dentofac. Orthop., v.114, n.5, p.530-7, Nov. 1998.

122-MOORREES, C.C.A., CHADHA, M.J. Available space to the incisors during dental development. Angle Orthodont., v.35, n.1 p.12-22, Jan. 1965.

123-MORO, A.; URIAS, D. Crescimento Condilar: alterações frente à propulsão mandibular. Ortodontia, v.27, n.2, p.78-97, maio/ago. 1994.

124-MORO, A.; SCANAVINI, M.A.; VIGORITO, J. Johnston analysis evaluation of Class II correction in patients belonging to Petrovic growth categories 3 and 5. Amer. J. Orthodont. Dentofac. Orthop., v.117, n.1, p.86-97, Jan. 2000. 
125-MOSS, J.P.; PICTON, D.A.C. Short-term changes in the mesio-distal position of teeth following removal of approximal contacts in the monkey Macaca fascicularis. Arch. Oral Biol., v.27, n.3, p.273-8, 1982.

126-MOYERS, R.E. et al. Diferential diagnosis of Class II malocclusions. Part 1. Facial types associated with Class II malocclusions. Amer. J. Orthodont., v.78, n.5, p.477-94, Nov. 1980.

127-NANDA, R.S.; NANDA, S.K. Considerations of dentofacial growth in longterm retention and stability: is active retention needed. Amer. $\mathbf{J}$. Orthodont. Dentofac. Orthop., v.101, n.4, p.297-302, Apr. 1992.

128-NOACHTAR, R.; et al. Long-term evaluation of orthodontic treatment with the morphogenetic analysis. Eur. J. Orthodont., v.2, n.5, p.607, Oct. 1999.

129-OLIVEIRA JÚNIOR, G. et al. Estudo da recidiva do apinhamento ânteroinferior de casos tratados com extrações de quatro primeiros pré-molares e mecânica do Arco de Canto. Ortodontia, v.24, n.1, p.24-30, jan./abr. 1991.

130-PANCHERZ, H. The Herbst appliance - its biologic effects and clinical use. Amer. J. Orthodont., v.87, n.1, p.1-20, Jan. 1985.

131-PAQUETTE, D.E.; BEATTIE, J.R.; JOHNSTON JÚNIOR, L.E. A long-term comparison of nonextraction and premolar extraction edgewise therapy in "borderline” Class II patients. Amer. J. Orthodont. Dentofac. Orthop., v.102, n.1, p.1-14, July 1992.

132-PARKER, W.S. Retention - retainers may be forever. Amer. J. Orthodont. Dentofac. Orthop., v.95, n.6, p.505-13, June 1989. 
133-PERERA, P.S.G. Rotational growth and incisor compensation. Angle Orthodont., v.57, p.39-49, Jan. 1987.

134-PETRELLI, E.; BAPTISTA, J.M. Ortodontia: fundamentos em cefalometria clínica. Curitiba, Editek, 1997.

135-PETROVIC, A. Experimental and cybernetic approaches to the mechanism of action of fuctional appliances on mandibular growth. In: McNAMARA JÚNIOR, J.A.; RIBBENS, K.A. Malocclusion and the periodontium. Ann Arbor, University of Michigan - Center for Human Growth and Development, 1984. p.213-68. / Craniofacial Growth Series, v.15 /

136-PETROVIC, A. Entretien avec le professeur A. Petrovic. Rev. Orthop. Dento Faciale, v.26, n.1, p.9-26, jan./mars 1992.

137-PETROVIC, A. Auxologic categorization and chronobiologic specification for the choice of appropriate orthodontic treatment. Amer. J. Orthodont. Dentofac. Orthop., v.105, n.2, p.192-205, Feb. 1994.

138-PETROVIC, A. et al. Does the Fränkel appliance produce forward movement of mandibular premolars? Eur. J. Orthodont., v.4, p.173-83, 1982.

139-PETROVIC, A. et al. Is it possible to modulate the growth of the human mandible with a functional appliance? Bull. Orthodont. Yugoslav., v.21, n.1, p.15-20, 1988.

140-PETROVIC, A.; LAVERGNE, J.; STUTZMANN, J. Tissue-level growth and responsiveness potential, growth rotation and treatment decision. In: VIG, P.S.; RIBBENS, K.A. Science and clinical judgement in orthodontics. 
Ann Arbor, University of Michigan - Center for Human Growth and Development, 1986. p.181-223. / Craniofacial Growth Series, v.19 /

141-PETROVIC, A.; LAVERGNE, J.; STUTZMANN, J. Diagnostic et traitement en orthopédie dento-faciale principes et diagramme de décision. Orthodont. Fr., v.58, p.517-42, 1987.

142-PETROVIC, A.; STUTZMANN, J. The concept of the mandibular tissue-level growth potencial and the responsiveness to a functional appliance. In: GRABER, L.W. Orthodontics: state of the art, essence of the science. Saint Louis, Mosby, 1986. p.59-74.

143-PETROVIC, A.; STUTZMANN, J. Aspectos referentes ao melhor momento para o tratamento ortodôntico. Ortodontia, v.26, n.1, p.4-13, jan./abr. 1993.

144-PETROVIC, A.; STUTZMANN, J. Orthopedically-induced growth stimulation of the mandible. In: McNAMARA JÚNIOR, J.A.; TROTMAN, C. Distraction osteogenesis and tissue engineering. Ann Arbor, University of Michigan - Center for Human Growth and Development, 1998. p.153-70. / Craniofacial Growth Series, v.34 /

145-PETROVIC, A.; STUTZMANN, J. Three short essays on some epistemological and methodological problems in orthodontic research. In: McNAMARA JÚNIOR, J.A. The enigma of the vertical dimension. Ann Arbor, University of Michigan - Center for Human Growth and Development, 2000. p.277-86. / Craniofacial Growth Series, v.36 / 
146-PETROVIC, A.; STUTZMANN, J.; LAVERGNE, J. Effect of functional appliances on the mandibular condylar cartilage. In: GRABER, T.M. Physiologic principles of functional appliances. Saint Louis, Mosby, 1985. p. 38-52.

147-PETROVIC, A.; STUTZMANN, J.; LAVERGNE, J. Mechanisms of craniofacial growth and modus operandi of functional appliances: A cell-level and cybernetic approach to orthodontic decision making. In: CARLSON, D.S. Craniofacial growth theory and orthodontic treatment. Ann Arbor, University of Michigan - Center for Human Growth and Development, 1990. p.13-74. / Craniofacial Growth Series, v.23 /

148-PETROVIC, A.; STUTZMANN, J.; LAVERGNE, J. Diferenças interindividuais no potencial de crescimento a nível tecidual e na capacidade de resposta ao tratamento pelo bionator ou pela técnica de Begg: abordagem metodológica, fundamentação auxológica; resultado clínico. Ortodontia, v.25, n.2, p.4-14, maio/ago. 1992.

149-PINTO, N.; WOODS, M.; CRAWFORD, E. Vertical facial pattern and orthodontic stability. Part I: pretreatment vertical pattern and stability. Aust. Orthodont. J., v.16, n.3, p.127-32, Nov. 2000.

150-PHILLIPS, C.; TULLOCH, J.F.C. The randomized clinical trial as a powerful means for understanding treatment efficacy. Semin. Orthodont., v.1, n.3, p.128-38, Sept. 1995.

151-PROFFIT, W. R. Equilibrium theory revisited: factors influencing position of the teeth. Angle Orthodont., v.48, n.3, p.175-86, July 1978. 
152-REDLICH, M. et al. The response of supraalveolar gingival collagen to orthodontic rotation movement in dogs. Amer. J. Orthodont. Dentofac. Orthop., v.110, n.3, p.247-55, Sep. 1996.

153-REITAN, K. Tissue rearrangement during retention of orthodontically rotated teeth. Angle Orthodont., v.29, p.105-13, 1959.

154-REITAN, K. Clinical and histologic observations on tooth movement during and after orthodontic treatment. Amer. J. Orthodont., v.53, n.10, p.72145, Oct. 1967.

155-RHEE, S.; NAHM, D. Triangular-shaped incisor crowns and crowding. Amer. J. Orthodont. Dentofac. Orthop., v.118 , n.6 , 624-8, Dec. 2000.

156-RICHARDSON, M. E. Late lower arch crowding: the role of differential horizontal growth. Brit. J. Orthodont., v. 21, p.379-85, 1994.

157-RICHARDSON, M. E. The etiology of late lower arch crowding alternative to mesially directed forces: a review. Amer. J. Orthodont. Dentofac. Orthop., v.105, n.6, 592-7, June 1994.

158-RICHARDSON, M. E. A review of changes in lower arch alignment from seven to fifty years. Semin. Orthodont., v 5, n.3, p.151-9, Sept. 1999.

159-RICHMOND, S. et al. The development of the PAR index (Peer Assessment Rating): reliability and validity. Eur. J. Orthodont., v.14, p.125-39, 1992.

160-RICKETTS, R.M. Planning treatment on the basis of the facial pattern and an estimate of its growth. Amer. J. Orthodont., v.27, n.1, p.14-37, Jan. 1957. 161-RICKETTS, R.M. Perspectives in the clinical application of cephalometrics. The first fifty years. Angle Orthodont., v.51, n.2, p.115-50, Apr. 1981. 
162-RIEDEL, R.A. The relation of maxillary structures to cranium in malocclusion and in normal occlusion. Angle Orthodont., v.22, n.3, p.142-5, July 1952.

163-RIEDEL, R.A. A review of the retention problem. Angle Orthodont., v.30, n.4, p.170-99, Oct. 1960.

164-ROGERS, A.P. Making facial muscles our allies in treatment and retention.

Dent. Cosmos., v.64, n.7, p.711-30, July 1922.

165-ROSSOUW, P.E. Terminology: semantics of postorthodontic treatment changes in the dentition. Semin. Orthodont., v 5, n.3, p.138-141, Sept. 1999.

166-ROSSOUW, P.E.; PRESTON, C.B.; LOMBARD, C.J. Longitudinal change in male and female orthodontic subjects and its value in assessing postorthodontic stability. In: McNAMARA JÚNIOR, J.A.; TROTMAN, C. Orthodontic treatment: management of unfavorable sequelae. Ann Arbor, University of Michigan - Center for Human Growth and Development, 1996. p.389-437. / Craniofacial Growth Series, v.31 /

167-RUBIN, R.M. Treatment planning in Class II malocclusions. Angle Orthodont. v.39, n.3, p.152-161, July 1969.

168-RUBIN, R.M. Orthodontic stability: an elusive goal. J. Clin. Orthodont., v.22, n.8, p.465-6, Aug. 1988.

169-SAMPSON, W.J. Current controversies in late incisor crowding. Ann. Acad. Med. Singapore, v.24, n.1, p.129-37, Jan. 1995.

170-SASSOUNI, V. The Class II syndrome: differential diagnosis and treatment. Angle Orthodont., v.40, n.4, p.334-41, Oct. 1970. 
171-SAKUDA, M. et al. Changes in crowding of teeth during adolescence and their relation to the growth of the facial skeleton. Trans. Eur. Orthodont. Soc., p.93-104, 1976.

172-SCAVONE JÚNIOR, H.; FREITAS, M.R.; HENRIQUES, J.F.C. Estudo cefalométrico longitudinal das alterações no perfil facial tegumentar, posteriores ao tratamento ortodôntico, em jovens leucodermas do sexo masculino. Ortodontia, v.26, n.1, p.38-57, jan./abr. 1993.

173-SCHUDY, F.F. The association of anatomical entities as applied to clinical orthodontics. Angle Orthodont., v.36, n.3, p.190-203, July 1966.

174-SCHUDY, G.F. Posttreatment craniofacial growth: its implications in orthodontic treatment. Amer. J. Orthodont., v.65, n.1, p.39-57, Jan. 1974.

175-SCHULHOF, R.J. JCO/interviews. On functional appliance results. J. Clin. Orthodont., v.17, n.2, p.125-9, Feb. 1983.

176-SCHULHOF, R.J.; BAGHA, L. A statistical evaluation of the Ricketts and Johnston growth-forecasting methods. Amer. J. Orthodont., v.67, n.3, p.258-76, Mar. 1975.

177-SHAPIRO, P.A. Mandibular dental arch form and dimension - treatment and postretention changes. Amer. J. Orthodont., v.66, n.1, p.58-70, July 1974.

178-SHIELDS, T.E.; LITTLE, R.M.; CHAPKO, M.K. Stability and relapse of mandibular anterior alignment: A cephalometric appraisal of first- 
premolar-extraction cases treated by traditional edgewise orthodontics. Amer. J. Orthodont., v.87, n.1, p.27-38, Jan. 1985.

179-SHERIDAN, J.J. The three keys of retention. J. Clin. Orthodont., v.25, n.12, p.717-8, Dec. 1991.

180-SIATKOWSKI, R. E. Incisor uprighting: mechanism for late secondary crowding in the anterior segments of the dental arches. Amer. J. Orthodont., v.66, n.4, p.398-410, Oct. 1974.

181-SILLMAN, J.H. Dimensional changes of the dental arches: longitudinal study from birth to 25 years. Amer. J. Orthodont., v.50, n.11, p.824-41, 1964.

182-SINCLAIR, P. M.; LITTLE, R. M. Maturation of untreated normal occlusions. Amer. J. Orthodont., v.83, n.2, p.114-23, Feb. 1983.

183-SIQUEIRA, V.C.V. et al. Avaliação da recidiva da sobressaliência, em pacientes com Classe II, primeira divisão, submetidos a extrações dos quatro primeiros pré-molares: estudo cefalométrico longitudinal, realizado ao início, final e 5 anos após o tratamento ortodôntico. $1^{\mathrm{a}}$ parte: a influência do crescimento craniofacial. Ortodontia, v.32, n.2, p.46-65, jun./jul. 1999.

184-SIQUEIRA, V.C.V. et al. Avaliação da recidiva da sobressaliência, em pacientes com Classe II, $1^{\mathrm{a}}$ Divisão, submetidos a extrações dos quatro primeiros pré-molares: estudo cefalométrico longitudinal, realizado ao início, final e 5 anos após o tratamento ortodôntico. $2^{\mathrm{a}}$ parte: a influência da terapia ortodôntica. Ortodontia, v.33, n.1, p.8-65, jan./abr. 2000. 
185-SIRIWAT, P.P.; JARABAK, J.R. Malocclusion and facial morphology. Is there a relationship. Angle Orthodont., v.55, n.2, p.127-38, Apr. 1985.

186-SKIELLER, V.; BJÖRK, A.; LINDE-HANSEN, T. Prediction of mandibular growth rotation evaluated from a longitudinal implant sample. Amer. J. Orthodont., v.86, n.5, p.359-70, Nov. 1984.

187-SOLOW, B. The dentoalveolar compensatory mechanism: background and clinical implications. Brit. J. Orthodont., v.7, p.145-61, 1980.

188-SOLOW, B.; HOUSTON, W.J.B. Mandibular rotations: concepts and terminology. Eur. J. Orthodont., v. 10, n3, p.177-9, 1988.

189-SOUTRARD, T.E.; BEHRENTS, R.G.; TOLLEY, E.A. The anterior component of occlusal force. Part 1. Measurement and distribution. Amer. J. Orthodont. Dentofac. Orthop., v.96, n.6 , p.493-500, Dec. 1989.

190-SOUTRARD, T.E.; BEHRENTS, R.G.; TOLLEY, E.A. The anterior component of occlusal force. Part 2. Relationship with dental malalignment. Amer. J. Orthodont. Dentofac. Orthop., v..97, n.1, p.41-4, Jan. 1990.

191-SOUTHARD, T.E.; SOUTHARD, K.A.; TOLLEY, E.A. Periodontal force: a potential cause of relapse. Amer. J. Orthodont. Dentofac. Orthop., v.101, n.3, p.221-7, Mar. 1992.

192-STEINER, C.C. Cephalometrics in clinical practice. Angle Orthodont., v.29, n.1, p.8-29, Jan. 1959.

193-STEINER, C.C. The use of cephalometrics as an aid in to planning and assessing orthodontic treatment. Amer. J. Orthodont., v.46, n.10, p.72135 Oct. 1960. 
194-STRANG, R.H.W. The fallacy of denture expansion as a treatment procedure. Angle Orthodont., v.19, n.1, p.12-7, Jan. 1949

195-STUTZMANN, J. Variations interindividuelles de la vitesse de renouvellement osseux de la mandibule. Intérêt en Orthodontie du jeune adulte. Orthodont. Fr., v.57, p.379-402, 1986.

196-STUTZMANN, J.; PETROVIC, A. La vitesse de renouvellement de l'os alvéolaire chez l'adulte avant et pendant le traitement orthodontique. Rev. Orthop. Dento Faciale, v.14, p.437-56, 1980.

197-STUTZMANN, J.; PETROVIC, A. Human alveolar bone turn-over rate: a quantitative study of spontaneous and therapeutically-induced variations. In: McNAMARA JÚNIOR, J.A.; RIBBENS, K.A. Malocclusion and the Periodontium. Ann Arbor, University of Michigan - Center for Human Growth and Development, 1984. p.185-212. / Craniofacial Growth Series, v.15/

198-STUTZMANN, J.; PETROVIC, A. Variations in the human mesial and distal alveolar bone turnover rate and orthodontically-induced tooth movement. In: DAVIDOVITCH, Z. The biological mechanisms of tooth movement and craniofacial adaptation. Columbus, The Ohio State University, College of Dentistry, 1992. p.241-55.

199-STUTZMANN, J.; PETROVIC, A.; SHAYE, R. Analyse en culture organotypique de la vitesse de formation-résorption de l'os alvéolaire humain prélevé avant et pendant un traitement comprenant le 
déplacement de dents: nouvelle voie d'approache en recherche orthodontique. Orthodont. Fr., v.50, p.399-419, 1979.

200-TANER, T. et al. Short-term effects of fiberotomy on relapse of anterior crowding. Amer. J. Orthodont. Dentofac. Orthop., v.118, n.6, p.617-23, Dec. 2000.

201-THILANDER, B. Biological basis for orthodontic relapse. Semin. Orthodont., v.6, n.3, p.195-205, Sep. 2000.

202-TODD, J.T.; MARK, L.S. Issues related to the prediction of craniofacial growth. Amer. J. Orthodont., v.79, n.1, p.63-80, Jan. 1981.

203-TOIGO, E.; MANDETTA, S. Estudo das alterações das dimensões e formas dos arcos dentários inferiores, ocorridas no final e cinco anos póstratamento, em pacientes com má-oclusão de Classe II, Divisão 1a, tratados com extrações de pré-molares pela técnica do Arco de Canto. Ortodontia, v.33, n.2, p.20-35, maio/ago. 2000.

204-TOIGO, E.; MORO, A.; VIGORITO, J.W. Proposta de um programa computadorizado para a análise de Petrovic/Lavergne. Ortodontia, v.29, n.2, p.16-26, maio/ago. 1996.

205-TWEED, C.H. The Frankfort mandibular incisor angle (FMIA) in orthodontic diagnosis, treatment planning and prognosis. Angle Orthodont., v.24, n.3, p.121-69, July 1954.

206-TWEED, C.H. Was the development of the diagnostic facial triangle as an accurate analysis based on fact or fancy?. Amer. J. Orthodont., v.48, n.11, p.823-40, Nov. 1962. 
207-VADEN, J.L.; HARRIS, E.F.; GARDNER, R.L.Z. Relapse revisited. Amer. J.

Orthodont. Dentofac. Orthop., v.111, n.5, p.543-53, May 1997.

208-VAN DER LINDEN, F.R.G.M. Theoretical and practical aspects of crowding in the human dentition. J. Amer. dent. Ass., v. 89, p.139-53, July 1974.

209-VIGORITO, J.W. Estudo comparativo de algumas características mandibulares em maloclusões de classe I e classe II, divisão 1 de Angle.

Rev. Fac. Odont. USP, v.11, n.1, p.75-82, jan./jun. 1973.

210-WALDRON, R.; NEWARK, N.J. Reviewing the problem of retention. Amer. J. Orthodont. Oral Surg., v.28, n.12, p.770-91, Dec. 1942.

211-WALTER, D.G. Comparative changes in mandibular canine and first molar widths. Angle Orthodont., v. 32, n.4, p.232-41, Oct.1962.

212-WEILAND, F.J. The role of occlusal discrepancies in the long-term stability of the mandibular arch. Eur. J. Orthodont., v.16, p.521-9, 1994.

213-WEST K. S.; MCNAMARA JÚNIOR, J.A. Changes in the craniofacial complex from adolescence to midadulthood: a cephalometric study. Amer. J. Orthodont. Dentofac. Orthop., v.115, n.5, 521-32, May 1999.

214-WILLIAMS, S.; ANDERSEN C.E. Incisor stability in patients with anterior rotational mandibular growth. Angle Orthodont., v 65, n.6, 431-41, 1995.

215-WOODS, M.; LEE, D.; CRAWFORD, E. Finishing occlusion, degree of stability and the PAR index. Aust. Orthodont. J., v.16,n.1, p.9-15, Mar. 2000. 
216-WOODSIDE, D.G. The significance of late developmental crowding to early treatment planning for incisor crowding. Amer. J. Orthodont. Dentofac. Orthop., v.117, n.5, p.559-61, May 2000.

217-WOODSIDE, D.G.; ROSSUW, P.E.; SHEARER, D. Postretention mandibular incisor stability after premolar serial extractions. . Semin. Orthodont., v.5, n.3, p.181-90, Sept. 1999.

218-WYLIE, W.L. Overbite and vertical facial dimensions in terms of muscle balance. Angle Orthodont., v.14, n.1/2, p.13-7, Jan./Apr.1944.

219-ZACHRISSON, B.U. Important aspects of long-term stability. J. Clin. Orthodont., v.31, n.9, p.562-83, Sept. 1997

220-ZAHER, A.R.; BISHARA, S.E.; JAKOBSEN, J.R. Posttreatment changes in different facial types. Angle Orthodont., v.64, n.6, p.425-36, 1994.

221-ZIERHUT, E.C. et al. Long-term profile changes associated with successfully treated extraction and nonextraction Class II Division 1 malocclusions. Angle Orthodont., v.70, n.3, p.208-19, 2000. 
ABSTRACT 


\section{ABSTRACT}

One of the most important objectives in the orthodontic treatment is the stability of treatment corrections. However, after many decades of research there is a consensus that stability of aligned teeth is variable and largely unpredictable. Considering the great importance that clinical orthodontists place on the ability to predict when posttreatment occlusal changes are prone to occur, and motivated by the promising aspects of Petrovic/Lavergne analysis with regard to relapse prognosis, we decided to evaluate it. The sample used consisted of 100 Class II Brazilian white patients, male and female, subdivided into Petrovic growth categories. The average initial age was 12.4 years. Treatment was carried out with a nonpreangulated edgewise appliance in conjunction with the extraction of four bicuspids. The lateral cephalogram and dental casts for each patient were measured at three different stages: pretreatment, end of treatment and on average ten years posttreatment. To assess relapse among the groups, dental casts, conventional cephalometric and Johnston analyses were used. Clinically, category 4 patients presented the best lower incisors posttreatment stability, with $78.57 \%$ of the cases showing a satisfactory result. Maxillary and mandibular growth did not present a significant correlation with lower incisor irregularity relapse. Category 1 patients presented the least tendency while category 3 patients presented the greatest tendency for posttreatment overbite relapse. The main factors in molar and overjet relapse were respectively, upper molar and incisor mesialization. Considering net change, in all categories anterior mandibular growth/displacement was the most important single factor for the molar and overjet corrections. Patients belonging to groups with neutral and posterior mandibular rotation/inclination presented forward mandibular rotation during treatment and posttreatment. Mandibular rotation did not present a significant relation with posttreatment lower incisor irregularity relapse. Categories 1,2 and 3 postretention soft tissue evaluation was satisfactory, while categories 4 and 5 showed a very retrusive profile. 
APÊNDICES 
TABELA A1:Resultados individuais das variáveis da análise de modelos para os pacientes pertencentes à categoria 1

\begin{tabular}{|c|c|c|c|c|c|c|c|c|c|c|c|c|c|c|}
\hline Número & IL I & IL F & IL PC & 6-6 I & $6-6 \mathrm{~F}$ & 6-6 PC & $3-3 I$ & 3-3 F & 3-3 PC & 4-4 I & 4-4 F & 4-4 PC & 5-5 I & $5-5 \mathrm{~F}$ \\
\hline 1 & 8,41 & 1,4 & 4,02 & 42,83 & 40,58 & 37,93 & 27,62 & 26,96 & 25,42 & 32,18 & 36,03 & 31,68 & 37,5 & \\
\hline 48 & 8,13 & 1,82 & 3,49 & 45,87 & 40,24 & 38,67 & 27,5 & 28,63 & 25,66 & 27,7 & & & 42,44 & 36,63 \\
\hline 54 & 13,83 & 1,25 & 5,84 & 37,34 & 36,33 & 4,5 & 22,6 & 24,06 & 22,52 & 26,12 & & & 30,63 & 2,13 \\
\hline 55 & 6,3 & 2,43 & 3,19 & 39,32 & 37,37 & 37,15 & 24,75 & 24,16 & 23,42 & 31,13 & 8 & 31,8 & & \\
\hline 61 & 5,11 & 0,79 & 10,13 & 38,34 & 38,39 & 38,32 & 25,67 & 26,09 & 22,66 & & & & 34,17 & 4,97 \\
\hline 79 & 7,76 & 0,94 & 2,57 & 42,11 & 39,19 & 39,29 & 24,27 & 25,69 & 23,4 & 32,92 & U, & 33,83 & 37,84 & \\
\hline 10 & 5,5 & 2,06 & 2,28 & 49,73 & 45,33 & 45,85 & 28,19 & 27,93 & 26,69 & 37,46 & & & 43,84 & 39,1 \\
\hline 111 & 7,76 & 2,25 & 2,63 & 39,86 & 41,87 & 40,99 & 25,59 & 29,11 & 28,7 & & & & 35,87 & 36,74 \\
\hline 115 & 12,4 & 1,78 & 4,38 & 42,64 & 41,93 & 40,85 & 26,97 & 27,33 & 26,8 & 34,66 & & & 38,23 & 37,19 \\
\hline 176 & 4,74 & 1,43 & 2,13 & 39,83 & 40,39 & 41,71 & 25,64 & 28,81 & 26,79 & 32,49 & & & 39,62 & 34,75 \\
\hline 184 & 6,58 & 2,68 & 2,15 & 44,91 & 39,73 & 41,93 & 27,54 & 26,37 & 25,68 & 34,75 & & & 40,76 & 34,64 \\
\hline 225 & 6,37 & 1,94 & 4,79 & 43,68 & 45,97 & 45,06 & 28,94 & 30,41 & 29,28 & & & & 41,18 & 41,32 \\
\hline 347 & 5,59 & 1,57 & 3,52 & 38,78 & 35,99 & 38,21 & 26,52 & 25,26 & 26,57 & 31,48 & & & 31,7 & 33,3 \\
\hline berta Los & 9,52 & 1,5 & 3,99 & 44,92 & 40,34 & 39,07 & 24,45 & 26,3 & 23,95 & 31,03 & 34,08 & 33,18 & & \\
\hline Valcirley Sill & 9,27 & 2,74 & 2,27 & 45,46 & 41,03 & & 26,24 & 27,27 & 26,12 & & & & 39,51 & 36,38 \\
\hline
\end{tabular}


TABELA A2: Resultados individuais das variáveis da análise de modelos para os pacientes pertencentes à categoria 2

\begin{tabular}{|c|c|c|c|c|c|c|c|c|c|c|c|c|c|c|}
\hline Número & IL I & IL F & IL PC & 6-6 I & $6-6 \mathrm{~F}$ & 6-6 PC & 3-3 I & $3-3 \mathrm{~F}$ & 3-3 PC & 4-4 I & $4-4 \mathrm{~F}$ & 4-4 PC & $5-5$ I & $5-5 \mathrm{~F}$ \\
\hline 6 & 2,2 & 1,93 & 2,88 & 42,11 & 39,84 & 39,23 & 23,96 & 25,35 & 23,3 & 30,96 & & & 38,37 & 34,16 \\
\hline 20 & 7,84 & 0,19 & 0,96 & 47,67 & 44,61 & 43,67 & 24,67 & 27,09 & 25,32 & 35,17 & 36,98 & 35,12 & 41,81 & \\
\hline 23 & 3,21 & 2,85 & 2,95 & 46,21 & 42,86 & 41,12 & 27,13 & 27,47 & 24,55 & 34,97 & 36,43 & 34,99 & 43,05 & \\
\hline 39 & 6,5 & 0,38 & 1,88 & 43,3 & 41,33 & 42,06 & 21,86 & 27,46 & 25,85 & 33,4 & & & 38,11 & 35,97 \\
\hline 51 & 17,42 & 1,12 & 2,42 & 46,43 & 42,75 & 44,49 & 24,35 & 26,45 & 25,35 & 34,44 & & & 40,79 & 34,94 \\
\hline 59 & 8,29 & 3,17 & 6,14 & 43,16 & 38,37 & 37,04 & 30,6 & 26,68 & 29,63 & 33,89 & & & 39,03 & 34,68 \\
\hline 81 & 2 & 0,33 & 2,58 & 43,54 & 39,74 & 39,94 & 29,04 & 27,82 & 25,9 & 34,08 & & & 38,69 & 35,19 \\
\hline 104 & 11,05 & 1,07 & 2,03 & 40,77 & 38,53 & 36,99 & 21,02 & 26,06 & 24,09 & 25,78 & & & 34,48 & 34,7 \\
\hline 110 & 9,25 & 0 & 2,81 & 40,34 & 41,68 & 39,85 & 26,67 & 25,73 & 24,36 & & & & 33,97 & 35,24 \\
\hline 169 & 8,67 & 1,11 & 3,22 & 45,28 & 44,36 & 42,88 & 27,71 & 29,02 & 27,33 & 36,64 & & & 38,28 & 38,9 \\
\hline 180 & 5,52 & 1,69 & 3,86 & 43,9 & 40,97 & 41,75 & 24,33 & 28,46 & 26,68 & & & & 40,18 & 35,7 \\
\hline 194 & 1,16 & 0,93 & 1,68 & 46,66 & 41,4 & 46,43 & 25,89 & 26,51 & 28,05 & & & & & 36,51 \\
\hline 219 & 7,78 & 1,33 & 2,17 & 45,3 & 39,19 & 41,59 & 22,83 & 25,53 & 25,48 & 32,13 & & & 39,26 & 36,55 \\
\hline 228 & 1,76 & 0,68 & 3,53 & 45,67 & 40,47 & 42,01 & 28,76 & 26,64 & 26,96 & 34,24 & & & 39,06 & 32,76 \\
\hline 288 & 5,6 & 0,64 & 2,22 & 44,01 & 41,26 & 42,55 & 26,55 & 27,27 & 26,83 & 35,26 & 34,72 & 34,77 & 39,73 & \\
\hline EricaMara & 2,58 & 1,24 & 4,71 & 41,88 & 41,24 & 40,58 & 27,38 & 26,98 & 24,26 & 34,62 & & & 35,21 & 35,33 \\
\hline Fabiane L & 3,6 & 2,21 & 2,88 & 40,65 & 37,38 & 37,76 & 22,41 & 23,65 & 23,64 & & & & 36,65 & 34,24 \\
\hline Martha $\mathrm{Pa}$ & 4,28 & 1,84 & 4,13 & 39,84 & 35,62 & 34,76 & 24,28 & 25,13 & 23,75 & 32,53 & 32,13 & 29,09 & 38,51 & \\
\hline PatriciaSk & 3,76 & 1,55 & 3,7 & 43,16 & 40,11 & 40,18 & 26,29 & 25,81 & 24,93 & 34,29 & 33,62 & 33 & 34,52 & \\
\hline Renata P€ & 4,78 & 2,38 & 6,76 & 43,28 & 37,15 & 38,75 & 27,19 & 26,15 & 22,5 & 31,5 & 33,38 & 31,51 & 39,18 & \\
\hline SimoneFe & 4,01 & 1,04 & 6,87 & 46,81 & 40,29 & & 27,36 & 26,47 & 24,89 & 36,69 & & & 40,01 & 36,2 \\
\hline
\end{tabular}


TABELA A2 (cont.): Resultados individuais das variáveis da análise de modelos para os pacientes pertencentes à categoria 2

\begin{tabular}{|c|c|c|c|c|c|c|c|c|c|c|c|c|c|c|}
\hline Número & 5-5 PC & 6-1 I & 6-1 F & $6-1 \mathrm{PC}$ & TH I & TH F & TH PC & TV I & TV F & TV PC & CS I & CS F & CS PC & GrupoRot \\
\hline 6 & 32,6 & 61,35 & 51,2 & 48,47 & 10,32 & 3,28 & 5,44 & 3,81 & 3,59 & 2,75 & $\begin{array}{l}3,88 \\
\end{array}$ & 1,35 & 1,64 & A2DDB \\
\hline 20 & & 61,43 & 51,09 & 49,44 & 1,86 & 2,28 & 1,7 & 2,13 & 2,35 & 2,86 & 5,36 & 2,88 & 2,54 & P1NN \\
\hline 23 & & 64,21 & 52,37 & 49,6 & 8,35 & 3,56 & 3,94 & 5,42 & 2,72 & 4,71 & 4,14 & 3,68 & 4,12 & A2DDB \\
\hline 39 & 35,15 & 60,92 & 50,8 & 49,75 & 6,77 & 1,58 & 3,68 & 4,36 & 2,79 & 4,53 & 4,6 & 1,06 & 2,43 & A2DDB \\
\hline 51 & 35,88 & 63,26 & 54,82 & 53,98 & 5,28 & 3,51 & 3,57 & 3,69 & 3,53 & 4,69 & 5,51 & 1,61 & 2,41 & 1NOB \\
\hline 59 & 32,41 & 61,19 & 54,8 & 47,6 & 1,2 & 3,24 & 3,18 & 1,55 & 2,76 & 0,75 & 1,84 & 3,94 & 1,28 & P1NOB \\
\hline 81 & 33,33 & 64,85 & 53,26 & 51,4 & 3,75 & 2,3 & 4 & 1,74 & 2,85 & 3,7 & 5,36 & 2,24 & 2,41 & P1NOB \\
\hline 104 & 32,43 & 53,79 & 48,64 & 45,61 & 1,91 & 2,22 & 2,24 & 0 & 2,89 & 1,24 & 5,25 & 0,43 & 1,68 & P1NN \\
\hline 110 & 32,74 & 61,25 & 51,27 & 48,94 & 6,69 & 3,52 & 2,64 & 5,19 & 4,92 & 4,48 & 4,94 & 3 & 2,55 & P1NN \\
\hline 169 & 36,98 & 65,34 & 53,2 & 54,19 & 14,68 & 2,88 & 4,23 & 7,26 & 4,1 & 4,34 & 8,52 & 1,36 & 2,45 & A2DOB \\
\hline 180 & 34,94 & 59,6 & 51,19 & 49,87 & 8,06 & 4,21 & 5,75 & 4,09 & 1,9 & 3,48 & 4,08 & 2,34 & 4,24 & P1NOB \\
\hline 194 & 37,04 & 61 & 52,02 & 52,54 & 5,85 & 3,05 & 3,3 & 4,29 & 2,7 & 3,73 & 1,29 & 1,64 & 3,22 & P1NOB \\
\hline 219 & 35,71 & 56,29 & 49,16 & 49,53 & 6,12 & 3,37 & 2,23 & 0,5 & 3,07 & 3,47 & 4,84 & 3,44 & 2,59 & P1NOB \\
\hline 228 & 35,52 & 67,08 & 53,31 & 51,77 & 7,56 & 2,07 & 2,64 & 2,6 & 1,84 & 2,4 & 3,48 & 1,7 & 2,99 & P1NOB \\
\hline 288 & & 67,34 & 53,01 & 53,04 & 5,85 & 3 & 3,18 & 4,23 & 2,26 & 5,93 & 2,91 & 1,27 & 2,21 & A2DN \\
\hline EricaMara & 35,81 & 59,3 & 51,73 & 49,54 & 5,96 & 3,35 & 3,58 & 3,67 & 1,52 & 3,03 & 10,06 & 1,74 & 2,99 & P1NOB \\
\hline Fabiane L & 32,94 & 56,57 & 46,03 & 45,76 & 1,46 & 2,24 & 2,49 & 1,86 & 1,22 & 1,95 & 4,18 & 2,55 & 3,09 & P1NN \\
\hline Martha $\mathrm{Pa}$ & ipas & 57,93 & 48,67 & 46,1 & 2,37 & 1,54 & 1,77 & 5,48 & 1,7 & 4,24 & 5,13 & 0,95 & 1,79 & P1NOB \\
\hline PatriciaSp & & 60,27 & 51,6 & 51,97 & 10,01 & 4,25 & 6,64 & 5,19 & 3,66 & 4,14 & 8 & 2,08 & 5,85 & A2DDB \\
\hline Renata $\mathrm{Pe}$ & reira & 61,08 & 51,58 & 46,96 & 3,53 & 2,37 & 3,35 & 1,79 & 2,28 & 2,78 & 1,88 & 3,8 & 5,47 & P1NDB \\
\hline SimoneFe & 37,23 & 65,3 & 52,89 & 50,82 & 11,07 & 4,33 & 6,67 & 4,28 & 3,36 & 6,63 & 5,13 & 2,34 & 4,45 & A2DDB \\
\hline
\end{tabular}


TABELA A3: Resultados individuais das variáveis da análise de modelos para os pacientes pertencentes à categoria 3

\begin{tabular}{|c|c|c|c|c|c|c|c|c|c|c|c|c|c|c|}
\hline Número & IL I & IL F & IL PC & 6-6 I & $6-6 \mathrm{~F}$ & 6-6 PC & $3-3 \mid$ & 3-3 F & 3-3 PC & $4-4$ I & 4-4 F & 4-4 PC & $5-5$ I & $5-5 \mathrm{~F}$ \\
\hline 10 & 5,74 & 1,93 & 4,58 & 44,91 & 41,4 & 40,73 & 26,11 & 26,9 & 24,87 & 31,92 & & & 45,39 & 35,52 \\
\hline 25 & 5,65 & 2,8 & 3,44 & 43,87 & 39,62 & 38,53 & 24,2 & 26,44 & 23,58 & 33,08 & & & 37,85 & 33,17 \\
\hline 42 & 15,32 & 0,76 & 2,53 & 40,18 & 39,17 & 39,87 & 25,35 & 27,13 & 25,09 & 28,46 & & & & 34,86 \\
\hline 60 & 4,63 & 0,8 & 2,33 & 42,92 & 40,82 & 39,36 & 25,98 & 26,57 & 25,17 & 31,73 & & & 37,52 & 36,04 \\
\hline 75 & 14,19 & 0,7 & 5,08 & 46,08 & 43,27 & 43,97 & 25,61 & 29,09 & 25,52 & 32,4 & & & 38,03 & 36,51 \\
\hline 83 & 6,21 & 0,65 & 0 & 44,07 & 42,07 & 42,78 & 24,06 & 25,94 & 25,44 & 31,9 & & & 36,01 & 36,13 \\
\hline 103 & 4,13 & 0 & 4,4 & 44,11 & 41,76 & 42,05 & 25,76 & 26,44 & 26,07 & 34,19 & & & 39,19 & 36,55 \\
\hline 112 & 13,33 & 1,37 & 2,35 & 39,61 & 38,84 & 37,21 & 24,21 & 25,23 & 24,38 & 28,55 & & & 33,58 & 34,61 \\
\hline 117 & 5,8 & 1,47 & 1,76 & 46,33 & 41,55 & 41,15 & 27,9 & 27,6 & 26,89 & 37,63 & & & 34,05 & 36,29 \\
\hline 121 & 9,41 & 1,28 & 2,41 & 48,49 & 42,95 & 44,52 & 25,79 & 28,25 & 27,71 & 36,89 & & & 42,13 & 37,51 \\
\hline 123 & 1,26 & 2,73 & 3,14 & 43,3 & 41,21 & 41,89 & 25,29 & 25,61 & 24,95 & 33,55 & & & 40,74 & 37,47 \\
\hline 142 & 2,69 & 1,66 & 6,36 & 46,03 & 43,99 & 42,9 & 31,07 & 30,04 & 28,27 & 37,62 & & & 44,84 & 39,77 \\
\hline 146 & 2,82 & 0,87 & 0,98 & 43,32 & 41,23 & 40,13 & 27,76 & 26,9 & 25,4 & 34,98 & & & 39,98 & 35,8 \\
\hline 174 & 2,11 & 0,44 & 1,27 & 40,99 & 40,66 & 39,41 & 26,49 & 26,25 & 25,6 & 32,75 & & & 37,27 & 36,61 \\
\hline 221 & 6,1 & 0,85 & 2,56 & 40,18 & 38,56 & 38,18 & 26,05 & 26,73 & 25,83 & 33,17 & & & 32,73 & 35,46 \\
\hline 229 & 8,18 & 1,23 & 2,06 & 44,16 & 39,91 & 41,16 & 24,75 & 25,26 & 23,61 & & & & 38,75 & 32,76 \\
\hline 236 & 4,8 & 1,76 & 2,03 & 41,99 & 39,61 & 40,33 & 27,45 & 27,61 & 26,71 & 34,59 & & & 37,23 & 35,11 \\
\hline 316 & 18,64 & 1,18 & 2,35 & 41,64 & 39,58 & 39,15 & 24,2 & 25,71 & 26,34 & 26,71 & & & 36,16 & 34,15 \\
\hline 330 & 2,26 & 1,34 & 1,99 & 38,59 & 37,39 & & 26,55 & 26,34 & 26,33 & & & & & 33,1 \\
\hline 385 & 16,73 & 1,19 & 4,06 & 42,23 & 43,22 & 39,27 & 21,84 & 28,18 & 26,71 & & & & 38,37 & 37,74 \\
\hline 474 & 8,94 & 0,76 & 2,53 & 42,08 & 40,06 & 40,2 & 27,16 & 27,77 & 28,18 & 34 & & & 37,38 & 34,98 \\
\hline Alexandra & 3,06 & 2,05 & 6,03 & 43,59 & 37,59 & 40,18 & 24,61 & 24,03 & 22,18 & 32,16 & 31,68 & 33,37 & 40,39 & \\
\hline EdilsonM & 6,8 & 3,26 & 7,8 & 43,63 & 42,93 & 42,74 & 31,94 & 31,33 & 29,35 & 37,85 & & & & 38,85 \\
\hline ElizaPapa & 5,33 & 0,98 & 6,59 & 39,7 & 37,52 & 36,2 & 24,17 & 23,91 & 21,28 & 29,61 & & & 37,42 & 33,83 \\
\hline Fernanda & 5,58 & 2,09 & 3,89 & 42,57 & 37,43 & 38,23 & 26,31 & 25,91 & 24,78 & 32,83 & & & 38,65 & 33,25 \\
\hline José Ması & 4,87 & 2,92 & 3,92 & 42,84 & 39,63 & 40,83 & 25,68 & 28,8 & 27,09 & 33,55 & & & 33,16 & 34,96 \\
\hline JulianaAtı & 5,72 & 2,36 & 4,04 & 45,58 & 36,96 & 39,5 & 27,3 & 26,79 & 27,11 & 33,31 & & & 38,34 & 32,58 \\
\hline
\end{tabular}


TABELA A3 (cont.): Resultados individuais das variáveis da análise de modelos para os pacientes pertencentes à categoria 3

\begin{tabular}{|c|c|c|c|c|c|c|c|c|c|c|c|c|c|c|}
\hline Número & 5-5 PC & 6-1 I & 6-1 F & 6-1 PC & TH I & TH F & TH PC & TV I & TV F & TV PC & CS I & CS F & CS PC & GrupoRot \\
\hline 10 & 35,01 & 57,35 & 49,82 & 46,82 & 11,42 & 5,07 & 8,63 & 3,01 & 3,38 & 3,38 & 7,74 & 2,6 & 4,02 & R2DN \\
\hline 25 & 32,06 & 56,84 & 51 & 47,76 & 9,42 & ,86 & ,19 & 4,4 & 2,16 & 63 & 3,63 & 0,94 & ,96 & R2DN \\
\hline 42 & 33,93 & 54,8 & 54 & 2,36 & 7,64 & ,47 & 3,58 & 4,48 & 3,94 & ,82 & 7,16 & 21 & 2,35 & 2DDB \\
\hline 60 & 32,37 & 60,7 & 51,06 & 48,56 & 9,12 & 3 & 1,92 & 4,5 & 3,21 & ,49 & 3,43 &, 04 & , 14 & 2DOB \\
\hline 75 & 34,77 & 62,8 & 4,48 & 52,66 & 8,94 & 3,96 & 4,25 & $-2,6$ & 3,09 & 62 & 3,49 & 1,3 & 2,18 & 2DOB \\
\hline 83 & 4,8 & 57,96 & 50,84 & 49,08 & 6,64 & 2,64 & 2,52 & 5,38 & 2,6 & ,99 & 6,5 & 1,25 & 1,5 & 2DDB \\
\hline 103 & 35 & 63,1 & 53 & 50,44 & 6,79 & 3,52 & 2,19 & 3,86 & 3,67 & 3,02 & 2,17 & 2,99 & 1,67 & 2DOB \\
\hline 112 & 32,55 & 58,52 & 52,57 & 50,55 & 10,08 & 2,9 & 3,77 & 6,94 & 4,01 & 39 & 5,16 & 1,02 & ,39 & 2DN \\
\hline 117 & 35,13 & 62,53 & 52,97 & 52,07 & 4,09 & 3,4 & 3,16 & 4,69 & 3,75 & 4,62 & 7,97 & 0,44 & 2,2 & R2DDB \\
\hline 121 & 38,94 & 62,78 & 53,6 & 52,13 & 2,29 & 3,12 & 1,14 & 2,54 & 2,76 & 2,56 & 3,9 & 2,72 & 1,89 & 22DN \\
\hline 123 & 35,34 & 64,17 & 53,36 & 50,75 & 11,83 & 2,22 & 1,37 & 6,32 & 4,25 & 5,18 & 5,43 & 2,57 & 2,99 & DB \\
\hline 142 & 38,42 & 64,94 & 53,9 & 54,94 & 8,9 & 2,63 & 1,9 & 3,37 & 2,51 & 2,16 & 2,91 & 1,58 & 1,44 & OB \\
\hline 146 & 32,59 & 62,8 & 52,57 & 48,64 & 8,83 & 3,78 & 5,29 & 2,23 & 3,26 & 2,14 & 4,64 & 2,78 & 2,24 & DOB \\
\hline 174 & 34,33 & 63,3 & 52,18 & 50,52 & 6,6 & 2,18 & 4 & 4,68 & 2,06 & 4,13 & 5,83 & 1,49 & 1,58 & R2DOB \\
\hline 221 & 33,68 & 56,94 & 50,98 & 48,47 & 5,03 & 3,34 & 4,78 & 3,16 & 3,47 & $2, \mathrm{C}$ & 7, & 3,39 & 3,34 & 22DN \\
\hline 229 & 34,25 & 56,35 & 48 & 46,66 & 3,43 & 4,43 & 4,11 & 2,35 & 3,52 & 2,48 & 5,17 & 2,22 & 1,69 & DOB \\
\hline 236 & 35,32 & 64,31 & 53,94 & 53,24 & 7,48 & 4,0 & 4,5 & 5,5 & 3,18 & 4,26 & 5,43 & 2,63 & 2,31 & OB \\
\hline 316 & 34,05 & 57,73 & 50,27 & 50,25 & 7,75 & 4,44 & 3 & 35 & 2,84 & 4.4 & 8,08 & 1,38 & 2,31 & DN \\
\hline 330 & 32,66 & 61,12 & 53,78 & 59 & 11,23 & 4,5 & 5,65 & 5,14 & 4,4 & 5,1 & 1,4 & 2,93 & 4,67 & OB \\
\hline 385 & 33,68 & 58,74 & 52,73 & 49 & 8,15 & 2,02 & 1,0 & 2,81 & 3,87 & 2 & 3,49 & 5,09 & 2,63 & DB \\
\hline 474 & 36,4 & 62,7 & 53,52 & 54,88 & 12,18 & 3,39 & 3,66 & 3,47 & & 1,00 & 4 & 2,38 & 2,25 & OB \\
\hline Alexanc & Pig & 56,5 & 47,24 & 47,18 & 9,51 & 2,55 & 5,27 & 4,07 & 3,47 & 4,74 & 8,12 & 2,29 & 3,44 & R2DDB \\
\hline EdilsonMı & 37,59 & 58,93 & 57,21 & 53,62 & 10,03 & 3,02 & 2,37 & 5,25 & 3,03 & 5,29 & 4,55 & 1,14 & 2,07 & R2DN \\
\hline ElizaPapa & 30,52 & 57,63 & 50,04 & 44,72 & 6,4 & 3,57 & 5,21 & 4,14 & 1,8 & 5,03 & 8 & 2,21 & 3,42 & R2DN \\
\hline Fernanda & 31,25 & 62,62 & 50,08 & 48,55 & 6,05 & 3,96 & 4,12 & 4,07 & 3,2 & 3,36 & 3,3 & 1,42 & 1,21 & R2DN \\
\hline José Ması & 34,25 & 59,2 & 52,3 & 49,09 & 8,87 & 3,51 & 2,07 & 5,72 & 3,06 & 3,52 & 8,82 & 2,02 & 1,94 & R2DOB \\
\hline JulianaAt 1 & 34,08 & 63,17 & 53,66 & 51,75 & 2,86 & 2,92 & 3,46 & 2,96 & 2,46 & 3,2 & 2,54 & 3,07 & 2,63 & R2DN \\
\hline
\end{tabular}


TABELA A4: Resultados individuais das variáveis da análise de modelos para os pacientes pertencentes à categoria 4

\begin{tabular}{|c|c|c|c|c|c|c|c|c|c|c|c|c|c|c|}
\hline Número & IL I & IL F & IL PC & $6-6$ I & 6-6 F & 6-6 PC & $3-3$ I & 3-3 F & 3-3 PC & 4-4 I & 4-4 F & 4-4 PC & $5-5$ I & $5-5 \mathrm{~F}$ \\
\hline 12 & 5,32 & 0,39 & 0,56 & 44,62 & 38,99 & 39,9 & 26,51 & 27,02 & 26,38 & 28,78 & & & 38,81 & 32,95 \\
\hline 27 & 0,4 & 1,45 & 1,43 & 42,86 & 39,69 & 39,24 & 23,98 & 25,11 & 23,52 & 31,45 & & & 37,15 & 33,99 \\
\hline 52 & 3,25 & 1,83 & 2,25 & 45,66 & 37,95 & 40,45 & 26,07 & 24,76 & 24,42 & 33,17 & 3 & 3,3 & 39,55 & \\
\hline 65 & 3,11 & 1,11 & 5,25 & 42,29 & 39,65 & & 24,87 & 25,52 & 23,87 & & & & 37,32 & 36,19 \\
\hline 105 & 10,7 & 2,34 & 2,08 & 44,35 & 42,4 & 42,79 & 23,8 & 25,45 & 25,4 & 30,77 & & & 37,53 & 36,22 \\
\hline 151 & 8,94 & 1,53 & 2,4 & 42,83 & 42,66 & 43,31 & 25,54 & 26,74 & 26,65 & 33,63 & & & 35,72 & 35,39 \\
\hline 152 & 9,73 & 0,91 & 0,46 & 47,57 & 43,9 & 45,5 & 27,23 & 27,31 & 27,19 & 35,49 & & & 42,43 & 37,99 \\
\hline 156 & 6,87 & 1,06 & 4,93 & 48,14 & 39,92 & 43,4 & 28,28 & 26,7 & 28,31 & 35,55 & & & 42,67 & 34,67 \\
\hline 168 & 8,07 & 0,73 & 2,67 & 45,17 & 42,04 & 43,08 & 24,31 & 26,55 & 26,12 & 35,88 & & & 40,22 & 35 \\
\hline 179 & 1,5 & 1,59 & 2,07 & 43,55 & 39,65 & 42,13 & 23,36 & 25,32 & 25,12 & 33,66 & 35,7 & 35,59 & & \\
\hline 202 & 4,99 & 1,3 & 1,69 & 43,51 & 41,19 & 42,37 & 28,3 & 28,18 & 27,43 & & & & 39,38 & 36,15 \\
\hline 338 & 8,88 & 0,79 & 2,04 & 43,35 & 37,26 & 37,82 & 25,54 & 25,46 & 24,92 & 31,57 & 33,14 & 33,07 & 38,81 & \\
\hline aqueli & 8,04 & 1,53 & 4,06 & 43,95 & 40,06 & 39,84 & 28,02 & 28,01 & 26,87 & & & & 37,24 & 34,22 \\
\hline Renata Mı & 1,43 & 1,08 & 1,54 & 44,41 & 37,96 & 39,2 & 25,7 & 26,23 & 24,58 & & & & 38,38 & 34,83 \\
\hline
\end{tabular}


TABELA A4 (cont.): Resultados individuais das variáveis da análise de modelos para os pacientes pertencentes à categoria 4

\begin{tabular}{|c|c|c|c|c|c|c|c|c|c|c|c|c|c|c|}
\hline Número & 5-5 PC & $6-1$ I & 6-1 F & 6-1 PC & TH I & TH F & TH PC & TV I & TV F & TV PC & CSI & CS F & CS PC & GrupoRot \\
\hline 12 & 33,51 & 58,23 & 46,52 & 46,12 & 9,72 & 2,49 & 2,07 & 4,76 & 4,35 & 4,35 & 6,79 & 2,22 & 3,05 & R1NOB \\
\hline 27 & 33,61 & 59,96 & 49,86 & 47,8 & 5,9 & 2,25 & 2,77 & 4,8 & 1,65 & 4,23 & 4 & l,48 & 2,58 & 1NOB \\
\hline 52 & & 62,02 & 49,55 & 48,84 & ,11 & 1,85 & 2,03 & ,01 &, 22 &, 08 & 4,79 &, 55 & 4,32 & OB \\
\hline 65 & 34,19 & 61,86 & 50,71 & 49,42 & 8 & 3,4 & 7,55 & 29 &, 58 & 4,3 & ,12 &, 41 & ,48 & NN \\
\hline 10 & 35,88 & 56,47 & 52,56 & 49,52 & 7,45 & 3,67 & 3,23 & 4,71 & 3,39 & 2,35 & 3,43 & 2,24 & 3,41 & NOB \\
\hline 151 & 35,68 & 58,67 & 52,26 & 53,05 & 2,61 & 2,2 & 2,52 & 4,07 & 1,62 & 1,59 & 5,35 & 2,66 & 2,72 & NN \\
\hline 152 & 37,39 & 64,87 & 55,65 & 53,85 & 1,75 & 1,7 & 1,6 & 3,9 & 1,67 & 3,33 & 2,38 & 1,26 & 1,58 & NDB \\
\hline 156 & 37,26 & 59,9 & 51,58 & 47,91 & 4,18 & 2,72 & 2,75 & 2,63 & 3,41 & 3,72 & 4,04 & 2,52 & 2,28 & NN \\
\hline 168 & 36,43 & 57,92 & 47,68 & 46,8 & 2,1 & 2,38 & 2,24 & 3,77 & 2,49 & 1,86 & 3,31 & 2,3 & 2,48 & $1 \mathrm{NN}$ \\
\hline 179 & & 54,5 & 47,92 & 47,91 & 5,82 & 4 & 3,99 & 4,96 & 2,39 & 3,06 & 4,08 & 2,03 & 2,96 & NDB \\
\hline 202 & 34,83 & 62,84 & 54,17 & 51,98 & 2,68 & 3,88 & 2,1 & 2,46 & 2,84 & 3,26 & 1,8 & 2,5 & 2,63 & NOB \\
\hline 338 & & 63,99 & 53,01 & 53,06 & 7,56 & 2,98 & 3,9 & 4,94 & 3,76 & 5,55 & 3,35 & 4,1 & 4,06 & R1NOB \\
\hline queline & 33,74 & 63,84 & 54,36 & 53,42 & 8,85 & 4,11 & 4,22 & 3,33 & 1,93 & 3,38 & 2,66 & 4,78 & 3,13 & R1NN \\
\hline enata Mı & 33,77 & 63,22 & 52,18 & 52,01 & 8,76 & 2,58 & 3 & 5,6 & 2,54 & 4,22 & 8,28 & 1,6 & 2,69 & R1NOB \\
\hline
\end{tabular}


TABELA A5: Resultados individuais das variáveis da análise de modelos para os pacientes pertencentes à categoria 5

\begin{tabular}{|c|c|c|c|c|c|c|c|c|c|c|c|c|c|c|}
\hline Número & IL I & IL F & IL PC & 6-6 I & 6-6 F & 6-6 PC & $3-3$ I & 3-3 F & 3-3 PC & 4-4 I & 4-4 F & 4-4 PC & $5-5 \mathrm{I}$ & $5-5 \mathrm{~F}$ \\
\hline 4 & 1,46 & 0,3 & 3,59 & 43,3 & 38,85 & 39,21 & 25,67 & 25,09 & 22,82 & 34,53 & & & 39,65 & 32,28 \\
\hline 29 & 2,81 & 1,24 & 3,55 & 43,79 & 41,19 & 42,87 & 26,47 & 26,46 & 25,64 & 34,87 & & & 41,15 & 37,7 \\
\hline 43 & 9,64 & 2,58 & 2,17 & 43,59 & 41,54 & 41,43 & 24,52 & 26,15 & 25,29 & 32,02 & & & 38,16 & 35,95 \\
\hline 49 & 2,12 & 0,91 & 2,74 & 43,07 & 41,4 & 40,29 & 28,2 & 27,71 & 25,5 & 35,25 & & & 39,21 & 37,94 \\
\hline 73 & 6,82 & 2,59 & 6,82 & 45,93 & 41,9 & & 28,73 & 28,3 & 26,44 & & & & 40,41 & 38,2 \\
\hline 74 & 3,2 & 1,48 & 5,06 & 39,63 & 39,07 & 38,91 & 24,64 & 26,08 & 24,37 & 32,68 & & & 33,08 & 35,8 \\
\hline 97 & 5,93 & 1,3 & 1,3 & & & & 32,2 & 29,17 & 28,78 & & & & 46,43 & 39,82 \\
\hline 107 & 7,93 & 1,96 & 0,82 & 46,38 & 45,49 & 44,82 & 31,09 & 30,13 & 29,18 & 35,26 & & & 42,63 & 40,19 \\
\hline 122 & 9,24 & 0,46 & 0,7 & 44,72 & 40,32 & 42,12 & 24 & 25,07 & 24,57 & 33,65 & & & 41,06 & 34,42 \\
\hline 129 & 1,89 & 0,81 & 1,64 & 46,24 & 42,67 & 44,67 & 30,31 & 26,07 & 26,45 & & & & 40,45 & 35,26 \\
\hline 147 & 7,36 & 2,34 & 3,44 & 43,45 & 41,51 & 41,74 & 25,21 & 28,03 & 27,09 & & & & 41,19 & 36,83 \\
\hline 157 & 18,15 & 0,68 & 6,86 & 43,1 & 43,25 & 42,36 & 19,49 & 26,34 & 24,9 & 28,48 & & & 38,05 & 36,14 \\
\hline 185 & 6,29 & 0,45 & 4,35 & 43,79 & 42,19 & 40,09 & 27,12 & 27,29 & 25,11 & 32,52 & 37,66 & 35,62 & & \\
\hline 188 & 7,14 & 0,67 & 4,79 & 41,93 & 40,25 & 39,23 & 26,36 & 26,34 & 24,26 & 33,02 & & & 38,6 & 35,67 \\
\hline 196 & 7,81 & 1,16 & 3,49 & 38,92 & 39,52 & 40,05 & 22,45 & 25,1 & 23,75 & 34,37 & & & 27,19 & 33,95 \\
\hline 235 & 1,74 & 1,88 & 1,96 & 43,1 & 39,45 & 40,34 & 26,97 & 26,12 & 24,39 & 34,54 & & & 35,08 & 32,1 \\
\hline 255 & 8,8 & 1,28 & 2,54 & 50,18 & 44,95 & 45,19 & 28,53 & 27,94 & 25,65 & 36,9 & & & 44,87 & 39,69 \\
\hline 257 & 3,28 & 2,02 & 3,91 & 45,9 & 40,47 & 39,62 & 24,05 & 25,96 & 25,2 & 35,91 & 35,07 & 32,63 & 39,06 & \\
\hline 368 & 5,77 & 0,96 & 5,34 & 41,87 & 36,72 & 37,01 & 24,14 & 27,63 & 25,55 & 33,42 & 34 & 33,43 & 40,92 & \\
\hline Fabio Luc & 6,73 & 3,65 & 6,48 & 42,08 & 35,76 & 36,74 & 26 & 25,54 & 23,8 & 29,55 & 32,55 & 32,59 & 36,66 & \\
\hline Janaina S & 10,06 & 0,67 & 3,88 & 40,6 & 37,4 & 38,41 & 25,26 & 26,82 & 26,77 & 34,81 & & & 40,3 & 34,2 \\
\hline Tania Mor & 6,28 & 2,28 & 2,98 & 42,33 & 36,86 & 39,26 & 25,01 & 25,28 & 24,48 & & & & & 33,64 \\
\hline Telma Abı & 5,38 & 1,59 & 8,22 & 43 & 39,08 & 38,44 & 23,49 & 26,58 & 22,46 & 31,06 & & & 36,94 & 35,3 \\
\hline
\end{tabular}


TABELA A5 (cont.): Resultados individuais das variáveis da análise de modelos para os pacientes pertencentes à categoria 5

\begin{tabular}{|c|c|c|c|c|c|c|c|c|c|c|c|c|c|c|}
\hline Número & 5-5 PC & $6-1 \mid$ & $6-1 \mathrm{~F}$ & $-1 \mathrm{PC}$ & TH I & TH F & TH PC & TV I & TV F & TV PC & CS I & CS F & CS PC & GrupoRot \\
\hline 4 & 32,11 & 61,66 & 49,42 & 46,64 & 7,49 & 2,82 & 3,34 & 4,65 & 3,43 & 4,91 & 6,05 & 1,06 & 2,45 & A1DDB \\
\hline 29 & 36,92 & 61,72 & 50,76 & 49,44 & 9,06 & 2,2 & 3,04 & 84 & 2,01 & 1,83 & 7,6 & 1,73 & 2,37 & A1NN \\
\hline 43 & 35,29 & 58,02 & 51,36 & 49,37 & 11,21 & 2,38 & 3,27 & , 18 & 34 & 4,26 & 5,83 & 1,74 & 2,1 & A1DDB \\
\hline 49 & 35,77 & 64,03 & 2,69 & 50,64 & 9,61 & ,32 & 5,1 & ,47 & 11 & 2,81 & 2,5 & 0,4 & 1,67 & A1DOB \\
\hline 73 & 36,37 & 65,59 & 4,08 &, 64 & 6,24 & 97 & 4,68 & 07 & 75 & ,78 & ,77 & ,25 & 3,4 & A1DDB \\
\hline 74 & 32,31 & 63,65 & 9,5 & 3,09 & 3,33 & 39 & 2,96 & 4, & 36 & 42 & 04 & 2,79 & 3,5 & A1DDB \\
\hline 97 & 38,49 & 68,65 & 55,28 & 52,56 & 3,9 & 2,89 & 3,17 & 4,6 &, 11 & 3,8 & ,93 & 1,68 & 3,01 & A1DOB \\
\hline 10 & 38,77 & 65,16 & 57,09 & 54,81 & 9,6 & 2,22 & 3,22 & 3,63 & 3,74 & 3,84 & 5,62 & 1,07 & 2,46 & A1DN \\
\hline 122 & 35,82 & 60,81 & 51,56 & 50,04 & 4,1 & 2,28 & 3,94 & 8,13 & 3,63 & 4,35 & 4,62 & 2,44 & 2,42 & A1NOB \\
\hline 129 & 39,62 & 57,47 & 57,37 & 54,9 & 4,33 & 2,7 & 2,49 & 5,54 & 3,61 & 3,57 & 7,31 & 1,02 & 3,07 & A1DDB \\
\hline 147 & 37,65 & 62,8 & 52,11 & 51,99 & 4,37 & 1,84 & 2,95 & 4,59 & 2,88 & 3,43 & 5,77 & 2,42 & 3,22 & A1NN \\
\hline 157 & 34,08 & 56,24 & 51,14 & 49,49 & 12,54 & 3,2 & 3,34 & 5,09 & 4,16 & 5,36 & 7,22 & 2,33 & 3,72 & A1DN \\
\hline 185 & & 64,45 & 50,36 & 49,19 & 3,23 & 2,88 & 3,62 & 3,89 & 3,08 & 3,79 & 3,79 & 1,36 & 2,98 & A1NN \\
\hline 188 & 34,09 & 58,98 & 50,62 & 49,54 & 11,38 & 3,33 & 6,13 & 3,55 & 3,49 & 3,97 & 4,96 & 2 , & 2,44 & A1DOB \\
\hline 196 & 33,3 & 50,91 & 49,14 & 47,73 & 2,42 & 3,1 & 3,66 & 8,88 & 3,42 & 4,97 & 9,97 & 1,19 & 2,44 & A1DN \\
\hline 235 & 34,16 & 61,29 & 51,59 & 50,96 & 9,35 & 2,44 & 2,56 & 3,57 & 2,78 & 4,94 & 6,34 & 2,51 & 3,44 & A1DDB \\
\hline 255 & 38,18 & 64,91 & 53,63 & 52,55 & 8,71 & 3,28 & 3,52 & 4,29 & 3,69 & 5,83 & 4,02 & 3,71 & 4,8 & A1DDB \\
\hline 257 & & 64,9 & 56,19 & 50,99 & 2,64 &, 95 & 2,58 & 5,2 & 3,6 & 3,75 & 5,25 & 4,03 & 4,36 & A1 \\
\hline 368 & & 57,37 & 50,47 & 49,9 & 11,84 & 6 & 3,07 &, 3 & $3,($ & 4,08 & 10,31 & 1,7 & 2,31 & A1NOB \\
\hline Fabio L & iano & 62,36 & 50,57 & 50,71 & 7,92 & 2,64 & 1,8 & 1,0 & 2,44 & 1,11 & 4 & 3,48 & 5,61 & A1DOB \\
\hline Janaina & 33,88 & 60,96 & 53,86 & 50,15 & 5,64 & 3,16 & 4,58 & 3,7 & 0 & 4,27 & 7,95 & 3,87 & 5,1 & A1NDB \\
\hline Tania Mor & 34,14 & 58,47 & 49,22 & 49,66 & 5,89 & 2,77 & 4,77 & 3,18 & 4,73 & 4,36 & 5,49 & 3,96 & 3,97 & A1NN \\
\hline Telma Abı & 32,4 & 59,3 & 49,93 & 45,59 & 13,78 & 2,93 & 2,38 & 5,11 & 2,37 & 5,05 & 6,3 & 2,36 & 2,02 & A1DN \\
\hline
\end{tabular}


TABELA A1 (cont.):Resultados individuais das variáveis da análise de modelos para os pacientes pertencentes à categoria 1

\begin{tabular}{|c|c|c|c|c|c|c|c|c|c|c|c|c|c|c|}
\hline Número & 5-5 PC & $|6-1|$ & $6-1 \mathrm{~F}$ & 6-1 PC & TH I & TH F & TH PC & TV I & TV F & TV PC & CS I & CS F & CS PC & Grupo Rot \\
\hline 1 & & 60,07 & 50,83 & 48,08 & 8,73 & 2,51 & 3,54 & 3,39 & 2,04 & 0,57 & 5,15 & 2,57 & 0,92 & P2DOB \\
\hline 48 & 33,7 & 63,06 & 53,18 & 52,48 & 4,27 & 2,76 & 1,27 & 1,98 & 2,21 & 1,42 & 6,82 & 0,7 & 2,41 & P1DN \\
\hline 54 & 29,69 & 52,84 & 48,06 & 43,92 & 6,23 & 2,78 & 3,77 & 6,09 & 3,51 & 3,25 & 4,79 & 1,79 & 1,56 & 2DOB \\
\hline 55 & & 53,51 & 48,87 & 48,17 & 7,36 & 3 & 2,35 & 3,54 & 3,75 & 2,94 & 5,16 & 0,96 & ,94 & 2DOB \\
\hline 61 & 33,28 & 56,14 & 50,3 & 46,09 & 11,76 & 2,85 & 6,34 & 6,49 & 2,75 & 5,52 & 10,47 & 3,22 & 3,89 & P2DOB \\
\hline 79 & & 57,15 & 49,91 & 47,5 & 11,39 & 2,54 & 1,97 & 5,88 & 3,53 & 6,21 & 6,28 & 1,19 & 1,96 & P2DDB \\
\hline 101 & 38,95 & 63,87 & 54,82 & 54,14 & 10,22 & 2,57 & 2,18 & 2,03 & 2,96 & 2,87 & 3,09 & 0,84 & 1,7 & P2DOB \\
\hline 111 & 35,35 & 58,84 & 51,33 & 50,03 & 2,72 & 2,84 & 3,37 & 1,99 & 2,93 & 3,36 & 1,99 & 2,36 & 2,19 & P2DOB \\
\hline 115 & 35,76 & 62,3 & 54,07 & 51,02 & 2,75 & 1,81 & 2,94 & 4,23 & 2,68 & 2,85 & 3,59 & 0,85 & 3,5 & P2DOB \\
\hline 176 & 35,8 & 54,51 & 49 & 48,42 & 7,95 & 3,67 & 3,7 & $-7,9$ & 3,15 & $-1,45$ & 1,2 & 1,58 & 1,12 & P2DOB \\
\hline 184 & 34,38 & 56,01 & 50,78 & 50,07 & 9,95 & 3,46 & 6,02 & 2,36 & 2,58 & 4,78 & 5,82 & 3,45 & 4,42 & P2DOB \\
\hline 225 & 40,47 & 61,3 & 60,58 & 57,76 & 12,85 & 3,63 & 3,7 & 7,49 & 2,56 & 2,65 & 5,83 & 2,01 & 3,06 & P2DOB \\
\hline 347 & 32,49 & 55,03 & 48,01 & 46,59 & 9,36 & 2,86 & 9,11 & 4,36 & 3,27 & 1,42 & 3,68 & 3,92 & 2,36 & P2DOB \\
\hline \multicolumn{2}{|c|}{ Roberta Losill } & 60,29 & 51,63 & 47,98 & 10,2 & 2,06 & 3,32 & 4,4 & 2,62 & 2,76 & 6,12 & 2,78 & 2,23 & P2DOB \\
\hline Valcirley Sil & 36,38 & 59,78 & 50,62 & 51,12 & 9,36 & 4,61 & & $-2,13$ & 3,15 & 2,91 & 3,4 & 1,21 & 2,97 & P2DOB \\
\hline
\end{tabular}




\begin{tabular}{|c|c|c|c|c|c|c|c|c|c|c|c|c|}
\hline Pac. $\mathbf{N}^{\circ}$ & $6 s$ & ABA & Max.-BC & $6 \mathrm{i}$ & Mand & $6 / 6$ & $1 \mathrm{~s}$ & $1 \mathrm{i}$ & $1 / 1$ & Rot Max & ROT Mand & EGU I-F \\
\hline 1 & $-5,1$ & 2,99 & $-1,23$ & 3,19 & 4,22 & 1,09 & 6,19 & $-2,91$ & 6,27 & $-0,5$ & $-1,5$ & 3,1 \\
\hline 48 & $-0,85$ & 2,07 & $-3,14$ & 1,46 & 5,21 & 2,6 & 3,37 & $-3,41$ & 1,77 & 0,5 & -3 & 2,82 \\
\hline 54 & $-4,17$ & 0,15 & $-2,09$ & 5,06 & 2,24 & 1,18 & 3,43 & 0,36 & 4,1 & $-1,5$ & -2 & 2,03 \\
\hline 55 & $-2,53$ & 6,06 & $-1,47$ & $-0,61$ & 7,53 & 2,62 & 1,08 & $-2,7$ & 4,6 & 2 & $-2,5$ & 1,14 \\
\hline 61 & $-1,88$ & 3,51 & $-2,68$ & 2,72 & 6,19 & 4,36 & 5,42 & 0,34 & 9,48 & 1,5 & -1 & 2,67 \\
\hline 79 & 0,79 & 1,09 & $-2,03$ & 2,83 & 3,12 & 4,96 & 6,7 & $-1,67$ & 6,28 & 3,5 & $-1,5$ & 0,2 \\
\hline 101 & $-3,38$ & 7,75 & $-0,79$ & 0,62 & 8,54 & 5,2 & 3,74 & $-6,11$ & 5,25 & 3,5 & 0 & 4,53 \\
\hline 111 & $-3,18$ & 4,81 & $-0,76$ & 1,18 & 5,57 & 2,95 & 1,39 & $-4,69$ & 1,53 & 1 & $-1,5$ & 2,76 \\
\hline 115 & $-3,5$ & 4,74 & $-3,12$ & 2,99 & 7,86 & 4,1 & 0,67 & $-4,65$ & 0,54 & 6 & 2 & 2,63 \\
\hline 176 & $-0,52$ & 3,54 & $-0,54$ & 0,48 & 4,08 & 3,59 & 7,58 & $-6,23$ & 4,95 & 5 & $-1,5$ & 2,74 \\
\hline 184 & 1,91 & $-1,6$ & -1 & 6,79 & $-0,6$ & 6,79 & 7,51 & $-1,67$ & 4,17 & 0,5 & 1,5 & 0,78 \\
\hline 225 & $-2,36$ & 4,03 & $-3,26$ & 0,6 & 7,29 & 2,42 & 6,07 & $-0,99$ & 9,23 & 4,5 & 4 & 2,29 \\
\hline 347 & $-3,37$ & 0 & $-0,51$ & 5,65 & 0,51 & 2,11 & 7,35 & $-0,38$ & 6,71 & 0,5 & 4 & 1,8 \\
\hline Roberta Los & $-4,81$ & 5,12 & $-1,26$ & 1,46 & 6,38 & 2,03 & 5,6 & $-3,81$ & 7 & 1,5 & -9 & 2,24 \\
\hline valcirlei Silva & $-0,16$ & 2,66 & $-2,84$ & 2,05 & 5,5 & 4,41 & 8,24 & $-5,14$ & 6,06 & 1 & $-2,5$ & 3,86 \\
\hline
\end{tabular}




\begin{tabular}{|c|c|c|c|c|c|c|c|c|c|c|c|c|}
\hline Pac. $\mathbf{N}^{\circ}$ & $6 s$ & ABA & Max.-BC & $6 \mathrm{i}$ & Mand & $6 / 6$ & $1 \mathrm{~s}$ & $1 \mathrm{i}$ & $1 / 1$ & Rot Max & ROT Mand & EGU F-PC \\
\hline 1 & $-2,43$ & 0,55 & $-0,26$ & 2,35 & 0,81 & 0,64 & $-4,09$ & 1,91 & $-1,41$ & 1 & $-1,5$ & 2,09 \\
\hline 48 & $-3,51$ & 3,27 & $-1,23$ & $-0,46$ & 4,5 & $-0,42$ & $-2,25$ & $-0,81$ & 0,14 & $-1,5$ & $-7,5$ & 0,98 \\
\hline 54 & $-1,98$ & 2,25 & $-2,45$ & $-0,48$ & 4,7 & $-0,1$ & $-0,12$ & $-3,72$ & $-1,4$ & $-1,5$ & -6 & 0,72 \\
\hline 55 & $-1,28$ & 1,09 & $-0,82$ & 0,35 & 1,91 & 0,28 & $-0,36$ & $-0,65$ & 0,1 & $-0,5$ & $-1,5$ & 0,17 \\
\hline 61 & $-0,59$ & $-3,47$ & 0,26 & 2,6 & $-3,73$ & $-1,52$ & $-0,3$ & $-0,23$ & $-4,16$ & -1 & 0 & 1,9 \\
\hline 79 & 0,23 & $-3,13$ & 0,64 & 1,3 & $-3,77$ & $-1,37$ & 3,17 & 0,67 & 0,43 & -3 & $-4,5$ & 0 \\
\hline 101 & 0 & $-0,94$ & 0 & 1,71 & $-0,94$ & 0,57 & 1,22 & 0,25 & 0,62 & -5 & $-4,5$ & 0,8 \\
\hline 111 & $-1,17$ & $-2,05$ & 0 & 2,04 & $-2,05$ & $-1,26$ & 0 & 2,23 & 0,28 & $-0,5$ & 0,5 & 0 \\
\hline 115 & 0,31 & $-2,94$ & 0 & 2,25 & $-2,94$ & $-0,2$ & $-0,37$ & 2,44 & $-0,79$ & $-2,5$ & 2 & 0,46 \\
\hline 176 & $-1,25$ & 0,65 & $-2,81$ & 0,41 & 3,46 & 0 & $-1,76$ & 0,87 & 0 & -2 & $-1,5$ & 2,76 \\
\hline 184 & $-1,24$ & $-1,49$ & 0 & $-2,1$ & $-1,49$ & $-4,96$ & 0,31 & $-1,41$ & $-2,8$ & 0 & -3 & 0 \\
\hline 225 & $-0,28$ & $-4,28$ & 0 & 4,95 & $-4,28$ & 0,26 & 1,2 & 3,89 & 1,01 & $-4,5$ & $-2,5$ & 5,23 \\
\hline 347 & $-3,33$ & $-2,81$ & $-2,48$ & 4,03 & $-0,33$ & $-2,27$ & $-4,06$ & 2,88 & $-3,87$ & 1,5 & 5,5 & 0 \\
\hline Roberta Los & $-1,07$ & $-0,2$ & $-0,54$ & 1,74 & 0,34 & 0,42 & $-2,43$ & 1,07 & $-1,39$ & $-0,5$ & $-1,5$ & 4,2 \\
\hline Valcirlei Silva & 0,27 & 0 & $-4,89$ & $-1,83$ & 4,89 & $-1,35$ & 0,51 & $-1,7$ & $-1,08$ & 1 & -2 & 2,07 \\
\hline
\end{tabular}




\begin{tabular}{|c|c|c|c|c|c|c|c|c|c|c|c|c|}
\hline Pac. $\mathrm{N}^{\circ}$ & $6 s$ & ABA & Max.-BC & $6 i$ & Mand & $6 / 6$ & $1 \mathrm{~s}$ & $1 \mathrm{i}$ & $1 / 1$ & Rot Max & ROT Mand & EGU I-F \\
\hline 6 & $-0,93$ & 0,15 & $-1,63$ & 5,76 & 1,78 & 4,74 & 4,38 & 0,36 & 4,98 & 2,5 & 1 & 1,42 \\
\hline 20 & 0,86 & 1,88 & $-0,68$ & 1,11 & 2,56 & 4,15 & $-0,5$ & $-4,05$ & $-2,6$ & 2 & $-0,5$ & 0,33 \\
\hline 23 & $-2,05$ & 2,91 & $-2,05$ & 3,26 & 4,96 & 4,78 & 4,98 & $-4,25$ & 3,62 & 2 & $-0,5$ & 2,72 \\
\hline 39 & 3,32 & 3,33 & $-0,18$ & $-1,15$ & 3,51 & 5,49 & 6,83 & $-7,37$ & 2,59 & -1 & -3 & 1,2 \\
\hline 51 & $-1,55$ & 2,32 & $-2,33$ & 1,92 & 4,65 & 2,65 & 1,17 & $-2,37$ & 1,01 & 1 & -1 & 3,03 \\
\hline 59 & $-2,32$ & 2,41 & $-1,58$ & 0,84 & 3,99 & 0,82 & $-1,7$ & $-1,9$ & $-1,29$ & 1 & 1 & 1,72 \\
\hline 81 & 0 & 1,35 & $-1,08$ & 0,58 & 2,43 & 1,83 & 3,42 & $-4,51$ & 0,52 & $-1,5$ & -2 & 0,59 \\
\hline 104 & 0,41 & 2,12 & 0 & 0,61 & 2,12 & 3,33 & 1,26 & $-3,83$ & $-0,35$ & 1,5 & -2 & 1,89 \\
\hline 110 & -2 & 3,93 & $-0,47$ & $-0,1$ & 4,4 & 1,61 & 5,23 & $-6,92$ & 2,37 & 4 & -1 & 0,72 \\
\hline 169 & 2,96 & 8,47 & $-2,27$ & $-3,49$ & 10,74 & 7,72 & 13,09 & $-12,04$ & 9,71 & 4,5 & -9 & 4,4 \\
\hline 180 & 1,2 & 0,14 & $-2,68$ & 3,54 & 2,82 & 4,87 & 3,11 & $-0,79$ & 2,32 & 0 & $-6,5$ & 3,99 \\
\hline 194 & $-3,42$ & 3,04 & $-3,07$ & 3,44 & 6,11 & 2,98 & 1,88 & $-3,64$ & 1,18 & 1,5 & -7 & 3,44 \\
\hline 219 & $-1,39$ & $-1,15$ & $-0,66$ & 3,84 & $-0,49$ & 1,11 & 3,68 & $-0,84$ & 1,46 & 0 & 2 & 0,91 \\
\hline 228 & $-3,06$ & 0,91 & $-1,4$ & 6,64 & 2,31 & 4,66 & 5,1 & $-2,43$ & 3,76 & 0,5 & -3 & 2 \\
\hline 288 & $-0,75$ & 2,9 & $-3,12$ & 2,33 & 6,02 & 4,19 & 5,65 & $-6,94$ & 1,35 & -1 & -12 & 4,52 \\
\hline EricaMarana & $-2,43$ & 6,93 & $-2,32$ & $-0,8$ & 9,25 & 3,41 & 2,66 & $-7,21$ & 2,5 & 3,5 & -5 & 2,75 \\
\hline Fabiane Lucl & $-3,6$ & 1,67 & 0,8 & 3,42 & 0,87 & 1,32 & 0,87 & $-3,16$ & $-0,43$ & 1 & $-3,5$ & 1,66 \\
\hline Martha Pap & $-4,05$ & 1,3 & $-0,1$ & 6,3 & 1,4 & 3,32 & 0,53 & 1,7 & 3,77 & -1 & -6 & 1,85 \\
\hline PatriciaSpac & $-1,59$ & 2,06 & 0 & 3,7 & 2,06 & 4,08 & 5,51 & -1 & 6,28 & 1,5 & -2 & 0 \\
\hline RenataPerei & $-0,9$ & $-1,85$ & $-1,08$ & 5,2 & $-0,77$ & 2,17 & 2,49 & 0,9 & 1,33 & $-1,5$ & $-2,5$ & 2,64 \\
\hline Simone Fern & $-0,3$ & 1,38 & $-0,48$ & 1,27 & 1,86 & 2,63 & 9,21 & $-5,51$ & 5,08 & 1 & -5 & 0,52 \\
\hline
\end{tabular}




\begin{tabular}{|c|c|c|c|c|c|c|c|c|c|c|c|c|}
\hline Pac. $\mathrm{N}^{\circ}$ & $6 s$ & ABA & Max.-BC & $6 i$ & Mand & $6 / 6$ & $1 \mathrm{~s}$ & $1 \mathrm{i}$ & $1 / 1$ & Rot Max & ROT Mand & EGU I-F \\
\hline 6 & 0,36 & $-3,9$ & 0,29 & $-0,2$ & $-4,19$ & $-4,04$ & 1,72 & 1,73 & 0,2 & $-2,5$ & 1,5 & 0 \\
\hline 20 & 0,54 & $-3,94$ & 0 & 3,17 & $-4,1$ & 0 & $-3,44$ & 0 & $-0,36$ & $-1,5$ & 0 & 0 \\
\hline 23 & $-1,21$ & 3,69 & $-4,13$ & $-2,05$ & 7,82 & 0,31 & $-2,15$ & $-1,61$ & $-0,1$ & 0 & $-3,5$ & 0,69 \\
\hline 39 & $-3,3$ & 0,36 & $-0,99$ & 1,73 & 1,35 & $-0,91$ & $-1,75$ & 0 & $-1,23$ & $-0,5$ & $-1,5$ & 0,02 \\
\hline 51 & 0,35 & 1,04 & $-0,39$ & $-1,15$ & 1,43 & 0,18 & 0 & $-1,77$ & $-0,85$ & 0,5 & $-4,5$ & 2,19 \\
\hline 59 & $-3,77$ & $-0,77$ & $-0,1$ & 6,08 & $-0,67$ & 1,43 & $-1,45$ & 2,61 & 0,39 & 0,5 & 1,5 & 0,27 \\
\hline 81 & $-1,41$ & $-0,19$ & $-0,56$ & 0,88 & 0,37 & $-0,57$ & $-0,97$ & 1,02 & 0 & 0,5 & 1 & 0 \\
\hline 104 & 0,58 & $-0,76$ & $-0,29$ & $-0,24$ & $-0,47$ & $-0,41$ & 0,1 & 1,05 & 0,12 & $-0,5$ & -1 & 0,08 \\
\hline 110 & $-0,5$ & $-0,42$ & $-0,22$ & 1,6 & $-0,2$ & 0,73 & $-0,23$ & 0,65 & 0 & -3 & $-4,5$ & 0 \\
\hline 169 & $-3,31$ & 4,28 & $-1,06$ & $-0,68$ & 5,34 & 0,1 & $-4,64$ & $-0,86$ & $-1,42$ & $-1,5$ & $-8,5$ & 2,93 \\
\hline 180 & $-5,04$ & 1,67 & 0,11 & 1,24 & 1,56 & $-1,98$ & $-2,22$ & $-0,49$ & $-0,95$ & -1 & -1 & 2,81 \\
\hline 194 & $-3,47$ & 7,76 & $-3,63$ & $-3,68$ & 11,39 & 0,43 & $-4,77$ & $-3,67$ & $-0,65$ & 1,5 & -8 & 4,52 \\
\hline 219 & $-1,24$ & 0,56 & 0 & 0,22 & 0,56 & $-0,27$ & $-0,56$ & $-0,38$ & $-0,58$ & -2 & $-2,5$ & 0 \\
\hline 228 & $-6,41$ & 7,57 & $-4,14$ & $-1,58$ & 11,71 & $-0,63$ & $-4,63$ & $-2,81$ & $-0,1$ & 2 & $-4,5$ & 7,34 \\
\hline 288 & $-0,78$ & 1,72 & $-1,99$ & $-2,47$ & 3,71 & $-1,25$ & $-0,81$ & $-1,55$ & $-0,54$ & -1 & -4 & 0,86 \\
\hline EricaMarana & $-2,72$ & 0 & $-1,36$ & 3,37 & 1,36 & 0,39 & $-2,57$ & 2,5 & $-0,18$ & $-0,5$ & 1 & 0,91 \\
\hline Fabiane Lucl & $-0,21$ & 0 & $-1,49$ & 0,42 & 1,49 & 0,28 & $-0,72$ & 0,69 & 0,12 & $-0,5$ & -3 & 0,13 \\
\hline Martha Pap & $-2,87$ & 6,44 & $-0,32$ & $-2,7$ & 6,76 & 0,61 & $-4,07$ & $-5,06$ & $-2,78$ & 4,5 & 6 & 0,13 \\
\hline PatriciaSpac & $-2,86$ & 0,1 & $-2,05$ & 2,23 & 2,15 & $-0,62$ & $-3,88$ & 0,56 & $-2,98$ & 0 & 0,5 & 0 \\
\hline RenataPerei & $-1,77$ & $-0,73$ & $-2,93$ & 2,61 & 2,2 & 0,1 & $-1,2$ & $-0,53$ & $-2,27$ & 1,5 & 0 & 0,78 \\
\hline Simone Fern & $-0,34$ & 0,87 & $-1,23$ & 0,43 & 2,1 & 0,99 & $-2,31$ & $-0,85$ & $-2,53$ & $-0,5$ & $-3,5$ & 0 \\
\hline
\end{tabular}




\begin{tabular}{|c|c|c|c|c|c|c|c|c|c|c|c|c|}
\hline Pac. $\mathbf{N}^{\circ}$ & $6 s$ & ABA & Max.-BC & $6 \mathrm{i}$ & Mand & $6 / 6$ & $1 \mathrm{~s}$ & $1 \mathrm{i}$ & $1 / 1$ & Rot Max & ROT Mand & EGU I-F \\
\hline 10 & $-2,61$ & 4,53 & $-1,23$ & 0,47 & 5,76 & 2,48 & 5,66 & $-3,02$ & 7,08 & 1 & $-4,5$ & 2,23 \\
\hline 25 & $-2,6$ & 3,73 & $-0,84$ & 1,21 & 4,57 & 2,4 & 5,61 & $-1,28$ & 7,85 & 2 & $-0,5$ & 0 \\
\hline 42 & 0,49 & 5,25 & $-0,41$ & 0 & 5,66 & 6,01 & 3,91 & $-4,56$ & 4,9 & 3,5 & -2 & 1,77 \\
\hline 60 & $-2,84$ & 1,8 & $-2,68$ & 4,25 & 4,48 & 3,25 & 5,25 & $-0,76$ & 6,37 & 2 & $-1,5$ & 3,02 \\
\hline 75 & 0,28 & 0,88 & $-1,37$ & 1,4 & 2,25 & 2,73 & 7,2 & $-3,05$ & 4,95 & 0 & -3 & 2,65 \\
\hline 83 & $-0,7$ & 3,57 & $-1,76$ & 1,06 & 5,33 & 3,88 & 4,6 & $-4,21$ & 4 & 0,5 & -6 & 1,95 \\
\hline 103 & $-5,05$ & 7,34 & $-2,92$ & $-0,5$ & 10,26 & 1,58 & 3,74 & $-7,96$ & 2,81 & 4,5 & -9 & 4,42 \\
\hline 112 & $-3,38$ & 2,77 & $-2,26$ & 3,36 & 5,03 & 2,95 & 5,28 & $-1,82$ & 6,36 & 1 & $-4,5$ & 2,63 \\
\hline 117 & $-4,02$ & 5,97 & $-3,32$ & 1,91 & 9,29 & 3,85 & $-1,68$ & $-4,46$ & $-0,15$ & 3 & -3 & 3,53 \\
\hline 121 & $-0,82$ & 0,79 & $-2,29$ & 2,11 & 3,08 & 2,23 & 2,07 & $-3,36$ & $-0,25$ & $-1,5$ & -4 & 4,93 \\
\hline 123 & $-0,68$ & 5,93 & $-1,66$ & 0 & 7,59 & 4,95 & 9,53 & $-7,08$ & 8,37 & 2,5 & -3 & 3,7 \\
\hline 142 & $-3,24$ & 6,97 & $-4,58$ & 1,62 & 11,55 & 5,35 & 8,18 & $-6,73$ & 8,34 & 5,5 & $-2,5$ & 5,2 \\
\hline 146 & $-2,4$ & 6,21 & $-1,27$ & 0,58 & 7,48 & 4,31 & 3,84 & $-4,99$ & 5,15 & 0 & -6 & 2,54 \\
\hline 174 & 0,75 & 2,49 & 0 & $-0,4$ & 2,49 & 2,73 & 8,17 & $-7,05$ & 3,46 & 0,5 & $-4,5$ & 2,3 \\
\hline 221 & $-4,57$ & 5,68 & $-1,38$ & 0,16 & 7,06 & 1,21 & $-0,88$ & -4 & 0,69 & 2,5 & $-4,5$ & 1,38 \\
\hline 229 & $-0,4$ & 0,4 & 0,38 & 2,24 & 0,02 & 2,24 & 1,35 & $-2,25$ & $-0,45$ & 1 & 0,5 & 2,49 \\
\hline 236 & $-0,99$ & 1,02 & 0,57 & 2,37 & 1,59 & 2,52 & 8,31 & $-5,5$ & 4,05 & $-0,5$ & -3 & 1,94 \\
\hline 316 & $-1,04$ & 2,27 & $-0,55$ & 0,54 & 2,82 & 1,77 & 6,86 & $-4,1$ & 5,17 & 0 & -3 & 2,29 \\
\hline 330 & $-3,43$ & 0,94 & $-2,9$ & 4,06 & 3,84 & 1,53 & 5,42 & 0,57 & 7,09 & 1,5 & -1 & 2,08 \\
\hline 385 & $-1,9$ & 5,66 & $-2,39$ & $-0,36$ & 8,05 & 3,1 & 4,82 & $-5,28$ & 5 & 4,5 & -4 & 4,07 \\
\hline 474 & $-1,85$ & 9,72 & $-2,49$ & $-0,65$ & 12,21 & 6,99 & 3,57 & $-6,76$ & 6,76 & 1,5 & -7 & 2,84 \\
\hline AlexandraPị & $-2,62$ & 0,18 & $-0,13$ & 5,62 & 0,31 & 3,21 & 4,75 & $-1,05$ & 3,92 & -1 & $-2,5$ & 0,98 \\
\hline EdilsonMediı & 1,13 & 4,07 & $-4,02$ & 0,89 & 8,09 & 6,29 & 3,69 & 0 & 7,96 & 2,5 & -1 & 3,82 \\
\hline Eliza Papa & $-1,62$ & 4,58 & $-2,01$ & 0,45 & 6,59 & 3,18 & 1,63 & $-3,8$ & 2,47 & 2,5 & $-1,5$ & 2,61 \\
\hline Fernanda Lo & $-3,82$ & 4,82 & $-1,96$ & 2,27 & 6,78 & 3,57 & 2,52 & $-5,94$ & 1,67 & 3,5 & -1 & 2,94 \\
\hline José Mascar & $-0,88$ & 5,39 & $-1,74$ & $-0,58$ & 7,13 & 3,69 & 7,39 & $-6,18$ & 6,6 & 1 & $-8,5$ & 3,13 \\
\hline Juliana Attuy & $-2,93$ & 0,19 & $-0,57$ & 4,82 & 0,76 & 1,85 & $-0,54$ & 0,2 & $-0,4$ & 1 & -2 & 2,55 \\
\hline
\end{tabular}




\begin{tabular}{|c|c|c|c|c|c|c|c|c|c|c|c|c|}
\hline Pac. $\mathbf{N}^{\circ}$ & $6 s$ & ABA & Max.-BC & $6 \mathrm{i}$ & Mand & $6 / 6$ & $1 \mathrm{~s}$ & $1 \mathrm{i}$ & $1 / 1$ & Rot Max & ROT Mand & EGU I-F \\
\hline 10 & $-2,22$ & $-1,43$ & $-0,46$ & 2,45 & $-0,97$ & $-1,45$ & $-3,86$ & 0,98 & $-4,37$ & 0,5 & $-0,5$ & 0,39 \\
\hline 25 & $-0,29$ & $-2,38$ & 0,16 & 1,7 & $-2,22$ & $-0,84$ & 0,3 & 0,36 & $-1,56$ & $-2,5$ & -2 & 0 \\
\hline 42 & $-0,79$ & 0,14 & $-1,16$ & 0,24 & 1,3 & $-0,41$ & $-2,55$ & 0,97 & 1,14 & -2 & -2 & 0,98 \\
\hline 60 & $-0,99$ & $-1,98$ & $-0,95$ & 2,64 & $-1,03$ & $-0,4$ & $-0,71$ & 1,46 & $-1,4$ & 0 & 4 & 0,52 \\
\hline 75 & $-1,32$ & 0,65 & $-1,28$ & 0 & 1,93 & $-0,66$ & 0,52 & $-0,17$ & 0,92 & 0,5 & 0 & 1,07 \\
\hline 83 & 0 & 1,26 & $-3,07$ & $-1,36$ & 4,33 & $-0,31$ & $-0,3$ & $-2,03$ & $-0,79$ & $-0,5$ & $-5,5$ & 6,16 \\
\hline 103 & $-3,32$ & 1,17 & $-0,18$ & 1,9 & 1,35 & 0 & $-1,02$ & 0 & 0,11 & -3 & $-7,5$ & 1,61 \\
\hline 112 & $-1,11$ & 1,44 & $-2,32$ & $-0,82$ & 3,76 & $-0,79$ & $-2,82$ & $-0,85$ & $-2,27$ & -2 & -3 & 0,91 \\
\hline 117 & 0,23 & 1,4 & $-0,47$ & $-0,73$ & 1,87 & 0,77 & $-0,41$ & $-0,51$ & 0,23 & -2 & $-5,5$ & 3,18 \\
\hline 121 & $-1,2$ & 0,11 & 0 & 0,88 & 0,11 & $-0,23$ & 0,78 & $-0,13$ & 0,72 & 0,5 & 1,5 & 2,31 \\
\hline 123 & $-1,34$ & 2,78 & $-0,33$ & $-0,78$ & 3,11 & 0,36 & $-0,91$ & $-2,64$ & $-0,69$ & 0,5 & -6 & 0,26 \\
\hline 142 & $-2,87$ & $-0,47$ & $-1,11$ & 3,06 & 0,64 & $-0,29$ & $-2,26$ & 1,37 & $-1,49$ & 0 & 0 & 1,07 \\
\hline 146 & $-1,21$ & 0 & 0 & 1,51 & 0 & 0,1 & $-0,8$ & 0,25 & $-0,32$ & -1 & $-1,5$ & 6,9 \\
\hline 174 & $-4,85$ & 3,04 & $-1,78$ & 2,52 & 4,82 & 0,9 & $-5,12$ & $-0,66$ & $-2,79$ & 1 & $-5,5$ & 0,33 \\
\hline 221 & 0,19 & $-3,43$ & $-0,99$ & 2,88 & $-2,44$ & $-0,1$ & 2,61 & 2,82 & 1,97 & $-2,5$ & $-4,5$ & 0,13 \\
\hline 229 & $-0,23$ & $-0,68$ & $-1,92$ & 1,08 & 1,24 & 0,1 & $-0,15$ & 0,88 & $-0,1$ & 0,5 & -1 & 0,27 \\
\hline 236 & $-2,67$ & 0,5 & $-1,55$ & 1,96 & 2,05 & $-0,2$ & $-3,92$ & 2,46 & $-0,81$ & 3 & 1,5 & 0,24 \\
\hline 316 & $-3,69$ & 6,54 & $-1,74$ & $-1,98$ & 8,28 & 0,63 & $-3,77$ & $-4,1$ & $-1,2$ & 1,5 & $-5,5$ & 4,94 \\
\hline 330 & $-4,6$ & 2,76 & $-1,65$ & 1,44 & 4,41 & $-0,24$ & $-3,53$ & $-1,13$ & $-2,18$ & 2,5 & 1 & 1,27 \\
\hline 385 & $-1,19$ & $-0,42$ & $-2,51$ & 1,65 & 2,09 & 0,1 & $-1,37$ & 2,3 & 0,21 & 2 & 1 & 2,76 \\
\hline 474 & $-1,37$ & $-0,35$ & $-0,1$ & 1,28 & $-0,25$ & $-0,28$ & $-0,91$ & 0,97 & $-0,39$ & -1 & $-1,5$ & 0,02 \\
\hline AlexandraPị & 0 & $-3,09$ & $-1,72$ & 2,33 & $-1,37$ & $-0,49$ & $-1,62$ & 0,79 & $-4,16$ & 0 & 1 & 0 \\
\hline EdilsonMediı & $-2,5$ & 0,94 & $-0,54$ & 2,03 & 1,48 & 0,35 & 0 & 0,17 & 0,99 & -2 & -2 & 2,68 \\
\hline Eliza Papa & $-1,24$ & 0,34 & $-1,64$ & 0,85 & 1,98 & 0 & $-0,6$ & $-1,91$ & $-1,97$ & $-0,5$ & -3 & 0,59 \\
\hline Fernanda Lo & $-2,12$ & $-2,25$ & -1 & 3,41 & $-1,25$ & $-0,87$ & $-0,71$ & 2,38 & $-0,85$ & -1 & 0 & 1,71 \\
\hline José Mascar & $-6,73$ & 11,2 & $-1,71$ & $-3,03$ & 12,91 & 1,2 & $-5,99$ & $-3,92$ & 1,02 & 1,5 & $-5,5$ & 4,1 \\
\hline Juliana Attuy & $-0,74$ & $-1,25$ & $-0,48$ & 1,75 & $-0,77$ & 0 & 0,84 & 1,11 & 0,98 & 0,5 & 0,5 & 2,64 \\
\hline
\end{tabular}




\begin{tabular}{|c|c|c|c|c|c|c|c|c|c|c|c|c|}
\hline Pac. $\mathbf{N}^{\circ}$ & $6 s$ & ABA & Max.-BC & $6 \mathrm{i}$ & Mand & $6 / 6$ & $1 \mathrm{~s}$ & $1 \mathrm{i}$ & $1 / 1$ & Rot Max & ROT Mand & EGU I-F \\
\hline 12 & 3,04 & 5,3 & $-2,32$ & $-3,96$ & 7,62 & 4,21 & 2,82 & $-6,41$ & 1,55 & 11 & 3 & 3,99 \\
\hline 27 & $-0,65$ & 2,18 & $-0,5$ & 2,12 & 2,68 & 3,8 & 6,82 & $-4,82$ & 4,45 & 1,5 & $-0,5$ & 0,24 \\
\hline 52 & 0,8 & 1,03 & $-2,47$ & 3,97 & 3,5 & 6,06 & 8,66 & $-1,89$ & 7,74 & 3 & $-0,5$ & 2,16 \\
\hline 65 & $-2,78$ & 0,17 & $-0,94$ & 4,54 & 1,11 & 2,03 & 6,86 & $-2,7$ & 4,26 & 0 & -5 & 2,71 \\
\hline 105 & 0,3 & 3,87 & $-0,45$ & 1,12 & 4,32 & 5,4 & 1 & $-2,07$ & 2,83 & 1,5 & -5 & 2,74 \\
\hline 151 & 0,55 & 3,94 & $-0,89$ & $-0,96$ & 4,83 & 3,67 & 0,93 & $-4,23$ & 0,72 & 1,5 & $-3,5$ & 3,37 \\
\hline 152 & 1,14 & 5,69 & $-2,21$ & $-3,15$ & 7,9 & 3,84 & $-0,4$ & $-4,86$ & 0,43 & 0,5 & 1,5 & 4,08 \\
\hline 156 & $-1,3$ & 0,2 & $-1,3$ & 4 & 1,5 & 2,9 & 0,9 & $-0,4$ & 0,8 & 0 & $-0,5$ & 2,58 \\
\hline 168 & $-3,03$ & 6,3 & $-0,85$ & 0,73 & 7,15 & 3,78 & $-1,35$ & $-3,94$ & 0,72 & -1 & $-9,5$ & 3,44 \\
\hline 179 & $-2,01$ & 1,65 & $-2,81$ & 3,38 & 4,46 & 2,92 & 0 & $-1,07$ & 0,28 & 0 & $-2,5$ & 3,02 \\
\hline 202 & $-2,62$ & 5,49 & $-0,85$ & 1,8 & 6,34 & 4,55 & $-1,89$ & $-2,86$ & 0,47 & 3 & $-1,5$ & 1,7 \\
\hline 338 & $-2,67$ & 3,06 & $-1,06$ & 2,78 & 4,12 & 3,41 & 6,32 & $-2,35$ & 7,22 & 1 & $-3,5$ & 3,01 \\
\hline Jaqueline $C_{\tilde{a}}$ & $-1,96$ & 5,54 & $-1,86$ & 1,27 & 7,4 & 4,73 & 5,04 & $-4,42$ & 5,88 & 3,5 & -2 & 1,98 \\
\hline Renata Mutrı & $-2,82$ & 2,22 & $-0,68$ & 3,88 & 2,9 & 3,39 & 6,97 & $-1,4$ & 7,7 & 1 & $-2,5$ & 2,86 \\
\hline
\end{tabular}




\begin{tabular}{|c|c|c|c|c|c|c|c|c|c|c|c|c|}
\hline Pac. $\mathbf{N}^{\circ}$ & $6 s$ & ABA & Max.-BC & $6 \mathrm{i}$ & Mand & $6 / 6$ & $1 \mathrm{~s}$ & $1 \mathrm{i}$ & $1 / 1$ & Rot Max & ROT Mand & EGU I-F \\
\hline 12 & $-1,36$ & 0,54 & 0,25 & 0,95 & 0,29 & $-0,22$ & 1,5 & $-0,77$ & 1 & -1 & -2 & 3,18 \\
\hline 27 & $-0,29$ & 1,4 & $-0,85$ & $-1,47$ & 2,25 & $-0,42$ & $-2,38$ & $-0,79$ & $-1,73$ & $-1,5$ & $-4,5$ & 0 \\
\hline 52 & -3 & $-0,63$ & $-0,1$ & 1,37 & $-0,53$ & $-2,4$ & $-1,12$ & 0,82 & $-1,2$ & $-0,5$ & 1 & 0,24 \\
\hline 65 & $-3,93$ & $-3,2$ & $-0,56$ & 4,3 & $-2,64$ & $-2,77$ & $-4,32$ & 2,96 & $-4,7$ & 4 & 4 & 1,62 \\
\hline 105 & $-1,92$ & 1,6 & $-1,59$ & 0,32 & 3,19 & 0 & $-0,33$ & $-2,3$ & $-1,1$ & 2,5 & -3 & 0,46 \\
\hline 151 & $-1,16$ & 0 & $-0,55$ & 1,17 & 0,55 & $-0,16$ & 0,49 & $-0,74$ & $-0,3$ & $-0,5$ & $-4,5$ & 2,31 \\
\hline 152 & $-1,12$ & 1,2 & $-0,55$ & $-0,27$ & 1,75 & $-0,27$ & 0,21 & $-1,97$ & $-0,51$ & 1 & $-4,5$ & 2,19 \\
\hline 156 & 0 & 0,9 & $-2,3$ & $-1,2$ & 3,2 & $-0,5$ & 1,1 & $-2,8$ & -1 & 1 & 0 & 0,85 \\
\hline 168 & $-3,47$ & 1,46 & 0 & 1,37 & 1,46 & $-0,44$ & 0 & $-1,27$ & 0,1 & 0 & -2 & 0 \\
\hline 179 & $-1,05$ & 1,8 & $-0,93$ & $-0,27$ & 2,73 & 0,4 & $-0,1$ & $-1,35$ & 0,1 & -3 & $-5,5$ & 1,07 \\
\hline 202 & $-3,6$ & 5,38 & $-2,94$ & $-0,99$ & 8,32 & 0,98 & $-1,05$ & $-5,45$ & $-0,91$ & -2 & $-10,5$ & 6,63 \\
\hline 338 & $-2,11$ & 3,41 & $-2,62$ & $-2,37$ & 6,03 & $-1,03$ & $-3,18$ & $-2,96$ & $-2,6$ & 0,5 & $-2,5$ & 0,78 \\
\hline Jaqueline $C_{\varepsilon}$ & 0,44 & $-2,25$ & 0 & 2,16 & $-2,25$ & 0,28 & $-1,83$ & 2,81 & $-1,54$ & -4 & 0 & 0,2 \\
\hline Renata Mutrı & $-0,24$ & 2,05 & $-2,16$ & $-3,27$ & 4,21 & $-1,47$ & $-0,62$ & $-2,36$ & $-1,16$ & 1,5 & -3 & 0,46 \\
\hline
\end{tabular}




\begin{tabular}{|c|c|c|c|c|c|c|c|c|c|c|c|c|}
\hline Pac. $\mathrm{N}^{\circ}$ & $6 s$ & ABA & Max.-BC & $6 i$ & Mand & $6 / 6$ & $1 \mathrm{~s}$ & $1 \mathrm{i}$ & $1 / 1$ & Rot Max & ROT Mand & EGU I-F \\
\hline 4 & 1,42 & 0,85 & $-1,27$ & 3,02 & 2,12 & 5,43 & 7,83 & $-3,59$ & 5,2 & 0 & -1 & 1,83 \\
\hline 29 & $-2,76$ & 2,83 & $-1,37$ & 3,19 & 4,2 & 3,2 & 5,74 & $-2,27$ & 6,24 & 2,5 & 1 & 0,72 \\
\hline 43 & $-0,1$ & 7,28 & $-1,98$ & $-0,56$ & 9,26 & 6,66 & 6,56 & $-4,58$ & 9,14 & 7 & 2,5 & 2,36 \\
\hline 49 & $-0,32$ & 3,23 & $-1,7$ & 1,98 & 4,93 & 4,88 & 7,15 & $-4,43$ & 6,01 & 3 & $-1,5$ & 2,67 \\
\hline 73 & $-1,79$ & 4,81 & $-3,4$ & 0,67 & 8,21 & 3,74 & 4,2 & $-5,13$ & 4,15 & 0 & $-2,5$ & 3,99 \\
\hline 74 & $-2,51$ & 2,5 & $-2,25$ & 2,64 & 4,75 & 2,43 & 1,56 & $-2,09$ & 1,83 & -1 & $-3,5$ & 3,21 \\
\hline 97 & 1,54 & 8,97 & $-4,52$ & $-1,73$ & 8,97 & 4,18 & 1,78 & $-6,49$ & 0 & 3 & -3 & 3,97 \\
\hline 107 & $-5,43$ & 9,4 & $-2,23$ & $-1,67$ & 11,63 & 2,01 & 4,94 & $-5,2$ & 9,2 & 4,5 & -3 & 5,81 \\
\hline 122 & 0,26 & 6,16 & $-3,48$ & $-0,56$ & 9,64 & 5,77 & 0 & $-5,22$ & 0,85 & 3,5 & 0 & 4,28 \\
\hline 129 & 1,25 & 0,11 & $-0,43$ & $-0,18$ & 0,54 & 1,2 & 0,16 & 0,17 & 0,49 & -1 & $-3,5$ & 1,23 \\
\hline 147 & $-1,67$ & 2,74 & $-0,88$ & 2,26 & 3,62 & 3,44 & 2,95 & $-4,37$ & 1,41 & 2 & -1 & 0,59 \\
\hline 157 & 0,86 & 8,72 & $-4,35$ & $-3,45$ & 13,07 & 6,21 & 9,12 & $-9,07$ & 8,83 & 5,5 & $-1,5$ & 3,53 \\
\hline 185 & $-3,41$ & 0,1 & $-1,33$ & 6,25 & 1,43 & 2,69 & 4,19 & $-4,32$ & 0 & 1,5 & 0 & 3,4 \\
\hline 188 & $-1,31$ & 3,16 & 0 & 2,56 & 3,16 & 4,25 & 6,56 & $-2,19$ & 7,25 & 1,5 & $-1,5$ & 2,03 \\
\hline 196 & $-3,06$ & 4,94 & $-2,38$ & 1,83 & 7,32 & 3,54 & $-3,69$ & $-1,71$ & $-0,23$ & 0,5 & -5 & 4,68 \\
\hline 235 & $-0,35$ & 0,36 & $-0,09$ & 2,2 & 0,45 & 2,2 & 8,58 & $-3,11$ & 5,96 & 1 & $-0,5$ & 0,27 \\
\hline 255 & 0 & 1,03 & $-0,62$ & 2,91 & 1,65 & 4,22 & 6,15 & $-3,06$ & 3,95 & 4,5 & -1 & 2,54 \\
\hline 257 & $-2,76$ & 0,65 & $-0,1$ & 5,41 & 0,75 & 3,4 & $-1,04$ & $-0,63$ & $-0,76$ & -1 & -6 & 1,33 \\
\hline 368 & $-6,03$ & 4,11 & $-1,11$ & 5,05 & 5,22 & 3,19 & 5,3 & $-1,96$ & 7,51 & 2 & 1 & 1,99 \\
\hline Fabio lucianı & $-0,41$ & 3,11 & $-1,35$ & 3,19 & 4,46 & 5,91 & 5,71 & $-3,98$ & 4,76 & 0,5 & 1 & 3,04 \\
\hline Janaina San & $-4,46$ & 5,06 & $-1,9$ & 2,79 & 6,96 & 3,31 & 0,94 & $-1,92$ & 4,09 & 3 & -1 & 2,16 \\
\hline Tania Morais & 0,72 & 5,91 & $-0,76$ & $-0,74$ & 6,67 & 5,71 & 1,65 & $-5,99$ & 1,67 & 0,5 & 2 & 2,55 \\
\hline Telma Abes & $-0,31$ & 2,8 & $-1,77$ & 0,97 & 4,57 & 3,22 & 11,61 & $-4,07$ & 10,32 & 4 & $-2,5$ & 0,46 \\
\hline
\end{tabular}




\begin{tabular}{|c|c|c|c|c|c|c|c|c|c|c|c|c|}
\hline Pac. $\mathrm{N}^{\circ}$ & $6 s$ & ABA & Max.-BC & $6 i$ & Mand & $6 / 6$ & $1 \mathrm{~s}$ & $1 \mathrm{i}$ & $1 / 1$ & Rot Max & ROT Mand & EGU I-F \\
\hline 4 & $-1,95$ & 0,25 & $-2,03$ & 1,05 & 2,28 & $-0,74$ & $-2,09$ & 0,28 & $-1,41$ & 1 & -3 & 1,14 \\
\hline 29 & $-0,4$ & $-2,24$ & 0 & 1,6 & $-2,24$ & $-0,75$ & 0 & 0 & $-2,09$ & -1 & 2 & 0 \\
\hline 43 & $-0,54$ & $-0,83$ & $-2,36$ & 0,84 & 1,53 & $-0,54$ & $-1,74$ & 0,11 & $-2,42$ & $-1,5$ & $-4,5$ & 5,34 \\
\hline 49 & $-0,53$ & $-0,15$ & $-0,87$ & 0,58 & 0,72 & $-0,1$ & $-2,08$ & 0,56 & $-1,51$ & $-0,5$ & -2 & 0,66 \\
\hline 73 & $-2,01$ & $-0,29$ & 0 & 1,55 & $-0,29$ & $-0,86$ & $-1,35$ & $-0,73$ & $-2,54$ & 1,5 & 0 & 1,34 \\
\hline 74 & $-0,62$ & $-0,53$ & $-0,99$ & 0,09 & 0,46 & $-1,28$ & 0,46 & $-0,73$ & $-1,05$ & $-1,5$ & -4 & 0,98 \\
\hline 97 & $-3,46$ & 2,78 & $-0,33$ & 1,31 & 2,78 & 0,53 & 0,17 & $-1,97$ & 0,36 & $-1,5$ & -7 & 3,55 \\
\hline 107 & $-0,17$ & $-0,87$ & $-0,1$ & 0,88 & $-0,77$ & $-0,3$ & 0,44 & $-1,27$ & $-1,8$ & $-2,5$ & -3 & 1,43 \\
\hline 122 & $-4,89$ & 1,56 & $-1,31$ & 1,53 & 2,87 & $-1,58$ & $-1,26$ & $-0,72$ & $-0,41$ & 0,5 & $-0,5$ & 4,52 \\
\hline 129 & $-3,63$ & $-0,18$ & $-0,44$ & 4,09 & 0,26 & 0,25 & $-0,2$ & $-0,27$ & $-0,39$ & 1 & 2 & 0 \\
\hline 147 & 0,1 & $-0,21$ & 0 & 0 & $-0,21$ & $-0,18$ & $-0,24$ & 0 & $-0,38$ & -3 & $-2,5$ & 0 \\
\hline 157 & $-1,91$ & $-2,15$ & 0,85 & 4,55 & -3 & 0,34 & $-0,31$ & 0,9 & $-1,31$ & $-4,5$ & -5 & 0,52 \\
\hline 185 & $-4,37$ & $-0,7$ & $-1,08$ & 4,15 & 0,38 & $-0,72$ & $-3,77$ & 3,96 & $-0,34$ & $-0,5$ & 1,5 & 1,05 \\
\hline 188 & 1,37 & $-2,97$ & $-0,22$ & 0,65 & $-2,75$ & $-0,72$ & $-0,25$ & 0,87 & $-2,11$ & 1,5 & $-0,5$ & 0,15 \\
\hline 196 & $-2,27$ & 0,48 & $-0,82$ & 1,52 & 1,3 & $-0,33$ & $-0,59$ & $-0,44$ & $-0,63$ & 1 & 0 & 2,56 \\
\hline 235 & $-1,14$ & 2,32 & $-1,85$ & $-1,72$ & 4,17 & $-0,47$ & $-0,91$ & $-1,64$ & $-0,32$ & 2 & 0 & 0 \\
\hline 255 & 2,45 & $-3,81$ & $-0,87$ & 0,33 & $-2,94$ & $-0,86$ & 2,68 & 0 & $-0,94$ & $-2,5$ & $-1,5$ & 0,08 \\
\hline 257 & $-3,05$ & $-1,32$ & $-1,49$ & 1,9 & 0,17 & $-2,23$ & 1,37 & 0,1 & 0,36 & $-1,5$ & -4 & 0 \\
\hline 368 & $-0,59$ & 1,63 & $-0,41$ & 0,1 & 2,04 & 0,99 & $-1,96$ & 0,48 & 0,1 & $-0,5$ & -2 & 0 \\
\hline Fabio luci & $-0,14$ & $-0,19$ & $-1,13$ & 0,11 & 1,13 & $-0,23$ & $-1,5$ & $-0,7$ & 2,69 & -1 & $-1,5$ & 1,34 \\
\hline JanainaSant & 2,38 & $-2,89$ & 0,63 & 0 & $-3,52$ & $-0,67$ & 1,38 & 0 & $-1,32$ & $-2,5$ & $-1,5$ & 0,24 \\
\hline Tania Mora & $-1,75$ & 0 & 0,1 & 0,72 & $-0,1$ & $-1,06$ & $-1,63$ & 0,78 & $-1,03$ & 2 & $-3,5$ & 0,66 \\
\hline TemaAbes & $-0,71$ & $-2,77$ & 0,1 & 1,35 & $-2,81$ & $-1,95$ & 1,3 & 1,42 & 0,23 & $-2,5$ & $-2,5$ & 0 \\
\hline
\end{tabular}




\begin{tabular}{|c|c|c|c|c|c|c|c|c|c|c|c|c|c|}
\hline $\begin{array}{c}\text { NÚMERO } \\
\text { VARIÁVEIS }\end{array}$ & $\begin{array}{l}\text { SNA } \\
\text { SNAI }\end{array}$ & SNAF & SNAPC & A-Nperp & A-NperpF & A-NperoPC & $\begin{array}{l}\text { Co-A } \\
\text { Co-A I }\end{array}$ & Co-A F & Co-A PC & $\begin{array}{c}\mathrm{Ar}-\mathrm{A} \\
\mathrm{Ar}-\mathrm{Al}\end{array}$ & Ar-A F & Ar-A PC & $\begin{array}{l}\text { SNB } \\
\text { SNB }\end{array}$ \\
\hline 1 & 82,7 & 79,6 & 80,3 & 4,5 & 3,5 & 4,2 & 82,7 & 82,5 & 84,5 & 81,1 & 80,4 & 81,8 & 76,8 \\
\hline 48 & 87 & 84,4 & 84,1 & 1,6 & -1 & $-0,9$ & 82,8 & 83,3 & 87,7 & 79,6 & 81,7 & 86,2 & 81,8 \\
\hline 54 & 83,5 & 80,9 & 80,8 & 0,2 & $-1,9$ & $-1,4$ & 79 & 79,7 & 80,2 & 75,3 & 77,2 & 78 & 76,6 \\
\hline 55 & 82,3 & 79,8 & 77,9 & $-1,6$ & $-3,9$ & $-6,2$ & 78,4 & 80,8 & 80,3 & 76,3 & 77,2 & 78,8 & 75,7 \\
\hline 61 & 82,1 & 80 & 80,6 & 0,8 & 0,5 & 0,6 & 81,2 & 82,3 & 83,2 & 79,5 & 79,3 & 78,7 & 74,5 \\
\hline 79 & 84,2 & 81,8 & 79,9 & $-0,1$ & $-3,3$ & $-1,9$ & 80,7 & 83,4 & 83,2 & 81,3 & 81,7 & 80,1 & 79,9 \\
\hline 101 & 84 & 82,3 & 83 & 2,1 & 0,6 & 1,5 & 89,2 & 89 & 90,7 & 88,9 & 88,6 & 89,4 & 76,7 \\
\hline 111 & 83,8 & 83 & 84,3 & 2,4 & 2,4 & 3,8 & 84,4 & 87,2 & 86,9 & 83,8 & 85,2 & 85,4 & 76,1 \\
\hline 115 & 84,5 & 81,2 & 80,7 & 2,6 & 1,6 & 4,1 & 80,1 & 80,7 & 85,4 & 79 & 79,2 & 78,3 & 76,3 \\
\hline 176 & 82,1 & 77,1 & 78,4 & 0,6 & $-3,7$ & $-1,5$ & 74,6 & 73,1 & 77,5 & 73,9 & 72 & 74,8 & 74,2 \\
\hline 184 & 83,1 & 82,7 & 82,2 & $-1,5$ & $-1,3$ & $-1,7$ & 82 & 82,1 & 79,3 & 82,7 & 82,5 & 81 & 77,2 \\
\hline 225 & 86,7 & 83 & 83,5 & 4,4 & 2,5 & 1,5 & 87,2 & 87 & 90,3 & 84,7 & 85,1 & 87,8 & 78 \\
\hline 347 & 84,4 & 85,6 & 84,3 & $-6,3$ & $-2,2$ & -2 & 82,4 & 78,9 & 82,8 & 80,9 & 77,3 & 80,4 & 76,7 \\
\hline Roberta Losil & 88,6 & 86,6 & 87 & 4,6 & 1,8 & 4 & 83,3 & 82,6 & 84,2 & 80,5 & 79,4 & 82,1 & 82,2 \\
\hline Valcirlei Silvã & 86,4 & 81,6 & 79,1 & 4,7 & 0,1 & $-4,6$ & 90,4 & 87,2 & 93,8 & 88 & 86,3 & 90,1 & 75,8 \\
\hline
\end{tabular}




\begin{tabular}{|c|c|c|c|c|c|c|c|c|c|c|c|c|c|}
\hline \multicolumn{2}{|l|}{ NÚMERO } & \multicolumn{3}{|c|}{ Pg-Nperp } & \multicolumn{3}{|c|}{ Co-Gn } & \multicolumn{3}{|c|}{ Ar-Gn } & \multicolumn{3}{|c|}{ ANB } \\
\hline VARIÁVEIS & SNB F & SNB PC & Pg-Nperpl & Pg-NperpF & Pg-NperpPC & Co-Gn I & Co-Gn F & Co-Gn PC & $A r-G n I$ & $A r-G n F$ & Ar-Gn PC & ANB I & ANB F \\
\hline 1 & 76 & 75,9 & 1,5 & 4,4 & 5,1 & 112,5 & 116,9 & 121,6 & 106,6 & 110,5 & 114,5 & 5,9 & 3,6 \\
\hline 48 & 81,2 & 80,8 & $-6,7$ & $-6,9$ & $-6,6$ & 104,4 & 109,3 & 116,2 & 95,6 & 102,9 & 107,8 & 5,2 & 3,2 \\
\hline 54 & 75,7 & 77,5 & $-9,1$ & $-10,2$ & $-4,9$ & 100,1 & 103,7 & 111,2 & 91,6 & 96 & 102,9 & 6,9 & 5,2 \\
\hline 55 & 75,3 & 74,7 & $-13,4$ & $-13,9$ & -16 & 99,1 & 104,1 & 107,6 & 90,8 & 94,9 & 100,1 & 6,6 & 4,5 \\
\hline 61 & 73,9 & 73,6 & $-12,5$ & $-10,6$ & $-11,7$ & 103,1 & 108,3 & 108,4 & 96,5 & 99 & 96,7 & 7,6 & 6,1 \\
\hline 79 & 75,4 & 74,8 & $-4,7$ & $-13,2$ & $-7,6$ & 102,7 & 103,8 & 104,3 & 99 & 97,7 & 96,2 & 4,3 & 6,4 \\
\hline 101 & 78,7 & 79,2 & $-10,1$ & $-6,2$ & $-3,9$ & 113,3 & 121,4 & 121,7 & 108,7 & 114,8 & 114,8 & 7,3 & 3,6 \\
\hline 111 & 77,8 & 76,7 & $-8,9$ & $-4,6$ & $-7,1$ & 104,4 & 108,4 & 108,3 & 98,7 & 102,4 & 101,1 & 7,7 & 5,2 \\
\hline 115 & 74,4 & 73,4 & $-11,3$ & $-10,4$ & $-7,9$ & 98,7 & 101 & 106,8 & 91,8 & 93,5 & 92,8 & 8,2 & 6,8 \\
\hline 176 & 73 & 76,1 & $-13,3$ & $-13,5$ & $-6,8$ & 100 & 102 & 111,7 & 93,5 & 95,9 & 103 & 7,9 & 4,1 \\
\hline 184 & 75,7 & 75,6 & $-12,9$ & $-14,8$ & $-14,6$ & 111,8 & 110,9 & 108,5 & 108,8 & 107,9 & 105,8 & 5,9 & 7 \\
\hline 225 & 77 & 78,8 & $-6,5$ & $-7,7$ & $-9,1$ & 107,2 & 111,5 & 117,9 & 99,6 & 103,3 & 109 & 8,7 & 6 \\
\hline 347 & 79,2 & 75,2 & $-25,9$ & $-16,9$ & $-22,6$ & 100 & 100,4 & 105,7 & 94 & 94,8 & 97,8 & 7,7 & 6,4 \\
\hline Roberta Losil & 83,8 & 82,5 & $-0,4$ & 2,1 & 4,3 & 104,7 & 109,5 & 110,2 & 96,7 & 101,1 & 103 & 6,4 & 2,8 \\
\hline Valcirlei Silvã & 75,6 & 74,7 & -13 & $-11,8$ & $-16,1$ & 111,8 & 119,8 & 127,8 & 103,3 & 113,3 & 117,2 & 10,6 & 6 \\
\hline
\end{tabular}




\begin{tabular}{|c|c|c|c|c|c|c|c|c|c|c|c|c|c|}
\hline \multirow{2}{*}{$\begin{array}{c}\text { NÚMERO } \\
\text { VARIÁVEIS }\end{array}$} & \multirow[b]{2}{*}{ ANB PC } & \multirow{2}{*}{$\begin{array}{l}\text { WITS } \\
\text { WITS I }\end{array}$} & \multirow[b]{2}{*}{ WITS F } & \multicolumn{3}{|c|}{ SN.PP } & \multirow[b]{2}{*}{ SN.PP PC } & \multirow{2}{*}{$\begin{array}{l}\text { SN.Ocl } \\
\text { SN.Ocl I }\end{array}$} & \multicolumn{5}{|c|}{ SN.GoMe } \\
\hline & & & & WITS PC & SN.PP I & SN.PP F & & & SN.Ocl F & SN.Ocl PC & SN.GoMe I & SN.GoMe F & SN.GoMe PC \\
\hline 1 & 4,4 & 1,2 & $-1,6$ & $-1,9$ & 3,8 & 6,5 & 5,5 & 19,1 & 21,9 & 22,4 & 39,9 & 42,1 & 41,9 \\
\hline 48 & 3,3 & $-5,1$ & $-2,5$ & $-1,7$ & 6,9 & 7,6 & 8,1 & 22,4 & 16,4 & 15,8 & 33,8 & 33 & 28,3 \\
\hline 54 & 3,3 & $-0,4$ & 2 & 0,2 & 10,6 & 10,9 & 8,7 & 23,9 & 18,9 & 15,5 & 41,8 & 43,6 & 38,9 \\
\hline 55 & 3,2 & $-0,8$ & 0,5 & $-2,4$ & 5,9 & 7,8 & 9,8 & 23,5 & 20,3 & 23,8 & 41,9 & 42,3 & 43,4 \\
\hline 61 & 7 & 0 & 2,6 & 0,2 & 7,3 & 10,2 & 8,1 & 28,3 & 22,1 & 27,7 & 45,6 & 46 & 45,9 \\
\hline 79 & 5,1 & $-1,9$ & 3 & $-0,2$ & 11,3 & 11,3 & 12,4 & 19,8 & 20,3 & 24,8 & 34,5 & 36,8 & 36,4 \\
\hline 101 & 3,8 & 2,4 & 2,1 & 2,7 & 5,7 & 5,7 & 6,1 & 18,5 & 13,9 & 12,3 & 42,3 & 40,6 & 38,7 \\
\hline 111 & 7,6 & $-1,1$ & 2,1 & 1,8 & 9,8 & 9,7 & 10,1 & 24,5 & 16,2 & 21,3 & 42,5 & 40,6 & 42,5 \\
\hline 115 & 7,3 & $-1,5$ & $-0,4$ & $-1,8$ & 6,6 & 10,6 & 10,7 & 25,7 & 24,9 & 28,4 & 41,1 & 41,7 & 42,2 \\
\hline 176 & 2,3 & $-2,9$ & 3,2 & $-2,3$ & 4,1 & 6,6 & 5,2 & 28,9 & 18,1 & 19,1 & 46 & 45,5 & 42,9 \\
\hline 184 & 6,6 & $-1,1$ & 2,8 & 3,9 & 4,7 & 4,8 & 4,8 & 21,4 & 17,5 & 17,8 & 39,3 & 40,7 & 40,1 \\
\hline 225 & 4,7 & 1,5 & 0,8 & 1,4 & 2,2 & 7 & 3,8 & 20,7 & 20,1 & 15,7 & 38,1 & 40 & 36,4 \\
\hline 347 & 9,1 & 1,5 & 0,9 & 3,8 & 8,1 & 6 & 8,5 & 21,2 & 18,4 & 21,9 & 41,6 & 42,5 & 49,9 \\
\hline Roberta Losil & 4,5 & 0,6 & $-1,9$ & 1 & 2,6 & 2,8 & 4 & 15,3 & 13,9 & 12,4 & 31,7 & 28,7 & 30,7 \\
\hline Valcirlei Silvã & 4,4 & 5,8 & 8,9 & 4,4 & 10,5 & 12,9 & 12,2 & 21,4 & 12,5 & 16,7 & 43,7 & 44,8 & 43,4 \\
\hline
\end{tabular}




\begin{tabular}{|c|c|c|c|c|c|c|c|c|c|c|c|c|c|}
\hline NÚMERO & N.S.Gn & & & Ba.N.Gn & & & FMA & & & $\mathrm{N}-\mathrm{Me}$ & & & S-Go \\
\hline VARIÁVEIS & N.S.Gn I & N.S.Gn F & N.S.Gn PC & Ba.N.Gn I & Ba.N.Gn F & Ba.N.Gn PC & FMA I & FMA F & FMA PC & $\mathrm{N}-\mathrm{Me} \mathrm{I}$ & $\mathrm{N}-\mathrm{Me} \mathrm{F}$ & $\mathrm{N}-\mathrm{Me} \mathrm{PC}$ & S-Go I \\
\hline 1 & 71,2 & 72,2 & 73,1 & 89 & 87,2 & 86,5 & 27,9 & 28,3 & 28,1 & 116 & 121,2 & 125,6 & 72,9 \\
\hline 48 & 67,1 & 67 & 67,4 & 84 & 85 & 86,4 & 28,9 & 28,5 & 23,4 & 108,1 & 114,9 & 118,7 & 74,7 \\
\hline 54 & 66,9 & 67,7 & 66,5 & 86,6 & 85,4 & 87,3 & 35 & 36,5 & 31,2 & 103,7 & 110,3 & 115 & 64 \\
\hline 55 & 69,8 & 70,2 & 71,2 & 84,9 & 84,7 & 84,4 & 36 & 36,2 & 37,8 & 106,2 & 111,3 & 115,3 & 66,5 \\
\hline 61 & 74,5 & 75,3 & 76,1 & 81,2 & 81,2 & 80,5 & 37 & 35,6 & 35,9 & 116,6 & 122,3 & 119,4 & 69,8 \\
\hline 79 & 65,7 & 68,9 & 67,9 & 91,7 & 87,9 & 89 & 28,8 & 31,9 & 28,2 & 104,7 & 109,7 & 106,6 & 69,9 \\
\hline 101 & 72,3 & 71,5 & 70,7 & 84,3 & 84,1 & 85,7 & 34,2 & 32,3 & 30,3 & 124,3 & 128,9 & 126,4 & 79,3 \\
\hline 111 & 69 & 67,5 & 69,4 & 85,9 & 89,7 & 87,2 & 33,7 & 31,2 & 32,8 & 111 & 111,2 & 113 & 65,2 \\
\hline 115 & 73,2 & 74 & 75,8 & 82,1 & 81,7 & 80 & 32,7 & 31,2 & 28,6 & 108,1 & 112 & 112,3 & 68,3 \\
\hline 176 & 75,3 & 75 & 73,7 & 82,2 & 81,3 & 83,9 & 37,4 & 36,5 & 32,9 & 111,2 & 113,7 & 119 & 66,2 \\
\hline 184 & 70,4 & 72,6 & 72,4 & 86,8 & 84,3 & 83,4 & 33,9 & 34,7 & 34 & 122,2 & 123,7 & 122,7 & 79,9 \\
\hline 225 & 69,5 & 70,8 & 69,5 & 89,8 & 88,3 & 88,6 & 29,8 & 30,4 & 28,4 & 109,1 & 115,6 & 121,9 & 71,6 \\
\hline 347 & 68,4 & 69,2 & 74,1 & 84,4 & 83,8 & 79,4 & 42,9 & 40,4 & 46,1 & 109,4 & 110 & 120,6 & 67,1 \\
\hline Roberta Losil & 64,4 & 61,7 & 63 & 94,1 & 96 & 95,2 & 24,8 & 23,2 & 23,1 & 101,7 & 102,5 & 106,2 & 68,9 \\
\hline Valcirlei Silvã & 73,7 & 74 & 74,2 & 80,1 & 80 & 80,8 & 35,8 & 36,4 & 36,2 & 124,1 & 135,6 & 140,7 & 77,7 \\
\hline
\end{tabular}




\begin{tabular}{|c|c|c|c|c|c|c|c|c|c|c|c|c|c|}
\hline \multirow{2}{*}{$\begin{array}{c}\text { NÚMERO } \\
\text { VARIÁVEIS }\end{array}$} & \multirow[b]{2}{*}{ S-Go F } & \multicolumn{3}{|c|}{ AFP:AFA } & \multicolumn{3}{|c|}{ AFAl } & \multicolumn{3}{|c|}{ 1s.SN } & \multicolumn{3}{|c|}{ 1.NA } \\
\hline & & S-Go PC & AFP:AFA I & AFP:AFA F & AFP:AFA PC & AFAII & AFAI $F$ & AFAI PC & 1s.SN I & 1s.SN F & 1s.SN PC & 1.NAI & 1.NA F \\
\hline 1 & 76 & 79,6 & 62,9 & 62,7 & 63,3 & 72 & 73,8 & 78,3 & 108,4 & 96,4 & 102,9 & 25,8 & 16,8 \\
\hline 48 & 81,7 & 88,1 & 69,1 & 71,1 & 74,2 & 65,4 & 69,6 & 70,3 & 115,8 & 107,9 & 110,1 & 28,8 & 23,5 \\
\hline 54 & 67,4 & 76,9 & 61,8 & 61,1 & 66,9 & 59,9 & 64,2 & 68,3 & 112,5 & 108,5 & 104,7 & 29 & 27,6 \\
\hline 55 & 69,5 & 72 & 62,6 & 62,4 & 62,4 & 65,9 & 68 & 69,9 & 110,7 & 101,6 & 99,9 & 28,4 & 21,9 \\
\hline 61 & 74,9 & 72,1 & 59,9 & 61,2 & 60,4 & 70,3 & 72,3 & 70,9 & 119,1 & 98,9 & 101,1 & 37 & 18,8 \\
\hline 79 & 72 & 68,2 & 66,7 & 65,7 & 64 & 57,1 & 61,8 & 58,2 & 117 & 95,8 & 87,6 & 32,8 & 13,9 \\
\hline 101 & 84,6 & 84,4 & 63,8 & 65,6 & 66,8 & 78,2 & 79,5 & 77,7 & 112,3 & 104,2 & 102,8 & 28,3 & 21,8 \\
\hline 111 & 66,6 & 67,2 & 58,7 & 59,9 & 59,4 & 66,8 & 66,4 & 67,6 & 102,9 & 102,8 & 99,7 & 19 & 19,8 \\
\hline 115 & 69,6 & 69,3 & 63,2 & 62,1 & 61,8 & 65 & 65,9 & 67,2 & 98,9 & 97,7 & 98,6 & 14,4 & 16,6 \\
\hline 176 & 66,8 & 74,6 & 59,5 & 58,8 & 62,7 & 71,6 & 71,1 & 74,8 & 115,6 & 101,9 & 112,7 & 33,5 & 24,8 \\
\hline 184 & 80,4 & 80,6 & 65,4 & 65 & 65,7 & 75,8 & 77,8 & 76,2 & 112,1 & 94,3 & 100,5 & 29 & 11,5 \\
\hline 225 & 73,1 & 81,7 & 65,6 & 63,2 & 67 & 67,8 & 70,1 & 76,6 & 126,3 & 106,4 & 107,1 & 39,6 & 23,4 \\
\hline 347 & 67,2 & 72 & 61,3 & 61,1 & 59,7 & 63 & 65,9 & 73,9 & 107,5 & 98,4 & 102,3 & 23,1 & 12,7 \\
\hline Roberta Losi| & 72,9 & 73,4 & 67,8 & 71,1 & 69,1 & 60,9 & 59,2 & 61,9 & 116,5 & 103,7 & 107,3 & 27,8 & 17 \\
\hline Valcirlei Silvã & 85,6 & 91,4 & 62,6 & 63,1 & 64,9 & 76,2 & 81 & 83,6 & 110,1 & 109,9 & 107,9 & 23,6 & 28,3 \\
\hline
\end{tabular}




\begin{tabular}{|c|c|c|c|c|c|c|c|c|c|c|c|c|c|}
\hline \multirow{2}{*}{$\begin{array}{c}\text { NÚMERO } \\
\text { VARIÁVEIS }\end{array}$} & \multirow[b]{2}{*}{ 1.NA PC } & \multirow{2}{*}{$\begin{array}{l}\text { 1-NA } \\
\text { 1-NA I }\end{array}$} & \multirow[b]{2}{*}{ 1-NA F } & \multicolumn{3}{|c|}{ 1.NB } & \multicolumn{3}{|c|}{ 1-NB } & \multicolumn{3}{|c|}{ FMAI } & \multirow[b]{2}{*}{ FMIA PC } \\
\hline & & & & 1-NA PC & 1.NB I & 1.NB F & 1.NB PC & 1-NB I & 1-NB F & 1 -NB PC & FMIA I & FMIA F & \\
\hline 1 & 22,6 & 6 & 1,8 & 5 & 23,9 & 20,1 & 26,3 & 5 & 4,2 & 6,7 & 64,9 & 69,6 & 63,4 \\
\hline 48 & 26 & 5,3 & 3,1 & 3,6 & 34,1 & 24,7 & 27 & 6,9 & 4,6 & 5,7 & 52,6 & 61 & 58,8 \\
\hline 54 & 23,9 & 4,9 & 2,8 & 4,4 & 27,1 & 23,7 & 24,3 & 6,2 & 6,8 & 5,1 & 56,2 & 59,1 & 60,9 \\
\hline 55 & 22 & 6,3 & 3,7 & 5,1 & 24 & 21,1 & 21,4 & 6,2 & 6,2 & 6,6 & 57,5 & 60,3 & 58,9 \\
\hline 61 & 20,5 & 8 & 0,4 & 2,4 & 26,8 & 29,5 & 32,8 & 6,1 & 7 & 6,4 & 56,3 & 54,8 & 50,7 \\
\hline 79 & 7,7 & 6 & $-2,3$ & $-2,2$ & 16,1 & 17,4 & 14,7 & 2,6 & 2,5 & 2,2 & 69,5 & 62,8 & 68,3 \\
\hline 101 & 19,7 & 7 & 2,9 & 1,9 & 33,3 & 27,9 & 24,6 & 8,6 & 4,9 & 5 & 51,5 & 59 & 63,1 \\
\hline 111 & 15,4 & 3,5 & 2,1 & $-0,3$ & 35,3 & 30,4 & 32,7 & 10 & 7 & 8 & 49,6 & 56,8 & 53,7 \\
\hline 115 & 17,8 & 2,4 & 1,4 & 2,1 & 35 & 34,2 & 37,1 & 10,7 & 8,6 & 9,5 & 49,7 & 50,7 & 49,9 \\
\hline 176 & 34,3 & 8,6 & 2,9 & 6,4 & 38 & 17,3 & 24,8 & 8,7 & 5,2 & 5,7 & 44,8 & 64,7 & 61,3 \\
\hline 184 & 18,4 & 7,3 & $-1,1$ & 0,6 & 28 & 31,4 & 23,5 & 7,9 & 5,6 & 3,9 & 54,5 & 50,3 & 58,2 \\
\hline 225 & 23,6 & 9,6 & 3,3 & 5 & 33,5 & 36,2 & 38,4 & 7,8 & 8 & 8,7 & 52,8 & 50,4 & 48,4 \\
\hline 347 & 17,9 & 5,7 & 1 & 2,9 & 34,3 & 34,8 & 35,5 & 8,7 & 8,1 & 10,8 & 41,1 & 46,5 & 43,5 \\
\hline Roberta Losi| & 20,3 & 5,8 & 2 & 2,9 & 28,5 & 24,9 & 32,7 & 4,5 & 3,3 & 4,9 & 60,6 & 64,4 & 57,4 \\
\hline Valcirlei Silvã & 28,8 & 3,8 & 1 & 3,4 & 36,6 & 24,8 & 21,6 & 10,9 & 7,9 & 7,2 & 47 & 59,3 & 60,3 \\
\hline
\end{tabular}




\begin{tabular}{|c|c|c|c|c|c|c|c|c|c|c|c|c|c|}
\hline NÚMERO & IMPA & & & 1i-APg & & & 1.1 & & & Ls-E & & & Li-E \\
\hline VARIÁVEIS & IMPA I & IMPA F & IMPA PC & 1i-Apg I & 1i-APg F & 1i-APg PC & 1.11 & $1.1 \mathrm{~F}$ & 1.1 PC & Ls-E I & Ls-E F & Ls-E PC & Li-E I \\
\hline 1 & 87,2 & 82 & 88,4 & 0 & 0 & 1,8 & 124,4 & 139,5 & 126,8 & $-1,2$ & $-6,7$ & $-6,8$ & 0,1 \\
\hline 48 & 98,5 & 90,6 & 97,9 & 4,6 & 2,5 & 3 & 112 & 128,6 & 123,7 & $-0,4$ & $-4,6$ & $-5,9$ & 2,6 \\
\hline 54 & 88,7 & 84,4 & 87,9 & 1,4 & 2,2 & 1,5 & 117 & 123,5 & 128,4 & 1,4 & $-0,8$ & $-2,9$ & 4 \\
\hline 55 & 86,5 & 83,5 & 83,3 & 2 & 2,9 & 3,8 & 121 & 132,6 & 133,4 & $-1,1$ & $-3,5$ & $-4,8$ & 1,2 \\
\hline 61 & 86,7 & 89,6 & 93,3 & 0,1 & 2,3 & 0,9 & 108,6 & 125,6 & 119,7 & 2,4 & $-2,7$ & $-2,5$ & 4,5 \\
\hline 79 & 81,7 & 85,2 & 83,5 & -1 & $-3,2$ & $-2,7$ & 126,8 & 142,3 & 152,5 & $-3,2$ & $-8,1$ & $-8,7$ & $-3,2$ \\
\hline 101 & 94,3 & 88,7 & 86,6 & 3,8 & 2,3 & 2 & 111,1 & 126,6 & 131,9 & 2 & $-2,2$ & $-3,4$ & 7 \\
\hline 111 & 96,7 & 92 & 93,5 & 5,7 & 3,6 & 3,6 & 118 & 124,6 & 124,3 & 2,1 & $-1,3$ & $-2,1$ & 4,6 \\
\hline 115 & 97,5 & 98,1 & 101,5 & 7,1 & 4,8 & 6 & 122,4 & 122,5 & 117,7 & 1,7 & $-2,2$ & $-1,7$ & 7,3 \\
\hline 176 & 97,9 & 78,8 & 85,8 & 4,9 & 2,1 & 4 & 100,6 & 133,8 & 118,5 & 1,9 & $-1,9$ & $-3,3$ & 3,3 \\
\hline 184 & 91,5 & 95 & 87,8 & 3,4 & 0,3 & $-1,3$ & 117,1 & 130,1 & 131,5 & $-3,5$ & $-6,6$ & $-5,6$ & $-2,3$ \\
\hline 225 & 97,4 & 99,2 & 103,2 & 3,5 & 5,2 & 6,9 & 98,2 & 114,4 & 113,3 & 3,2 & 0,8 & $-3,4$ & 3,7 \\
\hline 347 & 96 & 93,1 & 90,4 & 4,2 & 4,6 & 5,2 & 114,9 & 126,1 & 117,5 & 0,6 & $-6,3$ & $-1,4$ & 4,7 \\
\hline Roberta Losil & 94,6 & 92,4 & 99,5 & 0,9 & 0,6 & 1 & 117,2 & 135,2 & 122,5 & 1,4 & $-1,2$ & $-3,3$ & 1,4 \\
\hline Valcirlei Silvã & 97,1 & 84,3 & 83,6 & 3,2 & 2,5 & 2,4 & 109,1 & 120,9 & 125,1 & 1,8 & $-4,9$ & $-7,5$ & 4,9 \\
\hline
\end{tabular}




\begin{tabular}{|c|c|c|c|c|c|c|c|c|}
\hline \multirow{2}{*}{$\begin{array}{c}\text { NÚMERO } \\
\text { VARIÁVEIS }\end{array}$} & \multirow[b]{2}{*}{ Li-E F } & \multicolumn{3}{|c|}{$z$} & \multicolumn{3}{|c|}{ H-Pn } & \multirow[b]{2}{*}{ H-Pn PC } \\
\hline & & Li-E PC & ZI & ZF & $\mathrm{ZPC}$ & H-Pn I & H-Pn F & \\
\hline 1 & $-3,6$ & $-1,1$ & 72,2 & 80,8 & 75,1 & 2 & 11,4 & 11,4 \\
\hline 48 & $-0,8$ & $-1,8$ & 63,1 & 70,2 & 71,7 & 0,6 & 7,8 & 9,7 \\
\hline 54 & 1,2 & $-2,1$ & 56,2 & 64,2 & 75,2 & $-2,3$ & 1,3 & 5,2 \\
\hline 55 & $-0,1$ & $-1,4$ & 61,7 & 65,9 & 66,9 & 2 & 6,1 & 8,1 \\
\hline 61 & 2 & 0,9 & 56,9 & 54,8 & 56,7 & -4 & 5,7 & 4,8 \\
\hline 79 & $-7,9$ & $-7,1$ & 71,1 & 73,1 & 82,2 & 5,3 & 14,2 & 15,6 \\
\hline 101 & 1,4 & 0,1 & 54,5 & 66,5 & 71,4 & -3 & 3,5 & 5,1 \\
\hline 111 & 1,3 & 1,5 & 54,1 & 65,1 & 63,9 & $-3,5$ & 2,4 & 3,7 \\
\hline 115 & 3,4 & 1,9 & 44,4 & 56,3 & 60,4 & $-3,1$ & 4 & 3,3 \\
\hline 176 & 0,9 & $-0,3$ & 59,3 & 69,5 & 70,9 & $-2,8$ & 3 & 5,3 \\
\hline 184 & $-6,2$ & $-5,1$ & 71,4 & 74,2 & 71,7 & 6,2 & 11,3 & 9,1 \\
\hline 225 & 2,9 & 0,8 & 63,2 & 67,8 & 66 & -5 & $-1,3$ & 5,7 \\
\hline 347 & $-3,3$ & 3 & 45,4 & 75,3 & 52,8 & -1 & 9,5 & 2,4 \\
\hline Roberta Losil & $-1,5$ & $-2,5$ & 72 & 77,3 & 82,2 & $-2,5$ & 1,8 & 5,4 \\
\hline Valcirlei Silvã & $-1,1$ & $-5,6$ & 51,2 & 65,3 & 71,4 & $-3,2$ & 7,9 & 12,3 \\
\hline
\end{tabular}




\begin{tabular}{|c|c|c|c|c|c|c|c|c|c|c|c|c|c|}
\hline $\begin{array}{c}\text { NÚMERO } \\
\text { VARIÁVEIS }\end{array}$ & $\begin{array}{l}\text { SNA } \\
\text { SNA I }\end{array}$ & SNA F & SNA PC & $\begin{array}{l}\text { A-Nperp } \\
\text { A-Nperpl }\end{array}$ & A-NperpF & A-NperpPC & $\begin{array}{c}\text { Co-A } \\
\text { Co-A I }\end{array}$ & Co-A F & Co-A PC & $\begin{array}{c}\text { Ar-A } \\
\text { Ar-A I }\end{array}$ & Ar-A F & Ar-A PC & $\begin{array}{l}\text { SNB } \\
\text { SNB I }\end{array}$ \\
\hline 6 & 79,9 & 78 & 77,7 & 4 & 1,3 & 0,4 & 84,4 & 85,3 & 86,7 & 82,1 & 83,1 & 84,7 & 72,3 \\
\hline 20 & 87,3 & 86,5 & 85,1 & 1,8 & 1,2 & $-1,3$ & 82,7 & 81,6 & 80,1 & 81,4 & 81 & 80,2 & 83,7 \\
\hline 23 & 78,1 & 76,2 & 76,7 & $-1,6$ & $-4,1$ & $-4,9$ & 84,5 & 83,7 & 90,3 & 83,3 & 82,5 & 89,9 & 71,2 \\
\hline 39 & 81,7 & 80,5 & 79,9 & 1,5 & 1,7 & 0,1 & 83,6 & 84,2 & 85,9 & 82,3 & 82,4 & 83,6 & 75,4 \\
\hline 51 & 84 & 82,8 & 83,4 & 4,1 & 3,4 & 1,7 & 89,3 & 90 & 91 & 85,6 & 87,6 & 87,4 & 79,6 \\
\hline 59 & 78,3 & 77,1 & 77,7 & $-4,4$ & $-6,8$ & $-3,7$ & 76,4 & 78,1 & 77,7 & 76,4 & 76,2 & 75,1 & 73,7 \\
\hline 81 & 82,2 & 82,1 & 82,3 & $-2,1$ & $-0,6$ & $-1,5$ & 78,4 & 79,5 & 80,6 & 74,2 & 77,4 & 77,9 & 78,7 \\
\hline 104 & 78 & 77,5 & 76,8 & $-2,9$ & $-3,8$ & $-3,9$ & 79,7 & 80,2 & 79,7 & 75,8 & 76,1 & 76 & 76,5 \\
\hline 110 & 82,6 & 80,1 & 79,6 & 4,3 & 0 & 1,4 & 83,9 & 82,6 & 82,8 & 82,3 & 81 & 80,9 & 79,4 \\
\hline 169 & 81,4 & 77,4 & 77,3 & $-2,5$ & $-8,3$ & $-6,5$ & 84,6 & 84,4 & 87,7 & 81,9 & 83,1 & 84,8 & 72,8 \\
\hline 180 & 80,1 & 77,7 & 77,4 & $-1,6$ & $-6,7$ & $-4,4$ & 77 & 79,8 & 81,8 & 75,1 & 76,2 & 77,5 & 76,9 \\
\hline 194 & 84,2 & 83,3 & 82,6 & $-1,5$ & $-3,2$ & $-3,1$ & 78,8 & 84,2 & 89,3 & 77 & 81,1 & 83,8 & 79,9 \\
\hline 219 & 78,4 & 78,9 & 78,3 & $-4,8$ & $-4,3$ & $-4,8$ & 76,6 & 74,5 & 77,2 & 73,9 & 73 & 73,8 & 75,8 \\
\hline 228 & 85,7 & 84,5 & 84,3 & 2,1 & 0,8 & 2,3 & 82,4 & 85,6 & 94,6 & 80,7 & 81,8 & 90,9 & 80,3 \\
\hline 288 & 87,2 & 84,9 & 82,8 & 1 & $-4,7$ & $-0,2$ & 80,6 & 80,9 & 90,1 & 82,4 & 80,3 & 87,7 & 79 \\
\hline EricaMara & 82,9 & 80,9 & 81,3 & $-1,3$ & $-3,8$ & -3 & 81,1 & 81,6 & 83,2 & 77,8 & 76,9 & 82,3 & 78,3 \\
\hline Fabiane Lucl & 80,8 & 80,5 & 81,5 & $-0,4$ & $-2,5$ & 1,1 & 76,5 & 73,8 & 79,1 & 75,6 & 74,5 & 77,6 & 79,8 \\
\hline Martha RP & 83,3 & 82 & 82,3 & 2,1 & 1,4 & 0,9 & 83,7 & 84,5 & 87,1 & 81,4 & 82,3 & 85 & 79,2 \\
\hline Patricia Spac & 84,3 & 82,3 & 84,1 & 7,2 & 4,3 & 6,2 & 91,9 & 90 & 93,9 & 89,5 & 87,1 & 90,5 & 76,3 \\
\hline Renata Perei & 85,4 & 85,7 & 84,8 & 1,5 & 1,6 & 1,9 & 79 & 80,7 & 84,5 & 77,6 & 79,6 & 82,8 & 84,4 \\
\hline Simone Fern & 79,5 & 77,9 & 78 & $-1,4$ & $-1,1$ & $-1,7$ & 89,3 & 87,3 & 90,4 & 88,3 & 86,4 & 89,9 & 72 \\
\hline
\end{tabular}




\begin{tabular}{|c|c|c|c|c|c|c|c|c|c|c|c|c|c|}
\hline \multicolumn{2}{|l|}{ NÚMERO } & \multicolumn{3}{|c|}{ Pg-Nperp } & \multicolumn{3}{|c|}{ Co-Gn } & \multicolumn{3}{|c|}{ Ar-Gn } & \multicolumn{3}{|c|}{ ANB } \\
\hline VARIÁVEIS & SNB F & SNB PC & Pg-Nperpl & Pg-NperpF & Pg-NperpPC & Co-Gn I & Co-Gn F & Co-Gn PC & Ar-Gn I & Ar-Gn F & Ar-Gn PC & ANB I & ANB $F$ \\
\hline 6 & 70,6 & 70,1 & $-4,9$ & $-10,5$ & $-12,7$ & 106,3 & 107,9 & 109,4 & 98,9 & 100,8 & 100,9 & 7,6 & 7,4 \\
\hline 20 & 82,9 & 82,4 & $-0,2$ & $-1,1$ & $-4,5$ & 110,9 & 111,7 & 111,1 & 105,9 & 107,4 & 106,6 & 3,6 & 3,6 \\
\hline 23 & 72,4 & 73,4 & $-13,2$ & $-11,2$ & $-11,5$ & 103,4 & 107,7 & 118,1 & 98,2 & 103,2 & 113,5 & 6,9 & 3,8 \\
\hline 39 & 76,8 & 76,6 & $-8,3$ & $-2,5$ & $-4,1$ & 100,6 & 104,2 & 106,1 & 95,2 & 98,4 & 100,3 & 6,3 & 3,7 \\
\hline 51 & 78,9 & 80 & 0,2 & $-0,3$ & $-1,5$ & 117,4 & 122,3 & 123 & 107,7 & 113,1 & 111,7 & 4,4 & 3,9 \\
\hline 59 & 73,7 & 73,1 & $-17,6$ & $-20,4$ & $-17,2$ & 102,1 & 108,3 & 113 & 96,9 & 100,8 & 102,7 & 4,6 & 3,4 \\
\hline 81 & 78,3 & 78,1 & $-10,7$ & $-7,6$ & $-9,9$ & 109,7 & 110,4 & 112,9 & 100,6 & 102,8 & 104,2 & 3,5 & 3,8 \\
\hline 104 & 76,2 & 75,9 & -8 & $-7,8$ & $-7,5$ & 103,6 & 106 & 106,5 & 94,8 & 96,7 & 97,2 & 1,5 & 1,3 \\
\hline 110 & 79 & 78,7 & 3,7 & 0,5 & 3,5 & 110,3 & 111,6 & 111,9 & 103,3 & 104,7 & 105,4 & 3,2 & 1,1 \\
\hline 169 & 72,3 & 74,1 & $-19,9$ & -22 & $-12,9$ & 105,4 & 113,3 & 123,1 & 95 & 104,6 & 112,1 & 8,6 & 5,1 \\
\hline 180 & 75,5 & 75,1 & $-8,1$ & $-14,6$ & $-10,1$ & 105,7 & 114,3 & 117,2 & 98,1 & 104,6 & 107,3 & 3,2 & 2,2 \\
\hline 194 & 79,6 & 82,5 & $-11,3$ & $-11,7$ & $-2,8$ & 100,7 & 107,9 & 119,8 & 94 & 99,8 & 108,2 & 4,3 & 3,7 \\
\hline 219 & 75,3 & 74,8 & $-12,5$ & $-12,8$ & $-13,3$ & 106 & 104,3 & 107,1 & 99,4 & 98,2 & 99,5 & 2,6 & 3,6 \\
\hline 228 & 80,3 & 80,8 & $-5,5$ & $-4,7$ & 0,1 & 107,8 & 112 & 126,9 & 98,9 & 101,1 & 114,7 & 5,4 & 4,2 \\
\hline 288 & 78,8 & 78,6 & $-10,6$ & $-16,3$ & $-4,7$ & 94,8 & 100,3 & 113 & 92,2 & 96,1 & 106,1 & 8,2 & 6,1 \\
\hline EricaMara & 79 & 78,5 & $-8,8$ & $-7,3$ & $-7,1$ & 107,8 & 110,8 & 114,6 & 99,2 & 102,3 & 109,3 & 4,6 & 1,9 \\
\hline Fabiane Lucl & 79,6 & 80,7 & $-2,9$ & $-5,8$ & 2,3 & 100,6 & 99,8 & 106,2 & 96,3 & 98 & 101,2 & 1 & 0,9 \\
\hline Martha RP & 78,8 & 80 & $-0,8$ & 0,9 & 1,7 & 107,2 & 112,8 & 116,3 & 100,9 & 106,6 & 110,8 & 4,1 & 3,2 \\
\hline Patricia Spac & 77,1 & 77,7 & 0,7 & 0 & 2,1 & 107,7 & 109,5 & 113,1 & 100,5 & 101,8 & 103,8 & 8 & 5,2 \\
\hline Renata Perei & 84 & 81 & 2,1 & 2,1 & $-0,8$ & 100,4 & 104,4 & 107,3 & 95,9 & 99,4 & 101,6 & 1 & 1,7 \\
\hline Simone Fern & 71,3 & 70,6 & $-13,7$ & $-10,1$ & $-12,6$ & 107,8 & 110,3 & 110,7 & 101,3 & 102,8 & 105,4 & 7,5 & 6,6 \\
\hline
\end{tabular}




\begin{tabular}{|c|c|c|c|c|c|c|c|c|c|c|c|c|c|}
\hline \multirow{2}{*}{$\begin{array}{c}\text { NÚMERO } \\
\text { VARIÁVEIS }\end{array}$} & \multicolumn{3}{|c|}{ WITS } & \multicolumn{3}{|c|}{ SN.PP } & \multicolumn{3}{|c|}{ SN.Ocl } & \multicolumn{3}{|c|}{ SN.GoMe } & \multirow[b]{2}{*}{ SN.GoMe PC } \\
\hline & ANB PC & WITS I & WITS F & WITS PC & SN.PP I & SN.PP F & SN.PP PC & SN.Ocl I & SN.Ocl F & SN.Ocl PC & SN.GoMe I & SN.GoMe F & \\
\hline 6 & 7,6 & 4,7 & 4,9 & 4,9 & 13,6 & 13,7 & 13,4 & 21,3 & 24,4 & 24,1 & 38,4 & 41,4 & 42,1 \\
\hline 20 & 2,7 & 1 & 1,8 & $-0,6$ & 6 & 5,8 & 7 & 11,3 & 9,8 & 11,5 & 26,2 & 27,1 & 27,7 \\
\hline 23 & 3,3 & 4,7 & 4,7 & 2,4 & 12,9 & 14,1 & 12,5 & 21,1 & 17,1 & 18,5 & 36 & 35,3 & 32 \\
\hline 39 & 3,3 & 1,2 & 1,3 & 1,9 & 9,5 & 9,5 & 9,7 & 20,5 & 15,8 & 14,8 & 32,8 & 30,6 & 29,7 \\
\hline 51 & 3,4 & $-3,4$ & $-0,4$ & $-1,7$ & 7,3 & 8,7 & 8,6 & 21,1 & 16,6 & 16 & 35,8 & 36,1 & 31,1 \\
\hline 59 & 4,6 & $-4,5$ & 0,8 & $-2,8$ & 6,7 & 7,2 & 7,8 & 28,2 & 19,1 & 25,4 & 45,7 & 46,9 & 49,7 \\
\hline 81 & 4,2 & $-1,4$ & 0,3 & 1,4 & 4,3 & 5,2 & 4,8 & 16,8 & 16 & 14,2 & 41 & 41,2 & 41,8 \\
\hline 104 & 0,9 & $-3,5$ & 1,9 & $-0,1$ & 11,8 & 11,8 & 11,9 & 19,9 & 13,5 & 16,3 & 39,4 & 39,5 & 39,1 \\
\hline 110 & 0,9 & -2 & $-1,6$ & 0 & 7,6 & 9,8 & 9,9 & 16,7 & 15,4 & 12,6 & 34,1 & 33,8 & 33,8 \\
\hline 169 & 3,2 & 4,9 & 6,3 & 5,8 & 3,6 & 9,5 & 8,7 & 21,2 & 16 & 12,8 & 39,3 & 38,6 & 35,7 \\
\hline 180 & 2,3 & $-2,7$ & -1 & $-2,1$ & 4,9 & 6,1 & 7,1 & 21 & 19,1 & 22,4 & 43 & 45,3 & 44,6 \\
\hline 194 & 0,1 & $-2,8$ & $-2,1$ & $-5,2$ & 6,1 & 7,3 & 5,3 & 19,6 & 18,2 & 16,7 & 38,6 & 37,7 & 30,2 \\
\hline 219 & 3,5 & $-8,7$ & $-4,9$ & $-6,3$ & 11,2 & 11,1 & 10,1 & 29 & 26,7 & 29,2 & 43,8 & 43,8 & 43,5 \\
\hline 228 & 3,5 & -5 & $-3,9$ & -2 & 3,5 & 3,8 & 3,6 & 24,2 & 20,4 & 17,6 & 37,3 & 36 & 32,8 \\
\hline 288 & 4,2 & 8,3 & 6,3 & 6,4 & 4,8 & 6,8 & 7,1 & 9,2 & 10,5 & 7,8 & 27,5 & 28,1 & 24,3 \\
\hline EricaMara & 2,8 & $-1,4$ & 1,2 & 0,8 & 6,4 & 7,7 & 6,2 & 20,5 & 11,8 & 15,3 & 39,5 & 39,4 & 38,2 \\
\hline Fabiane Lucl & 0,8 & $-5,7$ & $-6,1$ & $-4,5$ & 9,4 & 9 & 8,6 & 21,3 & 22,1 & 17 & 35,6 & 34,9 & 33 \\
\hline Martha RP & 2,3 & $-0,6$ & 0,2 & $-1,4$ & 8,6 & 8,5 & 8,8 & 19 & 15,5 & 16,6 & 37,8 & 38,5 & 35,9 \\
\hline Patricia Spac & 6,4 & 4,9 & 2,9 & 4,1 & 10,9 & 11,4 & 10,9 & 18,2 & 17,3 & 16 & 27,4 & 26,9 & 24,9 \\
\hline Renata Perei & 3,8 & -5 & $-1,1$ & 0,8 & 6,2 & 3,6 & 6 & 17,3 & 9,4 & 14,2 & 26,3 & 25,8 & 27,8 \\
\hline Simone Fern & 7,4 & 7,6 & 6,6 & 10,1 & 10,7 & 10,2 & 13,2 & 16,7 & 18,9 & 15,8 & 29,2 & 29,9 & 29,7 \\
\hline
\end{tabular}




\begin{tabular}{|c|c|c|c|c|c|c|c|c|c|c|c|c|c|}
\hline NÚMERO & N.S.Gn & & & Ba.N.Gn & & & FMA & & & $\mathrm{N}-\mathrm{Me}$ & & & S-Go \\
\hline VARIÁVEIS & N.S.Gn I & N.S.Gn F & N.S.Gn PC & Ba.N.Gn I & Ba.N.Gn F & Ba.N.Gn PC & FMA I & FMA F & FMA PC & $\mathrm{N}-\mathrm{Me} \mathrm{I}$ & $\mathrm{N}-\mathrm{Me} \mathrm{F}$ & $\mathrm{N}-\mathrm{Me} \mathrm{PC}$ & S-GoI \\
\hline 6 & 74,2 & 77 & 77,3 & 89,1 & 84,2 & 85,8 & 24,2 & 28,1 & 29,4 & 109,7 & 115,8 & 118,1 & 69,2 \\
\hline 20 & 64,1 & 65 & 65,9 & 90,5 & 88,8 & 89,2 & 21,5 & 22,4 & 24,2 & 110,8 & 114,6 & 114,8 & 84,7 \\
\hline 23 & 73,7 & 73,5 & 72,5 & 85,7 & 85,9 & 86,6 & 25,7 & 25,2 & 22,8 & 112,2 & 118,2 & 126,6 & 75,6 \\
\hline 39 & 70,3 & 68,2 & 67,9 & 87,7 & 89,5 & 89,6 & 22,8 & 19,2 & 19,6 & 103,9 & 104,4 & 105,1 & 70,9 \\
\hline 51 & 68,7 & 69,7 & 67,3 & 88,1 & 86,6 & 91,1 & 25,5 & 25,4 & 22,8 & 117,9 & 125,2 & 120,8 & 78,3 \\
\hline 59 & 73,9 & 75,5 & 77,8 & 82 & 80,6 & 77,4 & 38,7 & 41 & 41,2 & 113,7 & 121,9 & 126,1 & 67,9 \\
\hline 81 & 69,2 & 69,6 & 69,3 & 85,4 & 86,3 & 86,1 & 35,7 & 34 & 35,7 & 112,2 & 115,1 & 116,5 & 75,4 \\
\hline 104 & 71 & 70,1 & 70,2 & 85 & 85,6 & 85,5 & 30,6 & 30,8 & 30 & 108,5 & 110,5 & 109,9 & 71,2 \\
\hline 110 & 67,3 & 67 & 67,2 & 92,8 & 91,9 & 91,8 & 22,2 & 23,9 & 21,9 & 110,1 & 111,8 & 111,4 & 74,1 \\
\hline 169 & 73,1 & 73,7 & 72,1 & 81,5 & 79,9 & 83,6 & 33,2 & 33,4 & 28,5 & 117,7 & 129,6 & 134,5 & 76 \\
\hline 180 & 73,4 & 75,4 & 75,4 & 80,3 & 80,1 & 80,4 & 34,8 & 39,1 & 35,9 & 117 & 128,1 & 131,1 & 75,1 \\
\hline 194 & 66,5 & 67,4 & 63,8 & 87,2 & 85,8 & 89,8 & 34,7 & 34,3 & 26 & 103,9 & 110,8 & 115,2 & 70,8 \\
\hline 219 & 72,6 & 73,7 & 73,4 & 84,4 & 81,4 & 82 & 37,5 & 37,2 & 36,9 & 114,7 & 116 & 116,7 & 72,9 \\
\hline 228 & 66,6 & 66,1 & 66,7 & 87,3 & 87,3 & 87,4 & 30,7 & 29,7 & 25 & 110,9 & 111,2 & 127,1 & 69,6 \\
\hline 288 & 63,6 & 64,5 & 64,1 & 90,8 & 89 & 89,8 & 23,6 & 27,5 & 17,3 & 100,7 & 109,5 & 114,4 & 75 \\
\hline EricaMara & 68 & 67,5 & 67,6 & 86,9 & 86,9 & 89,1 & 33,9 & 34,2 & 32,5 & 108,8 & 112,5 & 118,2 & 66,4 \\
\hline Fabiane Lucl & 66,2 & 66,3 & 65,1 & 90,4 & 89,7 & 92,6 & 26,9 & 28,3 & 23,3 & 100,6 & 102,5 & 103,3 & 65,4 \\
\hline Martha RP & 68 & 68,3 & 67,7 & 89 & 88,8 & 89,2 & 28,9 & 29 & 27,3 & 106,1 & 112,4 & 114,3 & 69,3 \\
\hline Patricia Spac & 68,1 & 67,7 & 66,8 & 94,4 & 95,2 & 95,1 & 14,2 & 14,9 & 12,8 & 104,8 & 105,6 & 107,1 & 74,9 \\
\hline Renata Perei & 61,6 & 62,2 & 64,3 & 93,5 & 92,1 & 89,8 & 20 & 19,7 & 20,5 & 96,3 & 100,3 & 106,8 & 73,3 \\
\hline Simone Fern & 72,7 & 73,5 & 74,3 & 88,4 & 87,7 & 86,7 & 20,2 & 19 & 19,2 & 113,4 & 116,3 & 119,5 & 82,6 \\
\hline
\end{tabular}




\begin{tabular}{|c|c|c|c|c|c|c|c|c|c|c|c|c|c|}
\hline \multirow{2}{*}{$\begin{array}{c}\text { NÚMERO } \\
\text { VARIÁVEIS }\end{array}$} & \multirow[b]{2}{*}{ S-Go F } & \multicolumn{3}{|c|}{ AFP:AFA } & \multicolumn{3}{|c|}{ AFAI } & \multicolumn{3}{|c|}{$1 \mathrm{~s} . \mathrm{SN}$} & \multicolumn{3}{|c|}{ 1.NA } \\
\hline & & S-Go PC & AFP:AFA I & AFP:AFA F & AFP:AFA PC & AFAII & AFAI F & AFAI PC & 1s.SN I & 1s.SN F & 1s.SN PC & 1.NAI & 1.NA F \\
\hline 6 & 70,4 & 71,4 & 63,1 & 60,8 & 60,4 & 61,9 & 66,9 & 69,2 & 102,5 & 94,9 & 88,9 & 22,6 & 16,8 \\
\hline 20 & 86,5 & 86,7 & 76,4 & 75,5 & 75,5 & 64,8 & 67,5 & 68,2 & 106,4 & 108,1 & 100,2 & 19,1 & 21,6 \\
\hline 23 & 81,4 & 90,4 & 67,4 & 68,8 & 71,4 & 63,3 & 68 & 71,8 & 102,9 & 100,4 & 97,2 & 24,8 & 24,2 \\
\hline 39 & 73 & 74,1 & 68,2 & 70 & 70,5 & 59,5 & 58,1 & 58,3 & 107,2 & 104,7 & 101,8 & 25,5 & 24,2 \\
\hline 51 & 84,7 & 85,4 & 66,4 & 67,7 & 70,7 & 69,3 & 75,1 & 70,9 & 107 & 106,1 & 105,9 & 23,1 & 23,4 \\
\hline 59 & 71,2 & 72,4 & 59,8 & 58,4 & 57,4 & 70 & 75,9 & 80,8 & 111,5 & 106 & 109 & 33,2 & 28,9 \\
\hline 81 & 78,1 & 75,6 & 67,1 & 67,9 & 64,9 & 68,3 & 69,7 & 70,8 & 111 & 98,2 & 100 & 28,7 & 16 \\
\hline 104 & 71,5 & 71,1 & 65,6 & 64,7 & 64,7 & 63,1 & 64,1 & 63,4 & 103,4 & 98,5 & 100,8 & 25,4 & 21 \\
\hline 110 & 76,3 & 76,3 & 67,3 & 68,3 & 68,5 & 64,2 & 62,7 & 63,4 & 115,7 & 104,1 & 107,3 & 33,1 & 24 \\
\hline 169 & 87,8 & 95,8 & 64,5 & 67,8 & 71,2 & 72,4 & 75,4 & 77,7 & 115,5 & 98,5 & 107,1 & 34,1 & 21,1 \\
\hline 180 & 83,2 & 87,2 & 64,2 & 65 & 66,5 & 69,1 & 77,9 & 78,9 & 110,6 & 108,8 & 109,6 & 30,5 & 31,1 \\
\hline 194 & 73,2 & 83,5 & 68,1 & 66,1 & 72,5 & 64,3 & 68,2 & 67,9 & 106,1 & 106,1 & 112,7 & 21,9 & 22,8 \\
\hline 219 & 74,4 & 76,1 & 63,5 & 64,2 & 65,2 & 67,6 & 70 & 69,7 & 102,4 & 91,4 & 90,4 & 24 & 12,5 \\
\hline 228 & 72,4 & 88,6 & 62,7 & 65,1 & 69,7 & 67,3 & 67,8 & 77,4 & 119,9 & 110,1 & 109,2 & 34,2 & 25,6 \\
\hline 288 & 81,1 & 88,6 & 74,5 & 74,1 & 77,5 & 58,5 & 63,5 & 65 & 107,9 & 106,1 & 101,4 & 20,7 & 21,2 \\
\hline EricaMara & 72,2 & 75,8 & 61 & 64,2 & 64,1 & 64 & 65,6 & 69,2 & 104,3 & 110 & 107,8 & 21,4 & 29,1 \\
\hline Fabiane Lucl & 68,6 & 71,1 & 65,1 & 66,9 & 68,8 & 56,4 & 58 & 57,8 & 112,2 & 102,3 & 109,7 & 31,4 & 21,8 \\
\hline Martha RP & 74,4 & 77,7 & 65,3 & 66,2 & 68 & 59,5 & 63,7 & 64,3 & 94,3 & 97,7 & 96,6 & 11 & 15,7 \\
\hline Patricia Spac & 76,5 & 79,6 & 71,5 & 72,5 & 74,3 & 55,4 & 56,2 & 58,2 & 112,3 & 109,4 & 116,8 & 28,1 & 27,1 \\
\hline Renata Perei & 76,5 & 79,6 & 76,1 & 76,3 & 74,6 & 52,1 & 55,8 & 60 & 110,5 & 107,9 & 97,6 & 25 & 22,1 \\
\hline Simone Fern & 84,5 & 87,2 & 72,8 & 72,6 & 72,9 & 64,9 & 66,6 & 68 & 110,8 & 91,1 & 93,6 & 31,3 & 13,1 \\
\hline
\end{tabular}




\begin{tabular}{|c|c|c|c|c|c|c|c|c|c|c|c|c|c|}
\hline \multirow{2}{*}{$\begin{array}{c}\text { NÚMERO } \\
\text { VARIÁVEIS }\end{array}$} & \multirow[b]{2}{*}{ 1.NA PC } & \multirow{2}{*}{$\begin{array}{c}\text { 1-NA } \\
\text { 1-NA I }\end{array}$} & \multirow[b]{2}{*}{ 1-NA F } & \multicolumn{3}{|c|}{ 1.NB } & \multicolumn{3}{|c|}{ 1-NB } & \multicolumn{3}{|c|}{ FMAI } & \multirow[b]{2}{*}{ FMIA PC } \\
\hline & & & & 1-NA PC & 1.NB I & 1.NB F & 1.NB PC & 1-NB I & 1-NB F & 1-NB PC & FMIA I & FMIA F & \\
\hline 6 & 11,2 & 3,6 & $-0,7$ & $-0,8$ & 29,4 & 25,1 & 26,6 & 4,9 & 5,7 & 5,7 & 57,1 & 58,7 & 56,2 \\
\hline 20 & 15,1 & 1,9 & 1,3 & 1,7 & 27,6 & 18,2 & 14 & 5,9 & 3 & 1,7 & 60,6 & 69,4 & 72 \\
\hline 23 & 20,5 & 4,2 & 1,8 & 1,3 & 28 & 16,8 & 17,4 & 6,1 & 3,2 & 2,5 & 53,4 & 65,7 & 65,1 \\
\hline 39 & 21,9 & 6,4 & 1,3 & 3,1 & 35,3 & 19,7 & 17 & 8,5 & 3 & 3,6 & 50,1 & 68,5 & 69,7 \\
\hline 51 & 22,5 & 3,7 & 2 & 2,2 & 25,2 & 26,3 & 19,9 & 5,4 & 4,1 & 3 & 64,8 & 63,2 & 68,5 \\
\hline 59 & 31,3 & 5,9 & 8,1 & 8,7 & 30,2 & 27,9 & 34,3 & 9,9 & 9,6 & 11,6 & 50,5 & 51,7 & 47,2 \\
\hline 81 & 17,7 & 7,5 & 3 & 4,2 & 34,1 & 22,5 & 26,7 & 8,7 & 5,1 & 6,7 & 49,9 & 63 & 57,4 \\
\hline 104 & 24 & 3,3 & 1 & 2,2 & 20,4 & 9,7 & 15,2 & 3,1 & 0,3 & 1,1 & 65 & 75,3 & 69,8 \\
\hline 110 & 27,8 & 7,2 & 2,8 & 4,2 & 26 & 15 & 20,7 & 5,7 & 1,1 & 1,9 & 65,4 & 73,8 & 70 \\
\hline 169 & 29,8 & 11,9 & $-0,8$ & 5 & 31,7 & 22,1 & 22,6 & 11,7 & 4,3 & 5,4 & 47,2 & 55,4 & 58,7 \\
\hline 180 & 32,2 & 7,8 & 7,1 & 8,2 & 25 & 25,4 & 24,3 & 5,8 & 5,7 & 6 & 60,1 & 56,4 & 59,5 \\
\hline 194 & 30,2 & 4,1 & 1,8 & 6,8 & 28,4 & 25,7 & 27,9 & 5,4 & 4,1 & 4 & 55,3 & 57,2 & 58,8 \\
\hline 219 & 12,1 & 5,7 & 1,7 & 2,2 & 19,4 & 18,1 & 16,6 & 3,3 & 3,1 & 3,1 & 62,7 & 63,7 & 64,8 \\
\hline 228 & 24,9 & 7 & 2,9 & 3,8 & 30,5 & 29,6 & 27,5 & 7,1 & 6,2 & 6,5 & 56,4 & 57 & 61,1 \\
\hline 288 & 18,6 & 4,3 & 0,6 & 2,2 & 39,9 & 26,5 & 21,5 & 10,2 & 5,9 & 4,6 & 43,1 & 52,9 & 64,1 \\
\hline EricaMara & 26,5 & 4,6 & 2,1 & 3,2 & 26,4 & 18,4 & 28,1 & 5,1 & 1,5 & 3,5 & 57,6 & 65,8 & 56,1 \\
\hline Fabiane Lucl & 28,2 & 5,9 & 4,1 & 5,7 & 30,3 & 26,1 & 27 & 4,9 & 2,7 & 4,2 & 58,3 & 60 & 63,4 \\
\hline Martha RP & 14,3 & 0,5 & 1,2 & 1,6 & 14,1 & 22,4 & 9,1 & 1,6 & 4,1 & 1,3 & 74 & 65,8 & 79,5 \\
\hline Patricia Spac & 32,7 & 4,7 & 2 & 4,2 & 24,4 & 37 & 29,2 & 5,3 & 5 & 5,8 & 65,1 & 52,1 & 60,6 \\
\hline Renata Perei & 12,9 & 4,3 & 2,8 & 1,8 & 26,7 & 29,6 & 26,1 & 2,4 & 3,2 & 3,1 & 64,1 & 60,5 & 62,2 \\
\hline Simone Fern & 15,6 & 8,7 & 0,8 & 2 & 38,5 & 31,3 & 26,5 & 10,1 & 6,3 & 6,1 & 42,6 & 51 & 54,5 \\
\hline
\end{tabular}




\begin{tabular}{|c|c|c|c|c|c|c|c|c|c|c|c|c|c|}
\hline $\begin{array}{l}\text { NÚMERO } \\
\text { VARIÁVEIS }\end{array}$ & $\begin{array}{l}\text { IMPA } \\
\text { IMPA | }\end{array}$ & IMPA F & IMPA PC & $\begin{array}{l}\text { 1i-APg } \\
1 \mathrm{i}-\mathrm{Apg} \mathrm{I}\end{array}$ & $1 \mathrm{i}-\mathrm{APg} \mathrm{F}$ & 1i-APg PC & $\begin{array}{c}1.1 \\
1.1 \mathrm{I}\end{array}$ & $1.1 \mathrm{~F}$ & 1.1 PC & $\begin{array}{l}\text { Ls-E } \\
\text { Ls-E I }\end{array}$ & Ls-E F & Ls-E PC & $\begin{array}{l}\text { Li-E } \\
\text { Li-E }\end{array}$ \\
\hline 6 & 98,7 & 93,2 & 94,4 & $-0,4$ & 0,1 & $-0,3$ & 120,3 & 130,6 & 134,6 & $-0,2$ & $-4,9$ & $-4,9$ & 0,6 \\
\hline 20 & 97,8 & 88,2 & 83,8 & 2,6 & $-0,5$ & $-1,1$ & 129,6 & 136,6 & 148,2 & $-5,2$ & $-5,7$ & $-8,1$ & $-1,6$ \\
\hline 23 & 100,9 & 89,1 & 92 & 0,6 & $-0,6$ & $-1,4$ & 120,2 & 135,2 & 138,8 & $-2,1$ & $-6,1$ & -10 & $-0,8$ \\
\hline 39 & 107 & 92,3 & 90,7 & 5 & 0,6 & 1,1 & 112,9 & 132,4 & 137,7 & 1,9 & $-3,1$ & $-3,4$ & 3,8 \\
\hline 51 & 89,7 & 91,4 & 88,8 & 2,6 & 1,3 & 0,2 & 127,4 & 126,4 & 134,2 & 0,1 & $-0,5$ & $-4,3$ & 0,1 \\
\hline 59 & 90,8 & 87,3 & 91,6 & 7,1 & 7,3 & 8,9 & 112 & 119,8 & 109,8 & -2 & -3 & $-2,1$ & 2,4 \\
\hline 81 & 94,4 & 83,1 & 86,9 & 6,5 & 2,5 & 3,8 & 113,6 & 137,6 & 131,4 & $-0,8$ & $-2,3$ & $-2,5$ & 1 \\
\hline 104 & 84,5 & 73,9 & 80,2 & 2,1 & -1 & $-0,1$ & 132,7 & 148,1 & 139,9 & $-3,5$ & $-4,6$ & $-4,6$ & $-1,6$ \\
\hline 110 & 92,5 & 82,3 & 88,1 & 3,4 & $-0,6$ & 0,6 & 117,7 & 139,8 & 130,8 & $-1,8$ & $-6,4$ & $-5,9$ & 0 \\
\hline 169 & 99,6 & 91,2 & 92,8 & 5,2 & $-1,1$ & 0,8 & 105,6 & 131,7 & 124,5 & 3,3 & $-5,9$ & $-8,3$ & 4,8 \\
\hline 180 & 85,1 & 84,5 & 84,6 & 3,4 & 3,1 & 3,1 & 121,3 & 121,3 & 121,2 & 0,7 & $-4,3$ & -6 & 0,9 \\
\hline 194 & 90 & 88,5 & 95,3 & 3,5 & 1,3 & 2,7 & 125,3 & 127,8 & 121,8 & 1,5 & $-0,4$ & -4 & 1,6 \\
\hline 219 & 79,8 & 79,1 & 78,3 & 0,9 & $-0,1$ & $-0,3$ & 134 & 145,8 & 147,8 & $-3,7$ & $-4,7$ & $-4,7$ & $-2,7$ \\
\hline 228 & 92,9 & 93,3 & 93,9 & 4,1 & 3 & 3 & 109,9 & 120,5 & 124,1 & 3 & $-0,7$ & -3 & 5,9 \\
\hline 288 & 113,3 & 99,6 & 98,6 & 5,7 & 0,9 & 0,4 & 111,2 & 126,2 & 135,7 & 2,6 & $-1,6$ & $-4,6$ & 3,3 \\
\hline EricaMara & 88,5 & 80 & 91,4 & 1,6 & -1 & 0,2 & 127,6 & 130,6 & 122,6 & $-1,7$ & $-4,2$ & $-6,7$ & $-1,2$ \\
\hline Fabiane Lucl & 94,9 & 91,6 & 93,2 & 4,5 & 1,9 & 3,1 & 117,3 & 131,2 & 124 & $-2,7$ & $-4,1$ & $-4,4$ & 0,6 \\
\hline Martha RP & 77,1 & 85,2 & 73,2 & $-1,9$ & 0,7 & $-1,6$ & 150,8 & 138,7 & 154,3 & $-2,8$ & $-5,1$ & $-6,7$ & $-3,5$ \\
\hline Patricia Spac & 100,7 & 113 & 106,6 & $-0,7$ & 0,9 & 0,7 & 119,6 & 110,7 & 111,7 & $-1,9$ & $-4,6$ & $-3,2$ & $-3,7$ \\
\hline Renata Perei & 96 & 99,8 & 97,3 & 1,6 & 1,6 & 0,1 & 127,3 & 126,5 & 137,2 & -2 & $-3,5$ & $-5,7$ & $-2,2$ \\
\hline Simone Fern & 117,2 & 110 & 106,3 & 4,1 & 0,6 & $-0,9$ & 102,7 & 129 & 130,5 & 0,2 & $-4,2$ & $-3,5$ & 1,6 \\
\hline
\end{tabular}




\begin{tabular}{|c|c|c|c|c|c|c|c|c|}
\hline \multirow{2}{*}{$\begin{array}{l}\text { NÚMERO } \\
\text { VARIÁVEIS }\end{array}$} & \multirow[b]{2}{*}{ Li-E F } & \multirow[b]{2}{*}{ Li-E PC } & \multicolumn{2}{|l|}{$\mathbf{Z}$} & \multicolumn{3}{|c|}{ H-Pn } & \multirow[b]{2}{*}{ H-Pn PC } \\
\hline & & & $\mathrm{ZI}$ & $\mathrm{ZF}$ & $\mathrm{ZPC}$ & H-Pn I & H-Pn F & \\
\hline 6 & $-1,1$ & -1 & 67,9 & 68,6 & 66,1 & 0,4 & 9,5 & 9,6 \\
\hline 20 & $-3,4$ & $-5,8$ & 75,7 & 78,6 & 83 & 9,1 & 9,9 & 14,1 \\
\hline 23 & $-4,8$ & $-9,8$ & 64,4 & 72 & 76,4 & 3,4 & 10,6 & 16,8 \\
\hline 39 & -2 & $-1,8$ & 56,9 & 77,5 & 75 & $-3,2$ & 5,5 & 6,2 \\
\hline 51 & $-1,2$ & $-4,8$ & 72,6 & 74,5 & 77,6 & $-0,1$ & 0,8 & 7,2 \\
\hline 59 & 2,4 & 4 & 61,7 & 59,6 & 58,6 & 3,4 & 5,1 & 3,6 \\
\hline 81 & $-1,1$ & $-0,5$ & 68,4 & 74,3 & 72,4 & 1,4 & 4 & 4,3 \\
\hline 104 & $-3,7$ & $-2,8$ & 73,9 & 77,7 & 76,4 & 6 & 7,9 & 7,6 \\
\hline 110 & $-4,9$ & $-4,3$ & 75,6 & 85,9 & 86 & 3 & 11,5 & 10,8 \\
\hline 169 & -2 & $-4,1$ & 56,6 & 64,2 & 72,7 & $-4,9$ & 11,3 & 14,4 \\
\hline 180 & 0,2 & $-3,5$ & 66,9 & 63,3 & 73,6 & $-1,2$ & 6,8 & 9,9 \\
\hline 194 & $-0,6$ & $-6,1$ & 63,9 & 68,7 & 76,8 & $-2,6$ & 0,8 & 6,6 \\
\hline 219 & $-2,9$ & $-3,4$ & 72,8 & 73,6 & 73,7 & 5,8 & 7,9 & 7,5 \\
\hline 228 & 1,9 & $-2,7$ & 60,8 & 67,3 & 79,3 & $-4,6$ & 1,2 & 4,9 \\
\hline 288 & -1 & -4 & 58,2 & 61,1 & 73,9 & $-4,4$ & 3 & 8,2 \\
\hline EricaMara & $-3,9$ & $-5,8$ & 71 & 76,8 & 85,2 & 3 & 7,4 & 12 \\
\hline Fabiane Lucl & $-2,4$ & $-2,3$ & 66,3 & 72,8 & 75,9 & 4,6 & 7,2 & 7,6 \\
\hline Martha RP & $-4,9$ & -6 & 76,1 & 80,3 & 87,1 & 5 & 8,9 & 12 \\
\hline Patricia Spac & -5 & $-5,5$ & 72,5 & 77,8 & 76 & 3,8 & 8,6 & 6,6 \\
\hline Renata Perei & $-3,3$ & $-3,8$ & 81,9 & 81,4 & 83,8 & 3,7 & 6,4 & 11,3 \\
\hline Simone Fern & $-1,8$ & $-2,3$ & 61,9 & 69,4 & 70,7 & $-0,2$ & 7 & 6 \\
\hline
\end{tabular}




\begin{tabular}{|c|c|c|c|c|c|c|c|c|c|c|c|c|c|}
\hline $\begin{array}{c}\text { NÚMERO } \\
\text { VARIÁVEIS }\end{array}$ & $\begin{array}{l}\text { SNA } \\
\text { SNA I }\end{array}$ & SNA F & SNA PC & $\begin{array}{l}\text { A-Nperp } \\
\text { A-Nperpl }\end{array}$ & A-NperpF & A-NperpPC & $\begin{array}{l}\text { Co-A } \\
\text { Co-A I }\end{array}$ & Co-A F & Co-A PC & $\begin{array}{c}\text { Ar-A } \\
\text { Ar-A I }\end{array}$ & Ar-A F & Ar-A PC & $\begin{array}{l}\text { SNB } \\
\text { SNB I }\end{array}$ \\
\hline 10 & 79,9 & 79,1 & 78 & 1,5 & $-0,9$ & 1,7 & 79,7 & 78,4 & 80,2 & 76,7 & 77,2 & 76,9 & 73,1 \\
\hline 25 & 83 & 81,6 & 81 & $-2,2$ & -1 & 0,8 & 84,3 & 83,7 & 85,9 & 81,1 & 80,4 & 80,8 & 78,8 \\
\hline 42 & 84,5 & 80,5 & 82,6 & 1,1 & $-2,1$ & $-0,7$ & 80,8 & 78,7 & 80,9 & 79,5 & 76,5 & 79,9 & 75,3 \\
\hline 60 & 80,8 & 77,7 & 77,8 & 1,4 & $-1,8$ & -2 & 79,5 & 80,3 & 80,2 & 78,2 & 78,8 & 78,9 & 73,9 \\
\hline 75 & 80,9 & 81,7 & 80,8 & 0,9 & 0,1 & 1 & 81,8 & 85 & 86,6 & 82,3 & 86,5 & 86,2 & 75,3 \\
\hline 83 & 86,1 & 81,6 & 82,7 & 1,6 & $-4,7$ & $-5,7$ & 84,5 & 84,6 & 90 & 81 & 80,9 & 88,9 & 79,2 \\
\hline 103 & 82,4 & 80,2 & 81,6 & $-0,6$ & $-3,7$ & $-3,6$ & 82,8 & 85,6 & 90,1 & 82,4 & 82,7 & 87,5 & 76,2 \\
\hline 112 & 82,4 & 80,6 & 81,6 & 0,7 & 1,1 & 1,2 & 84,8 & 86,9 & 92,6 & 83,5 & 84,2 & 89,5 & 77,5 \\
\hline 117 & 83,7 & 85,2 & 85,4 & 2,6 & 4,5 & 4,4 & 84,3 & 90,4 & 91,5 & 81,3 & 87 & 90 & 80,6 \\
\hline 121 & 80,3 & 79,5 & 78,9 & 0,2 & $-1,5$ & 0 & 86,8 & 90,5 & 89,5 & 86,6 & 90,9 & 89,7 & 75,4 \\
\hline 123 & 86,8 & 83,9 & 85,1 & 4,2 & 0,1 & 0,8 & 93,4 & 94,4 & 93,4 & 92,7 & 94,5 & 92,8 & 82,3 \\
\hline 142 & 85,2 & 82,9 & 81,2 & 2,9 & $-7,9$ & $-1,2$ & 91,1 & 90,7 & 94,8 & 88,9 & 89,7 & 92,9 & 76,2 \\
\hline 146 & 84,7 & 83,6 & 84,5 & 4,3 & $-1,2$ & 0,4 & 92 & 92,3 & 92,4 & 88,6 & 89,5 & 91,9 & 78,2 \\
\hline 174 & 81,5 & 79,5 & 77,1 & $-1,8$ & $-6,7$ & $-5,3$ & 83,1 & 83,9 & 85,6 & 82,3 & 80,7 & 82,9 & 75,7 \\
\hline 221 & 82,2 & 81,3 & 81,2 & -2 & $-1,6$ & $-1,7$ & 78,9 & 77,8 & 83,5 & 79,3 & 77,5 & 83,4 & 77,5 \\
\hline 229 & 80,7 & 78,6 & 78,9 & $-2,5$ & $-4,9$ & -3 & 78,9 & 75,4 & 78,7 & 75,2 & 74 & 74,5 & 75 \\
\hline 236 & 82,7 & 80,6 & 80,5 & 4,7 & 4,2 & 4,1 & 89,7 & 89,1 & 93 & 86,8 & 85,6 & 90,6 & 76,7 \\
\hline 316 & 84,6 & 85,1 & 86,3 & 0,1 & 1,6 & 4,2 & 76,7 & 82 & 84,7 & 77 & 80 & 84,1 & 80,1 \\
\hline 330 & 84,6 & 84,5 & 87,1 & 3,9 & 1,9 & 2,6 & 81 & 86,2 & 88,6 & 80,9 & 85,9 & 86,9 & 76,5 \\
\hline 385 & 81,9 & 76,2 & 76,9 & $-2,8$ & $-6,7$ & $-6,6$ & 79,6 & 78,2 & 86,6 & 77,9 & 76,2 & 84,4 & 75,4 \\
\hline 474 & 82,8 & 79,3 & 80,4 & 4,8 & 2,7 & 4,3 & 81,9 & 85,8 & 87,8 & 80 & 83,4 & 84 & 73,6 \\
\hline Alexandra Pi & 82,8 & 81,4 & 80,9 & 5,6 & 6,2 & 1,1 & 81,4 & 83,5 & 84,3 & 79,2 & 80 & 82,6 & 78,5 \\
\hline Edilson Medi & 84,6 & 82,3 & 85,6 & $-0,8$ & $-3,7$ & $-0,2$ & 86,1 & 88,4 & 92 & 84,2 & 86,6 & 90,5 & 78,4 \\
\hline Eliza Papass & 80,9 & 79,3 & 79,3 & $-1,2$ & $-0,2$ & $-1,2$ & 80,3 & 83,2 & 82,6 & 77,7 & 78,8 & 80,9 & 75,8 \\
\hline Fernanda Lo & 84,5 & 81,2 & 82,8 & $-1,1$ & $-1,9$ & $-0,4$ & 82,5 & 84,4 & 85,5 & 81,8 & 83 & 85,1 & 78,4 \\
\hline Jose Mascar & 84,8 & 82 & 81,3 & $-0,5$ & $-3,3$ & $-4,3$ & 89,7 & 91,5 & 98,5 & 86,5 & 88,3 & 95,4 & 79,5 \\
\hline Juliana Attuy & 81,3 & 80,8 & 80,3 & $-0,5$ & $-0,7$ & 1,5 & 80,9 & 80,6 & 81,9 & 77,4 & 77 & 78,7 & 77,1 \\
\hline
\end{tabular}




\begin{tabular}{|c|c|c|c|c|c|c|c|c|c|c|c|c|c|}
\hline \multicolumn{2}{|l|}{ NÚMERO } & \multicolumn{3}{|c|}{ Pg-Nperp } & \multicolumn{3}{|c|}{ Co-Gn } & \multicolumn{3}{|c|}{ Ar-Gn } & \multicolumn{3}{|c|}{ ANB } \\
\hline VARIÁVEIS & SNB F & SNB PC & Pg-Nperpl & Pg-NperpF & Pg-NperpPC & Co-Gn I & Co-Gn F & Co-Gn PC & Ar-Gn I & Ar-Gn F & Ar-Gn PC & ANB I & ANB $F$ \\
\hline 10 & 73,5 & 71,2 & $-8,6$ & $-10,5$ & $-7,6$ & 102,7 & 104,7 & 106,3 & 95,3 & 98,5 & 97,1 & 6,8 & 5,6 \\
\hline 25 & 78,2 & 76,3 & -8 & $-4,7$ & $-3,3$ & 110,1 & 112,8 & 115,6 & 100,8 & 103 & 101,9 & 4,2 & 3,4 \\
\hline 42 & 73,6 & 75,3 & -15 & $-15,7$ & $-14,6$ & 97,1 & 99,5 & 101,1 & 90,6 & 91,7 & 95,3 & 9,2 & 6,9 \\
\hline 60 & 72,2 & 72,5 & $-9,9$ & $-12,5$ & $-13,2$ & 94,5 & 99,8 & 101,2 & 89,7 & 93,7 & 94,7 & 6,9 & 5,5 \\
\hline 75 & 75,7 & 74,8 & $-6,7$ & $-8,5$ & $-7,1$ & 114,8 & 119,1 & 120,9 & 106,8 & 111,5 & 112,2 & 5,6 & 6 \\
\hline 83 & 79,3 & 79,5 & $-5,7$ & $-8,6$ & -10 & 101,8 & 108,4 & 114,7 & 93 & 100,6 & 110,4 & 6,9 & 2,3 \\
\hline 103 & 77,1 & 79,9 & $-12,8$ & $-10,6$ & $-7,1$ & 106,7 & 115,8 & 125 & 99 & 107,4 & 117 & 6,2 & 3,1 \\
\hline 112 & 78,3 & 78,7 & $-6,6$ & $-0,3$ & $-0,8$ & 104,1 & 110,7 & 117,5 & 99,2 & 103,9 & 110,6 & 4,9 & 2,3 \\
\hline 117 & 82,3 & 83,3 & 0 & 4,1 & 5,2 & 105,3 & 114,5 & 116,4 & 97,2 & 105,8 & 109,6 & 3,1 & 2,9 \\
\hline 121 & 75,5 & 75,6 & $-9,4$ & $-10,4$ & $-6,8$ & 111 & 118,9 & 120,7 & 105,2 & 114,3 & 115,7 & 4,9 & 4 \\
\hline 123 & 82,3 & 85,2 & 0,6 & 0,9 & 6,1 & 109,1 & 116,9 & 118 & 104,3 & 113,4 & 113,3 & 4,5 & 1,6 \\
\hline 142 & 77,2 & 75,7 & $-11,8$ & $-26,1$ & $-13,8$ & 110,8 & 116,4 & 121 & 101,3 & 110,2 & 112,5 & 9 & 5,7 \\
\hline 146 & 79,5 & 79,9 & $-3,3$ & $-7,2$ & -4 & 118,6 & 123 & 125,4 & 110 & 115,6 & 120,8 & 6,5 & 4,1 \\
\hline 174 & 75,9 & 73,6 & $-14,7$ & $-18,1$ & $-14,2$ & 105,5 & 109,8 & 112,8 & 99,1 & 100,9 & 103 & 5,8 & 3,6 \\
\hline 221 & 78,5 & 78,2 & $-11,3$ & $-7,2$ & $-8,1$ & 97,5 & 100,7 & 108,8 & 94,6 & 97,8 & 105,5 & 4,7 & 2,8 \\
\hline 229 & 74,8 & 75 & $-13,1$ & $-14,5$ & $-10,5$ & 105,2 & 104,5 & 109,6 & 94,9 & 96,1 & 98,2 & 5,7 & 3,8 \\
\hline 236 & 76,7 & 76,6 & $-1,5$ & 2,2 & 2,4 & 113,4 & 115 & 122,3 & 104,5 & 106,5 & 113 & 6 & 3,9 \\
\hline 316 & 82,3 & 84,3 & $-6,9$ & 0,6 & 8,3 & 102 & 109,6 & 117 & 97,8 & 103,1 & 111,9 & 4,5 & 2,8 \\
\hline 330 & 76,8 & 78,6 & $-6,8$ & $-10,8$ & $-11,4$ & 103,8 & 114,4 & 120,7 & 99,4 & 109,6 & 112,5 & 8,1 & 7,7 \\
\hline 385 & 73,8 & 72,3 & $-13,7$ & $-12,5$ & $-16,8$ & 99,2 & 103,2 & 114,7 & 93 & 97,3 & 107,5 & 6,5 & 2,4 \\
\hline 474 & 75,4 & 76,8 & $-6,5$ & $-1,1$ & 2,7 & 104,6 & 114,9 & 118 & 94,6 & 104,7 & 105 & 9,2 & 3,9 \\
\hline Alexandra Pi & 77,9 & 75,6 & 7,1 & 10 & $-2,1$ & 105,8 & 108,7 & 110,3 & 98,7 & 100,7 & 103,5 & 4,3 & 3,5 \\
\hline Edilson Med & 77,8 & 81,6 & $-11,3$ & $-13,8$ & $-6,8$ & 110,3 & 117,7 & 122,7 & 103,4 & 110,2 & 115,3 & 6,2 & 4,5 \\
\hline Eliza Papass & 75,7 & 76,5 & $-8,3$ & $-2,8$ & $-2,7$ & 99,7 & 106,8 & 108,7 & 92,4 & 97,7 & 101,9 & 5,1 & 3,6 \\
\hline Fernanda Lo & 77,5 & 77,5 & $-15,5$ & $-9,8$ & $-9,5$ & 99,1 & 105,1 & 105,5 & 92,5 & 98,2 & 100,1 & 6,1 & 3,7 \\
\hline Jose Mascar & 79,8 & 84 & $-9,5$ & $-7,7$ & 1,4 & 106 & 114,2 & 129,2 & 97,7 & 106 & 121,7 & 5,3 & 2,2 \\
\hline Juliana Attuy & 76,8 & 75,6 & $-8,8$ & $-8,7$ & $-6,6$ & 102,7 & 105,2 & 108,2 & 93,2 & 95,3 & 97,6 & 4,2 & 4 \\
\hline
\end{tabular}




\begin{tabular}{|c|c|c|c|c|c|c|c|c|c|c|c|c|c|}
\hline \multirow{2}{*}{$\begin{array}{c}\text { NÚMERO } \\
\text { VARIÁVEIS }\end{array}$} & \multicolumn{3}{|c|}{ WITS } & \multicolumn{3}{|c|}{ SN.PP } & \multicolumn{3}{|c|}{ SN.Ocl } & \multicolumn{3}{|c|}{ SN.GoMe } & \multirow[b]{2}{*}{ SN.GoMe PC } \\
\hline & ANB PC & WITS I & WITS F & WITS PC & SN.PP I & SN.PP F & SN.PP PC & SN.Ocl I & SN.Ocl F & SN.Ocl PC & SN.GoMe I & SN.GoMe F & \\
\hline 10 & 6,8 & 0,1 & 2,5 & 2,8 & 12,2 & 12,9 & 13,2 & 27 & 22 & 25,3 & 40,5 & 39,3 & 39,7 \\
\hline 25 & 4,7 & 2,3 & $-0,9$ & $-0,2$ & 7,7 & 9,1 & 10,2 & 14 & 17,9 & 21,5 & 29,8 & 29,8 & 31,1 \\
\hline 42 & 7,3 & $-0,3$ & 0,2 & 0,3 & 13,4 & 17 & 16,5 & 28,2 & 24,7 & 24,4 & 40,5 & 40,7 & 39,7 \\
\hline 60 & 5,3 & 0,6 & 0 & 0,7 & 8 & 9,8 & 8,6 & 26 & 26,4 & 24,2 & 40 & 44,1 & 44,6 \\
\hline 75 & 6 & $-2,3$ & 0,2 & $-1,1$ & 8,3 & 8,2 & 9,2 & 25 & 21,7 & 24 & 41 & 40,2 & 40,3 \\
\hline 83 & 3,2 & 2,8 & $-0,6$ & 2,8 & 8,4 & 8,6 & 10,3 & 17 & 15,5 & 12,5 & 28,1 & 28,8 & 21,8 \\
\hline 103 & 1,7 & 0,4 & 1,4 & $-2,4$ & 5,7 & 7 & 6 & 22,3 & 15,2 & 15,8 & 39,3 & 38,3 & 32 \\
\hline 112 & 2,9 & 2,8 & 1,8 & 1,9 & 6,4 & 7,4 & 7,7 & 15,8 & 12,4 & 13 & 31,4 & 31,6 & 31,9 \\
\hline 117 & 2,1 & $-1,3$ & $-1,5$ & $-1,9$ & 7,2 & 8,1 & 8,4 & 14,2 & 14,1 & 14,8 & 26,3 & 24 & 21,7 \\
\hline 121 & 3,3 & $-2,2$ & 4,9 & 3,7 & 9,2 & 8,1 & 8,2 & 24,8 & 14,7 & 15,7 & 38,4 & 38,7 & 36,7 \\
\hline 123 & $-0,1$ & 1,8 & $-0,7$ & $-1,6$ & 6,2 & 7 & 6,5 & 11 & 12,1 & 6,4 & 22,5 & 23,3 & 17,4 \\
\hline 142 & 5,5 & 6,2 & 1,2 & 3,2 & 6,8 & 9,4 & 10,4 & 16,7 & 20,3 & 18,7 & 36,4 & 34 & 32,9 \\
\hline 146 & 4,6 & 2,2 & 0,9 & 1,5 & 5,9 & 7,5 & 5,2 & 18,6 & 15,4 & 14,9 & 35,4 & 32,2 & 30,4 \\
\hline 174 & 3,5 & 2,8 & 7 & 6,9 & 6,6 & 6,3 & 8 & 17,9 & 9,8 & 12,1 & 39,6 & 38,3 & 37,5 \\
\hline 221 & 3 & 3,7 & 2,4 & 0,8 & 7,5 & 9,1 & 9,9 & 13,8 & 12 & 14 & 34,5 & 33,4 & 32,3 \\
\hline 229 & 3,9 & $-0,4$ & $-1,3$ & $-2,2$ & 6,8 & 7,8 & 6,9 & 21,4 & 24,2 & 23,7 & 41,3 & 41,6 & 41,7 \\
\hline 236 & 3,9 & 2,5 & 1,3 & 1,7 & 6,7 & 7,8 & 7,7 & 17,7 & 16,7 & 16,3 & 37,1 & 35,7 & 34,3 \\
\hline 316 & 2 & -1 & 0,3 & $-0,3$ & 7,8 & 6,6 & 7,8 & 19,9 & 11,8 & 9 & 31,1 & 27 & 22,8 \\
\hline 330 & 8,5 & 2,7 & 7,2 & 4,4 & 4,7 & 4,1 & 2,7 & 18,1 & 14,4 & 16 & 38,9 & 40,3 & 38,1 \\
\hline 385 & 4,6 & 0,7 & $-0,6$ & 3 & 11,4 & 14,5 & 14,1 & 22,9 & 20,8 & 20,7 & 36,7 & 37,9 & 37,4 \\
\hline 474 & 3,6 & 0,7 & -1 & $-0,3$ & 4,7 & 8,4 & 6,6 & 26,3 & 21,1 & 19 & 41,5 & 37,8 & 35 \\
\hline Alexandra Pi & 5,3 & 0,9 & 1,9 & 1,2 & 11,2 & 11,3 & 11,2 & 17 & 14,8 & 23,1 & 29,3 & 28,7 & 31,4 \\
\hline Edilson Med & 4 & $-2,6$ & $-2,3$ & 0,3 & 8,5 & 11,4 & 7 & 22,5 & 21,7 & 12,7 & 35 & 36,6 & 30,9 \\
\hline Eliza Papass & 2,8 & 1,3 & 1,9 & 2 & 10,9 & 13,4 & 12,2 & 20,2 & 16,5 & 15,3 & 36,2 & 34,8 & 31,6 \\
\hline Fernanda Lo & 5,3 & 2,1 & 0,9 & 3 & 6,6 & 8,4 & 8,6 & 17 & 17,3 & 17,3 & 30,9 & 30,1 & 30,2 \\
\hline Jose Mascar & $-2,7$ & 2,4 & 1,4 & -3 & 4,2 & 5,7 & 3,4 & 15,3 & 12,1 & 6,4 & 29,2 & 28 & 21 \\
\hline Juliana Attuy & 4,7 & 1,4 & 0,3 & 1,3 & 7,4 & 5,2 & 6,4 & 15 & 17,4 & 18,6 & 33,9 & 35,2 & 35,4 \\
\hline
\end{tabular}




\begin{tabular}{|c|c|c|c|c|c|c|c|c|c|c|c|c|c|}
\hline NÚMERO & N.S.Gn & & & Ba.N.Gn & & & FMA & & & $\mathrm{N}-\mathrm{Me}$ & & & S-Go F \\
\hline VARIÁVEIS & N.S.Gn I & N.S.Gn F & N.S.Gn PC & Ba.N.Gn I & Ba.N.Gn F & Ba.N.Gn PC & FMA I & FMA F & FMA PC & $\mathrm{N}-\mathrm{Me} \mathrm{I}$ & $\mathrm{N}-\mathrm{Me} \mathrm{F}$ & $\mathrm{N}-\mathrm{Me} \mathrm{PC}$ & S-Gol \\
\hline 10 & 74,1 & 74 & 75,3 & 79,2 & 79,3 & 78,5 & 28,9 & 29,3 & 26 & 111,9 & 116,2 & 116,9 & 71,2 \\
\hline 25 & 68,4 & 68,4 & 70,5 & 85,7 & 86,2 & 83,8 & 25 & 22,5 & 21,3 & 114,1 & 114,6 & 116,8 & 83,6 \\
\hline 42 & 72,3 & 73,7 & 72,5 & 83,9 & 82,8 & 84,2 & 33,8 & 33,4 & 33,1 & 105,4 & 109,8 & 110,4 & 66,5 \\
\hline 60 & 70,8 & 73 & 73 & 92 & 88,8 & 88,5 & 29,2 & 33,7 & 34,5 & 100,2 & 109,5 & 111,6 & 60,7 \\
\hline 75 & 73,1 & 72,9 & 73,1 & 81,4 & 83,1 & 85,3 & 30,9 & 31,8 & 30,1 & 126,6 & 130,5 & 131,1 & 79,5 \\
\hline 83 & 63,4 & 63,5 & 64 & 92,1 & 91,9 & 91,8 & 22,4 & 25,4 & 20 & 97,1 & 104,6 & 112,2 & 70,4 \\
\hline 103 & 70,8 & 71,8 & 68 & 83,2 & 84,5 & 88,8 & 32,3 & 31,7 & 26,8 & 115,4 & 123,5 & 126,1 & 74,8 \\
\hline 112 & 64,6 & 64,1 & 63,7 & 93 & 93,6 & 95,2 & 23,1 & 21,1 & 22,4 & 105,3 & 109,4 & 115,4 & 70,5 \\
\hline 117 & 64,5 & 64,4 & 63,2 & 93 & 91,3 & 93,4 & 16,9 & 14,4 & 12,6 & 100,6 & 108,5 & 110,4 & 73,4 \\
\hline 121 & 73,2 & 73,4 & 73,8 & 85,5 & 86,2 & 86,7 & 28,6 & 29,4 & 25,6 & 119,7 & 132,6 & 131,9 & 80 \\
\hline 123 & 60,2 & 60 & 56 & 99,1 & 99,5 & 102,9 & 14,6 & 17 & 11,7 & 100,6 & 109,2 & 105,6 & 76,2 \\
\hline 142 & 71 & 72,5 & 72 & 84 & 84,3 & 85 & 28,7 & 33,6 & 25,2 & 116,9 & 129,6 & 129,4 & 78,4 \\
\hline 146 & 68,3 & 66,6 & 66,1 & 87,7 & 91,1 & 91,6 & 26 & 26,9 & 24,5 & 121,3 & 126,3 & 128,2 & 80,8 \\
\hline 174 & 72,2 & 72,2 & 71,8 & 81,9 & 82,4 & 82 & 32,9 & 34,3 & 29,7 & 117 & 120,7 & 122,6 & 73,8 \\
\hline 221 & 68,4 & 68,7 & 69,7 & 90,5 & 90,7 & 90,8 & 29 & 26,4 & 25,2 & 103,7 & 107 & 115 & 70,4 \\
\hline 229 & 69,8 & 71,3 & 70,7 & 83,4 & 82,7 & 82,8 & 34,8 & 35,2 & 33,6 & 111,4 & 114,7 & 116,4 & 67,1 \\
\hline 236 & 69,1 & 68,2 & 69,4 & 89,3 & 89,7 & 88,7 & 25 & 22,2 & 20,9 & 115,8 & 116,2 & 122,8 & 73,3 \\
\hline 316 & 67,5 & 66,4 & 64,1 & 89,8 & 90,1 & 94,7 & 25,6 & 20,4 & 14,7 & 107,3 & 111,2 & 113,8 & 76,4 \\
\hline 330 & 71,7 & 71,9 & 71,1 & 83,7 & 83,5 & 84,8 & 29 & 32,8 & 32,3 & 112,5 & 123,7 & 125,9 & 72,1 \\
\hline 385 & 68,3 & 69,8 & 71,1 & 87,1 & 85,5 & 85,2 & 31,8 & 30,9 & 30,8 & 104,9 & 111,4 & 122,7 & 69,2 \\
\hline 474 & 74,3 & 72,8 & 71,2 & 79 & 82 & 83,1 & 29,4 & 24,7 & 21,4 & 114,8 & 122,6 & 121,6 & 73,6 \\
\hline Alexandra $\mathrm{Pi}$ & 65,8 & 65,5 & 68,3 & 90,9 & 91,8 & 87,2 & 16,1 & 13,9 & 21,2 & 104,6 & 106,4 & 112,9 & 74,1 \\
\hline Edilson Med & 67,8 & 68,4 & 64,8 & 90,5 & 88,1 & 91,1 & 30,4 & 32,4 & 26,7 & 109,5 & 119,2 & 119,6 & 71,5 \\
\hline Eliza Papass & 67,9 & 68,9 & 67,6 & 86 & 87,7 & 88 & 28,3 & 24,3 & 22 & 104,6 & 110,2 & 114,5 & 69,2 \\
\hline Fernanda Lo & 68,8 & 67,6 & 68,4 & 87,8 & 89,6 & 89,4 & 26,6 & 23,2 & 23,4 & 105,5 & 109,1 & 111,4 & 74,6 \\
\hline Jose Mascar & 66,4 & 66,5 & 61,3 & 90,4 & 90,4 & 98 & 24,5 & 23 & 16 & 105,5 & 113,8 & 119,6 & 76,9 \\
\hline Juliana Attuy & 72 & 72,5 & 73,8 & 82,9 & 83,4 & 81,9 & 25,7 & 26,7 & 24,1 & 108,7 & 111,9 & 116,2 & 74,1 \\
\hline
\end{tabular}




\begin{tabular}{|c|c|c|c|c|c|c|c|c|c|c|c|c|c|}
\hline \multirow{2}{*}{$\begin{array}{l}\text { NÚMERO } \\
\text { VARIÁVEIS }\end{array}$} & \multirow[b]{2}{*}{ S-Go F } & \multicolumn{3}{|c|}{ AFP:AFA } & \multicolumn{3}{|c|}{ AFAl } & \multicolumn{3}{|c|}{ 1s.SN } & \multicolumn{3}{|c|}{ 1.NA } \\
\hline & & S-Go PC & AFP:AFA I & AFP:AFA F & AFP:AFA PC & AFAII & AFAI F & AFAI PC & $1 \mathrm{~s} . \mathrm{SN} I$ & 1s.SN F & 1s.SN PC & 1.NAI & 1.NAF \\
\hline 10 & 75,7 & 75,1 & 63,6 & 65,1 & 64,2 & 64,8 & 66,9 & 68,4 & 110,7 & 93,4 & 103,8 & 30,8 & 14,3 \\
\hline 25 & 83,6 & 84,2 & 73,2 & 73 & 72,1 & 64,6 & 65,4 & 66,8 & 118,8 & 92,7 & 93,8 & 35,8 & 11,1 \\
\hline 42 & 70,3 & 71,8 & 63,1 & 64 & 65 & 61 & 61,8 & 62,6 & 104,6 & 90,3 & 96,9 & 20,1 & 9,8 \\
\hline 60 & 64 & 64,2 & 60,6 & 58,5 & 57,6 & 59,9 & 65,8 & 67,9 & 118,5 & 101 & 102,5 & 37,7 & 23,2 \\
\hline 75 & 84,9 & 85 & 62,8 & 65,1 & 64,9 & 77,5 & 80,1 & 80,1 & 117 & 102,5 & 95,5 & 36,1 & 20,8 \\
\hline 83 & 75,7 & 88,5 & 72,5 & 72,4 & 78,9 & 53,8 & 56,3 & 58,9 & 103,3 & 101,2 & 96,9 & 17,2 & 19,6 \\
\hline 103 & 81,7 & 89,7 & 64,8 & 66,2 & 71,1 & 66,2 & 69,7 & 72,2 & 107,8 & 99,4 & 109,3 & 25,4 & 19,2 \\
\hline 112 & 75,3 & 79 & 66,9 & 68,8 & 68,4 & 57,2 & 59,6 & 63,1 & 111,8 & 106,3 & 108,7 & 29,4 & 25,7 \\
\hline 117 & 82,3 & 85,9 & 73 & 75,9 & 77,8 & 55 & 59,5 & 60,1 & 110,5 & 104,4 & 106,6 & 26,9 & 19,2 \\
\hline 121 & 90,7 & 92,7 & 66,8 & 68,4 & 70,3 & 69,5 & 78,1 & 78,2 & 110,5 & 108,2 & 101,4 & 30,2 & 28,7 \\
\hline 123 & 83,2 & 85,1 & 75,7 & 76,2 & 80,6 & 55,5 & 59,2 & 57 & 123,2 & 98,4 & 105,4 & 36,4 & 14,5 \\
\hline 142 & 93,3 & 93 & 67,1 & 71,9 & 71,9 & 68,3 & 76,2 & 75,2 & 112,6 & 94,8 & 96,9 & 27,4 & 12 \\
\hline 146 & 86,9 & 91,1 & 66,5 & 68,8 & 71,1 & 74,6 & 76 & 79,5 & 117,1 & 108,2 & 113,9 & 32,3 & 24,7 \\
\hline 174 & 79,2 & 80,9 & 63,1 & 65,6 & 66 & 73,7 & 74,1 & 73,6 & 112,8 & 106,1 & 105,3 & 31,3 & 26,6 \\
\hline 221 & 75,5 & 82,8 & 67,9 & 70,6 & 72,1 & 59,2 & 61 & 65,6 & 106,9 & 107,2 & 99 & 24,7 & 25,9 \\
\hline 229 & 68,8 & 70 & 60,2 & 60 & 60,1 & 67,1 & 69 & 70,8 & 105,4 & 101,4 & 108,1 & 24,7 & 22,8 \\
\hline 236 & 75,6 & 82,4 & 63,3 & 65,1 & 67,1 & 69,8 & 69,3 & 72,9 & 115,3 & 107,7 & 107,5 & 32,5 & 27,2 \\
\hline 316 & 82,5 & 88,3 & 71,1 & 74,2 & 77,6 & 61,6 & 63 & 64,6 & 128,2 & 111,3 & 112,7 & 43,5 & 26,2 \\
\hline 330 & 79,7 & 84 & 64,1 & 64,5 & 66,7 & 69,2 & 79,9 & 82,7 & 114,9 & 92,9 & 95,5 & 30,3 & 8,4 \\
\hline 385 & 72,9 & 80,8 & 66 & 65,5 & 65,8 & 61,7 & 64,2 & 72,4 & 105,1 & 95,9 & 91 & 23,2 & 19,7 \\
\hline 474 & 81,6 & 83,6 & 64,1 & 66,6 & 68,8 & 73,2 & 73,8 & 72,6 & 116,1 & 106,1 & 112,3 & 33,3 & 26,7 \\
\hline Alexandra $\mathrm{Pi}$ & 76,4 & 78,8 & 70,9 & 71,9 & 69,8 & 57 & 57,6 & 64,7 & 114,1 & 106,5 & 104,8 & 31,3 & 25 \\
\hline Edilson Med & 77,8 & 83,4 & 65,3 & 65,3 & 69,7 & 62,8 & 68,5 & 70,9 & 115,9 & 102,5 & 105,7 & 31,4 & 20,2 \\
\hline Eliza Papass & 75,5 & 80,1 & 66,2 & 68,5 & 69,9 & 56,8 & 59,6 & 60,9 & 106,1 & 108,5 & 105,8 & 25,2 & 29,1 \\
\hline Fernanda Lo & 78 & 79,1 & 70,7 & 71,5 & 71 & 60,6 & 60,7 & 62,2 & 107,6 & 104,1 & 104,7 & 23,1 & 22,9 \\
\hline Jose Mascar & 85,1 & 94,1 & 72,9 & 74,7 & 78,6 & 60,4 & 63,2 & 64,1 & 122,8 & 99,5 & 113,4 & 38,1 & 17,6 \\
\hline Juliana Attuy & 76,2 & 78,9 & 68,2 & 68,1 & 67,9 & 63,6 & 66,6 & 70 & 102,8 & 105,3 & 98,7 & 21,5 & 24,5 \\
\hline
\end{tabular}




\begin{tabular}{|c|c|c|c|c|c|c|c|c|c|c|c|c|c|}
\hline NÚMERO & & 1-NA & & & $1 . N B$ & & & 1-NB & & & FMAI & & \\
\hline VARIÁVEIS & 1.NA PC & 1-NAI I & 1-NA F & 1-NA PC & 1.NB I & 1.NB F & 1.NB PC & 1-NB I & 1-NB F & 1-NB PC & FMIA I & FMIA F & FMIA PC \\
\hline 10 & 25,9 & 6,5 & $-0,5$ & 3,2 & 23,1 & 21,1 & 21,9 & 4,3 & 3,3 & 4 & 61,6 & 62,4 & 63 \\
\hline 25 & 12,8 & 8,9 & 1,9 & 1,5 & 23,8 & 32,5 & 28,7 & 5,3 & 4,7 & 5 & 59,7 & 53,1 & 57,4 \\
\hline 42 & 14,2 & 4,1 & $-0,2$ & 1,7 & 32,9 & 24,6 & 27,7 & 8,5 & 6,8 & 8 & 49 & 56,3 & 54,3 \\
\hline 60 & 24,7 & 6,3 & 1,4 & 3,4 & 23,8 & 26,2 & 26 & 4,9 & 5,1 & 5,8 & 60,8 & 56,5 & 56,6 \\
\hline 75 & 14,7 & 11,4 & 2 & 0,9 & 32,8 & 25,4 & 27,8 & 8,5 & 6,2 & 6,1 & 52,6 & 58,7 & 57,2 \\
\hline 83 & 14,2 & 1,5 & 0,4 & $-0,3$ & 27 & 15,1 & 17,4 & 3,9 & 1,4 & 1 & 58 & 67,6 & 63,8 \\
\hline 103 & 27,7 & 6,2 & 2,5 & 4,8 & 30,9 & 25,3 & 27,5 & 8,9 & 4,6 & 5 & 52,3 & 58,4 & 57,6 \\
\hline 112 & 27,1 & 7,1 & 4,4 & 5,2 & 23,1 & 26,3 & 23,2 & 5,3 & 5,1 & 4,7 & 62,7 & 62,5 & 65,1 \\
\hline 117 & 21,2 & 6,2 & 3,4 & 3,9 & 30,4 & 28,7 & 27,8 & 7,1 & 4,7 & 4 & 59,6 & 63,2 & 64,7 \\
\hline 121 & 22,5 & 5,1 & 3,5 & 2,9 & 33,6 & 23 & 20,2 & 8,8 & 5,9 & 5 & 51,6 & 61,7 & 66,5 \\
\hline 123 & 20,3 & 8,7 & 0,9 & 2,6 & 22,3 & 8,3 & 8,2 & 3,2 & $-0,1$ & $-1,1$ & 67,9 & 80,2 & 82,7 \\
\hline 142 & 15,7 & 5,8 & $-1,5$ & 0,5 & 35,8 & 21,9 & 28,3 & 8,6 & 5,5 & 5,6 & 48 & 55,6 & 55,1 \\
\hline 146 & 29,4 & 6,7 & 1,9 & 2,7 & 30,9 & 30,7 & 32,3 & 7,5 & 4,9 & 5,7 & 56,8 & 54 & 53,5 \\
\hline 174 & 28,3 & 6,9 & 1 & 5,2 & 31,4 & 17,4 & 21,9 & 8,6 & 3,4 & 5,1 & 50,9 & 62,5 & 59,5 \\
\hline 221 & 17,8 & 4,8 & 4,9 & 4 & 30,3 & 24,5 & 33,4 & 7 & 5,5 & 7 & 52,8 & 61,1 & 51,9 \\
\hline 229 & 29,2 & 2,9 & 3,2 & 5 & 32 & 21,6 & 26,2 & 6,8 & 4,8 & 6 & 49,5 & 59,6 & 56,8 \\
\hline 236 & 27 & 7,1 & 1,8 & 4,8 & 30,9 & 25,1 & 32,9 & 8,3 & 3,8 & 6,2 & 57,9 & 65,1 & 57,1 \\
\hline 316 & 26,4 & 12,2 & 5,7 & 6,3 & 33,9 & 31,9 & 25,3 & 9,2 & 5,6 & 4,7 & 51,6 & 56,9 & 67,1 \\
\hline 330 & 8,4 & 7,5 & 1 & 1,3 & 27,1 & 26,2 & 26,5 & 7,1 & 8,4 & 8,1 & 59,3 & 58,1 & 57,8 \\
\hline 385 & 14,1 & 3,1 & 0,6 & $-0,6$ & 20,5 & 14,9 & 18,7 & 3,2 & 1 & 3,6 & 59,8 & 65,8 & 60,3 \\
\hline 474 & 32 & 8,5 & 4,7 & 6,5 & 34,7 & 28,6 & 34,9 & 9,7 & 6,2 & 6,9 & 51,1 & 60 & 55,5 \\
\hline Alexandra Pi & 23,9 & 5,6 & 1,4 & 3,6 & 25,3 & 25,5 & 24 & 3,3 & 2,6 & 2,8 & 66,4 & 67,1 & 61,7 \\
\hline Edilson Med & 20 & 10,4 & 6 & 5,2 & 25,4 & 34,9 & 30 & 7,1 & 8,8 & 8,5 & 57,6 & 47,1 & 55,7 \\
\hline Eliza Papass & 26,5 & 4,9 & 3,1 & 4,2 & 24,5 & 23,7 & 16,7 & 5 & 3,8 & 1,9 & 59,1 & 62,4 & 69,4 \\
\hline Fernanda Lo & 21,9 & 4,6 & 3,2 & 3,9 & 39,7 & 44,3 & 43,1 & 7,9 & 5,4 & 7,5 & 43 & 40 & 41,2 \\
\hline Jose Mascar & 32,1 & 7,9 & 1,4 & 5,8 & 24,9 & 15,5 & 11,4 & 4,8 & 1,2 & $-0,2$ & 59,3 & 69,3 & 77,6 \\
\hline Juliana Attuy & 18,4 & 3,5 & 4,9 & 3,2 & 29,4 & 29,7 & 33,9 & 6,1 & 7 & 7,7 & 55,9 & 55,5 & 53 \\
\hline
\end{tabular}




\begin{tabular}{|c|c|c|c|c|c|c|c|c|c|c|c|c|c|}
\hline NÚMERO & IMPA & & & 1i-APg & & & 1.1 & & & Ls-E & & & Li-E \\
\hline VARIÁVEIS & IMPA I & IMPA F & IMPA PC & 1i-Apg I & 1i-APg F & 1i-APg PC & $1.1 \mathrm{I}$ & $1.1 \mathrm{~F}$ & 1.1 PC & Ls-E I & Ls-E F & Ls-E PC & Li-E I \\
\hline 10 & 89,5 & 88,4 & 91 & $-0,5$ & $-1,2$ & $-1,7$ & 119,3 & 139 & 125,5 & $-2,8$ & $-6,3$ & $-5,3$ & $-4,5$ \\
\hline 25 & 95,3 & 104,4 & 101,4 & 1,2 & 1,3 & 0,5 & 116,2 & 133 & 133,7 & $-1,2$ & $-2,4$ & $-3,2$ & $-1,7$ \\
\hline 42 & 97,2 & 90,3 & 92,7 & 3,4 & 2,5 & 3,2 & 117,7 & 138,7 & 130,8 & 1,4 & $-2,6$ & $-4,4$ & 3,2 \\
\hline 60 & 90 & 89,8 & 89 & 0,9 & 1,3 & 2,2 & 111,5 & 125,1 & 123,9 & 1,1 & $-3,4$ & $-2,5$ & 0,9 \\
\hline 75 & 96,5 & 89,5 & 92,6 & 4,1 & 1,1 & 1,2 & 105,5 & 127,8 & 131,5 & 0,3 & $-4,6$ & $-4,4$ & $-0,4$ \\
\hline 83 & 99,7 & 87 & 96,1 & $-0,9$ & $-1,5$ & $-3,3$ & 128,9 & 143,1 & 145,2 & $-0,4$ & $-5,6$ & $-7,8$ & 1,5 \\
\hline 103 & 95,4 & 89,9 & 95,6 & 4,8 & 1,5 & 2,7 & 117,5 & 132,4 & 123,2 & 1,2 & $-2,4$ & $-4,7$ & 4,1 \\
\hline 112 & 94,2 & 96,4 & 92,5 & 1,9 & 3 & 1,9 & 122,5 & 125,7 & 126,8 & $-0,4$ & $-5,4$ & $-4,3$ & 1 \\
\hline 117 & 103,5 & 102,5 & 102,8 & 5,4 & 2,7 & 2,5 & 119,7 & 129,1 & 128,9 & $-0,2$ & $-2,7$ & $-4,4$ & 0,4 \\
\hline 121 & 99,8 & 88,8 & 87,9 & 5,5 & 2,3 & 2,4 & 111,2 & 124,3 & 134 & $-0,8$ & $-2,7$ & -4 & 0,6 \\
\hline 123 & 97,5 & 82,8 & 85,6 & 0,4 & $-2,4$ & $-2,7$ & 116,7 & 155,6 & 151,6 & 3,6 & $-1,8$ & $-4,3$ & $-1,7$ \\
\hline 142 & 103,3 & 90,8 & 99,7 & 3 & 0,9 & 1,5 & 107,7 & 140,4 & 130,4 & 1,1 & -8 & -6 & 0,8 \\
\hline 146 & 97,2 & 99 & 102 & 2,5 & 0,8 & 0,9 & 110,3 & 120,5 & 113,7 & 1,1 & $-3,7$ & $-5,8$ & 2,3 \\
\hline 174 & 96,1 & 83,2 & 90,8 & 5 & 0,4 & 1,7 & 111,5 & 132,5 & 126,4 & $-1,3$ & $-6,2$ & $-4,1$ & 2,2 \\
\hline 221 & 98,3 & 92,5 & 102,9 & 4,1 & 3,5 & 4,8 & 120,3 & 126,9 & 125,8 & 0,1 & $-1,5$ & $-3,7$ & 1,5 \\
\hline 229 & 95,7 & 85,2 & 89,6 & 2,8 & 1,5 & 2,6 & 117,6 & 131,8 & 120,6 & -3 & $-3,2$ & $-5,6$ & $-1,8$ \\
\hline 236 & 97,1 & 92,7 & 102 & 4,2 & 0,6 & 2,8 & 110,5 & 123,9 & 116,2 & 1,5 & $-1,2$ & $-3,9$ & 3,1 \\
\hline 316 & 102,8 & 102,6 & 98,2 & 6 & 2,9 & 2,3 & 98 & 119,1 & 126,3 & 2,9 & $-1,2$ & $-2,9$ & 1,7 \\
\hline 330 & 91,6 & 89,2 & 89,9 & 2,9 & 3,4 & 3,1 & 114,5 & 137,7 & 136,5 & 1,9 & 2,4 & 0,3 & $-0,7$ \\
\hline 385 & 88,4 & 83,3 & 88,9 & $-1,7$ & -2 & $-1,4$ & 129,8 & 143 & 142,6 & $-1,2$ & $-5,9$ & $-8,3$ & 0,7 \\
\hline 474 & 99,5 & 95,4 & 103,1 & 3,8 & 2,9 & 3,8 & 102,9 & 120,7 & 109,5 & 4 & $-1,1$ & $-2,9$ & 4,5 \\
\hline Alexandra Pi & 97,5 & 99 & 97,1 & $-0,7$ & $-1,5$ & $-2,7$ & 119,2 & 125,9 & 126,7 & -2 & $-3,9$ & $-4,9$ & -3 \\
\hline Edilson Med & 91,9 & 100,5 & 97,5 & 3 & 5,1 & 5,2 & 117,1 & 120,5 & 125,9 & 3,1 & $-1,5$ & $-2,4$ & 1,6 \\
\hline Eliza Papass & 92,5 & 93,3 & 88,6 & 0,7 & $-0,2$ & $-1,6$ & 125,2 & 123,4 & 134 & $-2,3$ & $-5,6$ & $-9,2$ & $-2,9$ \\
\hline Fernanda Lo & 110,4 & 116,7 & 115,4 & 5,1 & 2,9 & 3,8 & 111,1 & 109,1 & 109,7 & 1,8 & $-1,5$ & $-1,6$ & 3,4 \\
\hline Jose Mascar & 96,2 & 87,7 & 86,3 & 1,2 & -1 & 0,7 & 111,8 & 144,7 & 139,2 & 1,6 & $-3,7$ & $-7,9$ & 3,4 \\
\hline Juliana Attuy & 98,4 & 97,8 & 102,9 & 4,1 & 4,6 & 5 & 125 & 121,8 & 123 & 0 & $-1,3$ & -3 & 2,2 \\
\hline
\end{tabular}




\begin{tabular}{|c|c|c|c|c|c|c|c|c|}
\hline \multirow{2}{*}{$\begin{array}{c}\text { NÚMERO } \\
\text { VARIÁVEIS }\end{array}$} & \multirow[b]{2}{*}{ Li-E F } & \multirow[b]{2}{*}{ Li-E PC } & \multicolumn{2}{|l|}{$Z$} & \multicolumn{3}{|c|}{ H-Pn } & \multirow[b]{2}{*}{ H-Pn PC } \\
\hline & & & $\mathrm{zI}$ & ZF & $\mathrm{ZPC}$ & H-Pn I & H-Pn F & \\
\hline 10 & $-5,8$ & $-3,9$ & 69,7 & 73,1 & 75,3 & 5,1 & 10,5 & 8,8 \\
\hline 25 & $-2,1$ & $-2,3$ & 71,1 & 75,1 & 76,9 & 1,9 & 3,8 & 5,4 \\
\hline 42 & $-1,5$ & $-2,4$ & 52,4 & 65,8 & 66 & $-2,3$ & 4,5 & 7,6 \\
\hline 60 & $-1,3$ & $-1,4$ & 66,1 & 68,4 & 68,4 & $-1,8$ & 5,5 & 4,3 \\
\hline 75 & $-3,2$ & $-4,6$ & 69,7 & 76 & 80 & $-0,5$ & 7,6 & 7,5 \\
\hline 83 & $-5,6$ & $-8,4$ & 61,8 & 73 & 73,8 & 0,7 & 10,2 & 14,9 \\
\hline 103 & $-0,3$ & -1 & 54,3 & 66,8 & 68,4 & -2 & 4,1 & 8 \\
\hline 112 & $-3,4$ & $-2,9$ & 67,6 & 77,8 & 74,7 & 0,5 & 9,5 & 8,1 \\
\hline 117 & $-0,6$ & $-3,6$ & 75,5 & 77,9 & 83 & 0,3 & 4,5 & 7,6 \\
\hline 121 & $-0,7$ & $-1,8$ & 71,3 & 71,2 & 75,1 & 1,3 & 4,4 & 6,6 \\
\hline 123 & $-3,3$ & $-7,2$ & 67,8 & 75,9 & 84,8 & $-6,8$ & 3,3 & 8,4 \\
\hline 142 & $-5,4$ & $-4,7$ & 65,4 & 72,2 & 76,5 & $-1,8$ & 13,5 & 10,4 \\
\hline 146 & $-1,2$ & $-4,9$ & 68,5 & 70,1 & 75,5 & $-1,6$ & 6 & 9,7 \\
\hline 174 & $-3,5$ & 1,3 & 61,1 & 72,8 & 64,8 & 2,3 & 10,3 & 7,1 \\
\hline 221 & 0,4 & $-1,8$ & 63,9 & 66,8 & 71,5 & $-0,1$ & 2,5 & 6,3 \\
\hline 229 & -2 & $-3,9$ & 69,7 & 68,4 & 74,4 & 4,9 & 5,1 & 9,2 \\
\hline 236 & $-1,5$ & $-3,7$ & 65,8 & 77,4 & 83,7 & $-2,7$ & 2,2 & 7,7 \\
\hline 316 & $-0,9$ & $-1,4$ & 69,8 & 79,9 & 83,6 & $-4,5$ & 2 & 4,7 \\
\hline 330 & 5,1 & 1,4 & 70,2 & 56,9 & 66,4 & $-2,9$ & -4 & $-0,5$ \\
\hline 385 & $-3,3$ & $-2,9$ & 63,4 & 74 & 70,5 & 1,8 & 9,5 & 13,7 \\
\hline 474 & 0,1 & $-1,6$ & 63,8 & 72,3 & 78,4 & $-6,4$ & 1,8 & 5,1 \\
\hline Alexandra Pi & $-4,6$ & $-5,4$ & 76,6 & 80,6 & 74,4 & 3,2 & 6,5 & 8,1 \\
\hline Edilson Med & $-1,2$ & $-2,3$ & 64,1 & 66,7 & 72,4 & -5 & 2,8 & 4,1 \\
\hline Eliza Papass & $-5,4$ & $-8,4$ & 72,1 & 79,2 & 83,3 & 4,3 & 9,9 & 16,5 \\
\hline Fernanda Lo & $-1,3$ & $-0,1$ & 60,2 & 72,2 & 69,6 & $-2,7$ & 2,1 & 2,4 \\
\hline Jose Mascar & $-1,5$ & $-7,2$ & 64,8 & 73,9 & 87,6 & $-2,3$ & 6,5 & 14,2 \\
\hline Juliana Attuy & 1,4 & 0,1 & 62,7 & 66,2 & 70,6 & 0 & 2,5 & 5,2 \\
\hline
\end{tabular}




\begin{tabular}{|c|c|c|c|c|c|c|c|c|c|c|c|c|c|}
\hline $\begin{array}{l}\text { NÚMERO } \\
\text { VARIÁVEIS }\end{array}$ & $\begin{array}{l}\text { SNA } \\
\text { SNAI }\end{array}$ & SNAF & SNA PC & $\begin{array}{l}\text { A-Nperp } \\
\text { A-Nperpl }\end{array}$ & A-NperpF & A-NperpPC & $\begin{array}{l}\text { Co-A } \\
\text { Co-Al }\end{array}$ & Co-A F & Co-A PC & $\begin{array}{l}\text { Ar-A } \\
\text { Ar-A I }\end{array}$ & Ar-A F & Ar-A PC & $\begin{array}{l}\text { SNB } \\
\text { SNB I }\end{array}$ \\
\hline 12 & 82,3 & 76,6 & 76 & $-1,2$ & -10 & $-9,4$ & 82,1 & 83,1 & 84,2 & 80,5 & 83,8 & 85,8 & 80,4 \\
\hline 27 & 78,1 & 77,1 & 77,4 & 0,2 & -1 & $-0,7$ & 81,7 & 81,4 & 84,3 & 80,2 & 79,4 & 81,6 & 76,2 \\
\hline 52 & 80,2 & 78,1 & 78,4 & $-2,4$ & $-4,6$ & $-3,2$ & 78,1 & 79,3 & 83,4 & 77,1 & 78,3 & 80,6 & 76,3 \\
\hline 65 & 73,5 & 71,9 & 70 & $-0,8$ & -1 & $-1,7$ & 72,2 & 76,5 & 78,6 & 71,6 & 72,8 & 73 & 69,9 \\
\hline 105 & 77,3 & 75,7 & 76 & $-0,7$ & $-4,5$ & $-3,5$ & 78,2 & 79,6 & 79,3 & 73,6 & 73,1 & 74,4 & 72,8 \\
\hline 151 & 77,7 & 76,1 & 76,7 & 0,4 & $-4,3$ & $-2,8$ & 83,1 & 84,6 & 83,5 & 80,4 & 79,6 & 78,9 & 75,1 \\
\hline 152 & 85,9 & 83 & 84,7 & 1,3 & $-1,3$ & $-1,6$ & 85,3 & 90,1 & 89,4 & 84,7 & 86,7 & 86,6 & 83,1 \\
\hline 156 & 77,9 & 77,1 & 79,1 & 2,3 & 0,4 & 1 & 79,1 & 78,3 & 81,7 & 77,4 & 77,6 & 78,6 & 74,2 \\
\hline 168 & 80,5 & 81,2 & 81,6 & $-0,5$ & -5 & $-0,6$ & 83,3 & 84 & 85,1 & 80,1 & 82,6 & 82,9 & 78,9 \\
\hline 179 & 80,2 & 79,3 & 83,1 & 4,2 & $-0,9$ & 0,7 & 80,2 & 81,7 & 86,2 & 78,8 & 77,5 & 84,8 & 77,3 \\
\hline 202 & 78,7 & 76,7 & 78,7 & $-1,4$ & $-1,4$ & 2 & 82,3 & 81,1 & 89,8 & 79,5 & 80,8 & 88,5 & 75,8 \\
\hline 338 & 79,1 & 80,3 & 79,8 & $-2,5$ & $-2,2$ & $-0,5$ & 75 & 76,7 & 78,4 & 71,5 & 72,8 & 77,8 & 74,9 \\
\hline Jaqueline Ca & 82,6 & 78,7 & 80,5 & 2,8 & $-0,7$ & $-0,1$ & 81,2 & 79,3 & 81,8 & 79,4 & 77,1 & 80,5 & 79,3 \\
\hline Renata Mutrs & 83,8 & 83,3 & 83,9 & $-0,2$ & 1,6 & 0,6 & 82,2 & 84,5 & 87,3 & 79,8 & 80,7 & 85,1 & 80 \\
\hline
\end{tabular}




\begin{tabular}{|c|c|c|c|c|c|c|c|c|c|c|c|c|c|}
\hline \multicolumn{2}{|l|}{ NÚMERO } & \multicolumn{3}{|c|}{ Pg-Nperp } & \multicolumn{3}{|c|}{ Co-Gn } & \multicolumn{3}{|c|}{ Ar-Gn } & \multicolumn{3}{|c|}{ ANB } \\
\hline VARIÁVEIS & SNB F & SNB PC & Pg-Nperpl & Pg-NperpF & Pg-NperpPC & Co-Gn I & Co-Gn F & Co-Gn PC & Ar-Gn I & Ar-Gn F & Ar-Gn PC & ANB I & ANB $F$ \\
\hline 12 & 74,8 & 74,4 & $-4,7$ & $-16,5$ & $-15,3$ & 106,9 & 107,1 & 108,5 & 101,4 & 105,1 & 107,8 & 1,9 & 1,8 \\
\hline 27 & 76,3 & 77,1 & $-1,5$ & $-1,1$ & 1 & 108,3 & 111,1 & 114,2 & 101,7 & 103,1 & 105,8 & 1,9 & 0,8 \\
\hline 52 & 75,2 & 74,9 & -9 & $-11,4$ & $-9,5$ & 100,6 & 105,2 & 108,1 & 95,5 & 99,5 & 100,6 & 3,9 & 2,9 \\
\hline 65 & 68,9 & 64,2 & -8 & $-6,2$ & $-12,3$ & 95,7 & 101,6 & 102,9 & 89,2 & 91,7 & 89,6 & 3,6 & 3 \\
\hline 105 & 74 & 74,1 & $-9,1$ & -9 & $-7,3$ & 102,6 & 106,9 & 108,2 & 90,8 & 95,2 & 96,5 & 4,5 & 1,7 \\
\hline 151 & 75,9 & 77,9 & $-2,6$ & $-4,4$ & 1,2 & 110,2 & 115,7 & 116,2 & 99,5 & 103,9 & 105,6 & 2,6 & 0,2 \\
\hline 152 & 82,8 & 85 & -1 & 2,6 & 3,6 & 109,5 & 120,9 & 121,3 & 103,1 & 112,3 & 112,9 & 2,8 & 0,2 \\
\hline 156 & 72,2 & 73,1 & $-2,4$ & $-7,3$ & $-8,2$ & 108,4 & 109,1 & 110,3 & 99,2 & 100,1 & 100 & 3,7 & 4,9 \\
\hline 168 & 81,3 & 81,7 & $-2,5$ & -3 & 5,8 & 108,7 & 114,6 & 117,1 & 100,8 & 109,3 & 110,4 & 1,6 & $-0,1$ \\
\hline 179 & 77 & 80,8 & 3,5 & $-4,1$ & $-0,3$ & 103,2 & 106,3 & 112,2 & 97 & 97,9 & 107,3 & 2,9 & 2,3 \\
\hline 202 & 75,6 & 78,7 & $-6,8$ & $-1,9$ & 8,8 & 109 & 111,7 & 127,3 & 100,4 & 105,1 & 120,6 & 2,9 & 1,1 \\
\hline 338 & 76,1 & 75,8 & $-11,3$ & $-9,8$ & -6 & 100,4 & 105,2 & 108 & 91,5 & 96,2 & 100,9 & 4,2 & 4,2 \\
\hline Jaqueline Ca & 78,7 & 78,8 & 1 & 1,5 & $-0,5$ & 103,8 & 108,3 & 109,8 & 97,9 & 101,3 & 104,2 & 3,3 & 0 \\
\hline Renata Mutrı & 80,9 & 80,4 & $-5,2$ & 1,8 & $-0,8$ & 108 & 114 & 115,8 & 100,5 & 104,1 & 107,4 & 3,8 & 2,4 \\
\hline
\end{tabular}




\begin{tabular}{|c|c|c|c|c|c|c|c|c|c|c|c|c|c|}
\hline \multirow{2}{*}{$\begin{array}{c}\text { NÚMERO } \\
\text { VARIÁVEIS }\end{array}$} & \multirow[b]{2}{*}{ ANB PC } & \multicolumn{2}{|l|}{ WITS } & \multicolumn{3}{|c|}{ SN.PP } & \multicolumn{3}{|c|}{ SN.Ocl } & \multicolumn{3}{|c|}{ SN.GoMe } & \multirow[b]{2}{*}{ SN GoMe PC } \\
\hline & & WITS I & WITS F & WITS PC & SN.PP I & SN.PP F & SN.PP PC & SN.Ocl I & SN.Ocl F & SN.Ocl PC & SN.GoMe I & SN.GoMe F & \\
\hline 12 & 1,6 & $-1,8$ & 0,6 & 2,4 & 1,8 & 10,4 & 10,6 & 14,7 & 18 & 15,1 & 30,9 & 34,5 & 33,1 \\
\hline 27 & 0,3 & $-4,6$ & $-5,1$ & $-5,5$ & 5,3 & 4,8 & 4,2 & 23,1 & 22,5 & 21,7 & 35,2 & 34,9 & 33,1 \\
\hline 52 & 3,5 & -1 & $-2,1$ & 1,1 & 5,3 & 6,9 & 6,7 & 19,2 & 21,5 & 19,4 & 38,6 & 40,9 & 39,2 \\
\hline 65 & 5,8 & $-6,7$ & $-2,7$ & 0,5 & 14,8 & 13,7 & 18 & 36,6 & 29 & 34 & 49,3 & 49,1 & 54 \\
\hline 105 & 1,9 & $-3,9$ & $-0,6$ & $-1,9$ & 11,5 & 10,7 & 12,9 & 29,3 & 20,1 & 23,1 & 44,5 & 43,6 & 41,2 \\
\hline 151 & $-1,2$ & -2 & $-2,4$ & $-2,1$ & 9,5 & 8,4 & 7,6 & 22,4 & 17,6 & 13,3 & 36,3 & 33,8 & 29,5 \\
\hline 152 & $-0,3$ & $-3,2$ & $-3,5$ & $-2,4$ & 5,8 & 7 & 6,3 & 17 & 12,8 & 9,9 & 22,5 & 20,8 & 16,8 \\
\hline 156 & 6 & $-5,3$ & $-2,5$ & -1 & 11,5 & 11,4 & 11,2 & 27,6 & 28,1 & 25,5 & 42,1 & 44,2 & 42,7 \\
\hline 168 & $-0,1$ & $-1,5$ & 0 & $-1,4$ & 6,7 & 3,6 & 3,7 & 15,2 & 8,2 & 10,7 & 33,4 & 27,6 & 25,8 \\
\hline 179 & 2,3 & $-1,7$ & -2 & -2 & 13,3 & 14,9 & 10,6 & 20,9 & 20,8 & 16,9 & 35,7 & 35,1 & 31,7 \\
\hline 202 & 0 & $-2,5$ & $-3,4$ & $-4,9$ & 5,9 & 6,5 & 7,3 & 21,9 & 21,2 & 19,4 & 36,4 & 36 & 27,3 \\
\hline 338 & 4 & $-0,1$ & -1 & $-0,1$ & 6,7 & 6,5 & 8,2 & 21,2 & 19,8 & 20,2 & 37,9 & 35,8 & 34,6 \\
\hline Jaqueline $\mathrm{Ca}$ & 1,7 & $-1,9$ & $-0,6$ & 1,3 & 5,9 & 7,4 & 8,1 & 19,5 & 12,4 & 10,4 & 29,9 & 29,2 & 28,5 \\
\hline Renata Mutrı & 3,5 & 1,2 & 0,6 & 3,2 & 2,6 & 2,1 & 2,1 & 12,5 & 11,2 & 9,5 & 28,8 & 26,5 & 24,9 \\
\hline
\end{tabular}




\begin{tabular}{|c|c|c|c|c|c|c|c|c|c|c|c|c|c|}
\hline NÚMERO & N.S.Gn & & & Ba.N.Gn & & & FMA & & & $\mathrm{N}-\mathrm{Me}$ & & & S-Go \\
\hline VARIÁVEIS & N.S.Gn I & N.S.Gn F & N.S.Gn PC & Ba.N.Gn I & Ba.N.Gn F & Ba.N.Gn PC & FMA I & FMA F & FMA PC & $\mathrm{N}-\mathrm{Me} \mathrm{I}$ & $\mathrm{N}-\mathrm{Me} \mathrm{F}$ & $\mathrm{N}-\mathrm{Me} \mathrm{PC}$ & S-Gol \\
\hline 12 & 65,1 & 69,3 & 69,4 & 92,5 & 90,6 & 91,8 & 24,7 & 30,5 & 27,9 & 106,1 & 115 & 116,2 & 74,1 \\
\hline 27 & 69,4 & 69,9 & 67,7 & 89,8 & 89 & 91 & 23,1 & 23 & 21,2 & 111,4 & 113 & 114,2 & 75,1 \\
\hline 52 & 67,9 & 69,3 & 69,4 & 87,7 & 86,8 & 85,7 & 31,3 & 33,7 & 30,7 & 105,6 & 114 & 114,3 & 69,8 \\
\hline 65 & 78,2 & 77,7 & 82 & 79,1 & 80,9 & 76,4 & 33,6 & 32 & 35,6 & 109,2 & 112,3 & 115,3 & 59,8 \\
\hline 105 & 73,9 & 73,4 & 72,2 & 83,3 & 83,8 & 84,3 & 32,5 & 33,6 & 30,7 & 111,3 & 115,5 & 113,5 & 66,4 \\
\hline 151 & 72 & 71,5 & 68,4 & 87,4 & 87,3 & 91,4 & 23,7 & 23,8 & 18,8 & 117,1 & 122 & 118,5 & 77,9 \\
\hline 152 & 62,2 & 61,3 & 59,8 & 92,4 & 94 & 97,3 & 17,1 & 15,1 & 13,2 & 104,7 & 112,7 & 110,8 & 81,9 \\
\hline 156 & 74,9 & 76,6 & 75,7 & 80,9 & 77,7 & 78,7 & 27,7 & 30,9 & 30,8 & 118,2 & 122,3 & 121,3 & 72,7 \\
\hline 168 & 66,9 & 62,4 & 62 & 91,1 & 96,4 & 97 & 24,4 & 23,8 & 18 & 109,2 & 110,4 & 109,8 & 74,7 \\
\hline 179 & 69 & 69,1 & 65,5 & 85 & 81,5 & 90,5 & 21,7 & 25,3 & 24,2 & 107,2 & 112,9 & 114 & 70,3 \\
\hline 202 & 70 & 70,4 & 67,8 & 86,6 & 86,9 & 90,5 & 26,7 & 24 & 14,2 & 112,6 & 116,8 & 127,2 & 74,1 \\
\hline 338 & 73,2 & 72,2 & 71,8 & 83,4 & 84,3 & 85,5 & 29,7 & 28,5 & 24,9 & 107,8 & 110,1 & 115,6 & 73,1 \\
\hline Jaqueline $\mathrm{Ca}$ & 66,8 & 67,6 & 67,6 & 89,3 & 88,5 & 88,2 & 19,5 & 18,6 & 19,1 & 104,3 & 108,6 & 111,4 & 74,1 \\
\hline Renata Mutrı & 66.9 & 66,1 & 64,6 & 88,1 & 87,9 & 89,8 & 22,9 & 18,1 & 18,1 & 109,8 & 112,8 & 115,3 & 79,6 \\
\hline
\end{tabular}




\begin{tabular}{|c|c|c|c|c|c|c|c|c|c|c|c|c|c|}
\hline \multicolumn{2}{|l|}{ NÚMERO } & \multicolumn{3}{|c|}{ AFP:AFA } & \multicolumn{3}{|c|}{ AFAl } & \multicolumn{3}{|c|}{ 1s.SN } & \multicolumn{3}{|c|}{ 1.NA } \\
\hline VARIÁVEIS & S-Go F & S-Go PC & AFP:AFA I & AFP:AFA F & AFP:AFA PC & AFAII & AFAI F & AFAI PC & $1 \mathrm{~s} . \mathrm{SN} I$ & 1s.SN F & 1s.SN PC & 1.NAI & 1.NAF \\
\hline 12 & 78,8 & 81,5 & 69,9 & 68,5 & 70,1 & 64,9 & 63,2 & 62,9 & 110,2 & 103,5 & 94,2 & 27,9 & 27 \\
\hline 27 & 75,8 & 78,3 & 67,4 & 67,1 & 68,6 & 65,3 & 67 & 67,7 & 106,1 & 89,7 & 96,7 & 28,1 & 12,6 \\
\hline 52 & 74,2 & 76,5 & 66,1 & 65,1 & 66,9 & 60,3 & 65,9 & 66,2 & 119,8 & 92,8 & 95,3 & 39,7 & 14,7 \\
\hline 65 & 62,5 & 58,5 & 54,8 & 55,7 & 50,7 & 62,3 & 63,5 & 65,3 & 106,1 & 91,6 & 98 & 32,6 & 19,7 \\
\hline 105 & 70,8 & 70,9 & 59,7 & 61,3 & 62,5 & 64,7 & 67,6 & 65,6 & 96,8 & 99,9 & 100,3 & 19,5 & 24,3 \\
\hline 151 & 84,6 & 85,7 & 66,5 & 69,4 & 72,3 & 62,9 & 65,8 & 62,8 & 101,5 & 105,1 & 112 & 23,8 & 29 \\
\hline 152 & 89,6 & 92,1 & 78,2 & 79,5 & 83,1 & 57,1 & 60 & 58,5 & 102,5 & 103,8 & 106,9 & 16,5 & 20,8 \\
\hline 156 & 75 & 75,9 & 61,5 & 61,3 & 62,6 & 68,6 & 72,1 & 71,1 & 97,3 & 92,7 & 85,7 & 19,4 & 15,6 \\
\hline 168 & 79,8 & 82 & 68,4 & 72,3 & 74,7 & 60,9 & 61,7 & 61,5 & 104,3 & 112 & 112,6 & 23,8 & 30,8 \\
\hline 179 & 75,3 & 79,2 & 65,6 & 66,7 & 69,4 & 55,1 & 57,4 & 58,9 & 105,6 & 106,5 & 110,8 & 25,4 & 27,2 \\
\hline 202 & 77,9 & 93,8 & 65,8 & 66,7 & 73,7 & 67,4 & 68 & 73,8 & 99,1 & 94,8 & 100,8 & 20,4 & 18,1 \\
\hline 338 & 76,4 & 81,1 & 67,8 & 69,4 & 70,1 & 62,9 & 65 & 67,8 & 117 & 97,6 & 97,6 & 37,8 & 17,3 \\
\hline Jaqueline $\mathrm{Ca}$ & 78,8 & 80,9 & 71 & 72,5 & 72,7 & 57,2 & 59,1 & 60,7 & 122 & 112,1 & 118,7 & 39,4 & 33,4 \\
\hline Renata Mutrı & 84,8 & 87,7 & 72,5 & 75,1 & 76 & 67,6 & 68,3 & 69,1 & 121,4 & 106,3 & 100,6 & 37,6 & 23 \\
\hline
\end{tabular}




\begin{tabular}{|c|c|c|c|c|c|c|c|c|c|c|c|c|c|}
\hline \multirow{2}{*}{$\begin{array}{c}\text { NÚMERO } \\
\text { VARIÁVEIS }\end{array}$} & \multirow[b]{2}{*}{ 1.NA PC } & \multirow{2}{*}{$\begin{array}{c}\text { 1-NA } \\
\text { 1-NA I }\end{array}$} & \multirow[b]{2}{*}{ 1-NA F } & \multicolumn{3}{|c|}{ 1.NB } & \multicolumn{3}{|c|}{ 1-NB } & \multicolumn{3}{|c|}{ FMAI } & \multirow[b]{2}{*}{ FMIA PC } \\
\hline & & & & 1-NA PC & 1.NB I & 1.NB F & 1.NB PC & 1-NB I & 1-NB F & 1-NB PC & FMIA I & FMIA F & \\
\hline 12 & 18,2 & 8,5 & 3,8 & 2 & 24,5 & 19,9 & 16,1 & 5 & 2,2 & 1,2 & 62,1 & 58,9 & 63,4 \\
\hline 27 & 19,3 & 8,3 & 2,1 & 4,2 & 25,1 & 15,9 & 15,6 & 5 & 1,1 & 1,1 & 63,3 & 72,3 & 73,3 \\
\hline 52 & 16,9 & 7,7 & 0,2 & 1,2 & 17,3 & 13 & 14,8 & 2,6 & 1,6 & 2,1 & 66,3 & 69,4 & 68,6 \\
\hline 65 & 28 & 8,5 & 2,5 & 6,4 & 21,3 & 17,8 & 24 & 4,7 & 2,5 & 5,7 & 64,3 & 68,2 & 58,5 \\
\hline 105 & 24,3 & 2,7 & 3,2 & 3,3 & 26 & 23,9 & 21,4 & 4,1 & 3,4 & 3 & 58,7 & 60,1 & 63,1 \\
\hline 151 & 35,3 & 3,9 & 4,7 & 6,4 & 26,9 & 22,6 & 22,2 & 4,8 & 3,2 & 2,6 & 60,8 & 63,3 & 66,5 \\
\hline 152 & 22,1 & 1 & 3,4 & 3,5 & 23 & 22,1 & 16,8 & 2,8 & 2,1 & 1 & 65,6 & 66,4 & 71,8 \\
\hline 156 & 6,6 & 3,1 & 1,7 & $-0,5$ & 28,1 & 29 & 26,7 & 5,5 & 6,5 & 4,9 & 60,4 & 56,5 & 58,3 \\
\hline 168 & 31 & 4,7 & 6,4 & 5,2 & 22,2 & 22,4 & 17,1 & 3,1 & 3,3 & 2,4 & 65,7 & 62,8 & 72,3 \\
\hline 179 & 27,7 & 3,6 & 3,6 & 2,9 & 24,9 & 26,9 & 20,7 & 3,5 & 3,1 & 2,5 & 66,5 & 59,9 & 67,5 \\
\hline 202 & 22,1 & 3,7 & 4,9 & 5,4 & 26,8 & 32 & 20,2 & 5,4 & 4,6 & 2,6 & 58,7 & 55,5 & 71,6 \\
\hline 338 & 17,8 & 10,8 & 2,8 & 3,7 & 25,3 & 29,2 & 23,4 & 8 & 6,9 & 5,7 & 57,7 & 54,2 & 62,2 \\
\hline Jaqueline $\mathrm{Ca}$ & 38,2 & 10,7 & 7,4 & 7,5 & 34,2 & 27,9 & 33,4 & 6,6 & 5 & 6 & 55,5 & 61,4 & 54,7 \\
\hline Renata Mutrı & 16,8 & 9,2 & 3 & 1,7 & 22,8 & 36,6 & 29,2 & 5 & 4,5 & 3,8 & 63,2 & 52,7 & 57,9 \\
\hline
\end{tabular}




\begin{tabular}{|c|c|c|c|c|c|c|c|c|c|c|c|c|c|}
\hline NÚMERO & IMPA & & & 1i-APg & & & 1.1 & & & Ls-E & & & Li-E \\
\hline VARIÁVEIS & IMPA I & IMPA F & IMPA PC & 1i-Apg I & 1i-APg F & 1i-APg PC & 1.11 & $1.1 \mathrm{~F}$ & 1.1 PC & Ls-E I & Ls-E F & Ls-E PC & $\mathrm{Li}-\mathrm{E}$ \\
\hline 12 & 93,2 & 90,6 & 88,7 & 3,5 & $-0,5$ & $-1,6$ & 125,7 & 131,4 & 144,1 & $-0,6$ & $-8,6$ & $-11,9$ & 1,8 \\
\hline 27 & 93,6 & 84,7 & 85,4 & 3,4 & $-0,3$ & $-0,2$ & 125 & 150,7 & 144,7 & 0,3 & $-2,5$ & $-6,2$ & 2,6 \\
\hline 52 & 82,4 & 76,9 & 80,7 & $-0,6$ & $-1,4$ & $-1,3$ & 119,2 & 149,4 & 144,8 & $-2,1$ & $-5,8$ & $-5,7$ & -1 \\
\hline 65 & 82,1 & 79,8 & 85,9 & 2,5 & 0 & 1,1 & 122,5 & 139,6 & 122,1 & $-1,2$ & $-4,6$ & $-3,1$ & 1,3 \\
\hline 105 & 88,7 & 86,3 & 86,1 & 1,2 & 1,6 & 0,8 & 130 & 130,2 & 132,4 & $-2,8$ & $-6,3$ & $-7,6$ & $-3,2$ \\
\hline 151 & 95,5 & 92,9 & 94,8 & 2,3 & 1,7 & 2,2 & 126,7 & 128,1 & 123,8 & $-2,6$ & $-4,1$ & $-10,6$ & $-0,8$ \\
\hline 152 & 97,4 & 98,5 & 95 & 0,5 & $-0,1$ & -1 & 137,6 & 136,9 & 141,3 & $-2,4$ & -5 & $-6,8$ & $-1,3$ \\
\hline 156 & 91,9 & 92,6 & 90,9 & 3,1 & 2,8 & 0,7 & 128,7 & 130,5 & 140,7 & $-3,4$ & $-3,9$ & $-5,5$ & $-0,6$ \\
\hline 168 & 89,9 & 93,4 & 89,7 & 1,6 & 1,3 & 0,1 & 132,5 & 127 & 131,9 & $-3,9$ & $-8,7$ & $-9,8$ & $-1,1$ \\
\hline 179 & 91,9 & 94,8 & 88,2 & 1,2 & 0,8 & $-0,2$ & 126,8 & 123,6 & 129,2 & $-2,5$ & $-6,2$ & $-7,4$ & $-3,3$ \\
\hline 202 & 94,6 & 100,4 & 94,3 & 3,2 & 2,9 & 0,8 & 129,8 & 128,8 & 137,7 & $-2,1$ & $-2,8$ & $-8,1$ & $-0,9$ \\
\hline 338 & 92,6 & 97,3 & 92,9 & 4,9 & 3,7 & 2,4 & 112,5 & 129,3 & 134,9 & 0,7 & $-1,5$ & $-3,7$ & 4,1 \\
\hline Jaqueline $\mathrm{Ca}$ & 105,1 & 100 & 106,1 & 4,1 & 4 & 3,9 & 103,1 & 118,7 & 106,7 & 1,7 & $-4,2$ & $-4,5$ & 2,6 \\
\hline Renata Mutrı & 93.9 & 109,2 & 103.9 & 1,9 & 1,9 & 0 & 115,8 & 118 & 130,6 & $-2,7$ & $-5,1$ & $-9,5$ & $-1,9$ \\
\hline
\end{tabular}




\begin{tabular}{|c|c|c|c|c|c|c|c|c|}
\hline NÚMERO & & & $\mathrm{Z}$ & & & H-Pn & & \\
\hline VARIÁVEIS & Li-E F & Li-E PC & $\mathrm{ZI}$ & ZF & $\mathrm{ZPC}$ & H-Pn I & $\mathrm{H}-\mathrm{Pn} \mathrm{F}$ & H-Pn PC \\
\hline 12 & $-7,7$ & $-10,4$ & 64,9 & 76,9 & 79,2 & 0,9 & 15,2 & 20,2 \\
\hline 27 & $-1,8$ & $-3,4$ & 64,9 & 78 & 84 & $-0,5$ & 4 & 10,4 \\
\hline 52 & -4 & $-4,2$ & 71,2 & 75,4 & 75,9 & 3,7 & 10,3 & 10 \\
\hline 65 & $-1,9$ & 1,3 & 63,9 & 72,6 & 58,5 & 2 & 8,2 & 5,1 \\
\hline 105 & $-7,1$ & $-8,5$ & 72,3 & 77,3 & 80,2 & 4,5 & 11,2 & 12,5 \\
\hline 151 & $-3,3$ & $-6,7$ & 73,6 & 77,9 & 88,5 & 4,5 & 7 & 16,2 \\
\hline 152 & $-4,8$ & $-5,6$ & 75,2 & 78,5 & 81,1 & 4,3 & 9,3 & 13 \\
\hline 156 & $-0,7$ & $-3,1$ & 71,9 & 67,7 & 72,2 & 5,3 & 6,5 & 8,7 \\
\hline 168 & $-4,6$ & $-5,7$ & 74 & 82,5 & 88,9 & 7,2 & 15,3 & 17,7 \\
\hline 179 & $-5,7$ & $-8,2$ & 77,9 & 77,4 & 81,2 & 4,4 & 10,9 & 12,4 \\
\hline 202 & -2 & $-6,8$ & 76,9 & 79,5 & 92,4 & 3,7 & 4,9 & 14,1 \\
\hline 338 & -1 & $-0,8$ & 58,7 & 70,4 & 71,8 & $-1,1$ & 2,3 & 6,2 \\
\hline Jaqueline $\mathrm{Ca}$ & $-3,3$ & $-2,1$ & 67,1 & 83,1 & 77,2 & $-2,8$ & 7,4 & 7,8 \\
\hline Renata Mutrı & $-5,8$ & $-7,3$ & 75,7 & 82,5 & 92 & 4,6 & 8,6 & 16,7 \\
\hline
\end{tabular}




\begin{tabular}{|c|c|c|c|c|c|c|c|c|c|c|c|c|c|}
\hline $\begin{array}{l}\text { NÚMERO } \\
\text { VARIÁVEIS }\end{array}$ & $\begin{array}{l}\text { SNA } \\
\text { SNA I }\end{array}$ & SNA F & SNA PC & $\begin{array}{l}\text { A-Nperp } \\
\text { A-Nperpl }\end{array}$ & A-NperpF & A-NperpPC & $\begin{array}{l}\text { Co-A } \\
\text { Co-A I }\end{array}$ & Co-A F & Co-A PC & $\begin{array}{c}\text { Ar-A } \\
\text { Ar-A I }\end{array}$ & Ar-A F & Ar-A PC & $\begin{array}{l}\text { SNB } \\
\text { SNB I }\end{array}$ \\
\hline 4 & 77,7 & 74,9 & 75,1 & $-3,2$ & $-3,6$ & $-3,8$ & 77,2 & 79 & 83,7 & 77,8 & 77,9 & 82,4 & 72,9 \\
\hline 29 & 78 & 75,2 & 77,5 & $-6,5$ & $-9,4$ & $-4,9$ & 76 & 75,7 & 77,5 & 76,6 & 75,7 & 76,2 & 74 \\
\hline 43 & 75,9 & 70,2 & 72,2 & $-1,6$ & $-8,5$ & $-7,8$ & 81,3 & 82,6 & 82,6 & 80,2 & 77,7 & 79 & 70,9 \\
\hline 49 & 78,3 & 73,9 & 75,3 & $-0,9$ & $-2,7$ & $-3,3$ & 83,5 & 85,3 & 83,7 & 83,1 & 83,7 & 81,9 & 70,6 \\
\hline 73 & 77,3 & 78,8 & 80,7 & -2 & $-3,8$ & $-3,5$ & 84,9 & 90,1 & 90,8 & 83,4 & 86,7 & 86,5 & 73,4 \\
\hline 74 & 74,6 & 74,9 & 75,8 & $-5,4$ & -4 & $-5,5$ & 76,9 & 82,7 & 84,5 & 76,7 & 80,4 & 78,9 & 71,5 \\
\hline 97 & 81,7 & 78,3 & 79,1 & 2,3 & $-0,4$ & $-1,7$ & 86,7 & 90,3 & 90,2 & 85,3 & 87,7 & 87,3 & 74,8 \\
\hline 107 & 84,9 & 80,1 & 80 & $-0,1$ & $-6,8$ & $-7,9$ & 92,2 & 94,8 & 95,6 & 89,3 & 89,8 & 91,8 & 78 \\
\hline 122 & 81,5 & 77,4 & 78,8 & -2 & $-2,3$ & $-3,1$ & 89,7 & 89,9 & 91,3 & 87,2 & 87,5 & 89,8 & 76,4 \\
\hline 129 & 79,2 & 79 & 79,5 & $-0,5$ & 0,5 & 1,1 & 82,9 & 85,8 & 86,1 & 82,8 & 84 & 84 & 75,3 \\
\hline 147 & 79 & 78 & 78,3 & $-6,6$ & $-7,6$ & $-7,2$ & 85,6 & 86,8 & 86,1 & 83,6 & 83,3 & 84,3 & 76,5 \\
\hline 157 & 82,6 & 79,4 & 82,1 & $-0,3$ & $-5,6$ & $-0,2$ & 76,3 & 78 & 80,9 & 77,2 & 78,5 & 82 & 75,6 \\
\hline 185 & 73,4 & 70,8 & 71,4 & $-5,2$ & $-7,8$ & $-7,7$ & 78 & 79,6 & 83,3 & 76,8 & 77 & 78,9 & 71,8 \\
\hline 188 & 77,1 & 76,2 & 75,6 & $-1,5$ & $-2,5$ & $-2,3$ & 80,1 & 79,9 & 80,1 & 77 & 76,3 & 77,6 & 70,7 \\
\hline 196 & 80 & 75,6 & 78,3 & $-4,2$ & $-12,9$ & $-10,4$ & 84,7 & 80,3 & 84,4 & 81,4 & 77,3 & 80 & 74,3 \\
\hline 235 & 80,8 & 80 & 79,9 & $-1,4$ & $-1,8$ & $-2,5$ & 84,3 & 81,4 & 86,1 & 83,2 & 81,6 & 85,2 & 75,9 \\
\hline 255 & 74,7 & 72,2 & 73 & 1,3 & 1,2 & 0,4 & 81,9 & 83,4 & 84,2 & 82 & 81,4 & 82,1 & 70,2 \\
\hline 257 & 80,6 & 78,5 & 79,6 & 0,9 & $-1,9$ & $-0,6$ & 81,1 & 78,8 & 81,3 & 78,4 & 75,5 & 79,1 & 77,4 \\
\hline 368 & 77,6 & 77,2 & 76,3 & $-2,1$ & -3 & $-1,4$ & 80,6 & 80,2 & 84,2 & 79,5 & 78,9 & 80,8 & 73,5 \\
\hline =abio Lucianc & 82,4 & 79,8 & 80 & 0,6 & $-2,1$ & $-1,3$ & 93 & 90,6 & 92,8 & 91,8 & 90,6 & 92,4 & 74,2 \\
\hline anaina Borge & 73,7 & 74,9 & 78,3 & $-2,4$ & $-0,4$ & 1,5 & 82,3 & 81,9 & 85,9 & 81,4 & 82,3 & 84,9 & 73,8 \\
\hline 「aniaMoraı & 79 & 78,6 & 78,5 & $-0,1$ & $-3,7$ & $-4,6$ & 89,2 & 88,1 & 86,7 & 84,2 & 85,3 & 85,5 & 75 \\
\hline TelmaAbes & 81 & 78,9 & 78,7 & 0,1 & 1,1 & $-0,5$ & 87,6 & 88,3 & 90 & 87,2 & 87,2 & 88,8 & 74,9 \\
\hline
\end{tabular}




\begin{tabular}{|c|c|c|c|c|c|c|c|c|c|c|c|c|c|}
\hline \multicolumn{2}{|l|}{ NÚMERO } & \multicolumn{3}{|c|}{ Pg-Nperp } & \multicolumn{3}{|c|}{ Co-Gn } & \multicolumn{3}{|c|}{ Ar-Gn } & \multicolumn{3}{|c|}{ ANB } \\
\hline VARIÁVEIS & SNB F & SNB PC & Pg-Nperpl & $\mathrm{Pg}$-NperpF & Pg-NperpPC & Co-Gn I & Co-Gn F & Co-Gn PC & Ar-Gn I & $A r-G n F$ & Ar-Gn PC & ANB I & ANB $F$ \\
\hline 4 & 73,2 & 72,3 & $-12,9$ & $-7,7$ & $-8,5$ & 94,2 & 103 & 107,2 & 90 & 96,5 & 100,4 & 4,8 & 1,7 \\
\hline 29 & 71,4 & 72,4 & $-16,5$ & $-19,9$ & $-14,5$ & 99,6 & 103,1 & 105,1 & 97,3 & 98,8 & 97,9 & 4 & 3,8 \\
\hline 43 & 70,3 & 72,5 & -10 & $-14,5$ & -12 & 97,5 & 108,7 & 109,9 & 91,1 & 98,5 & 101 & 5 & $-0,1$ \\
\hline 49 & 67,9 & 68,7 & $-15,4$ & $-14,2$ & $-16,5$ & 102,7 & 108 & 108,2 & 98,1 & 101,8 & 101 & 7,7 & 6 \\
\hline 73 & 75,8 & 76,7 & $-8,5$ & $-9,1$ & $-9,8$ & 108,5 & 118,8 & 119,7 & 102,8 & 110,9 & 111 & 3,9 & 3 \\
\hline 74 & 72,9 & 73,9 & $-15,7$ & $-9,7$ & $-10,9$ & 96,4 & 107,3 & 109,1 & 92,9 & 101,1 & 97,9 & 3,1 & 2 \\
\hline 97 & 73,7 & 75,8 & $-7,6$ & $-8,8$ & $-7,4$ & 106,3 & 114,7 & 118 & 97,9 & 105,3 & 108,2 & 6,9 & 4,6 \\
\hline 107 & 77,1 & 77 & $-10,9$ & $-13,2$ & $-13,8$ & 116,9 & 128,1 & 128,9 & 106,5 & 116,3 & 119,3 & 6,9 & 3 \\
\hline 122 & 76,5 & 77,1 & -11 & $-4,3$ & $-6,2$ & 109,4 & 115,3 & 118,3 & 101,2 & 107,6 & 111,6 & 5,1 & 0,9 \\
\hline 129 & 74,8 & 75,1 & $-8,9$ & $-6,7$ & $-6,3$ & 105,7 & 108,5 & 109,1 & 100 & 100,7 & 101 & 3,9 & 4,2 \\
\hline 147 & 76,8 & 77,5 & -15 & $-13,2$ & $-11,5$ & 104,4 & 107,2 & 107,1 & 96,4 & 98 & 99,1 & 2,5 & 1,2 \\
\hline 157 & 77,5 & 78,8 & $-9,3$ & $-10,6$ & -2 & 97 & 104,5 & 106,3 & 94,3 & 101,9 & 104,6 & 7 & 1,9 \\
\hline 185 & 70,2 & 69,1 & $-12,1$ & $-13,6$ & $-16,8$ & 98,1 & 103,8 & 108,3 & 91,1 & 94,9 & 98,3 & 1,6 & 0,6 \\
\hline 188 & 71,2 & 70,3 & $-12,4$ & $-10,9$ & $-10,8$ & 103,3 & 106,6 & 106,7 & 94,1 & 97,3 & 98 & 6,4 & 5 \\
\hline 196 & 75,5 & 77,8 & $-14,8$ & $-18,1$ & $-14,6$ & 102 & 108,7 & 113,2 & 93,2 & 100 & 102,2 & 5,7 & 0,1 \\
\hline 235 & 76,5 & 77,7 & $-9,4$ & $-7,6$ & $-5,9$ & 101,7 & 99,7 & 106,1 & 96,7 & 95,5 & 101 & 4,9 & 3,5 \\
\hline 255 & 67,5 & 67,3 & -3 & $-2,8$ & $-5,5$ & 103,2 & 105,8 & 106,2 & 99,2 & 98,9 & 99 & 4,5 & 4,7 \\
\hline 257 & 76,9 & 76,6 & $-2,3$ & $-2,1$ & $-1,8$ & 101,6 & 102,8 & 105,9 & 94,5 & 95,7 & 99,6 & 3,2 & 1,6 \\
\hline 368 & 75,6 & 75,4 & -9 & $-5,6$ & $-0,7$ & 106,1 & 109,8 & 117,2 & 99,1 & 102,7 & 107,4 & 4,1 & 1,6 \\
\hline =abio Lucianc & 74,3 & 74,2 & $-13,8$ & $-13,1$ & $-12,8$ & 117,6 & 120,1 & 121,6 & 110,5 & 114,5 & 115,3 & 8,2 & 5,5 \\
\hline anaina Borge & 74,9 & 76,4 & $-4,1$ & $-0,3$ & $-0,2$ & 108,1 & 109,5 & 111,2 & 103 & 105,1 & 105,8 & $-0,1$ & 0 \\
\hline 「aniaMoraı & 76,7 & 76,6 & $-3,9$ & $-7,1$ & $-7,6$ & 110 & 112,3 & 111,7 & 99,9 & 104,7 & 106,2 & 4 & 1,9 \\
\hline TelmaAbes & 73,6 & 73,5 & $-8,6$ & $-4,5$ & $-6,8$ & 108,5 & 110,7 & 112,5 & 103,5 & 104,9 & 106,7 & 6,1 & 5,3 \\
\hline
\end{tabular}




\begin{tabular}{|c|c|c|c|c|c|c|c|c|c|c|c|c|c|}
\hline NÚMERO & & WITS & & & SN.PP & & & SN.Ocl & & & SN.GoMe & & \\
\hline VARIÁVEIS & ANB PC & WITS I & WITS F & WITS PC & SN.PP I & SN.PP F & SN.PP PC & SN.Ocl I & SN.Ocl F & SN.Ocl PC & SN.GoMe I & SN.GoMe F & SN.GoMe PC \\
\hline 4 & 2,8 & 0,7 & $-0,4$ & 0,6 & 11,2 & 11,5 & 11,5 & 23,3 & 19,5 & 22,3 & 33,4 & 34,5 & 31,8 \\
\hline 29 & 5,1 & 0,9 & $-0,9$ & 0,9 & 7,7 & 10,2 & 8,8 & 19,5 & 24,5 & 22,8 & 35 & 37,1 & 36,5 \\
\hline 43 & $-0,3$ & -1 & $-0,1$ & $-3,4$ & 13,2 & 16,2 & 14,5 & 29,1 & 20,3 & 22,8 & 34,5 & 39,7 & 35,2 \\
\hline 49 & 6,6 & 3,2 & 1,4 & 2,6 & 9,9 & 14,8 & 13 & 26,6 & 29,7 & 27,4 & 44,8 & 46,2 & 45,4 \\
\hline 73 & 4 & $-0,6$ & $-1,4$ & 1,4 & 15,9 & 14,7 & 12,7 & 22,5 & 21,4 & 16,2 & 38,4 & 35,5 & 33,6 \\
\hline 74 & 1,9 & $-1,9$ & $-2,6$ & $-1,1$ & 13,4 & 11,1 & 11,1 & 26,1 & 23,9 & 20,9 & 39,5 & 37,6 & 35,9 \\
\hline 97 & 3,3 & 1 & $-1,4$ & 0 & 6,9 & 11,8 & 10,6 & 23,4 & 26,9 & 22,2 & 34,6 & 36,5 & 32,8 \\
\hline 107 & 3 & 1,5 & 2 & 4,1 & 6,8 & 9,9 & 9,4 & 20,2 & 15,2 & 12,5 & 29,8 & 29,6 & 25,3 \\
\hline 122 & 1,7 & $-0,5$ & -2 & $-2,7$ & 4,2 & 8 & 7,5 & 22,6 & 19,4 & 20,4 & 32,6 & 31,9 & 28,4 \\
\hline 129 & 4,4 & $-1,5$ & $-1,2$ & $-0,3$ & 8,9 & 9,4 & 9,7 & 22,3 & 21,3 & 22,4 & 38,4 & 36,4 & 37,1 \\
\hline 147 & 0,8 & 1,3 & 2,6 & 0,4 & 6,5 & 7,7 & 7,3 & 16 & 10,3 & 13,7 & 27,5 & 25,8 & 24,5 \\
\hline 157 & 3,3 & 2,9 & 3,1 & 6,3 & 8,1 & 10,2 & 7 & 17,6 & 9,5 & 6 & 33 & 32,7 & 28,8 \\
\hline 185 & 2,3 & $-3,6$ & $-0,9$ & 0,7 & 10,2 & 10,9 & 8,6 & 25,3 & 22,1 & 24,5 & 36,4 & 38,4 & 40,5 \\
\hline 188 & 5,3 & 0,4 & $-0,8$ & 0,3 & 6 & 6,2 & 8,5 & 27,4 & 27,9 & 28,1 & 43,8 & 43,3 & 44,3 \\
\hline 196 & 0,5 & 2,4 & 1,9 & 2,3 & 5,5 & 5,8 & 4,5 & 19,3 & 9,7 & 9,9 & 26,1 & 24,9 & 20,3 \\
\hline 235 & 2,2 & 2,3 & 1,2 & 0 & 10,8 & 10,8 & 8,9 & 17,9 & 17,6 & 17,4 & 27,7 & 24,6 & 23,3 \\
\hline 255 & 5,7 & $-2,2$ & 0,2 & $-0,5$ & 14,2 & 15,5 & 15,6 & 30,1 & 30 & 33,5 & 39,4 & 42,2 & 42,4 \\
\hline 257 & 3 & $-0,7$ & $-1,7$ & 0,3 & 13,1 & 13,1 & 11,8 & 20,2 & 21 & 19,7 & 28,4 & 26,9 & 28,6 \\
\hline 368 & 0,9 & 0,1 & 0,9 & $-1,7$ & 7,3 & 7,2 & 7,8 & 23,7 & 17 & 19,4 & 35,7 & 34,7 & 34,8 \\
\hline =abio Lucianc & 5,8 & 6,5 & 5,9 & 5,4 & 3,5 & 6,1 & 5 & 19,4 & 16,5 & 18,8 & 35 & 35,8 & 34,5 \\
\hline anaina Borge & 1,9 & $-4,5$ & -4 & $-0,3$ & 9 & 12,1 & 8,2 & 23 & 20,8 & 16,6 & 35,2 & 35,4 & 32,3 \\
\hline 「aniaMoraı & 1,9 & 2,1 & $-1,9$ & 0,6 & 8,3 & 8,6 & 8,9 & 16,9 & 19,2 & 15,2 & 35,5 & 34,5 & 32,7 \\
\hline TelmaAbes & 5,2 & 2,2 & 4,4 & 1,8 & 9,4 & 12,3 & 11,2 & 20,4 & 17,3 & 23 & 33,7 & 33,8 & 33,2 \\
\hline
\end{tabular}




\begin{tabular}{|c|c|c|c|c|c|c|c|c|c|c|c|c|c|}
\hline NÚMERO & N.S.Gn & & & Ba.N.Gn & & & FMA & & & $\mathrm{N}-\mathrm{Me}$ & & & S-Go \\
\hline VARIÁVEIS & N.S.Gn I & N.S.Gn F & N.S.Gn PC & Ba.N.Gn I & Ba.N.Gn F & Ba.N.Gn PC & FMA I & FMA F & FMA PC & $\mathrm{N}-\mathrm{Me} \mathrm{I}$ & $\mathrm{N}-\mathrm{Me} \mathrm{F}$ & $\mathrm{N}-\mathrm{Me} \mathrm{PC}$ & S-GoI \\
\hline 4 & 71,6 & 72,4 & 72,2 & 88,6 & 87,5 & 88,2 & 24,5 & 23 & 20,5 & 103,7 & 110,1 & 113,7 & 70,8 \\
\hline 29 & 70,1 & 71,9 & 72,5 & 92,4 & 88 & 87 & 30 & 32,2 & 29,2 & 109,9 & 115,2 & 115,8 & 73,1 \\
\hline 43 & 70,8 & 73,7 & 70,9 & 91,8 & 87,1 & 88,6 & 22,2 & 28,3 & 25,2 & 101 & 115,8 & 114 & 66,8 \\
\hline 49 & 75,9 & 78 & 77,6 & 84,3 & 82,7 & 84,8 & 34 & 32,5 & 33,8 & 116,9 & 122,9 & 122,9 & 72,4 \\
\hline 73 & 72 & 69,4 & 68,8 & 88,4 & 89,8 & 89,2 & 27,6 & 27,8 & 27,6 & 114,9 & 122,1 & 120,8 & 72,9 \\
\hline 74 & 74,8 & 73,1 & 71,4 & 85,7 & 84,8 & 85,7 & 29,8 & 26,1 & 26,7 & 108,7 & 116,7 & 116,7 & 69,4 \\
\hline 97 & 70,6 & 72,4 & 70,3 & 86,2 & 84,3 & 84,1 & 24 & 25,1 & 23,5 & 113,6 & 123,2 & 122 & 77,2 \\
\hline 107 & 67 & 67,5 & 67,1 & 84,8 & 85,3 & 87 & 24,8 & 25,5 & 22,1 & 120,6 & 133,5 & 132,3 & 87,7 \\
\hline 122 & 66,7 & 67,1 & 65,7 & 89,1 & 90 & 90,4 & 26,2 & 21,6 & 20,1 & 110,9 & 118 & 121,4 & 76,3 \\
\hline 129 & 72,3 & 71,9 & 72,2 & 89,9 & 90 & 90,5 & 28,2 & 24,8 & 25,4 & 112,2 & 111,8 & 111,7 & 72,5 \\
\hline 147 & 67,5 & 66,6 & 66,2 & 88,6 & 90,2 & 90,6 & 23,2 & 21,3 & 19,7 & 106,8 & 106,5 & 107,5 & 78,5 \\
\hline 157 & 68,7 & 68,6 & 67,6 & 91 & 90,6 & 92,1 & 25,9 & 28,4 & 21,1 & 100,8 & 108,4 & 110,6 & 71 \\
\hline 185 & 72,8 & 73,6 & 74,4 & 86,2 & 86 & 83,4 & 25,4 & 26,8 & 29,1 & 107,6 & 114,2 & 119,2 & 69,5 \\
\hline 188 & 75,6 & 75,7 & 77,2 & 82,3 & 82,1 & 81,8 & 32,5 & 32,1 & 32,2 & 114,3 & 116,8 & 117,7 & 70,5 \\
\hline 196 & 67,3 & 65,3 & 63,1 & 86,3 & 88,4 & 89,9 & 20,7 & 22,7 & 18,9 & 106,8 & 115,8 & 114 & 78,7 \\
\hline 235 & 68,4 & 67,2 & 66,4 & 89,3 & 91,8 & 90,8 & 20 & 16,5 & 15,7 & 105,4 & 102,5 & 107,4 & 76,2 \\
\hline 255 & 74,9 & 76,6 & 77,8 & 89,6 & 88,1 & 86,6 & 22,7 & 23,2 & 25 & 110,1 & 113,8 & 114 & 71,2 \\
\hline 257 & 67,9 & 66,5 & 67,1 & 89 & 90,4 & 88,4 & 18,1 & 17,3 & 18,8 & 104,8 & 103,7 & 109,6 & 75,3 \\
\hline 368 & 71,4 & 70,8 & 71 & 84,8 & 85,5 & 86,6 & 25,4 & 24,6 & 22,3 & 115 & 118 & 122,4 & 78 \\
\hline =abio Lucianc & 71,8 & 72,1 & 72,6 & 86,3 & 87 & 86,4 & 26,9 & 27,3 & 25,6 & 127,5 & 130,9 & 131,2 & 86,9 \\
\hline anaina Borge & 70 & 69,9 & 68,3 & 93,3 & 92,3 & 93,8 & 21,6 & 20,7 & 19 & 108,2 & 109,8 & 109,1 & 69,6 \\
\hline 「aniaMoraı & 68,5 & 66,9 & 66,5 & 88,9 & 90,4 & 92,4 & 24,6 & 27 & 26 & 108,3 & 113,2 & 112,7 & 70,6 \\
\hline TelmaAbes & 68,8 & 69,8 & 69,1 & 90,9 & 91,7 & 91,1 & 24,6 & 21,6 & 22,4 & 111,2 & 113 & 114,5 & 74,7 \\
\hline
\end{tabular}




\begin{tabular}{|c|c|c|c|c|c|c|c|c|c|c|c|c|c|}
\hline \multicolumn{2}{|l|}{ NÚMERO } & \multicolumn{3}{|c|}{ AFP:AFA } & \multicolumn{3}{|c|}{ AFAI } & \multicolumn{3}{|c|}{ 1s.SN } & \multicolumn{3}{|c|}{ 1.NA } \\
\hline VARIÁVEIS & S-Go F & S-Go PC & AFP:AFA I & AFP:AFA F & AFP:AFA PC & AFAII & AFAI F & AFAI PC & 1s.SN I & 1s.SN F & 1s.SN PC & 1.NAI & 1.NAF \\
\hline 4 & 75,7 & 79,8 & 68,3 & 68,8 & 70,2 & 59,7 & 63,6 & 65,1 & 112,6 & 100,1 & 100,1 & 34,9 & 25,2 \\
\hline 29 & 75,5 & 77,1 & 66,5 & 65,5 & 66,6 & 65 & 68,2 & 69,5 & 105,9 & 86,8 & 90,2 & 27,9 & 11,6 \\
\hline 43 & 73,9 & 77,9 & 66,2 & 63,8 & 68,3 & 55,2 & 63,1 & 61,1 & 105,6 & 94 & 99 & 29,7 & 23,8 \\
\hline 49 & 74,5 & 75,1 & 61,9 & 60,6 & 61,1 & 70,8 & 72 & 72,8 & 102,5 & 92 & 93,6 & 24,1 & 18,1 \\
\hline 73 & 83 & 84,8 & 63,5 & 68 & 70,2 & 61,4 & 66,7 & 68 & 107,9 & 98 & 102,6 & 30,5 & 19,1 \\
\hline 74 & 77 & 77,9 & 63,9 & 66 & 66,7 & 58,6 & 63,7 & 64 & 97,2 & 96 & 96,9 & 22,6 & 21,2 \\
\hline 97 & 82,2 & 85,2 & 68 & 66,7 & 69,9 & 65,3 & 68,5 & 67,6 & 97,8 & 96,4 & 97,1 & 16,1 & 18 \\
\hline 107 & 98,3 & 102 & 72,7 & 73,7 & 77,1 & 69,5 & 77,1 & 75,7 & 113,9 & 98,5 & 100,4 & 29 & 18,3 \\
\hline 122 & 81,2 & 86,9 & 68,8 & 68,8 & 71,6 & 66 & 69,1 & 71,9 & 96,1 & 107,6 & 104,3 & 14,6 & 30,1 \\
\hline 129 & 74,6 & 73,6 & 64,7 & 66,7 & 65,9 & 68,6 & 67,7 & 67 & 92 & 95,4 & 94,3 & 12,8 & 16,5 \\
\hline 147 & 79,7 & 82,1 & 73,5 & 74,9 & 76,4 & 57,6 & 57,3 & 57,1 & 106,8 & 110 & 114 & 27,8 & 31,9 \\
\hline 157 & 77 & 83,1 & 70,4 & 71 & 75,1 & 59,7 & 61,8 & 63,4 & 124,1 & 104,6 & 104,6 & 41,5 & 25,1 \\
\hline 185 & 74,1 & 73 & 64,6 & 64,9 & 61,2 & 60,4 & 63,6 & 70,2 & 97,6 & 99 & 93,6 & 24,2 & 28,3 \\
\hline 188 & 72,9 & 72 & 61,7 & 62,4 & 61,2 & 70 & 73,4 & 70,7 & 116,6 & 97,9 & 106,5 & 39,5 & 21,6 \\
\hline 196 & 87,7 & 91,5 & 73,7 & 75,8 & 80,2 & 59,2 & 64,5 & 64,7 & 77,5 & 111,9 & 110,5 & $-2,5$ & 36,2 \\
\hline 235 & 77 & 82,2 & 72,2 & 75,1 & 76,5 & 57,3 & 54,1 & 57,1 & 120,9 & 103,2 & 100,2 & 40,1 & 23,2 \\
\hline 255 & 72,5 & 70,5 & 64,6 & 63,7 & 61,8 & 60,8 & 63,5 & 63 & 100,5 & 83,8 & 80,6 & 25,9 & 11,6 \\
\hline 257 & 75,2 & 76,8 & 71,8 & 72,6 & 70,1 & 55,7 & 53,9 & 57,1 & 93,3 & 111,9 & 102,7 & 12,7 & 33,5 \\
\hline 368 & 81,3 & 84,7 & 67,9 & 68,9 & 69,2 & 65 & 66,5 & 71,2 & 114,8 & 110,3 & 108,8 & 37,2 & 33,1 \\
\hline =abio Lucianc & 89,9 & 92,1 & 68,2 & 68,7 & 70,2 & 81,2 & 82,4 & 82,8 & 104,9 & 100,3 & 98,4 & 22,4 & 20,5 \\
\hline anaina Borge & 70,2 & 73,3 & 64,3 & 63,9 & 67,2 & 61,9 & 63 & 63,3 & 111,5 & 106,5 & 105,1 & 37,8 & 31,6 \\
\hline 「aniaMoraı & 75,3 & 76,5 & 65,2 & 66,5 & 67,9 & 61,2 & 63,8 & 63,2 & 107,2 & 101,3 & 103,2 & 28,2 & 22,7 \\
\hline TelmaAbes & 75,5 & 76,5 & 67,2 & 66,8 & 66,8 & 64,1 & 63,8 & 64,1 & 116,3 & 92,3 & 85,8 & 35,3 & 13,4 \\
\hline
\end{tabular}




\begin{tabular}{|c|c|c|c|c|c|c|c|c|c|c|c|c|c|}
\hline NÚMERO & & 1-NA & & & $1 . \mathrm{NB}$ & & & 1-NB & & & FMAI & & \\
\hline VARIÁVEIS & 1.NA PC & 1-NA I & 1-NA F & 1-NA PC & 1.NB I & 1.NB F & 1.NB PC & 1-NB I & 1-NB F & 1-NB PC & FMIA I & FMIA F & FMIA PC \\
\hline 4 & 25 & 7,6 & 3,8 & 4,7 & 30,7 & 22,1 & 25,7 & 6,3 & 3,6 & 4,5 & 51 & 62,6 & 57,9 \\
\hline 29 & 12,7 & 7 & 1,1 & 0,1 & 21,7 & 24,8 & 19,4 & 3,7 & 3,7 & 2,4 & 57,3 & 51,5 & 60,3 \\
\hline 43 & 26,8 & 8,5 & 4,1 & 6,9 & 23,4 & 13,1 & 19,6 & 3,9 & 1,4 & 1,9 & 59,9 & 68,6 & 62,9 \\
\hline 49 & 18,3 & 4,9 & $-1,8$ & 0,1 & 30,8 & 28,5 & 27,8 & 6,9 & 4,2 & 5,4 & 50,6 & 53,1 & 52,7 \\
\hline 73 & 21,9 & 7 & 1,2 & 2,8 & 32,9 & 20,5 & 19,1 & 5,6 & 3,3 & 3,4 & 51,2 & 63 & 63,6 \\
\hline 74 & 21,2 & 4,9 & 3,2 & 3,7 & 22 & 19,1 & 17,2 & 4,4 & 3,2 & 2,3 & 59,2 & 65,4 & 65,9 \\
\hline 97 & 18 & 2,7 & 1 & 2,1 & 37,2 & 26 & 24,2 & 8,5 & 4,1 & 3,6 & 48,2 & 59,1 & 60,9 \\
\hline 107 & 20,4 & 5,8 & 1,8 & 2,3 & 22,3 & 24,3 & 19,6 & 5,2 & 5,1 & 3,7 & 60,7 & 56,8 & 60,6 \\
\hline 122 & 25,5 & 2,8 & 4,8 & 4,7 & 25,8 & 27,9 & 21,5 & 5,7 & 3,3 & 3,8 & 57,1 & 58,9 & 64 \\
\hline 129 & 14,8 & 1,9 & 1,7 & 1,4 & 22,5 & 24,7 & 25,6 & 4,4 & 4,9 & 4,5 & 63,1 & 61,7 & 61,2 \\
\hline 147 & 35,7 & 5,6 & 2,9 & 3,9 & 26,4 & 21,8 & 20 & 4,4 & 1,5 & 1,2 & 54,4 & 59,5 & 62,4 \\
\hline 157 & 22,6 & 12,1 & 4,5 & 4,2 & 27,5 & 21,9 & 22,9 & 8,7 & 4,4 & 4,2 & 55,2 & 59,9 & 63,6 \\
\hline 185 & 22,2 & 7 & 5,1 & 6,3 & 30,7 & 14,4 & 25 & 5,6 & 2 & 5,9 & 52,1 & 67,5 & 55,5 \\
\hline 188 & 30,9 & 9,2 & 2,1 & 4,5 & 27,8 & 31,7 & 32 & 6,9 & 6 & 6,4 & 54,1 & 50,7 & 50,3 \\
\hline 196 & 32,2 & $-3,3$ & 5,8 & 5,6 & 15,7 & 21,9 & 20,2 & 1,2 & 2,5 & 2,1 & 64,2 & 55,8 & 58,9 \\
\hline 235 & 20,3 & 8,3 & 1,6 & 2,3 & 25,5 & 24,8 & 18,9 & 5 & 2,4 & 1,4 & 58,1 & 59,8 & 66,4 \\
\hline 255 & 7,7 & 6,6 & 0,1 & $-1,3$ & 32,7 & 26,6 & 24,2 & 5,7 & 3,9 & 3,5 & 54,1 & 59,9 & 60,5 \\
\hline 257 & 23,1 & 0 & 4,3 & 2,3 & 22 & 28,1 & 26 & 2 & 3,1 & 3,3 & 65,7 & 58,4 & 60,4 \\
\hline 368 & 32,5 & 9,3 & 4,9 & 6,4 & 20,9 & 23 & 29,5 & 4,2 & 3,7 & 4,6 & 62,8 & 62,6 & 58,4 \\
\hline =abio Lucianc & 18,4 & 3,1 & $-0,7$ & 0,4 & 30,2 & 24,8 & 21,5 & 8,5 & 5,9 & 4,8 & 52,1 & 57,9 & 61,5 \\
\hline anaina Borge & 26,8 & 13 & 8,8 & 6,5 & 25 & 34,2 & 32,3 & 6,6 & 6,4 & 5,3 & 62,5 & 55,3 & 57,4 \\
\hline 「aniaMoraı & 24,7 & 6,4 & 3 & 5,5 & 32,9 & 19,7 & 23,4 & 5,9 & 1,9 & 3,2 & 53 & 64,5 & 59,9 \\
\hline TelmaAbes & 7,1 & 10,1 & $-1,2$ & $-1,1$ & 20,4 & 23,8 & 20,8 & 4,6 & 2,6 & 2,9 & 63,6 & 62 & 63,6 \\
\hline
\end{tabular}




\begin{tabular}{|c|c|c|c|c|c|c|c|c|c|c|c|c|c|}
\hline NÚMERO & IMPA & & & 1i-APg & & & 1.1 & & & Ls-E & & & Li-E \\
\hline VARIÁVEIS & IMPA I & IMPA F & IMPA PC & 1i-Apg I & 1i-APg F & 1i-APg PC & 1.11 & $1.1 \mathrm{~F}$ & 1.1 PC & Ls-E I & Ls-E F & Ls-E PC & Li-E I \\
\hline 4 & 104,4 & 94,4 & 101,6 & 2,9 & 1,8 & 1,4 & 109,6 & 130,9 & 126,5 & $-0,5$ & $-5,4$ & $-6,5$ & 2 \\
\hline 29 & 92,7 & 96,3 & 90,5 & 0,1 & $-0,9$ & $-2,5$ & 126,4 & 139,9 & 142,8 & $-1,1$ & $-5,3$ & $-6,8$ & $-2,1$ \\
\hline 43 & 98 & 83,1 & 91,9 & 0,6 & 1 & 1,3 & 121,9 & 143,2 & 133,9 & 3,5 & $-3,8$ & $-6,4$ & 2,8 \\
\hline 49 & 95,4 & 94,4 & 93,6 & 1,2 & -1 & 0 & 117,3 & 127,4 & 127,4 & 0 & $-6,6$ & $-5,4$ & 1,3 \\
\hline 73 & 101,1 & 89,2 & 88,8 & 2 & $-0,3$ & $-1,1$ & 112,6 & 137,3 & 135 & $-1,3$ & $-4,7$ & $-6,3$ & 0,9 \\
\hline 74 & 91 & 88,5 & 87,5 & 2,8 & 1,5 & 0,3 & 132,3 & 137,9 & 139,7 & $-3,7$ & $-5,8$ & $-7,9$ & 0 \\
\hline 97 & 107,8 & 95,8 & 95,6 & 4,1 & 0,5 & 0,3 & 119,8 & 131,4 & 134,4 & 0,4 & $-2,7$ & $-5,1$ & 0,3 \\
\hline 107 & 94,5 & 97,6 & 97,3 & $-0,9$ & 0,5 & $-1,3$ & 121,8 & 134,3 & 137 & $-2,3$ & $-8,8$ & $-10,8$ & $-1,9$ \\
\hline 122 & 96,8 & 99,5 & 95,9 & 2,1 & 2,1 & 1,8 & 134,6 & 121 & 131,4 & $-1,5$ & $-3,6$ & $-4,2$ & 0,2 \\
\hline 129 & 88,8 & 93,5 & 93,4 & 2,6 & 2,7 & 2,3 & 140,8 & 134,7 & 135,2 & $-3,5$ & $-3,9$ & $-5,2$ & $-1,4$ \\
\hline 147 & 102,4 & 99,2 & 97,9 & 2,4 & 0 & 0 & 123,3 & 125,1 & 123,6 & $-4,8$ & $-9,4$ & $-9,4$ & $-1,2$ \\
\hline 157 & 98,9 & 91,7 & 95,4 & 3,9 & 1,8 & 0,7 & 104 & 131 & 131,2 & 4 & $-2,9$ & $-1,8$ & 2,6 \\
\hline 185 & 102,5 & 85,7 & 95,4 & 4,5 & 1,1 & 3,8 & 123,5 & 136,8 & 130,5 & $-1,1$ & $-3,6$ & $-4,9$ & 1,3 \\
\hline 188 & 93,4 & 97,2 & 97,4 & 1,9 & 1,5 & 1,5 & 106,2 & 121,6 & 111,7 & $-0,8$ & $-5,4$ & $-7,3$ & 1,3 \\
\hline 196 & 95,2 & 101,5 & 102,2 & $-3,6$ & 0,8 & 0 & 161,1 & 121,7 & 127,1 & 2,2 & $-3,2$ & $-2,6$ & 1,4 \\
\hline 235 & 101,9 & 103,7 & 97,9 & 1,3 & $-0,3$ & $-0,9$ & 109,5 & 128,5 & 138,6 & $-5,4$ & -7 & $-9,3$ & $-2,7$ \\
\hline 255 & 103,2 & 96,9 & 94,5 & 2 & $-0,6$ & $-1,8$ & 116,9 & 137,2 & 142,5 & $-2,4$ & $-4,3$ & $-5,3$ & $-1,7$ \\
\hline 257 & 96,2 & 104,3 & 100,7 & $-0,6$ & 0,8 & $-0,4$ & 142,1 & 116,9 & 127,9 & $-3,7$ & $-5,1$ & $-5,3$ & $-2,7$ \\
\hline 368 & 91,8 & 92,8 & 99,3 & 0,4 & 1,5 & 2,8 & 117,7 & 122,3 & 117,2 & 0 & -5 & $-4,8$ & 1,7 \\
\hline =abio Lucianc & 101 & 94,8 & 92,9 & 1,4 & 0,6 & -1 & 119,1 & 129,1 & 134,2 & $-3,3$ & $-8,4$ & $-6,7$ & 1 \\
\hline anaina Borge & 95,9 & 104 & 103,6 & 6,6 & 6,2 & 4,1 & 117,4 & 114,1 & 119,1 & $-3,4$ & $-5,6$ & $-6,4$ & $-0,2$ \\
\hline 「aniaMoraı & 102,3 & 88,5 & 94,1 & 2,3 & $-0,6$ & 0,5 & 114,9 & 135,7 & 130 & $-1,4$ & $-4,6$ & $-5,9$ & 0,5 \\
\hline TelmaAbes & 91,8 & 96,4 & 94 & 0 & $-2,1$ & $-1,8$ & 118,2 & 137,5 & 146,9 & $-1,1$ & $-7,6$ & $-8,4$ & $-4,2$ \\
\hline
\end{tabular}




\begin{tabular}{|c|c|c|c|c|c|c|c|c|}
\hline NÚMERO & & & Z & & & H-Pn & & \\
\hline VARIÁVEIS & Li-E F & Li-E PC & $\mathrm{ZI}$ & $\mathrm{ZF}$ & $\mathrm{ZPC}$ & H-Pn I & $\mathrm{H}-\mathrm{Pn} F$ & H-Pn PC \\
\hline 4 & $-2,5$ & $-2,8$ & 59,7 & 75,7 & 74,4 & 0,8 & 8,7 & 11,2 \\
\hline 29 & $-4,9$ & $-5,9$ & 66,3 & 69,3 & 73,5 & 2 & 8,7 & 11,4 \\
\hline 43 & $-4,7$ & -8 & 62,3 & 72,1 & 77,2 & -6 & 7,4 & 12,3 \\
\hline 49 & -6 & $-2,8$ & 59,3 & 75,1 & 69,6 & 0 & 12,3 & 10,1 \\
\hline 73 & $-3,9$ & $-5,3$ & 63,3 & 73,4 & 75,7 & 2,2 & 8,5 & 10,9 \\
\hline 74 & $-1,9$ & $-5,5$ & 61,9 & 69,8 & 79 & 7 & 10,6 & 13,8 \\
\hline 97 & $-4,9$ & $-7,4$ & 67,7 & 70,2 & 72,8 & $-0,7$ & 4,5 & 8,9 \\
\hline 107 & $-6,8$ & $-9,2$ & 73,8 & 80,9 & 80,2 & 3,9 & 15,2 & 18,6 \\
\hline 122 & $-3,5$ & $-4,9$ & 66,4 & 72,9 & 73,2 & 2,6 & 6,4 & 7 \\
\hline 129 & $-1,9$ & $-2,8$ & 75,1 & 76,2 & 76,8 & 6,2 & 7,2 & 9,7 \\
\hline 147 & -6 & $-6,2$ & 67 & 80,8 & 82,5 & 8,8 & 17,2 & 17 \\
\hline 157 & $-4,3$ & $-2,2$ & 64 & 76,5 & 77,1 & $-5,9$ & 4,6 & 3,1 \\
\hline 185 & $-2,9$ & $-2,3$ & 61,1 & 70 & 69 & 1,9 & 6,5 & 9,3 \\
\hline 188 & $-1,9$ & $-3,7$ & 60,7 & 68 & 72,7 & 1,5 & 9,1 & 12,8 \\
\hline 196 & $-3,7$ & $-5,6$ & 61,2 & 66,3 & 70,1 & $-3,7$ & 5,6 & 4,5 \\
\hline 235 & $-5,2$ & -6 & 70,7 & 80 & 80,4 & 9,2 & 12,7 & 16,1 \\
\hline 255 & -2 & $-2,3$ & 72,3 & 73,1 & 72,6 & 4 & 7,7 & 9,1 \\
\hline 257 & $-2,8$ & $-3,9$ & 74,7 & 76,6 & 80,6 & 6,5 & 8,9 & 10,2 \\
\hline 368 & $-1,2$ & $-1,6$ & 59,8 & 69,8 & 72,8 & 0,1 & 8,7 & 8,3 \\
\hline =abio Lucianc & $-2,2$ & $-1,4$ & 61,1 & 67,9 & 68,3 & 5,7 & 14,6 & 11,4 \\
\hline anaina Borge & $-1,8$ & $-2,1$ & 76,3 & 82,5 & 83,8 & 6,6 & 10 & 11,5 \\
\hline 「aniaMoraı & $-2,1$ & $-2,8$ & 70,1 & 72,3 & 74,4 & 2,4 & 7,6 & 10,4 \\
\hline TelmaAbes & $-7,6$ & $-8,4$ & 70,5 & 82,3 & 80,4 & 1,8 & 13,8 & 14,9 \\
\hline
\end{tabular}

